\title{
3 HIGHER EDUCATION IN SOUIH AFRICA A SCHOLARLY LOOK BEHIND THE SCENES
}

EDITOR

ELI BITZER

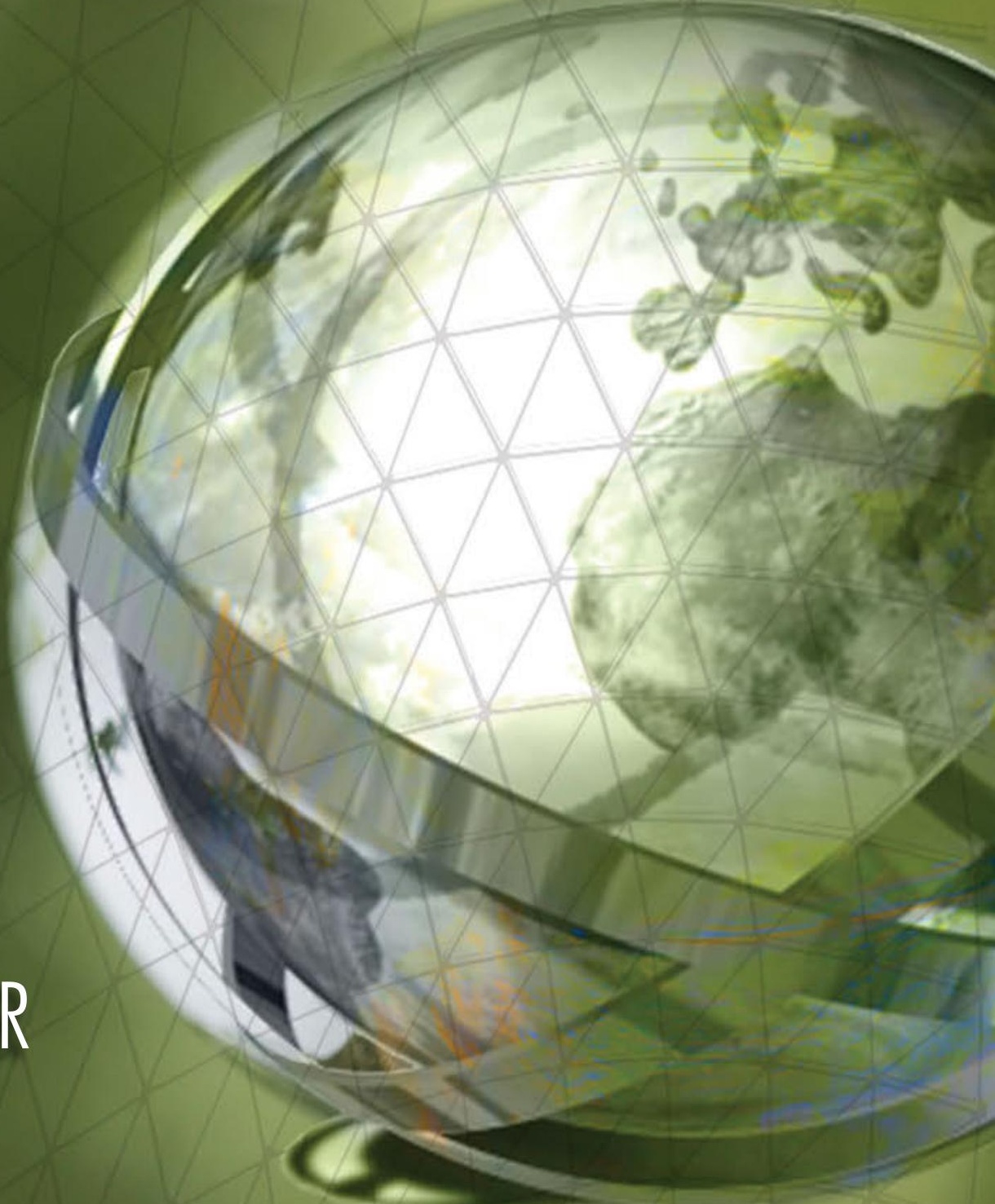




\title{
HIGHER EDUCATION IN SOUTH AFRICA
}

A SCHOLARLY LOOK BEHIND THE SCENES

\author{
EDITOR
ELI BITZER
}


Higher Education in South Africa - A scholarly look behind the scenes

Published by SUN MeDIA Stellenbosch

Copyright (C) 2009 SUN MeDIA

All rights reserved.

No part of this book may be reproduced or transmitted in any form or by any electronic, photographic or mechanical means, including photocopying and recording on record, tape or laser disk, on microfilm, via the Internet, by e-mail, or by any other information storage and retrieval system, without prior written permission by the publisher.

Views expressed in this publication are those of the authors and do not necessarily reflect the views of the publisher.

First edition 2009

ISBN: 978-1-920338-14-5

e-ISBN: 978-1-920338-18-3

DOI: $10.18820 / 9781920338183$

Cover design by llse Roelofse

Typesetting by SUN MeDIA Stellenbosch

Publisher: Liezel Meintjes

Set in Futura Lt BT 10/15

SUN PReSS is an imprint of SUN MeDIA Stellenbosch. Academic, professional and reference works are published under this imprint in print and electronic format. This publication may be ordered directly from www.sun-e-shop.co.za

Printed and bound by SUN MeDIA Stellenbosch, Ryneveld Street, Stellenbosch 7600.

www.africansunmedia.co.za 


\section{TO KALIE STRYDOM}

In recognition of a life's work in the field of higher education studies and research 


\section{CONTENTS}

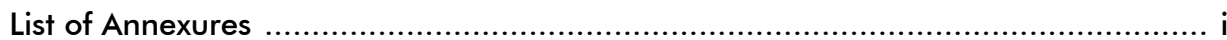

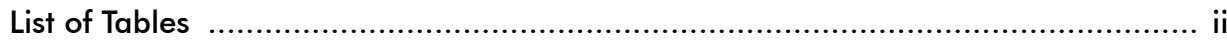

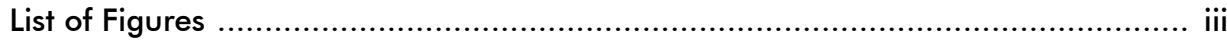

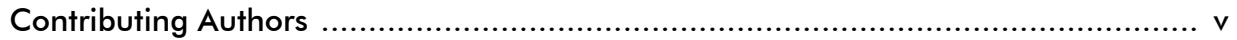

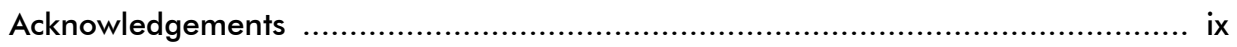

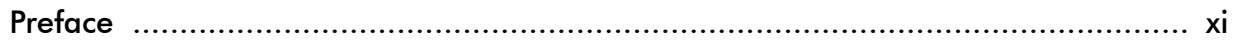

PART ONE • ISSUES OF POLICY IN HIGHER EDUCATION ................................ 1

1 South African higher education before and after 1994: A policy analysis perspective

Driekie Hay \& 'Mabokang Monnapula-Mapesela

2 Academic development in South African higher education

lan ScoH

\section{PART TWO • NORMATIVE AND EPISTEMOLOGICAL ISSUES IN}

3 The university as key concept in higher education studies: A journey

with research into a conceptual analysis of a university

Laetus OK Lategan

4 Universities and public goods: In defence of democratic deliberation, compassionate imagining and cosmopolitan justice

Yusef Waghid

5 Towards a pedagogy of possibility: Teaching and learning from

a 'social justice' perspective

Brenda Leibowitz

6 The university in a contemporary era: Reflections on epistemological shifts 103

Lesley le Grange

\section{PART THREE - TEACHING, LEARNING AND CURRICULUM IN} HIGHER EDUCATION

7 The curriculum as an institution in higher education

Jonathan Jansen

8 Some current curriculum issues in South African higher education

Nonnie Botha

9 Towards integrated assessment in South African higher education 
10 Improvement-oriented evaluation of undergraduate science programmes and the quality of student learning ....................................... 203 Jan Botha

11 Higher education and the world of Work James Garraway

\section{PART FOUR - TESTIMONIES AND REFLECTIONS ON PROFESSIONAL} DEVELOPMENT IN HIGHER EDUCATION

12 The professional development of academics: In pursuit of scholarship

Liezel Frick \& Chris Kapp

13 Two master's students' perspectives on higher education studies:

In pursuit of scholarship

Mariëtte Koen \& Marianne Bester

14 Journeying with higher education studies and research: A personal perspective 305 Eli Bitzer

\section{PART FIVE • STRUCTURES AND GOVERNANCE IN HIGHER EDUCATION}

15 Universities as organisations or institutions? The culture debate and one institution

Berté van Wyk

16 Institutional governance in SA higher education: For the common good or political power-play?

Magda Fourie

\section{PART SIX • RESEARCH FRONTIERS AND AGENDAS}

17 Higher education as a field of study and research 369

Eli Bitzer \& Annette Wilkinson

18 Research within the context of community engagement 409 Ruth Albertyn \& Priscilla Daniels

19 Higher education studies and research in South Africa: Perspectives on gaining authority and power

Kalie Strydom

A brief tribute to Kalie Strydom for his contributions to higher education studies and research

Index 453

Acronyms 


\section{LIST OF ANNEXURES}

ANNEXURE 10.1 Alignment of evaluation activities at the Stellenbosch University

ANNEXURE 17.1 Analytical perspectives from the Encyclopedia of Higher Education (Clark and Neave 1992)

ANNEXURE 17.2 The establishment of universities in South Africa (1829-1970)

ANNEXURE 17.3 Current public universities in South Africa (as in 2009)

ANNEXURE 17.4 South African universities that offer formal postgraduate programmes in $\mathrm{HE}$ studies and the type of programmes on offer (as in 2009) 


\section{LIST OF TABLES}

TABLE 5.1 Holistic model of teaching and learning as a pedagogy of possibility ...... 97

TABLE 10.1 The 'nested approach' as prescribed by the HEQF .......................... 207

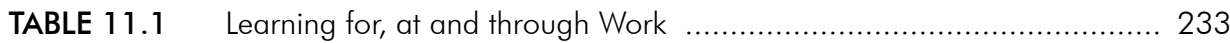

TABLE 11.2 A typology of trends in knowledge at Work and in the academy ........... 235

TABLE 11.3 Hybrid language in the third space ............................................ 242

TABLE 11.4 Edited transcript of interactions between Work and academic representatives

TABLE 12.1 Comparison between the Postgraduate Certificate in Higher Education and Training and the MPhil (Higher Education), adapted from the Centre for Higher and Adult Education (2004), the Ministry of Education (2004) and ETDP SETA (2003)

TABLE 12.2 Comparison between the Postgraduate Certificate in Higher Education and Training and the MPhil (Higher Education) in terms of structure and credit values, adapted from ETDP SETA (2003) and the Centre for Higher and Adult Education (2004)

TABLE 14.1 An observed picture of change in higher education studies and research in South Africa - early 1980s to mid-2000s

TABLE 17.1 A summary of key HE policy and publication initiatives at a national level (1990-2009) 


\section{LIST OF FIGURES}

FIGURE 6.1 Strategic management indicators for research excellence .................... 114

FIGURE 6.2 Targets for publication outputs for each faculty ............................... 115

FIGURE 8.1 Enmeshment of curriculum issue clusters .................................... 178

FIGURE 11.1 Proposed activity system of an academic department (After Trowler and Knight 2000) ................................................... 240

FIGURE 11.2 Interactions between two activity systems ...................................... 242

FIGURE 17.1 Themes of $M$ and D studies related to HE registered at the NRF and completed in 2003-2008

FIGURE 17.2 A South African extension of Tight's (2003) classification of themes

FIGURE 18.1 Issues related to community engagement 


\section{CONTRIBUTING AUTHORS}

Ruth Albertyn is a research associate at the Centre for Higher and Adult Education at Stellenbosch University. She supervised postgraduate students and taught research methods, community development and adult education at the University of the Western Cape for 17 years. Earlier she worked as a nutrition educator and community developer in a rural project in KwaZulu-Natal.

Peter Beets is a senior lecturer in the Department of Curriculum Studies in the Faculty of Education at Stellenbosch University. He teaches and researches in the fields of geographical education, educational assessment and curriculum. He has a number of academic publications (national and international) to his credit and is a research fellow of the Human Sciences Research Council.

Marianne Bester teaches in clothing and textiles with specialisation in clothing technology at the Cape Peninsula University of Technology (CPUT). She has read several papers on higher education teaching and learning as well as on clothing and textiles over the years. She has also undertaken study trips to Europe and is a guest lecturer in Clothing Studies at the University of the Western Cape. She currently heads the Department of Clothing and Textile Technology at CPUT and is studying towards an MPhil in higher education at Stellenbosch University.

Eli Bitzer is Director of the Centre for Higher and Adult Education in the Faculty of Education at Stellenbosch University. He worked in academic staff development at the then University of the Orange Free State for 19 years and for the past 11 years he has taught at the master's level and supervised a large number of $\mathrm{PhD}$ students at Stellenbosch University. He has published widely on South African higher education studies and research and his current fields of interest are higher education as a field of study, postgraduate supervision and different forms of quality promotion in higher education.

Jan Botha is Director of Institutional Research and Planning at Stellenbosch University. After an academic career of almost 20 years (teaching classics and religion) he became a university administrator. His current portfolio includes overseeing the institution's quality assurance management system. 
Nonnie Botha is currently Director of the School for Postgraduate Studies in the Faculty of Education at the Nelson Mandela Metropolitan University in Port Elizabeth. She has been teaching at various South African higher education institutions for more than 20 years and has occupied several management positions for the past 14 years, among others Dean of Education. Her areas of research and publication cover the teaching of mathematics and science in schools, selfactualisation, identity, HIV, teacher education, higher education curriculum and postgraduate research and supervision.

Priscilla Daniels is Associate Professor and Head of the Department of Human Ecology at the University of the Western Cape. She also manages service learning at this institution. Prior to her involvement in service learning, teaching and research in the field of family studies and management were key areas of interest.

Magda Fourie is Vice-Rector: Teaching at Stellenbosch University and a professor in the Faculty of Education. She comes from a background of teacher training and academic development, and has more recently been primarily involved in academic planning. Her research interests include governance and management of higher education, transformation, and quality assurance.

Liezel Frick is a lecturer at the Centre for Higher and Adult Education in the Faculty of Education at Stellenbosch University. She has been part of various research projects within higher and adult education. Her PhD studies were on the continuing professional development of university academics and her interests lie in the areas of continuing professional development (CPD), integrated scholarship, transdisciplinary research, student learning in higher education, lifelong learning, and community education.

James Garraway heads the foundation project at the Cape Peninsula University of Technology and chairs the national Higher Education Learning and Teaching Association of Southern Africa (HELTASA) foundation special interest group, producing annual publications in this field. He also teaches new staff on the Higher Diploma in Higher Education and trains staff as HE assessors. He researches and publishes within the university's Work-Integrated Learning Research Unit, having recently received his $\mathrm{PhD}$ in this field. 
Driekie Hay is Vice-Rector: Academic Planning at the University of the Free State and professor in higher education. She is particularly interested in optimising students' learning experiences and has published widely on issues in postgraduate supervision practices, higher education curricula and the management and implementation of quality assurance in higher education.

Jonathan Jansen is Honorary Professor of Education at the University of the Witwatersrand and was Scholar-in-Residence at the Oprah Winfrey Leadership Academy for Girls in Johannesburg. He is a recent Fulbright Scholar to Stanford University, former Dean of Education at the University of Pretoria, holds an Honorary Doctor of Education from the University of Edinburgh and is currently the Rector and Vice-Chancellor of the University of the Free State.

Chris Kapp is Emeritus Professor of Higher Education and a fellow of the Centre for Higher and Adult Education at Stellenbosch University. He has 30 years of experience in academic staff and professional development. At present he facilitates learning and development interventions with a focus on postgraduate supervision, assessment and writing for publication in higher education.

Mariëtte Koen worked as a remedial and Foundation Phase school teacher before she obtained a professional qualification as educational psychologist. Her doctorate is in the area of reading and spelling development and she has published several articles on the topic. She registered for the MPhil (Higher Education) at Stellenbosch University in 2008 and in 2009 she was appointed as lecturer in the Department of Curriculum Studies at the University of the Free State.

Laetus Lategan is Dean of Research and Development at the Central University of Technology, Free State, Bloemfontein. He holds doctorates in philosophy and systematic theology and has published on topics in higher education, philosophy, ethics and research development. He is a rated researcher with the National Research Foundation in South Africa and co-editor of a research series on research development and editor of the Journal for New Generation Sciences. $\mathrm{He}$ also holds an extraordinary professorship in research and professional ethics at the University of the Free State.

Lesley le Grange is Professor and Deputy Dean (Research) in the Faculty of Education at Stellenbosch University. Lesley teaches and researches in several fields, focusing on both schooling and higher education. He has more than 120 publications to his credit, serves on several editorial boards of peer-reviewed journals and is recipient of a number of research awards. 
Brenda Leibowitz is the Director of the Centre for Teaching and Learning at Stellenbosch University. Her research interests include social justice in higher education, collaborative research for the professional development of academics, and the relationship of identity to teaching and learning. She has been the chairperson of the Higher Education Learning and Teaching Association of Southern Africa (HELTASA) since 2005.

'Mabokang Monnapula-Mapesela is Associate Professor in Higher Education. She is a senior researcher at the Centre for Higher Education Studies and Development at the University of the Free State. Her main fields of interest are higher education policy and transformation, change management, postgraduate supervision and oral tradition in the field of indigenous knowledge.

Ian Scott is Director of the Academic Development Programme and Professor and Deputy Dean at the Centre for Higher Education Development at the University of Cape Town. He has worked on educational development with various national bodies, and his research interests include higher education policy related to teaching and learning, and comparative models for widening participation in higher education.

Kalie Strydom (please see the tribute at the back of this volume).

Berté van Wyk is Senior Lecturer in Philosophy of Education in the Department of Education Policy Studies in the Faculty of Education at Stellenbosch University. His research focuses on higher education, and institutional culture and African philosophy are two current projects.

Yusef Waghid is Professor of Philosophy of Education and currently Dean of the Faculty of Education at Stellenbosch University. His research focuses on ethics, education and critical transformations. He has published widely both nationally and internationally on these topics.

Annette Wilkinson is Professor and Head of the Division Higher Education Studies and Research at the University of the Free State. She holds a BSc and a PhD in Didactics. Her scholarly contributions include a large number of articles, book contributions and research reports. She is an experienced supervisor for master's and doctoral students. Her main research interests lie with teaching and learning, scholarship and action research. Over the years she has contributed comprehensively to teaching-learning innovation and the development of research capacity among lecturing staff in the central region of South Africa. 


\section{ACKNOWLEDGEMENTS}

I am pleased to acknowledge the different authors who have contributed to this book and made its publication possible. In particular I am indebted to my former mentor and 'academic soundboard' Kalie Strydom to whose work and contributions this book is dedicated. Those colleagues who acted as critical readers to the different chapters I also want to thank sincerely for their inputs and valuable comments. They include Chris Winberg, Cecilia Jacobs, Linda Cooper, Janice MacMillan, Arend Carl, Alan Chadwick, Sioux McKenna, Antoinette Tolken-Smith, Rona Newmark, Susan van Schalkwyk, Berté van Wyk, Laetus Lategan, Yusef Waghid, Liezel Frick and Ruth Albertyn. Ella Belcher deserves an editor's Oscar Award for the meticulous editing of the text and last, but not least, I want to thank our two external reviewers, Malcolm Tight (Lancaster University) and Hans Weiler (Stanford University) for their highly appreciated reviewing of the book which added much value.

The National Research Foundation is acknowledged for contributing financially to this publication and SUN MeDIA for their good offices and efforts to get the book published. In particular I would like to thank the managing editor, Liezel Meinties, for her support and advice throughout. 
What can be done to ensure that universities are well positioned to meet the challenges of the fast-moving twenty-first century? This is the central question that Burton Clark addresses in his book Sustaining change in universities (2004). Indeed a challenging question, because the conceptual framework suggested by Clark shifts the attention from transformation to sustainability rooted in a constructed steady state of change and a collegial approach to entrepreneurialism in higher education. The latter position seems increasingly to be a requirement for universities to adapt successfully to a fast-changing modern world. Similarly, Hans Weiler asks in an article "Scholarship between policy and science" [Zeitschrift für Erziehungswissenschaft, 11(4)] whether comparative higher education research could possibly render important theoretical insights into such issues as the institutionalisation of higher education, governance, access, curricula and quality assessment. To further deepen the argument, Sue Clegg, in a keynote address at HERDSA in Australia (2007) asks whether the boundaries of higher education research should not be extended beyond the pragmatic questions of 'what works' to more theoretical depth.

These are but three viewpoints among the many representing recent additions to perspectives in the field of higher education studies and research. It is therefore no wonder that many academics in higher education experience both frustration and a sense of powerlessness, because they do not understand the complexities of the contexts in which they work. Becoming aware of the values and issues of higher education seems to be a first step needed in organising for control of the significant aspects of academic professional development and in studying and researching the field of higher education. This observation concurs with Ron Barnett's view in Realizing the university in an age of supercomplexity (2000:6): "[P]rofessional life is increasingly becoming a matter of not only handling overwhelming data and theories within a given frame of reference (a situation of complexity) but also a matter of handling multiple frames of understanding, of action and of self-identity."

The main aim of this book is to take a scholarly look 'behind the scenes' in academia - particularly in South Africa where the field of higher education is still mostly underdeveloped. It aims to explore and come to grips with some perspectives, themes and issues that characterise and shape higher education institutions within a changing higher education system. This seems important, since in many cases, academics perform work for which they were not properly trained. This I say with great caution, 
but not without merit. If, for instance, the disciplinary preparation (for acceptance into any scholarly/disciplinary community) of academics is compared to their preparation for tasks such as teaching as a social practice, learning facilitation, curriculum development, assessing learning, engaging with different communities and managing academic units, much seems to be lacking in South African higher education. And if, for instance, one would ask both university academics and researchers in the field of higher education to define the concept 'university', a variety of mostly tenuous answers would probably be the result.

An attempt is made in this book to foreground some understanding of what higher education is essentially about and include examples of what higher education as a field of study and research entails. The focus for academics and those who investigate the field of higher education should clearly be to facilitate its core business. This also goes for any institution that claims to be of significance in higher education. Therefore, academic work, in general, primarily has two aims:

- To teach in such a way that students benefit maximally from their higher educational experiences by increasing their sensitivity towards historical, contemporary and future issues, and to assist students in becoming independent, intrinsically motivated and self-monitoring lifelong learners;

- To extend the publicly accessible body of knowledge through conceptual, theoretical and empirical research, scholarship and publication.

Everything else, including administration, professional entrepreneurship and leadership in any discipline or field of study, consultancy work and service should be subordinate to these aims. These sentiments will hopefully emerge from the book.

Having worked in the field of higher education studies for the past 30 years I have reached a point in my career where I sense the need to share what I have learned about higher education with a scholarly audience but, at the same time, celebrate the wealth of insights, knowledge and perspectives available in South Africa on higher education with prolific authors and contributors to higher education within the country. I cannot think of a better way to do this than by contributing to and publishing a book on higher education with a title such as Higher Education in South Africa - A sholarly look behind the scenes. My first 'boss' and pioneer in the field of higher education in South Africa, as well as my initial mentor, was Kalie Strydom, who has contributed in many substantial ways to the field and is still working tirelessly on research and development projects in higher education. I dedicate the book to him and have also asked him to write its concluding chapter. 
This publication is essentially divided into six parts and addresses different sets of higher education issues. These include policy issues, normative and epistemological issues and issues of teaching, learning and curriculum, as well as other issues pertinent to revealing current and future agendas for change and inquiry in the field of higher education. It is obviously impossible to include a complete set of issues and themes, as I have indicated in at least two of the chapters, but I think some important ones have been covered. Also, there will always be overlaps as inquiry into a particular set of issues might also relate to another one or several other ones. To keep them apart assisted in finding a logic structure for the book. As would sometimes be the case with a book of this nature, not all authors who were invited were able to contribute. This was due to various constraints - of which available time was an important one. I would really have liked to include a contribution on the issue of financing higher education in South Africa and something on university autonomy and the debate on the tension between higher education and the state; also the role of higher education in economic development and equity. Issues such as student access (a most important subject of investigation in the South African context) and staff workload studies are others that come to mind. Nevertheless, I have done as well as I could in attracting a number of valuable contributions. This leaves ample room for future volumes of research into the field.

The chapters in this volume represent a variety of authors: from Kalie Strydom, who is still one of the leading higher educationists in South Africa, lan Scott, a pioneer in the area of academic development and Jonathan Jansen, who has contributed to education transformation in major ways, to newcomers to the field such as Liezel Frick, Berté van Wyk and Peter Beets, who are currently establishing themselves in the field of higher education research. What might also be unique to the book is that I have invited two current MPhil (Higher Education) students, both academic staff at different universities, to contribute their lived experiences of studying in the field. Therefore this book does indeed represent quite a spectrum of authors - all hopefully contributing to the main idea, namely to reveal some 'behind the scenes' perspectives and themes and stimulate further debate, research and studies in higher education in South Africa.

\section{PART ONE}

\section{ISSUES OF POLICY IN HIGHER EDUCATION}

In this section, Driekie Hay and 'Mabokang Monnapula-Mapesela describe some theoretical underpinnings of policy analysis in their chapter with reference to one distinct approach, namely evaluative policy analysis. They explain why the study of 
policies and policy analysis is important in higher education studies and research and they explore how governments steer higher education through policies. South African and European examples are used to illustrate how steering and policies influence each other. The chapter focuses in particular on the complexities, reasoning and forces behind policy development and implementation in South Africa - prior to and after a water-shedding 1994. It concludes with a perspective on the challenges posed by policy development, implementation and evaluation in South Africa.

The contribution from lan Scott offers a perspective on the purposes, nature, scope and future challenges of Academic Development (AD) as it is has evolved in South African higher education. The role of $A D$ - its compass and meaning in the higher education sector - has been fundamentally shaped by the context of South Africa, in particular the effects of its history of colonialism and apartheid, its geopolitical position as a developing country, and its combination of first- and third-world constituencies from which major and persistent inequalities arise. $A D$, as an 'issue' and a field of practice and scholarship, can consequently not be fully understood without an awareness of its origins, the socio-political realities that have influenced it, and the intellectual forces and global higher education trends that have informed its development.

\section{PART TWO}

\section{NORMATIVE AND EPISTEMOLOGICAL ISSUES IN HIGHER EDUCATION}

A chapter by Laetus Lategan argues that new knowledge development (research) and knowledge transmission (teaching) are core to the university and that this has been the case throughout the history of universities. What has changed is the way in which these tasks have been performed. The chapter highlights the viewpoint that the university is a social organisation consisting of people (ranging from lecturing and managerial staff to students). What seems to be often forgotten is that universities and their activities need to be managed and since the university does not exist in isolation, it is challenged by partnerships, social engagement and developmental issues. Adding to Lategan's argument, Yusef Waghid proposes in his chapter that one of the most significant contributions to the advancement of modern higher education is a perspective that the public mission of the contemporary university is to assist in addressing social problems such as improving business organisation and capital investment, protecting the natural environment, preserving human rights and cultural diversity, resolving crises of governance and promoting democracy - all aspects that constitute what can be referred to as the public goods of higher education. To stress the public mission of the modern (African) university more clearly, the chapter offers a clear account of 
higher education as a public good which, according to Waghid, ought to build on conceptions of democratic deliberation, compassionate imagining and cosmopolitan justice. These are important perspectives given the unfortunate divided past of the country and of the higher education sector.

Brenda Leibowitz's chapter takes the argument of Yusef Waghid on higher education as a public good further by considering what university education would be like if it were to promote participatory parity for all students. With reference to a study on educational biographies of 100 students and 64 lecturers at one university, it highlights at least three dimensions of social justice, namely distribution, participation and recognition. It further considers the interrelationship of structure, agency and responsibility, and how this interrelationship impacts on the task of higher education to facilitate the potential for successful learning of all students. The chapter concludes with a model, depicting the responsibilities of the key role-players for realising higher education as a social good and promoting further research in this area.

Lesley le Grange's contribution proposes that the contemporary university is an institution that is transforming rapidly. Therefore, in an age of what Ron Barnett termed 'supercomplexity', the university too must become supercomplex and expand its epistemologies so as to engage with the challenges of a changing world. The chapter critically discusses epistemological transformations occurring in the contemporary university as a consequence of both inside-out pressures and outside-in pressures. It examines traces of these shifts in post-apartheid higher education policy in South Africa and in practices at both a systemic and an institutional level. It also argues that even though it appears as if the modern university is experiencing the end of the pursuit of universal reason and the ideal of a liberal education, globalisation creates new spaces for reclaiming some lost ground.

\section{PART THREE}

\section{TEACHING, LEARNING AND THE CURRICULUM IN HIGHER EDUCATION}

Le Grange's epistemological perspective is further articulated by Jonathan Jansen's chapter which addresses a project on curriculum as an institution. What counts as worthwhile knowledge at a university is the prime question posed by Jansen and, as is the case in at least some institutions in South Africa, the institutional curriculum appears to be embedded at the level of 'blood knowledge'. This refers to the emotional, psychic, social, economic, political and psychological inheritance of an institutional and wider community which appears to be perpetuated in the formal and informal 
university curriculum. The chapter ultimately aims to encourage further research in the field of higher education curricula in order to find out how change can be promoted - especially regarding syllabic knowledge which is seemingly firmly embedded in institutional knowledge, and which, in turn, is rooted in emotionally held social and historical understandings of race and identity in South African higher education.

The chapter by Nonnie Botha highlights some of the complex sets of issues that relate to the South African higher education curriculum. It outlines six interrelated clusters of current curriculum issues: vocational and liberal education, progression from certificate to diploma to degree, mass education compared to selective education, contact and distance education, internationalisation and localisation, and diffusion between disciplinary boundaries. The chapter also addresses the issue of the 'Africanisation' of the curriculum as part of the cluster on internationalisation and localisation. The inter-connectedness of the clusters with one another is pointed out and in my view the further value of this chapter lies in that it could be used as a point of departure for a more critical and scholarly review of higher education curricula in South Africa.

Peter Beets's main argument in this section is that higher education institutions in South Africa are increasingly challenged to address pressing societal needs. This situation has led to changes in the nature of knowledge production and the competencies students are required to develop through teaching programmes. According to Beets, one area in which this change is evident is in a shift from Mode 1 knowledge that refers to pure, disciplinary, homogeneous, expert-led university-based knowledge to Mode 2 knowledge characterised as applied, problem-solving, transdisciplinary, heterogeneous and network-embedded. Consequently, many teaching programmes now tend to focus not only on the knowledge (foundational) component, but also on the skills (practical) and application (reflexive) components of learning. The chapter contextualises the tensions between current assessment practices in higher education and what policies propose. It is argued that simply embracing these policies is problematic, because the priorities of higher education and the state vary due to the different constituencies they serve and their concomitant priorities and imperatives. From an analysis of current higher education assessment practices, ways of mediating this divide are suggested, also serving as pointers for further research in this area.

Jan Botha's chapter draws on insights gained from internal evaluation of 17 undergraduate programmes in the sciences conducted at one university during 2007 and 2008. These evaluations are reported and analysed with a view to their possible impact on the enhancement of the quality of student learning as an important research theme in 
higher education. The issue of authentic improvement plans as devised by lecturers and students in the sciences gives an indication of the shift towards student-centred learning and teaching which is gradually taking place in higher education institutions in South Africa. The chapter concludes with the notion that the formative evaluation of undergraduate programmes can be an effective instrument to improve student learning, and that its potential impact towards quality enhancement in higher education should be further explored.

In the last chapter of Part Three, James Garraway addresses the question of why it seems to be so difficult to successfully integrate ways of doing and thinking in workplaces with those of the university. A possible answer lies, in part, in the observation that knowledge in the workplace serves a different purpose from knowledge in the university, and that the two types of knowledge are, taken broadly, structured differently. Given this essential difference, the chapter proposes that the lack of integration needs not be seen as an impediment to further developments, but rather, drawing on activity theory, that it should be seen as a resource which can, under certain conditions, promote knowledge development. He argues that the modern university, particularly in South Africa, needs to create more positive conditions for integration if it is to recognise more properly the importance of knowledge from outside of itself.

\section{PART FOUR}

\section{TESTIMONIES AND REFLECTIONS ON PROFESSIONAL DEVELOPMENT IN HIGHER EDUCATION}

In their chapter, Liezel Frick and Chris Kapp explore the issue of academic professional development from both theoretical and practical stances. They provide a broad definition and an overview of the theories underlying the concept of professional development and continue to discuss the issues and challenges that it faces in higher education. The notion of scholarship forms the basis of the discussion. Ways of how academic professional development is practised are discussed and illustrated by using a South African case study of a formal programme in higher education studies for the professional development teaching and teaching scholarship. The chapter concludes with some proposals for future research in the area of academic professional development within institutions of higher education.

As an illustration of how students might experience their higher education postgraduate studies, Mariëtte Koen and Marianne Bester provide a perspective on how postgraduate studies in the field may hold promise for improving lecturers' professional development by exploring their learning journeys. It provides a brief description of the journeys 
of these two MPhil (Higher Education) students against a background of selfdiscovery, identity development and professional growth. They share with the reader the perspective that, by engaging in higher education studies, not only were their perceptions and conceptualisations changed, but they also acquired new skills and knowledge as they developed as teachers, researchers and scholars. They conclude that becoming scholars in teaching and learning in higher education is an ongoing process of professional development that requires integrity, persistence, enthusiasm, passion and courage.

From a somewhat different perspective, my own chapter attempts to capture several 'stages' of the development of a personal journey within the field of higher education studies and research. It reflects change and development in the field including experiences covering five 'developmental stages' over a period of almost 30 years.

\section{PART FIVE}

\section{STRUCTURES AND GOVERNANCE IN HIGHER EDUCATION}

In his chapter, Berté van Wyk attempts to conceptualise institutional culture by posing a critical question: are universities institutions or organisations? The question arises due to ambiguities in the literature: some authors describe universities as institutions rather than organisations, while others use the notions of 'organisation' and 'institution' interchangeably. In view of the importance of considering how and in what ways concepts of culture can enhance - or impede - institutional understanding, research and action is needed. As Van Wyk explores the culture debate, there seem to be complex conceptual issues associated with some of the baseline arguments around the nature of culture and, following from this, the nature of institutional cultures such as the institutional culture at Stellenbosch University. The discussion on two meanings of institutional culture (perceptions, and the language issue) indicates that culture is dynamic, and highlights how meanings change over time. Van Wyk suggests in conclusion that the usefulness of institutional culture in higher education should be studied further, that its potential value lies in the fact that it connects people and that it should be used for a purpose; it is not just something to have, which is where the discussion of the concept usually focuses.

Magda Fourie's contribution explores the role of institutional governance against the background of the nature of the university as an organisation, and the changing context in which universities currently operate. Three 'conventional' models of institutional governance are discussed, and more recent developments in this regard 
are investigated. She concludes with some guiding principles for effective institutional governance in a contested and changing university context.

\section{PART SIX}

\section{RESEARCH FRONTIERS AND AGENDAS IN HIGHER EDUCATION}

In our joint chapter, Annette Wilkinson and I address four issues concerning higher education as a field of study and research. The chapter highlights the typical characteristics of a field of study as opposed to a discipline and traces a number of moments in the development of higher education studies and research internationally and locally. It then suggests a way to 'map' the field in South Africa against the background of international mappings and finally proposes a number of issues to consider for possible future research to extend and promote higher education as a field of study and research in South Africa.

For Ruth Albertyn and Priscilla Daniels community engagement is a concept with a complexity of meanings, approaches and application. Derived from the scholarship of engagement of Ernest Boyer, community engagement reflects a commitment to relevance within the context of the higher educational institutions. As a result, they explore the issues that emerge in the continuing debate around engagement with communities. This is done from the perspective of a global era that impacts on knowledge production which is so integral to the mission of community engagement. The South African response to engagement also reflects conflicting interpretations and imperatives that influence the application of community engagement in universities. The dichotomies in the conceptualisations of community engagement influence higher educational institutions on three levels: that of management, the academics in their teaching and learning and the community. As the concepts of knowledge and power have implications for all three levels of engagement, they will all impact on the efficacy and sustainability of engagement efforts. The issues and challenges at these levels are highlighted for further debate and they suggest possible avenues for research at the level of management, the academic and the community.

The concluding chapter by Kalie Strydom portrays his views on higher educationists and researchers working in the field and how they could gain more authority and control of policy formation and implementation. Essentially, his argument involves the gaining of authority in the form of expert knowledge, striving for excellence and insight via practical experience in higher education studies and research. Such authority leads to power that may influence policy, planning and the practical implementation thereof in 
higher education more directly. He sketches the way forward regarding the recognition of higher education studies and research by briefly discussing a few points of departure that could possibly assist in gaining authority in this field of study. In my view this chapter contributes much to emphasise the importance of higher education studies and research in the country and provides a number of pointers for implementation and further research.

In the last instance I see three pertinent potential benefits of this book to higher education researchers. Firstly, it could assist in getting a firmer grip on higher education as a field of studies and research in South Africa; secondly, it could promote engagement with particularly challenging issues and themes prevalent in higher education in the country and thirdly, it could stimulate further inquiry into the field. Hopefully all three of these benefits will be realised in some ways. 


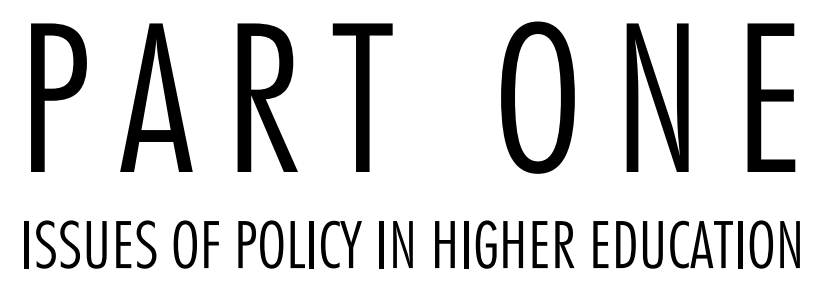




\section{SOUTH AFRICAN}

HIGHER EDUCATION

BEFORE AND AFTER 1994

\section{A POLICY ANALYSIS PERSPECTIVE}

\section{Driekie Hay \& 'Mabokang Monnapula-Mapesela}

\section{ABSTRACT}

In this chapter the authors describe some theoretical underpinnings of policy analysis with specific reference to one distinct approach, namely evaluative policy analysis. This is followed by an explanation of why the study of policies and policy analysis is important and of how governments steer higher education through policies. Both the South African and the European higher education systems are used to illustrate how steering and policies influence each other. The main focus of the chapter, however, is on the complexities, reasoning and forces behind policy development and implementation in South Africa, both before and after 1994. The chapter concludes with the challenges of policy development, implementation and evaluation facing South Africa.

\section{INTRODUCTION}

Since the dawn of a new democratic era in 1994 the history and development of South African higher education received intense attention and was embraced by many South African scholars. One could argue that not enough has been done to analyse the manifold policies with the intention to evaluate their appropriateness at a given time, as well as their success in delivering what they advocate. In this chapter we deliberately shift the focus from a mere political tracking of higher education policies and we provide a means to policy evaluation and analysis.

For any person studying higher education, the South African history and current practices provide interesting perspectives and background to the complexities, reasoning and forces behind policy development and implementation. The chapter will commence by providing theoretical underpinnings of policy analysis with specific reference to 
one distinct approach, namely evaluative policy analysis. An outline is provided to clarify why the study of policies and policy analysis is important and to illuminate what the trends are in policy development in South Africa. The chapter also explains how governments steer higher education through policies. Both the South African higher education and the European higher education systems are used to provide perspectives on government steering.

\section{THEORETICAL UNDERPINNINGS OF POLICY ANALYSIS}

Policy analysis in higher education is a process prone to various approaches and models depending on circumstances in which it is required. It could be disciplinespecific, context-specific or even ideology-driven.

In this chapter only one approach to policy analysis - the so-called evaluative policy analysis - will be explored. One interesting definition regards policy analysis as a form of evaluative research employed to improve or legitimise the practical implications (both positive and negative) of a policy or a policy-oriented programme. It is used where there is hope that the process can emancipate the policy by bringing about its review and change.

This approach (evaluative policy analysis), which is fast gaining recognition among scholars and education practitioners, has its roots in the works of renowned philosophers of Greece, Persia and Italy, such as Aristotle, Montesquieu and Machiavelli. Aristotle is known for his logical discourse and speculations about the origins and merits of different types of governments and their mutual obligations to society. In his naturalistic accounts the great political philosopher Baron de Montesquieu focused on various forms of government, the reasons why they existed and why their development was often advanced or constrained. Montesquieu argued that the best government was one that attains its purpose and acknowledges the needs of its people. Niccolo Machiavelli's treatises on realistic political theory may be regarded as unrealistic and brutal by many, for he advocated the employ of brute power in order to achieve practical, essential and good policy purposes (Kemerling 2006; Bok 2003; Richardson 2003).

Since one of the greatest virtues of higher education is to serve the public good, policy evaluation becomes a worthwhile approach to investigating the validity and course of policy development and implementation in higher education worldwide and in South Africa in particular. However, because higher education is a unique interdisciplinary field of study with a focus on various disciplines, two important challenges regarding policy analysis are apparent. On the one hand, it can easily fall prey to confusion 
when a choice of one method of analysis is taken to be an absolute, since no one size can best serve the distinctiveness of the disciplines entailed in higher education. On the other hand, one may argue that the sector has been spoiled by the choice of approaches and methods to policy analysis since a variety are at its disposal. Regardless of the existence of the manifold approaches and models none presents itself as an absolute that provides all the answers.

\section{EVALUATIVE POLICY ANALYSIS}

Sometimes referred to as policy or theory evaluation, policy analysis is an integral part of higher education systems worldwide. In evaluative policy analysis the overall aim is to evaluate the appropriateness of the policy course, its objectives, its rationale, as well as the route taken to meet the objectives and finally to ensure that appropriate interventions such as policy review, its cessation or improvement are put in place. The point of departure in the process is close scrutiny of the policy aims and objectives, its assumptions and its intentions (Van der Knaap 2004:1). In higher education, policy evaluation or analysis provides timely but appropriate interventions ensuring that institutions address the intended needs of the society they serve (students and communities). According to Blamey and McKenzie (2007:439), the outcome of evaluative policy analysis does not necessarily provide all the answers, but it can identify policies that are redundant - those making a significant contribution to service - and it can also expose shortfalls in policy. It can also create opportunities for policy managers to identify ways that work better.

Since evaluative policy analysis has to allow policy development and implementation to run their course, it is usually slow in bringing results. One of the impeding factors is that the social issues at which the policy is aimed are often resistant to change. This is so for reasons ranging from a lack of buy-in by consumers and implementers of policy, poor policy planning and sometimes a lack of resources (financial or human). In South Africa one of the biggest issues in the transformation agenda has been the development of a profusion of policies for higher education. The policy development process on its own has lasted well over a decade and seemingly more work is still to come. Due to the underlying democratic participatory policy-making process characterising all spheres of the South African society, the implementation of the proposed policies, acts and initiatives has been rather slow (Mapesela and Hay 2005:113), oftentimes forcing policy analysers to engage in policy analysis even before implementation is complete. 
Over 30 South African higher education policy initiatives have been promulgated in a very short space of time after 1994. Their voluminous nature, lack of clarity of implementation steps, the vast number of coordinating bodies, as well as the wrong assumption that institutions and academics have enough capacity and support to implement these policies have created and continue to create, among others, a stagnation in policy implementation, fears of encroachment in academics' sphere sovereignties, and sometimes animosity and resistance to change. Blamey and Mckenzie (2007:439) appropriately argue that however slow the policy process may be, over time the cumulative increments of evaluative policy analysis are not insignificant, and are indeed worth waiting for.

Policy analysis must happen at various levels of the system, from the highest to the lowest echelons. Although policy introduction frequently radiates from government as the macro- and political/steering level, all stakeholders in the sector have a shared responsibility in developing, implementing and evaluating policy. A critical expectation in evaluative policy analysis is that policy analysts remain dispassionate and emotionally uninvolved in order to achieve objective accounts/results from the process.

On the contrary, the lack of objectivity during policy analysis most often jeopardises policy development and implementation processes. Evidence of this is observed in the manifestation of the manifold problems and misunderstandings of what a university in a transforming country like South Africa should be, and how it should conduct itself, for example in allocating and utilising its resources for its diverse stakeholders (students and staff), and how it should ensure acceptable institutional culture(s), as well as good ethical conduct in the lecture rooms during teaching and learning.

However, all is not doom and gloom, since to a large extent the same policy expectations that were introduced by government after 1994 have been highly instrumental in the advancement of transformation - the absence thereof could easily send this country back to the era of global repudiation and sanctions.

It is therefore understandable that the lack of policy implementation and evaluation, as well as the economy of the country, are often blamed on retarded human resources and skills development. All citizens have to pay the price - the hardest hit being the voiceless, the powerless, the poorest of the poor and the less privileged who are seldom part of policy analysis teams and experts. However, problems in policy development and implementation are not unique to South Africa and occur throughout the world. Ample examples exist throughout the world of how governments, for example, steer higher education systems to achieve the governing ideologies and objectives of the day. 


\section{REASONS WHY GOVERNMENTS STEER HIGHER EDUCATION SYSTEMS THROUGH POLICIES}

Every government has a fundamental obligation to define clearly, through a process of public debate and affirmation, the purposes it expects higher education to achieve. Governments need to ensure that the funding of higher education institutions are commensurate with the purposes it expects those institutions to help achieve, balancing mandates with incentives to bring into alignment a state's public interests with the interests of institutions. Besides, governments also have the responsibility to ensure that higher education institutions perform well, deliver graduates of high quality, address short skills and research areas and contribute towards the socio-economic demands of a particular state. Through a well-balanced steering approach governments can create a climate that is conducive to economic development through initiatives that create partnerships among higher education, the private sector, and state government; invest in strategic and cumulative ways for improving infrastructure; and provide structures that encourage and reward collaboration among higher education providers within and across sectors.

\section{TYPES OF STEERING}

There are typically two types of steering: control by government (classical steering) and supervision by government ('new' steering) (Maassen and Van Vught 1994). The classical steering is based on the idea that society can be manipulated and in this approach steering is done through command and control of internal processes. The problem with classical steering is that higher education systems are too great for detailed top-down steering and that government has no monopoly on steering society. On the contrary, the new steering mechanism provides universities with greater autonomy and improves transparency of inputs and outputs. It furthermore enhances institutions' accountability and has the possibility to strengthen university managements.

In an attempt to further refine and explain the divergent ideas and views on the role of the state, Gornitzka and Maassen (2000) distinguish between the sovereign state, the institutional state, the corporate-pluralist state, and the classical liberal state (state supermarket model). The sovereign state steering model views higher education as a governmental instrument for reaching political, economic and social goals. Higher education is thus a strong ally to implement the state's higher education policy agenda. The institutional steering model provides higher education institutions with the task of protecting academic values and traditions against political instabilities. The corporatepluralist state steering model acknowledges that there are a variety of often competing 
centres of authority and control with respect to higher education. In the supermarket steering model the role of the state is minimal. This approach ensures that the market mechanism in higher education is not imprecise. In their study Gornitzka and Maassen (2000) found a predisposition towards the supermarket steering model. What seems even more interesting is that in most systems a blend of models is found-also referred to as a hybrid steering approach.

\section{THE LINK BETWEEN GOVERNMENT STEERING AND HIGHER EDUCATION POLICY DEVELOPMENT}

Government steering in higher education is a concept that refers to the attempts of a government to influence the decisions and actions of other actors according to its goals by using certain mechanisms or 'tools'. These 'tools', which are usually funding, regulation, planning and evaluation, often find their impetus in policies (Maassen and Van Vught 1994). Since 1980 quality assessment (Westerheijden 1998) and lately the ranking of universities have also become powerful steering mechanisms. In responding to increasing government steering, it is argued that although socio-political demands and expectations of higher education are increasing, government expenditure is either stagnating or decreasing. Many higher education institutions simply do not have the capacity to deal with all the demands.

We know that universities as institutions have always performed certain roles that were predominantly influenced by the cultural and ideological, social and economic, educational and scientific roles allocated to them. Yet, it is accepted globally that the 'modern' university as a project of the nation state with its cultural identity finds itself in uncertain times, since universities are involved in almost every kind of social and economic activity and are highly dependent on government for the bulk of their income. Universities today are increasingly urged to 'modernise', 'adapt', 'marketise', to become more 'efficient', more 'service-oriented' and more 'societally relevant'. All of these transformation issues can only be successful if the traditional steering relationship between state authorities and higher education institutions are in tandem - implying a rearrangement and renegotiation of relationships between the state and the public sector. Not surprisingly, an increasing strand of research is also noticeable in the field of higher education policy. It seems appropriate then to explore, on a concrete level, practical examples of how governments steer higher education. 


\section{EXAMPLES OF HOW GOVERNMENTS STEER HIGHER EDUCATION}

The following international examples are provided to illustrate how governments abroad steer higher education towards certain goals:

- The Bologna process with its implied changing degree structures as a European example of government steering;

- Internationalisation and globalisation;

- The changing organisation of research;

- Financial accountability and responsibility;

- Interactive governance.

\section{The Bologna process and changing degree structures}

In 1999, 29 European ministers in charge of higher education met in Bologna to lay the basis for establishing a European Higher Education Area by 2010 and promoting the European system of higher education world-wide. In their declaration, known as the Bologna Declaration, the ministers agreed to:

- adopt a system of easily readable and comparable degrees;

- adopt a system with two phases: the undergraduate and the graduate;

- establish a system of credits;

- promote mobility by overcoming obstacles;

- promote European cooperation in quality assurance; and

- promote European dimensions in higher education.

The Bologna Declaration is an example of intergovernmental steering and not of steering in one particular nation state only. The steering of the Bologna declaration is obviously to the advantage of all participating countries and hard to separate from internationalisation and globalisation imperatives.

\section{Internationalisation and globalisation as steering mechanisms}

It is accepted that in order to make internationalisation and globalisation succeed, intergovernmental relationships, planning and steering mechanisms are required. The implication is that even though the nation state is powerful, some of its capacities are likely to change, shift and be shared with other players, such as international and supranational role-players - even outside the academic and education sector 
(Beck 2000; Castells 2000). In Africa, South Africa has assumed custodianship of the other countries, particularly in the Southern African development countries and their regions.

In Australia, for example, the government's decision to adopt a neo-liberal policy has forced higher education to become market driven, with the result that individuals are increasingly required to pay for their studies. Furthermore, a unified higher education system has been developed. It is not yet clear what the unintended consequences of neo-liberalism may have for the university sector.

\section{Changing research infrastructures}

In 2000 the European Union initiated a process intended to be in place by 2010 as "the most competitive and dynamic knowledge-based economy in the world capable of sustainable growth with more and better jobs and greater social cohesion". In order to operationalise this goal a number of new policies, including education and research, were formulated - leading national governments to review, amongst others, their research infrastructure. As a result of these initiatives, universities began to coordinate their research activities effectively and to expand relationships with the 'outside' world. The rationale for the first theme was to focus and prioritise research activities in order to achieve excellence in the most efficient way.

\section{Shifting financial arrangements}

Within the realm of the theme 'finance' there are two international issues. The first one is the shift towards more individual responsibility for students, implying that they will bear an increased financial burden. There are a number of countries in which there are no tuition fees and where they are not on the agenda. In addition to the shifting responsibilities of government/higher education institutions with regard to students, there is also a trend towards greater responsibility and accountability for institutions regarding the efficient use of resources. Several measures have been introduced to stimulate universities and other higher education institutions to become more 'productive'.

Another important mechanism by which governments steer higher education is the use of base and non-base funding. Base formula funding is funding provided by the government to continue the basic operation and maintenance of higher education institutions. It is usually enrolment-driven and it provides operational stability. Nonbase funding comes in addition to the funding provided through the base formula and 
is usually a pool or pools of resources directed at specific purposes. Non-base funding includes earmarked funding, which is funds dedicated or earmarked for a specific programme.

\section{Interactive governance}

In terms of organisational governance one can detect a push towards a 'new openness' of universities in terms of their surroundings. The increasing autonomy, together with the push towards openness of universities and other higher education institutions, has made the governance of 'the university' very complex.

Having touched upon international trends in this field it is necessary to provide an overview of policy development and implementation as a result of government steering in South Africa. In order to understand recent developments better it is also necessary to touch briefly upon the period before 1994 .

\section{HIGHER EDUCATION POLICY DEVELOPMENT AND GOVERNMENT STEERING IN SOUTH AFRICA}

As expected, government steering before 1994 was aimed at mainly advancing white South Africans. The apartheid dispensation left South Africa with a highly contested and racially segregated higher education system, consisting of a typology of historically white and historically black universities (which also included two separate universities for Indians and 'coloureds'). This system originated in the establishment of colleges that were precursors of the University of Cape Town and the University of Stellenbosch.

Against the background of the political situation in the early $20^{\text {th }}$ century, white universities were established in South Africa on the basis of language of tuition. This resulted in a classification of historically white Afrikaans and historically white English universities. Apart from language differentiation there was also a noticeable distinction between the academic, intellectual and socio-political cultures and epistemic alliances of that time - the historically white English universities in the Anglo-Saxon historical tradition and historically white Afrikaans universities in the Dutch and German philosophical and theological traditions.

The proliferation of Afrikaans universities should also be viewed against the rise of Afrikaner nationalism in the early 1900s and the coming to power of the National Party in 1948. The establishment of the so-called black universities was based on the policy of separate development or segregation. This distinction was justified in the extension 
of the University Education Act of 1959 passed by the governing party of the time. Black universities had to adopt curricula and management models used by Afrikaans universities. Apart from race, universities were also classified according to ethnicity. The underlying ideology in this divide was to preserve the cultural identity of only a small part of society, namely white, and in particular Afrikaner, people.

A further distortion of the higher education system before 1994 was the lack of equity in the distribution of resources to institutions, huge disparities between historically black and historically white institutions in terms of facilities and capacities, and a skewed distribution of the student population in certain disciplines, with no more than a handful of non-white students in fields such as the sciences, engineering, and technology. The same stratification existed in the governance of these institutions. In a nutshell, the system was highly characterised by fragmentation, inefficiency and ineffectiveness.

\section{POLICY DEVELOPMENT AND GOVERNMENT STEERING AFTER 1994}

The year 1994 will always be known as the year of the culmination of liberation, transformation and the breaking away from a past whose corollaries are still endured by people today. The reality of 1994 was that, with a new government in place, a new but massive transformation agenda was set. High expectations were expressed to universities to refocus their roles and to fulfil their traditional role, namely that of contributing towards social, political and economic development, since during their conception they were earmarked as places where leaders were trained, minds shaped and ideas formed. In contrast, the inherited system was inherently unequal, its academic input outdated in many respects and not in step with the emerging ideas of the democratic South Africa. A further debilitating factor was the culture of research in many universities, which seemed to be incompatible with the progressive agenda of the new South Africa and the culture. Although the transformation agenda was fair, it also alienated a large majority of people with its technicalities. The subsequent challenge for the new policy makers was - and still is - to deal with the legacy of the past, and yet also to shape and prepare South African universities to embrace the future in a global world.

\section{MOST PROMINENT POLICY DEVELOPMENTS IN SOUTH AFRICA SINCE 1994}

Since 1994, South African policy development has largely been driven by the new constitution of the country. Its mandate is to realise a system of education that is transformed and democratised in alignment with the values guarding human dignity, equality, human rights and freedom, non-racism and non-sexism, and one that ensures 
the right to basic education for all citizens. Subsequently, the objectives of these policies are valid in light of the country's history, subtle undertakings of segregation/ discrimination, the inherited legacy of inequality that still looms in all sectors of work and that seems to be mutating into many different forms. The array of policies which saw the light after 1994 was supposed to bring hope for the nation - cutting across all sectors. The hope was expressed that with a number of well-grounded policies in place the South African society would soon see the benefits resulting from their implementation. However, soon their implementation became a colossal stride which some critics describe as a blind leap into the sea. Nonetheless, the legitimacy of such an overhaul is seldom questioned, particularly by those who stand to benefit from the proper implementation of such policy.

Policy development for the era after 1994 commenced with the appointment by former President Nelson Mandela of a National Commission on Higher Education (NCHE) whose role was to develop a policy framework for the transformation of South Africa's higher education sector which by that time comprised universities, technikons, and nursing, agriculture and teachers' training colleges. This process, which started in Parliament in 1995, culminated in the Higher Education Act of 1997.

The most important recommendations made by the NCHE in trying to transform the system were the following:

- An expansion of student enrolment and broadened access to reach a wider distribution of social groups and classes, including adult learners;

- Greater responsiveness to societal needs and interests;

- Increased cooperation and partnership in structures of governance, both at the system and institutional levels;

- A higher education system designed, planned, managed and funded as a single coordinated system comprising universities, technikons and colleges;

- Alignment of qualifications with the National Qualifications Framework allowing adequate channels, flexible entry, as well as exit points and horizontal and vertical mobility;

- A strategic public funding framework taking into account the number of students in different fields and levels of study; and addressing the special needs of institutions, such as equity, redress and research infrastructure;

- Establishment of a higher education quality committee responsible for programme accreditation, institutional auditing and quality promotion;

- Distance education and resource-based learning. 
These recommendations feature in the Higher Education Act, as well as in a number of policies and papers, namely the Education White Paper 3: A Programme for the Transformation of Higher Education (1997), the Council on Higher Education (CHE) report entitled Towards a new higher education landscape, meeting the equity, quality and social development imperatives of South Africa in the $27^{\text {st }}$ century (2000) the National Plan for Higher Education (2001) and the South African Qualifications Act (SAQA) Act of 1995. These policies were, amongst others, an attempt to steer higher education institutions towards driving and meeting transformational targets and strongly held beliefs. In the following paragraphs the Education White Paper 3, 1997 is used to illustrate how the post-1994 government steered the higher education system to achieve the transformation agenda which was set then.

\section{THE EDUCATION WHITE PAPER 3, 1997: AN EXAMPLE OF GOVERNMENT STEERING HIGHER EDUCATION IN SOUTH AFRICA}

The Education White Paper 3 (RSA DoE 1997) made it clear that in addition to funding for redress and student financial aid, there is a need to encourage innovation and adaptation, and to build capacity in new areas. In order to transform the entire South African higher education landscape, a number of key goals were formulated for the system. These include stabilising of institutions and the higher education system, improving efficiency, encouraging inter-institutional and regional cooperation, improving student equity, enhancing institutional planning capacity, encouraging mission differentiation, improving staff equity, enhancing quality and promoting development. The White Paper describes these goals and explains how they are supposed to contribute towards government's steering goals.

\section{Stabilising of institutions and the higher education system and improving efficiency}

In order to achieve this aim, a number of policy initiatives, such as the 3-year rolling plans, were put in place. By means of enrolment planning the South African government wanted to ensure that equity targets would be met and that there would be a more efficient way of enrolling students into particular fields of science, engineering and technology. Part of the motivation/steering in this case was that the subsidy that institutions would receive per student who graduated in these areas would differ from those in categories that were lower in priority.

In an attempt to move towards a more unified higher education system, the 36 institutions were merged and/or incorporated into 23 , doing away with the technikon sector and 
moving towards introducing universities of technology. Another reason behind this move was to do away with the legacy of apartheid which divided the system into historically black and disadvantaged institutions and historically white and advantaged ones. In addition, the government started to adjust cost units between higher education institutions and provided funding to improve the current infrastructure of the institutions. In 2008, an amount of R3,2 billion was earmarked for this purpose.

Another way of achieving greater efficiency in the system was for government to add time limits for funding of students and to add premiums for progression/graduation rates.

\section{Encouraging inter-institutional and regional cooperation}

Although not much has happened regarding regional cooperation the arrangements as proposed by institutions' programme and qualification mixes (PQMs) forced institutions to inform each other about their programme offerings and intended new programmes they would like to offer.

\section{Improving student equity}

By expanding the allocation of the national student financial aid and support many more students from economically disadvantaged backgrounds were afforded the opportunity to enrol for higher education. In addition, extended curricula were introduced in order to provide students with a better opportunity to obtain their degrees.

\section{Encouraging mission differentiation}

Mission differentiation was achieved through introducing the concept of universities of technology. Accordingly, institutions were provided the opportunity by the Higher Education Quality Committee to be evaluated and audited by them on their vision and mission statements - thus providing institutions the opportunity to differentiate.

\section{Improving staff equity, enhancing quality and promoting research development}

The South African government has invested in different strategies and projects to address the inequalities of the previous system and to strengthen in particular the research capacities of academics coming from designated groups and within the technikon sector. The Thuthuka Programme, which is part of the Human and Institutional Capacity Development (HICD) directorate of the NRF, serves as an example. The 
strategic objectives of Thuthuka are to improve the qualifications of participating researchers to doctoral and postdoctoral levels, to accelerate the progression of participating researchers into the mainstream of national and other research support opportunities, to contribute to the sustainable development of participating researchers and to increase the number of NRF-rated researchers from participating researchers at national level. In addition, the NRF has also implemented a mentoring programme, which interacts with mentees who form a substantial population of South Africa's academia. This project is a result of the lack of commitment that often exists from both the mentors and mentees to stay committed to such an intervention. The reality is that even today research expertise still resides largely in the white and white male 'seasoned researchers' most nearing retirement.

Three sub-programmes have been implemented by Thuthuka. Two of these are 'Researchers-in-Training' (RiT) and 'Women-in-Research' (WiR). The RiT is intended to develop entry-level researchers to be in a position to participate in other NRF funding streams with established researchers on a competitive basis, whilst the WiR should support women researchers in the advancement of their research careers and enable them to become more representative and to contribute to research discourses. The third project is that of the Research Development Initiative for Black Academics (REDIBA) which is aimed at preparing black South African researchers for positions of scientific and academic leadership, thereby diversifying, strengthening and sustaining the nation's research capabilities (NRF 2007).

Regarding quality, a number of developments took place, such as the introduction of quality audits by the Higher Education Quality Committee and programme reviews of which the evaluation of MBA programmes and teacher training programmes were a major part. In an attempt to ensure that all academic programmes and qualifications met minimum criteria and were accredited by the Council on Higher Education, the National Department of Education and the South African Qualifications Authority (SAQA), the National Qualifications Framework (NQF) were developed. The impact of legislation and policies regulating the accreditation and registration of academic programmes led to, amongst others, new posts being created within institutions, new committee structures to deal with curriculum issues and many administrative tasks for academic and administrative staff.

The introduction of teaching and learning development grants was another initiative to ensure the equity of success and the overall improvement of learning and teaching in South African higher education. Based on the success rates of institutions, a specific 
amount earmarked for the improvement of institutions' throughput rates was allocated to institutions. This money can be used for the expansion of tutorial systems, academic advising, academic support including academic language proficiency development, supportive educational technology, to name but a few.

\section{DISCUSSION}

Although the system can be hailed for significant milestones made in transformation, serious discrepancies are still the order of the day, hence the continuing transformation agenda, policy analysis and review. On the other hand, and despite the negative consequences of the apartheid legacy, the system as a whole is still currently the best developed in Africa, with substantial resources. Most institutions enjoy international attention and recognition since they have developed internationally competitive research and teaching capacities. These valuable features and achievements have been retained. But the system's inequities, imbalances and distortions still have a long way to go before being truly and sufficiently addressed.

A number of challenges for policy analysis in South African higher education still exist, as outlined in the following:

- Misconceptions about policy issues and their value by members of society hamper policy development, implementation, analysis and review.

- Certain stakeholders still deny their role in policy issues. This denial is usually accompanied by negative critique, engagement in deliberate confusing petty debates about what matters and what does not matter. This often shifts focus from the real purpose of policy.

- There is fear or unwillingness to take bold steps (make hard choices) in the advancement of transformation, particularly in cases where non-supporters have little to lose.

- A lack of faith and resistance to policy analysis, planning, and implementation by other stakeholders delays emancipation through evaluation.

- In many higher education institutions the already dwindling funds are misdirected and are not used for genuine transformation issues. This implies a continued cycle of mediocrity in implementation, as well as a never-ending game of blaming the government. 
- Policy needs to be scrutinised for the good it intends imparting to the stakeholders and not according to its origins or the evaluators' diverse worldviews and ideologies. This renders the process free of bias to a certain extent.

- Among other challenges, poor policy planning and inability to forecast accurately the essential requirements of managing transformation of the higher education system as a massive and highly complex project can also be regarded as debilitating forces in reaping policy dividends after 15 years of policy steering by government.

\section{SUMMARY AND CONCLUSION}

This chapter described the importance of policy development and implementation in higher education. It argued that often not enough is done to ensure that policies are adequately financed and capacitated with human resources, monitored, evaluated and re-adjusted. It was acknowledged that if dealt with in a pragmatic way, policy steering is a powerful mechanism to ensure that the social, economic and educational needs and aspirations of countries and higher education systems are met. Consequently the need for higher education practitioners and academics worldwide - and in South Africa in particular - to familiarise themselves with the nuts and bolts of policy analysis and to influence policy development and discourses cannot be overemphasised.

From this chapter a number of conclusions can be drawn regarding policy development and implementation. There seems to be a general move to a 'supermarket steering' model. The state is becoming less dominant in steering higher education and the (quasi-)market is becoming more influential. However, in none of the countries studied for this purpose a 'pure' market approach has been introduced. The current steering approaches with respect to higher education should rather be described as hybrid. Whilst higher education institutions appear to have increasing autonomy, governments, through regulation, appear to wish to ensure that this autonomy is used by institutions to achieve specific political expectations. This view is based on observations that innovations in national higher education policies have recently led to a partial 'deinstrumentalisation' of higher education and a renewed interest in other, e.g. social, and cultural, roles of higher education.

Effective structures for monitoring the implementation of national higher education policies or programmes are still rare. Yet, institutions are grappling with the idea of higher education as a social space and are therefore only now learning what it means to be a public service enterprise. Moreover, they are still in the process of developing approaches and methods to manage their resources effectively. Factors 
such as inherited staff and resources, common practice and values, subject mix, and management approaches have constrained institutions and profoundly affected their market position. The impact of governments on academic programme development in first-degree education is limited. Governmental attempts to influence university and college developments in the area of lifelong learning can in general be described as wishful thinking. Especially in continental Europe the traditional bilateral relationship between higher education and the state is rapidly becoming a multilateral relationship between higher education and various external actors, including the Ministry of Education.

Lastly, higher education policies that achieve accountability and link institutional performance to societal purposes are very much needed in South Africa. At the same time they must permit a wide scope for institutional autonomy, taking into account the primary roles of higher education institutions such as the building of knowledge bases (primarily through research), the creation of capabilities (primarily through teaching), the diffusion of knowledge, the maintenance of knowledge, societal needs, as well as the expectations of industry, employers, individuals and communities. The challenge is thus to deal with the tension that exists between the servicing function of the individual university to external interests and the innovative pursuit of knowledge generation.

\section{REFERENCES}

Asmal K. 2002. Press statement by the Minister of Education on Transformation and reconstruction of Higher education system, 30 May 2002, Pretoria, South Africa.

Beck U. 2000. The cosmopolitan perspective: Sociology of the second age of modernity. British Journal of Sociology, 1:79-105.

Blamey A \& Mckenzie M. 2007. Theories of change and realistic evaluation: Peas in a pod or apples and oranges? Evaluation, 13(4):439-455.

Bok H. 2003. Baron de Montesquieu, Charles-Louis de Secondat. Stanford Encyclopaedia of Philosophy [Online]. Available: http://plato.stanford.edu/entries/montesquieu [2008, 13 January].

Castells M. 2000. Materials for an exploratory theory. British Journal of Sociology, 51 (1):5-24.

Gornitzka A \& Maassen P. 2000. Hybrid steering approaches with respect to European higher education. Higher Education Policy, 13:267-285.

Kemerling G. 2006. Aristotle (384-322 BCE) [Online]. Available: http://www.philosophypages. com/ph/aris.htm [2008, 13 January].

Maassen P \& Van Vught FA. 1994. Alternative Models of Governmental Steering in Higher education. In: L Goedegebuure \& FA van Vught (eds). Comparative Policy Studies in Higher Education. Utrecht: Lemma. 
Mapesela M \& Hay HR. 2005. Through the magnifying glass: A descriptive theoretical analysis of the impact of the South African higher education policies on academic staff and their job satisfaction. Higher Education, 50:111-128.

NRF (National Research Foundation). 2007. Overview of grants, scholarships, fellowships and the rating of researchers [Online]. Available: www.nrf.ac.za [2008, 18 January].

Richardson B. 2003. Niccolõ Machiavelli. Wikipedia [Online]. Available: http://en.wikipedia. org/wiki/nicco\%c3\%b2machiavelli [2008, 13 January].

RSA DoE (Republic of South Africa. Department of Education). 1997. Education White Paper 3: A Programme for the Transformation of Higher Education. Pretoria: Government Publishers.

Van der Knaap P. 2004. Theory-based evaluation and learning: Possibilities and challenges. Evaluation, 10(1):16-34.

Westerheijden DF. 1998. Quality assurance and steering in higher education. In: A Rip (ed). Steering and effectiveness in a developing knowledge society. Utrecht: Lemma. 


\section{ACADEMIC DEVELOPMENT \\ IN SOUTH AFRICAN HIGHER \\ EDUCATION}

$\operatorname{lan} \operatorname{Scott}^{1}$

\section{INTRODUCTION}

What's in a name?

The term 'Academic Development' (AD) has a meaning and set of associations in South Africa that are different from the usage in various other parts of the world, where it refers predominantly to academic staff development.

The term was first used in South Africa in the mid-1980s, but its conceptual origins go back to 1980, to the 'Academic Support Programmes' (ASPs) that were founded in 1980 or shortly thereafter at the English-medium 'liberal' universities². ASPs were established to facilitate the entry and integration of black students into these institutions, which had been statutorily whites-only since the so-called Extension of University Education Act of 1959, so ASPs were centrally concerned with equity of access from the outset. Their work initially included material and general advisory as well as academic support, but progressively concentrated on the academic, mainly in the form of specialised teaching, tutoring and instructional design ${ }^{3}$. These two elements - equity and a focus on the formal educational process - have characterised South African ASP/AD work throughout its history.

1 The author is the Director of the AD Programme at the University of Cape Town. This contribution is thus written from an insider perspective, and it offers a personal view of the field.

2 Wits, Cape Town, Natal, Rhodes.

3 The importance of a holistic view of student development is well recognised, but material support and counselling are more effectively addressed by specialised units. 
The original ASP approach, which addressed the realities of black students as a disadvantaged minority in the institution, was clearly not suitable in historically black institutions ( $\mathrm{HBls}$ ), where educational disadvantage affected almost all students. Thus, as the commitment to dealing with inequalities grew in the context of the political ferment of the mid-1980s, interested academics argued that the position in the HBls called for improving teaching across the institution, and that the appropriate approach was to focus on staff development. It was in this context that the term AD came into use in the mid-1980s. 'Support' was seen to be too narrow and to have patronising connotations; more importantly, the concept of development was then experienced as forward-looking and positive as opposed to the idea of remediation and its associations of inferiority. Thus ' $A D$ ' in due course became the dominant term for tertiary educational development in the South African context, incorporating the ideas of student, staff, curriculum and institutional development. The HEQC's (2007:74) current definition captures this evolution:

\footnotetext{
A field of research and practice that aims to enhance the quality and effectiveness of teaching and learning in higher education, and to enable institutions and the higher education system to meet key educational goals, particularly in relation to equity of access and outcomes. Academic development encompasses four interlinked areas of work: student development (particularly foundational and skills-oriented provision), staff development, curriculum development and institutional development.
}

Despite its widening focus, $A D$ has continued to be understood as being fundamentally concerned with equity and redress. Some professionals in the area see this conception as too narrow and limiting, and want the field to be accepted as embracing all aspects of tertiary teaching and learning for all students. To signal this, new terms such as 'Higher Education Development' have come into use. However, distinctions of this kind are likely to become less and less significant because, as this chapter will argue, the field of work represented by these terms must - by its nature and to fulfil its purpose - encompass the full spectrum of the theory and practice of tertiary educational development, and also - given the social and economic imperatives of South Africa must have equity of access and outcomes as a central goal.

\section{AD as both an issue and a perspective}

This book aims to 'promote an understanding and appreciation of some important perspectives and issues that shape and drive higher education' (see Bitzer, Preface of this volume). $A$ theme of this chapter is that $A D$, or rather what it stands for, is a central 
and persistent issue in South Africa and at the same time provides a perspective on higher education that contrasts uncomfortably with the dominant ones.

$A D$ has been a significant issue for three decades: a matter of symbolic ideological contestation in the apartheid period and a focus of tension in policy, practice and academic ideology in the democratic dispensation. This is not because of power and influence in the $A D$ community itself - which has largely been marginal - but because of two contentious, interlinked issues that $A D$ has represented: equity and redress in the student body, and the status and significance of teaching in higher education. Under apartheid, the focus of contestation was of course racial equity. Since the political transition, the conflict has been more complex, lying not only in the classic issue of the relationship between equity and 'excellence', but also in the tension between 'teaching' and 'research', as reflected in the issue of academic identity (particularly in the developing-country context) and the priorities adopted by the institutions. These matters are elaborated in sections below.

$A D$ can also be regarded as a perspective. There has clearly been much change in South African higher education since 1994, but understandings of the nature and effects of the change vary in accordance with the perspective of the observer. Badat (2009) notes the importance of 'interrogating how change at the national level and at the level of institutions has been theorised, and how, in what ways and to what extent the methodological approaches that have been utilised have illuminated and/ or obfuscated the nature and trajectory of change'.

An 'AD' analytical perspective on higher education comes out of engagement with the equity and teaching-and-learning nexus. This lens produces a view of the performance of the system that raises critical questions about the purposes, identity and central obligations of the higher education sector in the South African context. This perspective accepts the conventional understanding of the essential purposes of higher education as being the production and dissemination of knowledge, but challenges the current prioritisation and orientation of higher education's main functions in contemporary South Africa. Key issues include what constitutes 'core business' and who higher education is for. The conditions and analysis that give rise to the AD perspective are outlined in the body of this chapter.

\section{THE ISSUE OF EQUITY: AD AND 'TRANSFORMATION'}

The issue of equity, or 'transformation', in higher education has a range of facets, notably equity in staffing and equity in the student body. Given its purpose, AD has 
always been centrally concerned with equity in the student body, and it is this form of transformation that is focused on in this chapter. (It should be noted, however, that representivity in staffing has also been an important consideration in $A D$ in the historically white institutions, as an end in itself and also as a means of facilitating student equity because of the importance of role models and diverse voices in the academic community.)

For many in $A D$, the essence of transformation is inclusiveness in who benefits from higher education. This broad idea of transformation encompasses indirect benefits the role of advanced knowledge and research in improving and enriching the country as a whole - as well as the benefits of participating directly in higher education. In this view, student equity is arguably the central way of bringing about progressive and sustainable transformation, through individual empowerment and harnessing the talent in all communities, which in itself should have far-reaching effects on development and the setting of the development agenda. It follows that equity of outcomes is as important as equity of access. While the term 'equity of outcomes' became current only in 1997 through being used in the higher education White Paper (DoE 1997), it had long been recognised in AD that access without success would be a meaningless achievement. The importance of equity of outcomes has profound implications for how educational development policy and practice should be conceived of and evaluated.

AD's primary site of work is the formal educational process in higher education in all its facets, from student selection and placement to curriculum design to practice in the classroom. Teaching-and-learning development is thus the main area of AD practice and research, along with the policy and institutional development work that is needed to provide space and resources for this. While this section focuses primarily on the equity issue, the close linkage with institutional attitudes to teaching and learning will be evident, and will also be discussed specifically later.

Detailed periodisation and analysis of the evolution of $A D$ are beyond the scope of this chapter, ${ }^{4}$ but the following sub-sections aim to outline how key focal points of $A D$ research and practice have evolved, and to suggest where AD must go if its underlying goals are to be achieved.

4 For an account of the evolution of $A D$ as experienced in one institution, see Scott et al. 2005. 


\section{AD UNDER APARTHEID: THE EVOLUTION OF KEY THEMES}

The institutional contexts into which ASP/AD was introduced in the 1980s were highly varied, within as well as between the broad categorisations that were current, viz. the 'liberal' universities, the 'Afrikaans' universities and technikons, and the historically black institutions. As is well known, relative to the population there were few black students enrolled in the sector, only a few hundred in each of the liberal universities and almost none in the Afrikaans institutions ${ }^{5}$. There was no government support or funding for $A D$ work, and attitudes to it within the institutions were very uneven pockets of support alongside much ambivalence or hostility (see for example Vilakazi and Tema 1985; Hofmeyr and Spence 1989) - reflecting the full spectrum of political and academic ideology. It was a difficult but rich period, still relatively unexplored analytically. For the purposes of this chapter, two key features of AD work that emerged in this early phase merit discussion.

\section{Recognition of the systemic nature of the equity challenge}

In the 1980s (and indeed well beyond) mainstream understanding of the challenges of equity and educational disadvantage might fairly be described as superficial or minimalist. In the liberal universities, ASPs were initially modelled on North American minority programmes. It was generally thought that all that was needed, and justified, was more of what the traditional students were given, that is tutorial support, together with some language intervention for English second-language students. In fact, on the grounds of perceived threats to academic standards, AD interventions were generally required to be of limited duration and intensity lest the students should be 'coached through'.

From early in the 1980s, however, academics in AD began to understand the complex nature of educational disadvantage in the South African context. They became conscious that there were major systemic obstacles to black students' succeeding in any substantial numbers in the historically white universities. In addition to the effects of language and socio-economic conditions, a key factor was a crippling combination of poor schooling and higher education curriculum parameters that had been designed decades before for a homogeneous, largely privileged student intake. This mismatch, or articulation gap, between secondary and higher education had the consequence that the assumptions about prior learning that underlay the traditional curricula were

5 As late as 1988, black (African) students made up only $10 \%$ of headcount enrolment in the liberal universities, only $1 \%$ in the Afrikaans-medium universities, and $32 \%$ in the sector as a whole (Cooper and Subotzky 2001). 
not valid for the great majority of black students. Unless the schooling available to the majority were to be drastically improved, black students - all but the most exceptionally talented - would continue to be denied the opportunity to realise their potential, because the tertiary educational process made no allowance for diverse educational and socio-cultural backgrounds.

It was this understanding that led to the development, as early as 1982-1983, of 'foundation' courses in key subjects, designed specifically to fill in the articulation gap with tertiary-style provision (rather than by re-doing school work). By the mid1980s, despite a total absence of state support and funding, such courses were being organised in coherent 'foundation programmes' attached to specific degrees in innovative ways that matched particular contexts. The range of models is exemplified by the Science Foundation Programme at Pietermaritzburg, the UNIFY programme at the University of the North (now Limpopo), the College of Science at Wits and ASPECT in Engineering at UCT, which addressed significantly different institutional and faculty contexts and intake profiles (Hofmeyr and Spence 1989). There were also inventive and pioneering initiatives that focused primarily on new approaches to secondary and further education provision, designed to bridge the gap from the other side, as it were. Most prominent among these was the Career Preparation Programme, expertly and adroitly devised by Kalie Strydom and colleagues at the then University of the Orange Free State (UOFS) to be workable in what was an unusually difficult environment for promoting equity. $A D$ was, and is, very much the art of the possible.

These models, and the many others that were successfully implemented, were necessarily distinctive because of their different contexts, but all had in common that they addressed the key systemic problem of the articulation gap. They were thus based on curriculum development designed to accommodate diversity, and this has been a characteristic feature of almost all successful AD initiatives ever since. However, AD specialists recognised, as early as the mid-1980s, that there were key problems with foundational interventions and that they were a necessary but not sufficient condition for equity. Foundation programmes were marginalised and served only a minority of the student intake (and were thus vulnerable to stigmatisation), yet the problem they were designed to address affected the majority of the population. Moreover, while every effort had to be made to improve schooling, the resources available in a developing country would almost certainly never be sufficient for the mass school system to be able to produce substantially more matriculants with the level of preparedness that traditional higher education programmes assumed to be in place. Thus the need for intervention was not going to diminish. 
It therefore became evident that equity would not be attainable until mainstream higher education curricula and teaching approaches developed the capacity to accommodate talented students from all communities and educational backgrounds (see for example Moulder 1991; Hunter 1991; Scott 1986). However, the gap between recognising this goal and realising it was dauntingly wide. Resistance to this kind of change was deeply embedded, not only in government (where the dominant position changed in 1994), but also in the higher education community itself (where conservative academic orthodoxy has persisted). These conditions produced two lasting responses in AD: a focus on working towards policy change, initially in the institutions and later in the state; and, especially in the historically white universities, a growing concern with systemic issues, such as the articulation of foundation courses with mainstream programmes (for which a number of innovative models were developed) and, later, the use of AD initiatives as sites for developing educational approaches that could accommodate talented but underprepared students and might in time be used to accommodate student diversity in mainstream programmes.

In the then-black institutions, the underlying $A D$ challenges were similar, but the focus on systemic issues came about via a different route. Since the main contextual difference was that the great majority of the students were from disadvantaged backgrounds, 'minority' approaches did not make sense, so the emphasis came on to staff development in a range of forms, aimed at encouraging mainstream academics to improve their teaching. While much good work was done, the strategy was obstructed by two main problems. First, the difficulty of achieving staff engagement was great. Second, the articulation gap was as big an obstacle as in the historically white institutions since, despite the majority of the intake having always come from disadvantaged backgrounds, the $\mathrm{HBls}^{6}$ had adopted the traditional South African curriculum structures. With some notable exceptions such as the UNIFY programme, the HBls did not focus on curriculum restructuring or foundational provision, perhaps because of the scale of the challenge. Unintentionally, this provided a 'control group' of a sort: despite all the AD efforts made to improve mainstream teaching, widespread and substantial improvement in student performance patterns did not materialise. This suggests that in the South African context, focusing only on 'teaching better' within the existing, flawed curriculum parameters is not an adequate response to the equity challenge.

6 An exception was the University of Bophuthatswana, which initially followed an innovative four-year degree structure. 
Thus key themes that emerged during the apartheid period included:

- recognition of the systemic origins of the obstacles to equity;

- the understanding that, not being a minority or ephemeral phenomenon, educational disadvantage and inequity could not be effectively addressed in South Africa by minority programmes, 'band-aid' approaches or initiatives on the fringes of the institutions or the sector; and

- the consequent need for change in the educational process in higher education ultimately in mainstream structures and practices - rather than an exclusive focus on schooling.

The emergence of these issues in the 1980s marked the beginnings of a decades-long effort to gain recognition of the need for mainstream educational reform, as outlined below. The persistence of these themes has had a major bearing on AD practice, research and policy-related work.

\section{The identity and role of AD: Tension between 'activist' and 'academic' orientations}

One effect of the essentially political nature of the origins of AD was that many of the people who were attracted to work in the field, particularly in its early stages, were motivated by strong social-change agendas. Some came from junior or temporary posts in regular academic departments, others from schools or private-sector organisations which offered little opportunity to express opposition to the political status quo. The nature of the staff and of $A D$ work at the time, often involving close relationships with students in the van of mass political action, established an activist rather than conventional academic ethos in many $A D$ units. The intense political turmoil and violence of the 1980s directly affected many AD staff and radicalised them further, creating tensions between $A D$ and regular departments particularly in the historically white universities. A result of the unconventional orientation of $A D$ was that much innovative teaching-and-learning work was not conventionally researched or published, and AD-related analysis for policy remained largely in institutional documents or conference proceedings of the emerging professional association, the South African Association for Academic Development (SAAAD). The substantial gaps in $A D$ literature have hindered research, and together with discontinuities in staffing due mainly to breaks in funding, have contributed to a failure to build on past experience that has unfortunately characterised AD work in a number of institutions. 
However, even in the 1980s the need for $A D$ to be theorised and systematically informed by international thinking was increasingly strongly experienced. Putting AD on a firmer academic base was seen to be important for the work itself, but also necessary for influencing the academic community and institutional (and later national) policy. The flavour of the early thinking is perhaps best captured in Merlyn Mehl's (1988) 'Academic Support: Developmental giant or academic pauper?' So, by the latter years of apartheid, vibrant theoretical debates on matters of learning, such as the nature of educational disadvantage in the South African context, were under way, informed by the work of a range of theorists such as the psychologists Vygotsky, Piaget and Feuerstein, Bourdieu and various social theorists, Perkins, Cummins and many others in Applied Linguistics, and to some extent the phenomenography movement ${ }^{7}$. The flavour of formative South African perspectives is interestingly illustrated in contributions to the 'Salt Rock' workshop in 1988, 'New students in old universities' (Lazarus et al. 1989). Issues of $A D$ identity and its role in institutional and social change were hotly contested (see for example Vilakazi and Tema 1986; Moulder 1991; Hunter 1991), but also located in change theory (see for example Agar 1994). Under apartheid, policy work, aiming to raise awareness of the equity issue and create space for $A D$ work, was focused on institutions since there was no prospect of any government support.

A significant point is that some of the various specialised groupings within or associated with AD have strong academic identities of their own. Prominent among these are 'Language Development', which focuses on key issues arising from the fact that the majority of South African students do not have English (the dominant medium of instruction) as their first language, and is located in Applied Linguistics; and (tertiary) Science Education, where, notwithstanding much common ground, there have been particular tensions between conventional academic positions and the 'political' side of AD. The area of 'alternative admissions' and assessment for student selection, while strongly organically connected with $A D$, also has a distinctive identity and discourse.

While its form has changed since the political transition, the underlying tension within the identity and role of $A D$ has to some extent persisted, and continues to influence practice and research. Teaching in all its various forms is at the heart of $A D$, but the primary tension - often creative, sometimes not - lies between a more conventional academic approach, expressed in research and publication in scholarly media, and a 'developmental' approach, focused on policy change, implementing interventions and engaging the state, the institutions and the academic community. These approaches

7 See References for a few examples of works by these theorists that were influential in AD. 
should of course be complementary, but in practice there is contestation about whether standard educational research is having (or should be expected to have) a discernible impact on mainstream practice, about what constitutes a valid academic basis for developmental interventions, and about the relationship between the academic role and the professional service responsibilities of $A D$ in the institution. This tension is experienced in other countries as well, but is perhaps more acute in the context of South Africa's urgent need for change.

A related matter is AD's relationship with what Clegg (2009) terms 'more radical pedagogies'. From an early stage, a number of AD specialists have been interested in approaches to curriculum and teaching and learning that are alternative to and sometimes fundamentally different from the dominant traditional ones. Interests have ranged from socio-politically radical approaches like Freire's, through issues of programme identity and content like the 'Africanisation' of curricula, to alternative pedagogies like problem-based learning and other manifestations of constructivist learning theory. Many AD staff have incorporated aspects of such approaches into their own (student- or staff-facing) teaching and development work, but influencing mainstream practice is clearly of a different order of complexity. By and large, except in the rare cases where a mainstream discipline is supportive of substantial change in orientation, $A D$ units have focused their attention on the teaching-and-learning aspects of educational development where they have judged progress with inclusiveness can be made. Nevertheless, working within curriculum orientations with which they do not personally identify, has been and will no doubt continue to be a difficult matter for AD specialists. The topic is referred to again later in this chapter.

In some respects the tensions within $A D$ reflect wider dilemmas about the identity and role of academics and universities in South Africa's developing-country context. The way these dilemmas play out has major implications for the goals of equity and development, as will be discussed below.

\section{AD IN THE DEMOCRATIC ERA: THE TENSION BETWEEN EQUITY AND DEVELOPMENT}

In the run-up to the political transition in 1994 and for some years thereafter, there was an unprecedented opportunity for $A D$ to engage with national education policy, which was being radically re-engineered. The new government clearly identified with the goal of equity, which became one of the main pillars of higher education policy (DoE 1997). However, the tensions involved in real-world policy making soon made their presence felt. There were enormous pressures on the Department of Education (DoE) to 'do 
everything', to satisfy the wide range of stakeholders and competing expectations. In particular, the essential academic conservatism of the higher education sector and traditional views of its contribution to society came into conflict with an overwhelming demand for admission to higher education from black students, who had historically been largely excluded.

It was in such conditions that Wolpe et al., in the early 1990s, articulated the tension between 'equality' and 'development', the latter referring to the rigour, standards and competitiveness needed for economic as well as social development (Wolpe, Badat and Barends 1993). This conceptualisation, in its broadest form and in different manifestations, has remained a valid characterisation of the central tension in South African higher education policy and practice, and has far-reaching implications for $A D$ work and research. In these circumstances, AD has seen its fundamental goal to be promoting a fair and productive balance between equity and development, which has in turn meant trying to ensure that the equity goal is not submerged by traditional academic culture, and that educational approaches are developed that enable greater inclusiveness to be achieved without devaluing the currency of academic quality. As a means to this end, it has been critical for $A D$ to overcome its marginalisation, to gain space and support for educational development through recognition and secure resourcing.

$A D$-oriented academics have consequently been involved in various forms of national education policy development over the last two decades, in a long-term effort to give concrete expression to the goal of development with equity. Fortunes have been mixed, but key milestones have included the following:

- contributions to the National Commission on Higher Education (e.g. SAAAD 1995) that resulted in the first state recognition of $A D$ in the higher education White Paper of 1997. The White Paper's coverage of AD was brief, but critically included a commitment to funding $A D$ interventions - particularly foundational provision within 'extended curriculum programmes' - as 'integral elements of a higher education system committed to redress and to improving the quality of learning and teaching' (DoE 1997:Section 2.34);

- emphasis in the 2001 National Plan on Higher Education on the role of AD and extended curriculum programmes as a central means of facilitating equity of outcomes rather than only of access - this being a critical evolution of the policy understanding of AD (DoE 2001 :Section 2.3.2); 
- the inclusion of earmarked funding for $A D$ in the new higher education funding framework of 2003 and the consequent introduction of 'foundation grants' to cover previously unsubsidised foundational provision within extended programmes (DoE 2003; 2006).

Recognition and funding took many years of stop-start progress to put in place, but have been instrumental in extending AD work to institutions that had not been involved, and strengthening it where it was already established. The funding arrangements have kept the focus on alternative curriculum development. A range of extended curriculum programmes have been developed that interweave foundational and mainstream provision in innovative ways (for example, the College of Science at Wits and the Commerce and Science extended programmes at UCT). Unlike the original preparatory foundation-year model, these programmes do not leave the traditional curricula intact, but increasingly problematise them and their capacity to accommodate educational diversity. In addition to $A D$ work on the ground, theoretical knowledge and research have grown strongly this decade, and a number of $A D$ specialists now contribute to international scholarship in higher education studies.

However, $A D$ and what it stands for have remained largely on the margins. Apart from the growth of extended programmes - which, however, still accommodate only about $10 \%$ of the student intake and are very uneven in quality - there has not been significant systemic change in the educational process. Besides the still-small Quality Promotion and Capacity Development Directorate of the HEQC, there are no state-supported agencies or networks for promoting research or professional development in teaching and learning. While there have been major changes in access - black African students now make up over $60 \%$ of headcount enrolment (DoE 2009) - there is widespread experience of failure in many undergraduate courses. Given the importance of higher education to the country, it is essential to monitor its outcomes across all institutions so that the contribution of the sector as a whole can be critically assessed. The following section offers an outline of recent research findings on the sector's performance in undergraduate education, and of some key implications.

\section{PROGRESS TOWARDS EQUITY AND DEVELOPMENT? HIGHER EDUCATION PERFORMANCE IN THE $2000^{5}$}

It is only in the last five years that longitudinal sector-wide student performance data have become available that can provide a basis for such monitoring. The data concerned take the form of cohort studies of the first-time-entering student intake in 
a given year, produced by the DoE. The studies track the performance of all students in the intake until they graduate or leave their original institution without graduating, for a maximum of five years. The cohort studies for the year 2000 and 2001 intakes (the latest 'completed' cohorts at the time) were made available to a CHE-sponsored project, Improving Teaching and Learning for Success (ITLS), for in-depth analysis including disaggregation by race, subject area and institutional type. The following summary of key aspects of undergraduate performance is drawn from the ITLS analysis of the 2000 cohort of which the main patterns have been confirmed by later cohort analysis. ${ }^{8}$

- Performance in the sector as a whole shows very high attrition. After five years, only $30 \%$ of the cohort had graduated. If the optimistic assumption is made that $70 \%$ of students transferring to other institutions and of those still registered after five years will eventually graduate, the final completion rate will still not exceed $45 \%$.

- High attrition occurs in a number of countries, but commonly in an environment of high participation. It is critical to consider performance in South Africa against its participation rates. On the UNESCO measure of Gross Enrolment Rate $(G E R)^{9}$, developed countries range from about 60\% to 90\% (UNESCO 2007), while South Africa's rate is $16 \%$ (against a benchmark of $20 \%$ for countries at a comparable stage of economic development). Of at least equal concern are the racial discrepancies in participation: whites are at $60 \%$ and black Africans at $12 \%$. Key implications include (a) that it is vital for the higher education sector to be able to accommodate a substantially higher proportion of the country's majority population group, and (b) that the current black intake represents a highly selected group - by and large the top decile of the age group in terms of achieved performance - and thus must be expected to have strong potential to succeed. The common academic staff view that large numbers of the student intake are 'not university material' errs in conflating academic preparedness with potential, and is belied by the participation rates.

- Poor performance is widespread. The traditional contact university degree programmes - primarily the three-year Bachelor's and the highly selective fouryear Professional Bachelor's programmes - make up the best-performing subsector, but even there the cohort graduation rate after five years is only $50 \%$. In the

8 For the full study, see Scott, Yeld and Hendry (2007), aspects of which are elaborated in Yeld (2009) and Scott (2009b and c).

9 The GER represents total enrolment (of all ages) expressed as a percentage of the 20-24 age group in the population. 
former technikon programmes (now offered in the universities of technology and the comprehensive institutions), the rate is $32 \%$.

- Equity of outcomes is in many respects the central challenge. In key contact university programmes, black completion rates are less than half of the white rates, resulting in the absolute number of black graduates being less than the number of white graduates. Lack of equity of outcomes is thus neutralising the gains made in access. The net effect is that less than $5 \%$ of the black age group is succeeding in higher education in South Africa. ${ }^{10}$

These patterns have major implications for all forms of development, and should be central to the evolution of the AD agenda. Key implications include the following:

- Graduate output is far from meeting national needs in respect of either equity or development.

- The current system is above all not meeting the needs of the majority - the majority population group as well as the majority of the student intake.

- The equity and development agendas have converged. Given the quantitative data, it is clear that the substantial graduate growth needed can come only from the historically disadvantaged groups. Thus catering successfully for student diversity has become a necessary condition for economic development as well as for social inclusion.

- Given the participation rates, access remains an issue, but further enrolment growth will only worsen performance unless the system becomes more effective.

- Substantially improving the performance of the majority of the student intake primarily black and coloured students - is the key to improving overall performance, but it is these groups in particular that are not being successfully catered for in the current mainstream system.

- The scale of the challenge highlights the inadequacy of the scale of current AD work. The main systemic interventions, extended curriculum programmes, have served to increase the number of black graduates in many fields, but their effectiveness continues to be restricted inter alia by the difficulty of integrating them with rigid traditional mainstream curricula and teaching approaches, their marginal status

10 It is interesting to compare this with the average GER of $5 \%$ in sub-Saharan Africa (SSA) as a whole (Unesco 2007). There are no reliable data on SSA success rates but, given the very selective nature of universities in most African countries, graduation rates may be higher than those in SA. Graduate production in SSA as a whole may therefore be only one or two percentage points behind that of the majority population group in SA. 
and consequent lack of capacity and resources in a number of institutions, and their limited reach (some 10\% of the intake).

Given the significance of good higher education outcomes for the country, it is essential to analyse what can be done to improve them. This is a complex topic, but the salient points of an $A D$ perspective can be outlined here.

First, the major effects of the legacy of apartheid, socio-economic inequalities and the state of the school system are not in dispute. However, if we are to depend on change in such external factors to address the problem of graduate output, it is important to analyse the prospects of substantial improvement in these areas. The conclusion is that there is little prospect of such improvement. Socio-economic disadvantage is persistent, and analyses from various perspectives (see for example Van der Berg 2004; Bloch 2008; Yeld 2009) point to the probability that substantial improvement in the outcomes of the school system cannot be expected for a generation or more.

Higher education therefore faces a choice: to accept the status quo as unavoidable for the foreseeable future - in which case the failure to adequately develop the country's talent will continue - or to seek to identify factors that are within the sector's control, and purposefully address these. In AD experience, key among these factors is the educational process in higher education itself. As demonstrated by systemic interventions such as foundational provision (and similar experiences in other countries, such as in community colleges in North America and 'foundation' degrees in the UK), the design and implementation of the teaching-and-learning process is in itself a major variable influencing who succeeds. Doing things differently can enable higher education participation to be successfully widened.

This represents the central educational challenge for AD and the sector as a whole: to develop and implement educational structures and teaching-and-learning approaches that can meet the needs of the majority of the (needed) student intake - now and in the future context of increasing need for growth - and are also flexible enough to successfully accommodate the high level of diversity of educational background that will continue to characterise the system, so that well-prepared students are not artificially held back. Proposing this focus on educational effectiveness is not intended to make light of the issues of content, canon and orientation in the curriculum, or the influence of these on inclusiveness and outcomes. It is contended, however, that creative curriculum ideas will have little or no effect if the educational framework and approaches of the higher education process are not aligned with the actualities of the students' learning needs. 
The sector's capacity to meet its core educational challenges depends greatly on raising the level of effort and expertise in this area, as is discussed in a later section.

\section{AD IN THE 20005: BROADENING THE AGENDA}

How then has AD work responded to these conditions over the last decade? Despite the major contextual changes that have occurred, the challenges are essentially the same as they have been since the inception of $A D$, though now more sharply delineated. It is therefore not surprising that the need for $A D$ work at national and institutional levels continues. However, growing concern about student performance - particularly in national bodies such as the DoE, CHE and JIPSA (2006) as well as in some institutions - has increased the need and opportunity for focusing on mainstream educational development, i.e. designing and implementing structures and approaches intended to improve the effectiveness of teaching and learning across the institution. As outlined earlier, this goal, in various manifestations, has a long history in $A D$, but has rarely had widespread support from regular academic staff or led to any substantial changes in mainstream practice.

Purposeful, credible and professionally accountable commitment to mainstream educational development has considerable implications for the identity, organisational location and knowledge base of AD. It does not mean a departure from AD's central concern for equity-related development - as the figures show, enabling historically disadvantaged student groups to realise their potential remains the key to improvement in the sector as a whole - nor from the specialised curriculum design and teaching that has been at the heart of $A D$ in many institutions. Dedicated work of this kind has constituted $A D^{\prime}$ s main laboratory where theory, practice and research can come together and where success is fundamental to AD's credibility. It does, however, call for a strengthened commitment to research-informed development, professional responsibility, and the ability to engage the cooperation and trust of academic colleagues at all levels of the university, primarily through scholarship and demonstrably good practice.

The nature and level of sophistication of AD work has continued to be uneven across the sector, not least because inadequate and insecure funding has discouraged career commitment and research specialisation among staff. However, the following examples of work undertaken in recent years are indicative of the trend in the AD agenda. 
As argued earlier, the significance of systemic change, and consequently of national policy development, is as great as ever. At this macro-level, AD-related policy work has focused on three inter-related areas:

- Curriculum: In addition to ongoing work with the DoE on the design and funding of extended programmes, there is widening debate on the need for and feasibility of curriculum reform. The Minister of Education has consequently requested the $\mathrm{CHE}$ to undertake a comprehensive study of this issue. The main driver of the reform initiative is the importance of creating more curriculum space, both to allow for accommodating the realities of the student intake within a flexible framework, and to enable undergraduate curricula to respond to the increasingly complex demands of the contemporary world - including, in South Africa, preparation for informed and responsible citizenship - without diluting core disciplinary knowledge. $\mathrm{AD}$ identification with both these key aspects of systemic educational development is a good illustration of the broadening of the $A D$ agenda.

- Student selection and 'placement': This strand of AD cannot be discussed here except to note that it is an essential complement to curriculum-based educational development. AD work in this area has focused primarily on (a) identifying students who have the potential to succeed in higher education, but because of their educational background do not perform well in standard school-leaving assessments such as the National Senior Certificate, and (b) gaining an understanding of students' levels of preparedness that can inform the key process of guiding them into the level of introductory provision that will best meet their learning needs. The import of this work for developing the country's talent should be clear. There is a 20-year history of AD work in this area, the most recent manifestation of which is the development of the National Benchmark Tests initiative in cooperation with national bodies, notably Higher Education South Africa (HESA) which is the representative body of the universities' leadership.

- 'Teaching development': The effectiveness of course design and teaching on the ground in the institutions is of course at the heart of the wider educational development agenda. While teaching approaches are not and should not be prescribed nationally, a major shortcoming in South Africa is the absence of any state-supported bodies or networks dedicated to supporting the development and dissemination of teaching-and-learning strategies that are effective for this context. The AD community, through senior individuals and its recently established professional association HELTASA (Higher Education Learning and Teaching Association of Southern Africa), has become increasingly involved in working for 
development in this area, including through participation in the DoE's task group on the Teaching Development Grant, a significant element (R300m-R400m p.a.) of the higher education funding framework, the strategic use of which is being conceptualised at national level. Development in this area could have a real impact on mainstream practice, and is a key and growing element of the AD agenda.

At the institutional level, the role of $A D$ differs markedly across universities, in a number of which it carries very limited influence. However, the process of maturing and broadening is evident in some key cases of cooperation between education development specialists and regular academic departments or faculties in mainstream curriculum development. Notable among these are major initiatives undertaken in recent years in Health Sciences, where as part of an international trend curricula are being radically renewed to adopt a Primary Health Care orientation, with in some cases a simultaneous shift to problem-based learning. The complementary knowledge and experience (and sometimes project management role) of the educational specialist becomes an integral and accountable part of the development process. In some recent projects, in an interesting departure from most historical AD contributions, the role of the educationist - where they have the necessary knowledge of the field - has not been content-neutral. This kind of project has provided strong indications of the value of complementary knowledges and expertise - in the relevant core disciplines, in research-informed curriculum design, and (in the South African context which has to cater to a range of linguistic backgrounds) in areas such as Language Developmentin the development and teaching of academic programmes that have to meet complex contemporary needs and accommodate a diverse student body. The various specialisms are not found in one person, hence the value of a team approach, especially if it is mutually educative.

Perhaps as a consequence of $A D^{\prime}$ s changing profile, renewed critiques of its role are emerging. In a challenging comparison of $A D$ in South Africa and the UK, Clegg (2009:x) raises the issue of the relationship between AD and radical pedagogies. Part of her argument is that in [AD's] constituting teaching and learning as its object other more radical, feminist, and critical pedagogies, which are capable of dealing with the power and curricula, were marginalised.

As noted earlier, related issues arose as early as the 1980s, when a number of AD units took strategic decisions to avoid overtly taking sides in struggles over curriculum content and orientation in order to concentrate on working with the departments on equity and inclusiveness. In South Africa, the question of the extent to which inclusiveness involves 
changing the content and orientation of the curriculum has been vexed and dependent on disciplinary context: think of Physics and English Literature, for example. A related issue is that most recently expressed by Boughey (2008), who critiques the $21^{\text {st }}$ century role of $A D$ as supporting the neo-liberal project as it is manifested in contemporary higher education in South Africa. This issue also has a long history, originating in the context of the struggle against apartheid in the 1980s with political critiques of $A D$ as reformist and insulating the educational establishment against change (see for example Lazarus et al. 1989; Vilakazi and Tema 1985) - critiques that were sharpened by the slogan 'No education before liberation'. These issues will no doubt continue to be important and controversial, and will be all the more pointed as opportunities arise (as in the Health Sciences example noted above) for AD specialists to have a voice in the orientation as well as the educational approaches of the curriculum.

If $\mathrm{AD}$ (or HED or whatever other terminology may become current) is to grow fully into a more comprehensive, prominent and accountable role - as it should if it is to meet its obligations in improving educational effectiveness across the sector - there are important implications for the way it organises itself and for the development and dissemination of its knowledge and expertise. A good proportion of permanent AD specialists have responded to changing conditions in the universities - and to the stimulus of identifying with the growing international community of higher education scholars and researchers - by undertaking advanced studies and formal research in the area of educational development, so South African contributions to the international literature are increasing. As staff have achieved sufficiently senior academic status, a number of institutions are now able to offer master's and doctoral programmes in Higher Education Studies.

Research-on-research designed to understand the underlying theories, themes and directions of AD-related inquiry is needed but still in its infancy. The influences on AD have widened greatly over the last decade as AD staff have increasingly linked up with the international higher education scholarly community. Broad influence comes prominently from UK and Australasian scholarship - particularly in the sociology and philosophy of higher education (cf. writers such as Trowler, Knight, Bernstein, Barnett) - as well as from North America, and the Scholarship of Teaching and Learning (SoTL) movement is gaining currency. Educational and social theory continues to underlie much work. Phenomenography's dominant position in Europe and Australasia is increasingly critiqued. 
Perhaps because of AD's historical focus on subject teaching in foundational provision, a good proportion of educational development staff continue to identify primarily with discipline-specific educational theory and practice, such as Science or Health Education, or other specialised fields such as Applied Linguistics and the New Literacies. While there are obvious overlaps with the core of $A D$, the different allegiances show up in the kind of conferences $A D$ staff participate in, the different literatures they consult, and the historical difficulty of establishing a common discourse among AD staff in the same institution. The differences can clearly be stimulating and critical of orthodoxies, but also present an interesting challenge for HELTASA. They also provide food for thought in conceptualising any future state-supported organisation for promoting research and development in teaching and learning.

This brief overview of the current stage of $A D$ omits much, but is intended to indicate some of the issues and challenges in the professional AD community itself. However, a fundamental element of the wider $A D$ agenda is that the goals of equity and development will not be met without mainstream systemic change in design and delivery, which in turn depends ultimately on behaviours, priorities and attitudes in the academic community at large. This key topic is addressed elsewhere in this volume but the following section offers a brief overview of the connections between AD and mainstream teaching.

\section{AD AND THE RECOGNITION OF 'TEACHING' IN HIGHER EDUCATION}

The progress of $A D$ has been strongly affected by the status of teaching in higher education. Moreover, given the importance of mainstream educational development for equity and development, the future of $A D$ and its goals is inextricably bound up with how the significance of the educational function of higher education is perceived, and what the consequences of this are for the recognition and rewarding, and thus the status, of teaching. It should be emphasised that 'teaching' here means engagement in all aspects of the educational process, from curriculum or programme development through course design to direct work with students.

In South Africa, as in many other parts of the world, the status of teaching in higher education has historically not been high across the sector. Evidence of this includes: there are few if any adequately resourced 'teaching development' operations in the institutions; the HEQC's Quality Promotion and Capacity Development directorate, which is still at an early stage of development itself, is the only statutory body with a mandate to improve teaching and learning; there are no state-funded national 
organisations or infrastructure for supporting educational research and development; and the perception that only certain forms of published research bring academic career advancement is rarely contradicted. There are in fact indications that teaching is being further neglected as a result of the new institutional 'landscape', in that the universities of technology and to some extent the comprehensive universities are concentrating on building up conventional research cultures, often from a low base.

The low status of teaching contrasts sharply with the pressing need to improve the educational effectiveness of the sector, and the consequences for the country if this is not done. There may be many contributory factors, including the rapidity of change in the institutions and the student body, but on the evidence of the performance patterns, current mainstream approaches to design and delivery are not meeting the national need. In the South African context where the majority are affected by educational disadvantage, educational development cannot be left only to AD specialists.

Both $\mathrm{AD}$ (as a specialism) and mainstream teaching are thus trying to emerge from marginalisation. The question of what it would take for teaching to be properly recognised as a legitimate and valued academic activity is a key strategic concern. Discussion of this complex matter is outside the scope of this chapter, but the literature and $A D$ experience suggest the following key points:

It is in the first instance essential that teaching be given greater 'attention' (Carey 2008) - that is, enjoy the care and effort that the importance of the educational function of higher education in a developing country calls for. This is most unlikely to happen without a significant shift in the dominant higher education value and reward system. Such a shift should not mean underrating the key role of research in development; however, while many university mission statements assert the interlinkage between research and teaching, in practice many academics experience the relationship as a stressful tension rather than one of mutual strengthening, and teaching suffers as a result. ${ }^{11}$ Since the dichotomy between research and teaching that has been created by current reward systems is highly undesirable, the goal must be to achieve a productive balance, based on respect for these different expressions of scholarship and, in particular, full appreciation of the significance of both in our developing country context.

'Attention', however, is not enough in itself. It is evident from institutional data, local experience and the national performance patterns that the traditional teaching approaches that are predominant in South Africa have proved less than adequate in

11 For an interesting range of perspectives on this topic, see Marwell (2007). 
facilitating quality learning in the majority of the student body. The craft knowledge underlying these approaches appears to lack the capacity to produce effective responses to educational disadvantage and the diversity of the student body in many institutions. What is called for is raising the level of educational 'expertise' (Kreber 2002) - that is, systematic knowledge of teaching-and-learning theory and practice. Such expertise is necessary for effectiveness not only in curriculum and course design but also in daily practice in the lecture hall, as well as in the real or virtual classroom. It should provide academic teaching staff with the conceptual tools to understand and adapt to new conditions for which their prior experience has not equipped them.

Promoting educational expertise also calls for changes in the material reward system, but this is not enough. Engaging academics' intellectual interest in teaching and learning, and achieving respect for the educational process as an academically challenging area of inquiry, are also necessary conditions for educational expertise to prosper and expand. This depends on awareness of the growing body of higher education theory and research literature, and particularly on the visibility of examples of successful teaching and learning that are informed by sound research. AD specialists no doubt need to play a leading role in working to establish a theorised environment for educational development, but the wider aim is to extend the scholarship of teaching and learning into the mainstream of the universities. This is not to say that all academic staff should become educational specialists; the goal is rather to ensure that an appropriate level of educational expertise is present in departments and programme teams and that the expertise is credible and respected enough to be effectively utilised.

There is a risk of unintended consequences in building an academic basis for educational development, namely that the connection between research and development may become increasingly tenuous, opening up the old fault-line (still present as a residual tension) between 'activist' and academic orientations. To a South African eye, this kind of division exists today in some developed countries - manifested in the USA, for example, in the organisational and academic distance between prominent higher education studies departments and minority education programmes in one or other form; or in England, between such departments and Widening Participation units. The concern is that in these circumstances, the research available is not well utilised by developmental operations on the ground, and the researchers do not see it as their function to become involved in development. Educational scholarship and research then have little if any impact on practice, and therefore on outcomes. In the context of South Africa (and no doubt other developing countries), this could well be seen as misdirection of scarce resources and losing sight of the overarching needs. In this 
context, it seems justifiable to try to focus educational research and development energy on the central goal of improving the effectiveness of teaching and learning across the sector, in terms of quality, inclusiveness and responsiveness to contemporary conditions.

\section{IN CONCLUSION: THE AD PERSPECTIVE}

This chapter has argued that $A D$, or rather what it represents, continues to be a major issue in South African higher education, and will if anything have growing significance as the elusiveness of equity and transformation strains the country's patience. Also, to revisit the theme raised earlier, the chapter has attempted to outline the situation that gives rise to the $A D$ perspective on the higher education sector, which contrasts uncomfortably with others in terms of priorities and orientation. What then is that perspective?

When the higher education sector is seen through an $A D$ lens, it seems clear that there is something fundamentally wrong at the heart of it. A system that is not able to successfully accommodate more than $5 \%$ of the majority population group is failing in a critical way. In contrast with the position in most other African countries, the shortcoming cannot be attributed in any simple way to lack of material resources, given that a very respectable proportion of GDP is allocated to higher education. In fact, HSRC researchers have estimated that state subsidy spent on students who fail or drop out currently amounts to over R3 billion a year (Letseka and Maile 2008). While socio-economic and schooling conditions are clearly a major factor, the performance patterns and $A D$ experience indicate that in key respects the sector is misaligned with the realities of its host society, and is not contributing adequately to what the country probably most needs from it, that is, good graduates in appropriate numbers from all communities. This is a central purpose of higher education - arguably the main one in developing countries - and failure to achieve it on the present scale diminishes successes in other aspects of the sector's role. In these circumstances, important debates on matters ranging from governance to world trends in curricula can have a hollow ring.

At the heart of the matter is the identity of the sector as a whole and the academic community in particular. The main identity tension affecting both the universities and individual academic staff is much the same, and is not surprising. An acceptance of the responsibility to meet local needs, particularly through undergraduate teaching, co-exists with, but is commonly outweighed by, the strong desire to be successful in the 
international world of scholarship, with all the intellectual, reputational and material rewards this brings. While mission statements declare institutional commitment to both these goals, the sector's performance patterns suggest otherwise; and formal and informal discourse in universities of all kinds on the 'burden' of dealing with the disadvantaged majority underlines the understandable but at present unequal contest.

This depiction of the sector is a disturbing one. However, the AD perspective at the same time provides a view of key measures that may make a substantial difference to effectiveness and inclusiveness, and are also within the power of the sector to implement. Curriculum reform of the kind outlined earlier is challenging but feasible, and if it were to save even a third of the 'wastage' in the system, affordability should not be an obstacle. It is feasible for the institutions to recognise the critical contribution of effective teaching and educational development to their core business, to introduce reward systems that stimulate educational effort and expertise, and through their recruitment and promotion systems to gather staff with complementary knowledge and skills of the kind that are necessary to deliver programmes and research that meet contemporary needs. It is also possible for the state and the institutions to agree on a form of mutual accountability for the outcomes of higher education that is founded on the importance of meeting national needs and the provision of resources to do so. If this can be done, the way can be opened to establishing a productive linkage between teaching and research, equity and development, and local and international obligations, which can go a good way towards addressing the 'frustration and sense of powerlessness' (Bitzer, Preface in this volume) that result from the unresolved tensions so commonly experienced by academics in South Africa.

To come back to AD itself, its primary challenge as a specialised field will probably be to continue strengthening the academic and professional foundations of its work at the same time as taking forward the educational development agenda in concrete forms: in policy advocacy and planning and in supporting implementation at sector and institutional level. Major forthcoming projects that AD will hopefully be centrally involved in - or that $A D$ should strongly advocate as priorities on the national agenda - include: (a) structural curriculum reform of the kind discussed earlier; (b) the establishment of state-sponsored national, regional and institutional structures and networks that support professional development in teaching, educational research and educational expertise in higher education; (c) continuing the development and expanding the use of alternative student selection and placement instruments that assess academic potential rather than only achieved performance, so that talented but 
disadvantaged students can be identified and admitted at an entry level that matches their learning needs. ${ }^{12}$

If $A D$ is to position itself to address these challenges effectively, there are implications for its own development agenda, including the following:

- If the AD perspective is to have a positive influence on the sector, the scholarship and research (quantitative and qualitative) that back it must continue to be strengthened. This means that the residual tension between the activist and academic orientations in $A D$ needs to be openly debated, to improve understanding of the different roles and particularly the relationship between research-for-policy, research-onpolicy, and the wider field of SoTL. A fundamental question here is to what extent educational research and SoTL will have the capacity to inform higher education development in such a way as to make a substantial difference to who benefits from higher education, particularly in contexts like South Africa where the significance of improvement of outcomes is so high (Scott 2009a).

- It can be expected that opportunities or calls for $A D$ to embrace more radical pedagogies or educational agendas will arise more frequently than has been the case. While the involvement of AD specialists in such developments should depend on their knowledge base and the merits of the case, more open debate and writing about the character and fitness of purpose of South Africa's mainstream curricula would add an additional critical dimension to educational development that could stimulate specialists and mainstream academics alike and ensure that $A D$ does not artificially confine itself within a 'technicist' approach (Clegg 2009).

- As the scope of AD has widened, more and more common ground has been found with similar fields abroad, not just academic development itself (in the British and Australasian sense), but a range of areas of higher education studies. However, most of the interaction has been with English-speaking first world countries. The time may well have come for AD to widen its horizons by actively seeking engagement with systems in the global South or other emerging economies - such as India, South American and Eastern European countries, and other African countries where challenges and constraints are similar to our own.

12 The complex topic of approaches to student selection and placement has been only superficially referred to in this chapter, but is a key element of successful curriculum reform. It is bound up with the question of who higher education in South Africa is for, and has key implications for responsible approaches to widening participation. 
It is commonly noted in South Africa that there is little if any AD, as we know it, in other sub-Saharan African countries. This may be the case, because higher education systems in these countries have historically been very small (GER averages 5\%) and highly selective. However, the situation is changing rapidly: higher education enrolment is increasing at $15 \%$ a year, the highest rate in the world (Africa Higher Education 2008), with much of the growth occurring in new private institutions, generating considerable problems of quality assurance and regulation. In these circumstances, and with class, ethnic or regional inequalities being chronic, widening participation is likely to be very challenging, and it would be surprising if the same kind of issues as affect South Africa (albeit not racially based) were not already arising. The next decade may thus offer a unique period of opportunity to engage with other parts of the continent, with mutual benefit and enrichment.

The situation of higher education in South Africa has features that create special difficulties, but at the same time make it an unusually interesting and significant area for research and creativity in educational development. In contrast with developed countries, educational disadvantage here is a majority phenomenon. In contrast with other African countries, the South African system is large and highly diverse, and there is a 30-year history of experience and experimentation with educational development, much of it in adverse conditions. Educationists in South Africa, both inside and outside of $A D$, are consequently in a good position to contribute to the theorisation of teaching and learning in higher education, to undertake sound empirical work, to implement innovative educational approaches, to influence the sector, and to interact constructively with colleagues and organisations in other countries. The extent to which this will happen depends much on how seriously national bodies and the sector itself take up the challenges of equity and development that are becoming increasingly visible and pressing.

\section{ACKNOWLEDGEMENT}

To Kalie Strydom: for marrying research and development better than anyone else in the first decades of $A D$, in which work he was selflessly and most ably partnered by Alida; for true courage in not resting content with a pioneering role in developing higher education scholarship, but also engaging an often hostile environment and producing innovative development on the ground, which has benefited many thousands of students over the years; and for giving generous developmental opportunities to inexperienced entrants to the higher education field, including this writer. 


\section{REFERENCES}

Africa Higher Education. 2008. Higher Education in Sub-Saharan Africa [Online]. Available: http://www.arp.harvard.edu/AfricaHigherEducation/Data.html [2008, 7 December].

Agar D. 1994. Universities and the academic profession: Implications for change. SA Journal of Higher Education, 8(2):5-8.

Badat S. 2009. Theorizing Institutional Change: Post-1994 South African Higher Education. Forthcoming in special edition of Studies in Higher Education.

Bitzer EM. 2009. Preface to this volume.

Bloch G. 2008. Fixing schools: A 30-year task. Pretoria News, 31 July: 12 [Online]. Available: http://www.iol.co.za/index.php?set_id=1\&click_id=13\&art_

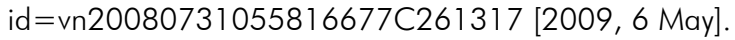

Boughey C. 2008. Educational Development in South Africa: From social Reproduction to Capitalist Expansion? Higher Education Policy, 20:5-18.

Carey K. 2008. Graduation Rate Watch: Making Minority Student Success a Priority. Washington DC: Education Sector [Online]. Available: http://www.educationsector.org/ usr_doc/Graduation_Rate_Watch.pdf [2009, 5 May].

Clegg S. 2009. Histories and institutional change: Understanding academic development practices in the global 'north' and 'south'. International Studies in the Sociology of Education, 16. In press.

Cooper D \& Subotzky G. 2001. The Skewed Revolution: Trends in South African Higher Education. Bellville: Educational Policy Unit, University of the Western Cape.

DoE (Department of Education). 1997. Education White Paper 3: A Programme for the Transformation of Higher Education. Pretoria: Government Gazette, No. 18207. 15 August.

DoE (Department of Education). 2001. National Plan for Higher Education. Pretoria: Department of Education.

DoE (Department of Education). 2003. Funding of Public Higher Education. Schedule to the Higher Education Act (Act No. 101 of 1997). Pretoria: Department of Education. November.

DoE (Department of Education). 2006. Funding for foundational provision in formally approved programmes: 2007/08 to 2009/10.

DoE (Department of Education). 2009. Education Statistics in South Africa 2007. Pretoria: Department of Education.

Feverstein R. 1980. Instrumental enrichment: An intervention program for cognitive modifiability. Baltimore: University Park Press.

HEQC. 2007. HEQC Institutional Audits Manual. Pretoria: Council on Higher Education.

Hofmeyr J \& Spence R. 1989. Bridges to the Future. Optima, 37(1):37-48.

Hunter P. 1991. Academic support or mainstream change? SA Journal of Higher Education, 5(2):5-6. 
Kreber C. 2002. Teaching excellence, teaching expertise, and the scholarship of teaching. Innovative Higher Education, 27(1):5-23.

Lazarus J, Miller R, Moll I, Slonimsky L \& Craig A. 1989. New students in old universities: Cognitive development in the South African tertiary education context. SA Journal of Higher Education, 3(1):153-172.

Letseka M \& Maile S. 2008. High university drop-out rates: A threat to South Africa's future: HSRC policy brief. March edition. Pretoria: Human Sciences Research Council.

Marwell P. 2007. Papers from an international colloquium: International policies and practices for academic enquiry [Online]. Available: http://portal-live.solent.ac.uk/university/ itconference/2007/colloquium_papers.aspx [2009, 5 May].

Mehl MC. 1988. Academic Support: Developmental giant or academic pauper? SA Journal of Higher Education, 2(1):17-20.

Moulder J. 1991. Remedial education programmes: Miracle or failure? SA Journal of Higher Education, 5(1):5-10.

Perkins D. 1986. Knowledge as Design. Hillsdale, New Jersey: Lawrence Erlbaum Associates.

Piaget J. 1972. Intellectual development from adolescence to adulthood. Human Development, 15:1-12.

SAAAD (South African Association for Academic Development). 1995. Facilitating Academic Development as a key element of transformation in Higher Education. Submission to the National Commission on Higher Education by the SA Association for Academic Development. Johannesburg: SAAAD.

Scott I. 1986. Tinkering or transforming? The contribution of academic support programmes to 'opening the doors of learning and of culture'. Aspects 7. Pietermaritzburg: University of Natal.

Scott I. 2009a. Towards an Agenda for SoTL in Africa? International Journal for the Scholarship of Teaching and Learning, 3(1), January 2009 [Online]. Available: http://academics. georgiasouthern.edu/ijsotl/v3n 1.html [2009, 28 Apri].

Scott I. 2009b. Who is 'getting through' in South Africa? Implications for the reconstruction of the formal curriculum. In: D Featherman, M Hall \& M Krislov (eds). The Next Twenty Five Years? Affirmative Action and Higher Education in the United States and South Africa. University of Michigan Press. Forthcoming.

Scott I. 2009c. First-year experience as terrain of failure or platform for development? Critical choices for higher education. In: B Leibowitz, A van der Merwe \& S van Schalkwyk (eds). Focus on First-year Success. Stellenbosch: SUN MeDIA. Forthcoming.

Scott I, Yeld N \& Hendry J. 2007. A case for improving teaching and learning in South African higher education. Higher Education Monitor No. 6. Pretoria: Council on Higher Education [Online]. Available: http://www.che.ac.za/documents/d000155/index.php [2009, 21 April].

Scott I, Yeld N, McMillan J \& Hall M. 2005. Equity and excellence in higher education: The case of the University of Cape Town. In: GB William, AM Kurzweil \& EM Tobin (eds). Equity and Excellence in American Higher Education. Charlottesville, VA: University of Virginia Press. Thomas Jefferson Foundation Distinguished Lecture Series. 
UNESCO. 2007. Education For All Report 2008. Paris: UNESCO.

Van der Berg S. 2004. School education and transformation [Online]. Available: http://transf. audit.co.za/articles/education/pdf [2009, 4 May].

Vilakazi H \& Tema B. 1985. White Universities and the Black Revolution. Paper presented at the 1985 Academic Support Programmes Conference. Johannesburg: University of the Witwatersrand.

Vygotsky L. 1978. Mind in society: The development of higher mental processes. Cambridge: Harvard University Press.

Wolpe H, Badat S \& Barends Z. 1993. The post-secondary education system: Beyond the equality vs. development impasse and towards policy formulation for equality and development. Cape Town: Education Policy Unit, University of the Western Cape.

Yeld N. 2009. Getting In: Admissions Policies. In: D Featherman, M Hall \& M Krislov (eds). The Next Twenty Five Years? Affirmative Action and Higher Education in the United States and South Africa. University of Michigan Press. Forthcoming. 


\section{PART TWO NORMATIVE AND EPISTEMOLOGICAL ISSUES IN HIGHER EDUCATION}




\title{
THE UNIVERSITY AS KEY CONCEPT IN HIGHER EDUCATION STUDIES
}

\author{
A JOURNEY WITH RESEARCH INTO A \\ CONCEPTUAL ANALYSIS OF A UNIVERSITY
}

\section{Laetus OK Lategan}

An occasional look at present ideas in the light of their intellectual origins serves to strengthen our resolution to press on with what we are doing today.

Guy Neave (2001:29)

\begin{abstract}
This chapter considers the questions: "What is a university? Exactly what does a university have to do with higher education studies?" The discussion on what a university is provides a framework that can be used in higher education policy studies in particular and higher education studies in general. The chapter begins from a philosophical perspective and builds on the concepts of continuity and discontinuity. Based on these concepts, it is argued that new knowledge development (research) and knowledge transmission (teaching) are central to the university and have been, throughout the history of universities. What has changed is the way in which these tasks have been performed. Needless to say, the author is well aware that this is but one way of dealing with the question at hand. The author points out that although he has remained true to his own paradigm, this did not prevent him from changing his views on the topic. The chapter highlights that the university is a social organisation consisting of people (ranging from lecturing and managerial staff to students). What is often forgotten is that both people and their activities should be managed. Since the university does not exist in isolation, universities are challenged by partnerships, social engagement and developmental issues. The chapter also highlights some images of the university caused by certain dominant factors impacting on the university, and concludes with some pointers and lessons based on the author's research into the concept 'university'.
\end{abstract}




\section{PLANNING THE JOURNEY}

My interest in the question "What is a university?" started some 20 years ago when I wrote a master's dissertation in philosophy on the "nature of the university" (Lategan 1989). Since then I have subscribed to the belief (no religious belief!) that without an understanding of what a university is, it is almost impossible for the university (as an organisation) to operate effectively in society. In addition, I am also of the opinion that this question and the ensuing answers form the basis of all higher education studies. If one says that the university is about social development, then one needs to ask how the university should address this issue. If one argues that the university exists simply to educate students for future careers, then the question would be how best a university can achieve this. Regardless of how one views the university, it should lead one to unpack those activities with which a university concerns itself.

A fundamental understanding of the complexities associated with a university as social organisation and how the university should function within society is central to all higher education studies. This orientation was confirmed over a period of 20 years, and four other observations have strengthened this belief.

Firstly, when I attended my first conference on higher education I realised that this question will always be a fundamental question in higher education studies. It was during the Ninth Biannual Conference of the South African Association for Research and Development in Higher Education (SAARDHE) in 1994 that no fewer than seven of the papers were devoted to some or other attempt to understand the concept 'university'.

Secondly, at the closure of a conference, What kind of University? organised by the Open University in London in 1996, the then Vice-Chancellor Sir John Daniels remarked that perhaps the theme of the conference should rather have been What is a university? His remark (according to my analysis) signalled that for one to understand what kind of university is needed for society one needs to understand what the purpose of a university is.

Thirdly, the UNESCO-awarded higher education researcher, Prof. Ulrich Teichler, observed in his book, Higher Education Systems (2007), that the conceptual analysis of a university is no stranger to higher education policy studies. The university needs to know itself, and to know what factors are impacting on it.

Fourthly, Van Vught (1997) refers to the university as a "micro cosmos" with its own laws and history. He advocates contemporary relevance, but argues for high quality, 
the stimulation of intellectual education and scholarship. Van Vught also reminded me that, since the university and its knowledge are so important, they have to be managed. Some management approaches can be regarded as characteristic of universities. He refers to three characteristics. First, there is the professional character of a university as organisation. Because the university is an organisation, a professional approach to university management cannot be compromised. Second, it should be remembered that the university consists of various disciplines. To this extent the fragmentation of the university should be managed. In the third place, the diversity of decision making in universities should be managed. The challenge is to unify this diversity, to unite the fragmentation and to awaken a new professionalism. He rightly says that a university is more than loose-standing disciplines and activities. Scientific disciplines and activities should jointly contribute towards solving societal challenges.

Many more (and similar) encounters can be sampled. Suffice it to say that the dynamic challenges facing a university as organisation, coupled with the ever-increasing demand for the university to be responsive to societal needs, call for a continuous revisiting of the role of a university. This call is furthermore informed by the postmodern philosophical orientation that neither a fixed structural understanding of what a university is, nor a 'one-size-fits-all' approach exists. On the basis of my rationalistic paradigm of conceptual analysis of a university, I cannot agree with the first statement of the post-modern philosophy (no fixed structure). My own research and exposure (as an employee of a university) have brought me to a fundamental understanding of a university namely that, taking on the metaphor of one-size-fits-all, there is a common size for a university (let's call it its core functions), but that this common size is fitted depending on the feet wearing them (each university takes care of its core functions in a different way). From an intellectual perspective this understanding was influenced by - to name but one uncontested name - Plato's view of continuity and discontinuity in his youth dialogue 'Kratylos'. If the university changes (for example, by adding new university types), is there still a structural identity to be found in the university as a social structure? Is there anything constant in the nature of the university which continues, regardless of any (structural) changes that may occur? Which fundamental structural principle can always be recovered, from the origin of universities, or is each new university and each new period of time purely the product of the organisational creations of humans? Plato realised that all changes can only occur on the basis of constants. No change is possible if there is no foundation for change. With reference to this perspective of Plato, it may be expected that even when the university changes by taking on new forms, the teaching, research and service still have to be continued. 
Although the university community, for example, may change by introducing new university forms (such as the comprehensive university or university of technology in South Africa), this new adjustment can never be removed from that which is typical of the university. [Kerr (1995) provides an excellent account of how a university can change to fit its context without bidding farewell to its core activities. A good example is American universities shifting their focus towards military science after the World Wars. Bok (2003) also describes what can happen to a university if it lets go of what its real purpose is. In his book on commercialisation in higher education he portrays a negative image of a university if it must become a business at all costs.] From an employee perspective this was observed/experienced through encounters such as the (political) transformation of a university, debates on what the core functions of a university really are, the change from a technikon (regarded as a non-university system) to a university (of technology), policy planning and implementation, and so on. This observation, namely that the university can change but its functions remain the same, will be further explored through my journey with research into understanding what a university is.

The broad theme of this contribution is to reflect on the question "What is a university?" Answers to this question will provide some perspectives on what a university is and how it can (best) execute its core functions in a post-industrial corporate society. In answering this question I will reflect, on my own research on this topic (Lategan 1989, 1996, 1998, 2000, 2005), amongst others. The reason for this approach is twofold. Firstly, research involves self-assessment. (Too many researchers never look at their own research.) Secondly, in doing higher education research there is also a need for methodological understanding, review and change. The approach taken to the question in this chapter should also tell something about methodological approaches.

\section{BUYING THE TICKET: A CONCEPTUAL UNDERSTANDING OF WHAT A UNIVERSITY IS}

In answering the question of what a university is, a number of approaches are needed to unpack the conceptual meaning of a university. It may be stated that neither the history of universities, nor the tasks assigned to universities, nor policy directives are sufficient to provide a comprehensive definition of a university (see Lategan 2005). This statement does not mean that policies and history are not important. It simply implies that conceptual knowledge is also needed to understand what a university is. To illustrate this point: 
The history of universities can briefly be divided into four stages (see Lategan 1989, 1998, 2005 for a detailed analysis). During the $12^{\text {th }}$ to the $14^{\text {th }}$ centuries, the medieval universities at Bologna, Parma, Paris and Oxford specialised in the training of professional clergy, lawyers and clerical and lay administrators, and could be regarded as vocational schools. It is not strange that the curriculum consisted of the trivium (grammar, logic and rhetoric) and quadrivium (arithmetic, geometry, astronomy, music and science) at undergraduate level, and theology, law and medicine at the postgraduate level. The former is in line with those subjects offered at the Academy of Plato, the Lukeion of Aristotle and education in general in the ancient Greek World. The $15^{\text {th }}$ to the $19^{\text {th }}$ centuries were characterised by education for the elite. Although the curriculum remained the same as that of the original vocational university, the purpose was not for training, but for education. Following this period, during the $19^{\text {th }}$ century up to the 1950s, knowledge was fragmented in the Cartesian reductionist fashion in which one could isolate a very small domain of possible knowledge and focus one's entire energy on it. The intellectual world became isolated from the world out there. Everything was done for the sake of knowledge. The notion of pure knowledge could of course not accommodate mundane technological enterprises with the result that engineering, for example, was at first avoided and only included in the late $19^{\text {th }}$ century. The 1960s introduced a new era in the existence of universities. University life was characterised by economic growth that led to esoteric studies of an unimaginable number of subjects, as well as democratisation that led to open access and the opening-up of the social conscience of universities.

From this brief overview it is evident that a university concerns itself with knowledge, the training of professionals and educating people.

Policy documents build on a similar understanding of a university and deal in more detail with the nature, development and application of knowledge. Despite several policy documents on the restructuring of South African higher education and its landscape, there is no clear definition in the policy documents of what a university is. The concept of a university is rather understood against the background of what universities should be. From a science perspective this can be regarded as a limitation. To identify tasks for a university and then to conceptualise a university on the basis of these tasks is logically inconsistent. What happens in this approach is that the desired role for universities is projected onto the nature of a university. The correct approach would be first to obtain clarity on exactly what a university is (the nature thereof) and then to indicate what its functions should be. One cannot use the characteristics of an entity to identify the nature of the entity instead of analysing the entity to identify 
the ensuing characteristics of the entity (see Lategan 2005)! This is evident from the National Plan for Higher Education (2001) and its forerunner the National Commission on Higher Education (NCHE) (1996a; 1996b), as well as from planning documents such as the National Education Policy Investigation (NEPI) (1993) and the Size and Shape Report (CHE 2000). The Higher Education Act (Act 101 of 1997 and all its amended forms) (South Africa 1997) does not give direction either. This does not mean that policy is not valuable in understanding what a university is. It simply means that yet another perspective is needed to unpack the university. In this regard I suggest that conceptual knowledge be used to comprehend the university. This means that rational analysis of reality can assist one in understanding the individual and universal character of an institution. By 'individual' is meant that only the form of the society concerned can determine the specific task. 'Universal' refers to different forms of society influencing one another. The individual and universal side of things can be explained in the following way: the church and the university both have a teaching function. The church undertakes religious instruction, while the university is accountable for academic instruction. Although the preparation of a sermon presupposes a particular exegesis, methodology and academic grounding, the sermon never degenerates into an academic lecture (at least, it should not!). Occasionally a lecturer may pass a religious judgement, but this does not change his/her lecture into a sermon. Even the presence of a faculty of theology does not turn a university into a church - just as a faculty of law does not turn it into a civil court. Therefore, although different forms of society influence one another, the one cannot take over the functions of the other. Built on this conceptualisation, it may be concluded that a university is qualified through knowledge which is further specified as scientifically oriented research and teaching. In the light of this, the following definition of a university may be rendered:

A university is an academic institution at which research is conducted and teaching/learning is offered within the organised cadre of the contact between lecturer and student.

Dillemans (2006) rightly emphasises the fact that a university exists because of science. It would therefore be safe to argue that this core function should be found in a university regardless of the university type. This view is supported by the Higher Education Act (No 101 of 1997, amended) which states that higher education institutions should be engaged in teaching/learning, research and service. The Size and Shape Report (CHE 2000) and the National Plan for Higher Education (2001) support mission and activity differentiation, though not different missions and activities. Within the context of the South African higher education band, three university types can be identified: classical 
universities, comprehensive universities and universities of technology. These university types share the core university activities as common denominator.

Where does this leave the core activities of a university (and its adjectives)? One may answer that the university functions are the same (still teaching/learning, research - therefore the functions are constant), but that these functions have taken a new direction (for example, contract research, commercialisation, innovation, applied research - therefore the dynamics of the functions). Two important conclusions can be drawn based on these arguments:

- If an institution is not engaged in teaching and research, then it cannot qualify as a university.

- Regardless of how a university changes, the core activities of the university should always be found back in its activities.

A question not yet addressed is that of service. Is this a core activity next to teaching and research or is it an activity following on teaching and research? On the one hand there is the point of view of the so-called Traditionalists. This group advocates the standpoint that the traditional identity of the university should be maintained. On the other hand, the so-called Pragmatists/Progressivists advocate contemporary relevance. Within both groups of opinion-makers, there is considerable consensus that the task reserved for the modern university is teaching and research. The way in which it should be concretised, however, elicits widely varying opinions. The Pragmatists regard active community service as a third task of the university, while the Traditionalists already regard the typical task of the university as community service. I have always favoured two arguments in support of the latter view. The first argument is that the best (community) service a university can render is to be active in its core activities. There is no point in the university being all things to all people, but not being able to be a good university. Society needs universities that can enlighten it (society), and not universities that undertake all kinds of activities except those in which the university should be engaged. This does not mean that the university cannot direct its activities to change or support society. A good example is a remark in the UNESCO's Report on Higher Education in the Twenty-first Century (1998) on the role of the African university. This report states that due to a lack of democracy in Africa and a lack of sufficient support systems for society, universities can assist government, business and industry in addressing these challenges. The universities therefore have a developmental role to take on. It goes on to say that no university can afford not be engaged in society. The ivory tower image of the university symbolises an institution removed from the realities 
of society. The university remains a societal structure and must contribute to society at large.

A perspective that may help one to understand the service of the university is the concept of engagement. Engagement simply refers to how the university engages with business and industry in addressing societal challenges. Engagement with society offers the university the unique opportunity to develop and transmit from and to society. An appropriate example may be found from the military. Castells (2001 b:209) makes the important remark that American universities got a major boost from World War II and the Cold War when it was required of universities to serve the needs of the military. Thomas (2000:53) has the same perspective. He refers to engineering practice prior to World War II. During that period, engineering was largely rule- and experience-based. This changed after World War II due to the defeat of Germany and Japan and especially in the pursuit of the Cold War. He further remarks that this engagement elevated the promotion of science and technology to unprecedented levels. This practice confirms a common strategy to reflect the engagement activities in the curriculum. It serves no purpose to engage with society if there is no spin-in to the core business of a university. It is in this context that the question of 'fitness for purpose' can be cited. If engagement has no positive impact on the university itself then one may wonder whether engagement was for the right reasons. Engagement is never about doing something for a community, but always about doing something with the community.

The engaged university is faced by another challenge: stakeholders. Neave (2001) correctly refers to employers, investors and customers as stakeholders. Students are regarded as one of the stakeholders, especially as customers. Neave (2001:22) regards them as more than agents of demand. He remarks that "governments came increasingly to see the student body as prime channel for the direct transmission into higher education of society's press for change". The stakeholder is a "conceptual being" and influences the university as institution. He refers to attempts to construct typologies of stakeholders. From these typologies it is quite clear that the university as organisation cannot be removed from its internal and external stakeholder. Umesiobi's (2006) study confirms that internal stakeholders are as important to the university as external stakeholders.

What should also be noted is that the university should exercise its choice regarding which market it wants to serve. The market ranges from local, regional and national to international (Neave 2001). It remains a pity that many (South African) universities 
want to be universities for all instead of serving only the community or communities they have the capacity to serve. Another tragedy is that universities are often good at setting up (inter)national partnerships, but poor at collaborating with local and regional partners. One possible reason for this is the common belief that an international partner can bring more prestige to a university than a local partner. A positive result of this approach may be that the international partner connects the university with the global village and assists with its (the local university's) participation in international education.

These few comments on a university, its nature and it functions, point out that the university is a unique societal structure that is integrated with society. It is quite obvious that through the ages the university always had a close relationship with society. This relationship is not only defined on the basis of society's scientific needs, but also by how universities employ society to carry out their mission.

\section{STATIONS ALONG THE WAY: VARIOUS IMAGES OF A UNIVERSITY}

Universities (in South Africa) undergo periodic redefinition. Here, the Heraclitic concept of panta rei - everything changes (moves) - is true. Different values in the university have resulted in different views on these institutions, which in turn have led to different expectations of universities. It is noticeable that three university ideals dominate university life. The ivory tower idea embodies the ideals of the Humboldian university (academic freedom at all costs), the new social role engages the Newman ideal (personal development) and the Napoleonic ideal (state regulation) has government as major partner and stakeholder of the university. In my research I found fragmentations of these 'images' back in universities. Consider the following images:

\section{Image 1: Racial and political universities}

Due to the previous composition of South African society as well as previous policies on universities, universities were classified in three distinct groupings, viz. Englishmedium universities, Afrikaans-medium universities and black universities. Needless to say, each of these types serves only the interests of its particular clientele. (Note that the first two groupings of universities were classified by language, while the latter grouping was classified by race.) This division provided the ideal climate for the politicisation of universities. Student bodies contributed to the enhancement of the politicisation of academia. The Afrikaanse Studente Bond was a gateway for Afrikaans students to take up prominent posts in society. English students were more interested in freedom of speech than in challenging the Calvinistic values ('Christian National Education') 
of the universities, while black universities propagated the slogan "Liberation before education". The impression is that the situation has not changed at all. One ideology has been replaced by another. In the past the emphasis was on Christian National Education (as ideology); now it has made room for Work Integrated Learning (also an ideology); equity and redress are uplifted as neo-liberal values in the place of merit only (neo-conservative value). Language is a dividing factor instead of an empowering factor to communicate cross-culturally and cross-nationally. The staggering of these examples simply says that the university has difficulty in escaping its political affiliation.

\section{Image 2: The 'free university'}

In the simplest terms university autonomy refers to the degree of self-governance of a university. Thus university autonomy entails the internal power of the university. In accordance with the private act on the university, it does have the competence to determine its own style and direction. The university arranges, in accordance with its own private act, matters such as the content and method of instruction, examination and the awarding of degrees. With this the university remains within the bounds of its competence as academic life form and at the same time it provides room for the university to implement internal self-management. This important value is challenged by a state-directed intervention characterised by transformation agendas, redress and social redress. Although important, a serious problem is that the transformation of the core university functions is not as high on the agenda as it should be. This is one of the biggest challenges facing universities in the world in considering whether their activities are still fit for their purpose.

Universities' freedom has also been challenged by funding policies. The current South African practice to fund research outputs (postgraduate degrees and publications) is acknowledged to build capacity and reward performance at the research level. What has not yet been sufficiently debated is the way in which funding influences what universities are doing. There is still the untested perception that academics are now writing articles to earn credits and not to expand the knowledge base of their discipline. If this is true, then creativity has been straitjacketed by funding.

The freedom of the university is not only challenged by state intervention, but also by the steering of its intellectual capabilities. The 'enterprise' has become the leading chorus of scientific activities and dictates to the university what should be on the agenda (see Lategan and Hooper 2009). Although this relationship has many positive benefits for 
the university, it remains a dominant power on the university agenda which leaves very little space for academic freedom.

\section{Image 3: The market-driven university}

The global economy, as well as information and communications technology, has compelled educational institutions to adopt a market-driven approach. This does not mean that a higher education institution should become a business - rather, it implies that business-like decisions and approaches should drive the core business of the university. An example of the latter is curriculum reforms reflecting educational, pedagogical, business and social values. Ensuing from this would be new learning approaches such as knowledge development. Knowledge development recognises the fact that learning outside the classroom and laboratory is becoming more important than learning within the classroom (so-called borderless learning). Institutions offering virtual and life-long education will secure employability instead of a job. What universities find in the era of customer service is that teaching itself is not enough. It is the kind of teaching offered that matters. Universities realise that prospective students are striving to study at the best institution (depending on different criteria). Universities have started to value students as clients, and students demand to be treated accordingly. Hawkins (1995) states that preparing graduates for employability goes far beyond the individual input of the student, the approach of higher education or the concerns of governments. He also states that career tactics are the concern of all people wishing to enter the world of work. A fundamental principle underlying career tactics is the learning of skills. Graduates (as important higher education customers) cannot prepare for their careers on their own. Career management must be viewed as a shared responsibility between the organisation and the individual.

No one of these images is the ideal image of a university, although each contributes towards the understanding of what a university is. In addition, one should not be too worried that there are so many (conflicting) images and expectations of what a university is. Kerr (1995:7) correctly observes that "[t]he university is so many things to so many different people that it must, of necessity, be partially at war with itself". Popma (1997) too, encourages one to keep on researching the "university in movement". There is not a fixed perspective as to how a university should be dealing with its core activities. Van Vught (1997) correctly says that it is easier to ask what a university is than to answer this question. 


\section{A MOMENT OF ENLIGHTENMENT}

In researching the university, valuable lessons have been learned with regard to higher education research. Four observations are made which do not only give direction to research on the university, but also to higher education in general:

- The researcher either clings to one paradigm which almost leads to a standard set of conclusions or the researcher does not subscribe to a set of scientific values, with the result that the conclusions very often lack merit and foundation. On a personal level, I am happy to report that even in the course of this chapter, I have shifted some of my own perspectives - a moment of enlightenment to understand things in a different way. However, I have also experienced that some perspectives and examples are contested through time and can be validated. I have to admit that scientific perspectives are both constant and dynamic - a missing link in many scientific debates. I therefore call upon intellectual fairness when arguments are formulated, revisited and validated.

- The danger exists that research results can very often be recycled (cut and paste approach) with no new results produced to further one's understanding of the topic. In my own research I have often discovered that one may have a fixed view on a topic and that more evidence is accumulated to support the view instead of asking whether the particular view still holds water. Here too, intellectual fairness must be applied.

- An emerging challenge for research is the quest for research integrity. The staggering of known evidence serves no purpose in research development. I am very much aware that one can (theoretically) not plagiarise one's own research, but the danger remains that existing knowledge may be recycled/repackaged and presented as something new when it is not new at all. This opens the debate for research integrity.

- Another form of enlightenment is the sharpening of one's conceptual knowledge. I am once more convinced that the mastering of this skill is imperative for higher education research. Without really understanding the meaning of a concept it is difficult to do research or to draft appropriate conclusions.

\section{LESSONS LEARNED DURING THE JOURNEY}

Several lessons have been learned during my journey to understand what the university is. The following lessons should give direction to stimulate the debate: 
As already stated, the university as organisation is central to all higher education studies. It is imperative to keep asking the question: "What is a university?" A range of people, starting from policy makers, university managers, lecturers, researchers and students, to businesspeople and industrialists, should know what a university is. To this extent it is an elitist institution in the sense that it is continuously subjected to analysis, review and discussion. The irony is that although conceptual answers are possible to this question there will always be an illusive side to the comprehension of exactly what a university is. After all, is this not what is expected from the 'intellectual home' of society?

As research object the university needs to be subjected to a problem statement, research methodology, analysis and conclusions. It is noticeable that scholars of the university either have no valid research methodology or their conclusions are based on personal opinions and orientations only. It is also observable that scholars at the university study more managerial or institutional issues and conclude, on this basis, what a university is. As already argued in this chapter, studies in management and institutional issues inform institutional behaviour and performance, but not conceptual understanding. It would be wrong to confuse the two approaches with each other and it would be equally wrong to think that it is of lesser importance to know how a university works and performs.

It would be impossible to understand the university without a philosophical framework. Take, for example, the Size and Shape Report (CHE 2000), which lacks an embedded theoretical paradigm. A post-modern view (any view holds ground) is characteristic of this report (and many other reports). It should still be proven that the Department of Education is not in the grip of relativism (remember the NCHE - not institutions, but programmes), pragmatism (gender, race, equity, etc.) and the over-generalised view that higher education will lead to the improvement of the economy (which economy?) and employability (career-specific or simply skills-based?).

Universities have to accept that they have lost their monopoly on knowledge development. The most innovative research and best laboratories are often found outside universities (for example, Silicon Valley). This new development forces universities to partner with business and industry. The good news is that these partnerships can only benefit the university. Positive examples are the availability of funds and facilities, quick turn-over time (opposed to the bureaucratic practices at universities), the applicability of the research and its results and that universities are reminded that they have to continuously renew the way in which their core business is practised. Two negative results of these 
partnerships are that the partners very often tell universities what to do (universities should know the innovation, not the other way around) and universities can easily become followers instead of leaders in a field.

In the knowledge economy knowledge is seen as 'raw' material. The result is that universities can sell their product (read knowledge). In doing so, the universities are acting like enterprises competing on the open market. The positive result is that universities should revisit their way of doing things to fit into a competitive environment. The negative results are that universities can easily abandon their academic responsibilities and cling only to enterprise behaviour, or that the universities may not be skilful enough to engage with a changing environment. The challenge for universities is to deliver programmes that can contribute towards knowledge-based professions.

Universities cannot only train people; they also need to educate them. Very often a clash is observed between the demands of the workplace (experts, professionals and skilled people) and what the origin of a university entails (intellectual concept crafters). It would be wrong to say that universities have no training responsibility. Even medieval universities acted as vocational schools. It is also an invalid assumption to think that work-directed education is a college activity and work-relevant education a university approach. Universities have to take the lead in training experts, professionals and skilled workers for the market. The training of students, though, should never exclude scholarship. Apart from having work-related abilities, students need to be scholars. If they are not, how will they ever be able to identify new problems and formulate new solutions if their training is limited to manual issues only? South African society runs the risk of having trained graduates, but not scholarly graduates. In a market-driven approach disciplines like philosophy are often in jeopardy since they are less of an income generator than, for example, MBA graduates.

A stimulated academic heartland, a concept used by Burton Clark (1998) and Frans van Vught (1997), amongst others, is central to the university. Conceptual knowledge needs to unpack the exact meaning of the university's present-day core activities. Academics should practise their field of study and research in such a way that the core activities are strengthened. This assignment is built on academics' scholarly and professional commitment. The Academy of Science in South Africa's report on scientific writing in South Africa alludes to the fact that in spite of growth in research publications, not all of these publications are of a scholarly nature. Several reasons can be listed why academics are not stimulating the academic heartland in South Africa. To list a few: students are under-prepared for higher education; too much lecturing time is 
spent on remedial activities rather than on creative ideas; universities cannot attract the best scholars, because international universities offer better opportunities and marketrelated jobs, which are more financially attractive; students are more interested in obtaining a qualification for market purposes than becoming scholars in their field; and transformation is limited to political issues, whereas knowledge transformation should question the way in which universities are dealing with knowledge in a changing world.

It is often forgotten that although the university is a structure consisting of core activities, a structure is not something abstract or a conceptual construct only. Universities consist of people - staff, students, partners, etc. The most important assignment for a university is to invest in human potential and to create human capital that can be invested in society. Too often the university is limited to mortar and bricks. This is the physical appearance of a university. A university is a collection of people who relate to knowledge - some as transmitters of knowledge (teaching), some as generators of knowledge (research), some as managers of knowledge (rectorate), some as seekers of knowledge (students), some as users of knowledge (business and industry) and some as end users of knowledge (society). But it is people who collectively constitute a university. This observation is too often omitted when we research the university.

\section{POSTSCRIPT: SENDING OUT POSTCARDS}

It would be presumptuous to think that almost a millennium of university history can be reflected on in a single chapter. It would be equally arrogant to state that the university is now fully understood. It is more modest to say that the university is conceptually a definable organisation. It is challenging for the university to state that it wants to engage with societal challenges, but it is difficult to identify appropriate strategies to address these challenges via its core functions. The university always stands before a window of opportunity. But, as soon as one opens this window, the university has moved on to another. In this sense the university is an elusive concept always willing to be subjected to research.

A universal benchmark that has stood the test of time is how best the university can generate and develop knowledge in a society. This remains the true social role of a university. To define a university simply in the context of its social role does not do justice to the fact that a university is an academic institution. 


\section{REFERENCES}

Bok D. 2003. Universities in the marketplace: The commercialization of higher education. Princeton: Princeton University Press.

Castells M. 2001 a. The new global economy. In: J Muller, N Cloete \& S Badat. Challenges of globalisation. Pretoria: Maskew Miller Longman. 2-21.

Castells M. 2001 b. Universities as dynamic systems of contradictory functions. In: J Muller, N Cloete \& S Badat. Challenges of globalisation. Pretoria: Maskew Miller Longman. 206-223.

Clark B. 1998. Creating entrepreneurial universities. Paris: IAU and Pergamon Press.

CHE (Council on Higher Education). Size and Shape of Higher Education Task Team. 2000. Towards a new higher education landscape. Meeting the equity, quality and social development imperative of South Africa in the $27^{\text {st }}$ century. Pretoria: Department of Education.

Dillemans R. 2006. Kennis als verantwoordelijkheid en ethische opgave. In: B Pattyn \& Van G Overwalle (eds). Tussen markt en Agora: Over het statuut van universitaire kennis. Leuven: Peeters. 7-29.

Hawkins P. 1995. Skills for Graduates in the 21 ${ }^{\text {st }}$ Century. Cambridge: The Association of Graduate Recruiters.

Kerr C. 1995. The uses of a university. Cambridge: Harvard University Press.

Lategan LOK. 1989. Die wese van die Universiteit. Published MA dissertation awarded by the University of the Free State. Bloemfontein: VCHO.

Lategan LOK. 1996. Images of the university: Which image would best serve the interest of the university in South Africa? Tydskrif vir Christelike Wetenskap, 32(1\&2):56-72.

Lategan LOK. 1998. The nature of a technological university within the context of the South African higher education band. Inaugural lecture. Bloemfontein: Technikon Free State. 26 November.

Lategan LOK. 2000. Revisiting the idea of a university. In: LOK Lategan (ed). The making of a university of technology. Bloemfontein: Technikon Free State Studies in Higher Education No. 3:1-14.

Lategan LOK. 2005. Relativism in national higher education policy documents: What is a university? Acta Academica, sup (2):185-201.

Lategan LOK \& Hooper P. 2009. Ethics, governance, research and enterprise. Perspectives, 13(2):55-60.

National Commission on Higher Education (NCHE). 1996a. A framework for transformation. (First draft.) Pretoria: Department of Education.

National Commission on Higher Education (NCHE). 1996b. A framework for transformation. (Final recommendations.) Pretoria: Department of Education.

National Education Policy Investigation (NEPI). 1993. The Framework Report. Cape Town: Oxford University Press.

National Plan for Higher Education (NPHE). 2001. National Plan for Higher Education. Pretoria: Ministry of Education. 
Neave, G. 2001. On stakeholders, Cheshire cats and seers: Changing visions of the university. Inaugural address as professor of Comparative Higher Education Policy Studies at the University of Twente. Enschede: University of Twente. March.

Plato. 1964. Kratylos. In The dialogues. New York: Bollingen Foundation.

Popma Th JA. 1997. Wat beweegt ons? Address as outgoing Rector Magnificus at the University of Twente. Enschede: University of Twente.

South Africa (Republic). 1997. Higher Education Act. Pretoria: Government Printers.

South Africa (Republic) Minister of Education. 2001. National Plan for Higher Education. Pretoria: Department of Education.

Teichler U. 2007. Higher education systems: Conceptual frameworks, comparative perspectives, empirical findings. Rotterdam: Sense Publishers.

Thomas G. 2000. The creation of a technological university: An example from the USA. In: LOK Lategan (ed). The making of a university of technology. Bloemfontein. Technikon Free State Studies in Higher Education No. 3. 52-63.

Umesiobi D. 2006. The role of research partners in supporting research outputs in higher education institutions: Insights from the Central University Technology, Free State. Unpublished MA dissertation. University of the Free State.

UNESCO. 1998. Higher Education in the Twenty-first Century. Final report. Paris: UNESCO.

Van Vught FA. 1997. De nieuwe academische collegialiteit. Inaugural address as Rector Magnificus at the University of Twente. Enschede: University of Twente. 


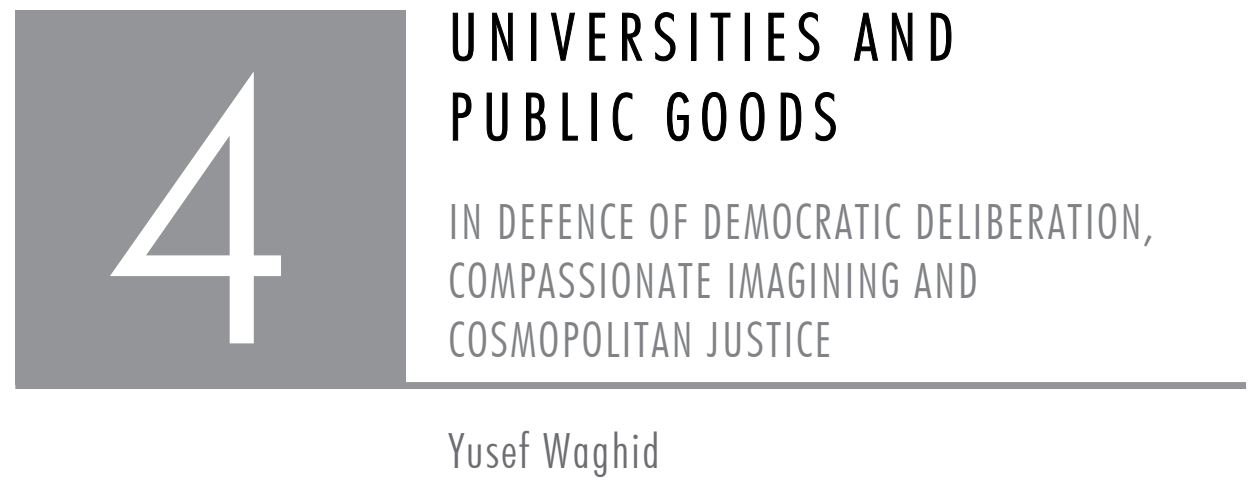

\begin{abstract}
One of the most significant contributions to the advancement of modern higher education is found in the work of Frank and Meyer (2007:290) who argue that the public mission of the contemporary university is to assist in addressing great social problems such as improving business organisation and capital investment, protecting the natural environment, preserving human rights and cultural diversity, resolving crises of governance and promoting democracy - all aspects that constitute what can be referred to as the public goods of higher education. In order to foreground the public mission of the modern (African) university more clearly, I offer an account of higher education as a public good which ought to build on conceptions of democratic deliberation, compassionate imagining and cosmopolitan justice.
\end{abstract}

\title{
INTRODUCTION
}

Any philosophical contribution to the end goals of university education cannot ignore the invaluable epistemological contributions research for 'its own sake' has made to erudite scholarship in most modern societies. I do not wish to deny that pursuing research for 'its own sake' or research that is not supposed to produce some kind of instrumental end result such as socio-economic development is of no use to increase the vast riches of scholarship. My use of the term research for 'its own sake' is meant to convey that knowledge is produced for understanding, but that such knowledge does not necessarily have in mind any concrete benefits for society. My point is that the production of knowledge for 'its own sake' has always contributed to the production of more knowledge and was not necessarily intended for developmental purposes. 
Examples of such knowledge can be related to questions such as: Do numbers exist outside of our minds? Do human beings have dreams outside of their real existence? Is the universe continuously expanding? Should virtue be taught? Often these questions, which were intrinsically pursued for 'their own sake', had other consequences which might have resulted in knowledge of benefit to societies. Hence, I am not suggesting that universities should not encourage the pursuit of knowledge for 'its own sake', because I do not conceive of knowledge for 'its own sake' as being unable to make any difference to human lives. The key argument of this contribution is not against the production of knowledge for 'its own sake', but is rather a defence of knowledge for the purpose of achieving substantive socio-economic development, especially on the African continent. For me a public university in the modern age has to make the pursuit of knowledge for the good of society one of its most important purposes, if not the most significant one. In line with this approach I shall make an argument for the cultivation of three public goods that ought to constitute university education on the African continent: deliberative democracy, compassionate imagining and cosmopolitan justice.

My defence of knowledge for the purposes of socio-economic development builds on the seminal work of Frank and Meyer (2007:267-268), who argue that any society is always distinguished by the degree to which that society is organised around the university's abstracted and universalised understandings of the world and its degreecertified graduates. For them, it is the university which provides the "differentiated training and research programs functionally required by complex societies or their power structures, and may even play a role in producing desired social development" (Frank and Meyer 2007:268). What this implies is that the university is called upon to help alleviate great social problems - improving business organisation and capital investment, protecting the natural environment, preserving human rights and cultural diversity, resolving crises of governance and promoting democracy in every country around the world. Simultaneously, the university is accountable for the way it addresses the immediate problems at hand - training local business leaders, preserving local cultures, improving local child-rearing practices, protecting local species, and so on (Frank and Meyer 2007:290). Simply put, university education ought to attend to and be accountable for societal development, albeit at a scientific, technological, political, cultural or economic level. As I have argued elsewhere, the university should indeed perform a public role by creating opportunities for its students and academics to take responsibility for their own ideas, to take intellectual risks, to develop a deep sense 
of respect for others, and learn how to think and engage critically with others in a democratic society (Waghid 2008:23)

Before I offer some indications of how and why this public role of the university can most appropriately be enhanced through democratic deliberation, compassionate imagining and cosmopolitan justice - those intrinsic goods which can engender university education as a public good - I first need to give an overview of the status of higher education on the African continent.

\section{CHALLENGES FACING HIGHER EDUCATION ON THE AFRICAN CONTINENT}

Undoubtedly, universities face many challenges on the African continent. AssiéLumumba (2006:71) poignantly argues that from the late 1970s to the 1990s higher education, especially in universities in Africa, was characterised by great instability as indicated by numerous confrontations between students, faculties, administrations and governments. This instability has been further compounded by economic failures, stagnation and regression, which adversely affect the advancement of higher education on the continent (Assié-Lumumba 2006:75). Some of the main reasons for the ill-preparedness of African universities to meet societal needs are their alienation from the broader society and business community, and the inefficiency of university administration, organisation and management (Assié-Lumumba 2006:78).

Teferra and Altbach (2003:4) argue that the influence of colonialism on African higher education contributed towards restricting student access, undermining the teaching of students in indigenous languages, limiting academic freedom and constraining the Africanisation of the curriculum. Colonial authorities were only interested in training limited numbers of African nationals to assist them in the administration of their colonies. Although France used to send members of the colonies to France for higher education training, Zaire (now the Democratic Republic of Congo) did not have a single national as an engineer, lawyer or doctor at the time of independence. Likewise, the higher education system in the colonies was also characterised by use of the adopted language of instruction, which was the language of the coloniser. This was coupled with limited forms of freedom within the academy. Teferra and Altbach (2003:4) also indicate that at independence the curricula of universities were dramatically restructured. The discipline of law tended to be favoured in the past more, because it aided the colonial administrator in his work, but other disciplines such as science were not much encouraged. Although the curriculum of African universities today includes almost all subject areas, one would expect that in a university the ties 
to the former colonial countries would remain strong, and in no case has a country in Africa dramatically changed its language of instruction.

War and conflict have also affected post-secondary education in some African countries. For instance, war and national strife virtually brought the higher education system to a standstill in countries such as Somalia, Angola and the Democratic Republic of Congo (Teferra and Altbach 2003:3). Also, as aptly put by Teferra and Altbach: "Inadequate financial resources compounded with unprecedented demand for access, the legacy of colonialism, long-standing economic and social crises in many countries and the challenges of HIV/AIDS in many parts of the continent present the higher education sector with a bigger challenge" (Teferra and Altbach 2003:3). According to these authors, the declining economies of African states have made it difficult for universities to train staff who can manage their systems. This problem is compounded by the high prevalence of HIV/AIDS on the continent, which has affected Africa's workforce in general.

The higher education landscape on the African continent has largely been sustained by funding from national governments. At the inception of these institutions national governments saw it as their mandate to provide for universities and they therefore completely subsidised this sector. But with the growing demand for public money in other sectors of life, national governments have begun to encourage universities to diversify the means of providing for their finances. South African universities rely less on state funding compared to other universities on the continent. There seems to be a general expectation across the continent that when government funds higher education, then the goals and aims of government should be promoted through the higher education system. For instance, Singh (2001:8) proposes that we should understand a university in Africa from a functional perspective in terms of the common good that higher education is meant to promote. What is clear in Singh's perspective is the idea that there is no university that exists for itself; neither is there such a thing as the pursuit of knowledge for its own sake only. This is the case, because examining the core functions of the university critically reveals that the functions of teaching, research and community engagement are interrelated, and that one function on its own cannot fully represent the core functions of the university. This thinking is very much at the heart of the view that at the end of the day any university is supposed to respond to, and enhance, the public good. I now turn to a discussion of this issue. 


\section{UNIVERSITY EDUCATION AND DEMOCRATIC DELIBERATION}

Against the backdrop of the afore-mentioned challenges faced by universities in Africa, I wish to explore how and why democratic deliberation can potentially contribute towards a defensible university education, which in turn can enhance socioeconomic development. Now, in the light of the fact that unproductive confrontations between students and university staff are cited as one of the main contributory factors towards eventual economic, political and social instability in African societies, I want to make a case for cultivating the practice of deliberative democracy in universities. Of course, practising deliberative democracy does not mean that people should be less confrontational and assertive. Instead, democratic deliberation has as its goal that university staff should not merely listen to the narratives of students, but actually encourage a spirit of living together in diversity - that is, through democratic deliberation university staff and students together establish opportunities which take into account people's linguistic, cultural, ethnic and religious commonalities and diversity. The idea of finding a deliberative space for the sharing of different people's commonalities is based on the understanding that people need to learn to live with the otherness of others whose ways of being may be deeply threatening to our own. And, by creating a deliberative space (Benhabib 2002:127) where people can enact what they have in common and at the same time make public their competing narratives and significations, people might have a real opportunity to co-exist. In this way they would not only establish a community of conversation and interdependence (that is, they share commonalities), but also one of disagreement (that is, they do not share commonalities) without disrespecting others' life-worlds (Benhabib 2002:35,41). Put differently, when university staff and students are engaged in deliberative engagement underpinned by interdependence and disagreement, they engage in democratic action with a collective identity - they share commonalities. And educating students to become deliberative democrats involves creating civil spaces where they can learn to share commonalities and to respect the differences of others.

My potential critic might legitimately ask whether deliberative democracy is necessarily good for Africa considering the diversity of views about the concept. In the first instance, deliberative democracy unfolds when educators and students engage dialogically; all have the same chances to initiate speech acts, to question, to interrogate and to open debate; all have the right to question the assigned topics of conversation; and all have the right to initiate reflexive arguments about the very rules of the discourse procedure and the way in which they are applied or carried out (Benhabib 1996:70). Such dialogical action, which involves interrelated actions such as debate, questioning, 
discussion and argumentation, constitutes public deliberation. Now considering that the word ubuntu (human interdependence through deliberative inquiry) is found in almost all African languages, although not necessarily under the same name, the argument can be made that the notion must have had currency amongst Africa's people in the past. For example, in Kenyan languages such as Kikuyu and Kimeru ubuntu is referred to as umundu and umuntu; in kiSukuma and kiHaya of Tanzania ubuntu is referred to as bumuntu; in shiTsonga and shiTswa of Mozambique ubuntu is referred to as vumuntu; in Bobangi spoken in the Democratic Republic of the Congo ubuntu is referred to as bomoto; and in kiKongo of Angola ubuntu is referred to as gimuntu (Kamwangamalu 1996:26). And, the fact that ubuntu like deliberative democracy (as I have articulated elsewhere) is a form of communal engagement which allows space for criticality, non-domination and ensuring that human relationships flourish, the practice of deliberative democracy can be considered as specifically of relevance to African societies because of its history of colonisation, racial oppression and segregation, and economic, political and social instabilities, insecurities and complexities - all those societal ills which potentially stand a better chance to be eradicated through democratic deliberation (Waghid 2009).

Callan (1997:215) favours a conception of democratic deliberation characterised by the distress and belligerence (that is, a rough process of struggle) of confrontation that will naturally give way to conciliation as moral truth is pieced together from the fragmentary insights of conflicting viewpoints. For him, the idea of democratic deliberation is not an attempt "to achieve dialogical victory over our adversaries but rather the attempt to find and enact terms of political coexistence that we and they can reasonably endorse as morally acceptable" (Callan 1997:215). Through democratic deliberation, participants disturb doubts about the correctness of their moral beliefs or about the importance of the differences between what they and others believe (a matter of arousing distress) accompanied by a rough process of struggle and ethical confrontation - that is, belligerence (Callan 1997:211). If this happens, belligerence and distress give way eventually to moments of ethical conciliation, when the truth and error in rival positions have been made clear and a fitting synthesis of factional viewpoints is achieved (Callan 1997:212). This is an idea of democratic deliberation, with which I agree, where no one has the right to silence dissent and where participants can speak their minds. In the words of Callan (1997:201-202), "real moral dialogue (as constitutive of democratic action), as opposed to carefully policed conversations about the meaning of some moral orthodoxy, cannot occur without the risk of offence, an offence-free school [university] would oblige us to eschew dialogue". It seems that 
some university staff listening to students' narratives become culpable of steering the conversation in such a way that the substantiveness of articulated views no longer has priority. Rather, these teachers seem to focus on who the students are and not also what they substantively have to say. I sometimes hear students' claims that it is difficult to write a section of a thesis, because they were not taught argumentation in their undergraduate studies. Of course, this might be true. But then, to have reached the stage of thesis writing, one should at least know what it means to present a lucid, substantiated and coherent argument. For this reason it would not be inappropriate to confront and even offend students. Simply put, tell students that their writing is not good enough and that they could do something about improving it.

The upshot of such a view of democratic deliberation is that university staff and students do not have to move towards non-confrontational relationships. Instead they need to confront one another with the intention of moving towards more amicable relations. Democratic deliberation does not mean that we have to police our engagements so as to avoid belligerent confrontations, because the latter situation can allow people to speak their minds, talk back and offer alternative points of view after having considered critically what others have to say. Student-staff relations at universities often lead to violent threats, causing much instability that can be counter-productive for societal development simply because people do not afford themselves the space to engage in democratic deliberation.

\section{UNIVERSITY EDUCATION AND COMPASSIONATE IMAGINING}

War and conflict (the latter often of a violent nature) seems to be endemic to many countries on the African continent. Elsewhere I have argued that religious extremism and political autocracy are major factors which perpetuate violence in African societies (Waghid 2007:192). In this chapter I want to extend my argument and attribute violent conflict to a lack of practising compassionate imagining, which I hold can be taught at universities. And if this can be done (hopefully so), African societies might have a real chance to experience peaceful human co-existence and interdependence - precisely those aspects which can enhance societal development. Martha Nussbaum (2001) raises the question of what a positive contribution emotions such as compassionate imagining can make in shaping relations amongst university staff and students. Her main argument in defence of compassionate imagining is that the latter ought to be the practice that should be most frequently cultivated when people embark upon democratic action in public life (Nussbaum 2001:299). It is her view that democratic deliberation ought to be occasioned by the impulse to treat others justly and humanely 
- with compassion. Certainly in African universities - where a diversity of students from advantaged and disadvantaged backgrounds are beginning to deliberate about matters of public concern such as crime, victimisation, homelessness, job discrimination, unemployment, domestic violence and abuse of women, poverty and lack of food, political alienation, alcoholism and drug abuse, and the absence of good prospects certain practical judgements have to be made by students about these variants of their public and personal lives. Invariably, judgements to be made will be based on students' perceptions of the distressing plight of others, undeserved misfortune, suffering, injustice, disability and disease. It is in this regard that compassionate imagining becomes a necessary condition to deliberate about such matters. Compassionate imagining not only prompts an awareness in people of the misfortune or suffering of others, but also pushes the boundaries of the self outward by focusing on others' suffering which might be caused by no fault of their own (Nussbaum 2001:299).

Nussbaum's understanding of compassionate imagining as painful emotional judgement embodies at least two cognitive requirements: firstly, a belief or appraisal that the suffering of others is serious and not trivial, and that persons do not deserve the suffering; and secondly, the belief that the possibilities of the person who experiences the emotion are similar to those of the sufferer. I shall now discuss these two requirements of compassionate imagining in relation to the way that students and university staff ought to deliberate rationally (which includes being good listeners), yet also at the same time cultivating in them the concern to be just and humane towards others - to be compassionate.

Insofar as one can become serious about the suffering of others, one believes them to be without blame for the kind of undeserved injustice they might have suffered, and one recognises that the person's plight needs to be alleviated. Many students, who are perhaps blameless for their inability to pay university fees because their parents did not enjoy economic prosperity after decades of racial discrimination, require the compassion of others. In such circumstances, deliberation at universities should rather take the form of ascertaining what could be done to ensure that students who do not have the finances to study remain part of the university community, rather than finding ways to penalise or at times humiliate them. So compassionate imagining requires an acknowledgement of blamelessness on the part of students who are unable to pay university fees, as well as onlookers who can make judgements about the need to expedite the creation of conditions under which the students in question can flourish. Similarly, a university staff member can have compassion for students from an impoverished educational background, which is not necessarily their responsibility 
(the parents might not have been able to afford to send their children to more affluent and organised schools or to pay for the services of extramural tuition, as is the case in South Africa). Such a university staff member recognises the need to find creative ways to assist disadvantaged students to come to grips with difficult concepts in their studies and at the same time acknowledges that the unjust education system to which these students might have been exposed is no fault of their own. One could argue that all students should be treated equally and that no student should receive preferential treatment in terms of additional pedagogical support. But then this would be to ignore the undeserved unequal education many students, certainly in South Africa, have been - or might still be - subjected to.

Also, compassionate imagining is best cultivated if one acknowledges some sort of community between oneself and the other, understanding what it might mean for one to encounter possibilities and vulnerabilities similar to those of the sufferer: "[One] will learn compassion best if [one] begins by focusing on their sufferings" (Nussbaum 2001:317). Again, "in order for compassion to be present, the person must consider the suffering of another as a significant part of his or her own scheme of goals and ends. She must take that person's ill as affecting her own flourishing. In effect, she must make herself vulnerable in the person of another" (Nussbaum 2001:319). What this recognition of one's own related vulnerability means is that students, who might have a clear understanding of, say, concepts in a literature classroom and become impatient with their peers for not grasping such concepts, should imagine what it would mean for them to encounter difficulty with concepts. Likewise, university academics teaching literature studies should become more aware of what it means for students to encounter epistemological difficulty. In the words of Nussbaum (2001:319), "the recognition of one's own related vulnerability is, then, an important and frequently an indispensable epistemological requirement for compassion in human beings".

In essence, compassionate imagining brings to the fore the intellectual emotions of people in ethical deliberation. It is simply not sufficient to educate by just focusing on democratic deliberation without also cultivating compassionate imagining. Democratic deliberation prompts students and university staff to question meanings, imagine alternative possibilities, modify practical judgements, and foster respect and critical engagement. Yet, it seldom brings into play those emotions of people that are necessary to make it worthwhile to continue the deliberative interaction. If one is going to ignore the pedagogical vulnerabilities of the weak, very little will be done in the direction of meaningful education. So we also need compassionate students and university staff. 
If people are taught compassionate imagining at universities, our institutions on the African continent would inevitably contribute towards producing a workforce capable of recognising the vulnerabilities of others. And this is what African societies require if we hope to eradicate the kinds of violent confrontations that are currently witnessed on the continent. This brings me to a discussion of university education in relation to cosmopolitan justice.

\section{UNIVERSITY EDUCATION AND COSMOPOLITAN JUSTICE}

I begin this section with the following questions: Should universities always promote the goals of government's higher education policies? What if the state expects of its universities to prepare staff who can contribute towards national policies and which can result in alienation of the other? For instance, should universities give preference in their appointments policy to the country's own citizens, although immigrants might be more suitably qualified to perform the job? On the one hand, the state provides the funding for higher education and rightfully so, and therefore expects cooperation from universities in implementing its policies and goals. On the other hand, universities are made up of academics who require the freedom to exercise their minds, which might not always connect with doing exactly what the state requires. For instance, if governments require the universities which they fund to restructure their academic offerings so as to ensure that students are produced who can serve the labour market economy, then universities should consider producing such marked-related academic offerings. But this does not mean that universities should forfeit their freedom to challenge and even undermine through critical inquiry what potential harm a marketdriven academic offering can do to society. Similarly, universities should not encourage a culture whereby those considered as other (for instance, immigrants) should not be afforded equal opportunities. Too much strife which leads to exclusion of the other is already alarmingly evident on the African continent, which does not augur well for peaceful human co-existence. This is where I would encourage universities to embark on the cultivation (through teaching and learning) of cosmopolitan justice.

Considering that cosmopolitan justice involves the right to temporary residence on the part of the "stranger who comes to our land" (Benhabib 2006:22), it follows that universities in Africa cannot deny access to students of immigrant communities. In most cases they are not refused. However, some students are excluded in subtle ways, considering that the language of instruction, for instance, is not in the mother tongue of these immigrant students. What cosmopolitan justice demands is for immigrant students to be taught initially in their mother tongue before they are assimilated into 
the broader public university life. Or, alternatively, they should simultaneously learn the language of instruction and be supported in doing so. The point I am making is that one should not take for granted that people with immigrant status would fit naturally into the public structures of their adopted countries or countries of temporary residence. They have to be initiated gradually into public life on the basis of a sense of obligation on the part of democratic states. Failing to do so by, for example, denying immigrant students gradual access into public universities and thus depriving them of the opportunity to develop and exercise their capacities would amount to treating others unjustly.

Also, 'the right to have rights' prohibits states from denying individuals citizenship rights and state protection against murder, extermination, enslavement, deportation and other inhumane acts such as persecution (whether political, cultural or religious) (Benhabib 2006:25). If Somali immigrant students wish to wear their headscarves in public universities, following 'the right to have rights' notion, these students cannot be discriminated against if they wish to do so. Asking these students to remove their scarves, which they might consider as important to their religious and cultural identity, would be a matter of treating them unjustly on the grounds that their right to be different would be undermined. In essence, cosmopolitan justice and its concomitant agenda of hospitality which ought to be afforded to other human beings (especially from immigrant communities) in many ways complement the duties and responsibilities associated with the activities of democratic citizens. Unless African countries and their peoples recognise the rights of others to be treated with dignity and respect, without suppressing their rights, the achievement of justice will remain remote from the minds and hearts of people.

What follows from the above is that universities cannot be exonerated from cultivating in their students and staff the notion of cosmopolitan justice. Too much anger, antagonism, hatred and violence seem to permeate African societies. And although one might argue that universities should focus on advancing the sciences, we cannot ignore our African realities. In any case, for universities to function as legitimate institutions in Africa, building and extending the canons of critical inquiry, advancing the disciplines and preventing and subverting dogmatism, we cannot afford to turn a blind eye to teaching and learning cosmopolitan justice. To begin with, we would learn what it means to treat another person with respect and dignity and in this way pave the way for more hospitable societal relations, whether at work, university or in our families. If such hospitable relations do not exist, the chances of universities advancing 
the rational sciences might become a remote impossibility - a situation that Africa could not even begin to tolerate.

\section{CONCLUSION}

In this chapter I have made a case for higher education, more specifically universities, to engender education for democratic deliberation, compassionate imagining and cosmopolitan justice. Only if universities are prepared to take seriously the cultivation of these virtues can we begin to revive the university systems on the African continent. Invariably, teaching these virtues creates the possibility for universities to make a constructive contribution towards advancing socio-economic development. And in this way they begin to take more seriously their public role.

However, would the pursuit of socio-economic development necessarily undermine the economic rationalist agenda the university in Africa ought to embark upon? One cannot dispute the economic importance of higher education. But to see the university as performing only this economic function is a misplaced and indefensible idea. Today, higher education has become a commodity in the global education market aiming to serve the knowledge society through "the production, transmission and dissemination of high-quality knowledge" (Simons 2006:33). In this chapter I have argued that the university in Africa has a role to play in cultivating democratic deliberation, compassionate imagining and cosmopolitan justice and, that this can most appropriately be done by reconsidering its public role in relation to socioeconomic development.

Finally, what are some the implications of this contribution to future research possibilities in higher education in and about Africa? This contribution attempts to foreground the public mission of African universities in relation to the concepts deliberative democracy, compassionate imagining and cosmopolitan justice. Yet, some of the most salient challenges currently faced by higher education institutions on the African continent, more specifically universities in relation to a restricted access to universities, persistent societal conflicts, inadequate financial resources and economic dependency, the commodification of knowledge, a curb on academic freedom and institutional autonomy, and a lack of quality education and qualified staff, remain unexplored in relation to deliberative democracy, compassionate imagining and cosmopolitan justice. This contribution potentially opens the possibility to pursue such explorations. Likewise, an issue that has not been addressed in this chapter is an argument as to why higher education in Africa ought to become more concerned with an extended notion 
of Africanisation - more specifically the practice of integrating ubuntu and deliberative democracy which can possibly advance the achievement of justice on the African continent. Then, I also think that overextending deliberative democracy to agonism would not necessarily be feasible for higher education institutions in Africa. This is also an issue which future researchers might wish to embark upon.

\section{REFERENCES}

Assié-Lumumba N. 2006. Higher Education in Africa: Crises, Reforms and Transformation. Dakar: Council for the Development of Social Science Research in Africa.

Benhabib S. 1996. Toward a deliberative model of democratic legitimacy. In: S Benhabib (ed). Democracy and Difference: Contesting the Boundaries of the Political. Princeton: Princeton University Press. 67-94.

Benhabib S. 2002. The Claims of Culture: Equality and Diversity in the Global Era. Princeton: Princeton University Press.

Benhabib S. 2006. The philosophical foundations of cosmopolitan norms. In: R Post (ed). Another Cosmopolitanism. Oxford: Oxford University Press. 13-44.

Callan E. 1997. Creating Citizens: Political Education and Liberal Democracy. Oxford: Oxford University Press.

Frank DJ \& Meyer JW. 2007. University expansion and the knowledge society. Theory and Society, 36(1):287-311.

Kamwangamalu NM. 1996. Ubuntu in South Africa: A sociological perspective to a PanAfrican concept. Critical Arts, 13(1):26-38.

Nussbaum M. 2001. Upheavals of Thought: The Intelligence of Emotions. Cambridge: Cambridge University Press.

Simons M. 2006. Education through research at European Universities: Notes on the orientation of academic research. Journal of Philosophy of Education, 40(1):31-50.

Singh M. 2001. Re-inserting the 'public good' into higher education transformation. Kagisano Higher Education Discussion Series 1. Pretoria: Kagiso.

Teferra D \& Altbach P. 2003. Trends and perspectives in African higher education. In: D Teferra \& P Altbach (eds). African Higher Education: An International Reference Handbook. Bloomington \& Indianapolis: Indiana University Press.

Waghid Y. 2007. Education, responsibility and democratic justice: Cultivating friendship to alleviate some of the injustices on the African continent. Educational Philosophy and Theory, 39(2): 182-196.

Waghid Y. 2008. The public role of the university reconsidered. Perspectives in Education, 26(1):19-24.

Waghid Y. 2009. Challenges for higher education in Africa, ubuntu and democratic justice. In: C Caloun \& D Rhoten (eds). Changes in Higher Education. New York: Social Sciences Research Council. Forthcoming. 


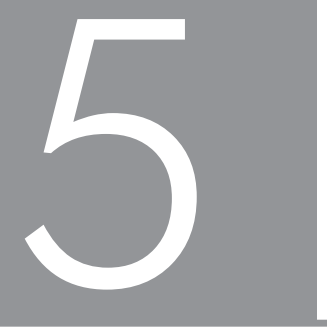

\section{TOWARDS A PEDAGOGY \\ OF POSSIBILITY}

TEACHING AND LEARNING FROM A

'SOCIAL JUSTICE' PERSPECTIVE

\section{Brenda Leibowitz}

\section{ABSTRACT}

This chapter takes the argument of Waghid (this volume) on higher education as a public good as its starting point and sketches the challenges presented in relation to this, by the educational biographies of learners and educators from varied social backgrounds. It considers what education as a public good would be like, especially if higher education were to ensure participatory parity for all learners. With reference to a study on educational biographies of 100 students and 64 lecturers at one South African university, it discusses the three dimensions of social justice posited by Fraser (2009), namely distribution, participation and recognition. It further considers the interrelationship of structure, agency and responsibility, and how this interrelationship impacts on the task of higher education to facilitate the potential for the successful learning of all students. The chapter concludes with a model, depicting the responsibilities of the key role-players for realising higher education as a social good. The model also contains references to research and findings on innovations by researchers and educators, whose work serves as examples of what can be done to realise this pedagogy of possibility.

\section{INTRODUCTION}

Waghid (this volume) argues for higher education as a public good, based on conceptions of democratic deliberation, compassionate imagining and cosmopolitan justice. He presents a strong philosophical account of what these three conceptions may mean, and draws examples from teaching and learning contexts. I would like to analyse the notion of higher education as a public good in more detail, with reference to a study on educational biographies undertaken at Stellenbosch University. With an emphasis on the need for higher education to establish participatory parity for students 
and lecturers from dominant and non-dominant groups, I have turned to the work of Nancy Fraser $(2003,2009)$. She offers a powerful analytic lens to understand the challenge to which the modern - and particularly South African - university should respond. The application of her views on social justice needs to be complemented by an understanding of structure, agency and responsibility, as I intend to show, with reference to the same study. I conclude this chapter with a discussion on what it may mean, in practical terms, for institutions of higher education to facilitate teaching and learning as a pedagogy of possibility.

\section{STUDY ON IDENTITY, TEACHING AND LEARNING}

The project which is used as the basis for this discussion was entitled 'Identity, teaching and learning'. It ran as a team-based study from 2004-2006. The team conducting the research consisted of a shifting group of eight individuals, all located within the academic support centres at Stellenbosch University (SU). The names of all the team members are listed at the end of the chapter. The broad aim of the project was to explore the relationship between matters of identity and teaching and learning at this particular university, and to help the team members to understand our roles as professionals engaged in a variety of tasks to support both lecturers and students in enhancing teaching and learning at the university. The study comprised one on one interviews with 64 university academics and academic support staff, and interviews with 100 students, conducted by team members and senior students who were trained for this purpose. Interviews were conducted with both staff and students, since staff were also students, and teaching and learning is a shared enterprise, involving both lecturers and learners as participants (Lave 1996). All interviewees were asked to describe their educational biography in relation to their present position as academic or student. The interviews were analysed and coded several times, in each case with different research questions in mind. (See Leibowitz et al. (2005b) for a consideration of identity in relation to language; Leibowitz et al. (2005a) for a consideration of identity in relation to diversity and dialogue and Leibowitz, in press, for a discussion of the data on educational biography and educational success). For this chapter I have used the data already analysed in order to illustrate the argument I am making. I do not believe this data is unique, and it could have been collected at many other South African universities, especially historically advantaged universities. 


\section{A THREE-DIMENSIONAL APPROACH TO PARTICIPATORY PARITY}

An important contribution to the understanding of teaching and learning within a 'social justice' paradigm is the work of the philosopher, Nancy Fraser (2003, 2009). Her understanding of social justice stresses the need for participatory parity, which

requires social arrangements that permit all to participate as peers in social life. Overcoming injustice means dismantling institutionalized obstacles that prevent some people from participating on a par with others, as full partners in social interaction (Fraser 2009: 16).

Her views have powerful analytic and normative value when applied, with further discussion, to the sphere of teaching and learning in higher education. Fraser (2009) argues that social justice is three-dimensional. The first dimension is for redistribution - in the Marxist sense of ensuring that all individuals or groups within an institution have access to the material resources they require in order to participate equitably. The second dimension is the political or representational, which involves who belongs, who may have a say in decision making, and how participation occurs. The third dimension is for recognition - of individuals or groups' identity, cultural affiliation or social status.

This three-dimensional approach to participatory parity is so important, because attempts to institute inclusive approaches to teaching and learning in higher education all too often tend to focus solely on the material, or on the affective and relational, or on the more directly academic and cognitive. Rarely are the various dimensions held in balance. A three-dimensional approach allows for a more complex, multi-faceted and flexible response to the inequities of our teaching and learning contexts.

\section{DISTRIBUTION}

Distribution of resources as a dimension of social justice in relation to higher education would consider the fact that some students do not have access to an adequate home learning environment, live too far from the university to be able to use the library in the evenings and cannot afford to live in residence, or lack sufficient funds in order to purchase textbooks or technology. The distribution of resources is not only relevant to the present learning conditions of the student, but to the retrospective biographies of students as well. An example of the biographical dimension of distribution is the account in the study, of a black female isiZulu speaking student, Lindi, ${ }^{13}$ who stresses the role played in her educational biography by the relative privilege of her family over

13 All names are pseudonyms. 
others in rural KwaZulu-Natal. Her father worked, she had quality food to eat and was hence able to concentrate at school:

I grew up in a rural area; I had to walk for like $8 \mathrm{~km}$ to school. From Grade 2 onwards I think I was always no. 1 in class, but I don't think that was because I was brilliant, it is just because, in comparison to the families that were around, our neighbours, we had better food because my dad was working, but I would only see him maybe once a week, so we had cheese, we had good food, so we could think better than other students.

Access to material resources, whether retrospective or current, is to some degree formative, as the individual would interact with the resources in order to acquire the skills repertoire which paves the way for future academic success. Trowler (2008:34) discusses the manner in which what is considered to be 'ability' is in fact "rooted in its social location" via the mediation of tools, of which educational materials and toys are a subset. In the interviews there were numerous examples of interviewees acquiring various skills through situated practices, in which material resources or artefacts played an important part. Examples of such artefacts are books, toys or electronic accessories. In the example which follows, a young boy, Stefan, engages in play and dialogue around artefacts such as a Mikano set and a crystal set. This predates his successful career as engineering student, and later, as a senior professor in engineering:

I had a Mikano set from when I was small which surely had an influence. You had an electronic set that you could build things with and then pull apart and then build something else ... And the other thing that I remember well, my uncle was a professor at Wits and he tells the story of how as a child he had a crystal set that you could use to build a radio ... and he came to visit us and he brought the crystal thing to show me, but he could not remember how the thing worked and then I tried build it.

Thus the presence of material resources is a significant dimension of socially just teaching and learning and its significance within the curriculum should not be underestimated.

\section{REPRESENTATION}

The political or representational dimension of social justice relates well to teaching and learning in debates about who is included in higher education, and how the rights of the participants are articulated and heard. The issue of representation is relevant to teaching and learning, in the sense that knowledge is power; and ability to express oneself within the discourses of power, enables a degree of representation of oneself, one's rights and the rights of those one wishes to represent. However, this description 
of representation does not cover the heart of what happens in teaching and learning. This is best dealt with in terms of socio-cultural theories on learning, on discourse and situated approaches, as will be described below.

Theorists as varied as Bernstein (1996), Bourdieu et al. (1994), Gee (1990), Heath (1994, 1983), Halliday (1995, 1994), Lave (1996) and Northedge (2003) have argued that the context in which we use language and the purposes to which we put this communication have shaped, and continue to shape, the way we use language and approach knowledge. Halliday particularly stressed the importance of the function of any communicative act and of context in shaping what linguistic forms we acquire, while Bourdieu, Heath, Gee and Bernstein have all stressed the key role of social class in influencing how young people acquire language. The influence of context, class, and forms of language individuals learn to use was borne out in the interviews in the SU study, where lecturers were able to cite examples of the language, literacy and oracy practices they engaged in as young people, and which prefigured they way they would use language once entering the academy. Bettina, a white Afrikaans-speaking female head of department in the humanities, described her familial legacy:

Through the way in which we were brought up I did get a lot of ... a lot of academic debate, ... you have to articulate your argument clearly ... if things are different then you have to show that they're different and not start muddling things ... and that part of being education [is typical] in this department.

These were the words of a head of department, who acknowledged the role of her father in encouraging debate in their middle class home. Zakes, a professor from a comparatively affluent, black family (which would, however, been part of the oppressed during the apartheid era) acquired a set of oracy practices that prefigured the study of African literature that he would master as a student and professor:

The main thing was the transference of knowledge from the parents by word of mouth. Well, my mother was a housewife. She brought us up with stories. We had to listen to her for language and, you know, learnt a lot more about how to speak your language properly. Most of the information would be communicated orally.

This extract suggests the professor might have elicited those aspects of his retrospective life story which cohere with his current disciplinary identity, but they point to a possible teaching and learning lesson: that, as with the previous extract, a 'fit' between a student's home discourse and his or her institutional, academic discourse, is highly beneficial. As a relatively uncommon example of the way indigenous knowledge is 
valued, this extract points to the need to create more opportunities for the valuing of indigenous knowledge, or of non-dominant uses of discourse.

The more challenging implication of these two extracts is the suggestion they present, that learning, or acquisition of a discourse, occurs through situated practice, over time and in context. The need to provide students with the opportunity to acquire academic discourse via contextualised and meaningful activities in disciplinary settings has long been acknowledged (Northedge 2003; Haggis 2006).

\section{RECOGNITION}

The role of recognition within teaching and learning is multi-faceted and multidirectional. In the first instance, it pertains to whether the individual feels welcome or included within the institution. This perception or feeling is linked to one's social location, as well as to various additional factors. Writing about issues of race and difference in South Africa, Thaver (2006) describes being 'at home' in an institution of higher learning as feeling secure and stimulated within the environment. In their research on students from various backgrounds entering higher education in the United Kingdom, Reay, David and Ball (2005:28) discuss the sense of confidence and entitlement of those who feel at home in the institution, mainly because they possess the cultural capital that is valued by the institution. They cite Bourdieu and Wacquant (1992:7): "And when habitus encounters a social world of which it is the product, it is like 'a fish in water': it does not feel the weight of the water and it takes the world about itself for granted." It extends to how the individuals perceive being treated by the institution. O'Connor, Hill and Robinson (2009:16) use the term 'refraction' to refer to identity which is shaped by how others, "based on their own structured and cultured positions", position individuals in relation to their academic performance. Race continues to be a factor influencing perceptions of being at home and not at home in South Africa, for black as well as white students (Walker 2005; Erasmus 2006). Erasmus, commenting on a study at the University of Cape Town, maintains racism had an impact on the learning of black students, who became withdrawn in teaching and learning situations. This impact is felt amongst academics as well (Mabokela 2000; Jansen 2005).

The argument that feeling at home or like a fish in water leads to greater comfort in teaching and learning situations, and hence greater affiliation with the university, as opposed to alienation, amongst those who do not feel at home, was borne out by many of the interviews. Thomas, an Afrikaans-speaking lecturer, who was also a 
student at this predominantly Afrikaans university, expressed gratitude for this feeling of being at home and for the influence it had on his studies:

I love the Afrikaans language and would hate to see it disappear. I have come to know the world through the medium of Afrikaans, and I believe that that experience bestows a texture on the meaning of the world that is unique and valuable. It is a great privilege to be able to enter the world of learning and knowledge in one's mother tongue. At the same time, I do not believe that it can ever be a basic function of a university to save a language ... If people, however, don't want it anymore, the university can't be the saviour.

Despite Thomas's sense of comfort, he did not feel that this privilege should necessarily be safeguarded at all costs, especially at the cost of diversity.

An example of the effect of alienation on learning was narrated by Lumka, who was made conscious of being black for the first time when she came to a university where she was part of a minority group. This contrasted with her experience in her home province in the Eastern Cape, where she was part of the majority. She felt almost traumatised when she attended an orientation session at the university and it was held in Afrikaans, a language she understood little of:

I am reminded about when we went for our induction, it was a traumatic experience actually, not being made to feel that you are part of [the university], not following most of what was said ... it was probably the Afrikaans.

There were other examples of alienation, for example that of a black lecturer who felt a lack of motivation and purpose with the academic enterprise of being at this privileged university. Ralph questioned the purpose of his job at the university, teaching middle class students. He felt unable to 'make a difference'. There were also examples of members of the majority, a powerful group, who felt alienated from the predominant culture at the university. One such person was a senior, white, Afrikaans-speaking professor who found the university too conservative and racist. He said of the institution: "I endure it."

Contrary to what one might expect, there were instances where individuals from disadvantaged backgrounds felt motivated and engaged with teaching and learning. Deborah, a black lecturer, insisted on succeeding and remaining at the university as a role model to black students:

I've been challenged by institutions outside of Stellenbosch about my motivation for being here... But I also feel that I have an important role to play at Stellenbosch 
being one of the few people of colour in terms of faculty members and that's what keeps me here.

There were also white students who engaged with their learning, despite their feeling of alienation. Janetta, the English-speaking daughter of a wealthy wine estate owner, was gay. She found her studies to be an escape from what she considered to be the empty, superficial life of her peers.

These examples seem to stress the salience of recognition in higher education settings in South Africa, but they also caution us against taking too simplistic approaches to this issue, and of making assumptions about how any one individual might behave.

The impact of recognition and the lack of recognition on learning has been discussed by various writers, for example Wenger (1998) who maintains that individuals who are part of a community of practice become invested in the practice. They are 'participative', and experience negotiability, which is the "ability, facility, and legitimacy to contribute to, take responsibility for, and shape the meanings that matter within a social configuration" (Wenger 1998:197). For Wenger (1998:51), identity is not just about how we describe ourselves and how we consciously affiliate, it is also about participating: "Identity in practice is defined socially not merely because it is reified in a social discourse of the self and of social categories, but also because it is produced as a lived experience of participation in specific communities." Thus identity is linked to experience and sense of competence. It is also linked to sense of purpose, which Bernstein (1996:73), like Clark and Ivanic (1997) sees as linked to identity and social location: "Identity arises out of a particular social order, through relations which the identity enters into with other identities of reciprocal recognition, support, mutual legitimisation and finally through collective purpose."

Waghid (this volume) suggests the need for democratic deliberation in order for lecturers and students to develop a space to understand commonalities. The significance of openness and dialogue as vehicles for recognition is underscored by many participants in the study. Bahia stresses how as a black, Muslim lecturer at this predominantly white, Christian university, she needs to remain aware of the fact that there are many different kinds of difference, and that she, like others, should remain open to sharing and asking, rather than assuming:

Don't tell me, "You people wear scarves." Ask me, you know, "Do you wear scarves?" Then I could tell you. So when people ask me questions I try as far as possible to be honest and to elaborate and to share. I feel that we all learn and so I always don't just see myself as I'm coming in [to an Afrikaans institution], because I also realise 
there are others who are coming in who are English-speaking or there are others who come in because they are international lecturers or students. So it's not just me saying, "I'm important, notice me or accommodate me," I'm also saying that I'm different because of my religion maybe, but somebody else will be different because of their language and somebody else may be different because of their ethnicity. But if you are sensitive to that and open to it then I think we learn from that.

The kind of confidence required to be open and vulnerable might need to be cultivated. It could be cultivated via exploration of issues of self and difference, within the curriculum or via action research projects. Shahieda, a senior student who was trained to conduct interviews with other students, saw herself as black, was a secretary of the Black Students Association, and yet she was surprised what she learnt after interviewing a group of black students:

I've started looking at diversity with greater depth ... and the funny thing is, when you sit and look at people you just assume that they're alike, but even in homogeneous groups you'll find people from completely different backgrounds and they view the world differently.

The cultivation of openness to difference and ability to recognise the 'other' could also be supported by reflexivity, which involves a criticality and questioning of one's own place in the world and one's own basic assumptions about knowledge (Taylor and White 2000). Reflexivity within the context of higher education is also enhanced by reflecting on one's own biography, which according to Tedder and Biesta (2007), facilitates the interrogation of one's own experience, interaction with others and the relationship between the self and the institution.

\section{STRUCTURE AND AGENCY}

So far I have presented social justice in relation to teaching and learning as primarily something that could be 'done' to students or to a lesser extent, to lecturers. The assumption might seem to be that distribution, recognition or political justice should be granted to students from disadvantaged backgrounds, or groups considered as 'other' or discriminated against. This would, however, be an extremely one-dimensional view of social justice in education and of human development. Statements like those of Lave regarding the socio-cultural nature of teaching and learning would seem to imply that learners are members of groups first and foremost: "A reconsideration of learning as a social, collective, rather than individual, psychological phenomenon offers the only way beyond the current state of affairs that I can envision at the present time" Lave (1996:149). However, interviews with students and lecturers in this study suggest 
that students' and lecturers' academic achievement and engagement are influenced by their social class origins, but not in ways which necessarily lead to predictable outcomes. In a discussion on complexity theory and its usefulness for thinking about teaching and learning Haggis (2004:349) writes: "It is arguably at least partly the unnamed and unexpected factors and interrelationships involved in 'learning', which deterministic/probabilistic models often do not result in the changes which teachers and policy-makers are hoping for." This complexity and unpredictability of outcome is most evident in the interviews cited in the section above on recognition.

According to Lave (1996), the tendency of traditional learning situations, where the focus is on the individual, is to define 'normal' as what successful students do, then to define whatever does not adhere to this as 'subnormal'. Yet, a potential danger of a socio-cultural approach with an emphasis on social structure and inequality is the potential tendency to attribute deficit, pathology or victimhood to members of oppressed groups. There is an easy slide, from compassion to "condescension and contempt" (Ecclestone 2004:132). One response to this might be to understand the strength or value that people from various backgrounds bring to education. In response to Bourdieu's theories of cultural capital as pertaining to the middle classes, Yosso (2005:77) argues that amongst communities of colour in the US, one should take into account "community cultural wealth", which is "an array of knowledge, skills, abilities and contacts possessed and utilized by Communities of Color to survive and resist macro and micro-forms of oppression". The forms of community cultural wealth amongst students from marginalised communities she describes, are all evident in the biographical stories told by lecturers and students in the study. Examples already cited thus far are linguistic capital, which according to Yosso, is the use of more than one language, and the ability to switch languages. This ability was cited by students and lecturers alike. It also exists in the extract of Zakes, where he describes the oral, storytelling discourse, which was an alternative to the dominant literacy-based discourse most typically cited in relation to cultural capital. An example of what she describes as "resistant capital" is evident in the story of Zakes, who obtained his undergraduate degree at the University of Fort Hare, which was a site of struggle in the apartheid era:

Of course, Fort Hare, those days known as the university for all sorts of activities within the liberation struggle. Well, there was no way that one would not get a qualification from Fort Hare, that was the objective of all of us who embraced, you know, a kind of success against all the odds. 
The fact that the interviews were able to provide examples of each of the forms of community cultural wealth as delineated by Yosso does not prove anything, it is not predictive, and it does not provide any sense of the weight of these as success factors amongst others. What these examples and Yosso's analysis does do, however, is to warn educators to guard against making easy assumptions about students based on their social background, especially in relation to deficit theories.

A solely deterministic approach seems to fail to account for the existence of agency, or the will to succeed against the odds, despite one's social class background. An example of agency is to be found in the story of Lindi, the isiZulu-speaking girl from a rural background in KwaZulu-Natal. She described her first year at Stellenbosch University as "great and bad":

I just knew that I had to do my best to be at the same level with the other students ... Also I had to realise I'm not like other students, in terms of my education background, and that influences me a lot because it's like one time I had to realise I'm not like other students and I felt like it was unfair for my lecturers to treat me like the rest of the other students and no one knows and no one cares you just have to adapt and be whatever you need to be.

I would still want to caution educators from taking comments like this to imply that agency is independent from social class and the availability of resources. A fuller discussion of Lindi's story would reveal that her parents were more well off than their neighbours, that the church remained a substantial cultural resource in her life, and that she was well supported by her parents, and even while at the university, by the Dean and other lecturers. There were several instances where a deeper investigation into the life history of a student, black or white, first generation or not first generation, displayed versions of Yosso's "community cultural wealth". Just to emphasise this point, a powerful white, Afrikaans-speaking Dean at the University, Stefan, came from a rural background where his father was unable to matriculate from high school, because his own father saw working on a farm as more important than gaining an education. Stefan's father made sure his children valued their education:

There were certain things that you could see [my father] acknowledging. One of the things he always acknowledged was the school reports, which he stored away carefully. He went to a single-teacher rural school and he used to store his own reports. Right from the beginning he used to store ours away. So you could see it was something valuable for him and it was one of the things which he respected if you did your side of the bargain at school. He was terribly dutiful, hard working; he used to work extra hours. He is also someone who rose above 
their circumstances. He was born during the war and his father did not believe a man should study, just work on a farm.

Stefan and Lindi's stories are not the same. Lindi is black and went to school in the 1980s and 1990s. Stefan is white and went to school in the 1960s and 1970s. He could be seen to have benefited from a form of affirmative action in favour of whites in the period, as Lindi could be seen to have done within her own context in the present era. Yet, in both instances their own sense of agency was bolstered by powerful familial and cultural support. These examples would appear to support the notion that agency and structure are interrelated. Arguing from a capabilities perspective, Walker (2006:43) maintains that individual agency and social arrangements are "on the same plane" and she argues that institutional arrangements, as well as pedagogic approaches, support individual flourishing. Norton (2000:8) sees material arrangements as crucial to the existence of human agency: "'The question 'Who am I?' cannot be understood apart from the question 'What am I allowed to do?' And the question 'What am I allowed to do?' cannot be understood apart from material conditions that structure opportunities for the realization of desires." Porteus (2008:13) sees the flourishing of agency as supported by two conditions: by "moving unfreedoms" (quoting Sen), in other words, by creating the conditions in which agency can be exercised, and by "by tapping into a human consciousness of powerfulness" (referring to Freire).

Haggis (2006) suggests that it may be the responsibility of the lecturer, not the student, to change the lack of fit between non-traditional students and the institution. This does not contradict the notion advanced by Barnett (2007), that in an age of uncertainty it remains the responsibility of the student to learn. Barnett and Coates (2005) also maintain that the responsibility for designing the curriculum, which includes the social context in which learning takes place, rests with the lecturers.

In order for students from various socio-cultural backgrounds to participate freely in higher education teaching and learning, it is the responsibility of the institution to ensure that material, structural and affective conditions exist for individuals to exercise agency. It is the responsibility of the lecturers to ensure that the curriculum is structured in such a way that all students can engage and grow academically, and it is the responsibility of the student to exercise agency, and to learn.

\section{IMPLICATIONS FOR A PEDAGOGY OF POSSIBILITY}

Fraser's view of social justice, accompanied by an account of structure, agency and responsibility as interconnected and complex (as summarised in Table 5.1), allows 


\begin{tabular}{|c|c|c|c|}
\hline \multirow{2}{*}{$\begin{array}{l}\text { Role-players and } \\
\text { responsibilities }\end{array}$} & \multicolumn{3}{|c|}{ Fraser's 2009 dimensions as applied to teaching and learning } \\
\hline & Distribution & Participation & Recognition \\
\hline $\begin{array}{l}\text { The student } \\
\text { Takes } \\
\text { responsibility for } \\
\text { learning }\end{array}$ & $\begin{array}{l}\text { E.g. Makes sure in } \\
\text { advance that he/she } \\
\text { has the time to attend } \\
\text { computer sessions in } \\
\text { advance }\end{array}$ & $\begin{array}{l}\text { E.g. Takes } \\
\text { responsibility to learn } \\
\text { from others in all } \\
\text { circumstances; } \\
\text { Takes responsibility to } \\
\text { have his or her voice } \\
\text { heard; } \\
\text { Collaborates with } \\
\text { others in groups in } \\
\text { order to learn and } \\
\text { share }\end{array}$ & $\begin{array}{l}\text { E.g. Respects and } \\
\text { acknowledges the } \\
\text { 'other', whether this } \\
\text { is a lecturer or fellow } \\
\text { student - develops } \\
\text { "compassionate } \\
\text { imagining" (Waghid, } \\
\text { this volume) }\end{array}$ \\
\hline
\end{tabular}

This model points the way forward for the work of innovators, researchers, teachers or administrators who wish to ensure that higher learning institutions are places where individuals from varied social categories may learn to grow and prosper. The responsibility to ensure that higher education is indeed a public good, rests with all the role-players, at whichever level they may make a contribution.

\section{ACKNOWLEDGEMENTS}

The Identity, Teaching and Learning project was supported financially by the National Research Foundation.

Members of the Identity, Teaching and Learning project team over the two years included: Hanelie Adendorff, Kwanele Booi, Sharifa Daniels, Ansie Loots, Sipho Nakasa, Celesté Nel, Nosiphiwe Ngxabazi, Rose Richards, Idilette van Deventer and Antoinette van der Merwe

\section{REFERENCES}

Archer A. 2006. Change as additive: Harnessing students' multimodal semiotic resources in an Engineering curriculum. In: L Thesen \& E van Pletzen (eds). Academic literacy and the languages of change. London: Continuum.

Barnett R. 2007. A will to learn; Being a student in an age of uncertainty. Maidenhead: OUP \& SRHE.

Barnett R. \& Coates K. 2005. Engaging the curriculum in higher education. Berkshire: SRHE.

Bernstein B. 1996. Pedagogy, Symbolic Control and Identity; Theory, research, critique. London: Taylor \& Francis.

Bourdieu P, Passeron J, De Saint M. 1994. Academic discourse. Cambridge: Polity Press. 
Bozalek V. 2004. Recognition, resources, responsibilities: Using students' stories of family to renew the South African Social Work curriculum [Online]. Available: http://igitur-archive. library.uu.nl/dissertations/2004-1203-094505/index.htm [2005, 1 January].

Clark R \& Ivanic R. 1997. The Politics of Writing. London: Routledge.

Department of Education. 2007. Education Statistics in South Africa [Online]. Available: http://www.education.gov.za/emis/emisweb/07stats/Education Statistics in South Africa2007.pdf [2009, 31 March].

Cross M \& Johnson B. 2008. Establishing a space of dialogue and possibilities: Student experience and meaning at the University of the Witwatersrand. South African Journal of Higher Education, 22(2):264-283.

Ecclestone K. 2004. From Freire to Fear: The rise of therapeutic pedagogy in post- 16 education. In: J Satterthwaite, E Atkinson \& W Martin (eds). The Disciplining of education: New languages of power and resistance. Stoke on Trent: Trentham. 117-135.

Erasmus Z. 2006. Living the future now: 'Race' and the challenges of transformation in higher education. South African Journal of Higher Education, 20(3):413-425.

Fraser N. 2009. Scales of justice: Reimagining political space in a globalizing world. New York: Columbia University Press.

Fraser N. 2003. Redistribution or recognition? A political-philosophical exchange. In: N Fraser \& A Honneth (eds). Social justice in the age of identity politics: Redistribution, recognition, and participation. London: Verso Publishers. 7-109.

Garraway J (ed). 2007. Conversations about foundation and Extended curriculum provision. Conference Proceedings. Cape Town: Cape Peninsula University of Technology.

Gee J. 1990. Social linguistics and literacies: Ideology and discourses. London: Falmer.

Gough D. 2000. Discourse and students' experience of higher education. In: B Leibowitz \& Y Mohamed (eds). Routes to writing in Southern Africa. Cape Town: Silk Road International.

Gutierrez K, Morales P \& Martinez D. 2009. Remediating Literacy: Culture, difference, and learning of students from nondominant communities. Review of Research in Education, 33:212-245.

Haggis T. 2006. Pedagogies for diversity: Retaining critical challenge amidst fears of 'dumbing down'. Studies in Higher Education, 5(31):521-535.

Haggis T. 2004. Meaning, identity and 'motivation': Expanding what matters in understanding learning in higher education. Studies in Higher Education, 29(3):335-352.

Halliday M. 1995. Language and the theory of codes. In: Sadovnik A (ed). Knowledge and pedagogy: The sociology of Basil Bernstein. Norwood: Ablex.

Halliday M. 1994. Language as social semiotic. In: J Maybin (ed). Language and literacy in social practice. Avon: Multilingual Matters/Oxford University Press.

Heath S. 1994. "What no bedtime story means": Narrative skills at home and at school. In: J Maybin (ed). Language and literacy in social practice. Avon. Multilingual Matters/Oxford University Press.

Heath S. 1983. Ways with words: Language, life and work in communities and classrooms. Cambridge: Cambridge University Press. 
Jacobs C. 2009. Teaching explicitly what is tacit; the challenge of disciplinary discourses. In: B Leibowitz, A van der Merwe \& S van Schalkwyk (eds). Focus on First-year Success. Stellenbosch: SUN MeDIA. Forthcoming.

Jansen J. 2005. Black dean: Race, reconciliation, and the emotions of deanship. Harvard Educational Review, 75(3):306-326.

Lave, J. 1996. Teaching, as Learning, Practice. Mind, Culture, and Activity, 3(3):149-164.

Leibowitz B. In press. What's Inside the Suitcases? An investigation into the powerful resources students and lecturers bring to teaching and learning. Higher Education Research and Development.

Leibowitz B, Booi K, Daniels S, Loots A, Richards R \& Van Deventer I. 2005a. The use of educational biographies to inform teaching and learning in an African university. South African Journal of Higher Education Special Issue:38-55.

Leibowitz B, Adendorff H, Daniels S, Loots A, Nakasa S, Ngxabazi N, Van der Merwe A \& Van Deventer I. 2005b. The relationship between identity, language and teaching and learning in higher education in South Africa. Per Linguam, 21 (2):23-37.

Mabokela R. 2000. "We cannot find qualified blacks": Faculty diversification programmes. Comparative Education, 36(1):95-112.

Northedge A. 2003. Rethinking Teaching in the Context of Diversity. Teaching in Higher Education, 8(1):17-32.

Norton B. 2000. Identity and language learning: Ethnicity and educational change. London: Pearson Education.

O'Connor C, Hill L \& Robinson S. 2009. Who's at risk in school and what's race got to do with it? Review of Research in Education, 33:1-34.

Porteus K. 2008. Decolonising inclusion. In: A Muthukrishna (ed). Educating for social justice and inclusion in an African context: Pathways and transitions. New York: Nova Science Publishers.

Reay D, David M \& Ball S. 2005. Degrees of choice: Social class, race and gender in higher education. Stoke on Trent: Trentham.

Rohleder P, Swartz L, Bozalek V, Carolissen R \& Leibowitz B. 2008a. Community, self and identity: Participation action research and the creation of a virtual community across two South African universities. Teaching in Higher Education, 13(2):131-143.

Rohleder P, Bozalek V, Carolissen R, Leibowitz B \& Swartz L. 2008b. Students' evaluations of e-learning as a tool in a collaborative project between two South African universities. Higher Education, 56(1):95-107.

Taylor C \& White S. 2000. Practising reflexivity in health and welfare: Making knowledge. Buckingham: Open University Press.

Tedder M \& Biesta G. 2007. Learning from life and learning for life: Exploring the opportunities for biographical learning in the lives of adults. Learning lives: Learning, identity and agency in life course. Working Paper 7. University of Exeter.

Thaver L. 2006. "At home"; institutional culture and higher education: Some methodological considerations. Perspectives in Education, 24(1): 15-26. 
Walker M. 2006. Higher education pedagogies: A capabilities approach. Berkshire: SRHE \& OUP.

Walker 2005. Rainbow nation or new racism? Theorizing race and identity formation in South African higher education. Race, Ethnicity and Education, 8(2):129-140.

Wenger E. 1998. Communities of practice: Learning, meaning and identity. Cambridge: Cambridge University Press.

Yosso T. 2005. Whose culture has capital? A critical race theory discussion of community cultural wealth, Race Ethnicity and Education, 8(1):69-91. 


\title{
THE UNIVERSITY IN \\ A CONTEMPORARY ERA
}

\section{REFLECTIONS ON EPISTEMOLOGICAL SHIFTS}

Lesley le Grange

\begin{abstract}
The contemporary university is an institution that is transforming rapidly. In an age of supercomplexity it too must become supercomplex and expand its epistemologies so as to engage with the challenges of a changing world. In this chapter I critically discuss epistemological transformations occurring in the contemporary university as a consequence of both inside-out pressures and outside-in pressures. I examine traces of these shifts in post-apartheid higher education policy in South Africa, and in practices at both a systemic and institutional level. I argue that even though it appears as if transformations that the modern university is undergoing mark the end of the pursuit of universal reason and the ideal of a liberal education, globalisation affords new spaces for reclaiming some lost ground.
\end{abstract}

\section{INTRODUCTION}

It is not an exaggeration to say that the higher education landscape, both globally and in South Africa, is changing rapidly. Since the inception of the modern university about 800 years ago, its central occupation has been the production, transmission and acquisition of knowledge. In the contemporary university this primary occupation has not changed. What has changed is the nature of knowledge production, transmission and acquisition, and the way that knowledge is legitimated and valued.

To understand these changes it might be useful to refer to three incarnations of the modern university which Bill Readings outlines in his book The University in Ruins. Readings (1996) characterises the contemporary university in terms of the idea of excellence to underscore the entrenched position of performativity. He also contrasts 
it with earlier incarnations: the Kantian University of Reason (for which the founding discipline was philosophy) and the Humboldtian University (in which philosophy was replaced with literature). In the Kantian University, knowledge was the product of reason - reason was foundational for enlightenment. With regard to the Humboldtian University, Readings refers to the German model of the university instituted by Von Humboldt at the University of Berlin in 1812. In the Humboldtian University, culture was the central organising principle and the emphasis was placed on literature (the arts). This model has served as the basis for what is generally called the Liberal (Arts) University - where students receive a broad general education which includes courses in the arts.

I wish to use Reading's distinctions to loosely frame my discussion of epistemological shifts which have produced the features that have come to characterise the contemporary university. I shall examine traces of these shifts in South African higher education policy and practice. Moreover, I shall reflect on the implications of this debate for the future of South African higher education. To support my claims I shall draw on examples from the South African higher education institution most familiar to me: Stellenbosch University.

\section{THE UNIVERSITY, THE KNOWLEDGE SOCIETY AND THE KNOWLEDGE ECONOMY}

The concepts knowledge society and knowledge economy have different histories and different homes. Knowledge society and knowledge economy belong to disparate disciplines/discourses: the sociology of knowledge and the economics of knowledge, respectively. Peters (2007:17) argues that, although these twin concepts appear to have similar characteristics, they are separate and parallel discourses that are not cross-threading. However, he points out that these concepts intersect in the area of policy, in policy studies and in policy discourses. This nexus is evident in the discourses of (trans)national higher education policy as well as in those of individual higher education institutions (which are of course shaped by broader national and international discourses). The intersection of the concepts (knowledge economy and knowledge society) embraces a number of blended discourses of policy and hybrid discourses in the field of management, such as human resources management, performance management and knowledge management. I shall not discuss the emergence of the constructs knowledge economy and knowledge society in any detail here. Peters (2007:17-29) provides a comprehensive discussion of the emergence of these twin concepts from the disciplines economics of knowledge and the sociology of knowledge, respectively. Suffice it to say that it is widely accepted (though not uncontested) that the 
knowledge society will increasingly be driven by a knowledge economy - not only in terms of the rapid speed at which knowledge travels over far distances, but also of its commodification - how it is packaged and sold on the global market.

Watson (2003) argues that the role of the university in a knowledge society is changing as a consequence of two sets of pressures: 'inside-out' and 'outside-in' developments. The inside-out developments refer to intrinsic pressures concerned with a set of epistemological challenges. He refers here to the theoretical intervention of Michael Gibbons and his colleagues - the shift from Mode 1 (pure, disciplinary, homogeneous, expert-led, supply-driven, hierarchical, peer-reviewed and almost exclusively university-based) to Mode 2 knowledge (applied, problem-centred, transdisciplinary, heterogeneous, hybrid, demand-driven, entrepreneurial, network-embedded and so on) (Gibbons et al. 1994). Outside-in developments refer to social concerns. These include aspects such as socio-economic patterns of participation, including who gets access to education, health care and so on. I shall give some attention to the first set of pressures and examine the extent to which it has (had) an influence on South African higher education policy and practice. I shall not devote much attention to the second set of pressures (outside-in developments) in this chapter. However, I shall discuss broader extrinsic influences on the contemporary university brought about by a competitive and interconnected global economy.

The link between knowledge and economy is not new. Much has been written in the $20^{\text {th }}$ century about the role that knowledge plays in contributing to the economic growth of nations. Two developments are particularly pertinent to our discussion: the ascendancy of neoliberalism and the concomitant capitalisation of knowledge. Neoliberalism can be traced back to certain liberal perspectives of the $17^{\text {th }}$ century, which became marginalised as a result of the rise of welfare state liberalism of the late $19^{\text {th }}$ century and Keynesian economics of the $20^{\text {th }}$ century. Its revival in the past few decades has been associated with the emergence of the 'new right' in Europe and the United States of America, often referred to as Reaganism and Thatcherism, after two of its key proponents. The revival of neoliberal politics has witnessed the erosion of the welfare state, the privatisation of state assets and a return to neoclassical economics. Needless to say, neoliberalism is a contentious term (both among its proponents and its critics). However, there are common principles which all neoliberals share. These are: a commitment to individual liberty and a reduced state, a shift in policy and ideology against government intervention and a belief that market forces should be allowed to be self-regulating. (For a comprehensive discussion on the ascendancy of neoliberalism, see Olssen, Codd and O'Neill (2004).) 
Neoliberal politics have had an influence on universities and we have witnessed what might be termed the 'rise of the neoliberal university'. Peters (2007:7) argues that the dangers of economic interest vested in the university through the dominance of technical reason (as espoused by Weber, Heidegger, Jaspers, Lyotard and Bourdieu, among others) and the controlling influence of the state on the academy through what Foucault called administrative reason, come together in new ways to produce the neoliberal university. The first involves the surrendering of norms of liberal humanism and the Kantian ethical subject to the revitalisation of economic rationalism and homo economicus, and the second entailed the imposition of structural adjustment programmes by the World Bank and IMF in the 1980s, which impacted negatively on universities in the developing world. The link between neoliberalism and the second development that I mention, the capitalisation of knowledge, becomes evident. As Peters (2007:7) cogently puts it:

Neoliberal universities, with little self-reflection, have been harnessed in service to the 'new economy' under conditions of knowledge capitalism that raises issues of intellectual capital, the ownership of the means of production, and depends upon the encouragement of all forms of capitalisation of the self.

Jacobs and Hellström (2000:1) point to three significant developments in the transformation of the university research system over the past two or three decades:

- the shift from science systems to global science networks

- the capitalisation of knowledge

- the integration of academic labour into the industrial economy, also known as the coming of the knowledge economy.

These developments have wide-ranging implications for universities - particularly for academics who work in and constitute these institutions. And they raise the question of the future role of the university. The transformation of the modern university has been described by many as a crisis. Some have expressed the crisis in dramatic terms: "After years of battering from without, the walls of the ivory tower are finally crumbling" (Jacobs and Hellström 2000:1). All of this points to the fact that the ideals of earlier incarnations of the university have become eroded, witnessing the emergence of a new unifying idea(I) which characterises the contemporary university - the idea $(I)$ of excellence. 
Readings (1996:119) characterises the contemporary university in terms of the idea of excellence so as to emphasise the dominance of the institution of performativity. ${ }^{14} \mathrm{He}$ argues that when university managers invoke the term excellence, they unwittingly bracket the question of value to favour measurement and accounting solutions in preference to questions of accountability. As mentioned, Readings contrasts the contemporary university with earlier incarnations: the Kantian University of Reason (for which the founding discipline is philosophy) and the Humboldtian University (in which philosophy is replaced with literature). But, unlike its predecessors, the ideal of excellence conceals a kind of vacuity. Barnett and Standish (2003:217) elaborate on this:

Globalisation and the decline of the nation-state create conditions where the currency of excellence can function ideally for a knowledge economy. Homogenized systems of transferability and commensurability enable the free flow of cultural capital, and these are realized through a downgrading in importance of content and a weakening of cultural attachments. The modern university is dominated by procedural reasoning - in its emphasis on skills and on management systems, and in an incipient reduction of knowledge to information (all accelerated by computerization) - to the detriment of a proper attention to content and to traditions of inquiry. In the University of Excellence academic freedom is not so much threatened as effaced.

Put differently, as a unifying principle excellence has the benefit of being entirely meaningless, that is, it is non-referential. Peters (2004:71) argues that the idea(l) of excellence

signifies the corporate bureaucratization of the university. Universities have become sites for the development of 'human resources'. Guided by mission statements and strategic plans, performance output is measured and total quality management (TQM) assures quality outcomes.

Against this background my interest now is examining traces of these changes in the transforming landscape of South African higher education policy and practice generally and, more specifically, with reference to Stellenbosch University.

14 Performativity is used here in the way in which Lyotard uses it in The Postmodern Condition. As Lyotard (1984:11) writes: "The true goal of the system, the reason it programs itself like a computer, is the optimisation of the global relationship between input and output - in other words, performativity." 


\section{THE TRANSFORMATION OF HIGHER EDUCATION IN SOUTH AFRICA}

After the legal dismantling of apartheid, several policy processes were put in place aimed at transforming higher education. Central to these processes was the need for higher education to respond to two broad challenges: its contribution to redressing inequities of the past and its response to the demands of an economically competitive 'global society'. Key policy texts that were produced after 1994 were the following: the final report of the National Commission on Higher Education (NCHE), entitled A Framework for Transformation (1996), the Department of Education's Green Paper on Higher Education Transformation (DoE 1996), the Education White Paper 3: A Programme for the Transformation of Higher Education (DoE 1997) and the Higher Education Act of 1997. The first challenge is captured in the Department of Education's White Paper 3: A Programme for the Transformation of Higher Education (DoE 1997:7):

In South Africa today, the challenge is to redress past inequalities and to transform the higher education system to serve a new social order, to meet pressing national needs, and to respond to new realities and opportunities. [Higher education] must lay the foundations for the development of a learning society which stimulates, directs and mobilizes the creative and intellectual energies of all people towards meeting the challenge of reconstruction and development.

Concerning the second challenge, the same White Paper emphasises that higher education in South Africa should address the needs of the labour market "in a knowledge-driven and knowledge-dependent society, with the ever-changing highlevel competencies and expertise necessary for growth and prosperity of a modern economy" (DoE 1997:10). In a document published later by the Council on Higher Education (CHE 2000) it is asserted that "[h]igher education must play a central role in meeting the difficult realities of international competition in an environment of rapid global change, driven, as it is, by momentous changes in information and knowledge systems". The first challenge links to what Watson (2003) refers to as outside-in pressures and the White Paper clearly addresses the importance of increasing participation in South African higher education and the provision of access to those who are historically disadvantaged. But it is the link made in the White Paper between higher education and the (global) economy that is more pertinent to my discussion in this chapter.

Watson (2003) refers to the shift from Mode 1 to Mode 2 knowledge production as an inside-out development. In certain senses this is so; for example, the transition to Mode 2 knowledge production is partly the consequence of the fragmentation of disciplinary knowledge - disciplinary knowledge is no longer adequate to address the complex needs and problems experienced in the contemporary world. I also agree 
with Beck (in Beck and Willms 2004) that globalisation is not only a set of external forces impacting on the local, but that it is as much concerned with the transformation of the local. By way of analogy I would argue that the transformation of knowledge production in late modernity is the consequence of both intrinsic and extrinsic pressures. Having said this, I wish to point out that broader extrinsic pressures on nation-states and universities should not be underestimated. I refer here to the erosion of the welfare state in European countries (and elsewhere) associated with the ascendancy of neoliberal politics, which has migrated to the developing world in various and complex ways, including through agencies such as the World Bank and the IMF. Also, I contend that Mode 2 knowledge production at an organisational level has created a tripartite alliance among university, industry and bureaucracy (the so-called triple helix), which Jacobs (2000:11) argues heralds a structural shift in the economies of industrialised countries towards a post-industrial phase in which knowledge is the prime motor of economic growth. In an integrated world capitalist system where knowledge is a primary commodity, the questions of who owns the means of production and how all of this impacts on universities in the developing world again come to the fore. So what does all of this have to do with the transformation of higher education in South Africa? I shall answer this by referring to some instances of the transforming landscape of South African higher education.

Jansen (2002:507) points outs that South African higher education policy documents (produced post-1994) bear the unmistakeable mark of Gibbons and his colleagues. In fact, some of Gibbons's colleagues such as Peter Scott served as consultants to higher education policy development in post-apartheid South Africa. However, Jansen argues that the accommodation of Mode 2 knowledge production in South African universities is uneven. For example, whilst Mode 2 knowledge forms thrive and are expanding at an institution such as the University of Pretoria, there is little evidence of their success in a historically disadvantaged university such as the University of Durban-Westville ${ }^{15}$ (as it was formerly known). I acknowledge the unevenness Jansen refers to. I also wish to acknowledge that there is not a simple linear relationship between policy and practice. However, some policies (or elements of them) do trickle down so as to influence practices (variously and in uneven ways). And so I shall show how Mode 2 thinking has penetrated universities in South Africa and how it has (re)configured academic programmes. I shall pay particular attention to what might be referred to as teaching/learning programmes (which I shall refer to simply as teaching programmes).

15 The University of Durban-Westville has since merged with the University of Natal and the amalgamated institution is now called the University of KwaZulu-Natal. 
Teaching programmes have always existed in universities. However, one outcome of higher education policy developments of the late 1990s was the reconfiguration of teaching programmes at all South African universities, in terms of both organisational and design aspects. Several universities have changed their organisational structures to create larger units such as schools and colleges, resulting in the abandoning of traditional academic departments organised along disciplinary lines. School and/or programme directors have been appointed and traditional heads or chairpersons of departments have been done away with. In many instances these larger structures are organised around programmes and not disciplines. Furthermore, in terms of programme design there has been a shift in the sense that academic disciplines do not necessarily inform the goals and vision of programmes, but outcomes do so (some generic to all teaching programmes in SA and some specific to particular programmes). These outcomes are linked to the needs of both global and South African societies (which include the 'needs' of the global and the national economies). The approach to curriculum design is a design-down/deliver-up one, where modules (which are traditionally organised around disciplines) now have to be (re)designed in the service of the vision and outcomes of a programme. This is at least how it works in theory - the extent to which these changes are reflected in practice would vary depending on the institution. North-West University is an example of an institution which has made fairly comprehensive changes to its organisational structures with respect to academic programmes (both research and teaching). At Stellenbosch University new programme structures have been put in place, but academic departments have been retained. Smaller programmes are located within departments and larger ones across departments. The situation of having both programme chairs and departmental chairs does create tensions. For example, staff are appointed by departments and departmental chairs manage operation budgets. But programme chairs are responsible for managing programme renewal, which might have staff implications, over which they do not have powers to decide.

There are a few cases at Stellenbosch University where departments have merged to form larger structures, for example, the former departments of Botany and Zoology. Even though the new name of the department is Botany and Zoology (retaining both identities) it, for example, presents a programme in Biodiversity and Ecology, which might indicate that the identities of Zoology and Botany are jeopardised. My question is: when a student now takes modules in Biodiversity studies instead of traditional modules in Botany or Zoology, what knowledge and skills are gained or lost? An analogy from the school system might provide further clarification. There have been 
those (such as Allais 2003, 2007) who have argued that South Africa's outcomesbased curriculum for schools has diluted disciplinary knowledge and that an integrated approach to curriculum does not develop continuity and progression, which is key in certain subjects/disciplines (see Beets and Le Grange 2008). A colleague pointed out to me that in a first-year BEd class of 250 students (many passed the new National Senior Certificate with top grades) not a single student knew that the Sahara desert was located in Africa. I am convinced that this would not have been the case 10 years ago. Of course, we can debate whether it is important to know on which continent the Sahara desert is. However, the students' 'lack' of what might be considered basic geographical knowledge does raise the question as to what else these students do not know and, of course, also what knowledge and skills they might have acquired that students who did their schooling before the new curriculum was implemented might not have known.

But how does this relate to Mode 2 knowledge production? Mode 2 knowledge production concerns a shift in the way knowledge is produced in a socially distributed knowledge system - essentially it has to do with research. What I have tried to show is that protagonists of Mode 2 thinking played a role in influencing higher education policy in South Africa, which has resulted in the reconfiguration of both the organisation and the design of teaching/learning programmes. Mode 2 thinking therefore does not only relate to the production of knowledge, but also to its transmission and acquisition in that the knowledge included in teaching programmes is reframed.

Teaching programmes have also been affected by another development in South African higher education, namely the emergence of an audit culture associated with the rise of neoliberalism. The emergence of quality assurance (and related terms) in discourses on higher education might be understood against the backdrop of a rising culture of performativity in society generally and in education more specifically. In his seminal work The Postmodern Condition (a commissioned report on the university sector to the government of Québec) Lyotard (1984) introduces the term performativity. Since its coinage this term has been widely invoked in the criticism of contemporary education practice. As Barnett and Standish (2003:16) write:

The term aptly exposes the jargon and practices of efficiency and effectiveness, quality assurance and control, inspection and accountability that have become so prominent a feature of contemporary educational regimes. Whatever is undertaken must be justified in terms of an increase in productivity measured in terms of a gain in time. 
Moreover, Ball (2003:216) argues that "performativity is a technology, a culture and a mode of regulation that employs judgements, comparisons and displays as means of incentive, control, attrition and change - based on rewards and sanctions". But how do we understand the emergence of this policy technology in recent years? The rising culture of performativity is closely intertwined with the ascendance of neoliberalism in the past four decades, which I discussed earlier in the chapter. My interest here is to look at how these developments have played out in South African higher education. The Higher Education Act of 1997 legitimised the establishment of a Higher Education Quality Committee (HEQC) responsible for monitoring and regulating the quality of all higher education programmes through a process of accreditation of such programmes/ qualifications. On the neoliberal agenda is the idea of self-regulation evident in the work of the HEQC through systems and processes of peer auditing, evaluation and review, leading to what is referred to as the attainment of self-accreditation status on the part of higher education institutions. Self-regulation and self-accreditation are misleading terms, because in a sense they imply an association with academic freedom and institutional autonomy. However, these terms do not mean the relinquishment of state control, but the establishment of a new form of control - what Du Gay (1996) calls "controlled de-control" or what Vidovich (2002) calls "steering at a distance". Performativity remains the regulatory regime. Teaching programmes in South Africa do not only have to be reconfigured because of Mode 2 thinking, but are also subject to regulation by the state even though this might be by 'remote control'.

I shall now move on to discuss another matter, namely how an interconnected global knowledge economy has influenced the way in which the state funds research publications in South Africa. Universities receive direct state funding by way of subsidy income based on teaching inputs, teaching outputs and research outputs. Research outputs comprise completed master's and doctoral research, and research publications. The state only gives funding for articles that have been published in accredited journals (peer-reviewed journals approved by the Department of Education). Prior to 2004, the national Department of Education (DoE) had a single list of accredited journals. Journals were included on this list based on submissions made by South African universities through their research divisions. The submissions were evaluated by a panel appointed by the DoE and decisions were made as to whether a journal was placed on the list - in other words, the journal received accreditation. This has changed after 2004. Journals are now automatically accredited only if they appear on the International Scientific Information (ISI) master list, the International Bibliography of Social Sciences (IBSS) list and the DoE list for South African journals. Editors of South 
African journals have been encouraged to have their journals placed on the ISI list. Of the three lists, ISI has by far the most journals. ISI, however, is owned by a private company, Thomson Reuters, which is a multi-billion USA dollar company. The upshot of this is that a private company is now indirectly controlling which journals South African academics publish in. If academics choose not to publish in journals (even though they may be the best quality journals) on the three lists, then the income that their institutions receive will be reduced. This will impact negatively on their research funding and their career advancement as well as on the status of their institution. South African academics and the universities in which they work have not been left unaffected by the capitalisation of knowledge.

In this section I have attempted to show by way of a few examples how the transformation of higher education in South Africa might be understood within broader transformations occurring in global society and its transition towards what has been variously described as a knowledge society, learning society, knowledge economy and post-industrialised age. Wittingly or unwittingly South African universities and academics are co-producers of this epochal change. And the question is: how should one engage with these developments in critical and productive ways? Before responding to this, I shall briefly discuss one more matter: the way that the unifying principle of excellence manifests itself at Stellenbosch University.

\section{STELLENBOSCH UNIVERSITY AND THE IDEA(L) OF EXCELLENCE}

In this section of the chapter I shall show how the idea(l) of excellence is manifested in Stellenbosch University's policies and practices, and will specifically refer to excellence in relation to research. Peters (2007) reminds us that the idea(l) of excellence denotes the corporate bureaucratisation of the university, guided by mission statements and strategic plans, and the measuring of performance output. In the strategic plan document entitled A Strategic Framework for the Turn of the Century and Beyond (2000), the mission of Stellenbosch University is described as follows:

The raison d'être of the University of Stellenbosch is to create and sustain, in commitment to the academic ideal of excellence in scholarly and scientific practice, an environment within which knowledge can be discovered, can be shared, and can be applied to the benefit of the community.

Its vision statement (called Vision 2012) says Stellenbosch University: 
- is an academic institution of excellence and a respected knowledge partner;

- contributes towards building the scientific, technological, and intellectual capacity of Africa;

- has a campus culture that welcomes a diversity of people and ideas;

- promotes Afrikaans as a language of teaching and science in a multilingual context.

Based on its Vision 2012 Stellenbosch University's management formulated Strategic Management Indicators (SMIs) with targets that each of the 10 faculties should achieve by the year 2010. For the category research excellence, targets were set in the areas indicated in Figure 6.1.

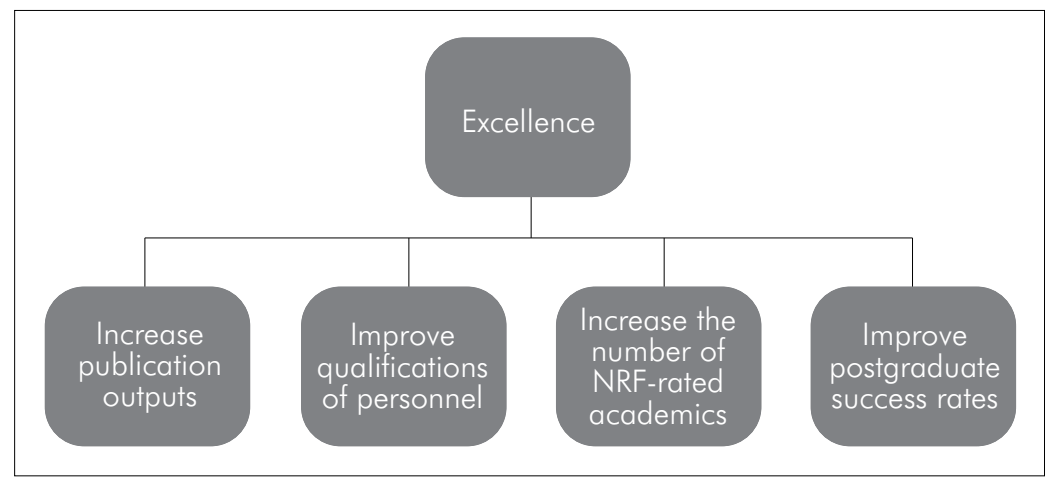

FIGURE 6.1 Strategic management indicators for research excellence

As an example, Figure 6.2 shows the targets set for publication outputs. The targets are presented in terms of the number of publication units per full-time equivalent $\mathrm{C} 1$ (academic) staff. The publication units are based on articles published in accredited journals and scholarly books approved by the Department of Education. 


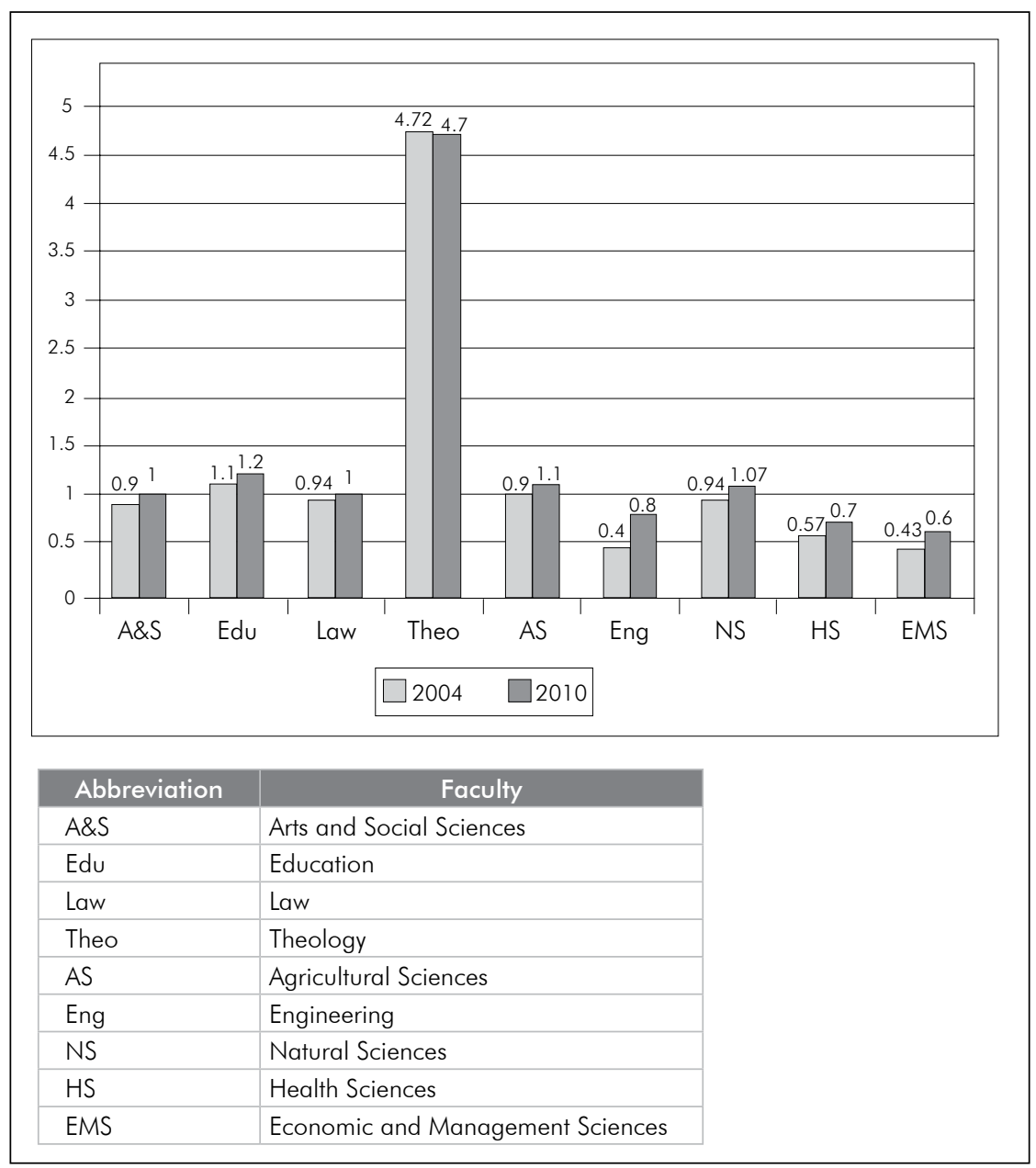

FIGURE 6.2 Targets for publication outputs for each faculty

Research excellence has been translated into performance indicators that are measurable - if Stellenbosch University achieves its targets, then it is an excellent university. What is researched and the traditions of inquiry are not primary considerations, so long as the targets are achieved. Excellence is viewed only in terms of what is measurable; this serves the needs of university managers who can use the statistics to position this university favourably in an increasingly competitive higher education systems in which universities are placed on world, continental and national ranking lists. But as Readings (1996) importantly points out, these indicators of excellence conceal the emptiness of the idea(I) of excellence, which was not the case of the earlier incarnations of the university. 


\section{SOME PARTING THOUGHTS}

Readings (1996) views the transformation of the modern university as a crisis - he speaks of "the university in ruins" Ruin has at least three meanings that suggest subtle differences: firstly, it could refer to something that has been damaged or destroyed, secondly, it could refer to something that is on the decline or decaying, and thirdly, it could refer to the remains of what was - what already has been destroyed. These different meanings enable us to gain a more nuanced understanding of the state of the contemporary university. The first meaning suggests that earlier incarnations of the university have passed and will not return. The second meaning suggests that the pillars of the university are cracking, but that there is the possibility of restoring the university - winning back what was valued in earlier incarnations. The third meaning helps us to understand that in practice, even when radical transformation occurs, there are always the remains of what had existed before that could be harnessed in a new era.

In this chapter I discussed how the contemporary university is transforming in an emerging knowledge society which is increasingly driven by a knowledge economy. In a system in which knowledge is socially distributed, the university is no longer the sole knowledge producer and now produces knowledge in alliance with industry and bureaucracy. The ascendancy of neoliberal politics and the concomitant rise of performativity regimes are strongly felt in universities. Furthermore, the capitalisation of knowledge implies that the means of production are increasingly controlled by those outside the university, such as private companies. These developments impact on those who work in universities, for example, on the professional identities of academics. In the South African context academics now have to take on indexed identities such as being $A_{-}$, B- or C-rated scientists. I wish to suggest that these developments are not simply external pressures acting on universities, but are just as much about the transformation of universities from within - that some of those who work in universities actively take up neoliberal and associated discourses.

I have shown that South African universities have not been left unaffected by these developments and that these changes are witnessed in all the key functions of the university: research, teaching and community engagement. Community engagement is concerned with a wide range of activities which HEls are involved with/in such as voluntarism, internships, service learning, community outreach and research and development projects in collaboration with communities and industry. But is the idea of cultivating humanity or Kant's ethical subject something of the past? I would suggest not. However, we cannot turn back the clock. The contemporary world is different from the 
one when the Western university was first conceived some 800 years ago and different from the world as it was a century ago. We need to accept this. Guattari (2001) argues that we cannot create new ways of living by reversing technological advancement and going back to old formulas which were pertinent when the planet was less densely populated and when social relations were much stronger than they are today. But new ways of living are to be found in responding to events (associated with integrated world capitalism) as potential carriers of new possibilities. As Pindar and Sutton (2001:9) write:

It isn't a question of exchanging one model or way of life for another, but of responding to the event as the potential bearer of new constellations of Universes of reference. The paradox is this: although these Universes are not pre-established reference points or models, with their discovery one realises they were always already there, but only a singular event could activate them.

The vectors of escape from the homogenising and normalising effects of contemporary discourses that are transforming the university do not lie outside these discourses, but in their deterritorialisation and reterritorialisation. Deterritorialisation helps us to understand that any idea or construct has the potential to become something other than what it is. As Colebrook (2002:xxii) so neatly states:

Life creates and furthers itself by forming connections or territories. Light connects with plants to allow photosynthesis. Everything, from bodies [concepts] to societies, is a form of territorialisation, or the connection of forces to produce distinct wholes. But alongside every territorialisation is the power of deterritorialisation. The light that connects with the plant to allow it to grow also allows for the plant to become other than itself: too much sun will kill the plant, or perhaps transform it into something else (such as sun-dried leaves becoming tobacco or sun-drenched grapes becoming sultanas). The very connective forces that allow it to become what it is (territorialise) can allow it to become what it is not (deterritorialise).

One vehicle of escape might be to take advantage of shifting solidarities within and between nation-states that globalisation affords. Fraser (1993) identifies two senses of such solidarity: solidarity premised on shared identity and solidarity premised on shared responsibility. She goes on to outline four ways of formulating an inclusive, global view of solidarity as shared responsibility which does not require shared identity (see Fraser 1993:22). One of the forms of solidarity that Fraser mentions is: "A radicaldemocratic view of global solidarity rooted in the fact that we inhabit an increasingly global public space of discourse and representation ... that might be redefined as a space in which all people deliberate together to decide our common fate." It is this 
global public space that affords the opportunity for building new knowledge cultures and for reclaiming lost ground.

\section{REFERENCES}

Allais S. 2003. The national qualifications framework in South Africa: A democratic project trapped in a neo-liberal paradigm? Journal of Education and Work, 16(3):305-324.

Allais S. 2007. Education service delivery: The disastrous case of outcomes-based qualifications frameworks. Progress in Development Studies, 7(1):65-78.

Ball S. 2003. The teacher's soul and the terrors of performativity. Journal of Education Policy, $18(2): 215-228$.

Barnett R \& Standish P. 2003. Higher education and the university. In: N Blake, P Smeyers, R Smith \& P Standish (eds). The Blackwell Guide to the Philosophy of Education. Oxford: Blackwell Publishing.

Beck U \& Willms J. 2004. Conversations with Ulrich Beck (trans. Michael Pollak). Cambridge: Polity Press.

Beets P \& Le Grange L. 2008. Has geography curriculum reform in post-apartheid South Africa strengthened continuity and progression? South African Geographical Journal, 90(2):68-79.

Colebrook C. 2002. Understanding Deleuze. Crows Nest: Allen \& Unwin.

CHE (Council on Higher Education). 1997. Higher Education Act: 101 of 1997. Pretoria: CHE.

CHE (Council on Higher Education). 2000. Size and shape task team discussion document. Pretoria: CHE.

DoE (Department of Education). 1996. Green Paper on higher education transformation. Pretoria: Government Printer.

DoE (Department of Education). 1997. Education White Paper 3: A programme for the transformation of higher education. Pretoria: Government Printer.

Du Gay P. 1996. Consumption and identity at work. London: Sage Publications.

Fraser N. 1993. Clintonism, welfare, and the antisocial wage: The emergence of a neoliberal political imaginary. Rethinking Marxism, 6(1):9-23.

Gibbons M, Limoges C, Nowotny N, Schwartzman S, Scott P \& Trow M. 1994. The new production of knowledge: The dynamics of science and research in contemporary societies. London: Sage.

Guattari F. 2001. The three ecologies (trans. Ian Pindar \& Paul Sutton). London: The Athlone Press.

Jacobs M. 2000. 'Mode 2' in context: The contract researcher, the university and the knowledge society. In: M Jacobs \& T Hellström (eds). The future of knowledge production in the academy. Buckingham: SRHE and Open University Press.

Jacobs M. \& Hellström T (eds). 2000. The future of knowledge production in the academy. Buckingham: SRHE and Open University Press. 
Jansen JD. 2002. Mode 2 knowledge and institutional life: Taking Gibbons on a walk through a South African University. Higher Education, 43:507-521.

Lyotard J. 1984. The postmodern condition: A report on knowledge (trans. Geoff Bennington \& Brian Massumi). Minneapolis: University of Minnesota Press.

National Commission on Higher Education (NCHE). 1996. A framework for transformation. Pretoria: NCHE.

Olssen M, Codd J \& O'Neill A. 2004. Education policy: Globalization, citizenship \& democracy. London: Sage Publications.

Peters M. 2004. Higher education, globalization and the knowledge economy. In: M Walker \& J Nixon (eds). Reclaiming universities from a runaway world. Buckingham: SRHE \& Open University Press.

Peters M. 2007. Knowledge economy, development and the future of higher education. Rotterdam/Taipei: Sense Publishers.

Pindar I \& Sutton P. 2001. Translators' introduction. In: F Guattari. The three ecologies (trans. lan Pindar \& Paul Sutton). London: The Athlone Press.

Readings B. 1996. The university in ruins. Cambridge, Mass. and London: Harvard University Press.

University of Stellenbosch. 2000. A strategic framework for the turn of the century and beyond [Online]. Available: www.sun.ac.za/university/StratPlan/stratdocs.htm.

Vidovich L. 2002. Quality assurance in Australian higher education: Globalisation and 'steering at a distance'. Higher Education, 43:391-408.

Watson D. 2003. The University in the knowledge society. In: S Bjarnason \& P Coldstream (eds). The idea of engagement: Universities in society. London: ACU. 


\section{PART THREE}

TEACHING, LEARNING AND CURRICULUM IN HIGHER EDUCATION 


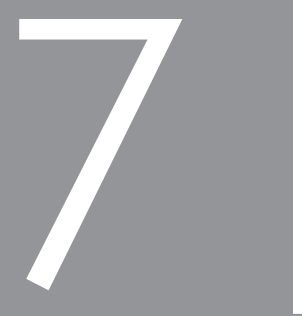

\title{
THE CURRICULUM AS AN INSTITUTION IN HIGHER EDUCATION
}

\author{
Jonathan Jansen
}

This chapter has been reproduced with the kind permission of UCT Press and Stanford University Press. It has been taken from Knowledge in the Blood by Jonathan Jansen: UCT Press, 2009.

When we look back on what we have done, or not done, we realize that it is the knowledge in the blood that has impelled us. ${ }^{16}$

\section{ABSTRACT}

What I contest in this chapter, at heart, is what counts as worthwhile knowledge in a university - 15 years after the official end of apartheid. From a leadership perspective as a first black dean of education at a previously predominantly white Afrikaans university, I illustrate the extreme complexity of transforming the institutional curriculum into a nonracial and non-dominant one. I conclude that to transform the lived curriculum in postapartheid South Africa and to change what people deeply believe about race, identity and knowledge is vastly challenging. At an academically conservative institution, for students and staff alike, curriculum change is painful, and in some instances, impossible. Ironically, the institutional curriculum is more powerful than the documented curriculum and calls for a deeper look into what lies at the foundations of the former. The institutional curriculum appears to be embedded at the level of 'blood knowledge', which refers to the emotional, psychic, social, economic, political and psychological inheritance of an institutional and wider community (Woods 2007). I also use the case of an 'Ubuntu' curriculum at the institution in question to portray the misconceptions and, in some instances, outright ignorance of the sensitivities surrounding the promotion of stereotypes. Inevitably, such actions perpetuate the outdated and ingrained institutional

16 From e-mail correspondence with the Irish poet Macadara Woods who used the phrase in a poem and as the 2007 title of a collection of his poems, Knowledge in the Blood: New and selected poems, Dedalus Press (first published in 2000). 
curriculum. I consequently suggest strategies for curriculum transformation, highlight the complexities regarding curriculum change and record the academic staff responses experienced. My aim with the chapter is ultimately to encourage further research to find out how change can be promoted in syllabic knowledge which is seemingly firmly embedded in institutional knowledge, and which, in turn, is rooted in emotionallyheld social and historical understandings of race and identity in South African higher education.

\section{BLOOD TIES}

The self-assured Western consultant who stepped off a plane in a third world country knew little about avoided asking his hosts for a briefing, demanding instead a simple set of documents with the rationale: Show me your curriculum and I'll tell you who is in power. With this well-told story in mind, I know that disturbing the institutional curriculum is tantamount to touching power. None of my graduate courses in curriculum theory had prepared me as an academic leader for what turned out to be the most difficult task in the transformation of the University of Pretoria and, in particular, its Faculty of Education. For what was codified in the curriculum was not simply information in the text; it was, I would soon discover, knowledge in the blood.

For the original author of the term, the Irish poet Macdara Woods (2007), knowledge in the blood is

[t] he sum total of what we learn (or have to learn - from experience), of love, disappointment, age, loss, and how this knowledge can both make the necessary ongoing human reaffirmation of life and hope possible and at the same time hinder it ... It is almost as though we are carrying psychological antibodies inside us. The knowledge in the blood, however it got there, is as ingrained as a disease - although at the same time it can be truly benign. In this sense the knowledge (which we have been gathering since childhood, as well as having it handed down from before) can be - even at its best - as pitilessly indifferent, as ultimately powerful, and as random in why it propels us in any particular direction, as a microbe...

In this vein, knowledge in the blood for me means knowledge embedded in the emotional, psychic, spiritual, social, economic, political and psychological lives of a community. Such is the knowledge transmitted faithfully to the second generation of Afrikaner students. It is not, therefore, knowledge that simply dissipates like the morning mist under the pressing sunshine of a new regime of truth, for then curriculum change would be a relatively straightforward matter (Jansen 1991a). Knowledge in 
the blood is habitual, a knowledge that has long been routinised in the ways the second generation sees the world, itself and the ways in which it understands others. It is emphatic knowledge that does not tolerate ambiguity, and this dead certainty was long given its authority by a political and theological order than authorised such knowledge as singular, sanctified and sure. But it is also a defensive knowledge that reacts against and resists rival knowledge, for this inherited truth was conceived and delivered in the face of enemies - the English imperialists, the barbarous blacks, the atheistic communists, all of them.

This does not mean that knowledge in the blood cannot change its outer coating and mimic in style and language what is ordered by the new state. Nor does it mean that through the transfusion of new knowledge the authority of received knowledge cannot be overcome. For this reason, knowledge in the blood is used here both as an assertion and a question. As an assertion the phrase draws attention to deeply rooted knowledge that is hard to change; as a question, knowledge in the blood is itself subject to change. ${ }^{17}$

Even so, knowledge in the blood is not easily changed. Afrikaners, in what I shall later call conditional pragmatism, will more energetically than most revise and realign curricula to fit the exacting demands of officialdom and seek to demonstrate responsiveness to the new authorities. But it would be a serious mistake to read bureaucratic responsiveness to the formal demands of reconstruction as altering deeprooted assumptions and beliefs about history, identity, knowledge and change - for the curriculum is, at base, an institutional subject.

\section{CURRICULUM AS INSTITUTION}

What does it mean to speak about curriculum as an institution? ${ }^{18}$ My perspective is inspired by the work of Reid (1999, 2004, 2006) and Terwel and Walker (2004).

17 I am grateful to Sam Wineburg for making the point that knowledge in the blood carries in itself genetic and determinist overtones reminiscent of Nazi ideology, hence my acknowledgment here of the redemptive path open to those who carry such knowledge. Perhaps the invocation of the phrase, as assertion and question, is precisely the emancipatory point in a nationalistic context where blood features prominently in the social discourses of Afrikaner history - such hematological mythology concretised most clearly in the memories of The Battle of Blood River.

18 This perspective on curriculum as institution is inspired by, though making significant elaborations on, the work of the leading theorist of curriculum on the subject, WA Reid. Reid describes and indeed reviews curriculum as institution as something that is socially pervasive, culturally contingent and holding a national character. Curriculum as institution is an abstract idea, "something that is simply there" (Reid 2006:19, Pursuit) apart from its 
It means regarding the curriculum not only as a text inscribed in the course syllabus for a particular qualification, but an understanding of knowledge encoded in the dominant beliefs, values and behaviours deeply embedded in all aspects of institutional life. Knowledge therefore becomes not only what is formally designated for learning, such as in the course syllabus, but what is widely understood within the institution to be acceptable forms of knowledge and recognised ways of knowing that distinguishes one university type (such as the Afrikaans universities) from the rest. To be sure, the course syllabus is an expression of the curriculum as an institution - but it is only one such manifestation of the regnant knowledge dispersed throughout the ceremonies, symbols, rituals, rules, regulations, discourses and countless other cultural transactions within the commonsense of, in this case, the public university.

If therefore an institution is "a socially embedded idea defined by well-known structures" (Reid 2006), then the university curriculum is that idea expressed in multiple ways that include but go beyond the ways of teaching, learning and assessing within a particular institutional context. It encapsulates what most workers within that institutional setting understand to be the character, content and boundaries of knowledge that come with being in that place, the university. It extends to include the understanding by institution dwellers of the particular link between knowledge and authority, about who

expression in organisational structures and processes; yet, it is habits, traditions, as well as organisational arrangements. I am closer to one perspective that he reviews which sees "curriculum as institution as about more than learning in the sense of achieving familiarity with facts and ideas ... skills and competence" (Reid 2006:22) and rather as something shaped by historical values, ideals and purposes (Reid 1999:187). And when curriculum as institution functions in the day-to-day life of an institution, it is indeed in the form of "abstract categories that enter into the consciousness of the community at large" (Reid 2004:92).

Where I depart from WA Reid is in his representation of curriculum as an institution as a consensual matter of democratic institutions set in place by the democratic state and which functions at the service of a democratic society. There is no divided community, society or government in his portrayal of curriculum, institutions or curriculum as institution. Whether in authoritarian or democratic states, I regard the institution as the product of social contests over what kinds of knowledge would be deemed legitimate; that is, institutions are formed in defence of particular positions setting themselves against the ideals, interests and values of competing groups. While historically established, these institutions are never socially settled as they become the subject not only of evolutionary, but also revolutionary change. The contests in the post-apartheid period is in fact a contest over divided institutions, ones established under apartheid - such as the University of Pretoria - and now occupied increasingly by those with different values, histories and ideals about what constitutes legitimate knowledge. Yet, because these are institutions and not simply organisations that succumb to the short-term whims of one or other social interest, changing the embedded knowledge of a university is very difficult indeed. 
possesses knowledge to act on and against others, and who are positioned simply as the recipients of authoritative knowledge.

This is what Amnon Karmon (2007:622-623), in reference to the institutional organisation of knowledge, calls the epistemic environment, where

the institutional level contains within it not only messages regarding ways of relating to learned knowledge, but also powerful messages regarding the very nature of knowledge itself ... this term (an epistemic environment) refers to a comprehensive system of epistemic messages that are conveyed through practices and organizational patters [with] a message that provides us with ideas about the nature of knowledge itself.

Learning this institutional knowledge therefore can lead to a specific qualification if the curriculum is understood to be the achievement of learning outcomes by those who choose (and indeed qualify) to pursue a particular course of study. But learning in an institutional perspective is more than the accumulation of modules and credit hours that signal the attainment of specific kinds of knowledge; it is also learning the concealed knowledges of an institution - about what counts as knowledge in the everyday operations of, in this case, the Afrikaans university; about the penalties and strictures that come with moving outside of this institutionally legitimated knowledge; and about the benefits and advantages that result from 'slotting in' to these dominant knowledge forms without breaking the historical resonances that cement relations between (in this case, white) staff, students, parents and community.

The curriculum in this view is therefore both tangible (course outlines) and intangible (discursive patterns), but throughout it is "a shaping force" (Terwel and Walker 2004) in the lives of those who teach, learn, administer, manage and lead within the institution. It is the knowledge the administrative clerk learns about who not to offend in an institution, which rules to follow and which to ignore, about the written rules and the unwritten rules, and about how to navigate this embedded script without harm to oneself and to one's career. It is the knowledge the young academic learns about what kinds of postures and positions can advance her career and which behaviours can inhibit promotion or even end a career; such knowledge goes way beyond what is written in the administrative guide to promotion for it includes the unspoken but obtainable knowledge about how to advance academically within the peculiarities of that institution. Without access to such embedded knowledge, the newcomer is often exposed and disciplined while the old hands can negotiate these hidden rules for behaviour almost instinctively. In all these examples, the curriculum as embedded 
knowledge, values and beliefs spreads throughout the operational crevices of the institution and transforms the behaviour of campus citizens.

By rendering the curriculum as an institutional subject, it is possible therefore to distinguish one institution from the next when comparing, in this case, the curriculum of different kinds of South African universities (see Cloete et al. 2006; Jansen 2001). The University of Pretoria (UP) and the University of Cape Town (UCT) are among the top three universities in South Africa and are regularly listed among the top 500 institutions in the world. Both universities boast impressive facilities, world class scholars, and high levels of research productivity. Yet, these two institutions are light years away from each other in terms of the curriculum as an institutional category; in fact, they might as well be in different national contexts. The open knowledge system of UCT and the closed knowledge system of UP, both established over 100 years, have in time inscribed very different contours, content and expressions of knowledge in the two institutions so that successfully navigating the curriculum (as defined here) in one institution could spell disaster for a young career in the other institution. So, for example, while the University of Cape Town regularly has openly hostile debates about access (see Benatar 2007a, 2007b; London 2007; Erasmus 2007) and fierce contestations over the institutional curriculum that make riveting reading in the local press, this never happens in the closed knowledge system of the University of Pretoria (Jansen 1998).

Although both institutions were shaped by apartheid and both are subject to the same regulatory policies and measurement matrices from external agencies such as government, an even cursory reading of the quality assurance reports of the two institutions by the same body (the Higher Education Quality Committee of the Council for Higher Education) would reveal the very different inscriptions of knowledge within these two universities. ${ }^{19}$ Knowledge - its character, substance and ambitions - therefore takes on very different forms in these two institutions.

What this means for curriculum change is that it is much more difficult in a place like the University of Pretoria to challenge the very deep assumptions, beliefs and values that hold institutional knowledge in place. It is not so difficult to change the exoskeleton of the institutional curriculum, the kinds of alterations that could impress external agencies such as government and signal alignment with bureaucratic expectations. It is infinitely more difficult to crack the "endoskeleton" (see Terwel and Walker 2004) of the curriculum, that hard surface that holds in place deep understandings, norms and

19 The institutional audit reports are accessible as Executive Summaries for the two institutions and others from the website of the Council on Higher Education at www.che.ac.za. 
commitments that over a century have come to represent settled knowledge within the institution. Here it is important to distinguish the practices of individual innovators or outsiders coming into an institution whose work might very well exist inside of, even challenge, institutional knowledge. As the University of Pretoria slowly opened-up its staffing to those from outside of its immediate community - white Afrikaans-speaking academics - it brought in black deans, black professors and also English-speaking and progressive Afrikaners whose knowledge formation and consciousness were the result of advanced training outside the ambit of the traditional Afrikaans universities.

But these individuals were, for the most part, too small in number and too limited in influence inside a large and complex organisation to erode at its centre what counted as institutional knowledge; and even as they pushed for curriculum change, their efforts were overwhelmed by the inertia of embedded knowledge. Nowhere was the institutional character of knowledge more profoundly expressed than in an official university curriculum called "Ubuntu".

\section{UBUNTU INTRODUCED}

Few words evoke more social confusion in South Africa than the term Ubuntu. A Zulu word translated commonly as "humanity towards others", Ubuntu has had many uses. It has been the subject of a crass commercialism selling books and merchandise that market 'humanity' for profit in post-apartheid society (see Mbigi 1997). Ubuntu was once mobilised for political purposes by the conservative Inkatha cultural movement and later political party behind its Zulu-based ethnic ideals (see Mdluli 1987; Gordon 1991). And Ubuntu has also been invoked by religious leaders like Desmond Tutu in an appeal to a broader African spirituality that recognises our common humanity against criminal behaviour and selfish individualism (Tutu 2004). Its troubled history notwithstanding, Ubuntu is often naively attached without much reflection to any product as a way of signalling acceptance of the new South Africa and alignment with its democratic values. Such was the case with an undergraduate curriculum at the University of Pretoria called "Ubuntu".

How Ubuntu (the curriculum) evaded my early attention is not clear, for in the sweeping reforms of five years of curriculum change at both the undergraduate and graduate levels, it had not surfaced on the modular-based curriculum radar screen. One reason might be that it was 'owned' by the Faculty of Humanities, but nevertheless prescribed as a short but intensive one-semester module required of all education students in the 
Faculty of Education. No student could therefore obtain a degree in education without taking and passing Ubuntu.

It would probably still have avoided my scrutiny as dean were it not for the fact that more and more of the students admitted to Education were no longer only from the white Afrikaner schools. The new students coming in did their school education at black and English-speaking white schools where there was a greater sensitivity and well-honed criticality towards anything that suggested racism or patriarchy or classism. And when one of these non-traditional UP students handed me the Ubuntu course outline, I at first denied that it was even possible within my faculty; I would have known about it, I told the bemused student in front of me.

Now, as the two academics from the Faculty of Humanities sat in front of me in my dean's office, they looked terrified. They were the authors of the Ubuntu module. They represented the face of political correctness: a young black academic and a senior white Afrikaner professor. How could they be so wrong, this picture of inter-racial partnership? They looked terrified because of what I had required them to read while sitting in my office:

This course runs contrary to the basic commitments of curriculum transformation in the Faculty of Education, and works in ignorance of theoretical advances in studies on race, culture, identity and education over the past 25 years. It resurrects a conception of African culture that is primitive, inferior, monolithic, stable, and essential in its assumptions about black people. It works within an apartheid paradigm of what constitutes culture and ethnicity, neatly reinforcing myths about migration and settlement that no serious historian would defend. It presents a uniformly naïve understanding of Ubuntu, ignoring its multiple and contested meanings within recent South African history, including its specific mobilization under Zulu nationalism to promote an ethnic separateness for narrow political ends. This romanticised representation of Ubuntu might be the subject of crass commercialism in the world of business tourism, but cannot be defended in any serious scholarly context. It exaggerates difference to the point of absurdity, and reinvents white people around full or qualified concepts of "Euro-ness". By sharply juxtaposing African and European culture, all the worst excesses of apartheid's construction of racial identity are not only resurrected, it is reinforced in the minds of unsuspecting students (South Africa has "cultural groups"). It is clear that this course was conjured up in an attempt to introduce white Pretoria students to African culture in the once insular social and institutional contexts of the University of Pretoria. It was in all likelihood well-meaning, despite the commitment of error and the misrepresentation of people. The audience alone suggests that this course has no relevance after 12 years of democracy given 
the growing numbers of not-white students and not-South African students in institutions such as Tukkies. Even so, the concept of the African in the curriculum outline is presented as one persona - that is, completely ignoring the many ways of being African within both urban and rural areas; hence impossible terms such as "the African culture"! Disturbingly, there are derogatory stereotypes of Africans littered throughout the materials, made worse only by holding up "Europeans" (presumably white South Africans) as the superior culture who should, among other things, correct such behaviour by teaching Africans table manners! Further, the promotion of Ubuntu as representing contemporary practice is so incredibly out of whack with empirical reality - such as one of the highest crime rates in the world - that it begs the question as to the knowledge claims surrounding this concept. Yet, the demise of Ubuntu within South African society, if taken seriously, would have to take account of colonialism and apartheid, racism and the migrant labour system, forced evictions and the criminalisation of black people (e.g. the hated pass law system) - and on, and on. None of this is dealt with in this partial account of Ubuntu, thereby denying students access to the social context within which such terms emerged, were contested, started to change, and became marginal to mainstream society. By locking Ubuntu into these rural ideals which might never have existed, all sorts of myths and unrealities are sustained. So, for example, with the un-interrogated notion of the extended family in contexts where child-headed households are becoming widespread and AIDS has decimated any traditional concept of family, Ubuntu cannot account for change in the countryside and in the cities. This course cannot therefore be the focus of a modern/postmodern curriculum formed at the intersection of powerful global, continental, regional and national cross-currents in teacher education.

My two colleagues were clearly stunned, but what happened next placed me in the position of disbelief. "Well," said the senior professor, "we hear you and that's no problem; you are the client, and you are not happy with what we did, so we will simply revise it so that you, as client, are satisfied." 20 Everything I had just said in the angrilyworded page of criticism went completely over his head; the deep ideological dilemmas represented in the curriculum were not going to be discussed; the clear indictment of racism would not be challenged. This was a market-related problem: Humanities was the service provider and Education was the client. Like a faulty computer-disk about which the client complained, this curriculum computer-chip would simply be replaced.

20 The language of clienthood had deliberately entered the managerial discourses of the University of Pretoria, sowing up as keywords in strategic planning documents and even in the naming of its newest building at the time, the Client Services Centre. 
They did not fail to remind me, however, that this curriculum endeavour had won an institution-wide award for "innovation". The white professor half-chided me that his black woman colleague understood black culture and that this reflected her "authentic" expression of what happened in the black community. And they told me about student evaluations that showed that students (in this case, white students) really enjoyed exposure to black culture through Ubuntu. But since I was the client, they would simply change the content accordingly. "I don't think you understand a word I wrote down," I irritably told my colleagues, and asked them to leave.

\section{EMBEDDED KNOWLEDGE ACROSS THE UNIVERSITY CURRICULUM}

I decided to raise the matter with the Dean of Humanities; somewhat predictably, she saw little problem with Ubuntu and was more concerned that by withdrawing this curriculum offering from her faculty they would lose critical funding in an academic unit that was constantly under threat because of the oversupply of academic staff in relation to income generated through courses and degrees. In this faculty, expensive but lowenrolment subjects like African languages (under which Ubuntu was registered), music and drama generated only a slow stream of income as South African students shifted their attention to economics and accounting subjects at Pretoria and everywhere else. As dean of the faculty, I was far less concerned about the offensive knowledge contained in Ubuntu than about financial survival or what the institution called "viability".

Beginning to feel that perhaps I was mad, and everybody else around me normal, I took my concerns to my senior colleagues in the university administration to whom the deans reported. Their reaction was mixed, but even among those who recognised the offensive material there was little energy or interest to act on this issue and to take on institutional power on this sensitive matter. By this time my concerns had little to do with Ubuntu in the Faculty of Education: they now centred on the need to review the institutional curriculum as a whole. This was one of the most difficult times for me I could not restrict change to the Education Campus given what I now knew about the university curriculum more broadly. Curriculum review was an urgent matter for the entire university and I felt that it was important to interrupt this unexamined knowledge that continued to prepare another generation of white and now also black students for the new South Africa.

The problem with embedded knowledge is that it is not out there; it is not easily read off the outer coating of a public curriculum. It entails the things concealed in the belief and value systems of those who teach and learn and which, behind the classroom door, 
influence and direct the substance of what counts as the actual knowledge transactions among participants in learning process. Teachers might, in an authoritarian and hierarchical culture, appear to be following the new curriculum script, but this does not translate into transformative knowledge in the classroom, and the students know this. Changing curriculum without changing the curriculum makers is especially difficult under conditions of a sudden and radical social transformation. And changing a curriculum too far ahead of the teachers, those who make the curriculum come alive in the classroom, might please the politicians and bureaucrats concerned with impressing new knowledge on their subjects, but it is unlikely to rearrange the epistemological order of things in the classroom. What the teachers of the new university curriculum were struggling with was knowledge in the blood.

This is the difficulty in conducting an analysis of the institutional curriculum. Its outer features would reflect the noticeable changes in the organisational technologies demanded from a new national qualifications framework. The curriculum is presented in the form of 'exit-level' learning outcomes; each learning outcome is stated in a demonstrable action form; the achievement of specified outcomes is measured against what is called "assessment criteria"; and the combination of learning outcomes, following established rules of combination, make up a qualification. The Afrikaans universities like Pretoria are told often by government and the qualifications authority that they are most responsive to the organisational rules that must be followed in this elaborate architecture. What they are not told is that nothing in the content, nature and purposes of knowledge have changed at all behind the walls of this organisational complexity called "the university".

Knowledge in the institutional curriculum of the University of Pretoria is fixed, certain, positive, controllable, linear, and predictable. Scientific knowledge matters much more than human knowledge, for the laws of science, in this view of truth, eliminate uncertainty and rule out ideology. It follows therefore that science, engineering and technology enjoy much more institutional funding and political support than the humanities, education and commerce - the latter group regarded as constituted by a less certain and controllable knowledge than the natural sciences. Accordingly, it is no coincidence that the humanities are weakest at the Afrikaans universities and the sciences strongest. This does not mean that 'science' carried the pretence of control and neutrality during the apartheid years; it was during this time that science was deployed in the service of the racist state and it is one of the untold stories of "truth and reconciliation' that the laboratories of the Afrikaans universities have not yet laid bare 
their role in providing the knowledge base for justifying and upholding apartheid as ideology and as practice (see Jansen $1991 \mathrm{~b}$ ).

We now know that volkekunde provided anthropological knowledge about the 'Bushmen' that would enable their deployment as trackers for the apartheid military machinery in places like the then South West Africa (now Namibia). We know that psychology provided so-called scientific studies of black behaviour that would justify racial segregation and the hierarchy of races. We know that education theory, under the guise of fundamental pedagogics, linked teaching to Christian National Education which gave divine justification to the racial ordering of schools and society under the pretence of what was called "a science of education". We know that botanists at Pretoria named one of their species after vicious military units (like Koevoet) in gratitude for funding received from the defence force for their research. We know also that sociology provided the social theory that justified separation and made these ideological commitments available to a nationalist regime (see Du Toit 1984).

Surely this racially-tainted knowledge could not have disappeared behind the facade provided by the reformatting of qualifications in terms of standards and outcomes? Surely values, beliefs and knowledge do not simply leave embodied teachers as easily as does the external packaging of a new curriculum? By viewing curriculum as an institution, therefore, it allows one to peer inside the knowledge legacy of apartheid, and Ubuntu is the most dramatic example of what has not changed despite the busyness of aligning old content with new structures.

\section{INSIDE UBUNTU}

At first glance, AFT 253 (the classification of the Ubuntu module) comes across as a reasonable effort to introduce students to multicultural education and what it calls "tolerance" for other cultures. But on closer inspection, it represents the intact knowledge of apartheid under the guise of teaching students respect for others. The first hints of trouble lies in what Ubuntu regards as worthwhile knowledge to be assessed: at the front-end the assessment criteria indicate that students will be judged on the basis of "ordering and presentation" as well as "appearance" and "punctuality". Here, writ large, is something I found over and over again among my students - an obsession with neatness and order in presentation, the systematic nature of organising writing, the colourful pens used to illustrate composition, the near obsession with what things look like. This is not a trivial point, for what their socialisation in school and society values is how things look from the outside rather than the substance of what is submitted 
for examination. Order trumps truth, appearance matters more than content, style conquers substance.

There is a deep psychological and epistemological grounding that generates this orientation towards knowledge, and one that requires further study (see Foucalt 1986). But in the end, what remain above close intellectual and social scrutiny are the qualities of argument, the value of positions taken, the originality of ideas put forward, the risk pursued in analysis, the courage of interpretation. Order enables control over knowledge and over students, and structures what is allowed and disallowed in this tightly managed environment. This is what Louis Brenner in her excellent study on the transmission of knowledge in Muslim schools calls "controlling knowledge" - it is "the conviction that social behaviour could be controlled through the knowledge transmitted in school", but also suggests that "some knowledges are imbued with determining attributes of which individuals may not be consciously aware" (Brenner 2001:8).

With such control through order comes the management exercised over knowledge through the appeal to the logic of science. Thus asks Ubuntu in one of its assessment criteria for students' work: "Is the process (followed) scientific?" On a subject as value-laden as Ubuntu, "the scientific process" nevertheless enables knowledge and control. ${ }^{21}$

But if patterns of knowledge that continue to constrain the institutional curriculum were limited to such subtle manifestations of ideologies of order, hierarchy, control and scientism, it would in many cases not be noticed by those concerned with curriculum analysis. However, when such knowledge breaks through in the more visible claims about race, identity and culture, then analytical and political attention is forced on the subject. To illustrate, a number of samples of the curriculum will be drawn for discussion of the broader politics of knowledge signalled within each selection. Consider the scenario from a sub-heading in Ubuntu called Getting to Know Other Cultures:

21 This is the story Christi van der Westhuizen wrote about so powerfully in White Power as she courageously wrote against the dominant narrative as a 17-year-old schoolgirl at Dr EG Jansen High School in Boksburg and as a student at the Rand Afrikaans University in Johannesburg. The power of watchful authority whether in the form of the Afrikaans teacher who edits down "provocative" thinking and warns of danger (p. 1) or the university dean of students who threatens to expel her for daring to move outside the frame of acceptable knowledge of past heroes (p. 6). In these rare but revealing snapshots of young Afrikaner lives under the strain of apartheid lies a much more important story of knowledge, power and curriculum under Afrikanerdom. The discipline of knowledge keeps potential rebels and critics in place through threat: the examinations will not tolerate dissent (the high school teacher) and your degree might not happen (the dean of students). 
Two school teachers went into a restaurant and ordered two baby chickens. The waiter set the table and completed bringing two silver bowls with lemon floating on top of the water. The two teachers looked at each other and without trying to find out from the waiter what the water was for, drank the water.

You see, in the African culture, you only wash your hands before sitting down at the table and you'll wash your hands again after eating. They did not know that in the Western culture you can hold your chicken with your fingers and wash your fingers in the silver bowl. I am sure that they struggled with the knife and fork trying to eat the baby chickens.

The only way these teachers could have known, was if someone from the Western culture who knew about table manners, could have taught them.

This scenario is read by every white education student at the University of Pretoria and every UP student who chooses Ubuntu as a module of choice. It is precisely the kind of racism that reinforces what white students bring into the university, a set of stereotypes consistent with their own socialisation. By casting whites as "Western", the story secures the notion among Afrikaners that they are non-Africans separated culturally, behaviourally and racially from black South Africans. The portrayal of black people in the $21^{\text {st }}$ century as backward and primitive diners out of touch with the basics of kitchen utensils and the modalities of restaurant dining fits perfectly with years of racist indoctrination visited on white youth. By depicting blacks as unsophisticated and at the same time placing the power of civilisation (last sentence) in white hands, this curriculum is unlikely to disturb received knowledge, but rather secure it. It is almost too easy to grant this kind of curriculum the respect of analysis, but it lies at heart of the argument that just below the external changes of the institutional curriculum to conform with new regulatory demands lies an as yet undisturbed set of assumptions about knowledge and identity in the former Afrikaans institutions.

Under another section called Finding Ubuntu in Myself, white students are treated to a picture of black people fighting amongst themselves:

[l] twas not only White South Africans who used to call Black South Africans names - Black South Africans also called other ethnic groups names. Even today there is ethnic undermining. The Zulus call the Sotho's "iZilwane" - things, the Sotho's calls the Zulus "Mapono" - the naked ones - does not make sense because all the Black groups disliked wearing clothes. That is why today South Africans refer to other Black people from other African countries as the "KKK's" Not the Kluck Klack Klan of America) that is the code or abbreviation that I discovered this Sunday at a flea market because one lady who is a "KKK" thought I am a "KKK" from Gabon. Then a black South African lady who overheard her, said to me, 
"We were also sure that you're a "KKK" meaning Kwere Kwere, a sound imitating expression meaning an ununderstandable cacophonic language ...

Holding aside, for the moment, the very poor quality of the content and the language usage especially for a university-level course, it is important to witness again what is being taught to white students through a now clearly personal account in the guise of a cultural story about black people. Blacks, like whites, act in demeaning ways towards each other. Blacks prefer a primitive way of life, eschewing clothing. Blacks in South Africa not only despise each other, they also despise blacks from other countries. Here the rationale for the continuation of white rule constantly expressed by apartheid politicians finds perfect resonance: whites are responsible for black people not annihilating each other because of their inherent tribal differences. Once again, the curriculum fits perfectly into the ideological apparatus that defines the historical knowledge about black people held by and transmitted through white South Africans to their children. The examples shared throughout the curriculum text are so outlandish that it is doubtful even the most bigoted white South African would really believe claims such as the recollection by the black lecturer that:

[a]s Black South Africans, our parents always told us that we are not supposed to fall in love with any Black person from Rhodesia - now Zimbabwe - because the people from there were cannibals. If you got married there, you will never be seen alive again.

It is truly stupefying that such an experience of intense prejudice of one person could be made the experience of "Black South Africans". It is even more distressing that for children coming in from white communities, this is the kind of knowledge that they receive about black people after apartheid. And that the chosen transmitter for this racist knowledge is a black woman.

One of the few times that I lost patience with this embedded knowledge of Others was in a sequence of exchanges with colleagues at another Afrikaans university, this time in the Free State province. I had conducted training there on research leadership and on scholarly publications. I invited colleagues who attended the publications workshop to submit abstracts and draft manuscripts electronically so that a post-workshop conversation and feedback could continue on their emerging writing ideas. Following a very positive and productive set of workshops, a young Afrikaner woman academic submitted the following abstract for comment:

Is it necessary to create new computer icons for black South African users of MS Office packages? 
Some authors propagate a Cultural User Interface that is intuitive to a particular culture because different cultures sometimes interpret things like colours and metaphors differently. The culture of most black South Africans is very different from the culture of Americans, who created the MS Office packages. Therefore, alternative computer icons were investigated to determine whether it could be better understandable by black South African computer users. Black South Africans without a computer background, as well as black and white computer literate students, completed a questionnaire that contained icons from the MS computer program as well as alternative icons. With the exception of one command, the black South Africans without a computer background chose an alternative icon as their first choice. It is deducted from the questionnaires that black computer literature students memorize the standard icons and do not have a problem using it. If people are allowed some time to master the necessary skills, it might not be necessary to design new interfaces for black South African computer users.

I suppose I was tired. I had so much to deal with on my own campus with this embrace of essentialist knowledge of black people that it was just so difficult again, in another place, to engage young colleagues on this matter. Once again the intentions were positive, if paternalistic, and for this colleague it was an important observation: that cultural/racial difference should not be an obstacle to learning - simply give blacks more time to learn necessary skills. My response was less than tactful:

This entire research project is on shaky grounds: any assumptions of essentialism that gives blackness certain features and predictable or different behaviours from other human beings will bring you very strong criticism, if not the " $R$ " word, if you were ever to present this in intelligent company. I would urge you to drop this line of thinking altogether.

To my initial surprise, the young Afrikaner woman did not reply; from the e-mail string I found that she had referred my comments to a man, the senior man in her department at the Free State institution, and the one who apparently led this research project. I was mildly irritated by this familiar display of the white male coming to the defence of the innocent female, but found his response intriguing. True to the rules of beleefdheid (courtesy), he started by praising me for the quality of the workshops and the positive responses of his colleagues, especially the young woman. But he wanted to engage me in an opbovende (constructive) manner and let me know that they had received criticism on this topic before, but that they had also published from this research programme. Then he said the following: 
As starting point I wish to make it clear that we are not racist at all nor do we want to be read in this way. In fact, the motto for research in our department is "IT for all". Our central focus is to make IT more accessible for people with less training and exposure to technology. As such we do work on the connecting points of office packages ("Office suites") and must of necessity determine the unique needs of users in this milieu. We regard the new South Africa on the one hand as an opportunity for research and on the other hand as an opportunity to do social upliftment work. We examine culture as indicator, but as you surely know, culture does not have one definition. That is why we also look at language and make a distinction between African languages and European languages ... THEREFORE we use black and white as indicators. We do not try to place people in boxes or to stereotype them, BUT in the Free State is it surely so that in $90 \%$ of the cases Black=socially less privileged and White=socially privileged ... We would not, to use your words, "drop this line of thinking altogether". This would mean than we would have to regard four years of building and publications as having no value whatsoever.

I use this extended quotation from the e-mail exchange to point to several important markers of embedded knowledge. The first is that the narrative of whites uplifting blacks is again continuous with a neglected dimension of apartheid in scholarly work: that hand-in-hand with the racial oppression of black people went the missionary objective of whites uplifting those described as less fortunate, that is, the blacks. The problem with such knowledge of black people is that it does not ascribe this state of "less fortunate" status to white oppression; it is, rather, a natural state to which the white Christian has the responsibility for civilisation and upliftment. It is with this same reasoning in the post-1994 period that Afrikaners speak of black people as agtergeblewe (left behind) as a voluntary state of being, not as a result of a purposeful and deliberate system of discrimination. Nevertheless, what the Free State colleagues here draw attention to is a responsiveness to those left behind, a reaching out to 'all', and doing so in the name of the white race lifting the black race from its unfortunate state.

In my next response I simply declared that it was not possible for me to continue the discussion since my arguments were simply not understood and because their ideas about race were "ingrained" within Afrikaner belief systems which led them to "believe deeply in race". My colleague responded with disgust: "Don't you think you have been a little brainwashed by the injustices of the old dispensation and therefore you overreact? Is it possible that you as a brown man inherently and unconsciously think in precisely the opposite ways from what you accuse us as whites?" 


\section{THE PROBLEM OF CHANGE}

The black person at a white university is a knowledge bearer of the institutional curriculum in one of two ways. First of all there are black people, however small the numbers, who were trained within the apartheid knowledge of the Afrikaner institutions during the crucial period of the early 1990s, i.e. after the University of Pretoria opened its doors to black people, but before the advent of democracy in 1994. This small group of black people included those hired by white Afrikaners from within their own ranks, i.e. blacks who could be trusted, who bore the ideological and epistemological birthmarks of their trainers, who accepted the white supremacist knowledge of superior and inferior cultures, and who achieved their degrees and their junior level posts within white universities precisely because they 'fitted in' and 'fitted the profile' that white people held of black citizens.

Who better to keep disseminating offensive knowledge about black people than black juniors themselves, like the young lecturer in the Ubuntu tale? Of course, the junior black lecturer works under the supervision of the senior white professor, and so while the curriculum gains legitimacy within the university because of the white professorial authority, it gains credibility among white students because it is represented by the 'authentic' voice of the black lecturer. Here is another aspect of the knowledge/power nexus after apartheid that requires much more sustained analysis of the institutional curriculum than is the intention for this chapter.

For these colleagues, the junior black persons trained within the apartheid academy, curriculum change is especially difficult. With my colleagues in Education there was a rigid knowledge of race and ethnicity as biological and cultural givens, not as social and political constructions, and this made it very difficult - especially in the context of the social sciences - to begin training or reorienting colleagues in a broader theoretical understanding of received knowledge. Knowledge for these colleagues was positive and accumulated on the basis of scientific principles, not constructed, tentative and changing as a consequence of human endeavour. Even when there was an intellectual understanding of such a new orientation towards knowledge, it was very difficult to change towards ways of thinking and seeing that required a more tentative understanding of knowledge and authority.

This often led to considerable frustration on the part of black junior colleagues, as was evident in the response to the Ubuntu lecturer to criticism of her module:

I don't understand what they mean when they said 'that it is primitive'. When they say 'it's primitive, it's inferior' I didn't understand, because I felt even if they say 
that it is inferior let them say what is inferior so that I can improve ... So I found myself frustrated and not knowing what to do. You see so it's really disheartening if somebody criticizes you, but they don't say that this is how you should do it. Criticism is good, because that is how one grows, but if you are criticized but there is no answer to the criticism ... ${ }^{22}$ (emphasis added)

Once the initial disorientation had been felt, and the sting of criticism experienced, black and white colleagues from the previous knowledge regime would often (though not always) express this sentiment with various degrees of anxiety or indignation: "So, you convince me that I am wrong, now how do I get out of this? Show me how to access this new knowledge. Train me in the new methods of research. Where can I go and what can I do to appraise myself of this different thinking?" These are hard questions, and it is extremely difficult for such colleagues to change, especially for those who are older or coming towards the end of their careers. Decades of socialisation in race essentialist thinking and in epistemological fundamentalism do not yield easily to what is, in the end, knowledge in the blood. It is as hard to change for black academics as it is for white academics, and it was with this frustration in mind that I sent an SOS to 10 colleagues around the world who worked on the problem of educational change. This is what went forth, the two examples constructed from real personae with whom I worked and interacted in the Faculty of Education:

When practitioners are presented with new knowledge that demands a change of behaviour, they adopt, adapt, or avoid such knowledge; such responses are well documented in the change literature. What is less well understood is why persons might resist new knowledge especially when what is new is justified as rational, evidence-based, and holding promises of improvement.

What teachers, for example, resist is not always based simply on cognitive dissonance, a conflict between the existing knowledge constructs and beliefs of the practitioner and that proposed in new knowledge. It often resides at a much deeper level of disassociation, what I wish to call emotional knowledge.

Consider teacher Mary who for more than 30 years has taught Grade 1 reading using phonics; her success with this methodology has built her confidence and self-esteem; attracted awards and acknowledgements from peers and parents; and given her a profound sense of fulfilment that her ways of teaching reading are both effective and efficacious for the children entrusted to her care. Along comes a new methodology for teaching reading, and Mary struggles to change,

22 Taken from the text of an extended interview conducted by Heidi Esakov, a Master's student in the Faculty of Education, whose thesis is an analysis of the Ubuntu module at the University of Pretoria. 
even though she is even persuaded intellectually to 'give the new thing a try'. Her knowledge of how to teach reading is not simply committed to the mind; it is encased in the heart, part of an emotional attachment to what it means to teach reading and to learn reading. In other words, what we have here is emotional knowledge of the subject.

Consider teacher Max who has taught South African history to Grade 11 students for more than 25 years. As a white South African, reared in the political vortex of the apartheid years, Max came to understand deeply that the history of white settlement was one of triumph over adversity, of civilisation over backwardness, of Calvinist faith against atheistic communism, of freedom against tyranny. $\mathrm{He}$ has lost male members of the family in the border wars, and he has witnessed the struggles of his parents against white poverty and their gradual rise, through the discipline of hard work, to a comfortable though not extravagant middle class lifestyle. Then 1994 happens, and a new history is to be taught with very different victor narratives to the ones he has come to believe, and through which he has come to order his choices in the world. For him, the teaching of history is emotional knowledge, even though he accepts, in the mind, the inevitability of a new official knowledge.

The standard intervention of governments to change teaching behaviour is training. The assumption is that teachers, when faced with the logic and appeal of an innovation or reform, will make the shift towards the new knowledge. But what if the behaviour to be changed is not simply a cognitive one, in which intellectual persuasion or political coercion are the means for securing compliance? What if the barrier is emotional knowledge?

Such knowledge is not amenable to training; changing the mind is in fact not the problem. It is perfectly possible for Mary and Max to find the intellectual arguments for change reasonable, even appealing, and yet to remain emotionally committed to their beliefs about teaching reading or history. They might even give the appearance of change in their statements of teaching (e.g. course outlines), but remain emotionally committed to a very different understanding of reading and history. This emotional dissonance between official knowledge and personal knowledge invariably shows up in what they choose to teach, how they teach it, and with what levels of commitment.

In this regard it is important to state that emotional knowledge is not emotional intelligence, that ability to perceive and express emotion, to express feelings that advance learning, and to regulate personal emotions in the face of conflict. In fact, Mary and Max might find it very difficult to articulate or express what exactly it is that underpins their beliefs and emotions; they might even wish to demonstrate their ability to change, their acceptance of the new knowledge. Emotional knowledge is therefore not knowledge of emotions, the latter being 
the subject of considerable research and conjecture. Does the literature on educational change have anything to say to, or about, emotional knowledge?

Perhaps not surprisingly, none of my international colleagues came back with any concrete suggestions from the literature on educational change, because this was new terrain. In these examples, the politics of emotional knowledge takes the literature beyond what it is comfortable with: first-order knowledge claims that emotions play a crucial role in decision making about everyday things and especially in the context of educational judgments. What the literature, as it stands, does not grapple with is power and especially racial configurations of power and how this plays out in a transition where power changes hands from a white minority to a black majority. Politics, in this otherwise sensitive literature on emotions, had not yet emerged as an intellectual meeting place between human emotions and racial power. And this was the heart of the curriculum dilemma with which I was struggling in a conservative institution where there was little support for, and even less understanding of, the harsh terrain of transformation on the knowledge front.

I have since come to a few tentative conclusions about the problem of curriculum change where the focus is transmitted knowledge and where the agents of change and continuity are real humans caught in the middle of a radical transition from longestablished racial rule towards a non-racial democracy. The first conclusion is that changing what people believe deeply about race, identity and knowledge is much, much more difficult than changing from say traditional mathematics to new mathematics. Both are difficult to accomplish, but emotionally held beliefs are attached to the soul in ways that are different where the subject of change is a new set of instructional technologies. There is no literature on such complexity, and the problems of changing emotional knowledge will require much more research and theory than has been possible in this text.

The second conclusion is that for some actors within a human endeavour such as schooling, change is simply too difficult. This is clearly not a training problem, for the nature of the dilemmas faced by teacher Max are so deep and complex that no amount of 'training' would be able to dislodge at an emotional level what Max believes even though intellectual consent to the change project can be achieved. It might even be unethical to demand that someone like Max should change under the terms of the new regime, for whole belief systems and indeed a personal sense of worthiness are now to be had. This position clearly requires further ethical and philosophical thought. 
The third conclusion is that for this kind of change to even start, the in-house black (and white) academics must be balanced in staffing plans by a completely new incoming stream of black (and white) academics from outside of the resident social and epistemological world, and that they work closely together over long periods of time learning the new languages and discourses of humanness and change beyond racial essences and knowledge fixedness. This is perhaps the most profound argument for the transformation of racialised patterns of staffing in former white universities; the challenge of transforming received knowledge.

The fourth conclusion is that this kind of change makes severe demands on the second kind of black academic in a place like Pretoria, those coming from the outside. These are the black scholars who know differently and who are schooled in 'structures of thought' perceived to be threatening to resident knowledge. They do not respect authority as much as they respect ideas. They respond better to leadership persuasion than to leadership edict. They are much more perverse in their reading lists than in the one true knowledge - scientific determinism - that dominates Afrikaans universities. They are more comfortable with open relationships across race and gender than the long-term residents. They experience tremendous frustration with the randomness with which power is wielded. They feel excluded from dominant cultural representations of knowledge and power. They feel that they have to make basic arguments about simple things, and this sometimes generates extreme feelings about marginality. And then they are tempted to leave, or not to come in the first place (see Tabensky 2004). It is this strangeness of knowledge that keeps outsiders marginal.

The fifth conclusion is that leadership matters in changing the institutional curriculum. Hierarchy works well when the senior leadership has democratic instincts and is able to advance change at a pace that would not be tolerated in universities more accustomed to a broader participatory ethos. Hierarchy, however, can also damn transformation when senior leadership seeks to conserve and protect the racial status quo and insist on investing all authority within itself. In the latter case strategy and position, while suggesting change, can in fact constrain it. For example, consider the university leader who decided to have white Afrikaner colleagues lead workshops on diversity on the Pretoria campus! I repeatedly raised objections arguing that you could not ask those who were shaped by, and benefitted from, social and institutional racism to be the same persons leading its undoing. Or in the memorable words of Audrey Lorde (1984), "The Master's tools can never dismantle the Master's house." Given the hierarchy, those objections fell on deaf ears, but at least the claim could be made that 'diversity' was receiving attention. 


\section{WHAT UBUNTU SAYS ABOUT THE INSTITUTIONAL CURRICULUM}

The curriculum analysis has pointed to three key concerns revealed in Ubuntu: the common sense of racial essences, knowledge scientism, and identity hierarchies. Ubuntu reinforces the notion that there are races and that race is real, given and fixed, and therefore that racial differences should be the starting point for student understanding. This essentialist understanding of race was the foundation on which apartheid established its legitimacy, especially among white people, and it was the notion of unbridgeable divides based on colour that justified the rigidities of social segregation. From this understanding the most extreme forms of repression could be visited on any of those who rebelled against apartheid, white or black. Ubuntu therefore resonated perfectly with incoming white student understandings that they received in family, church and cultural or peer groups en route to university.

It is also important to note in the curriculum text the easy exchange between culture and race. 'Race' remains a sensitive wording in post-1994 South Africa, though Ubuntu is less reserved about this kind of language. Still, cultural essences on how blacks behave substitute for racial essences about who blacks are. And in the Ubuntu narrative, ALL blacks are implicated in the allegedly aberrant behaviour - rural blacks, urban blacks, educated blacks, illiterate blacks. A single observation is a racially universal observation, and again this is the kind of racist logic that fits comfortably within the apartheid-originating understandings of white South Africans.

That such knowledge of race - and everything else - is founded on a scientific understanding of human behaviour is another important foundational plank of the institutional curriculum. Knowledge, as indicated earlier, is fixed, certain, predictable and knowable. Science so conceived removes "ideology" and "politics" from the conversation and reasonable people would therefore accept the status quo as given by higher (that is, scientific) authority. Knowledge in this understanding both imposes control over reality and is itself controlled by the rules of science. The word wetenskaplik (scientific) is therefore extended beyond the natural sciences to every subject of study from political science (called "political studies" or "politics" in other universities) to pedagogical sciences (called "educational studies" in other institutions). ${ }^{23}$

23 I did notice, however, the return of the entry 'science' into educational discourses in the United States in part because of the need to assert the scientific basis for educational inquiry and in part because of the evidence-based movement (with its roots in the medical sciences) driven from some quarters, including the federal government under George W Bush. 
It is not only that knowledge is fixed and races are given, but there is a distinct hierarchy among human beings with whites higher on the plane of civilisation and blacks lower in everything as indicated in their cultural practices. On the one hand Ubuntu, in essentialising black behaviour, desires whites to understand these lower behaviours (this is the crux of the multicultural education endeavour in the curriculum) rather than condemn such lifestyles and choices. On the other hand, Ubuntu requires those higher on the plane of civilisation to reach down, educate and uplift blacks so that they can come to a common and therefore white understanding of appropriate behaviour. This theme runs throughout the Ubuntu curriculum, with more than a hint of encouraging white amusement as these extreme stories of black aberration are handed to incoming white students.

Ubuntu's problem is not that it peddles this offensive knowledge on a university campus; its dilemma is that it makes explicit what is often concealed in white understandings of the Other and which is less evident in the knowledge, values and beliefs that underpin the supposedly neutral scientific knowledge presented across the institutional disciplines. To understand how Ubuntu is received as 'normal' within the institutional curriculum, the question must be posed: How did this curriculum pass approval at the level of the department, the faculty and, ultimately, the Senate of the university as a whole? Furthermore, how did this curriculum - reviewed intensely by a university-wide innovation committee - actually win an institutional award for Innovation? The answer is simple: it resonates deeply with white understandings in this Afrikaans university about what counts as legitimate knowledge of other people.

\section{CURRICULUM CHANGE: AN APPRAISAL}

I realised early on that changing the institutional curriculum was always going to be incomplete. Even as dean of a faculty in an authority-driven university, I did not have the energy or power to ensure that a completely new knowledge would sweep teaching, learning and assessment within the broad teacher education curriculum across two schools, seven academic departments, five faculty centres and any number of curriculum and research committees. The more than 500 modules made it almost impossible to scrutinise each and every learning unit to determine the extent to which it shifted the deeper understandings of race, knowledge and identity towards a more open, tentative and democratic knowledge of school and society. We decided on a number of strategies to support curriculum renewal with education. 
The first strategy was to conduct early-on departmental and programme reviews of the organisational units. In addition, external experts from other-minded universities and associates from leading international universities were requested to review the curriculum. Predictably, the reports pointed to the conservative nature of faculty knowledge, the distance of our curriculum from mainstream thinking in the disciplines, the anachronistic naming of some of our departments (like teacher training), and the narrow and instrumental character of teacher education knowledge at the expense of theoretical understanding. We used these reports to steer discussions within schools and departments about the need for change, and even made operational lists of 'things that needed to be done' to change the curriculum.

The second strategy was to appoint to headships a balance of persons from outside of the Afrikaans universities, but this was balanced with younger resident academics who showed an understanding of the larger change project and who were willing to take on board the imperative of knowledge transformation on which we deliberated. The theory was that with the right school-and departmental-level leadership the knowledge base of teacher education could be interrogated and academics within a unit could be inspired and led to change their values, knowledge and beliefs. Regular and intensive workshops and meetings were held with these unit leaders to develop a coherent and shared understanding of what we wanted to achieve with curriculum change.

The third strategy was to change the inherited names of schools and departments as far as possible. Thus "psychopedagogics" became educational psychology and "sociopedagogics" became the sociology of education, while "curriculum studies" replaced "department of didactics". The School of Educational Studies reflected in its new names the academic character of the faculty rather than its "teacher training" designation which reduced the intellectual endeavours of teaching to little more than training; of course, another school called "teacher training" was then established for reasons discussed later.

The fourth strategy was to change the criteria by which intellectual work was assessed. New and elaborate schemata changed the faculty promotion rating scales in favour of intellectual depth, creativity and originality (literally these words) rather than simply the production of large numbers of publication units. The evaluation of especially doctoral dissertations required a new set of performance standards that included contributions to new knowledge and innovation in theory and method; and the community of scholars involved (or required to be involved by faculty regulation) in the 'moderation' of student examinations was now drawn from a more cosmopolitan crew of national 
and international academics. The logic here was that by changing what was valued at the level of terminal outcomes or performance criteria, there would be a backwash effect onto knowledge and curriculum in the classroom.

There is little doubt that the combination of these strategies started to erode certain and fixed knowledge, and that as the standards of knowledge changed, different kinds of faculty and different kinds of academic work started to be noticed, and started to appear for evaluation. The university administration, to be fair, acknowledged and even admired these qualitative shifts in the academic culture of Education, and some even commented that we might be too 'strict' in what we required of academic quality and performance. Of course such attempts to change the deep structures of knowledge with their encasing beliefs and values cannot happen simply by changing what is valued, for reasons revealed later.

\section{THE TENSIONS BETWEEN DEEP CHANGE AND MANDATED CHANGE}

In the meantime, though, this attempt to revise the institutional curriculum at the level of the faculty had to compete with an even more compelling (from the perspective of the university administration) change project and that was to align the individual faculty curricula with the formats and standards of the South African Qualifications Authority (SAQA). This largely technical exercise did even less for knowledge transformation, even though the idea of placing all qualifications on a national framework expressed more idealistic ambitions for curriculum transformation. The energies of every academic were clearly devoted to this curriculum alignment exercise - it was easier to do, it did not question underlying belief systems, it did not disturb received knowledge, and it came with senior management instruction, die opdrag (the command) that pushed aside any other kinds of political and intellectual efforts to interrogate concealed knowledge.

In the midst of these efforts to change deeply the knowledge base of teaching came yet another overarching administrative command system called "quality assurance". Once again, hundreds of faculty hours would be diverted into preparing documentation for the new quality assurance review of a statutory body called the Council on Higher Education which, through its Higher Education Quality Committee (HEQC), made final judgments about the approval or closing down of funded programmes. The significance of attaining accreditation, without which no programmes could be offered, held severe repercussions for institutional reputation and faculty funding. Once again the energies of the staff were pushed towards compliance with external regulation with considerable pressure, of course, from central administration. 
The point of this discussion is that energetic pursuits of curriculum change seeking social justice and corrective knowledge are severely impeded when they happen in overarching social contexts where a new government places added regulatory frameworks over universities that demand and win the attention of academics and administrators within them. It is therefore not only the difficulty of changing a microenvironment (one faculty, Education) within a macro-institutional context that is so difficult; it is the added dimension of state regulatory changes that further complicates the process of change within an academic unit such as a faculty of Education. The academics concerned feel the burden of what they experience as one wave of change after another; they feel tired and frustrated trying to read the new rules of the game. The problem is that there are multiple and competing rules for change, and under such pressure, white (and indeed black) academics tend to lean towards those change forces which come from the higher authority and which pose the greater threat to the academic standing and employment security of staff.

Here then is the complex of curriculum change during periods of dramatic social transition. Changes happen simultaneously at multiple levels - the department, the faculty, the university, and the society. Each level of change has its own script and its own academic and ideological demands. Some demands are intellectual and others are bureaucratic; some seek compliance with set rules and others seek changes in beliefs and behaviours; some threaten personal and institutional penalties and others remain mainly exhortatory in nature; for some reforms the guidelines for change are relatively straightforward and technical, for others the change demands are more political and personal. When this happens, academics find it much easier to work with the technical and the regulatory rather than with the infinitely more troublesome changes that demand deep personal and emotional changes in understanding and commitment.

Beyond Ubuntu, smaller and less dramatic changes in the curriculum knowledge and ideologies were hard to shift. It was difficult to convince a colleague that a course on family and sex education was little more than an attempt to convince black students (the main if not exclusive audience) about the dangers of sexual liaison and the problem of HIV/AIDS; and that sexual correction and the promotion of a particular version of Christian living was not the goal of a university curriculum. It was hard to persuade my colleagues teaching about school discipline that it was important to go beyond teaching the different techniques of keeping children under control and to bring in Michel Foucault and others to grapple with the meanings of punishment and its institutionalisation under years of apartheid. It was especially difficult to convince 
colleagues about the contested standards of knowledge and the multiplicity of ways of knowing beyond the quantitative worlds of experimental science.

The supreme test of change proclaimed in new academic policies, pursued through a broad array of training programmes and engineered through bringing in new academics from outside the political and epistemological worlds of the Afrikaans university was, of course, what happened inside classrooms. Away from the foreboding offices of leadership and at some distance from the surveillance schemes of the new government bureaucracy, what did the curriculum-in-practice actually look like? There were three responses from the resident academics in how they expressed the curriculum in practice.

It must be remembered that this new knowledge was deeply disturbing and in some ways quite foreign to resident knowledge. Moreover, this new knowledge was disempowering, for the resident academic often experienced it as a message which held that everything they thought was true, was not. Suddenly there were crises of confidence in what colleagues knew, and some saw immediately that their doctoral degrees were of little value in this swirl of change that came into education.

The first response was to engage seriously and make sense of this new curricular knowledge. This response generally came from younger colleagues who either recognised the weaknesses of their received knowledge and/or saw the practical and personal interests that could be served by adapting as soon as possible to the new curricular demands. Sometimes this eagerness was reflected in a new language spoken, but often did not manifest in a new practice expressed in the classroom. I reviewed syllabi and gave feedback on revised curricula; we organised countless seminars and writing review sessions during which colleagues could gently access the new discourses and find ways of translating the new curriculum into their practices. For many - though not all - of these colleagues, this intense engagement led to higher levels of productivity, appearances in a broader range of scholarly journals, and eventually awards and recognition in South Africa and abroad.

Gradually, the writing and the teaching of these colleagues became more flexible, new reading lists were engaged in some depth, and the epistemological character of their beliefs started to show up as deep understandings of the new knowledge. This process of transformation is of course never complete, and every now and again there is evidence of the old, but at least for this group of younger scholars (not necessarily in age, but in terms of recent entrance to the academy) there was a reawakening that was 
expressed in terms of intense joy as they recognised, for the first time, the constrictions and the constructions of knowledge within which they had hitherto been bound.

The second response was outright rejection of the new curriculum, but never directly. The institutional culture did not allow for direct confrontation with authority; the way to do this was to feign allegiance to the new knowledge, but to continue in practice with the resident knowledge. I never believed that such responses to the new curriculum orientation were ever a deliberate attempt to undermine the new knowledge; it was simply too difficult and too risky to even begin to open up to these new demands. These were often older colleagues, often very gracious persons, but for whom the changes had come too late in their careers to hold any personal benefits and so radical in ambition that they would expose the limitations of existing knowledge. Such colleagues simply stood back and continued what they were doing, quietly hoping that there would be no external or internal pressure that forced change.

As dean I did not intervene. How does one coerce change that academics simply do not believe in? What kind of change results from compulsion? And again, is it ethical to demand change when it flies in the face of what people feel competent to do? And is a university not a place in which all kinds of knowledges - unless they are clearly offensive - should be tolerated? Fortunately this was a very small group.

The third response to the new curriculum orientation was the most difficult for me to deal with from the point of view of leadership. This came from a small group of colleagues who wanted to engage the new curriculum knowledge, but found the task very difficult. They would attend all the seminars and workshops, and they would frequently set up one-on-one meetings to make sense of the content and direction of what was required, but they were simply not able to make this transition. There were several reasons for their dilemma. The one was their poor intellectual grounding in the undergraduate and initial postgraduate training that simply had not prepared them for this level of teaching and inquiry; the second and related reason is that they should never have been appointed to university positions in the first place. This sounds harsh, but it reflected a reality that came with a number of structural reforms in the post1994 university environment - the forced incorporation of college-level personnel into universities. And there was another reason - those older academics who stayed on and supported the curriculum changes, but simply could not make the transition.

It is important for the education change literature to come to terms with this reality rather than succumb to that eternal optimism of Western change writings - everyone can change. In the restrictive labour relations regime of the new South Africa that 
protects workers in ways that make it very difficult to prove and act on incompetence, and in the racially sensitive political environment of transition, it would be very difficult to deal with this dilemma. More importantly, how does one release someone who through no fault of their own - but as a result of the harsh consequences of history found themselves marginalised and disempowered under new social and intellectual demands? And how, in such a context, does one release someone who does everything to demonstrate enthusiasm for the new curriculum and the project of change, even though they cannot?

\section{CONCLUSION}

Ubuntu offers a rare but powerful window on the nature and authority of the institutional curriculum of the University of Pretoria, and indeed other historically Afrikaans universities; but it also sheds new light on much broader problems associated with educational change in general, and curriculum change in particular, under conditions of social transition. By viewing curriculum as an institutional matter, knowledge is seen not simply as something codified within specific subjects and disciplines with psychological (learning) intent, but as the underpinning ideological, epistemological and indeed political assumptions and beliefs that govern resident knowledge. Curriculum as syllabic knowledge, it was shown, is difficult to change, because it finds its resonance, connectedness and authority in institutional knowledge, and such knowledge is in turn embedded in emotionally-held social and historical understandings of race, identity and history. In other words, knowledge in the blood.

The white Afrikaner students who therefore enter desegregated universities from their all-white social and educational experiences, do not enter former white institutions in which new curricular knowledge has been exchanged for the old. Rather, they enter universities in which the institutional curriculum is in the throes of upheaval in part because of new regulatory demands from the outside and in part because of new intellectual demands from the inside. What is being contested, at heart, is what counts as worthwhile knowledge inside these institutions. And white students are drawn into and become part of this contested environment carrying a very powerful but indirect knowledge that will add yet another dimension of struggle to a resilient institutional curriculum. 


\section{REFERENCES}

Benatar D. 2007a. Inaugural address. Monday Paper 11 April 2007 [Online]. Available: http://www.news.uct.ac.za/mondaypaper/archives.

Benatar D. 2007b. 'Affirmative Action' not the way to tackle injustice. Monday Paper 23 April 2007 [Online]. Available: http://www.news.uct.ac.za/mondaypaper/archives.

Brenner L. 2001. Controlling Knowledge: Religion, power and schooling in a West African Muslim Society. Bloomington, Indiana: Indiana University Press.

Cloete N, Fehnel R, Maassen P, Moja T, Perold H \& Gibbon T (eds). 2006. Transformation of Higher Education: Global pressures and local realities. The Netherlands: Springer.

Du Toit BM. 1984. Missionaries, anthropologists, and the policies of the Dutch Reformed Church. The Journal of Modern African Studies, 22(4):617-632.

Erasmus Z. 2007. Governing Whiteness! Now that cannot be allowed. Monday Paper 2007 [Online]. Available: http://www.news.uct.ac.za/mondaypaper/archives.

Foucault M. 1986. The Archaeology of Knowledge (Translated from the French by AM Sheridan). London: Tavistock.

Gordon D. 1991. Inkatha and its use of the Zulu Past. History in Africa, 18:1 13-126.

Hall M. 2007. The case for equity. Monday Paper 2007 [Online]. Available: http://www.news. uct.ac.za/mondaypaper/archives.

Jansen JD. 1991a. The State and Curriculum in the Transition to Socialism: The Zimbabwean Experience. Comparative Education Review, 35(1):76-91.

Jansen JD. 1991 b. Knowledge and Power in South Africa: Critical perspectives across the disciplines. Johannesburg: Skotaville Publishers.

Jansen JD. 1998. 'But our Natives are different!' Race, knowledge and power in the academy. Social Dynamics, 24(2):106-116.

Jansen JD. 2001. Why Tukkies Cannot Develop Intellectuals. Innovative Lecture Series, 11 May.

Jansen JD. 2009. Knowledge in the Blood. Cape Town: UCT Press.

Karmon A. 2007. Institutional Organization of Knowledge. Teachers College Record, 109(3):603-634

London L. 2007. Affirmative action and the invisibility of white privilege. Monday Paper 2007 [Online]. Available: http://www.news.uct.ac.za/mondaypaper/archives.

Lorde A. 1984. Sister Outsider: Essays and speeches by Audrey Lorde. Berkeley, California: The Crossing Press.

Mbigi L. 1997. Ubuntu: The African dream in management. Johannesburg: Knowledge Resources.

Mdluli P. 1987. Ubuntu-Botho: Inkatha's 'People's Education'. Transformation, 5:60-77.

Reid WA. 1999. Curriculum as Institution and Practice: Essays in the deliberative tradition. New Jersey: Lawrence Erlbaum. 
Reid WA. 2006. The Pursuit of Curriculum: Schooling and the public interest. Greenwich, Connecticut: Information Age Publishing.

Tabensky P. 2004. My Life at the University of Pretoria: A story of two evils. Centre for Civil Society, University of KwaZulu-Natal. Available: http://www.ukzn.ac.za/ccs.

Terwel J \& Walker D (eds). 2004. Curriculum as a Shaping Force: Toward a principles approach in curriculum theory and practice. New York: Nova Science Publishers.

Tutu D. 2004. God has a Dream: A vision of hope for our time. New York: Doubleday.

Van der Westhuizen C. 2007. White Power and the Rise and Fall of the National Party. Cape Town: Zebra Press.

Woods M. 2007. Personal e-mail communication. 20 December 2007. 


\section{SOME CURRENT CURRICULUM ISSUES IN SOUTH AFRICAN HIGHER EDUCATION}

Nonnie Botha

\section{ABSTRACT}

This chapter provides a brief discussion of some of the complexities that relate to the South African higher education curriculum. Firstly, the concept of 'curriculum' is theoretically defined, with the purpose of embedding the section to follow, in a theoretical context. Hence six interrelated clusters of current curriculum issues are outlined, namely that of vocational and liberal education, progression from certificate to diploma to degree, mass education compared to selective education, contact and distance education, internationalisation and localisation, and diffusion between disciplinary boundaries. Strong focus is placed on the Africanisation of the curriculum, as part of the cluster on internationalisation and localisation. The enmeshment of the clusters with each other is highlighted and this intertwinedness is illustrated in a table. The value of this chapter lies therein that it could be used as a point of departure for the scholarly review of the South African higher education curriculum.

\section{INTRODUCTION}

In the arena of higher education studies and research across the world, the curriculum debate and inquiry are increasingly drawing more attention from various parties. In South Africa, this attention manifests in several ways for several reasons. The Ministry of Education has displayed its attention to the curriculum, amongst others, through its official requirements regarding universities' programme and qualification mix (PQM); the registration, accreditation and approval of programmes with the South African Qualifications Authority (SAQA), the Higher Education Quality Committee (HEQC) and the Department of Education respectively; by distinguishing between the types of programmes offered by universities of technology, comprehensive universities and the 
'Other' universities, as well as by indicating that there will be only one distance education university (DoE 1999, 2001, 2002, 2007a, 2007b; RSA 1997, 2008; SAQA 1997). Prospective students and their funders (e.g. students themselves, parents, financial institutions, providers of bursaries and scholarships, employers) pay attention to the higher education curriculum to determine to what extent it will provide in their education and training needs within their particular contextual constraints. The curriculum of a South African university will therefore often be the deciding factor in students' choice of institution. Employers also expect from higher education institutions to provide them with human resources with appropriately specialised training (Beck and Young 2005; Bernstein 2000; Muller 2008). If universities fail to do this, employers are likely to develop their own training programmes. South African universities themselves are out of necessity deeply involved with all these external curriculum determinants. They also grapple with their own curricula internally. They need to match their academics to their programmes (which could be a dialectic process), their faculties/schools/departments to their programmes and their students to their programmes. They also need to balance their offerings with those of other universities - either in competition with them, or by offering curriculum alternatives, or both.

In the context outlined above, a number of curriculum issues emerge from the debates in South African higher education; a selection of these issues is presented in this chapter. They are clustered together in an effort to deal with the complexity of their interrelatedness and enmeshment. Each cluster therefore consists of more than one curriculum issue - in many cases the issues are theoretically separate, but in reality they occur inseparably. Due to the nature of the interrelatedness, it would be possible to cluster them together in several ways - the clusters as presented in this chapter are therefore not a unique categorisation. The six clusters that are discussed in this chapter deal with vocational and liberal education, progression from certificate to diploma to degree, mass education compared to selective education, contact and distance education, internationalisation and localisation, as well as diffusion between disciplinary borders.

The intention is not to suggest ways of dealing with the challenges associated with each cluster of issues, but rather to stimulate awareness of the complexity of these challenges, as well as to highlight the need for further investigation into the enmeshed manifestation of the issues and clusters in particular institutions. This chapter is therefore an attempt to paint the landscape of South African curriculum debates and issues that are currently under the magnifying glass in certain sectors of the higher education arena. In some cases, reference is made to a possible connection between a cluster 
and a particular curriculum paradigm or theory; however, as curriculum theory is not the main thrust of this chapter, these suggested connections are not discussed at all.

For various reasons the discussions of the clusters in this chapter are not equally weighted; some of these relate to the prominence of the current debate, the level at which the debate is taking place or the nature of the debate. An example of a cluster that receives much attention here due to the prominence of the debate is that of internationalisation and localisation, particularly referring to the idea of Africanisation.

To ground this presentation of South African curriculum issues, the concept 'curriculum' is briefly discussed as described in the literature on curriculum theory. This brief exposition of the notion of curriculum is not an analysis, but simply a reflection of how some of the current literature understands curriculum.

\section{Concept clarification of the notion 'curriculum'}

The concept 'curriculum', which has its origin in the Latin curro (I run) or currere (running) (Lovatt and Smith 2003:7), relates to the prominence of the athlete in ancient Greek culture, incorporating features of progress and competition. The conceptualisation of the curriculum varies according to the points of departure: some of them are easier to explain, while others are contrived in a much more complicated fashion.

Marsh (2004) considers various definitions from the literature, identifying the limitation of the definition in each case. This gives rise to 'two sides of the coin', namely that curriculum is

- permanent subjects as compared to the need to accommodate the changing state of knowledge;

- subjects that are most useful for living in contemporary society as compared to more long-lasting knowledge;

- planned learning, thus excluding unplanned learning (also assuming that learning has actually taken place if it was planned);

- the totality of learning experiences, thus leading to a large number of expected learning outcomes, which implies a technicist approach;

- what the learner constructs from electronic resources, thus assuming that what is available from these resources constitutes desired knowledge;

- a questioning of authority and searching complex views of human situations, which could be experienced as general, vague and confused.

(Marsh 2004:3-7) 
Posner has acknowledged that it is no simple matter to be clear about exactly what the curriculum is, as "definitions are not philosophically or politically neutral" (2004:5). He elaborates on the ends and means of the curriculum and how these co-determine the definition of the curriculum. His thoughts crystallise into seven concepts of the curriculum (Posner 2004:6-12), these being the curriculum as

- scope and sequence of intended outcomes, distinguishing between the ends and means of education, guiding instruction and assessment;

- syllabus, which is a plan for an entire course, including both ends and means;

- content outline, which is relevant in a context where the purpose of education is to transmit information;

- standards, which refers mainly to learning outcomes and processes towards achieving these;

- textbooks, used as guides to both the ends and the means of the curriculum;

- course of study, referring to a "series of courses that the student must get through";

- planned experiences, which includes all such experiences students have to go through, curricular as well as extra-curricular.

Posner also refers to the five concurrent curricula, namely the official curriculum (which is documented), operational curriculum (what is taught, how it is communicated to learners and the outcomes for which learners are held responsible), hidden curriculum (associated with norms and values), null curriculum (what is not taught) and the extracurriculum (planned experiences outside the subjects) (Posner 2004:12-14).

Schiro (2008) believes that the different visions of the curriculum are based on four curriculum ideologies or philosophies, each one requiring a particular purpose and specific methods for fulfilling that purpose. His four ideologies are the scholar academic ideology, social efficiency ideology, learner-centred ideology and social reconstruction ideology.

David Scott (2008) presents the history of the curriculum as 'episodes', these being scientific curriculum making, intrinsic worthwhile knowledge, innovative pedagogical experimentation, critical pedagogy, instrumentalism and effectiveness or improvement. $\mathrm{He}$ also refers to the four dimensions of the curriculum, namely aims or objectives, content or subject matter, methods or procedures and evaluation or assessment (Scott 2008: 19). 
The above-mentioned references to the literature focus on the notion of the curriculum in general. However, as this chapter deals with the curriculum in higher education in particular, it is necessary to draw the line of definition into the latter realm as well. The notion of a higher education curriculum is underpinned by the concept of curriculum and the construct of higher education. The former has been explained above; the latter could be based on the South African Higher Education Act of 1997, and its amendment in 2008. The Act states that higher education means "all learning programmes leading to qualifications higher than Grade 12 or its equivalent in terms of the National Qualifications Framework" (RSA 1997:8). This was amended in 2008 to read that higher education means "all learning programmes leading to a qualification that meets the requirements of the HEQF" (RSA 2008:2). For the purpose of this chapter the higher education curriculum is to be understood as being the curriculum of programmes provided in the higher education sector, i.e. beyond the further education and training level (above the National Qualifications Framework level 4).

The above-mentioned viewpoints on what the curriculum actually entails indicate that it is a multi-dimensional concept and its complexity requires that it cannot be approached in a simplistic manner. The context in which a curriculum is considered determines which theoretical understandings are appropriate. Thus, when the higher education curriculum is considered, the context of this multi-dimensionality becomes evident in the current issues and debates around this matter. The rest of this chapter is devoted to some of these issues, presented here as a clustered framework.

\section{SOME CURRENT CURRICULUM ISSUES IN SOUTH AFRICAN HIGHER EDUCATION}

A number of issues immediately come to mind when current higher education debates in South Africa are considered. Many of these issues seem to be associated with at least one other issue, thus presenting themselves as two extremes of a continuum, or positioned between the two extremes on the continuum. Examples of such issues are vocational/liberal curricula, certificate $\rightarrow$ diploma $\rightarrow$ degree, mass education/ selective education, contact/distance education, internationalisation/localisation and the extent of diffusion among disciplinary boundaries. The image of a continuum might create the impression that each set of issues is two-dimensional. On the contrary, they are rather multi-dimensional in nature, include many variations on the continuum and are not necessarily bounded. A more appropriate image would then be that of a number of unbounded, multi-dimensional sets that intersect with each other. Due to the intersections, some of the issues can be clustered together and some clusters linked with each other. What follows is such a clustered presentation of some current curriculum issues. 


\section{Cluster 1: Vocational and liberal education}

The first cluster of curriculum issues in South African higher education deals with the continuum regarding vocational education and what I will call liberal education. The incorporations and mergers that took place among higher education institutions in South Africa late in the previous and early in this century, resulted in three types of institutions, namely universities, comprehensive universities and universities of technology (DoE 2001:17). This typology of universities had a significant role to play in bringing the imperative of this curriculum continuum to the fore.

Prior to the incorporations and mergers referred to above, a variety of institutions in South Africa offered post-school education. These were colleges (e.g. teacher training colleges, agricultural colleges, technical colleges, nursing colleges), technikons and universities. It is necessary to note that post-school education in South Africa refers to education offered to school leavers, both those who opt to leave school before completing Grade 12, as well as those who complete Grade 12 - it thus includes formal, non-school education which is not at a higher education level (up to and including NQF level 4), as well as higher education (post-NQF level 4). All public colleges operating at the higher education level were incorporated into technikons and universities; those that remained did not have a mandate to offer higher education programmes. These incorporations were followed by mergers of technikons and universities, reducing the number of public higher education institutions in the country from 35 to 21 (RSA 1997).

Shortly after these mergers, much of the activity around the restructuring of university curricula, focused specifically on the distinction between university-type curricula and technikon-type curricula. The importance of retaining both types of curricula in order to respond appropriately to the social and economic needs of the country was acknowledged (DoE 2002:24). 'Academic drift' from technikon-type to universitytype programmes had to be avoided in order to serve these needs (DoE 2001:18). Christiansen and Baijnath's research on curricula of universities of technology has indicated a need for diversity "driven by careful reflections on knowledge production and 'distribution', and their politics, history and sociology" (2007:223).

Although the distinction between typical technikon programmes and typical university programmes was not always clear, particular notions of such a distinction have been identified in the South African literature. It is acknowledged that these notions often do not give rise to strong distinctions, but they are nevertheless present in the minds of the curriculators at universities. These notions are "'pure' compared to 'applied', 
disciplinary discourses compared to credit exchange discourses, higher education 'in' as compared to 'for' society and an expanded understanding of technology" (Christiansen and Baijnath 2007:223-227). The latter understanding indicates a particular feature of technology, namely that of the practical, the application, which could be very useful in curriculum design. Blunt (2005: 1030) highlights "democratization of higher education, being engaged institutions, an internationally comparable National Qualifications Framework, bridging arrangements for under-prepared students" and "language issues" as the main challenges in developing appropriate curricula for comprehensive universities. These challenges are clearly not unique to comprehensive universities, but apply to the whole of the higher education sector (and wider), but it would be wise to factor them into curriculum activities in vocational as well as 'liberal' programmes.

Since the merger dust has started to settle in South Africa, the original distinction between technikon-type and university-type programmes, at some universities has shown a tendency towards a distinction between education for the professions (e.g. engineering, design, architecture, nursing, teaching, law), as compared to education for other reasons, for example to ensure the development of all aspects of the human being (this could include languages, history, philosophy, mathematics, chemistry, geography, human movement science) - from there my labels of 'vocational' and 'liberal'.

Bar the issue of technikon-type and university-type programmes, there are no prescriptions for universities regarding the range and diversity of programmes they offer, thus they need to make such decisions themselves. Universities of technology are therefore likely to be offering mainly technikon-type programmes currently (with the focus on links to industry and some professions), comprehensive universities both technikon-type and university-type programmes (with links to industry and an even wider range of professions) and the remainder of universities, university-type programmes (with links to some professions). All of these institutions are thus offering professionally focused programmes and 'liberal'-type programmes (see Jansen 2004:5-18). In the chapter Higher education and the world of Work, Garraway (this volume) discusses this matter in greater detail when he deals with transferring and integrating work knowledge into university curricula.

During and shortly after the range of South African mergers, the allocation of human resources in institutions as well as recurriculation and restructuring were focused on the integration of the merger partners in all their dimensions, but as this process has now been completed, the focus has changed to other strategic priorities. Institutions 
therefore need to decide what the balance between professional and 'liberal' programmes will be in their curriculum bouquet. This decision will be based partly on what they are currently offering, the extent to which they desire and are able to change current offerings, as well as the pressure they experience (internally and externally) to make such changes.

The one extreme of the continuum, representing professionally-focused programmes, is receiving much support in South Africa currently. The strong outcry for universities to produce appropriately qualified human resources to serve the economy of the country emphasises the need for professional education. The scarcity of skills in many areas of the labour market highlights the importance of this outcry, as enacted by the South African Skills Development Act, No. 97 of 1998, and the Skills Development Amendment Act, No. 37 of 2008. The role professional advisory boards play in codetermining university curricula and other quality assurance issues is a manifestation of the symbiotic relationship between many professions and the university. The increase in work-based learning as an integral part of some university curricula, specifically curricula aimed at professional education, is another dimension of this symbiotic relationship. Theoretically, this extreme point on the continuum could be linked to a mode of knowledge production that relates to the postmodern knowledge society, namely that of promiscuous engagement. This concept refers to a situation where, in "order to compete and be relevant, academics and academic units enter into all sorts of partnerships and liaisons - mainly with external parties who seek to use science for innovation, enhanced productivity and competitiveness in global markets" (Naudé and Cloete 2003:18). Swartz contends that this engagement needs to go beyond mere linkages, requiring that universities should immerse themselves in a "sea of new relationships in and through which they" need to find their "meaning and existence" (2008: 15); this engagement must also not be uni-directional, but should benefit both sides and be initiated from both sides (2008:16).

The other extreme of the continuum sees rapidly dwindling student numbers in fields such as philosophy, history and languages other than English, as well as relatively low student numbers in science, engineering and technology (DoE 1999, 2006). Studies in all of these areas are not necessarily professionally focused; they could thus be perceived as providing the individual with a general education that needs to be taken a step further at some stage in order to produce a trained professional.

The challenge for each South African higher education institution lies in establishing a balance between the two extremes described above or, alternatively, in finding a 
niche for themselves somewhere along each of these continuums. Where the balance or what the niche will be for each institution depends on its vision and mission, its strategic priorities and its eventual action plans to manifest these priorities.

This cluster could be related to the notion of 'two sides of the coin'-type of curricula as indicated at the start of this chapter, namely either comprising subjects that are most useful for living in contemporary society (vocational) or subjects that cover more longlasting knowledge (liberal) (Marsh 2004). Theoretically, the cluster also relates to two of Basil Bernstein's curriculum models, namely one that is less strongly classified but strongly framed (focusing on an efficient economy), as well as one that is a decentred identity (of which the instrumental variety is market-oriented and locally embedded) (Bernstein 1996).

It is imperative that more research be carried out to develop guidelines for the structuring of vocationally focused as well as 'liberal' curricula for South African universities. In the aftermath of the mergers, there are still significant remnants of confusion and tensions around this matter, each institution grappling with it on its own and within its own context. Without any direction to the process, South African universities might lose some of its opportunities in the potential curriculum chaos.

In an effort to meet the needs of the studying public and other parties who have a stake in those studies, universities are also faced with a second cluster of curriculum challenges in South Africa, namely that of progression through the higher education system, with the start of the study path both in history and in the present.

\section{Cluster 2: Progression from certificate to diploma to degree}

In the past, a number of South African institutions offered post-school (not necessarily tertiary) education, usually aimed at qualifications for professions. Former teacher training colleges, agricultural colleges, nursing colleges and technical colleges did not include degrees in their programme repertoires; however, teaching, nursing and agriculture programmes were included in university curricula and technical programmes in technikon curricula for a long time. A gradual evolution took place in this situation: teacher training colleges were incorporated into universities and technikons; teaching strove towards becoming a graduate profession, but teacher qualification upgrading required the continued offering of certificates and diplomas (e.g. the Advanced Certificate in Education and the National Professional Diploma in Education); a number of technical colleges became technikons and could subsequently offer degrees; the establishment of further education and training colleges catered 
for the resulting gap in the education and training world; and some nursing and agricultural colleges continued to offer non-degree programmes alongside degree programmes offered at universities.

The above-mentioned situation gave rise to an ever-increasing demand for South African universities to recognise parts of or whole previously completed certificates and diplomas, by giving credit for such subjects/modules/qualifications towards part of an appropriate university degree. Many universities have some rules about exemptions and/ or credits relevant to completed teacher college qualifications; similar arrangements apply regarding some other college qualifications. In some cases, however, people who have to deal with applications for admission to university programmes are often not sure whether or how to recognise such qualifications. To be able to address this situation, it is necessary to analyse both the college and the university curriculum, to determine whether and how a sub-set of the former could dovetail into the latter. When this kind of situation arises very often at a particular institution, it would be wise to accommodate it in the curriculation process from its initial stages.

Two factors that further contributed to the complexity and importance of this matter were the institutional mergers in South Africa and the concept and encouragement of lifelong learning. The mergers brought technikon-type programmes and university-type programmes much closer to each other than ever before: they are now both offered by universities and even exist in the same institution in the case of comprehensive universities. This increased the need to consider whether and how credit can be given for work completed for one type of programme, towards the other type of programme (the demand for this is overwhelmingly - although not necessarily exclusively - in one direction: namely recognition for work done in a technikon-type programme towards a university-type programme). The debate around this articulation issue rages on, especially in relation to 'B Tech to non-M Tech Master's' and 'M Tech to non-D Tech Doctoral' studies.

The linking of technikon-type, college-type and university-type programmes to each other has been facilitated by the National Qualifications Framework and the envisaged Higher Education Qualification Framework (DoE 2007a), positioning certificates, diplomas and degrees in relation to each other. The successful implementation of the HEQF will be facilitated by, inter alia, the alignment of the National Policy Framework for Teacher Education and Development in South Africa (DoE 2007b). This issue remains a contentious one and there is no easy solution. Many universities deal with 
this internally in the Faculties, acknowledging that a blanket rule cannot apply to all situations.

In line with the concept of life-long learning, mature prospective students started knocking at the doors of the universities in South Africa with requests to further their studies there; such a request was usually accompanied by the need to obtain some form of recognition of previously obtained qualifications, often not from a university. Added to this, and infinitely more complex in nature, is the need that arose to acknowledge knowledge and skills gained through experience, without any formal qualification to certify this. The accreditation or assessment of prior learning can cater for such situations, as indicated in the White Paper on Higher Education and in documentation from the South African Qualifications Authority (SAQA 1997:16). This approach was actively embraced by some institutions at the time, but many pitfalls, such as the required rigidity, time and labour intensiveness and hidden costs eroded the initial enthusiasm with which the recognition of prior learning (RPL) was welcomed. Currently, most institutions will consider RPL only for admission into a programme of study but not for awarding a qualification, and even then it remains a very difficult matter to execute. If the application of RPL is to become a permanent feature of the South African higher education system, more research needs to be done on its implementation, funding and processes.

Regarding a link between this cluster of curriculum issues on the one hand, and notions of the curriculum as indicated at the start of the chapter on the other: a clear association could be found between the certificate $\rightarrow$ diploma $\rightarrow$ degree progression and one of Posner's (2004) conceptions, namely that the curriculum is the scope and sequence of intended outcomes, distinguishing between the end and means of the curriculum, thus guiding instruction and assessment.

The concepts of life-long learning and RPL have both been developed primarily to address the skills backlog in this country and to afford people who could historically not gain reasonable access to formal higher education the opportunity for both of these. This brings us to the third cluster of curriculum issues, namely the tension between mass higher education on the one hand, and the services that universities are able to render on the other.

\section{Cluster 3: Mass education and selective education}

One of the results of the progression from minority rule to a democratically elected government in South Africa in 1994 was the awareness of the need for increased access 
to higher education. This was prioritised in the National Plan for Higher Education as part of the five strategic objectives (DoE 2001:4), namely:

- to provide increased access to higher education and to produce graduates with the skills and competencies necessary to meet the resource needs of the country; [and]

- to promote equity of access and to redress past inequalities through ensuring that the student and staff profiles progressively reflect the demographic realities of SA society.

The position a university occupies on this continuum will influence the nature of the institution's programme and qualification mix, thus co-determining all curriculum matters of the institution. The balance or niche that each university in South Africa must find for itself with regard to this issue cluster also revolves around a number of factors that form the pivots of the mass education debate. Some of the main pivots of this debate are briefly highlighted below.

\section{Free higher education}

This issue needs to be seen in the context of financial resources for higher education, as the ability of this sector to offer free education depends on the funding available. Universities derive their income from study fees, subsidy from the National Department of Education, donations and income generated through their own entrepreneurial activities (third-stream income). Each of these income sources has been heavily debated. Student fees are an annual issue: university authorities try to align increased funding required to offer programmes with the fee students are required to pay for this service, while students demand that such fees must not be increased. The subsidy paid by the Department of Education is an ever-decreasing percentage of universities' income and they have to turn to other means of generating sufficient income to remain financially viable. It is also a fact that the funding of this departmental subsidy is sourced from the government's tax income, therefore the subsidy can only increase if there is an increase in the country's tax base. Lubisi (2008:15) points out that it "is inescapable to either levy special taxes or redirect expenditure from other areas of spending", if we want to realise this dream. He also refers to the question of free (higher) education for all or whether this should only be for the poor (2008:12). If these dilemmas cannot be solved, free higher education will remain no more than a pipe dream. 
2. RPL alongside formal admission requirements

RPL could be used as a mechanism to increase access to universities. However, this route will require that it is established and expanded, for at least some time to come. As indicated in the description of the previous cluster, this will require additional funding, curriculum analysis and the alignment of university rules to manifest this strategic priority.

3. 'Level of acceptance' and 'level of expectance'

Within the context of South Africa being a developing country with the concomitant economy, mass education and excellence in higher education will not necessarily always be compatible. A much higher level of funding for universities will be required to reconcile the latter two. Until that happens, universities will have to find a balance between the excellence level at which their academic offerings will be regarded as acceptable and the excellence level which is expected from their programmes.

\section{Function and role of a South African university}

Several questions need to be answered regarding this factor before the issue of mass or selective education can be adequately addressed, for example: 'Should/ could the skills needs of a country be addressed mainly through higher education?' 'Should/could everybody benefit from a university education?' 'What about postgraduate degrees: should everybody have one/two/three? Why? Why not?'

5. Under-preparedness, bridging/foundation programmes

Many potential students can benefit from university programmes only if they receive additional assistance before and/or during their study career. This applies to both under-and postgraduate programmes. Once again, this is a curriculum issue that demands either separate pre-programmes or additional support during the programme, and, once again, it can only be adequately addressed if sufficient funding is available.

6. Mass education and large classes

Mass contact education in the higher education sector initially results in increasing class sizes. Class sizes can only be reduced if additional physical and human resources become available. If this does not happen, different teaching and learning strategies need to be devised and different delivery modes must be implemented. In this process, the aim of higher education must still be served optimally. 
This cluster could be linked with two of Schiro's ideologies (2008) as mentioned at the start of the chapter: selective education can be interpreted as being based on the scholar academic ideology, while mass education can be viewed as underpinned by the social reconstruction ideology.

The numbered factors mentioned above all have a profound influence on the nature and outcome of the debate around mass education in South Africa; in each case further research is required. The last-mentioned factor, in particular, refers to the most appropriate delivery model that would bring education to the masses - bring it to where they live and work. This leads us to the idea of providing education away from the main site of a university, or what could be called 'distance education' or 'offcampus education' in all its variations. This leads to the next cluster.

\section{Cluster 4: Contact and distance education}

At the time of the mergers, the South African national Department of Education indicated that there would be only one distance education university, namely the new University of South Africa, merged with Technikon South Africa and the distance education campus of Vista University (DoE 2002). In spite of this, some of the so-called contact universities in the country involved themselves to some extent with distance education at the time and are still doing so. The drive by the Higher Education Quality Committee (HEQC) to carry out evaluations of selected university programmes through a combination of evidence-based self-evaluation reports and on-site visits, which have resulted in the reaccreditation, conditional accreditation or de-accreditation of such programmes, had a very specific focus on distance delivery as well. The HEQC evaluation requirements for such distance delivery were as stringent as those for contact delivery and this highlighted the need for quality in all modes of programme delivery. The fact that the departmental subsidy formula funds distance programmes at a lower rate than contact programmes, could be interpreted as a confirmation that the government (similar to the universities) viewed distance programmes as requiring a less budget-intensive delivery than contact programmes. Of course, this lower funding also serves as a disincentive for the contact universities to become overly involved with distance delivery.

The previous paragraph might create the impression that the sole or main reason for South African contact universities to be involved with distance delivery is that it provides greater economies of scale. This is, of course, not the case. Participants in this activity will agree that this type of delivery has its own unique challenges and costs and also serves its own noble purposes. 
Several variations of programme delivery can be identified, ranging from full contact, reduced contact, increased self-study, block release, satellite delivery and tutor delivery to technology delivery and e-learning. Each one of these has its own unique demands and impact on the curriculum and quality assurance - timetabling, venues, coordination, tutor/lecturer training, assessment, materials, access to library holdings and the Internet are only some of the factors that need adaptation as the delivery intensity varies. Herselman and Hay (2005:394) state that "today's learners live all over the world and they are reached on remote campuses; in government and business workplaces; and most probably directly in their homes". E-learning is increasingly used by education and training providers for both on- and off-campus learners (Carlner 1999:40).

Related to the issue around contact and distance education is that of part-time master's and doctoral studies. When considering the nature of research studies as undertaken by such students, the matter of distance or off-campus education as compared to contact education becomes rather diffuse. In South Africa, students in these programmes are usually not required to attend frequent contact sessions, either in groups or as individuals. Contact is scheduled according to need and for both monitoring and guiding purposes. If regular seminars or lectures form part of the delivery mode, these are by far less frequent and rigid than at undergraduate and honours level. The student's geographical proximity to the study supervisor is much less of a factor than for lower-level programmes. This mode of delivery could thus be perceived to be closer to the distance education extreme on the continuum than the extreme of full contact delivery. Against the background of under-preparedness and increased access, it might be regarded as necessary to move closer to the contact extreme on the continuum, especially when skills in independent research and self-motivated enquiry are considered. Whichever position a university or faculty decides to take up on this continuum in relation to postgraduate research studies, there are significant curriculum implications resulting from such a decision. Such decisions should be underpinned by sound research, which ought to be contextualised to enhance the chosen delivery model.

Schiro's (2008) idea of the curriculum being underpinned by an ideology (see start of this chapter), could be applied in this cluster as well: the learner-centred ideology and the social reconstruction ideology could both be viewed as relevant to this cluster.

When the concept of distance education is applied in higher education in its most extreme form, it is true that, assisted by technology, a South African university would 
be able to render a service to a student anywhere in the world. In addition, the imperatives of the first cluster, which indicate that the university must provide skilled human resources to the labour market (this not necessarily being local and national only), imply that alumni of the university will take their place in the work force where their skills are required. This notion points to the next cluster of curriculum issues in South African higher education to be highlighted in this chapter, namely that of internationalisation of our higher education sector.

\section{Cluster 5: Internationalisation and localisation}

This cluster deals with the related concepts of internationalisation, localisation and Africanisation in the South African higher education context. For the purpose of this chapter, 'internationalisation' refers to the all the dimensions of the process whereby a university engages with another university situated in another country in order to achieve certain academic, economic, political and cultural aims (Knight 2001). The concept of localisation in this context can thus be viewed as the opposite of internationalisation, namely as involving all the dimensions of the process whereby a university endeavours to retain its local character in order to achieve certain academic, economic, political and cultural aims. An example of localisation is Africanisation - this has been written about extensively in academic literature in recent years, particularly by South African academics. As this issue can be regarded as one of the most important contemporary curriculum debates in the country, it is discussed much more extensively in this chapter than any of the other issues.

The call towards internationalisation and globalisation has become a strong trend in economies and societies worldwide and specifically in Africa. Wa-Thiong'o (2004:2) said that thought should be given "as to how Africa can extricate itself from the seeming quagmire it finds itself in, by taking advantage of the enormous opportunities offered by the Global Village". This trend towards internationalisation and globalisation has also impacted on higher education institutions. Initially this was evident in a small way, for example by hosting conference presenters from abroad and inviting foreign academics for short visits to campuses. The trend has grown to include many other manifestations of internationalisation, such as an increase in the number of agreements and joint projects involving sister institutions across our borders on the continent, as well as across the oceans; also an ever-growing component of registered foreign students and academic staff from other countries on our campuses.

Some of the benefits and purposes of internationalisation are the following: 
- For students: securing a place in the job market; best most up-to-date and relevant training; multiple skills developed and maintained to cope with ever-increasing changes; skills that are transferable across cultures, climates, contexts (NealeShutte and Fourie 2006:119);

- For academics: expanded research and lecturing horizons through international links; generating income;

- For the institution: servicing a diverse student body with different cultures; also servicing students that are geographically situated outside the country's borders (this links with one of the previously-mentioned clusters on distance education);

- Strengthening government links relevant to trade, agriculture, development and the military.

Parallel to the need for internationalisation, the call for Africanising the higher education curriculum in South Africa has emerged very strongly and this can no longer be ignored. Local and foreign African students and academics on campuses have a strong influence on this imperative. The presence of a significant number of foreign African students on South African university campuses in 2003, is evident from the fact that $58 \%$ of all foreign students in the South African higher education sector originated from Botswana, Lesotho and Namibia (Futuse 2004:7), with 72\% of all foreign students coming from the SADC region (Kotecha 2004:11). The need for an African approach to the internationalisation of South African higher education is illustrated in what Kotecha (2004:1 1) refers to as the responsible approach "that aligns the international dimension of the sector to the enhancement of national, regional and continental development imperatives".

Le Roux (2001:35) has identified the "centralisation of a unique South African identity and culture" as one of the challenges for transformation and Africanisation of South African education. This challenge has much to do with the question whether such an identity could indeed be identified at all (Goduka 1999; Makgoba 1998; Mbeki 1998). Several voices have answered in the affirmative, such as those of Fhulu (1999), Le Roux (2001) and Luggya (1999). A strong belief in the existence of this identity is reflected in the statements that the "process for translating the African identity and vision in education is called Africanisation" (Seepe 2004:40) and "the African subject would be allowed to construct his or her own identity" (Williams 2000:74), while it has also been recognised that the notion of a unique South African educational identity "is beset with difficulties" (Viljoen 2005:5). 
Two strains of the current concept of 'Africanisation' developed, namely those of the 'negritude' movement and of the original conceptualisation of 'Africanisation'. The origins of these two strains can be traced back to the Pan-African movement (Urch 1968:4-5). The former flourished among people of African origin living in the United States of America and Europe and placed "African ideals in the centre of any analysis that involves African culture" (Asante 1987:6). Africanisation developed from the negritude movement, focusing on the rights of blacks against the claims of white supremacy (Urch 1968:5). The dominance of Western supremacy in the past and the resistance against it play a major role in the epistemology of Africanisation.

Coetzee (1999:130-131) contends that the concept 'to Africanise' developed during the nineteenth and twentieth centuries from its origins (as set out in the previous paragraph) to becoming connected to political, social and cultural transformation. This development took place in South Africa as well as in some other countries.

Vorster (1995:9) indicates that Africanisation can be synthesised as an appeal, in the first place to Africans and, in the second place, to Europeans and non-Africans. The first appeal relates to Africans upholding African aspirations; descent; cultural heritage; own ideas, rights, interests and ideals; self-concept and own rationality in intercultural context. The second appeal relates to non-Africans to respect and accommodate Africans' efforts to manifest the first.

Ramose (1998:iv) highlights the role of Africans in Africanisation, by describing it as follows:

Africanisation holds that the African experience in its totality is simultaneously the foundation and the source for the construction of all forms of knowledge. On this basis, it maintains that the African experience is by definition non-transferable but nonetheless communicable. Accordingly, it is the African who is and must be the primary and principle communicator of the African experience ... Africanisation is a conscious and deliberate assertion of nothing more or less than the right to be African.

Mngadi (1997:18) sees Africanisation as not being a necessary process for decolonisation. He contends that one of the problems associated with Africanisation is that there exists "a simple binarism: ... an insulated, consensual black Africa versus an equally insulated and consensual white Europe". The viewpoint of Kwesi Kwaa Prah (2004) is exactly the opposite: "One of the most important instruments for sociocultural decolonisation especially within civil bureaucracy, in the African experience, has been the policy of Africanization" (Seepe 2004:99). 
According to Botha (2007:206) the "concept of Africanisation has been dynamic in the past (as indicated above) and it can reasonably be assumed that it is currently still dynamic. This assumption implies that it is likely that the interpretation of the concept has developed further and additional nuances in the past decade in South Africa, mainly as a result of the influence of the abolishment of apartheid. These new nuances need to be explored intensively in further research." Botha (2007:214) identifies in such further exploratory research, a sequenced set of themes, namely the need to:

- recognise the complexity of the issue of Africanising the curriculum and hence identify the key issues of complexity relevant to the specific context in which the curriculum is to be Africanised;

- investigate lessons from the past as identified by information-rich people in the specific context;

- investigate and analyse the dissonance between, on the one hand, regarding the self as being African and, on the other hand, identifying with what is accepted to be African; then determine how this would influence Africanising of the curriculum in the specific context;

- carry out a conceptual analysis of Africanising the curriculum in the specific context;

- investigate the fear of Africanising in the specific context and its possible influence on Africanising the curriculum; then identify appropriate measures to accommodate this fear;

- interrogate the balance between the African and the non-African in the curriculum as it emerged from the data described above;

- interrogate the 'add-on' and the 'integrated' Africanised curriculum; hence identify other models and interrogate these as well;

- use the information and insights flowing from all of the above to create a content and process model for Africanising the curriculum in the specific context.

It is imperative that universities will find a balance between internationalisation and Africanisation: "In order to be competitors in internationalisation, African universities need to establish their own identities and develop their own niche" (Neale-Shutte and Fourie 2006:121) - in other words, if you do not know who you are, you do not have much to offer your international counterpart/partner.

Zeleza (2005) indicates that three levels of mutual exchange are necessary to ensure effective internationalisation, namely through students and staff, through 
institutional policies and collaboration, and through curriculum. This also holds true for Africanisation.

Scott (2008:137) refers to "a distaste for universalising modes of thought and global narratives" as one of the principles of postmodernism. By using this statement as a point of departure for further enquiry into the trends of internationalisation, globalisation and Africanisation in South African higher education, the discourse around this cluster could be further enriched.

The conception of curriculum as the totality of learning experiences as presented by Marsh (2004), as well as the curriculum as planned experiences, including all experiences students have to go through, curricular as well as extra-curricular (Posner 2004), could be viewed as relevant to this cluster.

Michel Foucault's view of knowledge being relative, with power having a strong relationship to knowledge, relates to this cluster. He contends that "the expression of any universal truth, in a curriculum for example, takes a particular form which is historically specific, and it is the determination of these forms that is of concern to curriculum theorists" (Scott 2008:54). He also argues that it is important to "take into account the underlying but changing social and political assumptions" (Marsh 2004:225). Further research on this relationship would greatly enrich the discourse on Africanisation.

While the virtual borders of countries are becoming increasingly penetrable due to technology, globalisation and internationalisation, a similar trend is developing within universities, namely the diffusion of disciplinary boundaries, but for different reasons.

\section{Cluster 6: Diffusion of disciplinary boundaries}

This cluster of curriculum-related issues deals with the matter of an ever-growing blurring of disciplinary boundaries. This blurring or diffusion, which occurs both incidentally and intentionally, has been induced by at least three developments. Two of these developments emanated from the South African national Department of Education, namely the notion of academic programmes and the creation of comprehensive universities. The third development arose from societal and labour market needs in South Africa that called for a shift from strict disciplinary boundaries to working in a more cross-disciplinary way. Soehnge (2004:105) recommends, amongst others, that academics should reflect critically on questions such as whether curriculum discourses function only within disciplinary boundaries or outside these boundaries as well. 
The notion of 'programmes' instead of 'courses' was advocated by the National Council for Higher Education (NCHE), including in its definition that a programme should be "a coherent, planned and integrated sequence of learning activities" and that it is "almost invariably trans-, inter- or multi-disciplinary" (1996:84). It was not as though this would necessarily lead to entirely different offerings at universities, but it required a new way of thinking about the formal learning experiences available to students. Many of the then existing curricula complied with the idea of a programme, especially at undergraduate level where a much lower degree of specialisation is usually required than at postgraduate level.

The establishment of comprehensive universities as a result of the implementation of the national plan for higher education (DoE 2001; 2002), required a rethink of the curricula of these institutions. This has been highlighted before in this chapter in the clusters on vocational and liberal education, as well as in the cluster dealing with progression from certificate to diploma to degree.

While universities in South Africa were getting used to the new terminology and ways of doing, as relevant to programmes and modules, another imperative was emerging from a different source. The need for interdisciplinary knowledge, competences, experiences, insights and applications grew from the new types of challenges that developed in the economic, political and social spheres of South African life - the needs of the 'real' world. Appropriately qualified people who were equipped to address these challenges became much sought-after and universities had to rise to the challenge to produce such graduands.

To illustrate the above idea, an example would be a BA curriculum that includes languages, history, geography and mathematics. Where such a curriculum would previously rather be aimed at developing several dimensions of the human being, the new mindset would require that it be aimed outwardly at addressing some of the needs of society - in this case perhaps to gain the competences, skills and knowledge required of a tour guide. Another example would be a BA with psychology, sociology, languages and some health science modules, that could be a preferred curriculum for someone who will work in HIV or AIDS counselling. Where previously a BSc in marine biology would secure a position in the labour market in exactly that, it is likely that today a similar position would require not only the marine biology knowledge, but also some economic, legal, psychology and social knowledge. This curriculum will straddle a number of disciplinary boundaries to optimally service the societal needs. 
Muller's (2008:35) report on the curriculum of the comprehensive university indicates some dangers in diffusing disciplinary boundaries, namely muddying the mission; identity confusion among students and employers; over-inclusion of programmes across the spectrum; lack of intellectual and social cohesion; difficulty in managing such a curriculum; emerging of differential criteria, standards and procedures; and the forming of sub-institutional silos that will undermine unity in the institution.

This cluster on diffusion of disciplinary boundaries relates well to the notions of a curriculum as consisting of subjects that accommodate the changing state of knowledge, subjects that are most useful for living in contemporary society (Marsh 2004), based on the ideology of social efficiency (Posner 2004), as well as Scott's (2008) idea that the current episode in the history of the curriculum reflects effectiveness or improvement.

The diffusion of disciplinary boundaries in the South African curriculum discourse is typical of postmodernism (Naudé and Cloete 2003:211) and is strongly related to the idea of "holistic inquiry" in postmodernism (Marsh 2004:229-230). Further research on these relationships will provide useful information towards the discourse and practice related to this curriculum cluster.

\section{SUMMARY AND CONCLUSION}

The previous sections broadly sketched some of the complexities that relate to the higher education curriculum in South Africa. Six interrelated clusters of curriculum issues were briefly outlined, namely that of vocational and liberal education, progression from certificate to diploma to degree, mass education compared to selective education, contact and distance education, internationalisation and localisation, and the diffusion between disciplinary borders.

The dialectic tensions that emerge from each of the clusters very strongly presents the post-modernist approach that enters into dialogue about what seems to be illogical, contradictory, domineering, of concern and uncertain in the traditional context. Another identifiable trend within the clusters is the movement away from what Bernstein (1975:103-106) called the collection code type of curriculum towards the integrated code type. Typical of this is the diffusion between disciplinary borders, the wider choice of curricula on offer to students, the wide variety of assessment modes employed (such as portfolios, presentations and research projects) and academics working as teams rather than individuals. When considering the curriculum in South African higher education, for whatever purpose, the strong enmeshment of many of the curriculum issue clusters referred to in this chapter, cannot be ignored. The intertwinedness of 
each cluster with one or more of the others increases the complexity of this dimension of South African higher education and highlights the circumspection with which it must be approached. Reference is also made to this enmeshment by Chritiansen and Baijnath (2007:223) when they indicate that the need for diversity in the curricula of universities of technology, comprehensive universities and other universities (cluster 1 above), might imply Africanisation of higher education (cluster 5 above) and narrowing of the distinction between disciplines (cluster 6 above), because, in the South African context, the latter two are likely to result from reflections on knowledge production and distribution, as well as on their politics, history and sociology.

Some aspects of the enmeshment of the clusters of curriculum issues referred to above are illustrated in Figure 8.1. The figure shows, for example, that mergers and academic drift are dimensions of four of the six clusters (vocational/liberal, certificate $\rightarrow$ diploma $\rightarrow$ degree, contact/distance and diffusion of disciplinary boundaries). This illustrates the enmeshment of these four clusters in these areas. When the higher education curriculum is revised after a merger or with the purpose of addressing academic drift, it is likely that there will be implications in all four of these clusters that need to be considered to facilitate successful recurriculation. Another example presented in the figure is that of human resources as an area of enmeshment of all the clusters, thus illustrating that all curriculum planning or revision will impact on human resources.

It is evident that the figure is not a definitive representation of the realities of all higher education institutions: when reconsidering its curriculum, an institution might want to adapt the figure by adding or omitting some of the areas of enmeshment, by rethinking which of the clusters are relevant to its own circumstances, by identifying whether and how each cluster is enmeshed with other clusters, or even find other ways of representing its own situation. In all cases, an adapted figure could then become a useful tool to guide curriculum planning and revision in such institutions. 


\begin{tabular}{|c|c|c|c|c|c|c|}
\hline $\begin{array}{c}\text { CLUSTERS } \\
\text { AREAS OF } \\
\text { ENMESHMENT }\end{array}$ & $\begin{array}{l}\text { Vocational/ } \\
\text { Liberal }\end{array}$ & $\begin{array}{l}\text { Certificate } \\
\text { Diploma } \\
\text { Degree }\end{array}$ & $\begin{array}{l}\text { Mass/ } \\
\text { Select }\end{array}$ & $\begin{array}{l}\text { Contact/ } \\
\text { Distance }\end{array}$ & $\begin{array}{l}\text { Internat/ } \\
\text { Local }\end{array}$ & $\begin{array}{l}\text { Diffusion of } \\
\text { disciplinary } \\
\text { boundaries }\end{array}$ \\
\hline Mergers & $x$ & $x$ & & $x$ & & $x$ \\
\hline Academic drift & $x$ & $x$ & & & & $x$ \\
\hline $\begin{array}{l}\text { University types } \\
\text { (technology, } \\
\text { comprehensive, } \\
\text { distance, other) }\end{array}$ & $x$ & $x$ & & $x$ & & $x$ \\
\hline Professions & $x$ & $x$ & & & $x$ & $x$ \\
\hline $\begin{array}{l}\text { Professional advisory } \\
\text { boards }\end{array}$ & $x$ & & & & & \\
\hline Industry & $x$ & & & & & $x$ \\
\hline Human resources & $x$ & $x$ & $x$ & $x$ & $x$ & $x$ \\
\hline Labour market & $x$ & & & & $x$ & $x$ \\
\hline Economy & $x$ & & & & $x$ & \\
\hline Skills shortage & $x$ & $x$ & & & $x$ & $x$ \\
\hline Work-based learning & $x$ & $x$ & & & $x$ & $x$ \\
\hline RPL & & $x$ & $x$ & & $x$ & \\
\hline Life-long learning & & $x$ & & $x$ & $x$ & \\
\hline Access & & $X$ & $X$ & $x$ & $x$ & \\
\hline Free higher education & & & $x$ & & & \\
\hline Under-preparedness & & & $x$ & $x$ & & \\
\hline $\begin{array}{l}\text { Bridging/foundation } \\
\text { programmes }\end{array}$ & & & $x$ & & & \\
\hline Large classes & & & $x$ & & & \\
\hline Delivery models & & & $x$ & $x$ & $x$ & \\
\hline E-learning & & & & $x$ & $x$ & \\
\hline Technology & & & & $x$ & $x$ & \\
\hline $\begin{array}{l}\text { Master's and doctoral } \\
\text { students }\end{array}$ & & & & $x$ & $x$ & $x$ \\
\hline Africanisation & & & & & $x$ & $x$ \\
\hline Localisation & $x$ & & & & & $x$ \\
\hline Globalisation & & & & $x$ & $x$ & $x$ \\
\hline $\begin{array}{l}\text { Cross-disciplinary } \\
\text { Inter-disciplinary } \\
\text { Knowledge }\end{array}$ & & & & & & $\begin{array}{l}x \\
x\end{array}$ \\
\hline 'Real' world & $x$ & & & $x$ & & $x$ \\
\hline Engaged institution & $x$ & & & & $x$ & $x$ \\
\hline Programmes & & $x$ & & & & $x$ \\
\hline
\end{tabular}

FIGURE 8.1 Enmeshment of curriculum issue clusters 
Breier (2001:ix) states that the "restructuring of higher education curricula was not a priority in the flurry of education proposals that accompanied the historic political transformation of South Africa". This situation has gradually changed and debates on this matter have emerged. At the start of a new chapter in South African democracy, the time is here to deal with higher education curriculum restructuring. Le Grange (2006:193) reiterates: "Curriculum is a neglected area in discourses on higher education." He advocates that higher education curriculators need to consider the curriculum implications of all debates and activities in this arena. This chapter could serve as a point of departure for the scholarly review of the South African higher education curriculum, with the purpose of stimulating further questions and debate for higher education researchers, as well as developing guidelines for dealing with the challenges associated with each curriculum cluster.

\section{REFERENCES}

Asante MK. 1987. The Afrocentric idea. Philadelphia: Temple University.

Beck J \& Young M. 2005. The assault on the professions and the restructuring of academic and professional identities: A Bernsteinian analysis. British Journal of Sociology of Education, 26(2):183-197.

Bernstein B. 1975. Class, codes and control volume 3: Towards a theory of educational transmissions. London: Routledge \& Kegan Paul.

Bernstein B. 1996. Pedagogy, symbolic control and identity. London: Taylor \& Francis.

Bernstein B. 2000. Pedagogy, symbolic control and identity. New York: Rowman \& Littlefield.

Blunt RJS. 2005. Challenges for the curriculum of a comprehensive university: A critical case study. South African Journal of Higher Education, 19(6):1021-1032.

Botha MM. 2007. Africanising the curriculum: An exploratory study. South African Journal of Higher Education, 21 (2):202-216.

Breier M (ed). 2001 . Curriculum restructuring in higher education in post-apartheid South Africa. Belville: EPU, University of the Western Cape.

Carlner S. 1999. On-line learning. HRD Press.

Christiansen IM \& Baijnath N. 2007. Perceptions of the 'university of technology' notion at higher education institutions. South African Journal of Higher Education, 21 (2):21 7-227.

Coetzee SA. 1999. 'n Blik op die Afrikanisering van universiteite. [Africanising of universities a brief overview]. South African Journal of Education, 19(2):130-139.

DoE (Department of Education). 1999. Higher education institutional plans: An overview of the first planning phase 1999/2001. Pretoria: Government Printer.

DoE (Department of Education). 2001. The restructuring of the higher education system in South Africa. Pretoria: Government Printer. 
DoE (Department of Education). 2002. Transformation and restructuring: A new institutional landscape for higher education. General Notice 855 of 2002. Pretoria: Government Printer.

DoE (Department of Education). 2006. Education statistics in South Africa. Pretoria: Department of Education.

DoE (Department of Education). 2007a. The higher education qualifications framework. Government Gazette, No. 30353. 5 October. Pretoria: Government Printer.

DoE (Department of Education). 2007b. The national policy framework for teacher education and development in South Africa. Government Gazette, No. 29832. 26 April. Pretoria: Government Printer.

Fhulu N. 1999. Education transformation and the African Renaissance. Paper presented at a conference of the Southern African Society for Education. October.

Futuse B. 2004. SA varsities cash in on foreign students. Sunday Times Business Times, 29 August 2004:7.

Goduka IN. 1999. Indigenous epistemologies - ways of knowing: Affirming a legacy. South African Journal of Higher Education, 13(3):26-35.

Herselman ME \& Hay HR. 2005. An investigation into e-learning practices: Implications for providers of education and training. South African Journal of Higher Education, 19(2):393-410.

Jansen JD. 2004. How mergers shape the institutional curriculum. South African Journal of Higher Education, 18(1):5-18.

Knight J. 2001. Monitoring the quality and progress of internationalization. Journal of Studies in International Education, 5(3):228-243.

Kotecha P. 2004. Determining a sectoral approach to internationalisation. IZWI: Voice of HE leadership, $3^{\text {rd }}$ quarter, 3:11.

Le Grange L. 2006. Curriculum: A neglected area in discourses on higher education. South African Journal of Higher Education, 20(2):189-194.

Le Roux A. 2001. African Renaissance: A quest for the transformation and africanisation of South African education. South African Journal of Education, 21 (1):31-36.

Lovatt TJ \& Smith DL. 2003. Curriculum: Action on reflection. Tuggerah: Social Science Press.

Lubisi RC. 2008. The quest for free education in South Africa: how close is the dream to reality? Solomon Mahlangu Education Lecture, Constitution Hill, Johannesburg, 17 June 2008. Johannesburg: Centre of Education Policy Development.

Luggya D. 1999. Multicultural education: An approach to equality in education in South Africa. Paper presented at a conference of the Southern African Society for Education, October 1999.

Makgoba MW. 1998. South African universities in transformation: An opportunity to Africanise education. In: S Seepe (ed). Black perspectives in tertiary institutional transformation. Johannesburg: Vivlia.

Marsh CJ. 2004. Key concepts for understanding curriculum. London: RoutledgeFalmer. 
Mbeki T. 1998. Statement by Deputy President Mbeki at the African Renaissance conference. Johannesburg. 28 September.

Mngadi S. 1997. Africanisation or the new exoticism [Online]. Available: http://www.unisa. ac.za/default.asp.

Muller J. 2008. In search of coherence: A conceptual guide to curriculum planning for comprehensive universities. Report prepared for the SANTED project. Cape Town: CEPD.

NCHE (National Commission on Higher Education). 1996. A framework for transformation. Pretoria: NCHE.

Naudé P \& Cloete N. 2003. A tale of three countries: Social sciences curriculum transformations in South Africa. Lansdowne: Juta.

Neale-Shutte M \& Fourie J. 2006. Challenges to internationalization in African higher education. South African Journal of Higher Education, 20(1):118-142.

Posner GJ. 2004. Analyzing the curriculum. Boston: McGrawHill.

Ramose MB. 1998. Foreword. In: S Seepe (ed). Black perspectives in tertiary institutional transformation. Johannesburg: Vivlia.

RSA (Republic of South Africa). 1997. Higher Education Act. Government Gazette, Vol. 390 No. 18515. 19 December. Pretoria: Government Printer.

RSA (Republic of South Africa). 2008. Higher Education Amendment Act. Government Gazette, Vol. 521 No. 31651. 27 November. Pretoria: Government Printer.

SAQA. 1997. SAQA bulletin, May/June 1997, 1(1):2-3.

Sawyerr A. 2002. Challenges facing African universities [Online]. Available: www.aau.org [2009, 13 April].

Schiro MS. 2008. Curriculum theory: Conflicting visions and enduring concerns. Los Angeles: Sage.

Scott D. 2008. Critical essays on major curriculum theorists. London: Routledge.

Seepe S (ed). 2004. Towards an African identity of higher education. Pretoria: Vista University and Skotaville Media.

Soehnge WF. 2004. Universitas of diversitas? - Enkele gedagtes oor postmoderne kurrikulêre implikasies vir die universiteit. South African Journal of Higher Education, 18(2):97-108.

Swartz D. 2008. New pathways to sustainability: African universities in search of meaning in a globalizing world. Conference proceedings: Universities in Southern Africa as catalysts for sustainable rural development. Centre for Education Policy Development, Johannesburg, 6-7 March 2008.

Urch GEF.1968. The Africanisation of the curriculum in Kenia. East Lansing: University of Michigan.

Viljoen CT. 2005. The quest for educational identity in South Africa. Paper presented at a conference of SAARDHE, Durban. 27-29 June.

Vorster PJ. 1995. Africanisation: An explanation and some educational implications. South African Journal of Education, 15(1):6-12. 
Wa Thiong'o JK. 2004. African higher education and internationalisation of higher education: The need for a new paradigm. Paper presented at an internationalisation colloquium, University of Port Elizabeth. 26-27 August.

Williams JJ. 2000. Transformation: Challenges for South Africa. Critical Arts Journal, 14(1):73-96.

Zeleza PT. 2005. Transnational education and African universities. In: Cross border provision and the future of higher education in Africa: papers and program. $11^{\text {th }}$ AAU conference, Cape Town, South Africa. Association of African Universities in collaboration with the University of Cape Town. 21-25 February. 


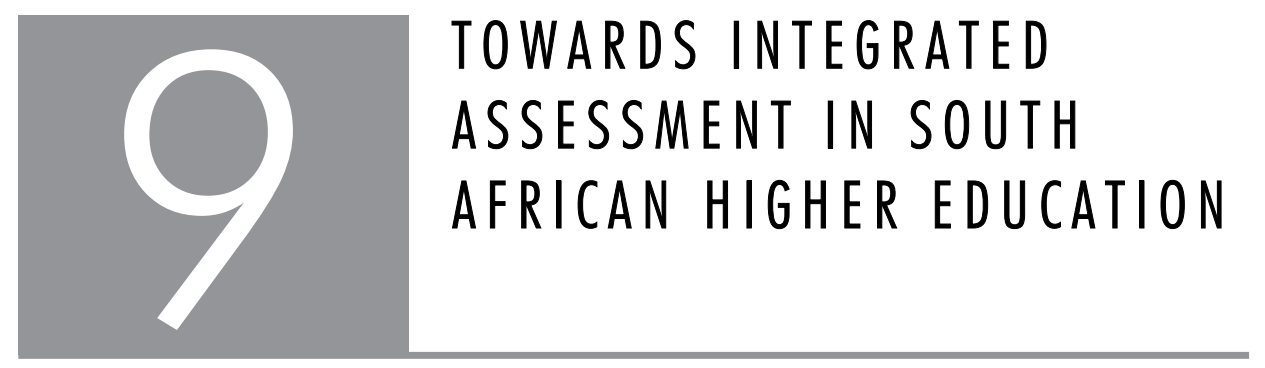

Peter Beets

\begin{abstract}
Assessment defines what students regard as important, how they spend their time, and how they come to see themselves as students and then as graduates. It follows, then, that it is not the curriculum which shapes assessment, but assessment which shapes the curriculum and embodies the purposes of higher education.
\end{abstract}

(Brown and Knight 1994:12)

\title{
ABSTRACT
}

Higher education institutions are increasingly challenged to address pressing societal needs. This has led to changes in the nature of knowledge production and the competencies students are required to develop through teaching programmes. One area in which this change is evident is in a shift from Mode 1 knowledge that refers to pure, disciplinary, homogeneous, expert-led university-based knowledge to Mode 2 knowledge characterised as applied, problem-solving, transdisciplinary, heterogeneous and network-embedded. Consequently many teaching programmes now tend to focus not only on the knowledge (foundational) component, but also on the skills (practical) and application (reflexive) components of learning. All these components are necessary to support students to not only acquire memorised factual knowledge, but also to integrate their acquired competencies in different contexts so as to fulfil roles in the world beyond higher education.

Assessment that serves as a catalyst for both teaching and learning can play a role in guiding and supporting the processes aimed at the attainment of applied competence. The response of the South African government to this challenge in higher education is to use assessment formatively and summatively in attaining applied competence. This chapter attempts to contextualise the tensions between the current assessment practices 
in higher education and what policies propose. It is argued that simply embracing these policies is problematic because the priorities of higher education and the state vary due to the different constituencies they serve and their concomitant priorities and imperatives. From an analysis of current higher education assessment practices, ways of mediating this divide are suggested, also serving as pointers for further research in this area.

\section{INTRODUCTION}

Assessment is probably the one function of higher education that produces the most apprehension amongst students and frustration amongst academics. Equally, assessment of student learning seems to be an important theme that has traditionally been under-researched in higher education. As the assessment movement has grown significantly in the last two decades, the term 'assessment' has acquired different meanings in varying contexts. Heywood (2000:9) highlights two broad trends: "On the one hand, it has been applied to the assessment of student learning, while on the other hand it has been applied to the assessment of institutions, programmes and teaching." It is precisely these diverse meanings and the many debates about issues of standards, reliability and quality assurance demands (Bryan and Clegg 2006) more particular in higher education, that make it a value-laden activity. Added to these is the concern about how well assessment supports teaching and learning in the process of preparing students for employment. Boud and Falchikov (2007) argue that "assessment should be seen as an act of informing judgement and proposes a way of integrating teaching, learning and assessment to prepare students better for a lifetime of learning".

Assessment is inextricably intertwined with both learning and teaching, because the evidence gained through a variety of assessment methods may on the one hand produce supportive learning structures for each student and, on the other hand, enhance the quality of teaching to serve the needs of individual students. While recognising the fact that students bring with them different socio-cultural capital to the education situation, the assumption is that all of them are somehow in the process of attaining the required competence as formulated in the learning outcomes. Through assessment process(es) that produce quality information about the student's progress, insight for both student and lecturer about the gap between what the [student] can achieve without help and what may be achieved with suitable help, may be obtained. From a teaching perspective, the assessment information should inform the feedback to the student as well as the scaffolding (Wood, Bruner and Ross 1976) along the zone of proximal development (Vygotsky 1986). From a learning perspective, quality 
feedback will indicate both strengths and weaknesses that students experience in the learning process. As part of feedback, feed-forward will indicate the next steps to be taken by both the lecturer and the student as they work towards realising their full potential in the context of each one's core business.

Students generally dislike the assessment component of their education, mainly because they experience it as something that is done to them and not something that is done with and for them. The teaching and learning mode in higher education institutions still tends to be largely lecturer-driven rather than student-driven. While research indicates the potential of formative assessment to raise standards (Black, Harrison, Lee, Marshall and Wiliam 2003) and while learning-enhancing forms of assessment such as portfolios, peer assessment, self-assessment and authentic assessment are increasingly introduced, assessment for learning is not commonplace in higher education and may even encounter resistance (Kvale 2007:57). Summative assessment and related pedagogies remain, however, the dominant practice. According to Barnett (2007:38) it is not surprising that these practices happen on a regular basis, because "summative assessment has the power to control, to classify students arbitrarily, to limit their educational development and to impair their own sense for themselves". Many lecturers who operate in such a mode would regard assessment that assesses competencies other than only knowledge as an extra responsibility that takes up too much time that could have otherwise have been spent more effectively on teaching. Furthermore, the ongoing debates around issues of fairness, reliability, validity and appropriateness do not make engagement with new forms of assessment an interesting consideration. Consequently assessment often elicits strong opinions from all concerned.

The understanding of how knowledge is produced has undergone significant change over time, from knowledge embedded in disciplines to knowledge that is produced in collaboration with and in the service of the world beyond higher education. However, to portray these types of knowledge as a dichotomy is problematic, as they are interdependent. This change in the way knowledge is produced was necessary, because the nature and the needs of the world have changed. In response to this, higher education institutions have, on the one hand, diversified their mission statement(s) so as to make them more socially relevant. On the other hand, the search for more appropriate knowledge that is much more informed by practical realities, has led to the slow, but increasing fragmentation of disciplinary knowledge. As higher education grapples with these epistemological shifts, governments have responded through policy making by, for example, introducing assessment systems that do not only address 
imperatives such as performance ability and accountability, but also systemic issues of alignment between learning outcomes/competence and assessment methods.

Consequently, teaching programmes are expected to focus not only on the knowledge (foundational) component, but also on the skills (practical) and application (reflexive) components of learning. All these components are necessary to ensure that students do not only have memorised disciplinary knowledge, but that they have also acquired the skills to construct that as well as other related knowledge and also have the ability to use the knowledge and skills in familiar and unfamiliar situations when the need arises. In order to fulfil their eventual roles in the world beyond higher education, students are expected to integrate their acquired competencies and use them effectively to the benefit of themselves, others and the natural environment. Assessment should therefore support the process of determining the ability of students to demonstrate satisfactory competence in the above-mentioned domains as well as to integrate it appropriately in the relevant contexts. the South African Qualifications Authority (SAQA) (2005:4) defines this type of assessment, called integrated assessment, as "a form of assessment which permits the learner to demonstrate applied competence and which uses a range of formative and summative assessment methods".

I suggest in this chapter that the nature of the learning outcomes on which teaching programmes are based influences the pedagogical points of departure of academics, as well as how and what students learn in higher education institutions. However, while recognising the epistemological and pedagogical priorities valued by higher education institutions, bureaucratic institutions like SAQA respond through policymaking to national educational priorities and imperatives. One such policy is that of integrated assessment as an assessment model to assess the acquired competence of students. An attempt is made to contextualise the tension between current assessment practices in higher education and what is proposed in terms of integrated assessment as described in national policies in South Africa. I argue that it is problematic to embrace these policies, because the priorities of higher education and the state differ. However, despite these differences, a number of critical areas of concern are highlighted in an effort to explore ways in which it may be possible to implement integrated assessment.

\section{THE CHANGING HIGHER EDUCATION LANDSCAPE}

Curriculum transformation in South Africa, especially since 1994, brought with it not only the challenge of changing educational pedagogies and perceptions, but also 
the expectation of a more just education landscape. It also necessitated continual initiatives for ensuring critical engagement with the realities of higher education in order to enhance quality and appropriateness. Despite the national quality assurance processes of organisations such as SAQA and the Higher Education Quality Committee $(H E Q C)$, aimed at infusing and strengthening the Higher Education Qualifications Framework (HEQF) in higher education and "newly" negotiated norms and standards respectively, the sector remains in a state of flux, as more pressures at a global level place even greater demands on it than ever before.

Traditionally, higher education institutions, including South African universities, have been regarded as the sole agencies of knowledge production. Consequently, these institutions have become enclaves (Le Grange 2006:369) - remaining to a large extent removed from the knowledge society in which they operate and which they serve. In response to modern-day societal and environmental challenges, this situation is rapidly changing. New economic imperatives, for example, permeate all spheres of society and put the demand for a highly educated workforce squarely on the agenda of higher education institutions as they are expected to provide graduates that have the key competencies that will enhance their employability and contribution to society and the environment. In a sense, these new pressures and demands forced higher education institutions to rethink their perception(s) of what their purpose(s) should be. According to Knight and Yorke (2003:vii) this "human capital approach gives higher education an instrumental twist which many academics find discomforting".

\section{FROM KNOWLEDGE TO APPLICATION}

Where this human capital approach may be regarded as a contemporary trend in research-oriented universities in South Africa, the focus on preparing graduates for specific areas of the job market has been a more integral and prominent part of the mission and vision of other institutions in higher education, namely universities of technology and to a lesser extent comprehensive universities. Universities of technology offer mainly practice-oriented qualifications in fields with a dedicated alignment with employment realities and demands. Comprehensive universities on their part offer a combination of this, as well as the more theory-oriented qualifications of researchdirected universities.

The following mission statements, first of a university of technology and then of a research-oriented university in the same province in South Africa, help to illustrate this 'difference' in what they regard as their core business: 
- Our mission is to develop and sustain an empowering environment where, through teaching, learning, research and scholarship our students and staff, in partnership with the community and industry, are able to create and apply knowledge that contributes to development. (http://www.cput.ac.za/institution/mission.php., 2009/03/22)

- The raison d'être ... is to create and sustain, in commitment to the academic ideal of excellent scholarly and scientific practice, an environment within which knowledge can be discovered, can be shared, and can be applied to the benefit of the community. (http://www.studysa.co.za/contentpage.aspx?pageid=4175, 2009/03/22)

On the one hand these mission statements confirm the primary task of knowledge production and transmission. On the other hand they reveal the differing contexts in which and for which this knowledge is produced. Universities of technology operate primarily in partnership with the community and industry to produce knowledge and human resources that will contribute to development in those sectors. Academic universities embed their knowledge production in the domains of scholarly and scientific practice with a central focus of discovering new knowledge and sharing or selling it where applicable and appropriate. This is manifested in the 'products' that are produced. Apart from contributing to human development through the academic and professional programmes, universities also produce research outputs in, for example, academic peer reviewed articles and books as well as inventions which are patented for use by society. Although these institutions represent so-called extreme positions along the higher education continuum, it is clear that there is a "shift away from the traditional liberal formulation of universities as a 'house of knowledge' - detached from the larger society ... towards a conception of universities in the service of the market" (Kraak 2000:iii). Drawing on the work of Gibbons and his colleagues (1994), this shift represents a change from Mode 1 knowledge that refers to pure, disciplinary, homogeneous, expert-led university-based knowledge to Mode 2 knowledge that refers to applied, problem-solving, transdisciplinary, heterogeneous, network-embedded knowledge. However, this shift implies that there is a need, not only for adaptations in terms of programme design, but especially for assessment as it is integral to both the instruction and learning processes.

The stance of the HEQC, whose primary function it is to promote quality assurance standards and systems in South Africa, is that higher education institutions should not only focus on classic "teaching-learning and research", but also on "community service" (Berger 2005:181). This shift to a greater responsiveness to the country's developmental needs has become characteristic of the research, teaching and community involvement programmes of most university faculties. Examples of this are 
the teaching and research programmes of faculties of engineering that are to a large extent geared towards providing the necessary human resources and knowledge to address related needs and challenges in the world of work and in society in general. This gradual shift is, however, not uncontested, because there are a number of complications, as alluded to by Botha (2000:7): "Should a university simply try to meet the (idealised) needs of its customers or should it pro-actively anticipate and even create those needs? Are students, as service users, in a position to specify exactly what they need? Are academics acting in isolation in a position to determine and create the requirements and needs of all these different groups and stakeholders?" Likewise, it can also be questioned whether the way in which students are assessed at South African higher education institutions reflect the shift from focusing mainly on the acquisition and reproduction of knowledge to one where the focus is on the integration of knowledge and skills for application in familiar and unfamiliar environments.

\section{CURRENT TEACHING, LEARNING AND ASSESSMENT REALITIES IN HIGHER EDUCATION}

Emanating from contemporary theoretical insights about teaching, learning and assessment (Boud and Falchikov 2007; Gibbs 2006; Gardner 2006; Gipps 2002) as well as the technological changes that are taking place in modern societies, education is compelled to become more learner-centred and competence-based. This emphasis represents a move away from the lecturer to the student who needs to be prepared to take up his/her place not only as a future competent professional, but also as a life-long and self-regulating learner. In respect of the creation of opportunities for addressing the needs of students, Baartman et al. (2007:144) identify two necessary areas of change in education: (1) "changing its focus from one of transmitting isolated knowledge and skills to one of acquiring complex competences," and (2) "guiding learners in developing skills for learning and getting information from the diverse range of sources available in modern society".

In South Africa, the promulgation of the South African Qualifications Act, 1995 (Act 58 of 1995) and the implementation of outcomes-based education and training are two policy initiatives that were designed to promote the above-mentioned areas of change. These policies challenged the traditional roles of academic teachers (Olivier 1999:v), who focused mainly on discipline-specific knowledge transmission, rather than on supporting the development of vital competencies that straddle the divides of theory and practice. In a study on an appropriate assessment model for higher education, specifically health sciences and technology, Friedrich-Nel, De Jager and $\mathrm{Nel}$ (2005:881-883) investigated current educational practices that are characteristic 
of higher education. They concluded that for most of the $20^{\text {th }}$ century, teaching in higher education was geared to exposing students to masses of facts up to the point where the facts became unmanageable. They concurred with Olivier (1999:69) that written examinations, traditionally associated with content-based education and training, remain the dominant form of assessment used in higher education in South Africa. Despite well-documented changes in educational theory from behaviourist to constructivist teaching and learning approaches (James 2006; Dann 2002), as well as the well-publicised shifts in assessment policy and practices in other education sectors in South Africa (Dreyer 2008; Maree and Fraser 2004; DoE 1998, 2005), embracing and implementing alternative assessment methodologies in the higher-education sector seem to remain limited and employed with trepidation (Kilfoil, in Dreyer 2008). Policies (structures) regarding the new emphasis on assessing applied competence and the principles underpinning outcomes-based assessment, as referred to earlier, are in place, but the translation of these policies into practice (agency) at all higher education institutions tend to remain similar to what has been the traditional practice.

Most higher education institutions tend to assess mainly propositional rather than procedural knowledge using a narrow range of assessment methods - mainly examinations or the longer coursework essays. What is therefore primarily assessed in universities is [students'] grasp of subject matter (Edwards and Knight 1995:11). Another tendency which seem to contribute significantly to the nature of assessment in many higher education institutions is the misalignment between course/module outcomes, the actual learning experiences, content and the assessment methods. Although courses/modules may be designed to promote knowledge and understanding of a topic in a disciplinary area, as well as related skills and application in known and unknown environments, the assessment methods used may only be able to assess, with an acceptable measure of validity and reliability, the disciplinary outcomes. The emphasis therefore remains on assessing mainly the foundational competence of the student and not really practical and reflexive competencies through assessment that creates opportunities for students to demonstrate competencies in all the previously mentioned spheres.

According to Leinster (2002:13), who researched medical education in England, the use of primarily traditional assessment methods of examinations and tests "encouraged a superficial learning style that promoted short-term recall but little understanding of the subject". The students understood learning to mean memorisation and rote learning even though the lecturers may have had other expectations. The most important skill that students acquired in situations like these is recall of factual knowledge which mostly 
led to a surface knowledge and understanding of the discipline, instead of crucial skills that are needed to enable students to apply their knowledge and understanding to deal with the challenges they might face in the world of work and beyond. Leinster (2002:14-15) argues that to develop competence in medical education, for example, apart from the required knowledge, emphasis is also needed in skills like clinical and communication skills, the ability to assimilate, evaluate and use information, while internalising and displaying attitudes that will sustain constructive interaction with all stakeholders including patients, as well as the ability to adhere to the ethical basis of health care. If these aspects are not all addressed through integrated learning, medical students would not develop the necessary competence to deal with expectations and challenges that the profession will produce.

Research by Baartman et al. (2007) indicates that learning is significantly influenced by the nature of the assessment - students tend to focus their learning on what they know/think will be assessed. If higher education institutions are therefore serious about fulfilling their mission statement of contributing to society through providing the needed intellectual and human capital, then assessment practices should be constructively aligned with instruction and learning (Biggs 1996). However, Eraut (2004:804) warns that "treating [required competences] as separate bundles of knowledge and skills for assessment purposes, fails to recognise that complex professional actions require more than several different areas of knowledge and skills. They all have to be integrated together in larger, more complex chunks of behaviour." In the following section, I will unpack competence assessment and show how it manifests in national policy.

\section{COMPETENCE-BASED ASSESSMENT}

Competence-based assessment first emerged with the promulgation of competence legislation for teacher certification in the United States in the 1970s and 1980s (Fraser, Killen and Nieman 2005:247). Later, competency-based assessment was introduced in the United Kingdom in vocational training (Thilakaratne and Kvan 2006:315). Before turning to describe how, in the South African context, competence-based assessment is given priority as the form of assessment for addressing the problems already identified, I shall start by describing how competence is defined in the literature. This is important, because the way competence is understood may influence the assessment process which is or ought to be closely related to the learning outcomes (Lizzio and Wilson 2004).

Baartman et al. (2007:115-116) indicate that two aspects seem to be common in most definitions of competence. Firstly, competence is defined in terms of the 
integration or performance of specific combinations of knowledge, skills and attitudes that will provide evidence of the required capability. Secondly, it is defined in terms of requirements linked to a specific profession or job situation. For these researchers the definition by Eraut et al. (1998, quoted in Baartman et al. 2007:116) captures both of these aspects when they describe competence as "competent professional behaviour within a range of relevant job situations and the knowledge, skills and attitudes it requires". What also emerges in literature is that in defining competence some scholars attach more emphasis and importance to Mode 1 knowledge, while others prioritise Mode 2 knowledge (explained earlier in the chapter). In attempting to explain this trend, Thilakaratne and Kvan (2006:318-319) suggest that the world of work is more interested in performance, while actual knowledge is valued more in academe (see earlier discussion).

According to SAQA (2000:16) the word 'competence' in an outcomes-based education system, as is in place in South Africa, is too narrow, because not enough emphasis is placed on "understanding or the moral issues surrounding the action". SAQA ascribes the scepticism and non-acceptance of the notion of assessment based on 'competence' to its behaviourist underpinnings and the fact that critical thought about action or performance in a particular context is too limited. There was, however, further development in and acceptance of the idea of assessing competence. Fraser et al. (2005:247), quoting Eltis (1997:130), describe these developments as follows:

The traditional approach has been developed to become a 'new' more holistic or integrated - approach that involves assessing a combination of attributes (knowledge, capabilities, skills and attitudes) and the performance tasks (that can be broadly defined and include professional judgement) at an appropriate level or standard, in a particular type of situation, usually practice.

It is in this context that SAQA $(2000: 17)$ proposes a broadening of the concept 'competence' to embrace the notion of applied competence. SAQA regards assessment as the process through which the applied competence of a student is assessed (SAQA 2005:3). According to the 'Norms and Standards for Educators' (RSA 2000) applied competence is the overarching term for three interconnected kinds of competence which should be used to guide qualifications and the design of courses/modules as well as the eventual assessment process. This competence is regarded as the ability to put the learning outcomes that have been developed through a learning programme into practice in the relevant context. Qualified students, therefore, must be able to understand what they have learnt and also do something useful with it in a real-world context. The notion of applied competence that becomes central in the 
assessment process suggests a broadening of the behaviourist notions of knowledge to include three dimensions of competence that are all necessary for the meaningful accomplishment of any task: (1) practical competence, (2) foundational competence and (3) reflexive competence. Practical competence is the demonstrated ability, in an authentic context, to perform a set of tasks - to do a particular thing, to consider a range of options/possibilities and make decisions about practice. It is grounded in foundational competence, which is the demonstrated understanding of the knowledge and thinking that underpins the action taken. This is integrated through reflexive competence, in which a student demonstrates the ability to integrate or connect performances and decision making with understanding and with an ability to adapt to change and unforeseen circumstances and to explain the reasons behind these adaptations (Rhodes University 2004:10).

Assessing applied competence thus requires not only a focus on one of these, but should be integrated into every demonstration of competence. However, this is where a major challenge for higher education institutions lies. The question arises: What should the nature of the assessment of applied competence be in order to ensure an assessment process that is characterised by practicability and authenticity (SAQA 2005:1), that will provide fair and transparent assessment moments, generate reliable evidence about the development level of the students that are measured against criteria that is aligned with all necessary competences and that will produce information from which valid inferences can be made on which feedback, feedforward and feedout can be based?

\section{INTEGRATED ASSESSMENT AND ITS IMPLICATIONS FOR HIGHER EDUCATION}

From a policy perspective, qualifications and related programmes based on the learning outcomes ought to be designed in such a way that the necessary opportunities are created for students to acquire applied competence and furthermore, that it provides a basis for further learning. As one of the enabling mechanisms but also the assessment method of choice for government, integrated assessment is premised as the tool higher education institutions in South Africa should use to engage and deal with the complexities of the above-mentioned assessment process. The insistence on assessing applied competence stems from the realisation that in most cases assessment focuses primarily on foundational competence, to some degree on practical competence and most of the times not on reflexive competence. 
A further question that needs to be answered is: What are the enabling mechanism(s) that should be put in place in higher education to ensure that the grand ideals embedded in integrated assessment are realised so that students will become life-long learners, self-regulated citizens and so that they will be thoroughly prepared for their profession and the challenges of life? In the last section of this chapter I shall first briefly highlight a few issues I regard as fundamental if integrated assessment in South African higher education is to be realised. I shall then conclude with the final proposition that despite perceived tensions, it might be possible to work toward a common goal of better and more integrated student learning assessment practices.

\section{CRITICAL ISSUES IN THE WAY OF IMPLEMENTING INTEGRATED ASSESSMENT}

A review of all the peer-reviewed research articles that appeared from 2004 to 2008 in the South African Journal of Higher Education, the only dedicated higher education journal in South Africa, shows that only two articles (Fraser et al. 2005; Friedrich-Nel et al. 2005) appeared that dealt specifically with the issues of 'competence' and/ or 'integrated/authentic' assessment. A number of articles reported on aspects of alternative assessment practices as academics started to engage with outcomes-based assessment. These can be broadly categorised in three groups. The first group (four articles) focused on the engagement of the lecturer with outcomes-based education assessment, e.g. processes and challenges of constructing a formative OBE assessment tool which included issues such as constructive feedback and addressing fairness (Thomen and Barnes 2005); using continuous assessment as a tool in curriculum development (Nair and Pillay 2004); assessment methods that will be feasible in institutions for distance education (Bohlmann and Fletcher 2008); how formal professional development can refine lecturers' assessment practices (Sayigh 2006) and an argument for a repositioning of assessment in the teaching of Geography in higher education institutions (Beets 2007). The second group (two articles) focused on aspects that deal with the student, e.g. developing an assessment model that targets student learning approaches aimed at enhancing (statistical) reasoning, thinking and literacy (Kasonga and Corbett 2008) and assessment methods that have the potential to bring greater learning (Lumina 2005). The third group (two articles) reported on research dealing with the use of portfolio assessment as an assessment strategy educational beliefs of students about this type of assessment and how it can support them in taking greater responsibility for their own learning (Tisani 2006), as well as the impact of computer-aided assessment technology in higher education (Tsibalo 2007). 
Taking into account the number and nature of research outputs in this regard and the determination with which SAQA made policy pronouncements regarding the 'new' emphasis on integrated assessment, it is clear that higher education researchers have not embraced this specific change in assessment practice. This indicates a serious policy/practice divide that exists despite insights from literature (Bryan and Clegg 2006; Gibbs 2006; Gardner 2006; Dreyer 2008) indicating that alternative assessment practices may have more significant gains for both teaching and learning. Some ways of knowing and ways of doing that may alleviate this inertia are put forward in the rest of this section. Moving towards the practice of integrated assessment will to a large extent depend on how these factors are dealt with.

Contemporary literature on assessment, teaching and learning indicates convincingly that "assessment and learning are inextricably intertwined" (Dreyer 2008:v) and that there is a "close relationship between assessment and pedagogy" (James 2006:47). However, many lecturers still regard assessment as an additional teaching responsibility that takes place after completion of the learning programme. What they fail to realise is that assessment does not only inform the both lecturer and the students about their achievements, but also creates the important and necessary reciprocal interaction between teaching and learning that opens up opportunities and possibilities to ensure the best possible pedagogy and learning. According to Mercer (2002:152) "the quality of education cannot be explained in terms of 'learning' or 'teaching' as separate processes, but rather in terms of the interactive process of 'teachingand-learning'". Quality teaching and learning should therefore be seen as embedded in and synchronised by the valid interpretations made on the evidence gained from different forms of assessment.

While recognising that the distinction between summative and formative assessment is blurred (Taras 2005:468) since all formative assessment is based on a summative judgement, assessment in higher education is still to a large extent dominated by summative assessment practices. These end-of-learning-programme assessments are usually high-stake activities and designed to sum up achievement as a grade or mark on which promotion or certification is based. From these activities only marks are generated, which do not improve learning or teaching, but lead mostly to feedout (certification or promotion to the next level). The situation is aggravated by the modularisation of courses in which marks/grades obtained through in-module/ course assessments that were intentionally designed to have a formative purpose (part of continuous assessment), but are eventually only used summatively to contribute to a mark on which a final competence judgment is based at the end of the study 
unit. In this sense, assessment has more to do with accountability and quality control, "almost exclusively as an act of measurement that occurs after learning has been completed, not as a fundamental part of teaching and learning itself" (Bryan and Clegg 2006:xviii). Although strong arguments have been developed for the prominent place of assessment of learning in higher education, the reality is that this dominant discourse constructs pedagogical practices within and beyond courses that do not address the essence of higher education, namely to support students in developing the acquired applied competence they themselves and the world at large needs.

Instead of continuing with assessment of learning as the dominant evaluative process in South African higher education, equal and greater emphasis should be placed on supporting students through assessment for learning to take ownership of their own learning and "to prepare them for the rest of their lives" (Boud and Falchikov 2007:3). However, this does not suggest that integrated assessment is automatically formative in nature. Assessment of learning, which is in many cases pen-and-paper-based assessment, is mainly applicable to the assessment of the knowledge (foundational competence) component of learning. This type of assessment or 'testing' is generally regarded as formal. Assessment of learning on the other hand also implies informal assessment activities which use a variety of assessment activities aimed at improving learning and teaching (Black et al. 2003:90). It is this range of assessment opportunities that allows lecturers to create situations in which students can demonstrate their ability to integrate their acquired foundational, practical and reflexive competence in different contexts.

The rise of the knowledge economy necessitates assessment that can provide feedback to students and lecturers about the quality of achievement in terms of foundational, practical and reflexive competence. But feedback per se is not without problems, nor is it a guarantee that integrated learning will occur. Bell (2005:129) indicates that feedback is more effective in improving learning outcomes when it is about the essence constituting the competences and not about superficial aspects. This is realised when the feedback is linked to setting outcomes, when it recognises and uses the student's strengths and weaknesses in doing the task, rather than being linked to the self in the form of praise. However, Black et al. (2003:122) argue that feedback can only fully serve learning if it involves both the evoking of evidence and a response to that evidence by using it in some way to improve learning. So it is in what is called feedforward that lecturers or supportive others can provide further steps to help the student to close the gap between what they know and can do (actual level) and what is required in terms of the learning outcomes (desired level). As the processes of feedback and feedforward 
create opportunities to focus on student strengths and weaknesses in terms of the listed competencies, they also allow space to show how they are integrated in pursuance of applied competence. Using assessment in these ways to guide the next step(s) in a continuous process of reaching increasingly higher levels of demonstrating applied competence should be part of the prevailing pedagogy and should not be experienced as an unnecessary requirement.

Developing applied competence, which is ideally assessed by integrated assessment as already explained, is closely linked not only to a specific disciplinary or interdisciplinary knowledge and understanding, but also to possible application situations in the world of work or beyond. In order to identify the assessment criteria against which the knowledge or performance of the student will be assessed a close relationship between the academic and the reality out there is needed. This creates a tension: are the programme outcomes designed based solely on the needs out there or are they also informed by what research is indicating? However, the success of addressing student needs as well as ensuring the quality of higher education programmes is embedded in maintaining a responsible balance between the priorities of the worlds of academe and the workplace. Using an example from assessing competence in teacher education, Fraser et al. (2005:249) state that in developing assessment criteria "it is necessary to consider both their performance in action (e.g. the teacher's ability to explain conceptual knowledge) and the quality of the products they produce to support their teaching (e.g. a learning programme developed by the teacher)". they also argue that these assessment criteria should not only be "attainable, observable and measurable", but that they should "arise directly from a consideration of authentic performance competencies".

On a programme level, the design of the outcomes is fundamental in ensuring that not only Mode 1 knowledge is eventually produced, but that the students will be exposed to the development of Mode 2 knowledge as well. Programmes at higher education institutions tend to consist of a number of different modules that have their own specific disciplinary knowledge and skills. So, for example, the Postgraduate Certificate in Education (PGCE) programme consists of a number of modules that are embedded in education-related disciplines like Curriculum Studies, Philosophy of Education, Educational Psychology, Didactics of Geography and English Medium and Information and Communications Technology. Each of these discipline-based modules collaboratively makes a contribution to the development of the acquired professional competence to be certified as a teacher. This creates a significant challenge for integrated learning and assessment. Processes need to be put in place to avoid 
fragmentation due to different lecturers focusing only on the discipline-specific learning outcomes. It is important to align module outcomes with programme outcomes so that students can experience synergy in the programme as a whole and feel that their needs are addressed as they prepare for the world beyond higher education. In this way the expectations of both lecturers and students can be accommodated (Birenbaum et al. 2006:65). Thus curriculum alignment is necessary, because "integrated assessment incorporates not only foundational, practical and reflexive competence but also looks to bringing overall purpose of the qualification under scrutiny - to what extent have the parts produced the whole" (SAQA 2000:22).

Changing (assessment) practices depend to a large extent on the willingness and understanding of the different role-players in agreement with Fullan's (1993:vii) argument that "[i]t is only by raising our consciousness and insights about the totality of educational change that we can do something about it". Developing a compartmentalised understanding of what constitutes applied competence or how integrated assessment should be conducted will in itself not lead to an internalised understanding of the philosophy behind the change in points of departure of the proposed teaching, learning and assessment approaches. Understanding the 'bigger picture' that contextualises the 'atomistic' pedagogical changes is a critical necessity for both academics and students. Assessing applied competence through integrated assessment is but a small dimension of the changing educational landscape conceptually and in reality. To inculcate fairness and transparency in both the teaching and assessment processes, it remains important for students to understand how all module outcomes contribute together to guide the development of applied competence and how integrated assessment will create an opportunity for them to demonstrate their applied competence at its best. At the same time, if integrated assessment is to serve its purpose(s), lecturers should have a deep understanding of the characteristics of good assessment practice, such as validity, reliability and fairness (Killen 2005: 102) and they should be able to use and apply it.

\section{CONCLUSION}

The educational landscape in South Africa has changed significantly over the last two decades. Higher education institutions, through their own processes of questioning their purpose and role, are continually redefining the epistemological relevance of their existence. Currently the pendulum is hovering above what can be classified as Mode 2 knowledge. At the same time, governments cannot ignore these developments and need to find ways of establishing 'enabling' structures that will reflect these changes. 
However, even more important for them is the need to design control measures that will put them in a position to manage the education system and demand performance and accountability.

This 'sensitive' relationship between higher education, driven by scholarly and scientific integrity, and the state, driven by political imperatives, is consequently always tainted with tension. This tension can emanate on both sides from factors that have been mentioned in this chapter. But despite these differences, both higher education with its increasing focus on Mode 2 knowledge and SAQA through its policy requirement of using integrated assessment to assess applied competence are in reality working towards a common goal. In the end both processes should have one common outcome - enhancing quality assessment to ensure better teaching and learning that will contribute to a sustainable world. It is against this background that higher educationists have identified the previously mentioned problem areas for further reflection and research. Put differently: if quality teaching, learning and assessment are the priority of higher education and government, then critical engagement, as well as cooperation of both sectors in emerging educational trends and challenges, is a much-needed responsibility.

\section{REFERENCES}

Baartman LKJ, Bastiaens TJ, Kirschner PA \& Van der Vleuten CPM. 2007. Evaluating assessment quality in competence-based education: A qualitative comparison of two frameworks. Educational Research Review, 2:114-129.

Barnett R. 2007. Assessment in higher education: An impossible mission? In: D Boud \& N Falchikov (eds). Rethinking assessment in Higher Education: Learning for the longer term. London: Routledge Farmer. 29-40.

Beets PAD. 2007. (Re)positioning assessment in higher education: the case of Geography in South Africa. Editorial: South African Journal of Higher Education, 21 (4):577-584.

Bell B. 2005. Learning in Science: The Waikato Research. London: Routledge Farmer.

Berger G. 2005. "Fit for purpose" - towards tracking the quality of university education of entry-level journalists. Ecquid Novi, 26(2):175-198.

Biggs J. 1996. Enhancing teaching through constructive alignment. Higher Education, 32:347-364.

Birenbaum M, Brever K, Cascallar E, Dochy F, Dori Y, Ridgway J, et al. 2006. EARLI position paper. A learning integrated assessment system. Educational Research Review, 1:61-67.

Black P, Harrison C, Lee C, Marshall B \& Wiliam D. 2003. Assessment for Learning: Putting it into practice. Maidenhead: Open University Press.

Bohlmann CA \& Fletcher L. 2008. Diagnostic assessment for mathematics in a distance learning context. South African Journal of Higher Education, 22(3):556-574. 
Botha J. 2000. Conceptions of quality and Web-based learning in higher education. University of Stellenbosch. Paper read at the CITTE conference, 29 June, Port Elizabeth.

Boud D \& Falchikov N (eds). 2007. Rethinking Assessment in Higher Education: Learning for the longer term. London: Routledge.

Brown S \& Knight P. 1994. Assessing Learners in Higher Education. London: Kogan Page.

Bryan C \& Clegg C (eds). 2006. Innovative Assessment in Higher Education. London: Routledge.

Dann R. 2002. Promoting Assessment as Learning: Improving the Learning Process. Londen: Routledge/Falmer.

DoE (Department of Education). 1998. Assessment Policy in the General Education and Training Band and ABET. Pretoria: Government Printing Works.

DoE (Department of Education). 2005. The National Protocol on Assessment for Schools in the Further Education and Training Band. Grades R-12. Pretoria, Department of Education.

Dreyer JM (ed). 2008. The Educator as Assessor. Pretoria: Van Schaik.

Edwards A \& Knight P. 1995. Assessing competence in Higher Education. London: Kogan Page.

Eraut M. 2004. A wider perspective on assessment. Medical Education, 38(8):803-804.

Fraser WJ, Killen R \& Nieman MM. 2005. Issues in competence and pre-service teacher education. Part 2. The assessment of teaching practice. South African Journal of Higher Education, 19(2):246-259.

Friedrich-Nel HS, De Jager L \& Nel MM. 2005. An assessment model in outcomes-based education and training (OBET) for health sciences and technology in South Africa. South African Journal of Higher Education, 19(5):880-899.

Fullan M. 1993. Change forces: Probing the depths of educational reform. London: Falmer Press.

Gardner J (ed). 2006. Assessment and Learning. London: SAGE.

Gibbons M, Limoges C, Nowotny N, Schwartzman S, Scott P \& Trow M. 1994. The new production of knowledge: The dynamics of science and research in contemporary societies. California and London: Sage.

Gibbs G. 2006. Why assessment is changing? In: C Bryan \& C Clegg (eds). Innovative Assessment in Higher Education. London: Routledge. 11-22.

Gipps C. 2002. Sociocultural Perspectives on Assessment. In: G Wells \& G Claxton (eds). Learning for Life in the $27^{\text {st }}$ Century: Sociocultural Perspectives on the Future of Education. Blackwell: Oxford.

Heywood J. 2000. Assessment in Higher Education: Student Learning, Teaching, Programmes and Institutions. London: Jessica Kingsley Publishers.

James M. 2006. Assessment, Teaching and Theories of Learning. In: J Gardner (ed). Assessment and Learning. London: SAGE. 47-60.

Kasonga RA \& Corbett AD. 2008. An assessment model for improving student learning of statistics. South African Journal of Higher Education, 22(3):602-614. 
Kilfoil WR. 2008. Assessment in higher education. In: JM Dreyer (ed). The Educator as Assessor. Pretoria: Van Schaik.

Killen R. 2005. Programming and Assessment for Quality Teaching and Learning. Thomson/ Social Science Press: Victoria.

Knight PT \& Yorke M. 2003. Assessment Learning and Employability. Berkshire: Society for Research into Higher Education \& Open University Press.

Kraak A (ed). 2000. Changing modes: New knowledge production and its implications for higher education in South Africa. Pretoria: HSRC.

Kvale S. 2007. Contradictions of assessment for learning in institutions of higher learning. In: D Boud \& N Falchikov (eds). Rethinking Assessment in Higher Education: Learning for the longer term. London: Routledge.

Le Grange L. 2006. The changing landscape of the contemporary university. Editorial: South African Journal of Higher Education, 20(4):367-371.

Leinster S. 2002. Medical education and the changing face of healthcare delivery. Medical Teacher, 24(1):13-15.

Lizzio A \& Wilson K. 2004. Action learning in higher education: an investigation of its potential to develop professional capability. Studies in Higher Education, 29:469-488.

Lumina C. 2005. Giving students greater responsibility for their own learning: portfolio assessment and peer-marketing as tools for promoting self-directed learning in a secondyear law course. South African Journal of Higher Education, 19(3):482-496.

Maree JG \& Fraser WJ. 2004. Outcomes-Based Assessment. Sandown: Heinemann.

Mercer N. 2002. Developing Dialogues. In: G Wells \& G Claxton (eds). Learning for Life in the $21^{\text {st }}$ Century: Sociocultural Perspectives on the Future of Education. Oxford: Blackwell. $141-153$.

Nair PAP \& Pillay J. 2004. Exploring the validity of the higher continuous assessment strategy in higher education institutions. South African Journal of Higher Education, 18(2):302-312.

Olivier C. 1999. Let's educate, train and learn outcomes-based. A 3D experience in creativity. Pretoria: Benedic.

Rhodes University, Academic Development Centre. 2004. Understanding and using 'Credits' and 'Notional hours' in course design. Grahamstown: Rhodes University.

RSA (Republic of South Africa). 2000. National Education Policy Act, 1996: Norms and Standards for Educators. Vol. 415, No. 20844. 4 February. Government Notice No. 82. Pretoria: Government Printers.

SAQA. 2000. The National Qualifications Framework and Curriculum Development. Pretoria: SAQA.

SAQA. 2005. Guidelines for Integrated Assessment. Pretoria: SAQA.

Sayigh EA. 2006. Refining lecturers' assessment practices through formal professional development at Rhodes University. South African Journal of Higher Education, 20(1):157-169.

Taras M. 2005. Assessment - summative and formative - some theoretical reflections. British Journal of Educational Studies, 53(4):468-478. 
Thilakaratne R \& Kvan T. 2006. Competence-based Assessment in Professional Education Validation. Quality in Higher Education, 12(3):315-327.

Thomen C \& Barnes J. 2005. Assessing students' performance in first year university tutorials. South African Journal of Higher Education, 19(5):959-968.

Tisani N. 2006. Assessment by portfolio: An encounter with contradictory discources. South African Journal of Higher Education, 20(3): 182-193.

Tsibalo AE. 2007. The potential impact of computer-aided assessment technology in higher education. South African Journal of Higher Education, 22(6):684-693.

Vygotsky LS. 1986. Thought and Language. Cambridge, MA: Harvard University Press.

Wood D, Bruner JS \& Ross G. 1976. The role of tutoring in problem solving. Journal of Child Psychology and Psychiatry and Applied Disciplines, 17:89-100. 


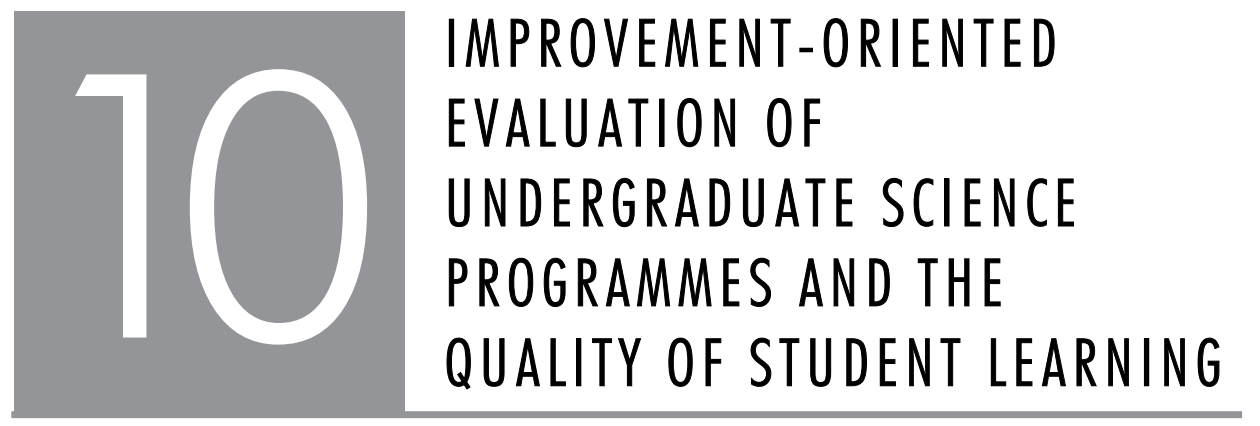

\section{Jan Botha}

\section{ABSTRACT}

The quality of student learning is considered by many as a key area in the study of higher education as student learning gain seems to be one of higher education's critical contributions to society. In this chapter insights gained from the internal evaluation of 17 undergraduate programmes in the sciences conducted by Stellenbosch University during 2007 and 2008 are reported and analysed with a view to the possible impact of these programmes on the enhancement of the quality of student learning. For the purposes of the analysis those improvement plans related to the achievement of studentcentred learning and teaching are considered to have the best potential to have an impact on the quality of student learning. The authentic improvement plans devised by lecturers and students in the sciences give an indication of the shift towards studentcentred learning and teaching which is gradually taking place. An important conclusion is that the evaluation of formative undergraduate programmes can be an effective instrument to improve student learning, particularly because such evaluations consider the academic activities from the students' perspective, namely the programme, and not the individual modules of different disciplines offered by different departments.

\section{INTRODUCTION}

Amongst the expected outcomes of quality assurance (QA) procedures in higher education, the enhancement of the learning experience of students continues to be of prime importance. It is an ongoing concern for role-players in $Q A$ to reflect on the question whether the numerous mechanisms and procedures in place do in fact contribute to the realisation of this outcome, and if so, whether the ratio of effort 
and outcome is at acceptable levels (see Morley 2003:132). Depending on their interests and perspectives, different role-players will probably respond differently. QA practitioners, who have a professional interest in the maintenance and development of QA systems, may tend to respond more optimistically than academic staff in higher education institutions who often see $Q A$ as an unwelcome but necessary addition to (or even intrusion into) their primary tasks of research and teaching (see Evans 1999:99ff).

QA in higher education usually involves different combinations of external and internal mechanisms and procedures. The same instrument may yield different results when applied by an external QA agency than when applied by an institution (or a unit within an institution) itself. QA mechanisms can include instruments that focus on organisational units at different levels, from a specific academic unit or department, to a school, a faculty, an institution or even a system consisting of a number of institutions at regional or national levels. So, for example, in the South African context, an institutional audit takes an institution as the object for evaluation or assessment. Although the enhancement of student learning may indeed be one of the expected outcomes of an institutional audit, such an effect will probably be more indirect. It is usually expected that an audit that focuses on the QA arrangements of an institution will contribute, further down-stream, to the quality of the student learning experience. QA mechanisms may also include instruments that focus on specific processes or services (e.g. the leadership and management processes within an institution, or the provision of access to academic information, or capital campaigns, or learning and teaching programmes or research programmes). When a learning and teaching programme is taken as the object of evaluation, the impact on student learning is arguably much more direct.

In this chapter a number of aspects related to programme evaluations are discussed in general and insights gained from internal evaluations of the undergraduate programmes in the sciences (17 programmes in total) at Stellenbosch University (SU) are reported and analysed with a view to their possible impact on the enhancement of the quality of student learning. These evaluations (conducted during 2007 and 2008), are interesting for a number of reasons:

- The evaluations were conducted internally mainly for improvement purposes and not for the purpose of (external) accreditation. The possibility of compliance and 'telling them what we think they want to hear' has therefore been limited. In fact, this self-evaluation process was purposefully not followed, as is usually the case 
in quality assurance, by an external peer review (see Challenges in the evaluation in formative undergraduate programmes below for a discussion of the reasons for this).

- For many of the academic staff members and students who participated in the 17 different self-evaluation committees this was the first experience of a programme evaluation (although many had previous experience of other forms of evaluation, e.g. of departments or research projects). Different self-evaluation committees were established for the different programmes. In each case colleagues and students from different departments participated, therefore facilitating evaluative and development-oriented discussions across departmental boundaries.

- The programme accreditation criteria of the South African Higher Education Quality Committee (see HEQC 2004), were grouped into 11 themes and also reduced and simplified (see Stellenbosch University 2005). Not all the role-players are necessarily sufficiently au fait with the terminology used in quality assurance. For many of the academic staff members this was the first exposure to these criteria and to the application of such criteria at programme level, and in particular, at the level of undergraduate programmes in the sciences. What resulted were therefore the actual and authentic responses and insights of academic staff members and students who are intimately involved with the programmes that have been evaluated.

For the purposes of this chapter the notion of 'the quality of student learning' is understood with reference to the official learning and teaching approach of Stellenbosch University, as stated in its Learning and Teaching Policy (Stellenbosch University 2007: ). The commitment of the University is

to actively move towards the creation of a student-centred learning and teaching environment. In other words, learning is central to the teaching process and serves as point of departure for the University's organisation of learning and teaching. Within student-centred university education, the "transferring knowledge" approach makes way for "teaching activities that facilitate learning" and the focus is on the nature, quantity and quality of learning that takes place. 


\section{DIMENSIONS OF PROGRAMME EVALUATION}

\section{Deciding on the object of evaluation: 'Programme'}

In the South African Higher Education Qualifications Framework (HEQF) a qualification is defined as

the formal recognition and certification of learning achievement awarded by an accredited institution ... The format for qualification specification should include the title and purpose of the qualification, its NQF level, credits, rules of combination for its learning components, exit-level outcomes and associated assessment criteria, entry requirements, forms of integrated assessment, and arrangements for the recognition of prior learning and for moderation of assessment (RSA 2007:6).

A programme is defined as

a purposeful and structured set of learning experiences that leads to a qualification.

Programmes may be discipline based, professional, career-focused, trans-, interor multi-disciplinary in nature (RSA 2007:6).

Although both definitions are fairly clear it remains a challenge to apply these definitions consistently, especially when the unit for evaluation is to be defined in the context of a programme evaluation process. A so-called nested approach has been developed by the educational authorities in South Africa to explain the different dimensions and levels of specification involved in understanding the relation between qualifications and programmes. The programmes discussed in this chapter can be defined in terms of the 'nested approach' as depicted in Table 10.1.

Considering the designators indicated in this table the difficulty in applying the definitions consistently becomes clear. Both 'science' (BSc) and 'agricultural science' (BScAgric) can be taken as designators in the same layer of the nest, or only 'agricultural' could be taken as being in the same layer which would then render the additional qualifiers to the layer of second qualifiers. In practice, however, the designators 'of Science' (BSc), 'of Agricultural Science' (BScAgric) and 'of Agriculture' (BAgric) are usually seen as being on the same level, especially because these qualifications are often offered in different faculties within a university. The differences become more pertinent when specifications at a deeper level are considered. So, for example, a BSc in Physics can have additional 'streams' or 'focus areas' such as 'Laser Physics' or 'Nuclear Physics', and similarly a BScAgric in Crop Production Systems can include more specific 'streams' or 'focus areas' such as 'Crop Protection and Crop Breeding' and 'Soil and Water 
Management'. And then, of course, sometimes at yet a deeper level of specification in all these programmes the notion of major disciplines of subjects classified different areas in terms of the 'Classification of Educational Subject Matter' categories (CESM categories) for funding purposes has to be catered for.

TABLE 10.1 The 'nested approach' as prescribed by the HEQF

\begin{tabular}{|c|c|c|c|c|}
\hline \multicolumn{2}{|c|}{ Layers in the 'nest' } & \multirow{2}{*}{\multicolumn{3}{|c|}{ Qualifications and programmes evaluated }} \\
\hline $\begin{array}{l}\text { NQF level and } \\
\text { level descriptor }\end{array}$ & Level 8 & & & \\
\hline \multirow{2}{*}{$\begin{array}{l}\text { Qualification type } \\
\text { as specified in terms } \\
\text { of a qualification } \\
\text { descriptor }\end{array}$} & Degree & Bachelor (B) & Bachelor (B) & Bachelor (B) \\
\hline & Designator & of Science (Sc) & of Science (Sc) & $\begin{array}{l}\text { of Agriculture } \\
\text { (Agric) }\end{array}$ \\
\hline \multirow{3}{*}{$\begin{array}{l}\text { Qualification } \\
\text { specialisation } \\
\text { (Usually taken } \\
\text { to be equivalent } \\
\text { the programmes } \\
\text { leading to these } \\
\text { qualifications.) }\end{array}$} & Qualifier & $\begin{array}{l}\text { in Physics } \\
\text { in Chemistry }\end{array}$ & in Agriculture & $\begin{array}{l}\text { in } \\
\text { Administration }\end{array}$ \\
\hline & & $\begin{array}{l}\text { in Mathematical } \\
\text { Sciences } \\
\text { in Earth Science } \\
\text { in Biodiversity and } \\
\text { Ecology } \\
\text { in Molecular Biology } \\
\text { in Human Life Sciences } \\
\text { in Sport Science } \\
\text { in Science Education }\end{array}$ & & \\
\hline & $\begin{array}{l}\text { Second } \\
\text { qualifier }\end{array}$ & & $\begin{array}{l}\text { in Animal } \\
\text { Production } \\
\text { Systems } \\
\text { in Agricultural } \\
\text { Economics } \\
\text { in Wine } \\
\text { Production } \\
\text { Systems } \\
\text { in Crop } \\
\text { Production } \\
\text { Systems } \\
\text { in Forestry } \\
\text { in Food Science } \\
\text { in Conservation } \\
\text { Ecology }\end{array}$ & \\
\hline
\end{tabular}


When a unit for evaluation is to be determined it is therefore not simply a matter of pinning it down at the level of the qualification specialisation as specified by the first qualifier. In the cases discussed above that would mean that nine BSc programmes would be evaluated, but only one BAgricAdmin programme and one BScAgric programme would have been evaluated, whereas the seven learning programmes as named by second qualifiers in the case of the BScAgric programmes are sufficiently different to justify each case to be taken as a separate unit of evaluation. On the other hand, the streams or focus areas within the BSc programmes are not necessarily sufficiently distinct to justify separate units of evaluation. Since programme design is one of the major issues to be considered during an evaluation (see Academic integrity below), one of the findings of an evaluation process may well be that inconsistencies in the application of design principles and naming conventions necessitate a reconsideration of existing programmes.

From this discussion it is clear that the decision on the units (or programmes) to be evaluated cannot be taken on a formal basis only. Many considerations are to be taken into account, including the type of evaluation envisaged, the purpose of the evaluation and the institutional context within which programmes have been developed over many years. It is somewhat of a chicken-and-egg situation: a decision on the unit of evaluation has to be made in advance, but the definition and delimitation of the unit itself is also evaluated during the subsequent process.

It has further become clear that it remains a challenge to distinguish between qualifications and programmes and to understand and apply the relationship between qualifications and programmes consistently in different contexts (e.g. different faculties, each with its own history and customs) and for different purposes (e.g. for funding purposes or for quality assurance or accreditation or certification purposes). Although the finalisation of the HEQF in 2007 has contributed significantly to close the policy gap which existed in this regard in South Africa for a decade or more, further research on these issues and subsequent system development will have to take place during the process of the implementation of the HEQF. Much work needs to be done to come to clearer understandings of what constitute a designator and a qualifier and to make clear how they differ. It is expected that the Council on Higher Education (CHE) will play a leading role in this regard since the responsibility for standards setting has been allocated to the CHE in terms of the National Qualifications Framework Act (RSA 2008). 


\section{TYPES AND PURPOSES OF PROGRAMME EVALUATIONS}

Evaluation outcomes are used by different role-players for different purposes.

Trow (1994) distinguishes between four types of evaluation, namely internal supportive, internal evaluative, external supportive and external evaluative. Babbie and Mouton (2001) explain that, in social research methods theory, three different purposes and types of programme evaluation are typically distinguished: (a) judgement-oriented evaluations, (b) improvement-oriented evaluations, and (c) knowledge-oriented evaluations. Although in evaluation theory, the term 'programme' is used to mean a 'social intervention', these three distinctions are nevertheless useful and insightful when applied to learning and teaching programmes. It could be argued that learning and teaching programmes are a form of educational intervention. One can therefore distinguish between three types of evaluation for academic programmes:

1. Judgement-oriented evaluations that aim to establish the intrinsic value, merits or outcome of a programme. Normally, the following kinds of questions are asked: To what extent is the programme successful? Has it achieved its goals? To what extent is the programme effective? Has the intended target group been reached? Are the people that benefit from the programme doing so in the most effective and efficient way? The most critical requirement for such a judgement to be made is the criteria that are used for the judgement.

2. Improvement-oriented evaluations typically ask the following questions: What are the strong and weak points of the programme? Has the programme been implemented properly? What constraints are there on the proper implementation of the programme? Do the people who benefit from the programme respond positively to the programme? Formative evaluation that is aimed at identifying weak points in the programme and at identifying unexpected problems needs to occur in time to make suggestions for improving the programme. Thus, evaluations aimed at improving programmes use information systems to monitor the programme, to sustain its implementation, and to provide continuous feedback to the programme managers.

3. Questions regarding the usefulness and suitability of programmes usually relate to programme evaluations aimed at both judging and improving programmes. In both cases, the end result of the evaluation is decision making for follow-up action. However, there is a third reason for conducting programme evaluations; to answer the following kinds of questions: How do programmes work? How do 
people change their mental models and/or behaviour? In the latter case, the generation of knowledge is the purpose of programme evaluation.

The evaluations discussed in this chapter were of an internally evaluative nature with the purpose of improving the programmes and enhancing the quality of the student learning experience.

\section{CHALLENGES IN THE EVALUATION IN FORMATIVE UNDERGRADUATE PROGRAMMES}

To understand the context within which the programme evaluations discussed in this chapter were conducted, it is necessary to take note of a number of challenges when formative undergraduate programmes are evaluated.

When the notion of 'a programme-based approach' became prominent in South African Higher Education in the late 1990s, in particular through the vision of White Paper 3: "... meets through well-planned and coordinated teaching and learning programmes" (RSA 1997:par 1.12), it presented a challenge in particular to those faculties offering broad formative programmes (e.g. Arts, Social Sciences, Natural Sciences, Economic and Management Sciences). They had to come to grips with the implications of a 'programme approach' to their undergraduate academic offering and academic structures. In contrast to the faculties offering more tightly structured professional programmes, these faculties usually tend to have a stronger disciplinebased approach in their academic offering, also at undergraduate level. Typically, students can choose one or two majors from the range of disciplines located in different departments within these faculties, and add the required minor subjects to meet the requirements of a $\mathrm{BA}, \mathrm{BS}$ ocSc, $\mathrm{BSc}$ or $\mathrm{BComm}$ qualification. During the initial processes for the recording and interim registration of qualifications through the South African Qualifications Authority (SAQA) in the late 1990s, many institutions redesigned their academic offerings to meet the requirements of a programme-based approach to curriculum/programme design. An issue debated at the time was whether the academic organisational structures of universities should continue to favour academic disciplines as organising principle or whether new organisational forms should be developed (see Naudé 2003:70-82). In many cases the academic organisational structures were not changed to provide the optimal environment for the effective management and delivery of programmes. This was the case at $\mathrm{SU}$, which did not re-organise its academic departments into schools. The organisational units (departments) in these faculties (offering formative programmes) remained based primarily on disciplines. Therefore the governance structures are not easily mapped onto programmes which include 
modules from different disciplines spread across different departments within a faculty and even across different faculties. Furthermore, the boundaries of departments are hardened by the fact that the funding is channelled through departments. Departments do not necessarily always see it as in their best interest to contribute to the success of a programme as a whole, especially if programme requirements, for example, require a department to agree to larger portions of the total credits to be allocated to other departments. It remains a challenge to ensure that departments do not end up competing instead of cooperating in the best interest of a programme, and therefore of the students' learning experience.

To provide for the needs of programme management, a system of programme committees chaired by programme coordinators was created (see University of Stellenbosch 2004a). However, in most cases these coordinators do not have any real power to enforce effective programme management. In many cases departments simply continue to offer their majors without paying sufficient attention to the contribution of their share in the context of the programme as a whole. In some cases in the past, the programme committees hardly functioned. So, when the programmes were evaluated, the programme coordinators and committees had to be revived. This was a positive effect of the evaluations. The committees were expected to think beyond the disciplines and consider the programme as a whole. This in itself brought the process closer to the students' experience, since they generally experience a programme as a whole and not only in its separate parts, as is the case with the lecturers. Therefore, by enforcing a process that requires academic staff to attend to programmes, the University ensured that the students' learning experience came more specifically into focus.

Good quality assurance practice requires a check by external peers (usually in the form of a visit) following the self-evaluation process. In the case of the evaluation of formative undergraduate programmes, this poses a problem (including issues of cost and time). Since many different disciplines are involved in the offering of these programmes it would mean that a large number of peers should be involved. For example, in the 17 undergraduate programmes considered here, 19 different departments are involved, and because many departments house more than one discipline, about 25 different academic disciplines are involved (or even more, depending on how one defines a discipline). It is clear that it will not be feasible to involve such a large team of peer reviewers. Since peer reviewers are always involved when academic departments are evaluated by SU it was decided to limit the programme evaluations to the selfevaluations conducted by the 17 programme committees consisting of academic staff and students of the University itself. This had the obvious limitation that the crucial and 
usually valuable external check and input remained lacking. On the other hand, it had the benefit that the process as a whole was more explicitly focused on improvement. There was not any sense of having to impress or satisfy external reviewers. Furthermore, the process was not linked to a formal accreditation decision to be taken on the basis of the evaluations. While a process without external peer review can be expected to lead to more open and frank discussions and conclusions, a problem could be that the process is not taken as seriously as it would have been if the external peers and a formal accreditation decision were also part of the process. The need for both internal and external dimensions to provide for improvement as well as accountability purposes in quality assurance is well-established good practice in QA, classically expressed by Vroeijenstein (1995) as "navigating between Scylla and Charybdis".

Given the fairly recent arrival of a range of quality assurance procedures in South African higher education, it is a challenge to ensure a satisfactory balance between the efforts and resources invested in evaluations and the gains made. Too many criteria to be attended to, too many documents to be collected and the writing of too extensive reports may defeat the purpose of an evaluation. There is a real danger that a core purpose - improving the quality of students' learning experiences - may get lost in the maze of systems, procedures and jargon. Part of this challenge is to ensure a sensible balance and coherence between different elements of a quality assurance system. At SU, for example, the periodic reviews of academic departments (including the modules taught by a department, the department's research, the department's community engagement activities) and the periodic reviews and (re)accreditation of programmes (undergraduate and postgraduate) by institutions and by professional bodies need to be aligned to avoid duplication (and an even bigger administrative burden). Furthermore, all these QA activities need to be aligned with the periodic comprehensive institutional audits. For example, having been through a thorough and comprehensive institutional audit in 2005 (conducted by the HEQC), the rationale for the evaluation of (formative undergraduate) programmes only a year or two later must be clear. And since many of the departments involved in the teaching of the science programmes discussed here have recently been evaluated as departments, it is even more important to have a clear understanding of the specific purposes of programme evaluations and how they differ from the other QA activities. (See Appendix A for an exposition of the way in which the different elements of the institutional quality assurance management system at SU are aligned and distinguished from one another.)

A final challenge to be mentioned here is the problem of conflating the process of evaluation with the reporting of the results of an evaluation process. Quite often 
evaluation is seen as being identical to report writing and thereby the reflective dimension of evaluation in the context of collegial discussions is lost from sight.

\section{EXPECTATIONS OF THE PROGRAMME EVALUATIONS}

Against the background of the challenges discussed in the previous section, a number of specific expectations of the process of programme evaluation were discussed and agreed upon by the programme committees before the evaluations commenced, including that

- it should lead to sustainable quality promotion;

- it is used as an instrument for change;

- it is properly integrated and aligned with other forms of evaluation; in particular departmental reviews;

- the outcomes should justify the effort, time and resources devoted to the evaluations;

- the approach used should be applicable to formative undergraduate programmes;

- the standard methodology used in QA should be adhered to, including a wellplanned and executed self-evaluation process based on explicit agreed-upon criteria or standards, the production of a self-evaluation report with evidence to substantiate the findings and claims, and the formulation of specific improvement plans, but excluding a visit by external peers (for the reasons discussed in the previous section); and

- the process should provide a good basis and preparation for formal external programme accreditations which may be required at some stage, and therefore the criteria expected to be used in external accreditation processes should be used as far as possible.

\section{CRITERIA (OR STANDARDS) CLUSTERED IN THEMES AS BASIS FOR EVALUATION AND STRATEGIES FOR IMPROVEMENT}

To give effect to expectation that the internal programme evaluation process should be a preparation for possible external accreditation processes in future, the HEQC's programme accreditation criteria were clustered into the following 12 themes: (1) programme rationale; (2) academic integrity; (3) student recruitment, (4) selection and admission; (5) staffing; (6) learning facilitation; (7) assessment; (8) infrastructure and academic information sources; (8) programme coordination; (10) student success and 
academic support for student success; (1 1) service learning and work-based learning; and (12) programme evaluation and development. When postgraduate programmes are evaluated a number of additional criteria specifically related to research and postgraduate supervision are also included.

In the next section a selection of the improvement strategies developed with reference to the criteria in a number of these themes are presented and commented on. A guiding principle for the selection is the relevance of the proposed plans for the improvement of the quality of the students' learning experience. Based on the same principle, not all the themes will be discussed below. For example, although the quality of staffing and infrastructure obviously has a direct impact on the quality of the students' learning experience, these themes are not discussed here, because they are traditionally considered when student learning is under discussion. Some of the other themes are more directly the result of the introduction of formal quality assurance measures, and it may be therefore be more relevant to consider their possible impact on the quality of student learning.

\section{WHAT ARE WE LEARNING FROM PROGRAMME EVALUATIONS?}

\section{Programme rationale}

\section{Criteria}

The programme is consistent with the faculty's mission, planning and resource allocation. The design maintains an appropriate balance of theoretical, practical and experiential knowledge and skills. It has sufficient disciplinary content and theoretical depth at the appropriate level. The programme offers opportunities for community interaction. The design offers learning and career pathways to students with opportunities for articulation with other programmes within and across institutions, where possible.

\section{A selection of improvement plans}

Amongst the 17 programmes evaluated, a total of 69 improvement plans were formulated covering all the different criteria. However, the following objectives seem to be more directly related to the improvement of the students' learning experience:

- To enhance interaction with stakeholders (subject-specific societies, industry, extraordinary lecturers, alumni) in order to broaden academic and industry-specific networks (inter alia through the use of advisory committees); 
- To review and restructure the subject matter covered in the programmes continuously to ensure that module-level outcomes are better aligned with the programmelevel specific and generic outcomes, taking into account student feedback and industry input;

- To develop new modules or to redesign existing modules to fill theoretical gaps and to provide for further deepening of theoretical knowledge and better preparation for attractive career paths;

- To communicate the programme outcomes more clearly and more consistently to students in order to contextualise lectures and other learning experiences; to communicate information about administrative and support services to students, staff and stakeholders (including, for example, to advertise student assistantships more effectively);

- To communicate the rationale for the approach followed in the programme during the first year of study, and to maintain a challenging learning environment for students, despite low student numbers (in some programmes) or rapidly increasing student numbers (in other programmes).

\section{Discussion}

The realisation that the programme architecture as a whole, specifically the programme outcomes themselves as well as the alignment of module outcomes and programmes outcomes, should be communicated better, is a major step forward in the context of faculties used to work primarily within academic disciplines. This can contribute significantly to the improvement of student learning. This should ideally not only be the responsibility of the programme coordinator, but also that of each lecturer in the context of each module. It is also interesting that there is a realisation in the more applied sciences (agriculture) as well as in the more basic sciences (natural sciences) that improved interaction with and exposure to the 'world outside the classroom' can significantly improve the quality of student learning.

\section{Academic integrity}

\section{Criteria}

Programme outcomes, learning methods, learning material and expected time of completion cater for the learning needs of the programme's target student intake and other stakeholders and meet international standards. The programme content is academically well-founded and meets international standards. Modules and/or 
courses in the programme are coherently planned with regard to content, level, credits, purpose, outcomes, rules of combination, relative weight and delivery.

\section{A selection of improvement plans}

Amongst the 17 programmes evaluated, a total of 65 improvement plans were formulated covering all the different criteria. However, the following objectives seem to be more directly related to the improvement of the students' learning experience:

- To increase research and benchmarking opportunities with international scholars to ensure the programme remains at the forefront of new developments, to make better use of the mutual enrichment opportunities offered through the University's emphasis on the teaching and research nexus; and establish new research institutes/ units/centres;

- To review the undergraduate programmes annually more rigorously and in this process specifically attend to the coherence of the modules in terms of content, level of difficulty and credit value, the curriculum, learning materials, learning methods and programme outcomes, and the feedback from external moderators;

- To enhance the collaboration of lecturers in order to improve programme cohesion, expose students as early as possible to the core themes, and balance practice and theory better. This could be done by identifying and removing obstacles inhibiting the use of experiential learning, increasing laboratory time and monitoring the efficacy of the practical parts of modules, by investigating coherent year-long practical modules at second and third-year levels and by reconsidering the module composition and structuring of the programme in order to make provision for a longer period of internship. The collaboration of lecturers could also contribute towards filling in possible theoretical gaps through the development of new and adapted modules and cutting out duplication. It could furthermore ensure the relevance of prescribed modules that are presented by other departments from both within, and external to, the school/faculty; to accept that a four-year degree is the norm (despite the formal minimum study time of three years for a BSc) to plan the curricula accordingly.

\section{Discussion}

These improvement plans confirm the deeply (and passionately) held conviction amongst scientists of the benefits of the teaching and research nexus. By being active researchers themselves lecturers are in a much better position to ensure a solid 
academic foundation to learning and teaching programmes and the achievement of international standards.

It is significant that through this evaluation process the academic staff came to realise the range of benefits that will emanate from better cooperation amongst themselves, and note that in almost all the aspects listed above the students will benefit. It is interesting that the issue of a proper balance between the theoretical and practical dimensions of learning and teaching programmes featured to prominently when the academic integrity of programmes is considered.

\section{Student recruitment, admission and selection}

\section{Criteria}

Advertising and promotional materials contain accurate and sufficient information on the programme with regard to admission policies, completion requirements and academic standards. Appropriate policy and procedures are in place for the selection and admission of students. Selection criteria are in line with the institutional priority to promote diversity, and are applied consistently. The quality and number of students take professional needs into account. Student numbers do not exceed the programme's capacity to deliver quality teaching. Bridging programmes are available where necessary.

\section{A selection of improvement plans}

Amongst the 17 programmes evaluated a total of 93 improvement plans were formulated covering all the different criteria. However, the following seem to be more directly related to the improvement of the students' learning experience, or, in this case, to provide students with the opportunity to study at a university in the first place:

- To monitor and, if necessary, reconsider admission requirements at SU as a possible mechanism to curb the high failure rate (this is possibly also needed for admission to honours programmes) and to prevent over-subscription to the programme, to cap student numbers (given the limited laboratory space available);

- To increase the diversity of the student body in terms of South African population groups as well as international students by taking the following actions:

- to monitor the bridging degree programmes to ensure that they do indeed contribute to the widening of participating and the promotion student diversity;

- to develop and implement mechanisms (including assessment methods) to broaden access, (e.g. summer school, bridging programmes); 
- to increase the number of undergraduate bursaries, in particular to ensure the continuous improvement of the University's diversity profile;

- to make the bridging programme compulsory for students with a Grade 12 mark of between $50 \%$ and $56 \%$;

- to reach out to underprivileged schools in the University's immediate vicinity and to sponsor prizes (e.g. book prizes) for the best Life Sciences student in Grade 12 at a few selected schools;

- To help students to make informed choices at different phases in the programme by taking the following actions:

- to ensure that admission requirements into the programmes are posted on departmental and faculty web pages and brochures and to improve the administrative implementation of admission criteria;

- to arrange visits to departments or to the experimental farm for second-year students to enhance informed choices on major subjects;

- to supply information on programmes at the Expo for Young Scientists and Olympiad candidates, as well as for high school science teachers;

- to encourage third-years to attend final years' product development presentations;

- to ensure that the web site inspires students;

- to promote the need for a Faculty-level Open Day with smaller, but more carefully selected learner groups (e.g. the top 10 learners within a grade with Mathematics as school subject or learners from strong feeder schools) so that departments can participate more effectively;

- to improve the quality and the distribution of marketing material.

- To implement extended degree programmes (and first-year academy) to benefit students that have to overcome academic backlogs; and

- To increase the number of available bursaries, inter alia by investigating the possibilities of increasing industry-funded bursaries.

\section{Discussion}

By having to apply their minds to this criterion, the awareness of programme committees of the issues related to student recruitment, admission and selection was undoubtedly raised among staff. Traditionally academic staff members are not directly involved with these issues since they are usually handled elsewhere within an institution. The fact that admission requirements have been treated in the evaluations under consideration the first place as a possible mechanism to keep under-prepared students out and as a possible mechanism for enrolment management is a reflection of the specific context of the programmes that were evaluated. The through-put rate in the undergraduate 
programmes in the sciences is the lowest of all programmes. Laboratory facilities are currently used at capacity. The hurdle function of admission requirements therefore seems to be prominent. However, this needs not be a negative observation. It can be very detrimental to the quality of students' learning experiences if they have been admitted to a programme for which they are not adequately prepared and are therefore constantly challenged to perform at unreasonable levels. It serves no purpose to set students up for failure.

It is clear from the improvement plans that the need to increase the number of black and women scientists is widely recognised and supported by faculty members. It is significant that they are not only aware of this need, but that they are proposing creative and practical ways to meet the challenge and that they are themselves prepared to become involved in recruitment efforts.

The range of plans proposed to help students to make informed choices once again underscores the importance of good communication with all students at all levels. This requirement was also pertinent when the design and academic integrity of the programmes were discussed.

\section{Learning facilitation}

\section{Criteria}

Learning facilitation (lecturing) takes place in accordance with Stellenbosch University's Learning and Teaching Policy. Learning and teaching methods are appropriate for the design and use of learning materials. Learning technology is used appropriately. Guidance is given to students regarding programme outcomes and programme integration. Suitable learning opportunities are provided to facilitate the acquisition of the knowledge and skills specified in the programme outcomes. Opportunities are created specifically for the acquisition of generic skills (in accordance with the SAQA critical outcomes). The effectiveness of learning and teaching interactions is regularly monitored and the results used for improvement

\section{A selection of improvement plans}

Amongst the 17 programmes evaluated a total of 70 improvement plans were formulated covering all the different criteria. From these plans, four themes have emerged. 


\section{Pedagogy (teaching and learning)}

- To gain more clarity on the meaning of student-centred teaching and its implications; to develop a policy on student-centred teaching so that independent, enthusiastic and spontaneous learning takes place consistently; to revisit the problem-based approach particularly with a view towards the improvement of lifelong learning abilities, critical thinking and professional reasoning; to review the links between problems and lectures; to review the problems addressed in lectures and evaluate students' demands over the four years (to ensure proper increments in depth and complexity; to employ a variety of assessment opportunities to enhance student learning;

- To encourage participation by academic staff in staff development courses focused on student learning and teaching skills;

- To utilise web-based course management systems more effectively, in particular to communicate effectively with large groups, but not to replace the face-toface lecturer-student interaction and the use of class notes.

2. Structure of the learning opportunities and the suitability of and access to the learning material

- To rearrange the curriculum so that assignments, seminars and research projects are better spread over all the years of study; to incorporate fundamental knowledge much more explicitly throughout the curriculum;

- To make more use of text books and journal publications in the sciences and less use of class notes.

3. Communication and class interaction with students and student feedback

- To request that lecturers always provide module frameworks which include the goals and outcomes of each module and a list of the literature to be covered in the module (in accordance with the module framework requirements stipulated by Senate);

- To organise focus group discussions at module and programme levels to gather student feedback; to improve efficiency of the process to gather student feedback; to workshop and act on students' feedback;

- To investigate ways to make the class experience more stimulating;

- To adequately communicate the module outcomes to the students annually by the chairperson and via the website; 
- To expose second- and third-year students to the layout and cohesion of the programme once more.

4. Critical skills

- To review the modules to ensure that they contain learning opportunities for the development of these skills, without unnecessary duplication;

- To highlight the fact that the ability to work in a team is one of the programme outcomes;

- To discuss with computer literacy conveners options to allow Mathematical Science students to do fewer but more relevant modules within Computer Literacy

- To investigate the possibility of introducing opportunities for students to improve and perfect their written and verbal communication skills at early stages in their studies;

- To develop oral presentation skills for senior students.

\section{Discussion}

It is significant that these four themes have emerged from the discussions of Science lecturers and students. It is clear that there is an awareness of the need to move away from one-directional lectures as the dominant form of learning facilitation. It is also significant that the need to make explicit provision for the acquisition and assessment of critical skills is considered to be so important. This indicates that an awareness of the ideals of education policy makers (of the late 1990s) is beginning to filter through to the level of the actual learning interactions provided for in a programme (although it may be largely due to the fact that the evaluation criteria specifically required the self-evaluation panels to attend to this). It is quite clear that this awareness has not yet materialised into sufficient understanding of the notion of student learning and successful practices in the inculcation and assessment of critical skills.

An issue for further research is to design a programme evaluation process more specifically to gauge the achievement of critical skills. It will also make sense to involve external evaluators who concentrate specifically on a programme's success in this regard. If this is the focus of the external evaluators, there would not be a need to have a subject expert in all disciplines provided for in a programme on the external evaluation panel. However, before an evaluation with such a focus can be conducted, it is clear that much more needs to be done to ensure that specific opportunities to learn and assess critical skills are included in the programme. 


\section{Assessment}

\section{Criteria}

Assessment takes place in accordance with the University's Assessment Policy. There are clear and consistent published guidelines/regulations for marking and grading of results, aggregation of marks and grades, progression and final awards, and credit allocation and articulation. Faculty and institutional policy and rules for assessment are communicated to students, as is policy on students' rights and responsibilities in this regard. Policy exists for the secure and reliable recording of assessment results, settling of student disputes regarding assessment results, ensuring the security of the assessment system especially with regard to plagiarism and other misdemeanours, and development of staff competence in assessment. Student progress is monitored. Policy and procedures are in place for assessment and both internal and external moderation. Policy and procedure ensures the validity and reliability of assessment practices (including issues regarding the identification and handling of plagiarism).

\section{A selection of improvement plans}

Among the 17 programmes evaluated, a total of 58 improvement plans were formulated covering all the different criteria. The following plans seem to be directly related to the improvement of the quality of the students' learning experience.

- Assessment competence and approaches to assessment

- To encourage continued assessor training of academic staff;

- To continuously check that assessment tasks are pitched at the required standards;

- To analyse all examination questions according to Bloom's taxonomy;

- To make assessment challenging, in particular to assess problem-solving abilities;

- To ensure a better balance of formative and summative assessment opportunities;

- To review the number of assessment activities that contribute to the marks and activities;

- To give more smaller tests rather than only a few major tests and an exam;

- To use a range of assessment methods such as a seminar, laboratory, written and oral examinations, including the use of peer reviewing within student/study groups.

- Communication with students and feedback on assessments

- To improve module frameworks to include all the assessments details (dates, type of assessment as well as expected timeframe for feedback); 
- To clearly communicate the means by which problem-solving abilities will be assessed, i.e. the quality of the questions to be expected, the level of insight that will be required;

- To update the assessment dates and weights on the website;

- To keep yearbooks updated with regulations regarding assessment and moderation at departmental level;

- To communicate the different assessment methods of different modules clearly to the students;

- To provide reasons or motivations for giving a particular mark, especially for essay-type projects and similar essay-type exam questions;

- To change fieldwork rubrics to be more user-friendly and precise (with student input).

- Student support and monitoring

- To conduct individual interviews with students scoring $>30 \%$ in a semester test to determine the reasons, and plan for support;

- To devise an early warning system for students who are struggling (more difficult with larger classes);

- To monitor individual student progress in terms of the First Year Academy's mechanisms.

- Meeting policy requirements

- To ensure that all tests and exams are aligned with the principles and requirements of the University's Assessment Policy;

- To ensure rigorous internal moderation, and external moderation;

- To handle question papers with care to avoid corruption of the assessment process;

- To enhance strategies to eradicate plagiarism including the use of the Turn-It-In software package for electronic submission of assignments.

\section{Discussion}

The University's Assessment Policy (University of Stellenbosch 2004b:1) states that "assessment forms the essence of an integrated approach to student learning. It is generally accepted that assessment probably constitutes the learning and teaching practice through which the most direct influence may be exerted on student learning". Judged against the background of the improvement strategies that emerged from these programme evaluations, it seems that an awareness of the importance of student learning is beginning to develop. It is interesting that so many of the proposed improvement plans can be listed under the rubric of better communication (as was the case with the improvement of learning facilitation - see the relevant section above). If these improvement plans are read as a kind of mirror of what is lacking in current 
practice, it is a concern that, despite the ease and efficiency of modern communication technology, there still seems to be inadequate communication with students about the learning and assessment opportunities. How is it possible that such an obvious requirement for effective student learning still seems to be so frequently overlooked? It is therefore very useful that these programme committees have listed this aspect for specific attention.

Although the evaluation criteria do not include any reference to Bloom's taxonomy, it is referred to in the proposed improvement plans. This is an indication that the staff development courses presented by the University are beginning to make an impact.

It is noteworthy that the proposed improvement plans suggest a balance between innovation in assessment practices (e.g. assessor training) and effective support and monitoring (e.g. the activities of the First Year Academy). Both dimensions are indeed important. The Science faculties offer many so-called service courses (e.g. in Mathematics and Biology) to large numbers of students of different faculties. Yet, the lecturers in the Science faculty are appointed in the first place on the basis of their research competencies and performance. In such a context assessor training is very important. This provides the opportunity to enhance the lecturers' assessment skills and contributes to a change in the whole environment that is more attuned to the provision of a high quality student learning experience.

\section{REFLECTION AND CONCLUSIONS}

Given that the themes and criteria for the evaluations were provided to the programme committees in advance, it will be a mistake to assume that the Science lecturers and students who evaluated the programmes would have designed these specific plans if they had not been confronted with the criteria. In this manner the criteria also served as guidelines for good practice. This is indeed the intention, and this is the reason why it was decided to work with 'criteria' and not 'minimum standards'. The mere fact that programme committees had to grapple with these criteria and consider their programmes against the criteria represented an important staff development opportunity. The formulation of all these improvement plans is an important phase in the ongoing process to assure and enhance the quality of the student learning experience. However, it is also clear that the real value of the process depends on whether these improvement plans are actually implemented. The closing of the loop is crucially important in the quality assurance processes. 
Since it was decided to work with criteria (which also serve as guidelines for good practice) and not minimum standards, and given the large number of criteria used, it may follow that a programme does not necessarily meet all the criteria, but still be considered of acceptable quality. This can be valid within a developmental context. However, in a strict accountability context (if this was an accreditation process) an interesting question to explore would be whether each student should meet all the outcomes of a programme and whether the evaluation process is geared to establish that.

In a study of the impact of quality assurance activities in various countries, Stensaker (2003) and Wahlén (2004) found that these activities often serve to facilitate discussion, cooperation and development within and between academic units with regard to quality assurance and improvement. This has perhaps been the most valuable outcome of the evaluation process discussed in this chapter. It seems obvious that the quality of the students' learning experience can best be understood and improved if the academic activities are considered in the manner in which students experience them, namely, as a programme, and not as individual modules in different disciplines offered by different departments. Therefore a programme evaluation process could contribute significantly to the improvement of the students' learning experience, especially in the context of formative undergraduate programmes offered by large faculties.

\section{REFERENCES}

Babbie E \& Mouton J. 2001. The Practice of Social Research. Oxford: Oxford University Press.

Evans GR. 1999. Calling academic to account. Rights and responsibilities. Buckingham: Society for Research into Higher Education \& Open University Press.

Harvey Lee \& Knight Peter T. 1996. Transforming higher education Buckingham. Buckingham: Society for Research into Higher Education \& Open University Press.

HEQC (Higher Education Quality Committee). 2004. Criteria for Programme Accreditation [Online]. Available: http://www.che.ac.za/documents/d000084/ [2009, 1 April].

Morley L. 2003. Quality and power in Higher Education. Maidenhead: Society for Research into Higher Education \& Open University Press.

Naudé P. 2003. Where has my department gone? Curriculum transformation and academic restructuring. In: P Naudé \& N Cloete (eds). A Tale of Three Countries: Social Sciences Curriculum Transformations in Southern Africa. Cape Town: Juta. 70-83.

RSA (Republic of South Africa). 1997. Draft Education White Paper 3. Programme for Higher Education Transformation. Government Notice No. 712.

RSA (Republic of South Africa). 2007. The Higher Education Qualifications Framework. Government Gazette, No. 30353. 5 October. Government Notice No. 928. 
RSA (Republic of South Africa). 2008. National Qualifications Framework Bill (As amended by the Select Committee on Education (National Council of Provinces)).

Stensaker B. 2003. 'Trance, Transparency and Transformation: The impact of external quality monitoring on higher education'. Quality in Higher Education, 9(2):151-159.

Trow M. 1994. Academic reviews and the culture of excellence. Kanslersämbetels Skriftserie. Stockholm.

University of Stellenbosch. 2004a. Duties and responsibilities of Programme Committee Chairs and Programme Coordinators [Online]. Available: www.sun.ac.za/inb [2009, 1 April].

University of Stellenbosch. 2004b. Assessment policy [Online]. Available: http://www.sun. ac.za/Onderrig/index.htm [2009, 1 April].

University of Stellenbosch. 2005. Themes and criteria for the evaluation of departments, programmes and support service units [Online]. Available: www.sun.ac.za/inb [2009, 1 April].

University of Stellenbosch. 2007. Learning and teaching policy [Online]. Available: http:// www.sun.ac.za/Onderrig/index.htm [2009, 1 April].

Vroeijenstein Al. 1995. Improvement and accountability: Navigating between Scylla and Charybdis: Guide for external quality assessment in higher education. London: Kingsley.

Wahlén S. 2004. Does National Quality Monitoring Make a Difference? Quality in Higher Education, 10(2):139-147. 
ANNEXURE 10.1

ALIGNMENT OF EVALUATION ACTIVITIES AT STELLENBOSCH UNIVERSITY

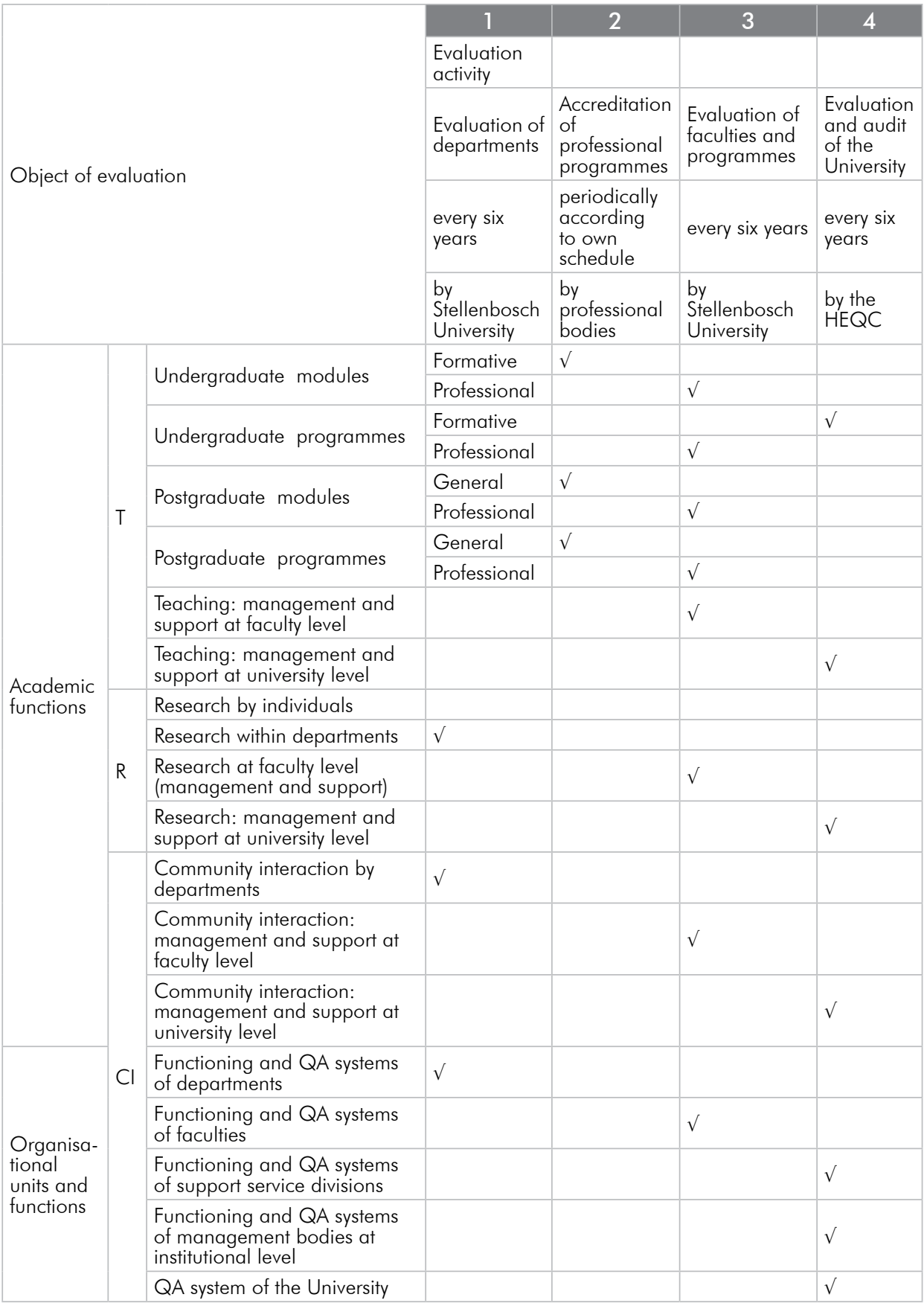




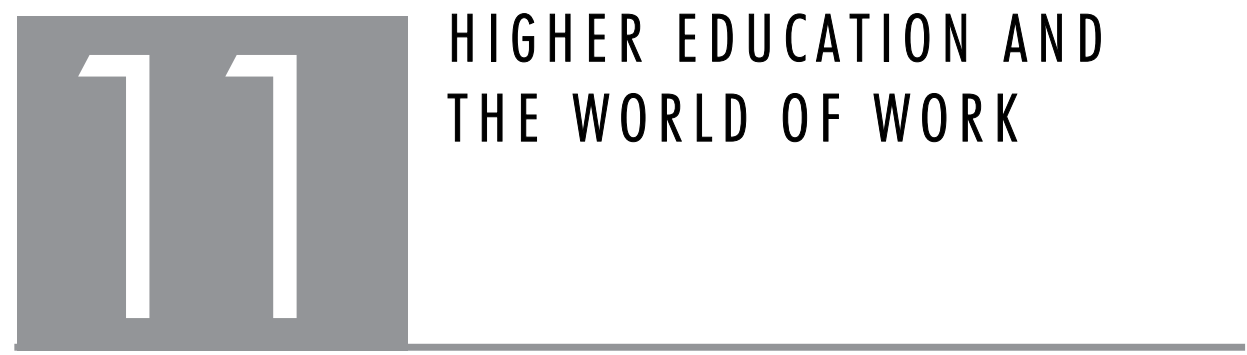

James Garraway

\section{ABSTRACT}

Although South African universities do invest in integration, for example in problem-based learning approaches and experiential learning, the outcome is often less successful than was expected; the two domains do not easily map onto one another. Why does it seem to be so difficult to successfully integrate ways of doing and thinking in workplaces with those of the university? The answer lies, in part, in the observation that knowledge in the workplace serves a different purpose from knowledge in the university, and that the two types of knowledge are, broadly, structured differently. Given this essential difference the chapter proposes that it need not be seen as an impediment to further developments, but rather, drawing on activity theory, it should be seen as a resource which can, under certain conditions, promote knowledge development. It is argued that the modern university needs to create these conditions, if it is to more properly recognise the importance of knowledge from outside of itself. Using evidence from research in South African universities, the author proposes that the university needs to develop 'boundary-crossing structures' and boundary-crossing expertise in order to better facilitate integration.

\section{INTRODUCTION}

The concept of different social groups separated by boundaries derives from work done by Wenger (1998) and Star and Griesemer (1989). The concepts of difference and boundary are nowhere more apparent than in South African society today. Notwithstanding the democratic elections of 1994, issues of race, culture and language, for example, still act as significant boundary markers in our society. The continued presence and often further development of these boundaries serves to 
make social integration difficult. Boundary is also apparent where new students with their own histories of learning are confronted with academic knowledge fields derived from quite different histories. Such difference and the resultant boundary create a very real barrier to student learning (Steinberg and Slonimsky 2004). What is less apparent, however, is that boundaries also exist between the institutions of Work ${ }^{24}$ and the university. Such boundaries make both the insertion of Work knowledge into the academic curriculum and the transfer of academic knowledge to Work more complex than our policy makers originally imagined.

In 1994, Gibbons, Limoges, Nowotny, Schwartzman, Scott, and Trow coined the now familiar terms 'Mode 2 ' and 'Mode 2 society'. These terms were again used in 2001 by Nowotny, Scott and Gibbons in an attempt to describe a move from a more regulated society of separate entities, a Mode 1 society, to one in which boundaries were continually being crossed and new knowledge, Mode 2 knowledge, was being produced in the context of application (Gibbons et al. 1994; Nowotny et al. 2001). Gibbons et al. (1994:3) explain the differences between these terms in the following way:

In Mode 1 problems are set and solved in a context governed by the largely academic interests of a specific community. By contrast, Mode 2 knowledge is carried out in the context of application. Mode 1 is disciplinary while Mode 2 is transdisciplinary ... Mode 1 is hierarchical and tends to preserve its form, while Mode 2 is more heterarchial and transient... Mode 2 is more socially accountable and reflexive. It includes a wider, more temporary and heterogeneous set of practitioners, collaborating on a problem defined in a specific and localized context.

The work of these authors signalled an emergent and significant global trend away from the separation of university and Work. More than ever universities were being pressurised to be responsive to the needs of society. In South Africa, higher education policy has been strongly influenced by Mode 2 debates (Kraak 1999) and by other responsive developments in Europe, for example the Dearing Report (Dearing 1997).

Support for the perceived need to cross boundaries between Work and the academy can be recognised in the early National Commission on Higher Education (NCHE) position paper. This paper suggested that university knowledge should be judged by its usefulness, embrace cross-disciplinarity and generally be more open to societal

24 'Work' is capitalised throughout where it refers to the workplace to distinguish it from more commonplace usage of the word. 
influences (NHCE 1996:49). This trend was further developed in the Higher Education Act of 1997 in which meeting global economic trends, in part through programme development, was promoted. Although the Act gave equal measure to both economic responsiveness and political redress, subsequent government directives indicated a shift towards a foregrounding of economic factors, such as the development of generic Work skills in academic curricula, creating academic/Work or society partnerships and efficiency (Cloete and Maassen 2002; Boughey 2002).

Despite much critique of boundary crossing (see Ensor 2002; Muller 2000) it is an existing, if not yet dominant, paradigm in higher education in South Africa. The question must then be raised: I If we are to transfer knowledge between the academic curriculum and Work (and vice versa) then how is it to be done? The simple answer might be merely to transfer elements from Work and integrate them into an academic curriculum, as has occurred in the more vocationally oriented university fields such as engineering and health. But, as Bernstein (2000) and Michael Barnett (2006) convincingly argue, Work knowledge, even in the vocational fields, has become substantially recontextualised as academic subject knowledge; vocational subject knowledge and the vocations they originally derived from are quite separate entities. Even where there are attempts to orient subject knowledge more closely to Work, as, for example, in problem-based learning (PBL), there is no guarantee of effective transfer; tensions between the structure of subject knowledge and the structure of the problem persist.

In attempting to answer the question of how Work knowledge may be successfully transferred and integrated into the university, Gibbons (2005) proposes that the nature of the university should move beyond developing academic mastery towards a greater focus on boundary-crossing expertise. While looking at Work and higher education responsiveness more generally, the main thrust of the chapter is to develop Gibbons's argument further by examining the nature of the Work/academic boundary and how best it might be crossed.

\section{UNIVERSITY RESPONSIVENESS TO WORK}

Universities respond to calls to be more responsive to Work in different ways. They could ignore the call entirely and carry on with what they have always done in transmitting large amounts of disciplinary knowledge and, hopefully, at the same time developing a critical, thinking individual. The typical university BA and BSc would embody this approach. The hope then would be that students would be able to apply what they have 
learnt at the university to new situations in the workplace. As Eraut (2004) reminds us, this is not a simple process, and may be more of a challenging proposition for students than acquiring the disciplinary knowledge in the first place, and doing so without the benefit of texts and expert guidance. The nature and problem of such 'natural' transfer is well summed up by Layton, Jenkins, Macgill and Davey (1993:58-59):

The problems which people construct from their experiences do not easily map on to existing scientific and pedagogical organisations of knowledge. What is needed in solving a technological problem may have to be drawn from diverse areas of academic science at different levels of abstraction then synthesised into an effective instrumentality for the task at hand.

\section{$[\ldots]$}

Solving technological problems means building back into the situation all the complexities of real life, reversing the process of reductionism by recontextualising knowledge.

It would seem therefore that higher educators have a responsibility at least to help the students in some way in this transfer. A dominant approach in Europe and particularly the UK, and which is also evident in South African policy, is the development of key skills alongside disciplinary knowledge acquisition. The skills, such as recognising and solving problems, working productively in groups, thinking systematically and reflecting on and managing one's own learning can then be transferred from university to Work situations (In South Africa the key skills are known as the critical cross-field outcomes). Another weaker version of the skills approach is that of subject integration in programmes as suggested in South African policy and taken up in many of the traditional universities (Moore 2003; Ensor 2001). The ability to integrate knowledge may be seen as a precursor to the idea of subject section selection in the face a of a real-life problem as put forward by Layton et al. (1993).

Integrated key skills learning can be included as an example of 'learning for Work' using the useful rubric of learning 'for, at and through Work' first proposed by Seagraves and Boyd (1996). The differences between these types of learning are illustrated in Table 11.1 . 
TABLE 11.1 Learning for, at and through Work

\begin{tabular}{|l|l|l|}
\hline \multicolumn{1}{|c|}{ Type } & \multicolumn{1}{|c|}{ Explanation } & \multicolumn{1}{c|}{ Example } \\
\hline Learning for Work & $\begin{array}{l}\text { The university curriculum } \\
\text { includes structured components } \\
\text { which prepare students for } \\
\text { thinking and doing at Work (e.g. } \\
\text { key skills approaches) }\end{array}$ & $\begin{array}{l}\text { Personal development plans, } \\
\text { problem-based learning, } \\
\text { integration and project work }\end{array}$ \\
\hline Learning at Work & $\begin{array}{l}\text { Work includes structured and } \\
\text { assessed opportunities for } \\
\text { learning }\end{array}$ & $\begin{array}{l}\text { Experiential learning } \\
\text { components, Work-based } \\
\text { learning }\end{array}$ \\
\hline Learning through Work & $\begin{array}{l}\text { Unstructured and tacit learning } \\
\text { occurs through engagement } \\
\text { with the Work community (e.g. } \\
\text { situated learning approaches) }\end{array}$ & $\begin{array}{l}\text { Work teams and critical } \\
\text { circles in which workers work } \\
\text { cooperatively on problems and } \\
\text { engage in some sort of reflection } \\
\text { on learning. }\end{array}$ \\
\hline
\end{tabular}

The problems with the key skills approach is that the skills still need to be transferred and mobilised to different situations from those I which they were originally learnt. As the possible situations students may encounter at Work are highly variable, there is no clear approach to what sorts of skills matter. Critics of the key skills approach, such as Ron Barnett (2004), claim that such skills, though important, would need to be overarched by a super skill or disposition to working with uncertainty, as Work is becoming increasingly changeable and flexible, though how this is to be accomplished is not made clear.

Key skills teaching can be packaged in different ways. One method that solves to some extent the generic nature of the key skills is to embed them in scenarios drawn from the workplace. The use of case studies, simulations, problem-based and project-based learning are all attempts to bring the real Work world into the university curriculum, and are successful to differing degrees. Such initiatives attempt to make students draw on and integrate relevant subject fragments as described earlier by Layton et al. (1993). One issue with all these approaches is the degree to which Work knowledge is absorbed and changed to meet the needs of the academy, and the degree to which the scenarios are offset from the dominant academic practices. Two examples illustrate these points. In PBL at one South African medical school, the dominance of the problem as the organising principle for teaching and learning events was undermined by the need of faculty to teach certain topics which they felt were under-represented in the problem situations. The result was a less immediate and less real Work problem. In another example from the University of Leeds in the UK (Kneale 2003), students were exposed to real-life problem scenarios which had already occurred and been solved in the workplace (the academic field was environmental and geographical sciences, 
EGS, and the related workplaces were local government). Students worked in groups for an afternoon on specific questions which needed to be answered from the cases. In working to solve the problems, students were using and presumably further developing many of the key skills mentioned earlier. However, the impact of the cases on the mainstream curriculum was small and the cases occurred largely as separate events. The addition of components to an already existent curriculum, rather than integration, may be said to be a typical response to the need to include elements of Work practice in the curriculum.

The point I wish to make is that PBL or the use of real scenarios in EGS can be improved, but that this is difficult to do within the ambit of university knowledge bases and practices.

A different approach to relating universities to workplaces in the universities of technology and in some of the more traditional university fields is the idea of experiential learning. Here, the student enters Work for extended periods of time at some point in the degree to gain Work experience, and in so doing to transfer university knowledge to the Work situation. This sort of approach fits in with the category of learning at or through Work, depending on the degree of structured learning occurring. The problem here is that Work and academic learning are almost entirely separated from one another, occurring at different sites and at different times. There is an expectation that transfer occurs, but this is not necessarily overtly promoted and may be expected to again occur 'naturally'. In research conducted at my university on chemistry experiential students we found that they spoke of analytic methods they had done or seen at the university which they were now doing 'for real'. They were less able, however, to relate their Work practice to particular theory and ways of doing in chemistry acquired at the university. We concluded that students were predominantly only able to transfer procedural knowledge and skills rather than higher level theoretical knowledge (cf. Garraway and Volbrecht 2007).

The final example of Work-based degrees is the opposite of the pure university courses such as the BSc. Here the workplace is the curriculum and each workplace and individual studying in it generates a unique curriculum (Boud 2001). The role of the university is to ensure that certain key principles of university education remain intact, but the involvement of traditional university disciplines is minimised if not entirely absent. The relationship between the knowledge and practices of those at the university and those in the workplace shifts strongly in favour of those in the workplace. This is an example of learning at Work, as the workplace now becomes a learning focus. 
The different trends in developing relationships between knowledge at Work and in the academy can be summed up in Table 11.2.

TABLE 11.2 A typology of trends in knowledge at Work and in the academy

\begin{tabular}{|c|c|c|}
\hline $\begin{array}{l}\text { Type of relationship } \\
\text { between Work and } \\
\text { academic knowledge } \\
\text { and practices }\end{array}$ & $\begin{array}{l}\text { Learning at, } \\
\text { through or for } \\
\text { Work }\end{array}$ & Problems \\
\hline $\begin{array}{l}\text { Traditional university } \\
\text { courses with no overt } \\
\text { relationship }\end{array}$ & For Work & $\begin{array}{l}\text { No overt relationship and it is unclear what } \\
\text { transfer, if any, occurs }\end{array}$ \\
\hline $\begin{array}{l}\text { Key skills in the curriculum } \\
\text { or elsewhere }\end{array}$ & For Work & $\begin{array}{l}\text { Skills may remain attached to the scenario } \\
\text { through which they are learnt - problem of } \\
\text { transfer }\end{array}$ \\
\hline $\begin{array}{l}\text { Work scenarios in the } \\
\text { curriculum }\end{array}$ & Learning for Work & $\begin{array}{l}\text { Academic needs predominate or scenarios } \\
\text { remain separated from academic Work }\end{array}$ \\
\hline $\begin{array}{l}\text { Work or experiential } \\
\text { periods in the curriculum }\end{array}$ & $\begin{array}{l}\text { Learning at or } \\
\text { through Work }\end{array}$ & $\begin{array}{l}\text { Physical and spatial separation of university } \\
\text { and Work and again no overt relationship }\end{array}$ \\
\hline Work-based degrees & Learning at Work & $\begin{array}{l}\text { No necessary overt relationship between } \\
\text { academic disciplines and Work learning } \\
\text { and experiences }\end{array}$ \\
\hline
\end{tabular}

The typology does not cover all possible approaches to relating academic and Work practices, but it should be possible to position most approaches on it.

The discussion so far has attempted to describe approaches through which Work and academic knowledge may be integrated. Whether these approaches concern interventions such as PBL in the curriculum or Work practice, they all have some benefits as well as limitations in integrating Work and academic knowledge. The limitations, it is argued, concern less than ideal integration in which Work and academic knowledge remain mostly separate.

Throughout the text thus far there has been the theme of separation or boundary between ways of knowing and doing at Work and in the academy in one way or another. The following section explores this separation further.

\section{Differences between Work and academic knowledge}

A key difference between Work and academic knowledge is difference in purpose to which the knowledge is to be put. At Work, knowledge is essentially used to enhance the productivity, innovativeness and skills base of the firm whereas in the academy it is concerned with the mastery of disciplines and their (possible) application in the world. 
Eraut (2004) explores this difference in purpose as it manifests itself within the nature of knowledge.

He typifies workplace knowledge as being largely context-bound, acquired through interaction with similar contexts and adaptive to prevailing conditions which may include the following: the degree of collaboration/supervision; time constraints and their conditions of performance; the culture of the workplace; and unpredictable situations to which the worker must adapt. Most Work knowledge is not codified and there is little time for critical reflection and analysis.

On the other hand, professional academic knowledge tends, to consist of codified academic knowledge in the form of academic subjects (like sciences), academic professional fields (like medicine or engineering) and some elements of the occupation itself, as described earlier by Barnett (2006). According to Eraut (2004), the relative prominence of these components is usually weighted in favour of the academic as this is the 'culture' that staff work in. Knowledge is developed and circulates predominantly through interactions with other field specialists and research. The more occupational aspects are often interpreted through seminars, simulations and on-site experience.

\section{VERTICAL AND HORIZONTAL DISCOURSES}

Following Bernstein (2000; 1999), vertical discourses have broadly accepted guiding theories and are systematic in that there are interlocking concepts. They operate in a context-independent arena (and so across contexts) at a high level of abstraction; they are furthermore highly coherent and explicit. All vertical discourses are theoretical, abstract in nature and internally coherent. What sets them apart from one another is their different internal logic and structure (for example, between different subject knowledges) and, overall, their abstract nature and internal coherency sets them apart from typically everyday knowledge in society or at Work. Within vertical discourses there are also two main types of knowledge structure, hierarchical and horizontal. The former is hierarchically organised as in the sciences and the latter consists of a number of parallel, competing and equivalent specialised languages, modes of enquiry and rules for the realisation of texts (Bernstein 1999:159), as in arts and social science subjects. There is, too, a further sub-division of horizontal knowledge structures into those with weak and those with strong grammars. Horizontal structures such as linguistics and psychology would be classified as having strong grammars whereas fields such as cultural studies, sociology and education would be seen as having weak grammars. The difference would be that fields with strong grammars 
would be immediately recognisable as such whereas within weakly 'grammared' fields a student may be uncertain as to what counts as valid knowledge. Within strongly grammared fields the internal rules for legitimate enquiry and realisation of texts would be explicit whereas within weakly grammared fields rules may be more tacit and thus more dependent on tacit and contextual acquisition. Bernstein (1999:165) further suggests that such weakly grammared fields have much in common with horizontal discourse, the discourse of everyday Work and society. Gamble (2002) illustrates the nature of such weakly grammared fields through the description of cabinet-making craft apprenticeships. Though occurring at Work and largely tacit in nature, there is still a holistic, integrated system of meaning into which individual events in crafts may be positioned and explained, thus enabling their classification as a form of vertical discourse.

Vertical discourses tend to be insulated to differing degrees from other forms of knowledge, whether everyday knowledge or other vertical discourses. There are furthermore, explicit rules (pedagogic recontextualising principles) for the transformation of knowledge from one to another vertical discourse. Vertical discourses are typically acquired through access to the organising principles of the discourse which in turn can be operationalised to explain different events.

Horizontal discourse, on the other hand, is likely to be "oral, tacit, local, specific to particular contexts, multi-layered and contradictory across but not within contexts" (Bernstein 1999:157). This is the dominant discourse of the workplace. Central to this discourse is its segmented nature; it is differently realised according to the different activities and specialisations it is embedded in. Learning in the workplace has a strong component of explicit exchange of situated narratives which are potentially inexhaustible, each new experience generating another narrative. Such segmented acquisition of horizontal discourse is also likely to involve trial and error experimentation, exploration and tolerance of dead ends (Brown and Duguid 1996). Learning in the academy is different as lecturers deal in predominantly sequential, codified, abstract and theorydriven knowledge, or vertical discourse, which students are expected to acquire in their interactions with academics.

Horizontal discourses, being often tacit, context-bound and flexibly applied, do not insert well into vertical discourse ways of doing which are more cross-contextual and abstract. Similarly, vertical discourse sits uncomfortably with horizontal discourse knowledge. 
Young's (2005) interpretation of Bernstein's concept of vertical and horizontal discourse is that these are ideal-type analytical categories rather than knowledge types that occur empirically. Vertical and horizontal discourse may thus occur in different proportions in all types of knowledge. For example, Breier (2003:83) argues that in labour law teaching practices vertical discourse is not the preserve of the disciplinary lecturer, but is produced, too, by trade union workers during interactions with the lecturer. Furthermore, everyday practices (horizontal discourse) emerge in the discourse of law within formal lecture delivery mode. There is, she asserts, a "complex relationship" between vertical and horizontal discourse in pedagogic discourse. Labour law is more of an in-between hybrid of the two.

\section{PROBLEMS OF KNOWLEDGE TRANSFER BETWEEN THE UNIVERSITY AND WORK}

According to Bernstein (1999), vertical discourse cannot generate horizontal style discourse and vice versa. For Eraut (2004) the transfer of knowledge from the academy to the workplace involves substantive work, an issue which is seldom realised by lecturers. The two types of knowledge, from Work and from the academy, seem to be doomed to a state of almost perpetual separation; crossing boundaries between them. Effecting some form of hybridisation is always going to be difficult to accomplish.

Scholars such as Young (2003), Bernstein (2000) and Muller (2000) have critiqued notions of hybridity as assuming that all boundaries are permeable and thus anything can be put with anything else. This suggests that disciplinary knowledge based on ways of thinking that have been developed over the past 150 years or so can be simply broken up and reformed at will. Furthermore, hybrid approaches are defended by 'hybridisers' (such as, for example, Gibbons et al. 1994) through their being something inevitable and unavoidable, tied up with changing modern economies and the crossing of previously "hard" boundaries (Muller 2000:57).

Broadly, one can position these authors as predominantly concerned with boundary maintenance. Those who support boundaries between different discourses across disciplines and between disciplinary and social knowledge as a given are most likely to adhere to a broadly structuralist paradigm where structures are seen as anterior to, and to some extent determining of, social action (Carter and New 2004).

When, in contrast, all disciplinary knowledge can and should be integrated and hybridised with social knowledge, authors may well take the epistemological position that all knowledges are relative and of equal value. In this version it should be possible to substitute social phenomena within disciplines with no ill-effect on either the social 
or the disciplinary world. Here, structural constraints and enabling factors are muted or absent (Muller 2000) and authors favouring this approach would tend towards a more constructivist paradigm.

For Muller (2000) the hybridisation of school knowledge with everyday knowledge is driven by self-styled (though ultimately deluded) 'progressive' educational thinkers. Here, the assumption is that more universal access to schooled knowledge is facilitated through the erosion of boundaries between school and everyday knowledge. Boundaries are seen as an impediment to learning. Muller (2000) demonstrates that hybridising mathematical and everyday knowledge serves to prevent learners from acquiring the overall logic of school mathematics and hence becoming mathematical thinkers. Some learners, usually from lower socio-economic backgrounds, are thus deprived access to 'full' mathematics.

The duality of 'maintainers versus hybridisers' or 'structuralists versus constructivists' does not, however, hold in practice; some maintainers also support hybridisation of more academic and local knowledge, though only under certain conditions. For example, Muller (2000) argues for the possibility of hybridisation of mathematics and the social world using the work of Walkerdine (1998). Here mathematical and everyday knowledge are "prised apart from their set of relations of signification" (Muller 2000:69) and rearticulated through a succession of recontextualising events. In addition, Muller and Subotzky (2001:177), in discussing community outreach at universities, conclude that university subjects and practical community issues should only be brought together where it is "operationally and epistemologically appropriate". The point raised by Muller and his co-author is not that disciplinary/social knowledge hybridisations are bad, but that they should be systematically performed within the confines of what knowledge is appropriate to hybridise at an appropriate level of disciplinary expertise, and with recognition of boundary. Without boundary there can be no meaningful knowledge development or conditions for hybridity (Muller 2000:76).

The argument thus far is that differences between Work and academic knowledge, whether these be concerned with purpose, context or knowledge structures, make the transfer and hybridisation of knowledge difficult. Activity theory, it is proposed, through acknowledging boundary and theorising boundary crossing, provides us with tools to better understand and promote knowledge transfer and hybridisation. 


\section{ACTIVITY THEORY}

Activity systems theory understands human activity as being object-oriented, i.e. there is some focal point towards which the activity is directed. For example, the lecturers of an academic department have students as their teaching and learning object and their hoped-for outcome would be learning. In order to achieve this objective, outcome tools such as lectures, texts and so on are used. The top half of the diagram in Figure 11.1 represents this triadic structure. The problem with this well-known representation of a teaching and learning system is that the complex social web, which acts on lecturers, tools and students, is not recognised. Engeström (1999) thus extends the basic triangle to include the influences on teaching and learning of the division of labour (and power) in the department, the overt and tacit rules of the department and the broader community within which the departmental lecturers operate.

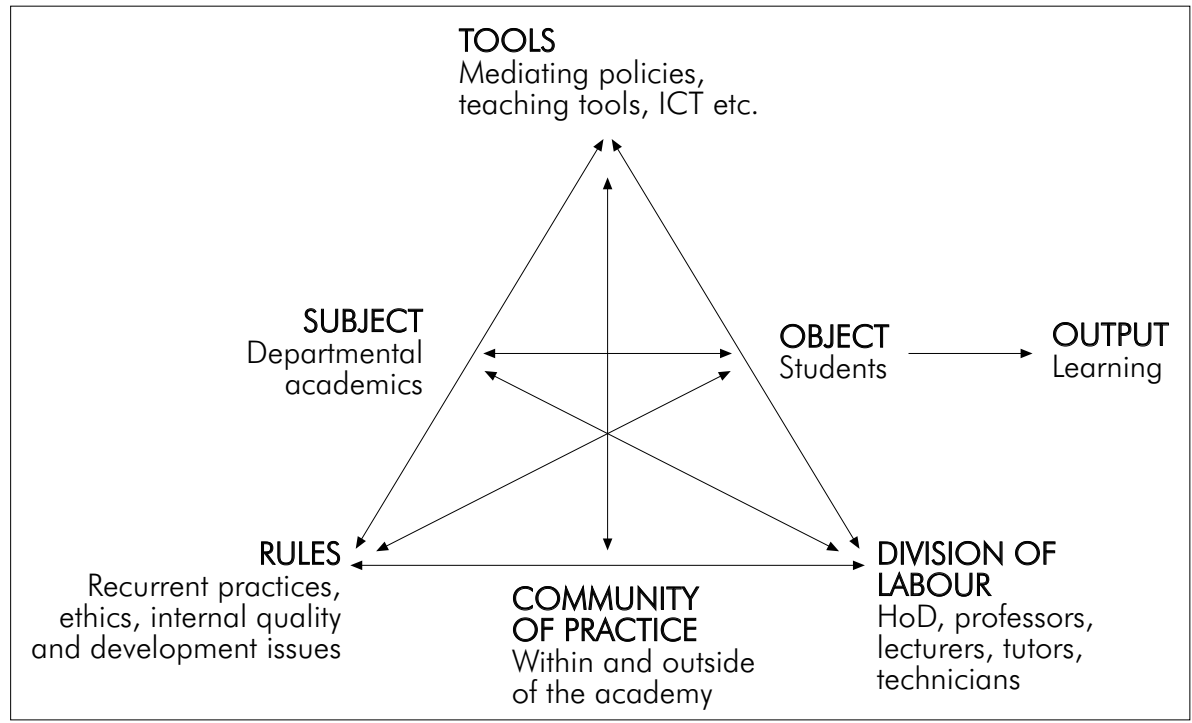

FIGURE 11.1 Proposed activity system of an academic department (After Trowler and Knight 2000)

The activity triangle is used as a heuristic to expose contradictions among its various components. The contradictions then act as a first stimulation for actors to examine how difficulties may be overcome, and further tools are brought into play as additional stimulations.

The description of workplaces as activity systems has been extensively studied by Engeström and his associates (Engeström 2001; 1999) in the fields of health and 
engineering in order to understand their internal dynamics and possibilities for change, as well as to study differences and interactions between like systems.

\section{Activity systems, boundary-crossing and hybrid developments}

Activity theorists working within the ambit of so-called third generation activity theory (Engeström 2001; Konkola, Tuomi-Grohn, Lambert and Ludvigsen 2007) are currently exploring the ideas of boundary-crossing between different activity systems. The following example illustrates important activity theory concepts concerned with boundary-crossing between different activity systems. These are the importance of hybrid forums, visibility of difference and disruption in opening up developmental hybrid spaces in which hybrid objects may be produced.

\section{DISRUPTION AND HYBRIDITY}

Gutierrez, Baquedano-Lopez and Tejeda (1999) analysed a classroom situation where the different social worlds of teachers and pupils interact within a 'third space' which extends the knowledge of both worlds. The authors then propose the development of an inter-language which bridges between these two worlds, but does more than this.

The authors show how the interaction of social groupings, each with its opposing social characteristics and epistemologies, creates disruptions and the possibility for hybrid transformations. Their example focuses on the school, on a particular attempt to teach the subject of reproduction to junior school children. Their methodology is first to examine the different discourses used by teachers and children, and then to look at how the teacher incorporates the children's discourse to create a hybrid language which talks to both the 'rude' world of the children and the official requirements of the curriculum. The authors identify two activity systems, that of the teacher, school and official schooled knowledge, and that of the 'rude' lived experiences of the children, each with its own language of description for reproduction. The two systems disrupt one another. Between them lies a third space in which a bridging, hybrid object in the form of a hybrid language develops that is understandable and operative for both systems (see Table 11.3). The hybrid language practices in the third space mediated the ways students and teacher interacted with one another and mediated student learning and intellectual development. The third space can be depicted with samples of language from both activity systems and resultant hybrid language practices inscribed (Gutierrez et al. 1999:297). 
TABLE 11.3 Hybrid language in the third space

\begin{tabular}{|c|c|c|}
\hline $\begin{array}{c}\text { Teacher } \\
\text { talk }\end{array}$ & $\begin{array}{c}\text { Third space (hybrid space) } \\
\text { tudent } \\
\text { talk }\end{array}$ \\
\hline The chest & "In some families the chest is affectionately known as chi-chis." & Chi-chis \\
\hline
\end{tabular}

The examples of interacting activity systems above can now be used to explain how new knowledge forms may arise. Outputs presented from each system (which result from the action of the system on its objects) come into contact with one another and there are similarities, differences and gaps between them. Where there are differences they may serve to challenge and disrupt the previously held knowledge of the other. The processes of disruption are that knowledge is questioned, analysed and potentially remodelled in a way which satisfies both activity systems. A new zone of potential knowledge development can be opened up between the two activity systems such that "potentially shared or jointly constructed objects" may arise and be identified (Engeström 2001:136).

Work responsiveness involves interaction between Work and academic representatives. We are now in a position to describe an academic department as an activity system whose outputs (e.g. knowledge and procedures) interact with those of another activity system from Work. In between the two systems there is a zone of potential development. This zone arises, because differences raised between the two systems disrupt one another, and these disruptions can be mediated by boundary- crossing work. The interactive structure is shown in Figure 11.2.

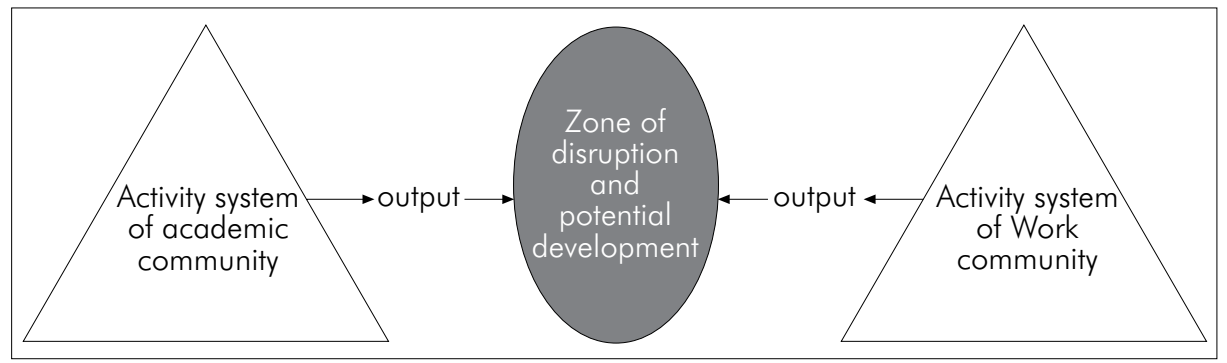

FIGURE 11.2 Interactions between two activity systems

Under certain conditions the zone of potential development can become, a productive in-between space or third space. Third spaces, as is argued by activity theorists, are the result of boundary work and can also be developed further by such work. 


\section{THIRD SPACE DEVELOPMENT BETWEEN UNIVERSITY AND WORK KNOWLEDGE}

\section{Project work}

An example from the Finnish Polytechnic (Miettinen and Peisa 2002) involves thirdyear students in a technology and a business department working cooperatively with one another in partnership with a truck cab industrial firm. Even though some of the students are training as engineers, the focus of the students is on how the truck cab business is run. The purpose here is to engage students in more real Work scenarios rather than in often clearly (to the students) contrived simulations. The task involves learners in moving from simulation with no consequences to consequential, creative, exploratory work in the zone of development beyond that actually practised by both the firm and the institution. In so doing both workplace and academic theoretical knowledge is developed.

Students are divided into four groups within the institution, each group representing the different functions of the truck cab firm (production, finance, logistics and accounting). Each group is asked to step outside the institution and do in-depth research and analysis of one function of the firm. This involves limited experiential work, observations in the firm, interviews with the firm's members and reading up on the firm so that they really come to know that part of the firm. The hybrid forum thus involves students, academic tutors and Work representatives. Once they really know how one of the functions of the firm works, they are asked to identify dilemmas or issues which arose.

The next step for students is to ask the question: "If this is what the firm is currently doing, and this is the issue that is arising, how can they extend their current practices to deal with it?" In identifying the issue and in suggesting ways in which it may be dealt with, learners are asked to mobilise what they have learnt in the institution in new and innovative ways - new, because they have never seen these problems before, and innovative, because they have to bring their academic and Work knowledge to the problem all at once in order to come up with a creative solution.

The solutions the groups come up with are not simply theoretical. The students are required to write these up and present them persuasively to the company; they have to say why they think the company could benefit from such changes. Evidence as to whether or not their ideas are good comes from the type and level of critique coming from the company, thus there is again the involvement of the Work hybrid forum representatives. A new object emerges in the third space - a Work problem about which solutions are sought through mobilising academic knowledge. 
The project involves another level of knowledge development. The academic curriculum is interrogated from the point of view of the students' Work experiences: students with their tutors are asked to identify gaps and areas to be mutually developed. This is a mirror process of the one in the workplace in which academic knowledge is now transformed.

The nature of the project is that new knowledge to deal with a Work issue is mutually constructed from both Work and academic components. Furthermore there is an impact on the academic curriculum as it is re-examined in the light of workplace learning.

Differences between Work and the curriculum are highlighted in hybrid forums consisting of lecturers, students and workers. The tension created by the necessary differences opens up a 'third space' in which a new, hybrid object, the solution to a Work issue, arises and develops through the collaborative actions of the actors.

These processes performed by the participants constitute 'boundary work'. Boundary work enables the transfer of knowledge across boundary and its successful hybridisation.

As already pointed out with reference to a South African medical school, hybridisations between Work and more traditional academic knowledge are not always without conflict. In this problem-based learning example the contents of subjects such as pathology and anatomy were forwarded by academic staff as necessary for student learning, even though not all the content elements were necessary to solve the problem situation being studied. The tendency was for these elements now to be included through restructuring the problem, or for content to continue being taught in traditional format alongside the problem-based approach to ensure no elements were left out. Even though the courses operated within a broadly integrated PBL structure, disciplinary knowledge structure still exerted a strong influence.

\section{Advisory committees}

The second example concerns advisory committees in South African universities of technology. Advisory committees consist of an assortment of field-relevant Work representatives and the academic staff of a department. They are thus hybrid forums. They meet once or twice a year. The role of the committee is to decide upon curriculum issues so that the academic courses are more closely aligned to what Work wants, 
and to changes which are occurring in industry. There is no fixed way in which the committees operate and they may have different protocols.

These committees are heterogeneous, purposeful curriculum design meetings and fulfilled the following criteria: they involved interaction between Work and academic representatives in some sort of formal, purposeful manner; they involved negotiation of procedures and knowledge; and they were concerned with developing some aspect of the curriculum.

In the advisory committee I observed differences in the kind of knowledge which was highlighted as 'relevant' for students, and interactions involving the force with which different propositions were presented. Unlike in the previous example, I could examine the actual actions of actors in raising differences and attempting to cross boundaries between the activity systems of Work and the institution. In an examination of over 22 such meetings I found that most contained elements of boundary crossing, but these were mostly not developed. In most cases it was possible to identify distinct developmental phases that were either successful or unsuccessful. Table 11.4 shows an edited version of an excerpt from a more successful meeting.

TABLE 11.4 Edited transcript of interactions between Work and academic representatives

\begin{tabular}{|c|c|}
\hline Representative & Statement \\
\hline Work & $\begin{array}{l}\text { The students do not know the difference between minerals and rocks. You } \\
\text { need to include geology. }\end{array}$ \\
\hline Academic & $\begin{array}{l}\text { A good idea. We should also think of the other specialisations we need ... } \\
\text { should this go into the current diploma or is there too much already? }\end{array}$ \\
\hline Work & A talk from industry then? \\
\hline Academic & It must be formal and assessed \\
\hline Academic & But the curriculum is already very full ... \\
\hline Work & $\begin{array}{l}\text { What about a new geology module and modules in the other } \\
\text { specialisations? }\end{array}$ \\
\hline Academic & $\begin{array}{l}\text { We should think of integrating knowledge rather than adding on extra } \\
\text { modules. }\end{array}$ \\
\hline Academic & We could replan the whole course to do this. \\
\hline Work & $\begin{array}{l}\text { Remember to have integrated assessments when you do this (not just } \\
\text { across subjects). }\end{array}$ \\
\hline Work & $\begin{array}{l}\text { The new integrated curriculum should relate to what the training boards } \\
\text { are doing. }\end{array}$ \\
\hline Academic & $\begin{array}{l}\text { It is not just geology, but also communications and maths which should be } \\
\text { integrated. }\end{array}$ \\
\hline
\end{tabular}

What is interesting here is how the academics are willing to mediate between the needs of industry (the need for a geology component) and the requirements of the academic 
curriculum (the fact that it is already quite full, and that components must be assessed). Here, the academics are acting as knowledge brokers (Wenger 1998:10).

In terms of boundary work performed by participants, this excerpt can be analysed as:

Participants raise differences $\rightarrow$ differences disrupt and create a new third space for discussion $\rightarrow$ actors work on boundary-crossing processes between Work and the academic world $\rightarrow$ a new hybrid object forms (integrated curriculum) $\rightarrow$ it is developmental as it can undergo further change through collaborative work.

Other meetings were more conflictual in nature with representatives taking opposing positions which became further cemented during the course of the meetings. In one meeting the issue of a sandwich workplace training year (experiential year) was raised. Industry representatives wanted the experiential year rather to occur after two full years of academic training, after which, they believed, students would be more trainable and useful in the workplace. The academics, on the other hand, stated that the experiential year provided a platform for later learning in the second, fully academic year. Industry accepted this argument and offered shorter periods of Work exposure for students after the first academic year. However, the academics rejected this proposal insisting that the full sandwich year was essential for student development. Despite being dependent on industry for 'hosting' students in their experiential year, the academic logic dominated that from the workplace.

The chemistry meeting was successful, because a mutually developed, in-between hybrid object emerged (or at least began to emerge). Likewise, the Miettinen and Peisa (2002) project was successful because of a similar development. Successful integration, or at least the potential for success, can be understood in terms of the productivity of interactions between Work and academic knowledge.

\section{Productivity}

As pointed out earlier, knowledge transfer involves both movement from one world to another and change in this knowledge. Where knowledge transfer has successful outcomes it can be referred to as productive. The concept of productivity derives, firstly, from Wenger's understanding that new meaning is a product of interaction between existent (and often fixed) meanings generated within separate communities of practice (Wenger 1998:54), Secondly, productivity has its origins within the activity theorists' understanding and promotion of the development of "potentially shared or jointly 
constructed objects" in the interstices between different activity systems (Engeström 2001:136).

Productivity relies, firstly, on boundary recognition and hence the existence of some degree of difference between different knowledge forms. Boundary recognition involves making difference which may have previously been implicit explicit. It is not, however, necessarily a barrier to further development; boundary, rather is a pre-requisite for hybrid developments. When two different communities interact, their differences become a resource and there is the possibility that previous contextual constraints fall away or are muted as a new, intermediate space develops. On its own the space will not necessarily result in interactions which may be productive. There need to be actions by actors to cross these boundaries.

Productivity is now measured as the extent to which new, collaborative knowledge formations arise within this intermediate space through the collaborative actions of the actors involved. Being productive is therefore more than just communication across differences. It involves the production of new knowledge with elements of both higher education and Work which has value in both of these contexts.

The concept of productivity can be further elucidated with reference to another activity theorist, Van Oers (1998), and his generative conception of 'recontextualisation'. Van Oers describes depthful integration and development of one form of knowledge within another as vertical recontextualisation and contrasts this with horizontal contextualisation in which, for example, Work and academic discourses do not undergo mutual development. In horizontal recontextualisation the workplace activity would be relatively un-problematically inserted into the curriculum. For example, learners may perform mathematical calculations of real situations within engineering classes. The workplace here serves to connect different strands of mathematics to one another in order to solve a problem, or to specify particular aspects of mathematics and exclude others. Horizontal recontextualisation can be recognised in the earlier description of experiential learning in chemistry. Recontextualisation only becomes vertical when the process opens up new avenues of thinking or new ways of doing things and becomes more generative, often applying theoretical subject knowledge in new ways to do this, as was illustrated in the Finnish engineering project (Miettinen and Peisa 2002).

\section{CONCLUSIONS}

Boundary crossing between Work and academic knowledge within the academic curriculum is a world-wide phenomenon which is further forwarded in South African 
higher education policy. The problem raised in this chapter is that there is an expectation from policy makers that boundary crossing and subsequent knowledge transfer and integration is an uncomplicated process which should occur naturally. On the contrary, this chapter has argued that Work and academic knowledge are in general differently structured, have different purposes and differ in practice. If this is the case then there needs to be a theory as to how the two may be successfully integrated.

In third generation activity theory, structural and other differences between interacting activity systems are seen as a resource for future development of new knowledge, rather than as an impediment which needs to be 'eroded'. As was earlier argued, it is the very existence of boundary that sets up the conditions for hybrid developments. The process of development typically begins with the setting up of hybrid forums and the raising of differences, followed by mutual disruption and the emergence of new hybrid objects. The concept of productivity develops activity theory further in order to better understand the formation of mutually developed, Work/academic hybrid knowledge constructs, and the stages described can be recognised in the two idealised examples of curriculum development discussed.

However, 'productive' interactions in new curriculum formation as described in this chapter may generally be a somewhat rare occurrence. As indicated earlier, Work and academic communities may take on conflicting positions which are difficult to bridge. As I have argued elsewhere (Garraway 2005) this may, because the initial differences between the groups are simply too large for any boundary-crossing activity to follow successfully.

Another consideration pertaining to whether or not academics and Work representatives will successfully hybridise knowledge concerns their relative positions of power. We have, for example, seen how curriculum interactions between Work and academic representatives are often skewed in favour of the academics. As Ensor $(2001$; 2002) suggests, despite post-1994 attempts by Government to make universities more accountable to Work and society, traditional universities have, by and large, managed to hold onto their academic power base. As she puts it, the dominant organising principles for new programmes are vertically structured disciplines. Where Work practices were brought into the traditional curriculum, for example, desktop publishing in applied language studies, they appear as separate modules.

Looking forward, Gibbons's (2005) thesis is that the university of the past was one in which what happened in the university was relatively impermeable. The university of the future is one in which "the new contract will be based upon the joint production of 
knowledge by society and science" (Gibbons 2005:5). The actualisation of the new contract will necessarily imply that individuals in institutions will engage with transaction spaces where knowledge difference is negotiated. If this is the case then the facilitation and management of hybrid forums and boundary crossing between disciplines and Work will become core work within the university, even if this was done to some extent in the past, and particular skills and resources will need to be developed to enable productivity within these processes.

In terms of skills, the development of academics as knowledge brokers would be important. Brokers are those who occupy positions of dual membership of communities. They use this multi-membership to transfer elements of one practice to another (Wenger 1998:109). In Work/academic boundary situations brokers may be those academics who have recently come from industry, or who still perform part-time industry work, though the problem may now be their under-developed disciplinary and teaching expertise, or what Schulman (1986) calls "pedagogic content knowledge". Established academics could also spend 'research time' time at Work and be engaged with student Work projects in order to better act as brokers. This form of brokering work could be seen in the Finnish engineering project described earlier. Konkola et al. (2007) also describe lecturers acting as brokers in student health projects, and explain how the project itself serves to articulate the different expertise of lecturers, students and Work practitioners towards the solution of a Work problem. Work brokers are typically those who have been involved in education projects and thus have some knowledge of teaching and learning.

Being a broker does not necessitate direct involvement in both communities; it can also be more symbolic. In the chemistry advisory committee example, academics were able to act as brokers through thinking beyond the confines of their disciplinary cultures and 'imagining' how Work knowledge could be incorporated into the curriculum.

In the experiential sandwich year example discussed earlier, a Work broker had attempted to act as a bridge between academic and Work needs. It was possible to do this as they had been involved in an in-house bursary and mentorship schemes, and had conducted discussions on teaching and learning. Although they had the required expertise, the academics did not recognise it and consequently refused to accept the ideas of the industry representatives. Brokers, whether they are from work or from the academy, need to have confidence and courage to transgress into the knowledge of the other community, and to manage this transgression. It is always possible that they 
will be viewed as non-legitimate by members of the community into which they are transgressing.

For knowledge brokers to have a better chance of success there needs to be an enabling environment; having brokers alone is not enough. Moreover, there need to be hybrid forums consisting of Work and academic representatives, in which to conduct knowledge brokerage. One type of forum discussed here, the advisory committees, tended to meet only once or twice a year, meaning that the extent to which extensive and continuous boundary work can be done was limited. If advisory committees, and other hybrid curricula forums like them, are to be more productive, then specialist groups accreted around particular knowledge issues should hive off from the main group. They would interact over time. Interesting work has been done in Finland and France on the idea of 'boundary (or learning) laboratories' (Engeström 2001). Differences between cultures, knowledge bases or even procedures are deliberately raised and amplified by trained 'boundary analysts'. The role of the analysts is then to identify conflicts within each activity system and, over time, to position these as sites for further mutual development. Boundary analysts are also in a good position to support and develop attempts by representatives of either community to broker knowledge.

\section{REFERENCES}

Barnett M. 2006. Vocational knowledge and vocational pedagogy. In: M Young \& J Gamble (eds). Knowledge, Curriculum and Qualifications for South African Further Education. Cape Town: HSRC Press. 143-157.

Barnett R. 2004. Learning for an unknown future. Higher Education Research and Development, 23(3):247-260.

Bernstein B. 1999. Vertical and horizontal discourse: An essay. British Journal of Sociology of Education, 20(2): 157-173.

Bernstein B. 2000. Pedagogy, Symbolic Control and Identity (revised edition). Lanham, Maryland: Rowman and Littlefield.

Boud D. 2001. Creating a work-based curriculum. In: D Boud \& N Solomon (eds). WorkBased Learning. A New Higher Education? Buckingham: Open University Press. 44-58.

Boughey C. 2002. From equity to efficiency. Access to higher education in South Africa. Arts and Humanities in Higher Education, 2(1):65-71.

Breier M. 2003. The Recruitment and Recognition of Prior Informal Experience in the Pedagogy of two University Courses in Labour Law. Unpublished doctoral thesis. University of Cape Town.

Brown J \& Duguid P. 1996. Organisational learning and communities of practice. In: M Cohen \& L Sprout (eds). Organisational Learning. London: Sage Publications. 
Carter B \& New C. 2004. Realist social theory and empirical research. In: B Carter \& C New (eds). Making Realism Work: Realist Social Theory and Social Research. London: Routledge.

Cloete N \& Maassen P. 2002. Global reform trends in higher education. In: N Cloete, R Fehnel, P Maassen, T Moja, H Perold \& T Gibbon (eds). Transformation in Higher Education: Global Pressures and Local Realities in South Africa. Cape Town: Juta.

Dearing R. 1997. National committee of inquiry into higher education. Higher education in the learning society. Report of the National Committee. Norwich: HMSO.

Engeström Y. 1999. Innovative learning in work teams. In: Y Engeström, R Miettinen \& R Punamaki (eds). Perspectives on Activity Theory. Cambridge: Cambridge University Press.

Engeström Y. 2001. Expansive learning at work: Towards an activity theory reconceptualisation. Journal of Education and Work, 14(1):133-156.

Ensor P. 2001. Academic programme planning in South African higher education. In: M Breier (ed). Curriculum Restructuring. Bellville: University of the Western Cape Educational Policy Unit.

Ensor P. 2002. Curriculum. In: A Cloete \& B Bunting (eds). Transformation in Higher Education: Global Pressures and Local Realities in South Africa. Cape Town: Juta.

Eraut M. 2004. The transfer of knowledge between settings. In: H Rainbird, A Fuller \& A Munro (eds). Workplace Learning in Context. London: Routledge.

Gamble J. 2002. Teaching without words: Tacit knowledge in apprenticeship. Journal of Education, 28:62-82.

Garraway J. 2005. Creating productive interactions between work and the academy. Higher Education, 52:447-464.

Garraway J \& Volbrecht T. 2007. Theorising experiential learning in terms of Bernstein's recontextualisation principles. In: S Walters \& L Cooper (eds). Proceedings of the $5^{\text {th }}$ International Conference on Researching Work and Learning, Universities of the Western Cape and Cape Town. Cape Town. 2-5 December.

Gibbons M. 2005. Engagement with the community: The emergence of a new social contract between society and science. Paper Presented at the Griffith University Community Engagement Workshop, South Bank Campus, Queensland, Australia, 4 March 2005.

Gibbons M, Limoges C, Nowotny H, Schwartzman S, Scott P \& Trow M. 1994. The New Production of Knowledge. London: Sage.

Gutierrez K, Baquedano-Lopez P \& Tejeda C. 1999. Rethinking diversity: Hybridity and hybrid language practices in the third space. Mind, Culture and Activity, 6(4):286-303.

Kneale P. 2003. Researching intrapreneurship: Delivering skills and work experience through case-studies. Paper presented at the South African Academic Development Association Conference. Cape Town, South Africa. December 2003.

Konkola R, Tuomi-Grohn T, Lambert P \& Ludvigsen S. 2007. Promoting learning and transfer between school and the workplace. Journal of Education and Work, 20(3):21 1-228.

Kraak A. 1999. Competing education and training policy discourses. In: J Jansen \& P Christie (eds). Changing Curriculum. Cape Town: Juta. 
Layton D, Jenkins E, Macgill S \& Davey A. 1993. Inarticulate Science? Perspectives on the Public Understanding of Science and Some Implications for Science Education. Nafferton: Studies in Education Limited.

Miettinen R \& Peisa S. 2002. Integrating school-based learning with the study of change in working life: The alternative enterprise method. Journal of Education and Work, 15(3):303-319.

Moore R. 2003. Adaptive Responses to Curriculum Restructuring Policy in Two South African Universities. Unpublished doctoral thesis. University of Cape Town, August 2003.

Muller J. 2000. Reclaiming Knowledge: Social Theory, Curriculum and Education Policy. London: Routledge Falmer.

Muller J \& Subotzky G. 2001. What knowledge is needed in the new millennium? Organisation, 8(2): 163-182.

NCHE (National Commission on Higher Education). 1996. Discussion Document: A Framework for Transformation. Pretoria: Human Sciences Research Council Publications.

Nowotny H, Scott P \& Gibbons M. 2001. Science, Knowledge and the Public in an Age of Uncertainty. Cambridge: Polity Press.

Seagraves L \& Boyd A. 1996. Supporting learners in the workplace: Guidelines for learning advisers in small and medium sized companies. Stirling: University of Stirling.

Schulman LS. 1986. Those who understand: Knowledge growth in teaching. Educational Researcher, 15(2):4-14.

Star L \& Griesemer J. 1989. Institutional ecology 'translations' and boundary objectives. Social Studies of Science, 19(3):387-420.

Steinberg C \& Slonimsky L. 2004. Pedagogical responsiveness to learning: Students confronting an unfamiliar text-based reality. In: H Griesel (ed). Curriculum Responsiveness: Case Studies in Higher Education. Pretoria: South African Universities Vice-Chancellors Association.

Trowler P \& Knight P. 2000. Coming to know in higher education: Theorising faculty entry to new work contexts. Higher Education Research and Development, 19:27-42.

Van Oers B. 1998. The fallacy of decontextualisation. Mind, Culture and Activity, 30(2):143-164.

Walkerdine V. 1998. Counting Girls Out (Second Edition). London: Falmer Press.

Wenger E. 1998. Communities of Practice: Learning, Meaning and Identity. Cambridge: Cambridge University Press.

Young M. 2003. Transfer and transition in vocational education. In: T Tuomi-Grohn \& Y Engeström (eds). Between School and Work: New Perspectives in Boundary Crossing. Amsterdam: Elsevier Science.

Young M. 2005. The knowledge question and the future of education in South Africa: A reply to Michelson's 'On trust, desire and the sacred: A response to Johan Muller's Reclaiming Knowledge'. Journal of Education, 36:7-18. 


\section{PART FOUR}

TESTIMONIES AND REFLECTIONS ON PROFESSIONAL DEVELOPMENT IN HIGHER EDUCATION 


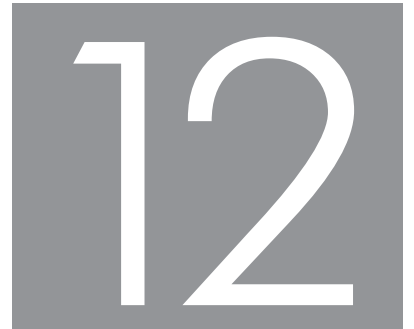

\section{THE PROFESSIONAL \\ DEVELOPMENT OF \\ ACADEMICS}

\section{IN PURSUIT OF SCHOLARSHIP}

Liezel Frick \& Chris Kapp

\section{ABSTRACT}

In this chapter we explore the development of academic staff as an area or theme for study and research in the field of higher education - from both a theoretical and a practical stance. We start by providing a broad definition and an overview of a number of theories underlying the concept and continue to discuss the issues and challenges that it faces in higher education. The notion of scholarship forms the basis of the discussion. A brief discussion on how academic professional development is practised ensues and a South African case study of formal education for academic professional development and the scholarship of teaching is explored. We conclude this chapter with a number of ideas on future developments in the field, which may be of interest to scholars who wish to study the professional development of academics within institutions of higher education.

\section{INTRODUCTION}

Higher education worldwide has been experiencing change at a rate unknown in the past and several chapters in this book highlight this reality. The so-called knowledge society and information age within which we live are characterised by an increased rate of knowledge production and greater access to information. Universities are experiencing this information boom in many ways, but the most significant changes affecting higher education have been dealt with by transforming the system. New types of institutions have emerged, new academic programmes have developed, the traditional disciplinary approach has been questioned, and learning has been transformed by new technologies. The drive for transformation has also led to a questioning of what universities do and how well they are doing it (the drive for quality). 
The academic staff member stands at the centre of all these changes. Despite all the transformative changes attacking the "soul" of the university (Levine 2000), academic staff have had to continue with their scholarly business: teaching, research and interaction with communities. University lecturers as professionals function within a unique area of professional practice, as their practice requires elements of both discipline-specific and educational expertise. Academic professional development (APD) has emerged as an area of practice (and study) in higher education as a way in which to help academic staff to adapt and to keep abreast of all these changes and challenges.

This chapter provides a conceptualisation and overview of APD and explores the rationale for engaging in APD initiatives. A comparative case study of two South African programmes aimed at developing the scholarship of teaching is used to illustrate a formal approach to APD. We conclude by considering APD as a field of study. An overview of scholarly research contributions to the area of APD illustrates the interests and approaches of scholars interested in the study of APD. This synthesis allows us to consider the way forward for APD as an area of study.

\section{THE PROFESSIONAL DEVELOPMENT OF ACADEMICS: DEFINITION AND UNDERLYING THEORIES}

Academic professional development (APD) is not easily defined, and scholars need to take heed of various related and underlying terms and theories in the study of such a phenomenon. For the purposes of this book it was consciously decided to use the term 'academic professional development' rather than related terms such as 'continuing professional development' (CPD), 'continuing professional education' $(\mathrm{CPE})$, 'continuing professional learning' (CPL) or 'staff development' (which could include employees of the university at all levels), as the chapter specifically focuses on lecturers as professional practitioners in academia. APD is seen as the broadest possible concept that incorporates both the education and learning that academics as professionals engage in during their transition from novices to experts and beyond. (This would include self-directed and informal learning experiences, as well as formalised and non-formal learning.)

Why the emphasis on development? Webb (1996:65, in Land 2001:4) describes development as a contestable and non-unitary concept, and therefore "of necessity a site for encounter and dispute". As such, development goes further than education (the transfer of knowledge and/or skills through various means in its broadest sense) 
and learning (incorporating education into existing knowledge and/or skill systems). Development includes incorporating and adapting all that is learnt (in whichever way) into professional practice, making it appropriate to the individual professional's context. Professional development stretches beyond knowledge and skills to the values and attitudes that define an individual's professional identity as a scholar. It also places greater emphasis on the organisation than on the individual in terms of needs, purposes and provision of development initiatives. Therefore APD is seen as more appropriate in the higher education context as it implies a holistic approach to learning, transformation and application that takes place within the total context of academics' professional practice. APD includes the actions, activities, policies and procedures that an institution puts in place to ensure the continuous professional growth and development of its most expensive and precious commodity, namely its academic staff. In the context of this book APD can therefore be defined as any formal, non-formal or informal initiative beyond initial training whereby the lecturer as professional practitioner obtains knowledge and/or skills that can transform professional practice and/or professional identity. APD refers to the enhancement of professional competence and expertise to the benefit of the individual professional, the organisation, its clients and society as a whole (see Frick and Kapp 2007 for a more detailed discussion).

The work environment in academic practice makes diverse demands on the lecturer as a professional practitioner. These demands can be summarised according to the various scholarship roles (discovery, teaching, engagement and integration) initially defined by Boyer (1990) and later expanded by various authors (O'Meara and Rice 2005; Badley 2003; Sorcinelli 2002; Zahorski 2002; Rice 1991, 1996, 2002; Diamond 1993, 1999; Lynton and Driscoll 1999; Schulman 1999; Lynton 1995 -amongst others). Lynton (1995) and Lynton and Driscoll (1999) later added the scholarship of engagement. The four scholarly roles of Boyer (1990) will be used as a basis for the arguments posed in this chapter. Boyer's (1990) dimensions of scholarship provide a mandate for APD, as academic renewal (and therefore APD) is essential to the life of the university. What it means to conduct scholarly work in academe will be discussed in greater depth in some of the other chapters in this book.

The idea of APD therefore needs to be placed within the context of academic practice and the notion of scholarship for the purposes of this chapter. Scholarship is determined by having scholarly credentials within a specific discipline (usually by means of research), staying abreast of the latest developments in a field, maintaining the standards of integrity of a discipline (thus refraining from any unethical behaviour), and through the assessment of scholarly work in whichever form (often through 
publication and peer review). Glassick, Huber and Maeroff (1997) translate these scholarly prerequisites into more definite criteria for scholarly practice, namely clear goals, adequate preparation, appropriate methods, significant results, effective presentation, and reflective critique. These criteria apply to all activities deemed as scholarly - be it discovery (research), teaching, engagement (service) or integration. Boyer (1990) concludes that a delicate balance exists between systematic rigour and flexibility in the assessment of scholarship.

Scholarship is a multidimensional concept and the scholar is expected to negotiate what Barnett (2000, in Harris 2005:426) describes as "dynamic relationships between social and epistemological interests and structures". Scholarly identity is a product of individual values and beliefs, as well as institutional culture and positioning of the particular discipline. Developing a scholarly identity has become increasingly difficult in an academic environment that places multiple demands on the scholar (Harris 2005), in an environment where research is seen as "the strongest academic currency in higher education" (Henkel 2005:164). Scholarly development and identity therefore tend to focus on the scholarship of discovery in a specific discipline (Andresen 2000).

Very few lecturers excel naturally and equally in all their scholarship roles (Andresen 2000). The majority of lecturers need to continuously develop their professional skills in all their scholarly roles. An integrated model of academic professional practice in higher education is therefore implied, which integrates the lecturer's scholarly roles of teaching, research, engagement, integration and administration. This is in contrast to a more one-dimensional model, where the academic practitioner would focus on only one of these roles and develop linearly within the specific role. McDonald (2001), Kachingwe (2000) and Cobb (1999) point out the difficulty in developing, integrating and balancing these roles and responsibilities in practice. The question is whether academic professional development can be seen as a coping mechanism for modern-day lecturers in their constant quest for professional balance and excellence as scholars.

\section{A BRIEF HISTORY OF ACADEMIC PROFESSIONAL DEVELOPMENT}

The period 1979-2000 was characterised by a search for a definition, a context, a purpose and a philosophy of APD. The first documented and purposeful attempt to define the concept and to describe the context, purpose and philosophy of APD was made by an international group of 'new' so-called staff developers from 30 countries at a workshop on Staff Development that was sponsored by the British Council and 
held at Oxford University from 1-12 April 1979. These staff developers came from a diverse range of disciplines, although most of the early leaders in APD came from a teaching and learning (education) background (especially in South Africa), which may have influenced the evident emphasis on the scholarship of teaching and learning in APD. This initial workshop was facilitated by Alan Harding (an engineer) and the proceedings of the workshop captured perspectives from all the participating countries. The participants eventually defined APD, then referred to as staff development, as "all actions, activities, procedures and policies that an institution puts in place to enhance the performance and productivity of their staff" (Harding, Kaewsonthi, Roe and Stevens 1981). The consensus on the purpose of staff development was that it would improve and develop the quality of teaching and learning in higher education by providing a support service to academic staff.

From a South African perspective, the lead in establishing APD as an area of practice and later as an area of study within higher education was taken by Kalie Strydom from the University of the Free State, who called the first conference on this topic in 1979. The movement towards establishing APD units was triggered by several government reports that expressed concern about the high failure rate of first-year students and put the blame for this partially on the lack of teaching skills of academic staff (also see the chapter by Bitzer and Wilkinson). The main activities of these units in South Africa were similar to those in other countries, as the focus of the majority of units (called bureaus) was mainly on curriculum design, teaching and learning, and assessment. This included induction courses for new academic staff, skills-based workshops on aspects related to teaching and learning, consultation services to individual staff members, student feedback and related activities and policy development.

The representatives from South African APD units (bureaus) regularly met as most of them represented their institution on a sub-committee for university teaching of the Committee of University Principals (CUP). It was from these meetings and the conferences arranged by Strydom that the South African Association for Research and Development (SAARDHE) was established in 1979. One of the first objectives of SAARDHE was to establish an academic journal, the South African Journal of Higher Education, in 1987.

A later international survey by Frick and Kapp (2006a) revealed a number of significant changes that took place between 1995 and 2005. The main change in APD was reportedly the change in the profile of APD. The acceptance of continuing professional development (CPD) in APD (even replacing academic staff development in terms of 
accepted terminology in some cases) was also noted within the responses of APD managers, whereas the past revealed a 'train and release' approach - as stated by one respondent. Changes in reports and policies seem to have had a determining effect on the practice of APD in higher education. Examples of these changes include the Dearing Report in the UK (National Committee of Enquiry into Higher Education 1997), a move to outcomes-based education (OBE) in South Africa (RSA 1996), New Zealand's Education Amendment Act (New Zealand Government 1990). A progressive move to learner-centred education and teaching has required a change in APD, and e-learning has necessitated an informed input from the APD sector. The increase in demands placed on academic staff in higher education has also influenced the practice of APD. Other noted changes include changes in the strategic positioning of APD within institutions, and more specialised input that is required into the key focus areas of APD, such as research specialisation and e-learning as well as policy changes towards outcomes-based education. The main trend observed in the particular study was related to the focus of APD centres/units, which remained strongly linked to improving teaching. This emphasis on the scholarship of teaching and learning in institutionalised APD was clearly illustrated by the names given to or adopted by most of the units.

\section{THE RATIONALE FOR ACADEMIC PROFESSIONAL DEVELOPMENT}

Professionals do not have the luxury of predictable career paths in the postmodern organisation. Grzyb, Graham and Donaldson (1998) found that career instability was a determining factor in professionals' decisions to participate in APD activities. Technological advances and changes in student demographics add to the changed (and still changing) academic context within which academic professionals have to function. Within the South African context the digital revolution with its emphasis on e-learning, the diversity of student populations and academic staff after 1994, the move towards outcomes-based education and the initial introduction of the National Qualifications Framework (NQF) and later the Higher Education Qualifications Framework (HEQF) formed part of this changing context. Continuous research and debate in the field of scholarship development is necessary to understand the current context of academic practice and help shape its future. The need for APD is therefore not just to keep abreast of the latest developments, but also to improve the continuing employability of professionals (Kabouridis and Link 2001; Kachingwe 2000; SadlerSmith, Allinson and Hayes 2000; Challis 1999; Grzyb et al. 1998). 
Professionals seek APD as additional educational experiences to remind them of what they once knew and have forgotten (affirm and refresh), to acquaint them with the latest developments in knowledge (update) and to help them solve problems (reflect and apply). APD is a vital instrument through which professionals can channel their creative energy, talents and skills in order to remain relevant in society and continue to be viable in the profession. The learning in APD can either be incremental, which refines or adds to past learning, or transformational, which is new and fundamentally different from previous learning. Each individual therefore makes a unique combination of theory and practice (Alemna 2001; Beatty 2001; Daley 2001; McDonald 2001).

APD is also influenced by the organisation. This leads to the central problematic question surrounding APD: Whose interests are being served by APD? The conflict between the self-fulfilment of the individual professional and the expectations of the organisation is integral to the different purposes stated in the literature on APD (McDonald 2001; Wilson 2000; Battersby 1999). Grzyb et al. (1998) found that organisations use subtle ways to exercise power over professionals, including power over the decisions to participate in APD. The role of organisational context in APD is becoming increasingly important. Performance and learning take on multiple forms within organisations and are influenced by the context, the organisational setting and the learners' personal motivation, job satisfaction, morale and activity. Socialisation of professionals into practice tends to be founded on the organisation rather than on the profession itself, as the organisation creates the social and structural context of successful professionalisation (Hart et al. 2000; Knox 2000; Odini 1999; Bitzer and Kapp 1998; Grzyb et al. 1998). Livneh and Livneh (1999) support the influence of external motivators, referring to organisational influences such as promotion and remuneration in the professional's decision to pursue APD. Internal motivation, however, remains the strongest force in the professional's quest for further education.

The interplay between individual and organisational interests raises questions on whether professional development (generally speaking) should be of a compulsory nature. The need for such development can also be approached from other perspectives, such as legislative forces, where accreditation and certification play determining roles in the APD sphere. McDonald (2001) and Mott (2000) specifically refer to increased public pressure and demand for recertification and even relicensure for professionals. Globally, governments have turned to professional credentials in ensuring professional competence, establishing standards of practice, protecting public interests and maintaining minimum levels of ethical practice. Mandatory professional development as a means of maintaining credentials remains an unresolved issue. Critics argue 
that it leads to higher costs to the consumer and is based on a remedial approach to education, whilst there is no evidence that mandatory initiatives ensure professional competence. Current assessment or evaluation methodologies cannot ensure that mandatory professional development will lead to improved or maintained competence (McDonald 2001; Daley 2000).

Lecturers in higher education, more specifically, are faced with a unique situation due to the multifaceted nature of their practice. The academic culture often places a higher value on scientific knowledge and research skills than on other forms of scholarship (Daley 2001; McDonald 2001). The segmentation of knowledge into sequential, discipline-specific credit units has made the integration of scholarship roles even more difficult. In order to adhere to the demands of this knowledge-based curriculum, these lecturers lose touch with the practice for which they are supposed to prepare prospective professionals. McDonald (2001), however, warns that lecturers should not become estranged to the realities of practice. Lecturers in higher education are often caught between advancing their own careers within the academic sphere and preparing their clientele for professional practice (Daley 2001; McDonald 2001). In academe, this means developing as a scholar in research, teaching and engagement. Lecturers as academics are therefore expected to maintain expertise within their specific field of practice, and they need to understand the pedagogy of conveying this expertise to their students and the wider community. Learning - as an essential component of scholarly development - is then envisioned as a transforming process for all concerned, rather than a mere transfer of information. This is increasingly difficult in a system that places diverse demands on its members in terms of research, teaching, engagement, integration and administration.

Challis (1999) summarises these different perspectives into three broad purposes of APD: firstly, it is the updating of knowledge and skills in existing and new areas of practice; secondly, it is the preparation for a changing role in the organisation, new responsibilities and promotion; thirdly, it increases competence in a wider context with benefits to both professional and personal roles. Cervero (2000) concludes that the bottom line of APD is to improve practice, whatever it entails.

\section{MODELS AND APPROACHES}

APD models and approaches need to be placed against a contextual backdrop. Aspects such as institutional culture (Land 2001) and the influence of academic tribes and territories (Becher and Trowler 2001) provide the growth medium for APD within the 
wider higher education climate. Academic practice in higher education is multifaceted and it is influenced by a multitude of contextual changes. Higher education institutions in South Africa have had to deal with changes in context, such as globalisation, massification of the education system that has led to a more diverse learner population, diminishing resources, demands for quality, responsiveness and accountability and greater competition among institutions of higher education (Boughey, in Gravett and Geyser 2004; Quinn and Vorster 2004). Land (2004) concurs that massification has changed the higher education landscape and influenced the growth in APD. He adds that managerialism in higher education and the pressures for accountability, the increase in learning technologies, marketisation and consumerism, as well as pedagogic and epistemic changes have also influenced models and approaches to APD. The type and amount of work required from lecturers in higher education have changed considerably as a result of these contextual changes. Lecturers are increasingly required to professionalise their practice as educators, carry larger administrative loads and achieve higher standards with fewer resources as a result of downsizing, mergers and/or financial constraints (Boughey, in Gravett and Geyser 2004). This frequently requires role changes in terms of the lecturers' scholarly responsibilities, for which they are often ill prepared. Higher education institutions locally and abroad expect lecturers to excel in their scholarly roles, but the extent to which the institution itself engages in the APD of lecturers is changing.

Land (2004) accordingly describes different stances academic developers may have towards change. These include diffusion, systemic, rationality, motivational, power, dialectical, bricolage, ambiguity and contingency stances. Land (2001, 2004) furthermore argues that academic developers' stances towards change may influence their orientation to APD and consequently describes 12 such possible orientations: managerial, political-strategic, entrepreneurial, romantic (or ecological humanist), opportunist, researcher, professional competence, reflective practitioner, internal consultant, modeller-broker, interpretive-hermeneutic, and provocateur (disciplinespecific). These orientations refer to academic developers' attitudes, knowledge, aims and tendencies for action in relation to contextual practices and challenges (see Land $2001: 6,19$ for more detailed descriptions). Land (2004) concludes that variations of these stances and orientations may exist. The interplay between stance and orientation will obviously have an influence on the models and approaches employed within a particular institution. Land's (2001:9) perspective is useful as it theorises APD as an interplay between a systems/person focus on the one axis, and domesticating/liberating 
focus on the other. APD can therefore be positioned according to the institutional culture as

- anarchic (a liberating, person-centred culture);

- collegial (a more person-oriented environment that balances domesticating and liberating influences);

- enterprise (a liberating focus in a systems-oriented environment);

- hierarchical (a person orientation, within a domesticating environment);

- managerial (a systems orientation with a domesticating focus), or

- political (with a balance between all four above-mentioned institutional foci).

McNay's (1995) model of universities as organisations is of particular interest here, since universities seem to have moved towards more corporate or corporation modes of policy definition and implementation. This trend is also evident in the way in which APD is practised. Both Boughey (2004, in Gravett and Geyser 2004) in the South African context and Cervero (2001) in the United States of America context indicate an increase in the decentralisation of APD. Traditional providers of higher education, such as universities, can no longer ignore the corporate sector as a determining role-player in the provision of APD to academic staff. APD has become part of an education-forprofit trend. Current competition among professional associations, higher education institutions, business and industry and entrepreneurial agencies has resulted in a variety of APD programmes that are offered simultaneously to lecturers within universities. Each of these providers promotes his/her programme as timely, relevant and of the highest quality. The lack of established international educational standards for APD programmes offered to lecturers makes it nearly impossible to make an informed choice from all the offerings. A more integrated approach is called for, which will support dialogue, collaborative inquiry, research that is sensitive to practice, and improved learning and practice. This will contribute to growth and sustainability within the area of APD and bridge possible gaps between initial theoretical education and practice in professions (Daley 2001; McDonald 2001; Cervero 2000; Daley and Mott 2000; Knox 2000; Castle, Holloway and Race 1998). Properly planned and monitored collaboration and integration between APD providers (both internal and external to the university) should not be seen as a threat to the university in terms of academic professional development. Outsourcing certain aspects of APD offered to lecturers to private providers may lead to further collaborative opportunities as well as to the incorporation of specific expertise otherwise unavailable to the academic sector, which could benefit all stakeholders and contribute to the development of scholarship in all its facets. 
Higher education institutions, however, continue to play an important role in the continuous development of their academic staff through institutional units or centres aimed at increasing staff competence for the institutional good. Frick and Kapp (2006a) provide an international view on the past, present and future in APD with a particular focus on institutional centres or units. Frick and Kapp (2006a) found that the strategic positioning of APD within institutions is mainly within the academic realm, although some reported a more non-academic/administrative positioning. As could be expected, the main focus seemed to be on the scholarship of teaching, and more particularly on e-learning and the use of technology, assessment, curriculum review, the promotion of student-centred approaches to teaching, skills development (writing and library skills development) and distance education. General support in the areas of policy development and implementation, research, quality promotion, transformation, provision of funding, development of management skills and academic integrity were noted to a lesser extent. Support for the induction of new academic staff seem to be an important focus area in APD, while more advanced academic staff seem to receive less focused attention. Involvement in staff performance management is an interesting focus area that warrants further investigation. How the support in the focus areas takes place seemed to vary among workshops, qualification-based initiatives, discussions/ forums, lectures/presentations and individual consultations.

The main challenges that managers in APD reportedly have to face include a lack of resources, achieving buy-in from all stakeholders, gaining support from senior management, achieving an equitable balance between teaching and research in the higher education environment, managing their staff and the centre/unit as a whole, dealing with a lack of understanding for educational principles in the higher education environment in general, dealing with institutional pressures, coping with the divergent needs of the clientele, dealing with policy, assessing academic professional development output in a sensible manner, effectively positioning the centre/unit strategically, and combating low morale amongst lecturers (Frick and Kapp 2006a). The data in the particular study revealed that several of the centres/units were not aligned to the institutional direction and were going off on their own tangents. There may have been several reasons for this trend. One could be that institutions did not always have clarity on their direction and did not have a clear vision of the role and function of APD within their institutions. A second reason for this lack of alignment may be related to the first. Because of a lack of direction from the institutional leadership, directors of APD units developed their own niche and moved in a direction they thought was appropriate. In some cases units were closed down after national reviews. 
Major changes in the staffing and functioning of these units could also be attributed to changes in institutional leadership. Name changes (such as in the case of the Learning Support Network) indicate a change in focus from teaching to learning and from giving direction to supporting and from a unit to a network. This may align such centres/units more closely to institutional mission statements and a broader conceptualisation of scholarship roles. Several cases were found where units were linked to information technology, although there were institutions where no such link existed. One significant shift that could be observed was one away from a generic approach to APD to the use of practitioners - in many cases subject experts who had a proven success record in their fields of expertise.

Moyo, Donn and Hounsell (1997) found that lecturers themselves are ready and willing to adopt new coping strategies in higher education. They see APD programmes as a way to cope with the changes and transitions that are eminent in the South African higher education arena. The challenges presented to lecturers have led to the introduction of accredited professional development courses for academics by means of formal qualifications. The need for increased professionalisation within education calls for a clear articulation of qualifications that includes formal education and acknowledges prior experiences or learning (Shah 1998; Florez 1997). Quinn and Vorster (2004) recommend a strong and well-articulated theoretical foundation for APD programmes for lecturers. Quinn and Vorster (2004), Moyo et al. (1997), Brew (1995) and Murray (1995) furthermore emphasise the importance of support if academic practices are to change in an ongoing and meaningful manner. Castle et al. (1998) stress the importance of recognition of prior learning for those professionals who have already achieved a certain level of expertise and competency. Constructing a professional identity for lecturers in higher education has, however, been problematic in terms of control over the production of and access to knowledge and the establishment of formal qualifications. Apart from the normal academic qualifications in higher education in South Africa, there is currently no general mandatory professional certification or requirement that guards entry and continuing practice as an academic (although specific professions, such as nursing, do have more structured systems in place).

Moyo et al. (1997) support the introduction of an accredited, award-bearing programme in South African higher education as part of APD for lecturers in higher education, while Åkerlind (2007) notes an increase in compulsory teaching courses and/or qualifications for lecturers in higher education in the United Kingdom. Formal APD seems to centre on the development of teaching as a scholarly endeavour, while the development of other scholarly roles seems to be self-initiated and informal. Quinn 
and Vorster (2004) explain that the emphasis on the scholarship of teaching and learning is necessary since the traditional lecture format does not seem suitable any longer. They also argue that lecturers need to cultivate a spirit of lifelong learning in their learners and therefore lecturers and their learners need to be actively engaged in the learning process. Brew (1995) adds that accreditation can serve to recognise and reward development initiatives formally. Åkerlind (2007:34), however, notes negative reactions of academics towards compulsory initiatives aimed at improving teaching in higher education:

Of course, any compulsory course is likely to put academics off, but this only partially explains the negative reaction of some participants. An additional explanation is that academics who believe that the best route to improving teaching is to focus on becoming more familiar with what and how to teach, through increasing content knowledge and acquiring practical experience ... must logically see no purpose to such courses [in reference to compulsory courses aimed at improving teaching]. From this perspective, staying in touch with the research literature in their field and gaining teaching experience would always be seen as more valuable for teaching development. The particular perspective would also lead to the common argument that experience as a teacher makes participation in such courses redundant.

However, Akerlind (2007:34-35) goes further to explain that there are lecturers who view educational programmes or courses as a way in which to develop as scholars of teaching. It is therefore essential for any formal programme aimed at enhancing teaching expertise to aim at finding the nexus between lecturers' understanding of what it means to develop as a teacher, and what academic developers (as facilitators of these programmes) view as teaching development (Åkerlind 2007). Åkerlind (2007) concludes that, in order to be effective, any teaching development initiative needs to be tailored to individual academics' intentions and understandings of teaching and teaching development. This means that either the development support provided should be closely aligned to these lecturers' understandings, or that their understandings have to be expanded in order for a broader range of support initiatives to be adopted.

The following comparative case study of two South African programmes aimed at developing the scholarship of teaching is used to illustrate a formal approach to APD. Quinn and Vorster (2004) propose the Postgraduate Certificate in Higher Education and Training (PGCHET) as one example of an option to encourage and develop critical reflection on teaching. Quinn and Vorster (2004) describe the PGCHET (referring to the format presented at Rhodes University) as a practice-based course that facilitates 
the professional development of lecturers in terms of learner assessment, evaluation of own practices, developing knowledge within the field of higher education and providing professional accreditation. A complementary programme to the PGCHET could be the MPhil (Higher Education) offered by the Centre for Higher and Adult Education at Stellenbosch University. These two qualifications are compared in Table 12.1. (A list of formal qualifications in the area of higher education studies in South Africa appears in Annexure 17.4 of the chapter by Bitzer and Wilkinson.)

Table 12.1 indicates that the two qualifications are comparable in terms of most aspects. There is, however, a difference in HEQF levels and subsequently possible further studies. The PGCHET is at an honours level (HEQF level 8) and therefore leads to a master's or equivalent qualification in comparison to the MPhil (Higher Education), which is at a master's level (HEQF Level 9) and can therefore lead to a PhD degree. Table 12.2 compares these two qualifications in terms of structure and credit values.

It is clear that the PGCHET is highly comparable to the MPhil (Higher Education). The thesis component in the latter programme makes the main difference in the research emphasis and total credit values, and therefore also in the possibilities for further study.

In terms of international comparability of the PGCHET, the Staff and Educational Development Association (SEDA) of Great Britain developed a scheme as late as 1994 that sets benchmarks for the area of academic professional development. The scheme is based on the submission of a portfolio of evidence (similar to that required in the PGCHET in South Africa) that might be accredited towards a Fellowship or an Associate Fellowship (the latter having only one third of the portfolio size of the former). The SEDA qualification is highly comparable to the PGCHET in terms of its standards and core objectives. However, the PGCHET includes additional aspects relevant to the South African context, such as a core unit standard on mission, policies and legislation. Furthermore, the PGCHET contains specific elective unit standards (such as Web-based learning and Experiential Learning and Supervising Research), which are indirectly addressed in the British SEDA (ETDP SETA 2003).

The PGCHET is comparable to Australia's Prompts for Good Practice (ETDP SETA 2003), which is published by the Higher Education Research and Development Society of Australasia (HERDSA). It consists of collections of questions on the roles of the higher education educator. These roles are similar to those that give structure to the PGCHET. The PGCHET's unit standards and core objectives also compare favourably to the prompts given in the above-mentioned publication, which forms the basis for the 
development and certification of higher education professionals in Australasia (ETDP SETA 2003).

Professional practice in higher education in the USA has been greatly influenced by the Seven Principles for Good Practice in undergraduate education (Chickering and Gamson 1987). These principles are based on a synthesis of decades of relevant research and provide guidelines for the development of higher education professionals. The principles can be closely associated with the unit standards and core objectives of the PGCHET. There are, however, no cited university programme qualifications in the USA that are directly comparable to the PGCHET. Most of the programmes that are offered are at master's and doctoral level and focus on administration, student affairs, leadership, policy studies, student development or counselling and research (ETDP SETA 2003).

Quinn and Vorster (2004) concluded that encouraging lecturers to reflect critically on their practices, to examine the epistemologies underlying their disciplines and the implications thereof for teaching and learning, and introducing them to a variety of theoretical frameworks can change their conceptions of teaching. However, these authors also warn that course facilitators of this type of APD programme should understand the factors that inhibit or prevent lecturers from implementing new ideas and developing their professional practice in terms of teaching competence.

Attaining a qualification does, however, not guarantee that competence or expertise will be maintained. The actual practice of APD in maintaining competence needs more investigation, especially in terms of the link between professional work, constructivist learning and transformative learning. APD providers often assume that the simple transmission of information in the educational setting will influence practice, yet Ryan, Campbell and Brigham (1999) report that research results regarding the effect of APD on behavioural change have not been consistent. It cannot be assumed that APD will have a positive effect on practice. APD is only effective in terms of the extent to which it is implemented in practice and the outcomes can be assessed. Variables, including both individual and organisational variables, need to be considered to determine why behavioural change does or does not occur.

Wenger's (1998) work on communities of practice makes an important contribution to the understanding and support of APD within higher education institutions. The components of a social theory of learning that form the basis for Wenger's (1998:5) notion of communities of practice include the elements of meaning (how individuals and/or groups communicate on understanding the world and essentially what is 


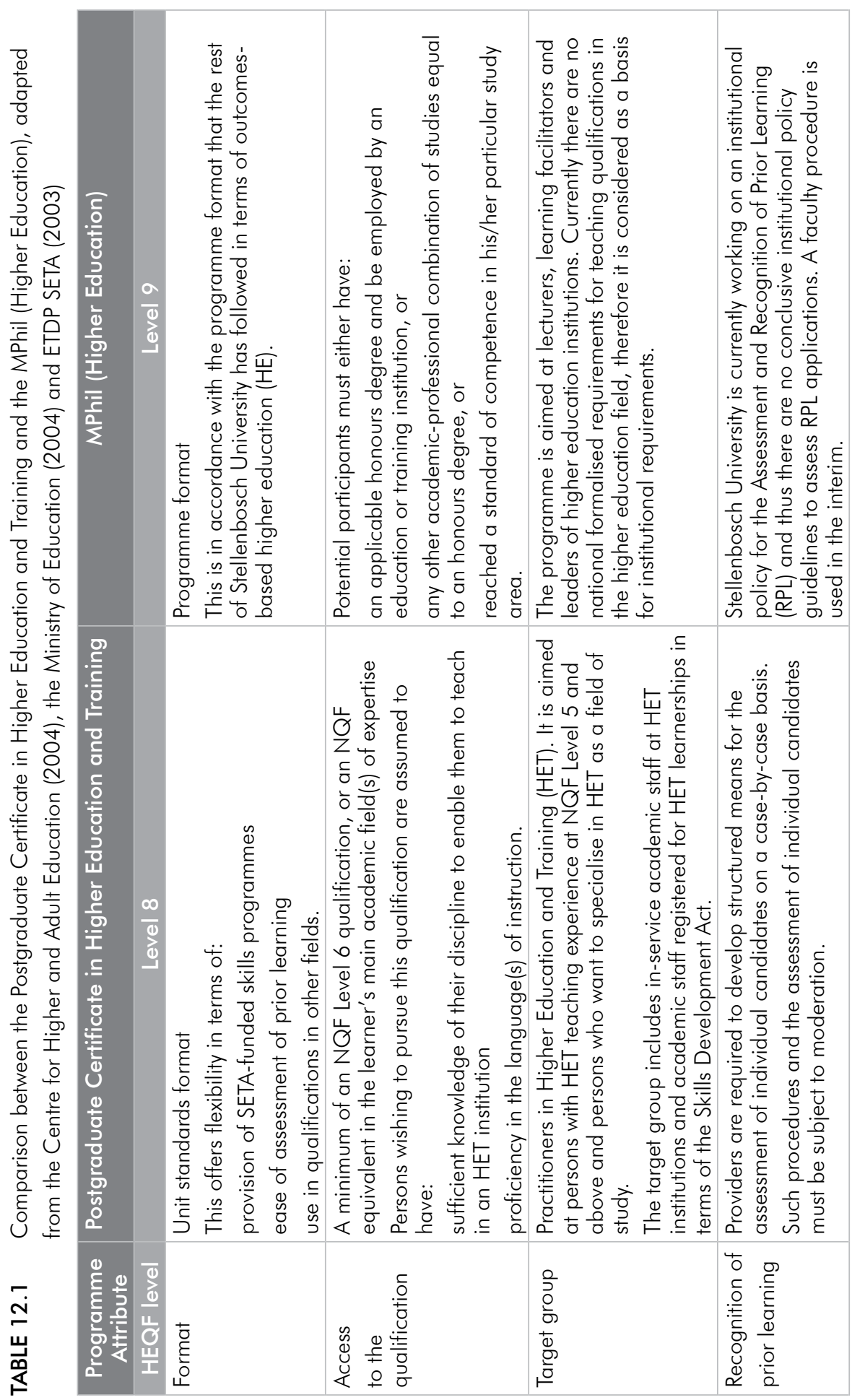




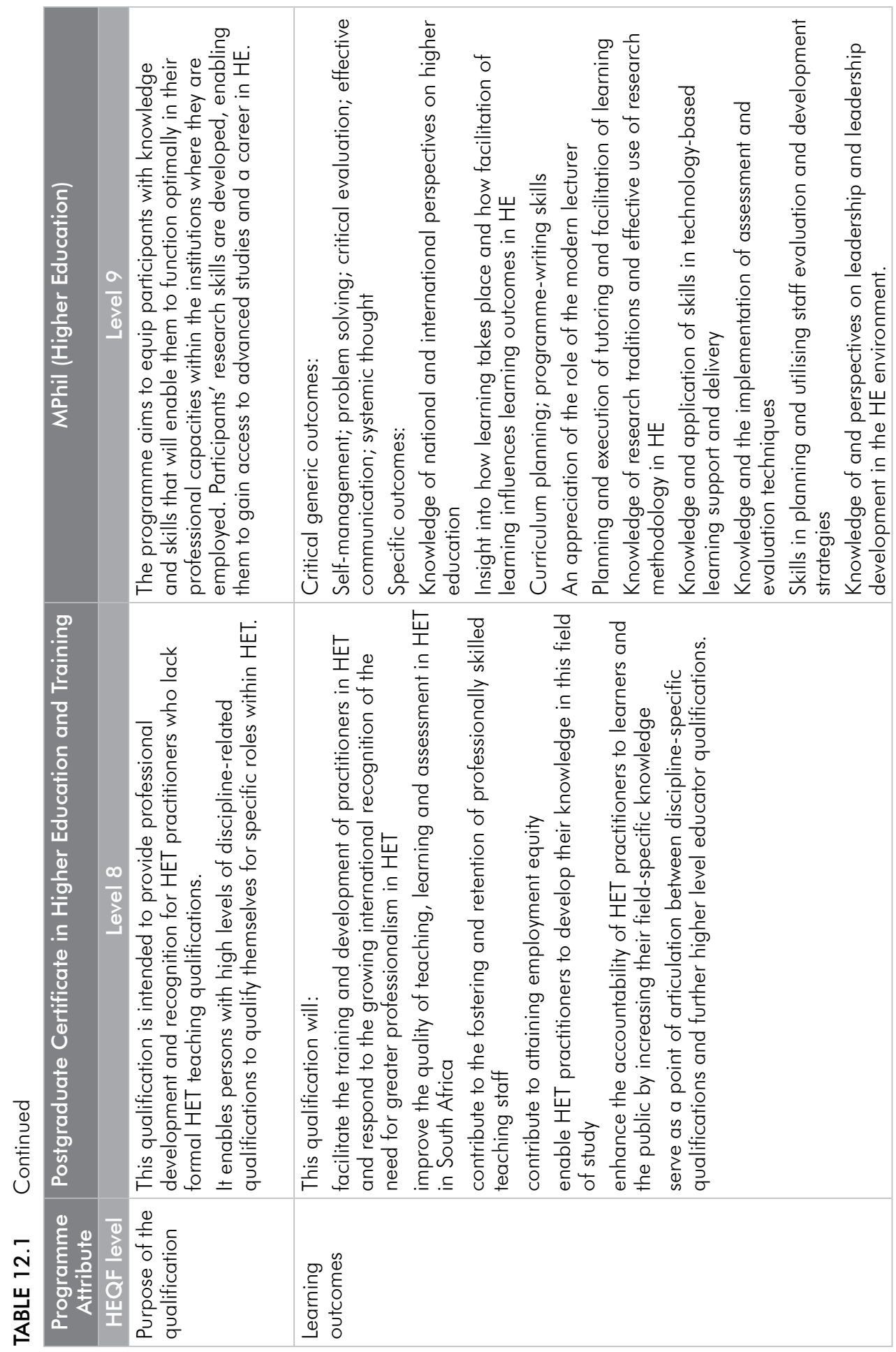




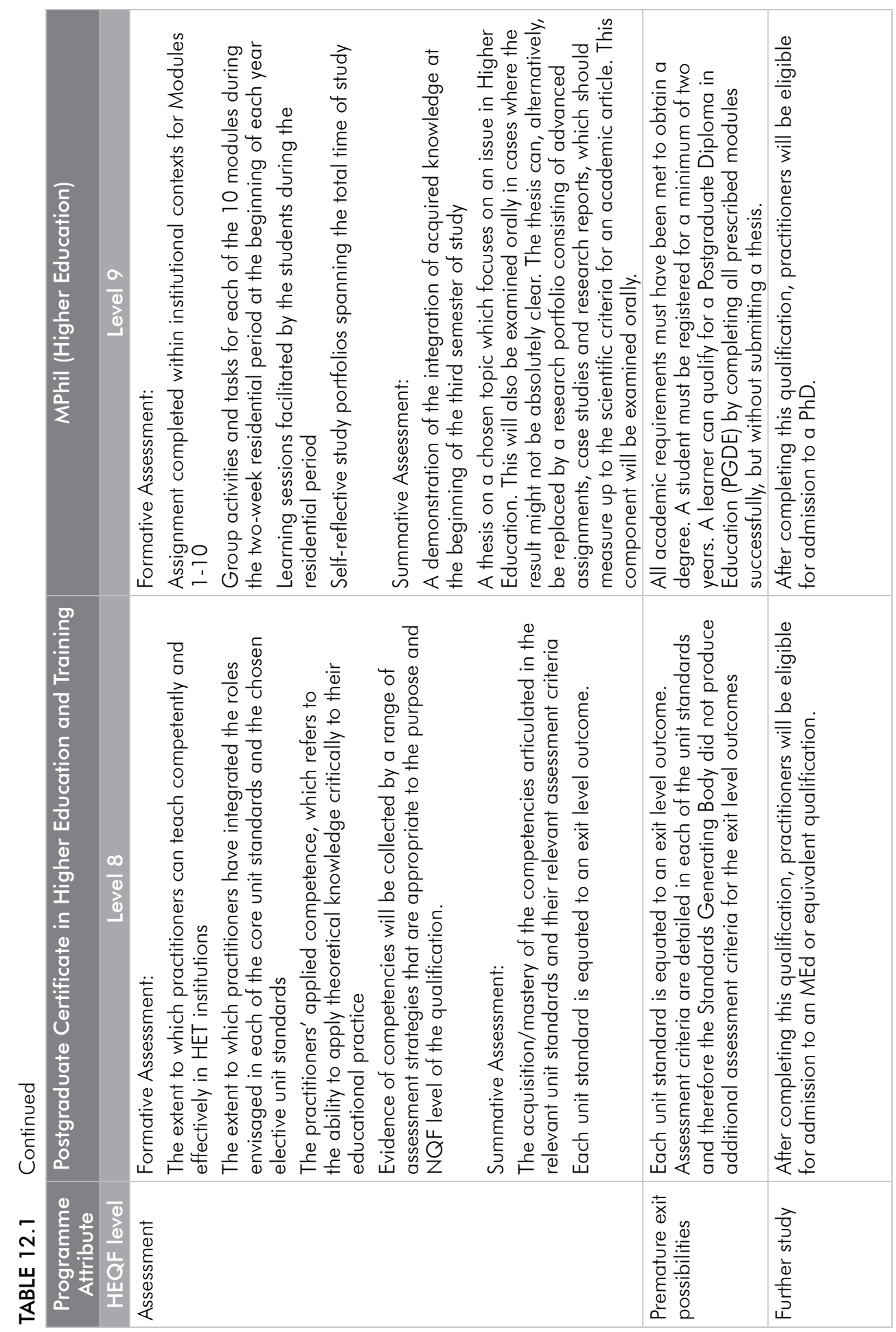


TABLE 12.2 Comparison between the Postgraduate Certificate in Higher Education and Training and the MPhil (Higher Education) in terms of structure and credit values, adapted from ETDP SETA (2003) and the Centre for Higher and Adult Education (2004)*

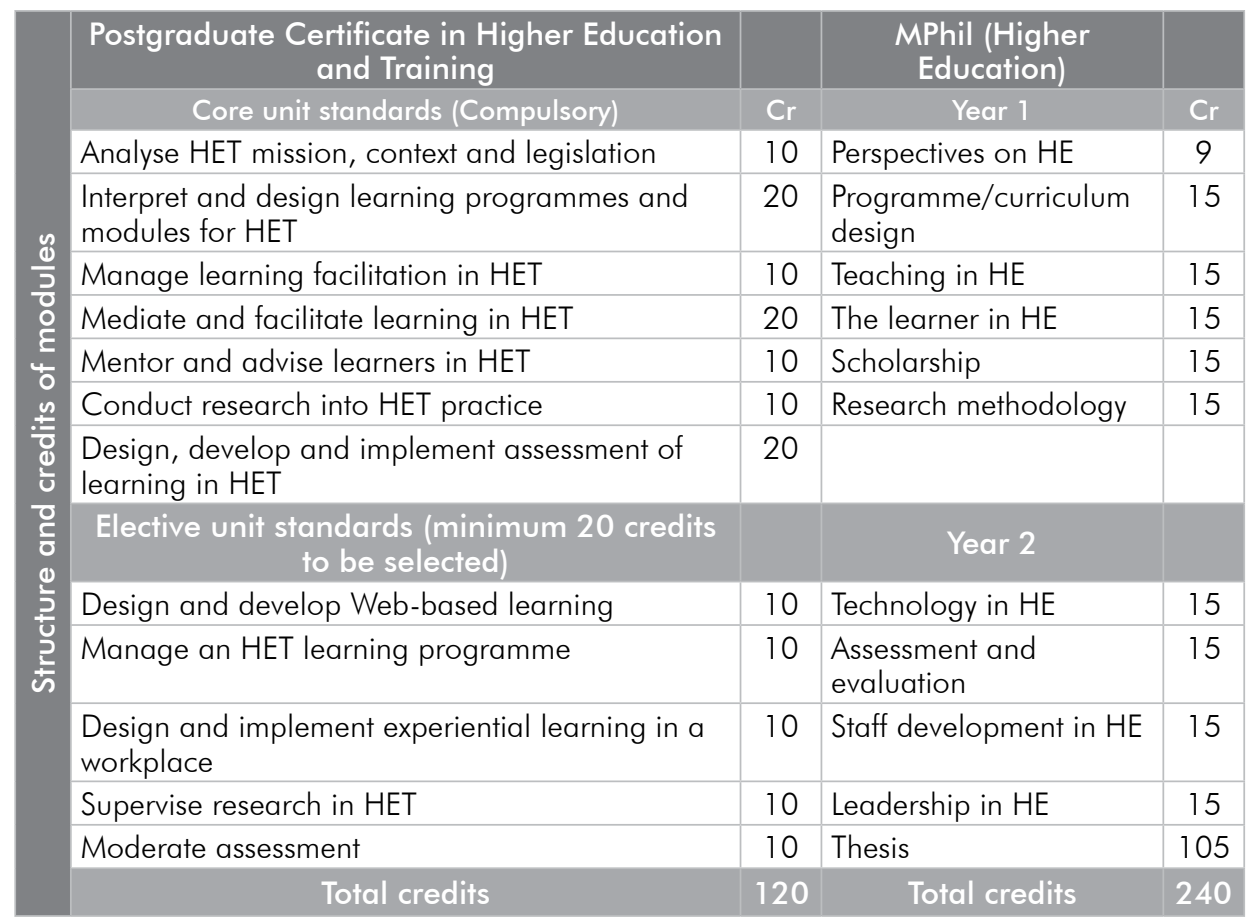

* For the latest information on the MPhil (Higher Education) see www.sun.ac.za/chae

considered as meaningful), practice (the sharing of historical and social resources, frameworks and perspectives that can sustain all stakeholders' engagement in action), community (with reference to specific social configurations that influence what is seen as worthwhile actions and within which competence is defined and recognised), and identity (how learning leads to change and creates personal histories of becoming in

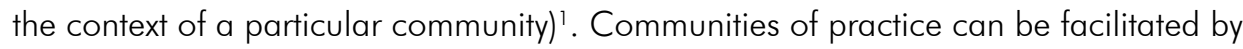
creating shared spaces for critical discourse - for example, conference participation, tearoom discussions, interdisciplinary research groups, journal clubs, regular seminars, and mentoring programmes. These spaces are to serve as a place of belonging and a sounding-board for scholars (Christiansen and Slammert 2006; Johnson 2006; Sorcinelli 2002). Henkel (2005) adds that the proliferation of research centres and institutes as structures that cut across disciplinary divides is evidence of a more networkbased approach to academic practice and scholarly development. 


\section{SCHOLARLY RESEARCH CONTRIBUTIONS TO THE AREA OF ACADEMIC PROFESSIONAL DEVELOPMENT}

What does the future hold for APD as a field of study? A synthesis of the literature reveals that APD is a complex and ever-evolving area of practice in higher education. Input from a variety of countries indicates an initial shift from an instructional approach to a more strategic and facilitative one. There seems to be a focus on developing the scholarship of teaching and learning, even though a broader perspective on the scholarship of teaching is evident which integrates research-based practice and a lifelong learning orientation.

There is an impressive body of literature on APD from scholars in a variety of countries. Several country-specific perspectives, as well as international perspectives, are to be found in the recorded literature. Most of these have been published in academic journals such as the International Journal for Academic Development. Looking at the literature more or less chronologically, one of the first publications on the topic was the outcome of the 1979 British Council course on Staff Development in Higher Education at Oxford. Harding, Kaewsonthi, Roe and Stevens (1981) refer to the development of professionals in academe as "all activities, actions, processes and procedures that an organisation develops or uses to enhance the performance and the potential of its human resources". Since then several books have been published on the topic, but none of them have attempted to provide a broad overview of the past, present and future of APD. However, these publications have all made significant contributions to the area. Professional development in higher education: A theoretical framework for action research by Zuber-Skerrit (1992) provides an excellent example of scholarly work within APD. Publications by Brew (1995), Webb (1996) and Rowland, Byron, Furedi, Padfield and Smyth (1998) also fall within this category.

In the past couple of years several relevant articles have been published that have made major contributions to the area of APD. Noteworthy contributions from an Australian perspective were produced by Kirkpatrick (2001), Kandlbinder (2003) and Smyth (2003) and from a United Kingdom perspective by Gosling (2001). Sandretto, Kane and Heath (2002) provided insight into APD processes in New Zealand and Canadian authors such as Kreber (2000) and Kreber and Cranton (2000) approached APD from a scholarship perspective.

More recent publications that provide a major overview of past and present APD activities include The Scholarship of Academic Development by Eggins and Macdonald (2003), which can be regarded as the most comprehensive view on APD in recent 
times from a United Kingdom perspective. Also within the United Kingdom, Becher and Trowler (2001) and Bath and Smith (2004) have written about academic tribes and their territories. Macdonald (2005) reports on recent developments in learning and teaching and an article by Blackmore and Wilson (2005) covers problems in APD. APD in the United States of America has received extensive attention, and it is essential to take cognisance in particular of the work done by Lieberman (2005) on centres for teaching and learning as laboratories for learning, and the publication by Sorcinelli, Austin, Eddy and Beach (2006) entitled Creating the future of faculty development: learning from the past, understanding the present, which also provides valuable insights. Harland and Staniforth (2003) provide an international perspective on APD. Jarvis, Kondrashova, Efendiev and Tukhfatullin (2005) report on APD in Russia while Odabasi (2005) contributes an opinion on the status and need for APD in Turkey. Taylor (2005) discusses APD as a part of institutional leadership in Canada.

Contributions to the South African point of view have been sparse. The report by Moyo, Donn and Hounsell (1997) on Academic Development and Strategic Change in Higher Education and a Manual for Staff Developers by Bitzer and Kapp (1998) are noted, as well as some articles on the topic (Volbrecht 2003; Quinn 2003; Frick 2007; Frick and Kapp 2005, 2006a, 2006b, 2006c, 2006d, 2007). The audit completed by Moyo, Donn and Hounsell (1997) on academic development and strategic change in South African higher education may have presented a skewed or limited perspective on APD, as it was approached mainly from a student perspective and not from a staff perspective. Quinn (2003) and Quinn and Vorster (2004) reported on one approach to APD at one university, while Volbrecht (2003) questioned the appropriateness of approaches to APD in South Africa. The work done by Frick (2007) and Frick and Kapp (2005, 2006b-d, 2007) focuses particularly on the CPD of academic staff within the natural sciences at one university.

What does the future hold for APD as an area of study? A synthesis of consulted literature reveals that APD is a complex and ever-evolving area of practice and inquiry in higher education. Developments in a variety of countries indicate an initial shift from an instructional approach to a more strategic and facilitative approach. There also seems to be a broader perspective on the scholarship of teaching which resulted in integrating research-based practice and a lifelong learning orientation. 


\section{CONCLUSION}

APD continues to form an integral part of the higher education system, also in South Africa. Some of the future trends seem to be a continuation of what is presently on the agenda. These include an emphasis on the importance of the context in which the academic professional operates. APD aimed at helping academics cope with the recent and current fast pace of change in the South African national higher education system is at the forefront of national debates. Internationally, as well as locally, the influence of the information age and technology on education systems is receiving much attention. Along with this, a greater emphasis on the scholarship of teaching has been observed. The merging with information technology and consequently a stronger emphasis on e-learning as support will remain an issue. Approaches to the development of academic staff may continue to be less generic and more focused on the discipline, which implies an increase in the involvement of subject experts or practitioners.

In terms of institutional APD structures, evidence suggests that some development units have become too bureaucratic and too much focused on administrative/policy/rules and regulation issues, instead of on academic issues. In the South African context this trend may be explained by the high incidence of post-1994 national policy changes that have necessitated a reinterpretation of institutional policies. A more academic orientation in these units may make it necessary for academic staff of APD units to become more research-oriented. To secure buy-in from academic staff, the focus will have to be on those things valued by staff, such as research. A related challenge concerns the workload of the staff of APD units, and more specifically their career development. The latter is directly related to research, for which staff in APD units will have to find sufficient time.

Although the above does not claim to be comprehensive, some clear trends can be deducted. One trend seems to be the ongoing battle for identity and recognition or 'territory'. Further seemingly valid claims made in the above-mentioned literature include the following:

- $A P D$ seems to have evolved from a singular focus on teaching to an understanding of teaching within a broader framework (the context of the institution), to programme design, to learner-centredness, to networking in communities of scholars, to the integration of technology, and to integrated scholarship. 
- The primary purpose of APD has concurrently shifted, with a sustained emphasis on teaching and even more so on learning, to helping individual staff members to act as change agents.

- The structures for APD seem to remain stagnant, although there are stronger indications of a realisation by institutional leadership of the important roles it has to play in an institution and of the diversity of needs it has to address.

From the above overview it has become clear that there are gaps in the way the field has been covered. Perspectives were perhaps too narrow or too protective, or in some cases too broad. This chapter is an attempt to plot the field, to do a reconnaissance of the field and then to provide possible areas of interest for future research, particularly in the domain of South African higher education studies and research.

\section{REFERENCES}

Åkerlind GS. 2007. Constraints on academics' potential for developing as a teacher. Studies in Higher Education, 32(1):21-37.

Alemna AA. 2001. Perception of continuing education for librarianship in Ghana. New Library World, 102(1 160):44-47.

Andresen LW. 2000. A usable, trans-disciplinary conception of scholarship. Higher Education Research and Development, 19(2):137-153.

ETDP SETA. 2003. Towards learnerships and skills programmes linked to the PGCHET for tertiary educators. Proceedings of the ETDP SETA Workshop. Birchwood Conference Centre. 6-7 August 2003.

Badley G. 2003. Improving the scholarship of teaching and learning. Innovations in Education and Teaching International, 40(3):303-309.

Bath D \& Smith C. 2004. Academic developers: An academic tribe claiming their territory in higher education. International Journal for Academic Development, 9(1):9-27.

Battersby D. 1999. The learning organisation and CPD: Some philosophical considerations. The Learning Organization, 6(2):58-62.

Beatty RM. 2001. Continuing professional education, organizational support and professional competence: Dilemmas of rural nurses. The Journal of Continuing Education in Nursing, 32(5):203-209.

Becher T \& Trowler PR. 2001. Academic tribes and territories. Intellectual enquiries and the culture of disciplines. 2nd Edition. Buckingham: Open University Press.

Bitzer EM \& Kapp CA. 1998. A manual for new academic staff developers in further and higher education. Centre for Higher and Adult Education. Stellenbosch: Stellenbosch University.

Blackmore P \& Wilson A. 2005. Problems in staff and educational development leadership: Solving, framing, and avoiding. International Journal for Academic Development, 10(2):107-123. 
Boyer EL. 1990. Sholarship reconsidered: Priorities of the professoriate. Princeton: Carnegie Foundation for the Advancement of Teaching.

Brew A. 1995. Directions in staff development. London: Society for research into Higher Education.

Castle A, Holloway DG \& Race AJ. 1998. A review of issues in continuing professional development in teaching, nursing and radiography. International Journal of Lifelong Education, 17(5):328-340.

Centre for Higher and Adult Education 2004. MPhil (Higher Education) pamphlet. Stellenbosch: Stellenbosch University.

Cervero RM. 2001. Continuing professional education in transition, 1981-2000. International Journal of Lifelong Education, 20(1/2):16-30.

Cervero RM. 2000. Trends and issues in continuing professional education. New Directions for Adult and Continuing Education, 86:3-12.

Challis M. 1999. AMEE Medical Education Guide No. 11 (revised): Portfolio-based learning and assessment in medical education. Medical Teacher, 21 (4):370-386.

Chickering AW \& Gamson ZF. 1987. Seven Principles for Good Practice. AAHE Bulletin, (39):3-7.

Christiansen IM \& Slammert L. 2006. A multi-faceted approach to research development (II): Supporting communities of practice. South African Journal of Higher Education, 20(1):15-28.

Cobb VL. 1999. In international comparison of teacher education. ERIC Digest, ED436486.

Daley BJ. 2000. Learning in professional practice. New Directions in Adult and Continuing Education, 86:33-41.

Daley BJ. 2001. Learning and professional practice: A study of four professions. Adult Education Quarterly, 52(1):39-54.

Daley BJ \& Mott VW. 2000. Continuing professional education: From vision to reality. New Directions for Adult and Continuing Education, 86:80-85.

Diamond RM. 1993. Changing priorities and the faculty reward system. In: RM Diamond \& BE Adam. Recognizing faculty work: Reward systems for the year 2000. San Francisco: Jossey-Bass.

Diamond RM. 1999. Aligning faculty rewards with institutional mission: Statements, policies and guidelines. Bolton: Anker.

Eggins H \& Macdonald R. 2003. The scholarship of academic development. Buckingham: Society for research into Higher Education and Open University Press.

Florez MAC. 1997. The adult ESL teaching profession. ERIC Digest, ED413794.

Frick BL. 2007. The evolution of scholarship in the natural sciences: Providing a framework for Continuing Professional Development (CPD). Centre for Research in Lifelong Learning Conference: Researching transitions in Lifelong Learning, 22-24 June 2007, University of Stirling (Stirling, Scotland). 
Frick BL \& Kapp CA. 2005. Making quality count in continuing professional development. South African Development Association Conference, 28-30 November 2005, Durban Institute of Technology (Durban, South Africa).

Frick BL \& Kapp CA. 2006a. Academic staff development: past, present and future. International Consortium for Educational Development, 11-14 June 2006, Sheffield Hallam University (Sheffield, United Kingdom).

Frick BL \& Kapp CA. 2006b. Future trends in continuing professional development for natural science lecturers in higher education - survival of the fittest in the academic jungle. Teaching and Learning Forum 2006, 1-2 February 2006, University of Western Australia (Perth, Australia).

Frick BL \& Kapp CA. 2006c. Continuing professional development (CPD) of lecturers in the natural sciences: Enhancing the quality of learning. Education as Change, 10(2):81-96.

Frick BL \& Kapp CA. 2006d. Mapping the provision of continuing professional development in the natural sciences in higher education. Acta Academica, 38(2):229-253.

Frick BL \& Kapp CA. 2007. Plotting the playing field for continuing professional development in the natural sciences. South African Journal of Higher Education, 21 (3):443-456.

Glassick CE, Huber MT \& Maeroff GI. 1997. Scholarship assessed. Evaluation of the professorate. San Francisco: Jossey-Bass.

Gosling D. 2001. Educational development units in the UK - what are they doing five years on? International Journal for Academic Development, 6(1):74-90.

Gravett S \& Geyser H. 2004. Teaching and learning in higher education. Pretoria: Van Schaik.

Grzyb SW, Graham SW \& Donaldson JF. 1998. The influences of organizational and demographic variables on participation in continuing professional education. The Journal of Continuing Higher Education, 46(1):2-15.

Harding AG, Kaewsonthi S, Roe E \& Stevens JR. 1981. Professional development in higher education. Bradford, UK: University of Bradford, Educational Development Service.

Harland T \& Staniforth D. 2003. Academic development as academic work. International Journal for Academic Development, 8(1/2):25-35.

Harris S. 2005. Rethinking academic identities in neo-liberal times. Teaching in Higher Education, 10(4):421-433.

Hart G, Clinton M, Edwards H, Evans K, Lunney P, Posner N, Tooth B, Weir D \& Ryan Y. 2000. Accelerated professional development and peer consultation: Two strategies for continuing professional education for nurses. The Journal for Continuing Education in Nursing, $31(1): 28-37$.

Henkel M. 2005. Academic identity and autonomy in a changing policy environment. Higher Education, 49:155-176.

Jarvis DK, Kondrashova MV, Efendiev AG \& Tukhfatullin M. 2005. Faculty development in Russian higher education. International Journal for Academic Development, 10(2):125-137.

Johnson B. 2006. South African academia in crisis: The spread of "contrived collegial managerialism". South African Journal of Higher Education, 20(1):56-69. 
Kabouridis G \& Link D. 2001. Quality assessment of continuing education short courses. Quality Assurance in Education, 9(2): 103-109.

Kachingwe AF. 2000. Diversity and continuing professional education: Defining and synthesizing. The Journal of Continuing Higher Education, 48(2):28-36.

Kandlbinder, P. 2003. Peeking under the covers: on-line academic staff development in Australia and the United Kingdom. International Journal for Academic Development, 8(1/2):135-143.

Kirkpatrick D. 2001. Staff development for flexible learning. International Journal for Academic Development, 6(2):168-176.

Knox AB. 2000. The continuum of professional education and practice. New Directions for Adult and Continuing Education, 86:13-22.

Kreber C. 2000. How university teaching award winners conceptualise academic work: Some further thoughts on the meaning of scholarship. Teaching in Higher Education, 5(1):61-78.

Kreber C \& Cranton PA. 2000. Exploring the scholarship of teaching. The Journal of Higher Education, $71(4): 476-495$.

Land R. 2001. Agency, context and change in academic development. International Journal for Academic Development, 6(1):4-20.

Land R. 2004. Educational development. Discourse, identity and practice. Berkshire: Open University Press.

Levine A. 2000. The soul of the new university. New York Times, 13 March 2000.

Lieberman D. 2005. Beyond faculty development: How centres for teaching and learning can be laboratories for learning. New Directions for Higher Education, 131:87-98.

Livneh C \& Livneh H. 1999. Continuing professional education among educators: Predictors of participation in learning activities. Adult Education Quarterly, 49(2):91-106.

Lynton E. 1995. Making a case for professional service. Washington DC: American Association for Higher Education.

Lynton E \& Driscoll A. 1999. Making outreach visible: A guide to documenting professional service and outreach. Washington DC: American Association for Higher Education.

Macdonald R. 2005. Recent developments in learning and teaching in the UK. HERDSA News, April 2005: 18-20.

McDonald C. 2001. A review of continuing professional education. The Journal of Continuing Higher Education, 49(1):29-40.

McNay I. 1995. The Changing University. Buckingham: SHRE and Open University Press.

Merriam SB. 2005. Emerging trends and research in adult learning theory. Presentation at Stellenbosch University. 11 November 2005.

Ministry of Education 2004. The Higher Education Qualifications Framework. Policy issued under the Higher Education Act, Act No. 101 of 1997. Draft for discussion. Pretoria: State Publishers.

Mott VW. 2000. The development of professional expertise in the workplace. New Directions for Adult and Continuing Education, 86:23-31. 
Moyo C, Donn G \& Hounsell D. 1997. Academic development and strategic change in higher education. SAAAD Needs Assessment and Audit of Academic Development in South Africa Report.

Murray JP. 1995. Successful faculty development and evaluation: The complete teaching portfolio. ASHE_ERIC Higher Education Report No. 8. The George Washington University, Graduate School of Education and Human Development. Washington DC.

National Committee of Enquiry into Higher Education. 1997. Higher education in the learning society: Report of the National Committee. London: HMSO.

New Zealand Government. 1990. Education Amendment Act. Wellington: Government Printer.

Odabasi HF. 2005. The status and need for faculty development in Turkey. International Journal for Academic Development, 10(2):139-142.

Odini C. 1999. Training and development of skills in a changing information environment. Library Management, 20(2): 100-104.

O'Meara KA \& Rice RE. 2005. Faculty priorities reconsidered: Rewarding multiple forms of scholarship. San Francisco: Jossey-Bass.

Quinn L. 2003. A theoretical framework for professional development in a South African university. International Journal for Academic Development, 8(1/2):61-75.

Quinn L \& Vorster J. 2004. Transforming teachers' conceptions of teaching and learning in a postgraduate certificate in higher education and training course. South African Journal of Higher Education, 18(1):364-381.

Rice RE. 1991. The new American scholar: Scholarship and the purposes of the university. Metropolitan Universities Journal, 1(4):7-18.

Rice RE. 1996. Making a place for the new American scholar. Washington DC: American Association for Higher Education.

Rice RE. 2002. Beyond Scholarship Reconsidered: Toward an enlarged vision of the scholarly work of faculty members. New Directions for Teaching and Learning, 90:7-17.

Rowland S, Byron C, Furedi F, Padfield N \& Smyth T. 1998. Turning academics into teachers? Teaching in Higher Education, 3(2):133-141.

RSA (Republic of South Africa). 1996. National Education Policy Act, 1996 (Act 27 of 1996). Pretoria: Government Printers.

Ryan M, Campbell N \& Brigham C. 1999. Continuing professional education and interacting variables affecting behavioral change in practice: Instrument development and administration. The Journal of Continuing Education in Nursing, 30(4):168-175.

Sadler-Smith E, Allinson CW \& Hayes J. 2000. Learning preferences and cognitive style: Some implications for continuing professional development. Management Learning, $31(2): 239-256$.

Sandretto S, Kane R \& Heath C. 2002. Making the tacit explicit: A teaching intervention programme for early career academics. The International Journal for Academic Development, 7(2): 135-145. 
Schulman L. 1999. Professing educational scholarship. In: E Lagemann \& L Shulman (eds). Issues in Education Research: Problems and Possibilities. San Francisco, CA: Jossey-Bass. 159-165.

Shah SY. 1998. Professionalisation of Indian adult education. Asia Regional Literacy Forum [Online]. Available: http://www.literacyonline.org/products/ili/webdocs/shah.html [2004, 21 October].

Smyth R. 2003. Concepts of change: enhancing the practice of academic staff development in higher education. International Journal for Academic Development, 8(1/2):51-60.

Sorcinelli MD. 2002. New conceptions of scholarship for a new generation of faculty members. New Directions for Teaching and Learning, 90:41-48.

Sorcinelli MD, Austin AE, Eddy PL \& Beach AL. 2006. Creating the Future of Faculty Development: Learning From the Past, Understanding the Present. Bolton: Anker Publishing.

Taylor KL. 2005. Academic development as institutional leadership: An interplay of person, role, strategy, and institution. International Journal for Academic Development, 10(1):31-46.

Volbrecht T. 2003. The story of South African academic development in international perspective: have we lost the plot? South African Journal for Higher Education, 17(2):110-117.

Webb G. 1996. Understanding staff development. London: Society for research into Higher Education.

Wenger E. 1998. Communities of practice. Learning, meaning and identity. Cambridge: Cambridge University Press.

Wilson AL. 2000. Professional practice in the modern world. New Directions in Adult and Continuing Education, 86:71-79.

Zuber-Skerrit O. 1992. Professional development in higher education: A theoretical framework for action research. London: Kogan Page.

Zahorski KJ. 2002. Nurturing scholarship through holistic faculty development. New Directions for Teaching and Learning, 90:29-37. 


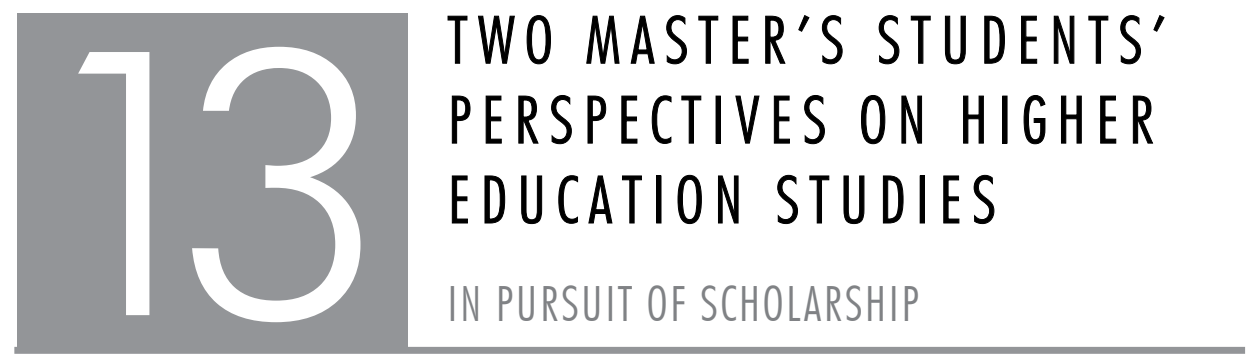

\section{Mariëtte Koen \& Marianne Bester}

\section{ABSTRACT}

This chapter reviews how higher education studies can hold much promise for improving lecturers' professional development by exploring the journey of two master's students under the same supervision. The intention of this chapter is to provide a concise description of two journeys against the background of self-discovery, identity development and professional growth. First the authors argue that new expectations, knowledge, globalisation and demands engulf almost all aspects of academics' lives in the changing world of higher education in South Africa today. As a result academics, like other professionals, need to update themselves and be engaged in professional development, a lifelong engagement that allows them to expand, develop and deepen their understanding of teaching and learning. In the subsequent section the authors explain that in higher education studies the line between epistemological and ontological realities becomes blurred when a student acquires new knowledge and skills while joining the quest for new ways of being a teacher, researcher and scholar. In the final section the authors describe how higher education studies allowed them to enhance and transform their ways of being as higher education teachers and they highlight the way that higher education studies challenged them to embrace scholarship. They share with the reader the idea that as a result, engaging in higher education studies did not only influence and/or change some of their perceptions and conceptualisations, but they also acquired new skills and knowledge as they developed as teacher, researcher and scholar. They conclude that becoming scholars in teaching and learning is an ongoing process of professional development that requires integrity, persistence, enthusiasm, passion and courage. 


\section{INTRODUCTION}

A number of chapters in this book highlight how higher education (HE) studies and research in South Africa have contributed to and promote the field in preparing students for academic and professional life. Worldwide, and for centuries, HE institutions have shown to be remarkably resilient and adaptable, continually developing their role as society evolves. However, new expectations, perspectives and demands have been mounting rapidly in the $21^{\text {st }}$ century as knowledge and globalisation engulf almost all aspects of our daily lives. Few would dispute that HE is confronted with formidable challenges and changes in today's competitive environment. Furthermore, its central role in a knowledge-based society has become increasingly important in developing individuals, communities and nations. Given these realities the dual aim of public higher education, namely to promote public and private gain, seems a strategic priority of HE institutions the world over. In a way, the tension between academic and public concern was identified by Kant (1798) centuries ago when he recognised the conflict between knowledge creation and transmitting of knowledge (Nicholls 2001:1). HE professionals are now faced with the challenge to overcome this constraint in order to fulfil Kant's ideals in the $21^{\text {st }}$ century (MacDonald Ross 2005:13).

Pekel (2008:1) notes that everyone who has been a lecturer or a student knows that 'magic' can happen when students meet committed lecturers with motivated ideas. This would imply the sort of 'eureka' experience students get when they learn something. However, discovering what can instigate this 'magic' for lecturers and how best to motivate them for sustained and improved performance, remains a complicated challenge. People are trained for all professions, but promotion of scholarship and academic skills in HE depends heavily on intrinsic rewards such as self-respect, responsibility and a sense of accomplishment. Seldin (1995:4) argues that lecturers, "like other professionals, should have a hungering need to update themselves, to engage in professional growth, to expand and deepen understanding". This idea would perhaps imply that even the best lecturers may compromise standards and performance if they do not take advantage of continuous professional development programmes, because even excellent lecturers need to learn continuously in order to "remain the best" (Seldin 1995:4). Therefore, it is plausible to investigate the way HE studies can strengthen the personal and professional development of academics, which would ultimately enhance the quality of teaching and learning at universities.

The aim of this chapter is to explain some of the authors' personal experiences, identity confusion and reflection on individual growth. We shall share with the reader the idea 
that during a academic journey the questions may arise: Who am I? How does the university value me? How do I value myself? We shall explain that self-discovery is part of such a journey during which one embarks, one travels and one sometimes gets off. Some academics, like us, may get back on and travel further. There are accidents and there are delays. At certain stops there are surprises. Some of these incidents will translate into great moments of joy, but some will result in profound sorrow (Slideshare 2009:1). In the vein of Slideshare we conclude by hinting at challenging questions to the reader, such as: Have you discovered your academic journey, yet? Are you sitting in the waiting room? Or perhaps: Have you decided to go home?

\section{CASE STUDY 1: IN PURSUIT OF HAPPINESS (MARIËTTE KOEN)}

The sub-title I have chosen is borrowed from a movie (2006) based on a true story about a man named Christopher Gardner. Gardner invested heavily in a device known as a Bone Density Scanner, but it did not sell very well and Gardner was desperate to find a steady job.

\section{Investment}

According to Dictionary. Com (2009) an investment refers to the choice (money, time or effort) by an individual with the hope of gaining from the effort. Although Gardner invested heavily in his dream, he lost his wife, money, house and credit cards. In the same way I invested in my dream of an academic career by obtaining professional qualifications in education, psychology and later by completing a PhD. However, these academic shares did not guarantee a permanent position in $\mathrm{HE}$. It felt as if the narrator of this movie was talking to me when he said: "It turned out his best wasn't enough."

One of the hardest things in life is to deal with the feeling of disappointment. The second hardest thing is to find the drive and energy to handle your disappointment in a healthy and positive way in order to overcome the disappointment and persist with your undertaking. This feeling of darkness is captured in Sondheim's musical (Sondheim and Lapine 1996) "Into the Woods" where he uses a metaphor to explain this dark side of a dream:

Into the woods you have to grope,

'Cause that's the way you learn to cope

Into the woods to find there's hope,

Of getting through the journey. 
A disappointment forces you to decide how to alter your investment in a smarter way. It is at this point where my journey with HE studies began. Gardner's motivational words to his son: "You got to dream and you got to protect it" made me realise that protecting a dream requires active participation. I needed to find a tool which would not only nurture, but also cultivate and realise my dream.

\section{Choices}

Fortunately there are many paths in defining personal meaning in life and often the choices you make may have unexpected outcomes. Centuries ago Socrates (470 BC-399 BC) believed that "the unexamined life is not worth living" (Thinkexist.com, 2009). Socrates uttered these words at his trial for heresy. He could have avoided a death sentence, but Socrates believed that if he revised his beliefs it could rob him of the only thing that made life useful, namely "to examine life" (Palachuk 2008:1). Like Socrates, Gardner and I decided to take the plunge and examine something new. My friends and colleagues were puzzled that a part-time lecturer would even consider embarking on another academic journey, especially if this implied registering for a second master's degree and travelling a thousand kilometres to attend the programme. Yet, I knew that this journey could be the tool to re-create new dreams, an opportunity where a psychologist can learn about teaching, learning and research in the HE context. I listened to Gardner: "Don't let anybody ever tell you you can't do something."

\section{Personal and professional development}

"It seems as if scholarship is only something we can pursue, but never have."

(Adapted from the movie, 2006)

We live in a time where the higher education landscape is changing, a multiplicity of roles is emerging and more is expected from academics than ever before (Nicholls 2001:1-13). In addition, Fischer (2009:1) states that professional development has become necessary, because learning can no longer be divided into a place and time to acquire knowledge (tertiary institutions) and a place and time to apply this acquired knowledge (the workplace). Clearly the idea that learning primarily occurs during formal education is inadequate in today's 'knowledge age'. Nicholls (2001:48) emphasises that "learning from learning are keys to success". I therefore concur with Sutherland and Crowther's view (2006:4) that if I want my university education to be useful, it must be an ongoing process, a lifelong activity that engages and re-engages me continually in learning. 


\section{"Riding the bus"}

Gardner named one part of his life "Riding a bus". I identified my 'riding the bus' as the time when I had to rethink my professional role and chose HE studies to answer the question: How can I improve what I am doing? Although this field of study has been growing at universities in the USA, the UK and Europe for over 30 years, it is regarded as a relatively new field in South Africa (University of the Western Cape Online 2009:1). HE studies aim to bring academics up to date with new trends in the $\mathrm{HE}$ context and to assist them in becoming reflective practitioners. According to Illeris (2006:15) professional development has been a key issue in international education policies during the last few years.

Publications advocate that universities should create an environment where academics teach, learn and enhance their exceptional abilities. This can be done by means of formal/informal professional development and lifelong learning. Since I believe the saying that "theory without practice is dead; practice without theory is blind" (Sims 1997:1), I chose a formally structured MPhil (HE) programme as my source for learning. One can argue that the content of a structured programme, for example an MPhil in HE studies, is grounded in an established and accepted theoretical framework. Perceptions and conceptualisations regarding HE studies require therefore a strong sense of ownership from the students. In HE studies the line between epistemological and ontological realities becomes blurred when a student acquires new knowledge and skills and at the same time joins the quest for new ways of being a teacher, researcher and scholar (Kincheloe 2003:3). From an ontological perspective, my HE studies helped me to conceptualise new ways of analysing teaching and learning in the HE context and to apply them to the reconstruction of my selfhood. It made me realise that the self was not pre-formed as I entered the HE environment, but that it emerged (and is still emerging) in its relationship to other selves and other things in the HE environment (Kincheloe 2003:48). As a result, engaging in HE studies did not only influence and/or change some of my perceptions and conceptualisations, but also helped me to acquire new skills and knowledge as I developed as teacher, researcher and scholar.

Professional development is essential to competitiveness and employability, social inclusion, active citizenship and personal development (Sorcinelli, Austin, Eddy and Beach 2006:157-176). As such, HE studies promoted the skills and competences I needed, both for personal development and career advancement. However, investigating issues in the $\mathrm{HE}$ context can be very time consuming. I believe that academics are 
not opposed to the need to develop and maintain the professional competence necessary to provide high-quality service to students, but I cannot help but raise the question: Where are academics to find the time for professional development in their already busy schedules? McCarthy and Higgs (2005:3) examined lecturers' favourite expression "There is no time" and concluded that "lecturers should make time". In fact, they argue that lunch times can be very productive meeting times, "if lunch were provided - a case, indeed, of providing food for thought".

From the above it appears that managing academic time effectively is more easily said than done. At one time Gardner exclaimed: "It seems as if happiness is only something we can pursue, but never have it." Faced with an array of departmental and administrative demands, readings and assignments, I often found myself drained of energy, stressed out and thinking that the effective use of time remains an ideal at best. Then there are those who argue that professional development and lifelong learning are more about an attitude, which involves a belief that one can manage one's time while being opened to new ideas, decisions, skills or behaviours. To prove this idea, Canfield (2009:1) notes: "If you're passionate about what it is you do, then you're going to be looking for everything you can to get better at it." This notion implies that it is critical for lecturers to come to terms with the concept professional development in order to cater for students. If this development does not happen, it is likely that there will always be a mismatch between what HE institutions are prepared to offer and what many students actually need to facilitate their learning. At times I wanted to rearrange the words in Gardner's exclamation and replace it with this idea: "It seems as if scholarship is only something we can pursue and never have."

\section{Scholarship}

"Man, do I want to learn that."

(Movie, 2006)

Following a survey by the Carnegie Foundation in the United States, Ernest Boyer documented how the notion of scholarship had become narrowly conceived in terms of basic research (Boyer 1990). Therefore he challenged academics to embrace the definition of scholarship beyond the emphasis of discovery and to include the scholarship of integration, application and teaching. He argued that each dimension offered different opportunities to be engaged in academic activities. Boyer's original concept has developed in a much contested debate as he portrayed scholarship as an ideal rather than an applied practice (Braxton, Luckey and Helland 2002:1). 
Consequently a number of models have emerged that feature activities ranging from keeping up with the literature on teaching and learning to publishing educational research as a quest for scholarship (Priest 2005:1).

Scholarship is embedded in the passion to pursue research, teaching, integration and application (Andresen 2000:138). Each dimension of scholarship offers different opportunities to engage staff members, and the proper balance between the four dimensions is a concern of the academic community. At one stage Gardner asked a happy man: "Man, do I have two questions for you. What do you do and how do you do it?" And this is what I as an MPhil student wanted to know from my supervisor during my higher education studies: "Professor, I have two questions for you: One: What does one do to improve teaching effectiveness, student learning outcomes and the continuous transformation of academic cultures and communities? And two: How does one become a scholar in doing that?" He warned me, however, that scholarship does not emerge overnight (Bitzer 2004:29) and emphasised that scholarship is an exhausting journey where only truly intrinsically motivated academics will succeed as scholars. It appears as if the key to scholarship is to be tirelessly inspired - an action that cannot be faked. In other words, scholarship in HE is not for the faint at heart (Hatch 2006:1).

Although the development of skills and competence has become one of the top teaching priorities in many universities, a missing link in this equation can be the absence of passion, commitment and motivation of lecturers. Without an understanding of the importance of HE studies, lecturers can be left without a vital tool for making decisions in their daily practice and ultimately neglect to improve the quality of their teaching and research. It is true that one of the major distinguishing characteristics of a scholarly department is lecturers who are deeply committed to and excited by the ideas which they bring with enthusiasm to their classroom. Academics that influence students are those who love their subject and desire to engage them in their enthusiasm and sense of excitement of discovery (Rowland 2005:92). In the same vein, Macfarlane (2005:177) claims that "if I was in it purely for the rewards I wouldn't be an academic in the first place". He argues that service is about a broader range of scholarly activities that form the surrounding infrastructure that supports the domains of scholarship. Naturally the focus of scholarship should be on the moral obligation to students and colleagues, and not on the indirect or direct career benefits. Equally important, Andresen (2000:138) declares that scholarship is "a term of recommendation, of challenge". Kreber $(2002: 160,161)$, who agrees with this point of view, explains that scholarship of teaching "is not the same as teaching excellence, 
is not the prerogative of the educationist, and is not limited to publishing research on teaching in peer-reviewed journals". In other words, scholarship of teaching actually refers to the "nature and depth of the work done by academics and professionals" and should therefore not be confused with the narrower term "scholarly work" which refers to work of a particular academic quality (Bitzer 2008). It can be argued that although scholarship of teaching is not equal to excellent teaching, it develops from scholarly teaching. Hutchings and Shulman (1999:11) emphasise that teaching is not merely a transmission of what is already known, but rather an integration between discovery, application and integration. Scholarship will allow a transparent symbiotic relationship where scholarly teachers can reflect, evaluate, document and communicate the results to others (Trigwell, Martin, Benjamin and Prosser 2000:164).

I had several excuses why I was not engaged in scholarship yet ... time, money and a part-time contract - all very legitimate reasons. My HE studies forced me, however, to re-investigate my passionate commitment to scholarship. I realised that scholarship requires daredevils, adventurers and champions. It was time to realise that scholarship in the HE context is no longer a luxury. It is a necessity. As Gardner stated: "I still remember that moment they all look so damn happy to me. Why couldn't I look like that?"

\section{Closing thoughts}

"If you want something, go get it, period."

(Movie 2006)

My studies taught me that instead of academics being either teachers or researchers and who work in institutions that specialise in teaching or research, these two key aspects can be integrated. In my case it meant integration of psychology, education and research. Furthermore, my studies contributed to enhancing the quality of being a lecturer by various means, for example: to share and benefit from insights of academics from different disciplines, to challenge participants, to stretch my thinking, to design, facilitate and assess workshops, to investigate new sources and to encounter new ways of engaging with teaching and learning. My studies provided me with an opportunity to interview 10 academic leaders and to gain new perspectives on the importance of a "followership" approach in HE. HE studies did not only realise my dream by means of a permanent appointment, but made me feel like a new coin with two different but essential sides. On the one side there were opportunities for learning new skills and knowledge regarding teaching and learning and on the other side there was the 
opportunity to implement these ideas practically in the classroom. It made me feel that I do not just exist as a lecturer, but that I am actually getting to where I want to be, something Shulman (2004:1) explains as follows:

Scholarly teaching is what every one of us should be engaged in every day that we are in a classroom, in our office with students, tutoring, lecturing, conducting discussion, all the roles we play pedagogically. Our work as teachers should meet the highest scholarly standards of groundedness, of openness, of clarity and complexity. But it is only when we step back and reflect systematically on the teaching we have done, and that systematic analysis and reflection leads to a recounting of what we've done, in a form that can be publicly reviewed and built upon by our peers that we have moved from scholarly teaching to a scholarship of teaching.

A new question arises: Which route will my academic journey take now? I believe that HE studies did not only assist me thus far to grow as a scholar, but will probably continue to do so long after I have completed the formal programme. The structured and supported process enables me to reflect upon my own teaching, performance and achievement. I have become aware of different aspects in the HE context, namely scholarship, research, assessment, leadership, staff development, technology, teaching, learning and curriculum development. It has emphasised the importance of authentic assessment in the HE context and enticed me to explore educational and psychological aspects regarding assessment in $\mathrm{HE}$ in the near future. This brings me to the final point which my case study seeks to underline, namely that HE studies can be a powerful tool to develop passionate lecturers. And any passionate lecturer involved in teaching will invest his or her intellectual powers in becoming a scholar of teaching, learning and research. Dirks (1998:1) makes it clear that such passion could result in the greatest honour for most academics - namely to be labelled as a scholar.

Just as Gardner's life story inspired me, I would like to inspire the reader by highlighting a basic underlying value that might motivate him or her to embark on a journey of scholarship: "If you want something, go get it, period."

\section{CASE STUDY 2: AN ONGOING JOURNEY OF SELF-DISCOVERY AND IDENTITY DEVELOPMENT (MARIANNE BESTER)}

\section{Introduction}

My contribution to this chapter on students' perspectives of HE studies is framed against extensive literature on the concept of identity as well as on the association of one's 
identity with different roles, which in turn impact on an individual's professional identity development. My intention is to provide a concise description of my journey of selfdiscovery and identity development against the background of a changing world of HE worldwide, but particularly in South Africa over the past two decades, which prompted my decision to engage with $\mathrm{HE}$ studies as a postgraduate student.

For ages mankind has asked questions such as: Who am I? How do I see myself? How do others see me? These questions are at the root of our being and identity, with answers that shift as we move through contexts, come to embrace and relinquish particular goals, values and roles, and operate within and outside different communities of society. The concept of identity is defined in various ways. Erikson (1968, in Beijaard, Meijer and Verloop 2004:107) outlines a chronological and changing concept of identity, indicating that each stage has its own characteristics relating to the individual's interaction with his or her environment. The writings of the symbolic interactionist George Herbert Mead (1934) focus on the concept of identity in relationship with the concept of self. Mead indicates that the "self reflects society" (Stryker and Burke 2000:286), which implies that the self is multifaceted. In addition to the work of Erikson and Mead, the work of McCormick and Pressley (1997), as well as of Purkey (1970), indicates that "identity is not a fixed attribute of a person, but a relational phenomenon" (Beijaard et al. 2004:108).

Based on the work of Stone (1962), Vryan, Adler and Adler (2003, in Smit and Fritz 2008:93) developed the notion of identity using concepts such as situational, social and personal identity. Situational identity emerges from collective behaviour and meaning-making between oneself and the people around one. Social identity is shaped and forged with socially constructed categories of people (learners, colleagues, friends and family) or the position within a social structure (department, faculty and institution). This identity will last within the socially structured relationship for the duration of the position. Vryan et al. (2003:371, in Smit and Fritz 2008:93) indicate that "we define ourselves and others in the light of our social identities across many of the different kinds of contexts in which we find ourselves, thus providing continuity even as we step in and out of various situational identities". The remaining construct of personal identity involves the uniqueness of an individual, including personal history and personality traits. In my opinion, it also includes discourse as defined by Gee (1996:131) "as a socially accepted association among ways of using language, other symbolic expressions, and 'artifacts' of thinking, feeling and believing, valuing and acting" to identify oneself as a member of a 'social network' or to signal one's role within this network. I view identity as a "reflexive process" (Giddens 1991) whereby an 
individual constructs and manages his or her identity as a self-narrative within a social context, which both enables and constrains the individual's choices.

\section{Shaping professional identity - dominant frames of reference}

An individual's identity is often associated with a particular role, or a professional and social position. Colbeck (2008:10) indicates that role labels convey meaning and expectations of behaviours that have evolved over years through countless interactions among people within a social network. The role labels of 'student', 'lecturer' and 'researcher', to name only a few, would convey varying sets of expectations, mostly defined by others, and which could either be accepted or rejected by an individual in defining his or her own identity.

As a university academic I interact professionally with learners, colleagues, the broader university community and industry representatives as part of my ongoing process of identity development, of interpreting myself as a certain kind of person and being recognised in a given context or situation. In this ongoing process of self-discovery and shaping of my personal and professional identity, I have often asked myself these questions: Who am I at this moment within a particular context or situation? Am I an academic? Am I a lecturer or am I an HE teacher? Am I a reflective practitioner? Am I a student in HE studies? Am I a scholar in teaching and learning? Am I a technical expert in my field of study? Am I a researcher? Am I leader? Am I an agent for pedagogical change in my academic department? What is the relationship between these different 'identities' and what role do relationships within my social and situational contexts play in my professional identity development? Furthermore, how do these different 'identities' impact on my continuing professional development and journey of selfdiscovery? In my opinion, these 'identities' form part of a "trajectory of the self" as defined by Giddens (1991) to describe the sense of shaping one's self-identity, which in turn also indicates that identity construction and development can be viewed as a reflexive 'sense-making' socially constructed situational learning process.

An individual's sense of identity is influenced by dominant frames of reference as defined by Blenkinsopp and Stalker (2004:419). These dominant frames of reference serve to inform, both explicitly and tacitly, the different levels of consciousness creating a "cognitive framework for interpreting new experiences" (Colbeck 2008: 10). According to Blenkinsopp and Stalker (2004) identity may also be shaped discursively by the individual's engagement in discourse communities. Harré (1998, in Blenkinsopp and 
Stalker 2004:420) suggests that identity is discursively created in interactions with others, but also in 'conversation' with oneself.

Over the years a number of dominant frames of reference and discourse communities have impacted and are still impacting on my levels of consciousness. They are therefore also shaping my cognitive frameworks. These include, amongst others, ontological and epistemological modes of voice, the impact of educational change taking place in South Africa, as well as the role, responsibilities and educational practices of modernday South African HE institutions in addressing the development needs of society and in providing students who should contribute meaningfully in a knowledge-driven and knowledge-dependent society to the growth of the country.

Although I assume different identities and perform different roles as an academic, i.e. that of HE teacher, that of head of a department at a South African university of technology and that of a colleague, this paper will offer the reader a personal reflection on my own journey of self-discovery and professional identity development viewed from the perspective of a 'student' in HE studies.

\section{The changing world of Higher Education}

The changing world of HE worldwide, but particularly in South Africa over the past two decades, provided impetus to my decision to engage in HE studies. Since the 1990s higher education worldwide has undergone profound changes which, according to Partington and Brown (1997:208), include the following:

- An increase in size and diversity of the student population

- Increased expectations of quality by stakeholders

- Greater accountability of academic functions such as research and teaching

- Increased emphasis on efficient and effective management.

I completed my undergraduate studies in education at a traditional South African university before the mid-1990s when outcomes-based education triggered "the single most important curriculum controversy in the history of South African education" (Jansen 1999:3). My conceptions of teaching and learning during my childhood and undergraduate study years were mostly influenced by the curricula of the apartheid state in South Africa. The apartheid state managed a centralised curriculum policy system which was described as "racist, Eurocentred, sexist, authoritarian, prescriptive, unchanging, context blind and discriminatory" (Jansen 1999:4). It is also important to remember that the traditional education practice during this time centred on content- 
driven, examination-oriented and teacher-centred curricula with pupils and students as passive participants in the learning process.

I experienced the early years of my teaching career at a historically black technikon in South Africa during the mid-1980s as particularly stressful and emotionally demanding. The pressures of role transition from student in education at a traditional, historically white university to an academic staff member at a historically black technikon as well as the impact of unprecedented political demands from the liberation movements such as the rhetoric of 'People's Education' characterised by access, curriculum reform, learned-centred teaching and community involvement (Kraak 1999) forced me to consider conflicting meanings and expectations in terms of my identity and role. The period that followed after 1990 witnessed a plethora of policies initiating and seeking educational change in South Africa by redressing past inequalities, transforming the HE system to serve a new social order, while also addressing the national economic needs and responding to new realities and opportunities created by globalisation.

The White Paper on the Transformation of Higher Education (SA 1997) argues for the restructuring of $\mathrm{HE}$ to meet the "needs of an increasingly technological economy with the capacity to participate in a rapidly changing global context". For the HE sector, especially universities of technology (former technikons) to meet these demands, learning programmes have to ensure that qualifying students have extensive knowledge and skills they can apply in a world of constant change. The learning process should not only prepare learners for a qualification, but should enable students to continue learning and adapting to the constantly changing world of work, which Gibbons (1998:12) interprets as the "dynamics of relevance" for higher education by drawing attention to the fact that relevance is not static, but rather a functional concept, "one that is intended to be adapted to a particular, but evolving, technoeconomic environment". Linked to these epistemological changes reflected in Mode 1 and Mode 2 knowledge production promoted by Gibbons (1998), is the fact that in a knowledge-driven society, education has the task of preparing people to perform difficult jobs competently, with a realisation that in a constantly changing world, a world of "super-complexity" as described by Barnett (2000), they must be equipped to deal with change. Gibbons (1998:14) states: "The only skill that does not become obsolete is the skill of learning new skills."

Educational change, however, only becomes reality once it is implemented at classroom level by academic staff. Since the mission of outcomes-based education in South Africa after 1990 has been to focus on the needs of the learner, to acknowledge human 
diversity by allowing learners to develop to their full potential in a quality education system characterised by access, accountability, relevance, learner-centredness, social responsibility, integration and Ubuntu (Mohamed 1999:158), I became increasingly aware of the fact that my undergraduate studies in education during the late 1970s (based on notions of content-based, teacher-centred education for homogeneous student groups) had not prepared me adequately for these challenges. I had the choice of continuing with traditional ways of teaching, reproducing practices that I was accustomed to, thus ignoring the shortcomings of these practices, or to adopt new ways of teaching that could potentially improve the quality of students' learning experiences.

The various aspects of educational change in South Africa since 1994 became dominant frames of reference and formed part of prevailing discourses, explicitly and tacitly, influencing different levels of my consciousness, altering my cognitive frameworks and shaping my professional identity from 'lecturer' to higher education 'teacher' with less emphasis on delivery of lectures and greater emphasis on 'facilitator' of significant learning experiences while reflecting on teaching practice. As stated by Dall'Alba (2005:371), "teaching is not only what we know and do, but who we are".

\section{Bringing about conceptual change in my teaching practice}

These educational changes in South Africa after 1990 suggested to me that I had to revisit, rethink and evaluate the beliefs or conceptions of teaching and learning, and reflect on how these conceptions of teaching and learning were influencing my teaching practice. Studies by Kember and Kwan (2000) and Trigwell and Prosser (1996) show that in higher education, it is reasonable to draw the conclusion that university teachers adopt conceptions or beliefs regarding teaching which are consistent with their beliefs about teaching. Richardson (2005:677) reports on an interview-based investigation on conceptions of teaching by Kember (1997) which converged into five different conceptions:

- Teaching as imparting information

- Teaching as transmitting structured knowledge

- Teaching as an interaction between the teacher and the student

- Teaching as facilitating understanding on the part of the student

- Teaching as bringing about conceptual change and intellectual development in the student. 
Richardson (2005:677) also indicates that many researchers assume that teachers' conceptions of teaching in higher education change with experience, but in fact very little evidence is available to substantiate such a claim. If one's teaching beliefs are deeply rooted in old ways of doing things, it becomes an obstacle, because in a way these beliefs strengthen resistance to conceptual change. It was evident to me that although my teaching conceptions earlier in my academic career were oriented towards imparting information and transmitting structured knowledge, various aspects of educational change in South Africa at the time urged me to change my teaching practice towards facilitation of students' understanding and to bring about conceptual change and intellectual development in students. This realisation forced me to consider questions such as: What is good teaching? How should I change my teaching practice to bring about improved student learning?

Trigwell $(2001: 65)$ indicates that firstly, good teaching is oriented towards and related to high quality student learning and that secondly, good teaching is scholarly. Good teaching, according to Trigwell (2001:65) is "more than what happens in a classroom or on-line: it includes planning, compatibility with the context, content knowledge, being a learner, and above all, reflection and a way of thinking about teaching and learning." Ramsden, Margetson, Martin and Clarke (1995:24, in Trigwell 2001:66) declare that good teachers are also good learners. Good teachers participate in a variety of professional development activities by listening to their students and by reflecting on classroom interactions and the achievements of their students as part of a dynamic, reflective and constantly evolving process. Good teachers demonstrate the ability to transform and extend knowledge by using the knowledge of their learners, as well as their own disciplinary and pedagogical knowledge, to transform concepts of the discipline, rather than merely through transmission of knowledge. Ho (2000:31) states that if a teacher wishes to adopt a student-centred approach to teaching and for students to adopt a meaningful approach to learning, teachers should engage in professional development programmes and reflective practice as a means of directing conceptual change.

When I was confronted with the reality of having to implement good student-centred teaching practice in class, I once again realised that I had to move beyond the level of routine responses to classroom situations and achieve a higher level of awareness of how to teach, of the kinds of decisions I should make when teaching and of the value and consequences of particular instructional decisions. I realised that observation and critical reflection could be a way of bringing about conceptual change as indicated by Bartlett (1990:267): 
Asking 'what and why' questions gives us a certain power over our teaching. We could claim that the degree of autonomy and responsibility we have in our work as teachers is determined by the level of control we can exercise over our actions. In reflecting on the above kind of questions, we begin to exercise control and open up the possibility of transforming our everyday classroom life.

A reflective approach to teaching allowed me to change the way I usually perceive teaching and my role in the teaching process. It also allowed me to develop changes in attitudes and awareness which I believe benefit my professional growth and development as a teacher. Despite my engagement with reflective teaching, I also realised that it is important to develop and equip myself with scholarly knowledge, skills and attitudes to function optimally as a professional curriculum designer, learning facilitator, assessor and scholar. It was at this point in my journey of self-discovery and professional identity that I became aware that being a reflective practitioner and becoming a student in higher education studies are inseparable.

\section{Being a student in HE studies}

According to Brew and Boud (1996:20) "development is a concept concerned with the process of change" and that "[c]hange, in turn, generates new development needs". Worldwide, there is a demand for recognised, accredited programmes in professional development of academic staff in higher education. These programmes in higher education studies encourage academic staff to explore the ontological and epistemological underpinnings of their disciplines and to examine their conceptions of teaching and learning as well as their teaching practice. Although I had previously undergone training as a teacher, I was ill-equipped for the growing emphasis on quality assurance and accountability in higher education, and for the challenges brought about by the transformation of higher education institutions in South Africa.

Kasworm (2008:27) indicates that "learning is an act of hope" - a hope of entering learning experiences that will be life-changing. Adults, like myself, who enter HE studies do not view entering (or re-entering) $\mathrm{HE}$ as physical separation from past worlds as would typically be the case with younger adult learners who start their student life away from home. Being a student becomes an additional challenge and responsibility - it forms part of the complex life of work and home. I agree with Kasworm (2008:31) who indicates that the epistemological beliefs of adult learners are embedded in two worlds: the world of academic knowledge (of books and theory) and the world known by many adults as the real-world knowledge (of tacit understandings and everyday applications). According to Kasworm (2008:31) these "knowledge voices" also 
represent affective connections to self, life roles and life actions. In considering these "knowledge voices" Kasworm (2008:32) contends that when adult learners are able to integrate knowledge engagement across both life worlds, it demonstrates a unification of the cognitive and emotional worlds of the adult learner as well as the epistemological beliefs of different worlds of academic knowledge and real-world knowledge. I agree, once again, with Kasworm (2008:32) based on my own experience as adult learning in higher education studies that this unification of the worlds of academic and realworld knowledge leads to "actions of transformation of self through an ongoing active cycle of reflection and action integrating knowledge and life applications".

For me, the pursuit of a postgraduate qualification in HE studies is a choice and a life-changing engagement that allows me to develop a greater understanding of my teaching as I feel less threatened about changing my practice, since it allows me to advance my practice from "a conception of teaching as transmission to one of teaching for changing conceptions (self-enlightenment)" (Smyth 2003:54). I agree with Smyth (2003:54) that "teachers can achieve transformation when they are supported to change conceptions in a managed change process where they are given time for discussion and reflection". Yet, it is also important to remember that "knowledge and skills acquisition do not ensure skilful practice" and that, as argued by Dall'Alba (2005:363), by merely focusing on epistemology we fail to facilitate and support transformation of the self. It is important to direct attention to ontology, since "it means that knowing is not simply something we possess, but who we are". Dall'Alba (2005:367) argues that "transforming the self is ontological, it involves integrating knowing, acting and being".

The most significant result of my engagement in HE studies as a postgraduate student relates to my sense of self-discovery - of finding out about my inner strengths, about hidden abilities, and about unacknowledged passions for learning. It has been and still is a transforming experience that allows me to gain knowledge and skills directly related to my role as a higher education teacher, allowing me to apply the knowledge in a real-world classroom situation, encouraging me to reflect on my practice in a scholarly manner, which in turn stimulates me to ask questions about my very being as a higher education teacher.

\section{CONCLUSION}

We have shared in this chapter the ontological dimensions of our respective journeys of self-discovery and professional identity development as students in HE studies. 
We have indicated that educational change in $\mathrm{HE}$ worldwide - and this includes South Africa - over the past decades has shaped our identity, influenced our roles as university academics and forced us to interrogate and reflect on our teaching practices as HE teachers, which has provided the impetus for our search for meaning and knowledge. Since postgraduate HE study places emphasis on ontology while it also addresses epistemology, it allows us as students to enhance and transform our ways of being as higher education teachers. Finally, we realised that our engagement with HE studies challenges us to go beyond being good teachers and reflective practitioners by embracing the scholarship of teaching as part of our journey. We understand that becoming scholars in teaching and learning is an ongoing process of professional development that requires integrity, persistence, enthusiasm, passion and courage. We have embarked on a journey of lifelong learning with a sense of purpose for the future. We are working towards achieving our short-term goals of completing our studies in HE successfully as well as towards achieving future career goals. The longterm rewards of our engagement in HE studies that motivate us to remain self-directed learners, reflective practitioners and scholars in teaching and learning will continue to enrich our lives forever.

\section{REFERENCES}

Andresen LW. 2000. A useable, trans-disciplinary conception of scholarship. Higher Education Research \& Development, 19(2):137-153.

Barnett R. 2000. Realizing the university in an age of supercomplexity. Buckingham: SRHE \& Open University Press.

Bartlett L. 1990. Teacher development through reflective teaching. In: JC Richards \& D Nunan (eds). Second Language Teacher Education. New York: Cambridge University Press.

Beijaard D, Meijer PC \& Verloop N. 2004. Reconsidering research on teachers' professional identity. Teaching and Teacher Education, 20(2):107-128.

Bitzer EM. 2004. Scholarship and professional profiling: Possibilities for promoting quality in higher education. South African Journal of Higher Education, 18(1):19-37.

Bitzer EM. 2008. Scholarship in higher education. Lecture during MPhil in higher education. Stellenbosch. 12 February 2008.

Blenkinsopp J \& Stalker B. 2004. Identity work in the transition from manager to management academic. Management Decision, 42(3/4):418-429.

Boyer EL. 1990. Scholarship reconsidered. Priorities of the professoriate. New Jersey: Princeton University Press.

Braxton JM, Luckey W \& Helland P. 2002. "Institutionalizing a broader view of scholarship through Boyer's four domains". Eric Digest [Online]. Available: http://www.ericdigests. org/2003-3/four.htm [2008, 6 April]. 
Brew A \& Boud D. 1996. Preparing for new academic roles: A holistic approach to development. The International Journal for Academic Development, 1 (2): 17-25.

Canfield J. 2009. "Jack Canfield's quotes." Woopidoo Quotes [Online]. Available: www. woopidoo.com/business_quotes/authors/jack-canfield/index.htm [2009, 4 March].

Colbeck CL. 2008. Professional Identity Development Theory and Doctoral Education. New Directions for Teaching and Learning, 113, Spring:9-16.

Dall'Alba G. 2005. Improving teaching: Enhancing ways of being university teachers. Higher Education Research \& Development, 24(4):361-372.

Dictionary.com. 2009. [Online]. Available: http://dictionary.reference.com/browse/investment. html [2009, 23 February].

Dirks AL. 1998. "The new definition of scholarship: How will it change the professoriate?" Bridgewater [Online]. Available: http://webhost.bridgew.edu/adirks/ald/papers/skolar.htm [2008, 8 April].

Fischer G. 2009. "Center for Life Long Learning and Design (L3d)." University of Colorado, Boulder [Online]. Available: http://www.13d.cs.colorado.edu/philosophy.html [2009, 19 February].

Gee JP. 1996. Social linguistics and literacies: Ideology in discourses. 2nd Edition. London: Taylor \& Francis.

Gibbons M. 1998. Higher education relevance in the $21^{\text {st }}$ century. UNESCO World Conference on Higher Education, Paris. 5-9 October.

Giddens A. 1991. Modernity and Self-Identity: Self and society in the late modern age. Stanford: Stanford University Press.

Hatch T. 2006. Into the classroom: Developing the scholarship of Teaching and Learning. International Scholarship for Teaching and Learning [Online]. Available: http://www. academics.georgiasouthern.edu/ijsotl/v1n2/book_reviews/bergland/index.htm [2009, 8 April].

Ho ASP. 2000. A conceptual change approach to staff development: A model for programme design. The International Journal for Academic Development, 5(1):30-41.

Hutchings P \& Schulman LS. 1999. The scholarship of teaching: New elaborations, new developments. Change, September/October:11-15.

Illeris K. 2006. What is so special about adult learning? In: P Sutherland \& J Crowther (eds). Lifelong learning: concepts and contexts. Routledge: London. 15-23.

Jansen JD. 1999. Setting the Scene: Historiographies of Curriculum Policy in South Africa. In: J Jansen \& P Christie (eds). Changing curriculum: Studies on Outcomes-based Education in South Africa. Cape Town: Juta. 3-17.

Kasworm CE. 2008. Emotional Challenges of Adult Learners in Higher Education. New Directions for Adult and Continuing Education, 120:27-34.

Kember D. 1997. A reconceptualisation of the research into university academics' conceptions of teaching. Learning and instruction, 7:255-275.

Kember D \& Kwan K. 2000. Lecturers' approaches to teaching and their relationship to conceptions of good teaching. Instructional Science, 28:469-490. 
Kincheloe JL. 2003. Critical ontology: Visions of selfhood and curriculum. JCT: Journal of Curriculum Theorizing, 19(1):47-64.

Kraak A. 1999. Competing education and training policy discourses: A 'systemic' versus 'unit standards' framework. In: J Jansen \& P Christie (eds). Changing curriculum: Studies on Outcomes-based Education in South Africa. Cape Town: Juta. 21-55.

Kreber C. 2002. Controversy and consensus on the scholarship of teaching. Studies in Higher Education, 27(2):151-167.

MacDonald Ross G. 2005. "Kant on teaching philosophy." Leeds University [Online]. Available: www. philosophy.leeds.ac.uk/GMR/articles/KantonTP0805.doc [2009, 19 February].

Macfarlane B. 2005. Placing Service in Academic Life. In: R Barnett (ed). Reshaping the University. New relationships between Research, Scholarship and Teaching. London: Open University Press. 165-177.

McCarthy M \& Higgs B. 2005. The scholarship of teaching and its implication for practice. AISHE Readings [Online]. Available: http://www.aishe.org/readings/2005-1/biographies. html [2008, 30 April].

Mohamed H. 1999. The implementation of OBET in South Africa: Pathway to success or recipe for failure? In: J Jansen \& P Christie (eds). Changing curriculum: Studies on outcomes-based education in South Africa. Cape Town: Juta. 157-170.

Movie. 2006. The Pursuit of Happyness (DVD). Columbia TriStar Motion Picture Group.

Nicholls G. 2001. Professional Development in Higher Education. New dimensions \& directions. London: Routledge.

Palachuk KW. 2008. "The Unexamined Life is Not Worth Living." [Online]. Available: www. relaxfocussucceed.com/Articles/2003010002.htm [2009, 5 March].

Partington P \& Brown G. 1997. Quality assurance, staff development and cultural change. Quality Assurance in Education, 5(4):208-217.

Pekel K. 2008. Minnesota education: Motivation matters. Minnesota education [Online]. Available: www.minnpost.com/community_voices/2008/10/10/3832/minnesota education_motivationmatters [2009, 25 February].

Priest A. 2005. But is it scholarship? Group reflection as a scholarly activity. Studies in Learning, Evaluation, Innovation and Development [Online]. Available: http://sleid.cqu. edu.au [2008, 7 April].

Richardson JTE. 2005. Students' Approaches to Learning and Teachers' Approaches to Teaching in Higher Education. Educational psychology, 25(6):673-680.

Rowland S. 2005. Intellectual love and the link between teaching and research. In: R Barnett (ed). Reshaping the University. New relationships between Research, Scholarship and Teaching. London: Open University Press. 92-102.

Shulman L. 2004. Dedicated to the Pursuit of Teaching Excellence. Central Connecticut University [Online]. Available: www.ccsu.edu/Forum/Default.htm [2009, 23 February].

Sims T. 1997. Theory and Practice [Online]. Available: http://www.dtl.org/ethics/article/theory. html [2009, 29 February]. 
Slideshare. 2009. A journey on a train. Slideshare [Online]. Available: http://www.slideshare. net/vijay2623/life-a-journey-On-train.html [2009, 3 March].

Smit B \& Fritz E. 2008. Understanding teacher identity from a symbolic interactionist perspective: Two ethnographic narratives. South African Journal of Education, 28:91-101.

Smyth R. 2003. Concepts of change: Enhancing the Practice of Academic Staff Development in Higher Education. International Journal for Academic Development, 8(12):51-60.

Sondheim S \& Lapine J. 1996. Into the Woods. Imagination.com [Online]. Available: www. imagi-nation.com/moonstruck/albm29.html [2009, 23 February].

Sorcinelli MD, Austin AE, Eddy PL \& Beach AL. 2006. Creating the Future of Faculty Development. Learning from the Past, Understanding the Present. Bolton: Anker.

South Africa. Department of Education. 1997. Education White Paper 3: A programme for the transformation on Higher Education. Government Gazette, Vol. 386 No. 18207. 15 August.

Stryker S \& Burke P. 2000. The Past, Present and Future of an Identity Theory. Social Psychology Quarterly, 63(4):284-297.

Sutherland P \& Crowther J. 2006. Introduction: The lifelong learning imagination. In: P Sutherland \& J Crowther (eds). Lifelong learning: concepts and contexts. Routledge: London. 1-14.

Thinkexist.com. 2009. "Quotes" [Online]. Available: http://www.thinkexist.com/quotation/ education_is_the_kindling_of_a_flame-not_the/189442.html [2009, 20 February].

Trigwell K. 2001. Judging university teaching. The International Journal for Academic Development, 6:66-73.

Trigwell K, Martin E, Benjamin J \& Prosser M. 2000. "Scholarship of teaching: A model." The Australian Scholarship in Teaching Project [Online]. Available: http://www.clt.edu.au/ Scholarship/A/Model.html [2008, 9 April].

Trigwell K \& Prosser M. 1996. Changing approaches to teaching: A relational perspective. Studies in Higher Education, 21:275-284.

University of the Western Cape Online (UWC). 2009. "Higher Education Studies." UWC [Online]. Available: www.uwc.ac.za/index.php? module $=\mathrm{cms \& action}=$ showfulltext\&id=ge n11Srv7Nme54_8187_1210050547\&sectionid [2009, 24 February]. 


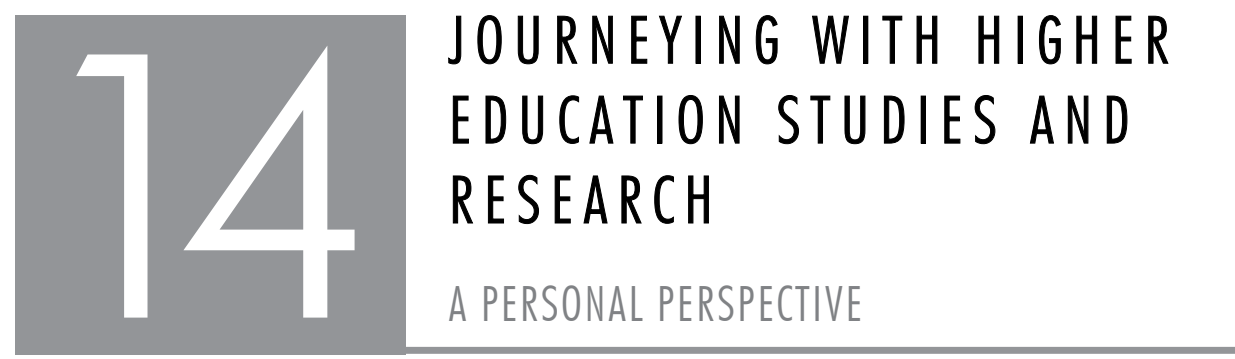

\section{Eli Bitzer}

\section{ABSTRACT}

This chapter captures different 'stages' of the development of my own journey with the field of higher education (HE) studies and research. It reflects change and development of the field from personal experiences covering five 'developmental stages' and a period of almost 30 years. Stage one represents a novice position from where I knew absolutely nothing about the field of HE and when the learning curve was exceptionally steep. Questions I try to answer include: What literature was available at the time? What were the seminal works? What were the themes that dominated the field? The second stage covers my own master's and doctoral studies. In each instance there were dominant influences, forces and literature that guided my postgraduate work. I explore the question of how these studies influence my perspectives concerning higher education and how they impacted on my future work. The third stage deals with projects and post-PhD research and the initial stages of publishing in the field leading onto a fourth stage where I started supervising PhD students. Stage five represents the present with a broader view is taken within the limitations of one person's perspective to take such a stance. This last section also ties in with the chapter by Bitzer and Wilkinson elsewhere in this book that addresses aspects of higher education as a field of study in South Africa.

\section{INTRODUCTION}

Jules Verne's classic 1864 science fiction novel A Journey to the Centre of the Earth tells the story of a professor who leads his nephew and a hired guide down a volcano in Iceland to 'the centre of the earth'. They encounter multiple adventures, including close-up meetings with prehistoric creatures and natural hazards. The living organisms 
they encounter as they travel through the rock layers reflect geological time and the creatures they face become more ancient and overtly aggressive. Eventually, after a magnificently challenging journey, they surface again in southern Italy in all peace and tranquillity. From a scientific point of view Verne's story seems not to have aged as well as his other science fiction stories, since much about what 'Centre of the Earth' contains have since been proven wrong. However, a redeeming point to the story is Verne's own belief, told within the novel from the viewpoint of a character that the inside of the earth does indeed differ from that which the characters encounter. The story apparently inspired many script writers, film makers and proponents of other media to produce none less than 13 films, TV series, plays, comic books and music albums with the same title and plot - the latest of which was released in 2008 as Eric Brevig's Journey to the Centre of the Earth 3D (http://en.wikipedia/journey3D).

My journey is not in the least as dramatic as the one suggested by Verne and it is far less fictional. In fact, it resembles much more a typical road trip from $A$ to $B$ with the difference that $B$ does not represent a destination, but a viewpoint along the way. No hairy creatures or dinosaurs spotted, but ample rough spots, smooth patches and excitements. Without a modern-day geo-positioning system, I started out with only blurred road maps and pointers that added to the wonder as the journey unfolded. Therefore, to capture a career of almost thirty years in higher education studies and research in one chapter is obviously impossible. I merely aim to generate a few glimpses or perspectives of a thirty odd year journey, closely involving two higher education institutions in South Africa.

Without being aware of it at the time, my potential career in higher education started off with a leadership course at the University of the Free State (UFS or the University of the Orange Free State as it was known then) when I was still attending high school in 1969. It so happened that I was part of a group of head girls and -boys from secondary schools in the Free State province who participated in a leadership course organised by the Department of Culture and in particular involved a person who would later become my mentor and supervisor at FSU, Kalie Strydom. The programme included a week's lectures and activities in Bloemfontein followed by a train trip to Cape Town, a visit to Parliament, a boat cruise to Durban and a plane trip (very novel at the time) back to Bloemfontein. The money for this round trip, priced at less than R100 (which was, of course, a lot of money in 1969), I had to borrow from my dad. During the initial week's lectures at the leadership course, I guess the first seeds were sown for me to attend university as the group was immersed into topics such as 'leadership', 'public speaking', 'management and organisation', 'public etiquette' 
and 'endurance and discipline' - the latter presented at the time by one of Free State's sporting heroes, Ewie Cronjé (father of the late South African cricket player, Hansie Cronjé). The message was clear - a university education takes you into leadership positions and is an option worthwhile to consider. Coming from a small rural town in the Free State, this leadership course contributed to my decision to pursue a higher education and evoked my interest in the topic of leadership which would later become one of the main themes in my PhD studies. This, in turn, allowed me into the 'realms of higher education', which would otherwise have been impossible - I guess.

After compulsory military service in 1970, I joined the University Free State (UFS) in 1971 as a first year BSc student, but shortly thereafter changed to BA with majors Maths and English to pursue a career in school teaching. 1974 represented the year of my first encounter with Education as a discipline in the Faculty of Education at UFS by enrolling for the Higher Education Diploma (HED) that would allow me to teach Maths and English to high school students. My first experience with Christian higher education, which was the dominant paradigm at UFS then (and probably is, to a large extent, still the case) included exposure to the works of Christian philosophers such as Abraham Kuyper, HG Stoker, Herman Dooyeweerd (De Wijsbegeerte der Wetsidee - A new critique of theoretical thought), JM Spier (Orientation to Christian Philosophy), DFM Strauss (Science and Reality), P G Schoeman (A Christian Education Philosophy), JJ Fourie (Theme and variation in Education) and CFG Gunter (Aspects of Theoretical Education). This was supplemented by related works such as Introduction to Socio- Pedagogics (PAE Hoffman), Comparative Education (PE Jones) and Responsible Education (NT van Loggerenberg and AJC Jooste) as well as Introduction to Pedagogics ( $F$ van der Stoep and W J Louw, who were more representative of a phenomenological stance). I thus had a firm grounding in Christian philosophy of science and education in particular, which was further entrenched by my part-time BEd studies in 1977. Being a Christian myself, I did not object to the views that were propagated ex cathedra. However, I later came to realise that there were many other world and life orientations and perspectives that were neglected at UFS at the time (and equally so at its counterpart, the Potchefstroom University for Christian Higher Education). Fortunately, later studies and exposure brought some 'balance' as to my epistemological and ontological perspectives, but I never regretted the firm grounding in at least one philosophical tradition that provided a point of departure to explore and contrast broader and radically different understandings of human and natural phenomena. 


\section{A REAL START: FIRST ENCOUNTERS WITH RESEARCH AND DEVELOPMENT IN HIGHER EDUCATION}

After teaching Maths and English (second language) at a high school for four years, I joined the Bureau for University Education (BUE) in 1979. The late Professor Wynand Mouton, who became vice chancellor of the UFS shortly before, appointed Kalie Strydom, who was teaching at the Faculty of Education, Stellenbosch University at the time, as director of the BUE. The BUE brief was to improve the quality of teaching and learning at UFS. As one of the first support services of its kind (the first being at the former Rand Afrikaans University established in 1976), the BUE rendered three main services as a support unit at UFS, namely to advance the use of technology in teaching, to improve the teaching skills and educational grounding of lecturers and to conduct research into university teaching that would support the BUE's two main functions and promote the field of higher education teaching and learning. My first job at the newly established BUE was to study the latest literature concerning educational and staff development and recommend possible innovations concerning teaching and learning facilitation practices to both faculty committees and lecturers. This brought me to fresh encounters with the field of higher education which I hardly knew anything about, except from what I have learnt during my studies in education and my experiences as an education student. First readings that interested me were mainly from the USA and to a lesser extent from the UK. They included literature on the structure of institutions and systems of higher education in an attempt to make more sense of 'a broader picture'. This broader picture was, of course, heavily shaded by utilitarian motives or what Sue Clegg (2007:1) refers to as "... what works".

An urge to ask the difficult questions about higher education or to properly theorise in those early years was obviously lacking in South Africa. Publications such as those of Rossouw (1993), addressing the complex relationship between higher education, science and culture in the South African context, only became available much later. Authors on systemic and institutional issues and perspectives that come to mind from that era were, amongst others: Anderson (1974), Axelsson and Rosenburg (1976), Baldridge (1971 and 1971a); Clark (1963), Dressel and Mayhew (1974), Goodman (1962), Gross (1968), Kerr (1963), Millett (1962), as well as Pauw (1978) and Viljoen (1977) in South Africa. Authors that published work most relevant to my own inquiries at the time, which were mainly in the areas of professional and curriculum development, included Gaff (1975), D-W Piper (1976), McKeachie (1978), Nicholls and Nicholls (1974), Tyler (1975), Trow (1976) and Wheeler (1967). The important role of academic leadership and management at the departmental level was anything 
but neglected and was propagated by authors such as Startup (1976) and Thomas (1977) at the time.

During the first two years of research into higher education three things became clear. First, I realised that the literature on $\mathrm{HE}$ was largely dominated by North American authors and what the BUE was doing in terms of the development of teaching and learning was heavily influenced by the available North American literature. The only exception was the work and publications of the Society for Research into Higher Education (SRHE) in the UK that produced outstanding publications on teaching and learning at the time. Secondly, it was clear that few academic staff at the UFS knew anything of, let alone having an affinity for, the field of $\mathrm{HE}$ research and practice. Academic staff was very much immersed in their disciplinary thinking, research and teaching and hardly took any notice of the limited, but excellent theoretical work that was done on teaching innovation and its links to learning theory. To a large extent it was business as usual for most lecturers with wonderful exceptions here and there in many higher education institutions because of lecturers' personal interest in the field. It thus became extremely hard work to interest academic staff in critically reviewing their (in many instances outdated) teaching practices and to take notice of the broader field of higher education other than merely the disciplines in which they were working. Academic development staff was mainly seen as aliens within the existing 'academic tribes' as they had few academic credentials at the time. Thirdly, it was clear that the field of HE research and development and in particular reform in terms of teaching and learning, was emerging with several units or divisions that started at various universities. The universities of Cape Town, Durban-Westville, Pretoria, Port Elizabeth, Potchefstroom, Stellenbosch, Witwatersrand and others represented cases in time. In spite of political strife and turmoil in South Africa during those years, the development of educational and staff development (at least in the so-called 'white Afrikaans' universities) took new dimensions with a number of fresh initiatives, including the foundation of the South African Association for Research and Development in Higher Education (SAARDHE) and the beginnings of the South African Journal of Higher Education (SAJHE), both which were still active by 2009 .

\section{THE JOURNEY GETS TOUGHER: INQUIRING CRITICAL ISSUES}

A clear second stage of developing more sophisticated perspectives on higher education was embedded in my own master's and doctoral studies. During the early 1980s, the UFS embarked upon an investigation towards a more extensive after-hours and off-campus system of teaching and learning in order to make better provision 
for students outside of the typical 18-25 age group and for off-campus students. One part of this vision was to extend learning provision to other centres such as Kimberley in the Northern Cape as well as the Eastern and Northern parts of the Free State. I attempted in my research, which was in part sponsored by the Human Sciences Research Council (HSRC), to work out an educationally sound system for off-campus studies (Bitzer 1980) and in the process learnt much about non-traditional education designs such as distance and adult education systems. The results of a questionnaire survey amongst 1,159 lecturers, students and potential students lead to a more user-friendly system design for extra-mural studies that was firmly grounded in adult learning theory. Apart from Professors Kalie Strydom and Johann Nortié who facilitated my study, key sources that particularly influenced my thinking about $\mathrm{HE}$ at that juncture included most valuable sources from the Council of Europe (1977), Crossley (1976), Goodman (1976), Houghton and Richardson (1974), the Organisation for Economic Cooperation and Development (1974) and the seminal work of Ortega $Y$ Gasset (1964).

My PhD studies took me along a related, but different path when the BUE attracted a grant from the Anglo American Chairman's Fund in the early 1980s to conduct research and development work on academic leadership in universities. I was 'commissioned' to a sub-project that investigated the role of departmental chairs in order to promote effective teaching and learning in academic departments (Bitzer 1984). This journey took me to the USA, the UK, Europe and Israel to investigate elements of university life such as how universities are organised, the roles and functions of departmental chairs as well as educational leadership development. Eventually this endeavour contributed to propose a leadership and management programme for departmental chairs to improve their capabilities in promoting teaching and learning in university departments at UFS. It was at this stage of my career that I realised to a much larger extent the importance of the inter-disciplinary nature of higher education studies as I borrowed and used ideas from management sciences, psychology, industrial psychology, leadership studies and teaching and learning studies in my doctoral programme. Kalie Strydom was once again my promoter and Calvyn du Toit, coming from a background in Business Economics and professor at the then University of Port Elizabeth (currently Nelson Mandela Metropolitan University), was my co-promoter. The work of Baldridge, Curtis, Ecker and Riley (1983), Cohen, March and Olsen (1972), Mintzberg (1979), Montgomery, McLaughlin and Smart (1974), Tucker (1981) and others were of immense value in shaping my ideas around how universities function in different contexts worldwide and how academic departments and disciplines fit the picture. 
I came to realise the immense complexity of university work and the multiple layers of academic and administrative bureaucracy academic leaders and managers were confronted with (see Tucker 1980). I also became acutely aware of the fact that business management models and strategies would not work in university settings if they were not radically adapted to fit disciplinary and academic contexts. By trying to implement such a programme, this important lesson was learnt the hard, experiential way.

\section{A PUBLICATION PATH: HUMBLE BEGINNINGS}

The third identifiable stage of my encounters with higher education studies and research began when I steadily started publishing in the field during and after completion of my doctoral studies. Four major themes dominated the field during this period: (1) Academic leadership and management - particularly as they apply to university departments; (2) Academic staff development and staff appraisal; (3) Student learning and student development, and (4) Quality assurance and quality promotion, especially in courses and programmes of study. If I was working at a university in Europe, the UK, the USA or Australia at the time, I would have probably focussed on any one of the listed themes, but at UFS we were only a few BUE staff and all of these areas were important and urgent to investigate. It was thus a question of breadth over depth, but somehow we did manage to keep up with the latest literature and got involved in several institutional and national projects around these themes. The academic leadership project sponsored by the Anglo American Chairman's Fund assisted to attract one of the most influential exponents of departmental leadership at the time, Professor Alan Tucker, to South Africa. Tucker had presented workshops to department chairs for the American Council on Education all over the USA for many years and we were fortunate to have him contributing at two national and two institutional workshops on departmental leadership. I also visited Tucker at the University of Florida in the early 1980s to establish contact and attend a number of his workshops on departmental leadership elsewhere in the USA. From these activities a number of publications materialised (e.g. Bitzer and Strydom 1986, 1987; Strydom and Bitzer 1990). These publications mainly served to establish a theoretical framework for developmental work on academic leadership and management in departments that, in turn, contributed to the facilitation of workshops and a number of BUE seminars at a national level. These activities added in different ways to new and innovative actions vis-à-vis academic leadership and management at a number of universities in South Africa as it later became clear from either studies or actions taken towards improved academic leadership and management. 
Another theme that was very topical in the mid-1980s and will in all probability remain a hotly debated theme in higher education, is academic staff appraisal. At UFS, as at a number of other universities in South Africa, it was a constant struggle to conduct fair staff appraisals, particularly when it came to evaluating the quality of teaching and learning and linking academic performance to rewards. Questions that constantly emerged were: What would be the evaluation criteria? What evidence would be available for judging the quality of teaching and learning? Who would be the 'judges' of quality? How could the appraisal of teaching be done as validly and reliably as possible? Many of these questions are still not properly answered today, but, as Seldin (1984:24) rightly remarked:

There is no perfect evaluation programme, nor can there be. Such a system will probably always remain beyond reach. But with enough time, effort, and goodwill, we can come reasonably close.

It was for this very reason that Seldin, who was working at Pace University in New York at the time and still writes influentially on the appraisal of teaching and other scholarly activities (e.g. Seldin 1984, 2008), was invited to conduct a number of workshops at UFS and at a national level. When I visited Peter at his home in Croton-on-Hudson in 1986 he observed quite ironically that while many universities in the USA and abroad were asking for his services to update them on his research about staff appraisal, his own institution did not even bother to ask his opinion on the matter. Nevertheless, useful advice and identification of several research opportunities emerged from Seldin's visit during those years (e.g. see Bitzer and Strydom 1987b) and much more clarity were gained on the contextualised nature of university teaching and learning and how appraisal of these activities could both be extremely complex, highly subjective and cause a lot of upheaval amongst academic staff if not handled carefully.

One further important perspective that emerged during my research into educational and professional development during our inquiry into staff appraisal was the importance of an understanding of the relationship between learning theory and student academic performance. During the late 1980s the Centre for Student Counselling (CSC) at UFS was incorporated into the structures of the BUE and I had the opportunity of working more closely with its staff. Koos Venter, the director of the CSC, in particular played an important role of alerting us to the importance of a holistic view of student learning and making the student as an individual the point of concern rather than indiscriminately judging groups of students. The use of David Kolb's Experiential Learning Theory (ELT) and the Learning Style Inventory were at a peak of use at the time and therefore much of the literature (Boud 1985; Kolb 1981; Kolb 1984; Brookfield 1983) announced 
and acknowledged this seminal contribution. Insights into learning at the theoretical level assisted me and many academic staff in workshops to see how student learning styles could potentially influence the way university courses were designed and taught. Differentiated learning facilitation in particular received increased attention while it is also interesting to note how Kolb's work influenced training and staff development programmes in commerce and industry at the time. From closer cooperation with student counsellors some publications emerged (e.g. Strydom, Bitzer and Venter 1990) and inspired me to work and further research the area of student talent development and student performance during later years when I joined Stellenbosch University (e.g. Bitzer 2003; Bitzer and Troskie-de Bruin 2004; Bitzer 2005).

The last theme I want to highlight from this period of 'emerging publications' is quality and quality assurance in higher education. During the mid-1980s quality assurance regimes in the Netherlands, the UK, the USA, New Zealand and in a number of other countries really took off. South Africa benefited greatly from an accompanying surge of conferences, publications and work in this regard and it was after visits by colleagues such as Frans van Vught, Peter Maassen and the late Jitze de Haan from the Netherlands (as well as Lee Harvey, who later became the chief editor of the journal Quality in Higher Education in the UK) that a project initiated by Kalie Strydom on quality assurance got off to a good start. Institutional, departmental and programme quality came to scrutiny and these early inputs served as promoting the formal quality assurance structures of the later Council on Higher Education (CHE) and the Higher Education Quality Committee (HEQC). Visiting Professors Herb Kells and James Ratcliff from the USA added to the thrust and this resulted in a conference and number of projects and articles that inter alia investigated the difficult tension between quality and equity (Bitzer 1992; Strydom and Bitzer 1993; Bitzer and Malherbe 1995). In 1996 the Unit for Research into Higher Education, which was the first HSRC funded research unit dedicated to researching $\mathrm{HE}$ as a field of study and based in the BUE at Free State University, started publishing at least three extensive volumes of material on quality assurance in South African higher education. These publications (see Strydom, Lategan and Muller 1996, 1997; Fourie, Strydom and Stetar 1999) still stand as major contributions to local literature in the early days of quality assurance in the country.

From a historical perspective and as is elaborated upon elsewhere in this book, it is evident that between 1984 and 1994 a lot happened on the political and constitutional front that affected higher education. Alongside these developments and not always in conjunction with them, however, other initiatives also took stage. Amidst the work of the National Commission on Higher Education (NCHE) later chaired by Dr Jairam 
Reddy and the legislation that emerged from that, the themes of academic leadership and management, staff appraisal, student learning and quality assurance stood out as important ones in which work was done at several universities and at UFS in particular. Under the leadership of Kalie Strydom many of these initiatives later became fortuitous as staff trained by the BUE and the Unit for Research into Higher Education were appointed to research and managerial positions in other HE institutions such as universities of technology and others.

\section{TRAVELLING TOGETHER: POSTGRADUATE SUPERVISION IN THE FIELD}

Postgraduate supervision of higher education studies, particularly at the doctoral level, happened quite late in my career. This came as a notable fourth theme in acquiring a further additional perspective on higher education studies and research. However, it was not before 1996 that the first DEd student assisted by my supervision graduated. One problem at UFS (as at many others) was that the BUE was only affiliated to the Faculty of Education for academic purposes and its' staff was not really seen as academics in the full sense of the word. Similarly, higher education was not seen or recognised as a worthwhile branch of educational research. At many South African universities the tension between academic units and academic support units prevailed and to this day remains a sensitive point. Therefore, to supervise doctoral students one had to be 'accredited' as competent by the related faculty which depended on experience and which, in turn, could not be gained without supervising students. I was thus awarded one doctoral student in 1994 with two co-promoterships (the late Professor Dudley Vermaak and Professor Steve Niemann) from the Faculty of Education at UFS. Fortunately for me, this was an exceptionally bright student by the name of Magda Fourie who was also, incidentally, a student friend and colleague. The result was a highly successful graduate, but I think I have learnt much more from the supervisory experience than Magda did. We published together (see Fourie and Bitzer 1994), she later became deputy vice chancellor at two institutions and a chapter from her appears elsewhere in this book.

Between 1994 and 2009 I have supervised or co-supervised a total of thirty-five doctoral and master's students: eighteen at the PhD and seventeen at the MPhil level. The topics of their dissertations and theses varied among the following themes:

- University leadership and governance (1 PhD);

- Assessment in the curriculum (3 PhD; 1 MPhil);

- Curriculum analysis and curriculum frameworks (9 PhD; 3 MPhil); 
- Teaching and learning (3 MPhil);

- Student attrition (1 PhD);

- Student/academic development (2 PhD; 7 MPhil);

- Professional development of academic staff (1 PhD; 2 MPhil);

- Community engagement (1 PhD);

- Quality assurance (1 MPhil).

Due to my direct involvement with curriculum development as well as being appointed in a department of Curriculum Studies later, most of these studies were in the area of curriculum, teaching and student learning. When I arrived at Stellenbosch University and the Centre for Higher and Adult Education (CHAE), we deliberately made a decision to steer clear from, for instance, higher education policy and management studies as other institutions in the Western Cape region were already doing work in those areas.

In terms of research design most projects constituted contextualised case studies either as part of institutional, departmental or programmatic cases. In fewer studies survey designs were used, while phenomenography, grounded theory and action research were all used in only one study each. Most studies had a qualitative research approach and in only a few cases quantitative or mixed mode methodologies were deemed suitable.

One important perspective that I have gained from postgraduate supervision in higher education studies is that it indeed constitutes a specialised area of work that needs a lot of expertise and attention to detail - particularly in the study design phases. As Creswell (2009:7) has aptly pointed out:

[The] creation of a research design requires looking from the vantage point of a framework, an overall design, as well as focused attention on the detail ... which also shows the interrelatedness of the parts of the whole ... where each element contributes to and influences the shape of a complete study.

Most studies in the field of higher education contain either inter- or trans-disciplinary elements which make them both interesting and challenging. Over the years I have preferred in most instances to involve co-supervisors or -promoters from relevant disciplines or fields of study who contributed to studies in most meaningful ways and attended to the broader picture of HE studies as well as looking into project detail.

As master's or doctoral students in higher education are usually older and more mature compared to other fields of study, another important perspective that emerged is that 
joint publications with these students are highly valued by them - not only to further their own academic careers, but also to recognise them as potential and upcoming contributors to the field. Through the years I was fortunate in working with a number of such students and co-publish with them (e.g. De Villiers and Bitzer 2005; Beylefeld, Bitzer and Hay 2007; Ernstzen and Bitzer 2007; Crafford and Bitzer 2008). This does not mean that all postgraduates are always happy with their study experiences. Followup with alumni and current students is needed to ensure that supervisory capacity and practices constantly improve. When I joined the CHAE at Stellenbosch University in 1998, my colleague Chris Kapp was already working on an extensive study exit questionnaire for HE students which he refined over the years. Recently, after more than ten years of implementation, we took a retrospective stance on the feedback received (Albertyn, Kapp and Bitzer 2008) and tried to determine whether and in which respects studies in higher education indeed contribute to the academic professional development of graduates (Bitzer and Albertyn forthcoming).

One worrying factor through the years was the relatively high attrition rate of MPhil (Higher Education) students in particular. The MPhil (HE) programme at Stellenbosch as it stood in 2009 is a 240 credit programme that includes seven compulsory and two (out of four) elective modules (see www.sun.ac.za/chae). The compulsory coursework modules are: (1) Perspectives in higher education, (2) Student learning in higher education, (3) Foundations of research, (4) Research in higher education, (5) Curriculum and programme design in higher education, (6) Teaching in higher education and (7) Assessment and evaluation in higher education. The four elective modules are: (8) Scholarship in higher education, (9) Technology in higher education, (10) Staff development in higher education and (11) Leadership in higher education. The required research thesis constitutes half of the programme credits and usually spans the latter half of the second study year and goes into a third year. Over the years the attrition in the programme was between 30 and 40 per cent and was mainly due to students not completing their research theses. In the past students could exit the programme with a Postgraduate Diploma in Education (PGDE) after successful completion of their coursework. However, the Higher Education Qualification Framework (HEQF) stipulates that students cannot exit a programme early with an alternative qualification from 2009 onwards. I have found this ruling unfortunate as MPhil students who complete their coursework, but drop out of a programme before completing the thesis requirement (sometimes because of circumstance), are left with absolutely nothing for their efforts. 
In response to the attrition phenomenon we conducted a study at the $\mathrm{CHAE}$ on the problem as it emerged from our higher education programmes (Albertyn, Kapp and Bitzer 2008). The study indicated that increased globalisation, internationalisation and universal change impact highly on postgraduate supervision practices at higher education institutions in general. Our study investigated in particular the experiences of master's and doctoral students in higher education studies where increasingly larger numbers of international students (especially from neighbouring African countries) pursue their studies. Inquiry into a topic such as student experiences reflected something of a more holistic view or 'seeing the bigger picture' rather than merely the topical issues studied in the earlier part of my career. Broad change, transformation and quality, and student and staff experiences of these complex issues come to mind as those that have emerged for me as later important themes of inquiry.

\section{APPROACHING HIGH GROUNDS: SEEING THE BIGGER PICTURE}

In 1997 Altbach wrote a thought-provoking article in Daedalus in which he asked the question whether there might be an international academic crisis (Altbach 1997). Linked to other concerns (Levine 1997; Clark 1997; Gumport 1997), he outlined problems facing the contemporary university and their effects on the academic profession. One conclusion Altbach arrived at was that the academic profession continued to function without realising basic changes or taking note of the external forces that buffeted universities. Against the backdrop of the inevitability of change he predicted that the working conditions of the professoriate would deteriorate and that the profession's 'golden age' (characterised by institutional expansion and increased autonomy, availability of research funds and growing prestige and salaries), at least in industrialised countries, apparently had come to an end. Altbach also noted that the full-time American professor, on the average, remained largely insulated from the broad changes in higher education and had a little understanding of these trends. If this position reigned in South Africa by the mid-1990s, the situation has drastically changed. For example, the average staff member in local (i.e. South African) higher education has been showered (or literally bombarded) with the realities of radical change and transformational challenges at all levels of academic life. Institutional mergers, policy changes, changing student profiles, pressures to perform excellently in various roles, institutional commitments to public good and language issues are all examples of such challenges the average South African academic could have hardly ignored or escaped. For example, Chrissie Boughey's chapter in a recent book highlighted these and other changes well, also addressing the changes in a higher education context, 
mission and legislation (Boughey 2004). Involvement in and dissemination of higher education studies contributed not only to raise the awareness and implications of these challenges, but involved a number of academic staff in studies at various universities and hopefully contributed to broaden views and understanding.

When I joined Stellenbosch University in 1998, one of my first assignments was to prepare an inaugural lecture (see Bitzer 1998). Due to factors out of my control I had to draft the document under immense pressures and could not devote much time to the task. The topic attempted was: Higher education as a field of study - Challenges in a time of transformation (title translated from Afrikaans). In this address I firstly attempted to indicate the aims of recent higher education legislation (e.g. the Higher Education Act 101 of 1997) and explored the concepts transformation and higher education. Taking these key concepts as a point of departure, I tried to explain the difference between an established discipline (such as Education) and a field of study (such as HE) - also looking into the developmental path and growth of the field since 1974. In South Africa, apparently few publications dedicated to HE have appeared before 1920. The earliest one I could detect was by Malherbe (1925) who recorded the history of education between 1652 and 1922, also including references to higher education. Other early authors included Metrowich (1926), Malherbe and Cook (1938) and Cilliers (1944). In the second part of the lecture I discussed the changing higher education landscape in South Africa at the time and touched upon elements such as the influence of international and national socio-political trends. I concluded by pointing to a number challenges regarding the field of HE studies and research that remained important and seemed unaddressed at that stage:

- Building research capacity via partnerships and promoting postgraduate studies in HE (particularly in Africa and Southern Africa);

- Promoting and supporting research on issues of strategic importance to HE systems, institutions and programmes;

- The promotion of publications on HE and facilitating publication opportunities and outlets;

- Developing programmes of studies in HE among higher education institutions and linking these to the professional development capacity of academic and professional staff, and

- Promoting the field via short courses, workshops, conferences, HE forums and building accessible information systems on higher education. 
Since the inaugural lecture in 1998, I have published more than thirty articles in various journals on topics related to these issues, but the more important question is what the landscape changes were that I had observed along the journey? My attempt at a picture is given in Table 14.1 and I will explain these changes further below.

TABLE 14.1 An observed picture of change in higher education studies and research in South Africa - early 1980s to mid-2000s

\begin{tabular}{|l|l|}
\hline \multicolumn{1}{|c|}{ Area } & \multicolumn{1}{c|}{ Amount of change } \\
\hline Available literature & $\begin{array}{l}\text { Evolved from little to almost overwhelmingly much, but mostly from } \\
\text { abroad, particularly the USA. South African literature on higher } \\
\text { education, especially in the form of books, still appears to be quite } \\
\text { limited. }\end{array}$ \\
\hline Research expertise & $\begin{array}{l}\text { Initially expertise was only available abroad. It gradually became } \\
\text { more recognised and available in South Africa. HE studies attracted } \\
\text { interest beyond institutional boundaries and increasingly applied more } \\
\text { sophisticated methodologies. }\end{array}$ \\
\hline $\begin{array}{l}\text { Policy studies and } \\
\text { analysis }\end{array}$ & $\begin{array}{l}\text { A surge of national policies and policy development, in particular since } \\
\text { 1996; an average volume of critique and a lack of implementation } \\
\text { studies before 2006. }\end{array}$ \\
\hline $\begin{array}{l}\text { Research and study } \\
\text { leadership }\end{array}$ & $\begin{array}{l}\text { Initially limited and weak. Confined to institutional contexts where only } \\
\text { limited pockets of leadership and expertise were available. Currently } \\
\text { leadership is more available nationally in more areas of specialisation } \\
\text { as more students graduate in HE studies. }\end{array}$ \\
\hline Research projects & $\begin{array}{l}\text { Initially limited or non-existent. Increased with the evolvement of } \\
\text { publication outlets and as funding became more available. Current } \\
\text { research (including institutional research) appears to be too voluminous } \\
\text { for available local publication outlets. Initially, in-breeding - but now } \\
\text { much more cross-breeding via subsystems and regional systems of } \\
\text { higher education. }\end{array}$ \\
\hline $\begin{array}{l}\text { Recognition of the } \\
\text { field }\end{array}$ & $\begin{array}{l}\text { HE a field of study and research is much more recognised now within } \\
\text { institutions (demonstrated by funding for research and development } \\
\text { units) than in the past. Compared to 'pure' disciplinary recognition, } \\
\text { however, appreciation of the field is limited. }\end{array}$ \\
\hline
\end{tabular}

In order to justify my views as summarised in Table 14.1, I shall only focus in detail on the first two areas and deal with the rest more briefly due to limited space.

I have already indicated that during the earlier days of HE studies and research in South Africa literature was limited in volume and also limited to particular areas of $\mathrm{HE}$ (e.g. teaching and learning) compared to what was available abroad. The South African Journal of Higher Education (SAJHE) was only started in 1987 and before then most South African HE literature relevant to the field appeared in SAARDHE conference publications (e.g. 'Excellence in Teaching and Learning' Conference Papers, 2-4 April 1986, published by the University of Stellenbosch; 'Intercultural issues in teaching and learning in Higher Education' proceedings published by the University of Natal) or 
books [e.g. 'Universiteit en Onderrig' (University and Teaching) published by the then Rand Afrikaans University as a Lecture Series in 1968; 'Die suksesvolle dosent" (The successful lecturer') published by Strydom and Helm at Free State University in 1981]. After 1987 things went much smoother for HE publications. A consolidated index compiled by David Adey, the first editor of SAJHE, of ten years' of SAJHE publications in 1997 indicated a much wider scope and range of publications. For instance, more than 40 articles on student academic support and related issues, 27 articles on the assessment of student learning, 21 on computers in education and 16 articles on Chemistry education in HE were published in the SAJHE. So-called 'bulletins' and leaflets on teaching and learning or other aspects of HE at several universities served as examples of trying to bridge the gap of indigenous South African literature [e.g. the 'Bulletin vir Dosente' (Bulletin for Lecturers) at the then Rand Afrikaans University that started already in 1976, the publication series on university teaching and related aspects at Potchefstroom University under the leadership of Paul du Plessis and Nic Vreken, the 'Bulletin for Academic Staff' at the University of Durban-Westville which started in 1979 and the 'Journal for Technikon Research and Education' which started in 1982].

Two examples illustrating the contrast with the range of publications from abroad and in particular the USA might suffice. The National Institute of Education, US Department of Education, published two volumes of 'Higher Education' in 1981. These two volumes contained brief overviews of legislative documents, books, articles and other documents under 38 rubrics that varied from topics such as student admissions, student retention and campus planning to curriculum, educational technology and higher education public affairs. The list of publications cited in the reference list spans more than 30 pages, covering the twelve year period between 1968 and 1980 . Another example: 1976 saw the third edition of a 537 page book by John Brubacher and Willis Rudy titled: 'Higher education in transition' describing and commenting on the history of American colleges and universities from 1636 to 1976. In short, the level of availability and sophistication of literature at that period in time seems reasonably clear. I must point out, however, that after 1994 and particularly during the late 1990s and early 2000s literature on HE in South Africa proliferated and as many projects were supported by international charities, useful accounts of research and developmental work in higher education in South Africa were published (e.g. see Cloete, Fehnel, Maassen, Moja, Perold and Gibbon 2002). It remains a pity, however ideologically understandable, that the good work that was done and published on $\mathrm{HE}$ before 1994 did not receive any mention in later works. 
Research expertise in any scientific field are normally illustrated by the range and quality of research projects successfully completed, the number of postgraduate students supervised as well as the quality of that supervision, publications that emerge from the research and the number of projects funded in some or other way - preferably by national funding agencies. Apparently, in all of these categories $\mathrm{HE}$ studies and research in South Africa was quite immature in the late 1970s and early 1980s. However, at both the level of theory and practice there were exceptions such as an in-depth look at the problem of school-university transition at a conference in 1979 hosted by the then Committee of University Principals (CUP), the seminal work of Johann Pauw (1978) of the then Rand Afrikaans University on the nature of the Western university and its future in an African context, research on student counselling and development of distance education students by Hendrik Gous at Unisa and some of the research done for the so-called Van Wyk De Vries Report on Higher Education in 1974 (see RSA 1974). Overall, however, school and other forms of education received the bulk of the funding for research and HE was not well recognised as a field of study in South Africa. It was only in the early 1990s that the first Unit for Research into Higher Education, funded by the then HSRC and directed by Kalie Strydom was established at the BUE at the University of the Free State as pointed out earlier. In terms of research methodology, research projects from abroad mostly guided methodology (e.g. Chronbach 1946; Popper 1972; Marton and Säljo 1976; Marton 1981), the HSRC had just started to publish more extensive literature on research methodology (e.g. Mouton and Marais 1985; Mouton 1996) and many researchers - in the Afrikaans fraternity at least - used Landman's (1980) 'Inleiding tot die Opvoedkundige Navorsingspraktyk' [Introduction to the Practice of Educational Research] as a prime source for research methodology.

On the issue of HE policy studies and analysis Hay and Monnapula-Mapesela provide a perspective on policy and legislative developments elsewhere in this book. It therefore suffices to say that since 1996 South Africa has seen a surge of debates and documentation. Although these developments provided a rich source for studies and research, the new drafted policies were not necessarily implemented well. It is only by 2004-2006 that new policy implementation really came out of the woodwork and currently (that is 2009) it appears as if the 'policy fatigue' of the early 2000s has made room for a more stabilised HE sector in general and a greater availability of policy critique.

Similarly, leadership in HE studies and research was, in my view, quite limited in its earlier days as the field was emerging. Institutions that established centres or bureaus for teaching and learning development appointed directors who mainly came from 
faculties of Education and had some or other interest in educational technology. These directors took the academic lead as their centres grew and at institutions such as the former Rand Afrikaans University, University of the Witwatersrand (Wits), University of Durban-Westville, University of Potchefstroom, Free State University, Stellenbosch University, the University of Cape Town and the former University of Port Elizabeth. As the field grew, students who had graduated from these units took on leadership roles in HE study supervision and research.

The more limited a field, the more limited its research. In turn, limited research puts boundaries to the field of study. This chicken-and-egg argument also appeared to be true for HE studies in the 1980s. The field was relatively new in South Africa and funding was unavailable - both from internal sources (as only a few people conducted research into $\mathrm{HE}$ ) as well as the limits due to apartheid where no funding was available from abroad. The Committee of University Principals (CUP), however, supported a number of research and development initiatives in the field by the late 1980s in providing resources for the publication of the SAJHE and organising a number of conferences on burning HE issues. The formation of associations such as SAARDHE and SAAAD (the former South African Association for Academic Development which later became Higher Education Learning and Teaching in Southern Africa - HELTASA) and the forming of the Committee of Technikon Principals (CTP) also contributed to boosting the field. With the formation of new national structures after 1996 such as the Council on Higher Education, Higher Education South Africa (a non-profit company of rectors of $\mathrm{HE}$ institutions) as well as an influx of funding from abroad (e.g. the Ford Foundation, Nordic and Scandinavian development funds, Dutch funding) much 'cross-fertilisation' among institutions and regional groupings were stimulated. Examples include issues such as $\mathrm{HE}$ student retention, quality in $\mathrm{HE}$, e-learning and others.

Contrary to earlier trends, $\mathrm{HE}$ as a field of study and research is much more recognised today than in the previous two decades. Recognition has come in the form of appreciating HE not only as a specialised field within education, but also as a multiand interdisciplinary area of inquiry spanning disciplines and professional fields of study such as sociology, psychology, history, management, economics and others. Proof was evident in funding from sources such as the National Research Foundation (NRF) which became more readily available, and in the past five years, a number of researchers in the field have been rated and recognised by the NRF. However, compared to 'pure' and 'established' disciplines and professional studies, recognition of $\mathrm{HE}$ as a field of studies and research still has a long road ahead in South Africa. 


\section{CONCLUSION}

What did I learn from my five-staged journey with HE studies and research? One realisation was that in the early stages the field in South Africa was dominated by North American literature. Also, that there was little affinity among the regular university academics for HE research and development work and the emergence of the field happened mainly through the establishment of staff or academic development units in South African universities. Further, my own master's and doctoral studies assisted me greatly in widening perspectives on curriculum design, modes of HE delivery and academic leadership. The value of the inter- and transdisciplinary nature of HE studies and research clearly surfaced and I also realised how different and incompatible the values of the academic and corporate worlds seemed to be. The start of the publication stage of my journey brought a realisation how difficult it is, particularly in the South African context where resources are limited and staff is few, to engage in 'deep research' in the field. In many instances the pragmatic paradigm (see Creswell 2009) reigned and achieving theoretical depth in several areas of HE inquiry did not seem possible - at least not in my case. This was compensated for to some extent in the PhD and master's studies I have supervised. Making use of co-promoters and study leaders through the years have enriched my views of HE inquiry and also exposed me to different methodologies which would have not been possible otherwise. At the 'high grounds' stage of my journey, I gained a wider perspective of the field as much of the previous work came together in topics of inquiry such as scholarship in $\mathrm{HE}$, changing contexts, transformational challenges and the deterioration of the status of the professorial position in South Africa.

This personal 'journey' made me realise that various important changes in emphases concerning $\mathrm{HE}$ studies and research took place over a period of thirty years. Particularly in terms of available literature, research expertise, policy studies and analysis, research and study leadership, the types of research conducted and a recognition of the field. Extending HE boundaries is complex, because the field of higher education studies and research is complex, not easy to de-code and are constantly shifting (Clegg 2007). What might therefore be needed are many more accounts of past and current journeys within the field of HE to extend theoretical and practical vocabularies and to pose new questions for inquiry. 


\section{REFERENCES}

Albertyn RM, Kapp CA \& Bitzer EM. 2008. Profiling exiting postgraduate students' performance and experiences. South African Journal of Higher Education, 22(4):749-772.

Altbach P. 1997. An international academic crisis? The American professoriate in comparative perspective. Daedalus, 126(4), Fall.

Anderson GL. 1974. Trends in education for the professions. Washington DC: American Association for Higher Education.

Axelsson R \& Rosenburg L. 1976. Applications of organisational theory on problems of the Swedish system of higher education. Umea: Umea University.

Baldridge JV. 1971. Power and conflict in the university. New York: John Wiley.

Baldridge JV. 1971 a. Academic governance. Berkeley: McCuthcan Publishing Corporation.

Baldridge JV, Curtis DV, Ecker GP \& Riley LP. 1983. Alternative models of governance in higher education. In: R Birnbaum (ed). ASHE reader in organization and governance in higher education, Lexington, MA: Ginn Custom Publishing.

Beylefeld A, Bitzer EM \& Hay HR. 2007. Action research: A wonderfully uncomfortable mode of creating knowledge. Acta Academica, 39(1):146-175.

Bitzer EM. 1980. 'n Prinsipieel-didaktiese studie van die onderwysstruktuur van die UOVS, met besondere verwysing na 'n didaktiese ontwerp vir ' $n$ buitemuurse afdeling [A principlebased didactic study of the educational structure of the UOFS, with particular reference to a didactic design for an extra-mural branch]. Bloemfontein: University of the Orange Free State. Unpublished MEd thesis.

Bitzer EM. 1984. Leierskap- en bestuursontwikkeling van departementshoofde aan die Universiteit van die Oranje-Vrystaat, toegespits op onderwysleierskap en -bestuur [Leadership and management development of department heads at the University of the Orange Free State, focused on educational leadership and management]. Bloemfontein: University of the Orange Free State. Unpublished DEd dissertation.

Bitzer EM. 1998. Hoër onderwys as ' $n$ studieveld: Uitdagings in ' $n$ tyd van omvorming [Higher education as a field of study: Challenges in a time of transformation]. Stellenbosch University: Inaugural lecture, Faculty of Education. 15 April.

Bitzer EM. 2003. Assessing students' changing perceptions of higher education. South African Journal of Higher Education, 17(3):164-177.

Bitzer EM. 2005. First-year student perceptions of generic skills competence and academic performance: A case study at one university. South African Journal of Higher Education, 19(3):172-187.

Bitzer EM (ed). 1992. Proceedings of the eighth congress of the South African Association for Research and Development in Higher Education: Quality and equality in higher education. South African Journal of Higher Education, Research Supplement, 7(1).

Bitzer EM \& Albertyn RM. Forthcoming. Academic professional development by higher degree.

Bitzer EM \& Malherbe WS. 1995. Internal quality assurance in university teaching: A case study. Quality in Higher Education, 1 (1):25-37. 
Bitzer EM \& Strydom AH. 1986. Management development of department heads at a medium-sized South African university. South African Journal of Education, 6(4):17-29.

Bitzer EM \& Strydom AH. 1987a. Leierskap en bestuur in akademiese departemente [Leadership and management in university departments]. Acta Academica, Series New B 5/87:36-47.

Bitzer EM \& Strydom AH. 1987b. Indications of academic staff appraisal at tertiary education institutions. South African Journal of Higher Education, 1(1):12-24.

Bitzer EM \& Troskie-de Bruin C. 2004. The effect of factors related to prior schooling on student persistence in higher education. South African Journal of Education, 18(1):119-125.

Boud D (ed). 1985. Reflection. Turning experience into learning. London: Kogan Page.

Boughey C. 2004. Higher education in South Africa: Context, mission and legislation. In: S Gravett \& H Geyser (eds). Teaching and learning in higher education. Pretoria: Van Schaik Publishers.

Brookfield SD. 1983. Adult learning. Adult education and the community. Milton Keynes: Open University Press.

Chronbach CJ. 1946. Response sets and test validity. Educational and Psychological Measurement, 6:475-494.

Cilliers AC. 1944. The state and universities (1910-1943). Cape Town: Maskew Miller.

Clark B. 1963. Faculty organization and authority. In: TF Lunsford (ed). The study of academic administration. Boulder: Western Interstate Commission of Higher Education.

Clark B. 1997. Small worlds, different worlds: The uniqueness and troubles of American academic professions. Daedalus, 126(4), Fall.

Clegg S. 2007. Extending the boundaries of research into higher education. In: Enhancing Education, Theory and Scholarship, Proceedings of the 30 th HERDSA annual conference [CD ROM]. Adelaide, Australia. 8-11 July.

Cloete N, Fehnel R, Maassen P, Moja T, Perold H \& Gibbon T. 2002. Transformation in higher education. Global pressures and local realities in South Africa. Lansdowne: Juta \& Company.

Cohen MD, March JG \& Olsen JP. 1972. A garbage can model of organizational choice. Administrative Science Quarterly, March.

Council of Europe. 1977. Reform and development of higher education - A European Symposium. Windsor: NFER Publishing Company.

Crafford S \& Bitzer EM. 2008. A curriculum framework for promoting consumer learning with students in higher education. Journal of Family Ecology and Consumer Sciences, 36:49-57.

Creswell JW. 2009. Research design. Qualitative, quantitative and mixed methods approaches. Los Angeles: Sage.

Crossley B. 1976. The future of higher or university adult education in Britain and the USA. Comparative Education, 12(1):116-127. 
De Villiers DB \& Bitzer EM. 2004. 'n Kurrikuleringsraamwerk vir volhoubare sportbestuuropleiding in Suid-Afrika [A curriculum framework for sustainable Sport Management education in South Africa]. Journal for Research in Sport, Physical Education and Recreation, 26(1):122-135.

Dressel PL \& Mayhew LB. 1974. Higher education as a field of study. San Francisco: JosseyBass Publishers.

Ernstzen D \& Bitzer EM. 2008. Effective teaching and learning opportunities during clinical education. Medical Teacher, (11-12):1-14.

Fourie M \& Bitzer EM. 1994. Constant and changing emphases on values in higher education. Journal for Christian Science, 30, First quarter.

Fourie M, Strydom AH \& Stetar J. 1999. Reconsidering quality assurance in higher education: Perspectives on programme assessment and accreditation. Bloemfontein: Unit for Research into Higher Education, University of the Orange Free State.

Gaff JG. 1975. Toward faculty renewal. San Francisco: Jossey-Bass Publishers.

Goodman P. 1962. The community of scholars. New York: Random House.

Goodman R. 1976. Part-time tertiary education for employed persons in Australia. Paris: Educational, Scientific and Cultural Organization (UNESCO).

Gross E. 1968. Universities as organisations: a research approach. American Sociological Review, 33(4):76-87.

Gumport PJ. 1997. Public universities as academic workplaces. Daedalus, 126(4), Fall.

Houghton V \& Richardson K. 1974. Recurrent education - A plea for lifelong learning. London: Ward Lock Educational.

Kerr C. 1963. The uses of the university. Cambridge: Harvard University Press.

Kolb DA. 1981. Learning styles and disciplinary differences. In: AW Chickering (ed). The modern American college. San Francisco: Jossey-Bass.

Kolb DA. 1984. Experiential learning. Englewood Cliffs, NJ: Prentice Hall.

Landman WA. 1980. Inleiding tot die Opvoedkundige Navorsingspraktyk [Introduction to the Practice of Educational Research]. Durban: Butterworth.

Levine A. 1997. How the academic profession is changing. Daedalus, 126(4), Fall.

Malherbe EG. 1925. Education in South Africa (1652-1922). Cape Town: Juta.

Malherbe EG \& Cook PAW. 1938. The relationship of entrance age of university students to their academic success. Pretoria: South African Council for Educational and Social Research.

Marton F. 1981. Phenomenography - Describing conceptions of the world around us. Instructional Science, 10:177-200.

Marton F \& Sälio R. 1976. On qualitative differences in learning - Outcome as the function of a learner's conception of the task. British Journal of Educational Psychology, 46:1 15-127.

McKeachie WJ. 1978. Teaching tips: A guidebook for the beginning college teacher. Lexington, MA: DC Heath and Company. 
Metrowich FC. 1926. The development of higher education in South Africa, 1873-1927. Cape Town: Maskew Miller.

Millett J. 1962. The academic community. New York: McGraw-Hill.

Mintzberg H. 1979. The structuring of organizations. Englewood Cliffs, NJ: Prentice-Hall.

Montgomery JR, McLaughlin GW \& Smart JC. 1974. A role analysis of department chairmen at state universities. Blacksburg, VA: Office of Institutional Research.

Mouton J. 1996. Understanding social research. Pretoria: Van Schaik.

Mouton J \& Marais HC. 1985. Basic concepts in the methodology of the social sciences. Pretoria: HSRC Publishers.

Nicholls A \& Nicholls H. 1974. Developing a curriculum. London: Allen \& Unwin.

Organisation for Economic Cooperation and Development (OECD). 1977. Learning opportunities for adults. Paris: General Report. Vol. 1.

Ortega Y \& Gassett J. 1964. Mission of the university. London: Kegan Paul.

Pauw JR. 1978. Die Westerse universiteit: Sy aard, ontstaan en toekoms [The Western university: Its character, origin and future]. Johannesburg: Boekhandel De Jong.

Piper D-W. 1976. Staff development in universities. In: L Elton \& K Simmonds (eds). Staff development in higher education. Guildford: Society for Research into Higher Education.

Popper KR. 1972. Objective knowledge: An evolutionary approach. Oxford: Clarendon Press.

Rossouw HW. 1993. Universiteit, wetenskap en kultuur [University, science and culture]. Cape Town: Tafelberg.

RSA (Republic of South Africa). 1974. Hoofverslag van die Kommissie van Ondersoek na die Universiteitswese [Main report of the Commission of Inquiry into the University System]. RP 25/1974. Pretoria: Government Printer.

Seldin P. 1984. Changing practices in faculty evaluation. New York: Jossey-Bass Higher and Adult Education Series.

Startup R. 1976. The role of the department head. Studies in Higher Education, 1 (2):96-108.

Strydom AH \& Bitzer EM. 1990. 'n Ondersoek na 'n akademiese bestuursraamwerk vir universiteite in Suid-Afrika [An investigation into an academic management framework for universities in South Africa]. South African Journal for Education, 10(1):134-147.

Strydom AH \& Bitzer EM (eds). 1993. Quality assurance in South African higher education. South African Journal of Higher Education, Research Edition, 8(1).

Strydom AH, Bitzer EM \& Venter JA. 1990. Astin se konsep van potensiaalontwikkeling as benadering tot voortreflikheid in hoër onderwys [Astin's concept of potential development as an approach towards excellence in higher education]. South African Journal of Higher Education, 4(2):62-75.

Strydom AH, Lategan LOK \& Muller A. 1996. Quality assurance in South African higher education: National and international perspectives. Bloemfontein: Unit for Research into Higher Education, University of the Free State. 
Strydom AH, Lategan LOK \& Muller A. 1997. Enhancing institutional self-evaluation and quality in South African higher education: National and international perspectives. Bloemfontein: Unit for Research into Higher Education, University of the Free State.

Thomas WE. 1977. The chairperson's role in promoting better teaching. New Directions for Community Colleges, 17. San Francisco: Jossey-Bass Publishers.

Trow M. 1976. The American academic department as a context for learning. Studies in Higher Education, 1(1):54-67.

Tucker A. 1981. Chairing the academic department. Washington: American Council on Education.

Tyler RW. 1975. Specific approaches to curriculum development. In: J Scaffarzick \& DH Harp (eds). Strategies for curriculum development. Berkeley: McGutchan.

Vilioen GvN. 1977. Future perspectives on the structural framework of universities. Koers, 42(4).

Wheeler DK. 1967. Curriculum process. London: University of London Press. 


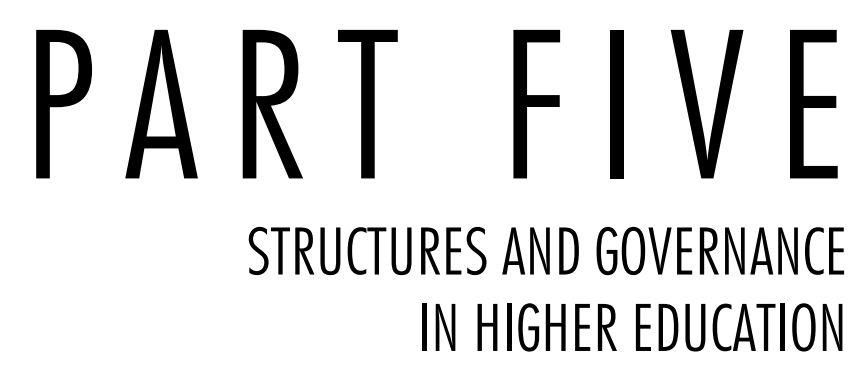




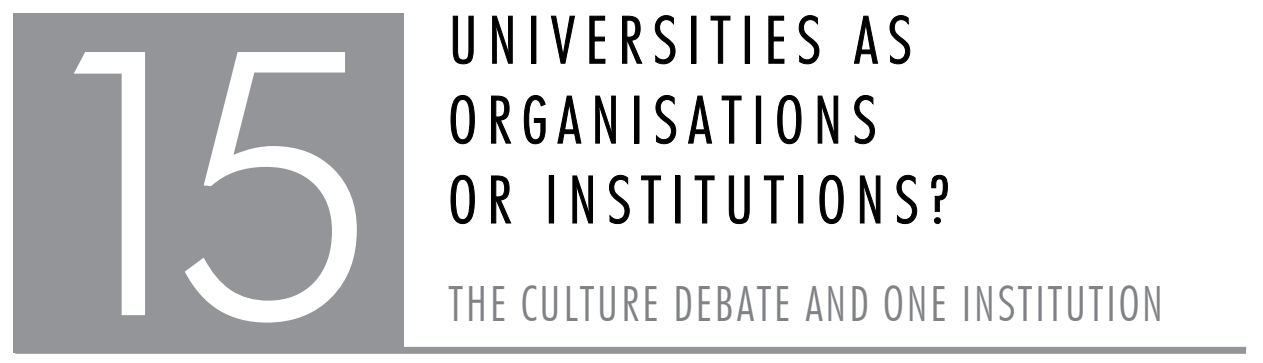

Berté van Wyk

\section{ABSTRACT}

This chapter attempts to conceptualise institutional culture by posing a critical question: Are universities institutions or organisations? The question arises due to ambiguities in the literature: several authors describe universities as institutions rather than organisations, while others use the notions of 'organisation' and 'institution' interchangeably. In agreement with Hoffman (1999) that it would be critically important to consider how and in what ways concepts of culture can enhance - or impede - understanding, research and action in education, I explore the culture debate. There seem to be complex conceptual issues associated with some of the baseline debates on the nature of culture and, following from this, the nature of institutional cultures. The literature suggests that institutional culture as a social construct is embedded in a very definite historical context and purpose (Louw and Finchilescu 2003), and this historical context becomes very useful in an analysis of what constitutes institutional culture at Stellenbosch University. The discussion on two meanings of institutional culture (perceptions, and the language issue) indicates that culture is dynamic, and highlights how meanings change over time. The essay suggests that there is no easy definition of 'institutional culture', as there is no one single characteristic of an institution that can be cited to define this culture. I conclude that the usefulness of institutional culture is that it connects people and should be used for a purpose; it is not just something to have, which is where the discussion of the concept usually focuses (Toma, Dubrow and Hartley 2005).

\section{INTRODUCTION}

Whenever I visit the university campuses of Stellenbosch, Cape Town and the Western Cape, I get an almost intuitive sense of the uniqueness of each of these three 
institutions, but also of the differences between them. It has prompted me to reflect on what makes these institutions different from each other: is it the buildings (they certainly have different architectural styles), the students, the staff or the programmes? Or is it something else? I have come to realise that it is a complex task to explain what makes each of these institutions unique or different, keeping in mind that they are located not far apart geographically. Put differently, it appears at surface level that there is a (cultural) difference between institutions, but it is very complex task to describe such differences.

I find Harold Silver's (2003:157) question: "Does a university have a culture?" a good starting point for this discussion. He argues that "organisational culture" (that is, a culture applied to higher education institutions) has no basis in the day-to-day operation of most academic staff in most institutions. My contention is that while academics may not pay much attention to the culture of their institutions in their dayto-day activities, there is an inescapable, pervasive culture that determines how things are done at each institution.

However, due to the assumption that universities are organisations, Silver's use of the term 'organisational culture' with respect to universities is not unproblematic. I hold that, while it is true that institutions such as universities are pressurised to function increasingly as organisations, and (non-university) organisations tend to adopt a university culture, we should be careful not to conflate the two concepts. There is evidently an encroachment of organisational or corporate culture on the university in the form of managerialism, hence the difficulty to distinguish conceptually between institutions and organisations. I suggest a distinction between these two concepts, and will discuss that later.

This inquiry notes that the concept of institutional culture has not been sufficiently studied and that more research is needed. Two official documents share this view. The Council on Higher Education (CHE 1999:25) concludes that the extent to which institutions have developed institutional cultures is difficult to gauge, since no data on institutional culture has been gathered in any systematic way at either an institutional or a national level. The Ministry of Education (2001:46) emphasises that an important strategy that institutions have largely ignored is the need to change institutional cultures, and it highlights several points worthy of consideration. Firstly, the Ministry suggests that there is a need for refocusing institutional cultures nationally. I agree, as this is important for consolidating democracy and ensuring a unified national system of higher education, geared towards meeting the challenges of a democratic society. Secondly, institutions 
have largely ignored the need to change their institutional cultures. This may impact on the capacity of institutions to transform their cultures. Thirdly, institutional cultures can be either alienating or accommodating. Certainly this can be related to how institutions deal with diversity. The question is therefore how the institutional culture deals with such challenges. Since these pronouncements were made, institutional culture has received more attention and has become a topic for master's and doctoral research. In this regard Higgins (2007) observes that institutional culture has become a buzzword in recent discussions of higher education in South Africa. He points out the growing sense that institutional culture may well be the key to the successful transformation of higher education in South Africa. Similarly, Jansen (2004:1) observed: "[T]he last frontier in the quest for social integration and non-racial communities in former white institutions will always be this hard-to define phenomenon called 'institutional culture.'" This interpretation of institutional culture may account for the apparent lack of research data on the concept.

The merging of institutions also added to the complexity in describing the concept of institutional culture. The CHE (2004:54) briefly refers to this issue and identifies incompatible institutional cultures as possible consequences of institutional restructuring. I contend that institutional cultures resulting from mergers are hard to describe, since such institutions grapple with multiple factors in their re-organisation. This is a complicating factor in the study of institutional culture. In an attempt to further understand institutional culture in higher education institutions (universities), I next provide a conceptual exploration of the concept. This conceptualising assumes that a university (as an institution) does have a culture.

\section{CONCEPTUALISING INSTITUTIONAL CULTURE}

In an attempt to explore possible meanings of institutional culture I draw on the resources of philosophy. Here I agree with Wittgenstein (in Barnett 1992:1897) who states: "Through a searching analysis of the key concepts and terms that permeate the language of higher education, philosophy can help to clarify our thinking about the beliefs, presuppositions, and values on which higher education as a social practice is founded." An analysis of key concepts associated with the notion of an institutional culture may therefore assist with this inquiry; it follows that an exploration of institutional culture may be assisted by exploring the nature of institutions, the concept of culture, and discourses pertaining to institutional culture. I start this conceptualisation by posing a critical question. 


\section{Are universities institutions or organisations?}

Before I continue with a discussion of the concept of culture, I want to touch briefly on the concept of institution, and I want to consider the above critical question which points to ambiguities in the literature. Several authors describe universities as institutions rather than organisations (see Kulati and Moja 2002; Neave 2001; Scott 2000; Chomsky 2003; Becker and Kogan 1992; Välimaa 1998) and I share this view. But there are also others (Toma et al. 2005; Thaver 2006) who use the notions of 'organisation' and 'institution' interchangeably in their discussions of universities. (They then refer to "organisational culture" and "institutional culture".) I find this problematic, as it assumes that organisations and institutions are similar. As far as institutions are concerned I share the view that an institution is not a place: it is a system, and a system functions - whatever its degree of coherence and integrity - as a de facto community. Thus, the community shapes the institutional character.

Tierney (in Higgins 2007) was one of the first scholars to propose the extension of the concept 'organisational culture' to cover the work and running of universities as organisations. The introduction of 'organisational culture' into higher education can be viewed as an encroachment of organisational or corporate culture on the university in the form of managerialism, and points to the blurring of the organisational and institutional roles of universities. This blurring of roles has impacted on the special role of the university as an institution dedicated to the pursuit of significant knowledge and lasting values.

I can understand the conflation of 'organisation' and 'institution', because universities, by nature of their institutional mandate, have to organise themselves in specific ways, and such organisation has a bearing on the way they conduct their affairs. Over the past few decades we have seen a change of higher education from a social institution to an industry; universities had to find innovative ways to deal with decreased state funding. As a result they had to become more competitive in order to boost student numbers, to attract the best staff and to conduct market-related research. These realities forced universities to pay more attention to the way they organise themselves, and in the process their institutional and organisational character became intertwined. It is not the intention to analyse the concepts of 'organisation' and 'institution' in greater depth, but these concepts are important in an inquiry of institutional culture, and for that matter, the role of culture in the ways universities are organised. 


\section{The culture debate}

My argument in exploring this concept is that a deeper understanding of culture can be very useful in an exploration of institutional culture. Hoffman (1999:465) suggests that it would be critically important to consider how and in what ways concepts of culture can enhance - or impede - understanding, research and action in education. But culture seems to be a very difficult concept to work with, and Välimaa (1998) cautions that culture is difficult to use as an instrument of research, because it can be defined in far too many ways. He adds that culture may also be problematic as a general framework of analysis, because it has to include as many elements of higher education institutions as possible (ecological characteristics, historical events, and institutional traditions and missions). Bauman (1999) explores culture as concept, as structure, and as praxis, and his analysis can be beneficial for this inquiry. Parekh (2000) provides further insights into understanding culture when he discusses the following aspects thereof: nature and structure, dynamics, cultural community, loyalty to culture, cultural interaction, cultural diversity, and evaluating cultures. Culture has also been described as ubiquitous (WASC 2001). This implies that every organisation, every department and even every little informal work team has a culture and that people are constantly surrounded by culture, which shapes their behaviour. Culture makes its presence known whenever a new leader appears or there is a change in managerial style. The fact that an institution has a culture implies that institutions are living and changeable entities, as are the people who comprise them. These brief references suggest that culture is a very difficult concept to work with, and that the concept lends itself to a variety of interpretations. Culture thus takes on many different meanings and directions, and that makes it difficult to explore institutional culture.

Since this essay explores institutional culture in higher education, I want to explore a conceptual link between higher education and culture. Barnett (1990) addresses this question when he explains how this culture works on two distinct levels. Firstly, the idea of culture has application in relation to the academic community. Secondly, culture manifests at the level of the process of higher education itself, the level which comes close to that of the student experience. Here the idea of culture suggests a shared set of meanings, beliefs, understandings and ideas - in short, a taken for granted way of life in which there is a reasonably clear difference between those on the inside and those on the outside of the community. There is value for society in the culture of higher education. Barnett's (1990) view is that the value does not lie in the acquisition of specific competencies, but that it is in direct proportion to the critical capacities of its students. 
When exploring the concept of culture, there are both old and new ideas that can be considered. Wright (1998) mentions that according to the old views, culture is: bounded and a small-scale entity; defined characteristics (checklist); unchanging, in balanced equilibrium or self-producing; an underlying system of shared meanings: 'authentic culture'; identical, homogeneous individuals. Some new ideas are the following:

- Culture is an active process of meaning making and contestation over definition, including of itself.

- People differently situated in social relations and processes of domination use economic and institutional resources available to them to try and make their definition of a situation 'stick', to prevent others' definitions from being heard, and to garner the material outcomes.

- Sites are not bounded - people draw on local, national and global links.

- The way clusters of concepts form is historically specific, and ideas never form a closed or coherent whole.

- In its hegemonic form, culture appears coherent, systematic, consensual, like an object, beyond human agency, not ideological - like the old idea of culture. New ideas of culture seem to be more relevant for this inquiry.

Sackman et al. (1997:25) add to the debate when they suggest that the core of culture is composed of explicit and tacit assumptions or understandings commonly held by a group of people; that a particular configuration of assumptions and understandings is distinctive to the group; that these assumptions and understandings serve as guides to acceptable and unacceptable perceptions, thoughts, feelings and behaviours; that they are learned and passed on to new members of the group through social interaction; and that culture is dynamic - it changes over time, although the tacit assumptions that are the core of culture are most resistant to change.

In my view, there seem to be complex conceptual issues associated with some of the baseline debates on the nature of culture and, following from this, the nature of institutional cultures. For instance, one may ask: Is culture something that higher education institutions 'have', or are institutions themselves artefacts of culture? I contend that the relationships between social practices within institutions and the larger structural currents of society (as highlighted by Tierney 1988) must be considered to some extent in order to clarify assumptions about the extent to which social practices (and institutional cultures) influence the way universities are managed. 


\section{Institutional culture and higher education}

After having considered the nature of universities (institutional and organisational) and having explored the role of culture, I now come to a discussion of institutional culture. The latter is used widely in describing the personality of institutions. Toma, Dubrow and Hartley (2005) build on work on institutional culture of Tierney (1988), Kuh and Whitt (1988) and Schein (1992) and describe institutional culture as the shared beliefs, values, assumptions, and ideologies that bind a group together. They posit that institutional culture has subjective dimensions (e.g. shared assumptions, values, meanings and understandings) and also more objective aspects (physical artifacts, organisational stories, heroes and heroines, rituals and ceremonies), the former being less apparent than the symbols, language, narratives, and practices needed for conveying them.

Kuh and Whitt (1988), who also contend that culture is a difficult concept to work with, suggest that a study of institutional culture is, however, not unproblematic, because the concept of culture as a general framework of analysis has to include as many elements of higher education institutions as possible (ecological characteristics, historical events and institutional traditions and missions). Lee (2004) emphasises this point by concluding that a study of institutional culture must acknowledge the heterogeneity of values, beliefs, and priorities across, for instance, the independent academic departments. Thus, one cannot assume that people attached to an institution have a uniform understanding or meaning of institutional culture. In my view, a study of the theme has to acknowledge that institutional culture as a social construct is embedded in a very definite historical context and purpose (Louw and Finchilescu 2003), and is usually taken for granted and continues to be played out in an 'invisible manner' (Steyn and Van Zyl 2001).

When speaking about institutional culture, one can also consider academic or university culture as a key aspect. According to Mora (2001:95), university culture can be regarded as the beliefs of the members of the university community developed over centuries and transmitted through both language and symbols. He states that university culture is decisive in determining the behaviour of members of the university community and in the governance and decision-making processes of the institutions themselves. He further suggests that it is often unspoken common assumptions that best explain the behaviour of members of the academic world. Since academic culture is evident in the way that academic departments are organised, my observation is that departments organise themselves very differently as a result of those who shape the ideas and practice within a distinct community. Thus, an institution consists of many 
(and a variety of) institutional cultures. But let me also add that there is very often a dominant view or group that articulates the common and/or shared meanings.

To make sense of "unspoken common assumptions" can be a very difficult exercise. This difficulty is eloquently articulated by Fay (1996:115):

The interpretation of the meanings of actions, practices and cultural objects is an extremely difficult and complicated enterprise. The basic reason for this is that the meaning of something depends upon the role it has in the system of which it is a part, and this system may be exceedingly complex and rich. In order to know the meaning of certain overt movements interpreters must understand the beliefs, desires, and intentions of the particular people involved. But in order to understand these, they must know the vocabulary in terms of which they are expressed, and this in turn requires that they know the social rules and conventions which specify what a certain movement or object counts as. Moreover, in order to grasp these particular rules, they also have to know the set of institutional practices of which they are a part, and how these relate to other practices of the society.

Drawing on the nature of universities, I suggest institutional culture should also imply that institutions establish a stable structure for human interaction, and construct forms of consciousness. Since culture is composed of explicit and tacit assumptions or understandings commonly held by a group of people, and its core is resistant to change, such resistance could explain why universities, in their efforts to transform, have largely ignored transforming institutional cultures. A complicating factor could be that cultures in universities are multiple, and that they are generated at the level of the workgroup within departments; and in order to address the issue of culture it may be necessary to go down to this level (Trowler 2008:15). There are also many aspects pertaining to universities (environment, mission, socialisation, information, strategy, leadership, management, institutional practices, institutional traditions, language, symbols, institutional priorities, national and local policies and procedures) which may influence institutional culture. I shall refer to some of these in the next section.

\section{STELLENBOSCH UNIVERSITY: A CASE STUDY OF INSTITUTIONAL CULTURE}

Since the Higher Education Quality Committee (HEQC 2007:14) recommended that "Stellenbosch University develop a comprehensive strategy to transform its institutional culture" there has been a renewed debate on campus. The following aspects are under discussion: disillusionment and estrangement, embracing of new ideas, how to deal with difference, perceptions of the university, race and ethnicity, religious beliefs, sexual orientation, the role of language, and the idea of a secular culture. 
An underlying idea in the debate is how to create a home for all at the university. The debate is very useful in that it provides an opportunity for a critical engagement on the culture of the institution. However, I find that these debates do not pay attention to the question whether universities are institutions and/or organisations. Consideration of this question could add a critical dimension to the debate.

At a policy level, the university makes various pronouncements on institutional culture in its documents, and I find the Concept 2 Diversity Framework (University of Stellenbosch 2003) perhaps the most useful in its articulation of the theme. The document identifies and discusses the following meanings of institutional culture within the context of diversity: values and codes of conduct, perceptions, physical symbols, language, ceremonies, university structures and bodies, corporative facilities, and sport.

These meanings, as articulated by the university, provide a very neat description of what the university regards as constitutive of its institutional culture. Although I would have liked to analyse all of these, for purposes of this inquiry I shall touch briefly on only two meanings which seem to be quite prominent in the news and debates, namely the 'language issue' and 'perceptions'.

\section{The language issue}

Undoubtedly, language is a very important and controversial current issue of Stellenbosch University (SU), and there are many opinions on it. The university acknowledges that for most of its existence the ethnic exclusivity of the institution was guaranteed and reinforced by the fact that it adopted Afrikaans as a medium of instruction. With the repositioning of the institution a language policy was designed in 2002 and Afrikaans was identified as the default institutional language of choice for academic and communication purposes. While the policy acknowledges the special status of Afrikaans which must be promoted, it accords such privileged status in terms of a multilingual context. This position, understandably, has been received both positively and negatively by different internal and external constituencies. The positive dimension of the language policy is often raised, although not exclusively, by those whose mother tongue is Afrikaans and those who are reasonably proficient in Afrikaans and English. The negativity with regard to Afrikaans, while it does criticise the language in terms of it being a tool for communication, is perhaps due to the fact that Afrikaans is being elevated to an institutional 'core value', alongside equity, diversity and scholarship.

The importance of language is shown by research findings of the Department of Journalism (2005) on Stellenbosch University as a topic of readers' letters in the 
newspaper Die Burger (2002-2005). During the period 13 May to 28 October 2002, $14 \%$ (137 out of 957 ) of all the letters published had SU as subject. Altogether $83 \%$ (1 14 out of 137) of the SU letters focused on the theme Language Policy.

In interviews conducted with relevant editorial staff from Die Burger (Department of Journalism 2005:17,18) the following views are expressed:

Like all other higher education institutions, SU is going through a process of transformation. Against this background, transformation at $\mathrm{SU}$ is something that we will always approach as a news item: how it is approached, the critique around it, where the university is heading, the future of the university. Connected to that is the emotive component of Afrikaans. One of the products of the transformation process is that Afrikaans as a language at the university is endangered. People talk about it. The public's involvement at SU and the Afrikaans language a combination of these two factors makes it newsworthy. It is not happening on the same scale at other universities.

We see SU as a breeding ground for Afrikaans, and it will always be, and it must always be so. But that does not mean that - within the greater institution that gives a platform for Afrikaans academics to publish and lecture in Afrikaans, etc. - it should be a narrow-minded institution that has to function within the greater South Africa and international academic circles ... We naturally see SU as an Afrikaans institution and we will focus on that. To us it is important that it should remain that, even if it becomes the only one in the country that has that status at a tertiary level.

Stellenbosch University positions itself as a language-friendly university, with a responsive and flexible approach to language of instruction, and with Afrikaans as its point of departure (University of Stellenbosch 2000). In its Concept 2 Diversity Framework (2003) the university acknowledges that its language policy necessarily impacts on the development of diversity. There have been many debates at the university about the impact of its language policy, which have been articulated by students as the advancement of Afrikaans as the basic teaching and institutional language of the SU, within a multilingual context. Consequently, the university has failed to attract large numbers of black students (who prefer English as medium of instruction). I have been part of numerous discussions on the medium of instruction, and have listened to many views in support of Afrikaans. But I do get the impression that it is not as simple as that - it is not just about language, it is also about the ideology in which discussions on language is embedded.

The ideology, and history, of the language debate is articulated by Prof Chris Brink (2005a), former Rector of Stellenbosch University, as follows: 
Stellenbosch was one of the main intellectual sources of apartheid ... the association of the University with the power structures of Afrikanerdom was, for a long time, a close one. DF Malan, the first apartheid Prime Minister, was a Stellenbosch man. Hendrik Verwoerd was a Professor of Sociology and Social Work here before turning to politics. John Vorster was a prominent student leader who later, as Prime Minister, became Chancellor of the University. The last apartheid President, PW Botha, likewise became Chancellor at the time of his political power (even though he had no previous connection with the University). Rectors of the University were typically prominent members of the Afrikaner Broederbond.

My observation is that language at Stellenbosch University accounts for a major part of its institutional culture, and this impacts negatively on its student and staff profile. For instance, contrary to national trends where South African university profiles are becoming increasingly more diverse, with a concomitant drop in white students, the white student profile at Stellenbosch has remained unusually high and steady (2005:71.55\%; 2006:71.59\%; 2007:70.51\%; 2008:68.6\%). To emphasise the importance of language, there were renewed debates on the issue in May 2009, and the University Council (2009:2) responded by stating that "in 2010, parallelmedium instruction will be presented in the first year of study in four faculties - Science, Engineering, Agrisciences and Economic and Management Sciences ... Management will facilitate further consultation and discussion within the framework of the Language Policy and Plan, specifically on the teaching language model for the senior years of study as of $2011 . "$

To conclude this section: I have also heard colleagues openly arguing for substantial change in the language policy, and calling for a change to English as the medium of instruction. It is not such a far-fetched idea, as many of our students who graduate as teachers in the Faculty of Education (where over $90 \%$ of students at undergraduate level are white) prefer to teach in the United Kingdom, where they teach in English. The option of parallel-medium instruction also presents considerable challenges. Moreover, one has to consider whether there are enough Afrikaans-speaking students to ensure the sustainability of the university. What cannot be denied, though, is that language carries institutional meanings, and an Afrikaans medium of instruction might exclude African students from gaining access to the institution.

\section{Perceptions}

Despite efforts of the university to change perceptions, there is still a perception that Stellenbosch University is largely white-, male-, Afrikaans-, and Christian-dominated, 
and conservative. These perceptions are reinforced by the language of policy documents of the institution. Despite a national focus on transformation, my scrutiny of the Strategic Framework of the university (2000) has revealed a total absence of the concept of transformation. Concepts such as 'positioning', 'changing', 'reposition', 'redesign', 'self-renewal', 'self-scrutiny', 'reassessment' are prevalent in the text, but 'transformation' does not appear even once. What does this mean? Two seminal government policy documents (Education White Paper 3 and the National Plan for Higher Education) revolve largely around the concept 'transformation' and meanings which underscore its manifestation in higher education. Given the historical and political background of Stellenbosch University, there seems to be a subtle reluctance to use the concept. My inference is that it seems as if the notion of transformation as articulated in some government policy documents might not necessarily be commensurate with the institution's 'positioning' in terms of the changes which currently transpire in higher education - hence the perception that the university is lagging behind on transformation.

Let me illustrate my point. On 27 July 2005 a former rector and vice-chancellor, Professor Chris Brink (2005b) delivered a speech entitled "Annual Public Report by the Rector on transformation and Quality at Stellenbosch University". I find the title of his speech very striking. Transformation is spelt with a lower case ' $t$ ' and quality with a capital ' $Q$ '. I can only assume that this is a very deliberate formulation. If my assumption is correct, then the message is conveyed that transformation at Stellenbosch is not so high on the agenda, but quality certainly is. Such incidents confirm, rather than negate, perceptions about the institution.

Brink (2005b:3) further enforced perceptions of the institution when he stated that amongst many of the institution's traditional constituency, as manifested by Group 2 in the university's CREST (Centre for Research and Science and Technology) Report, there is a recurrent fear that transformation will erode quality. He also stated that many Afrikaner alumni are of the view that Stellenbosch was always an outstanding university, but that it is now sadly in decline, or at least in imminent danger of decline, because of transformation. Professor Brink made two striking observations. The first is that during the long time of Afrikaner political dominance, Stellenbosch had no need to measure its own quality other than by its own yardstick. Inevitably, this led to an unsubstantiated self-image of overall excellence. Secondly, in terms of all the usual measurable parameters, academic quality at Stellenbosch has slowly but surely been increasing at the same time as the university started opening up to the outside world. 
I will now attempt to explore the self-image which Brink talks about. The first postapartheid Minister of Education (Professor Sibusiso Bengu) issued a communiqué in 1995 to all South African higher education institutions to encourage them to establish Transformation Forums (TFs); at the same time he expressed an unwillingness to interfere in institutional management and to resolve disputes between TFs and other structures of governance, or to accede to the demands of student organisations. While two neighbouring universities (the University of Cape Town and the University of the Western Cape) heeded the call to establish TFs, Stellenbosch completely ignored it. Later, however, the Higher Education Act 101 of 1997 legislated for the establishment of four higher education governance structures: Council, Senate, SRC and Institutional Forum (IF). Stellenbosch was then forced to establish an IF without having had the experience of a TF; and managed to establish the IF in September of 1999, thereby meeting the deadline. It is interesting to note also that only Stellenbosch has decided upon a perfect balance across all four categories of representation (government and management, staff, students, and other community-based representatives). Harper et al. (2002) provide a possible explanation when they conclude that many institutions have tended to give preference to the letter of the Act, while ignoring the transformational purpose of the IF in earlier policy documents.

Perceptions about the university are further articulated by CREST (2005:vii) which also conducted an investigation into the "SU Trademark". They tested current students on the pace of change at SU, and these are the key findings:

- White Afrikaans-speaking students are largely divided over transformation at SU. Similar proportions believe that transformation is being handled responsibly or somewhat irresponsibly.

- White non-Afrikaans-speaking students also fall into two groups - one group that feels that transformation is being conducted in a responsible manner (47\%), and a second group that feels that the rate of transformation is unsatisfactory (42\%). Interestingly, this profile is very similar for black, coloured and Indian Afrikaans speaking students.

- The largest percentage of black, coloured, Indian and non-Afrikaans-speaking students (60\%) does not believe that SU is being adequately transformed. There is, however, also a large percentage (36\%) of this sub-group who believes that $\mathrm{SU}$ is not only being transformed, but that this is also being done in a responsible manner. 
This discussion on perceptions shows that, despite exemplary institutional plans, Stellenbosch has failed to change negative perceptions about the institution. It also highlights that there is still a great challenge for the institution to free itself from the historical and ideological burdens of the past. These perceptions cannot be ignored, as they impact on the ability of the institution to function effectively in a democratic society. It is encouraging to note that the current (2009) Rector, Professor Russel Botman, talks more readily about transformation, and boldly addresses the perception of people from previously disadvantaged communities who indicate that race and ethnicity should be important considerations in discussions on institutional culture. The Overarching Strategic Plan (OSP) of 2009, which seeks to promote democracy and to maintain and promote human dignity, has the potential to change perceptions of the university.

\section{CONCLUDING REMARKS}

This inquiry assumes that a university (as an institution) has a culture, and I have argued that a deeper understanding of the concept of culture is very useful in an exploration of institutional culture. I have pointed out that there are complex issues associated with debates on culture, and following from this, the nature of institutional culture. My exploration indicates that there is, however, no easy definition of 'institutional culture', as there is no one single characteristic of an institution that can be cited to define this culture. It also acknowledges that an institutional culture does not develop overnight (WASC 2001). I support the view that a strong institutional culture has concrete uses in universities and colleges, and that culture is not simply something that is, but is something that can do. The usefulness of institutional culture is that it connects people, and is not just something to have, which is where the discussion of the concept usually focuses, but that it is something to use (Toma et al. 2005). Human interaction should thus be an important feature of an institutional culture, and attention should be paid to how the institutional culture facilitates diverse groups to interact with each other. An exploration of institutional culture in higher education also assists us in organising ourselves, as institutional culture does the following (Toma et al. 2005:6): it conveys a sense of identity (who we are), facilitates commitment (what we stand for), enhances stability (how we do things around here), guides sense-making (how we understand events), and defines authority (who is influential).

Currently, many universities in South Africa are attempting to construct a new and shared institutional culture. This might require that institutional culture be deconstructed in order to reconstruct a new culture, and one has to be mindful that an institution 
consists of many and a variety of institutional cultures. The reconstruction of (new) culture(s) is proving to be a major challenge.

Finally, some comments on possible future areas of research on the topic. Firstly, more research is needed on the institutional versus the organisational character of universities. This is a crucial area which seems to have been overlooked in the literature. Secondly, since this essay indicates that culture takes on many different meanings and directions, there is a need to explore how these meanings shape institutional culture at different levels (macro-, meso- and micro-levels). Thirdly, I suggest that we continue to explore institutional culture in relation to what Trowler (2008) refers to as educational ideologies: the aim of higher education (a liberal education or a vocational one), content (discipline-based propositional knowledge or general transferable skills), and the important functions taking place within it (research or teaching).

\section{REFERENCES}

Barnett R. 1990. The Idea of Higher Education. Buckingham, Bristol: SRHE \& Open University Press.

Barnett R. 1992. Philosophy. In: BR Clark \& G Neave (eds). The Encyclopedia of Higher Education. Vol. 3. Analytical Perspectives. Oxford, New York: Pergamon Press. 1896-1907.

Bauman Z. 1999. Culture as Praxis. London, Thousand Hills, New Delhi: Sage.

Becker T \& Kogan M. 1992. Process and Structure in Higher Education. 2nd Edition. London \& New York: Routledge.

Brink C. 2005a. On the juxtaposition of apparent opposites. Opening Address at the Workshop on Transdisciplinarity presented by the Sustainability Institute, Stellenbosch University. Stellenbosch. 11 April.

Brink C. 2005b. Annual public report by the rector on transformation and quality at Stellenbosch University. Stellenbosch. 27 July.

Centre for Research on Science and Technology (CREST). 2005. Investigation into the 'SU Trademark'. Stellenbosch: Crest.

CHE (Council on Higher Education). 1999. Annual Report 1998/99. Pretoria: CHE.

CHE (Council on Higher Education). 2004. South African Higher Education in the First Decade of Democracy. Pretoria: CHE.

Chomsky N. 2003. Chomsky on Democracy and Education. New York \& London: Routledge Falmer.

Council of Stellenbosch University. 2009. Communication from Council. Stellenbosch: Priority Bulletin. 4 May.

Department of Journalism. 2005. Stellenbosch University as a topic of readers' letters in the newspaper Die Burger (January 2002-March 2005). Stellenbosch University: Department of Journalism. 
Fay B. 1996. Contemporary Philosophy of Social Science. Oxford, UK: Blackwell Publishers.

Harper A, Olivier N, Thobakgale S \& Tshwete Z. 2002. Institutional Forums: An Overview of their Establishment and Functioning at South African Public Higher Education Institutions. Pretoria: Centre for Higher Education Transformation (CHET).

HEQC (Higher Education Quality Committee). 2007. Audit Report on Stellenbosch University. Pretoria: $\mathrm{CHE}$.

Higgins J. 2007. Institutional culture as keyword. In: Review of Higher Education in South Africa: Selected Themes. Pretoria: CHE. 97-114.

Hoffman DM. 1999. Culture and Comparative Education: Toward Decentering and Recentering the Discourse. Comparative Education Review, 43(4):464-88.

Jansen J. 2004. How Far Have We Come? Mail \& Guardian, 13-19 August: 1 Getting Ahead Supplement.

Kuh GD \& Whitt EJ. 1988. The invisible tapestry: Culture in American colleges and universities. ASHE-ERIC Higher Education Reports. Washington, DC: Association for the Study of Higher Education.

Kulati T \& Moja T. 2002. Leadership. In: N Cloete, R Fehnel, P Maassen, T Moja, H Perold \& T Gibbon (eds). Transformation in Higher Education. Global Pressures and Local realities in South Africa. Lansdowne: Juta. 230-260.

Lee JJ. 2004. Comparing Institutional Relationships with Academic Departments: A Study of Five Academic Fields. Research in Higher Education, 45(6):603-623.

Louw J \& Finchilescu G. 2003. UCT organizational climate survey. Unpublished report. University of Cape Town.

Ministry of Education. 2001. National Plan for Higher Education. Pretoria: Ministry of Education.

Mora J-G. 2001. Governance and management in the new university. Tertiary Education and Management, 7:95-110.

Neave G. 2001. The European Dimension in Higher Education: An Excursion into the Modern Use of Historical Analogues. In: J Huisman, P Maassen \& G Neave (eds). Higher Education and the Nation State: The International Dimension of Higher Education. Oxford: Elsevier Science. 13-72.

Parekh B. 2000. Rethinking Multiculturalism. Cultural Diversity and Political Theory. Hampshire and London: Macmillan Press.

Sackman SA, Philips ME, Kleinberg MJ \& Boyacigiller NA. 1997. Single and Multiple Cultures in International Cross-Cultural Management Research: Overview. In: SA Sackman (ed). Cultural Complexity in Organizations. Inherent Contracts and Contradictions. Thousand Oaks: Sage Publications. 14-48.

Schein EH. 1992. The Corporate Culture. Sense and Nonsense about Cultural Change. San Francisco: Jossey-Bass.

Scott P. 2000. A Tale of Three Revolutions? Science, Society and the University. In: P Scott (ed). Higher Education Re-formed. London \& New York: Falmer Press. 190-206. 
Silver H. 2003. Does a University Have a Culture? Studies in Higher Education, 28(2):157-168.

Steyn M \& Van Zyl M. 2001. Like that statue at Jammie stairs. Students' perceptions and experiences of institutional culture at the University Cape Town. 1999. Institute for Intercultural and Diversity Studies of Southern Africa. Unpublished report. University of Cape Town.

Thaver L. 2006. "At home", institutional culture and higher education: Some methodological considerations. Perspectives in Education, 24(1):15-26.

Tierney WG. 1988. Organizational Culture in Higher Education: Defining the essentials. The Journal of Higher Education, 59(1):2-21

Toma JD, Dubrow G \& Hartley M. 2005. The uses of Institutional Culture. Strengthening Identification and Building Brand Equity in Higher Education. ASHE Higher Education Report, 31 (2). Wiley Periodicals, Inc.

Trowler P. 2008. Cultures and Change in Higher Education. New York: Palgrave Macmillan.

University of Stellenbosch. 2000. A Strategic Framework for the turn of the century and beyond. Final copy edited following the Council meeting of 20 March 2000, Stellenbosch.

University of Stellenbosch. 2003. Concept 2 Diversity Framework. Stellenbosch, 17 March.

Välimaa J. 1998. Culture and identity in higher education research. Higher Education, 36(2): $119-138$.

WASC (Western Association of Schools and Colleges) 2001. Institutional Culture. Self-Study for an Accreditation Review prepared by the WASC Committee, Department of Academic Affairs, California State University Pomona - Chapter 5 [Online]. Available: http://www. csupomona.edu/ wasc/archive/selfstudy/culture/index.html/ [2009, 23 January].

Wright S. 1998. The politicization of culture. Anthropology Today, 14(1):7-15. 


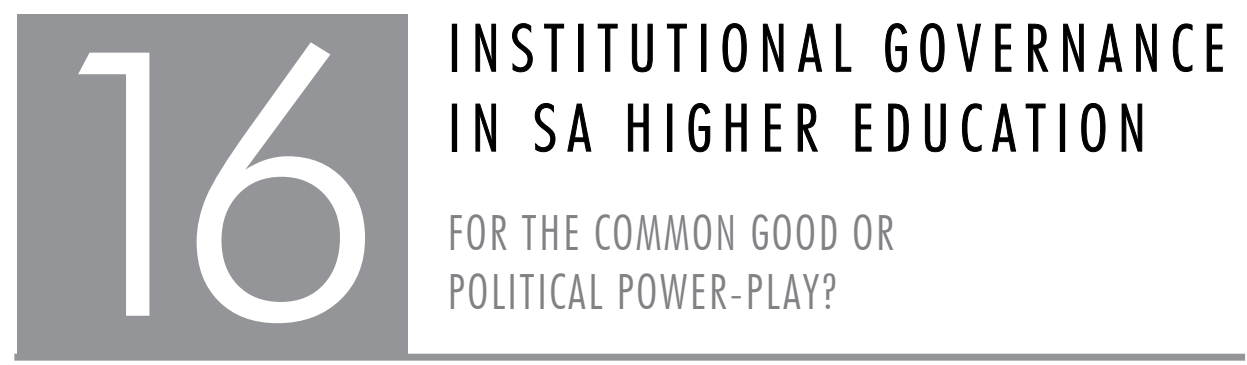

\section{Magda Fourie}

\section{ABSTRACT}

This chapter explores the role of institutional governance against the background of the nature of the university as an organisation, and the changing context in which universities currently operate. Three 'conventional' models of institutional governance are discussed, and more recent developments in this regard are investigated. She concludes with some guiding principles for effective institutional governance in a contested and changing university context.

\section{INTRODUCTION: THE NATURE OF THE UNIVERSITY AS ORGANISATION}

Universities, being complex organisations, can be examined at distinctly different levels:

- the inter-organisational or systems level that portrays the relationships among different institutions in a region or country, and particularly the relationship between institutions and government, institutions and society and institutions and the market;

- the organisational level that studies the institution as an organisation, attempts to understand its functions, structure and dynamics, and particularly the relationships between different actors in the organisation;

- the intra-organisational level that focuses on the individual units of the organisation, how they are organised and managed and how they interact.

The focus of this contribution is the second level, namely the university as organisation and, more specifically, how it is governed at the institutional level. Admittedly, the 
national policy environment greatly influences institutional governance. South Africa is not the only country where regulatory measures by the government have increased over the past 10 years. Rhoades (1992:1380) points out that "the exercise of state level bureaucratic as well as political authority over higher education organizations is on the rise. From one country to the next, the 1970s and 1980s have seen external as well as internal challenges to the structure and function of academic institutions". The exercise of authority takes various forms, from attempts to reform the curriculum (cf. the SA Higher Education Qualifications Framework), restructuring the higher education system (cf. the SA National Plan for Higher Education), to increasing the accountability of academics (cf. the programme accreditation and institutional audit system of the SA Higher Education Quality Committee).

Tapper and Palfreyman (1998:153) cite the example of the Research Assessment Exercises (RAEs) of the British government that inexorably shifted the balance between teaching and research within universities, resulting in (possibly unintended) changes in institutional governance. Similarly, Harman and Treadgold (2007) posit that Australian higher education has in recent years experienced much more direct government intervention than in the past.

Similarly the power and perceptions of power of units inside the institution have an effect on how the institution is governed and managed. One example would be the restructuring of institutional governance bodies in order to include a broader range of stakeholders in decision making. Rhoades (1992:1380-1381) describes the situation in Western Europe as follows:

In some cases this meant creating or expanding the power of university councils that had representatives from lay community. Throughout Western Europe what it meant was democratization or participation in the form of creating corporatist arrangements in which a certain proportional representation was accorded various groups. The proportion of students, different levels of faculty, and other groups varied from one country to the next, as did the types and levels (e.g. department, faculty, university) of the corporatist councils, conferences or whatever. But the form of politics followed the corporatist forms that mark European political institutions. Moreover, in a sense these various governing bodies introduced a considerable measure of bureaucratization into campus governance, of formal mechanisms and chains of command that decision making and decision makers had to go through.

Governance of universities is quite different from this function in other service institutions like schools, churches or hospitals. Also, universities are governed very differently from 
businesses or other institutions in the corporate world. An understanding of governance of higher education therefore necessitates a basic understanding of the nature of the university, because the governance and management structures and processes are very specific to and typical of universities.

Even though universities possess characteristics common to most forms of organisation, there are fundamental differences between universities and other organisations in society. Universities are not, for example, guided by instrumental rationality towards clear, welldefined goals. Lockwood (1985) explains the uniqueness of the university in terms of the pluralistic nature of its essence, and argues that universities function simultaneously as organisations, communities and institutions. The distinguishing characteristics that set universities apart from other organisations include the following:

- Universities are loosely coupled systems in which the different divisions have but tenuous links between them and with the organisation as a whole.

- Universities are often described as professional bureaucracies in which the academics are professionals with relatively large measures of autonomy. Academics often have stronger allegiances to their subject disciplines and the disciplinary community than to the university.

- Universities have diffuse missions and vague, ambiguous goals, and they must devise decision-making processes to contend with a high degree of uncertainty and conflict. Even though they are described as knowledge organisations which have the primary purposes of producing knowledge, disseminating knowledge and applying knowledge, how these purposes are being pursued and the value and importance of the different purposes can differ substantially from one institution to another. Furthermore, universities are traditionally non-profit service organisations that are in many cases today forced to become entrepreneurial.

Clearly then universities are among the most complex forms of organisation, and the level of complexity increases as the size of the institution grows and the scope of its functions expands, resulting in the need to add specialised and differentiated units. Hartman and Scott (1990:2) maintain that the very nature of the work of higher education (producing, conserving and distributing knowledge) contributes to this complexity, because of the "fundamental tensions between the need to create conditions that foster the development of knowledge in its various divisions and the demands of managing the institution as a coherent entity". It can be expected that this complexity will be reflected in the challenges faced by the structures and processes of governance. It can also be expected that these challenges will be exacerbated 
in a context of change. Kaplan (2006:213) makes the point that understanding the behaviour of higher education institutions as organisations is of increasing importance "in an economy in which knowledge work and the production of knowledge are increasingly the drivers of economic advancement and growth".

\section{INSTITUTIONAL GOVERNANCE: WHAT ARE WE TALKING ABOUT?}

Institutional governance is based on the principles of pluralistic representation, joint effort, extensive communication, and shared but differentiated participation by the different constituents (Kauffman 1993:225). In general terms governance is about power and authority - the distribution of power and authority within an organisation, the structures and relationships by means of which the power and authority are obtained and the processes through which the power and authority are used. This power and authority is employed by different actors in governance structures and processes. In these structures and processes sets of explicit and implicit rules determine actors' behaviour: "These rules indicate who, from which position, and with what authority, may command whom, and impose sanctions if the rules and commands are not complied with" (Frederiks et al. 1994:98).

From the above it can be gathered that institutional governance pertains particularly to the decision-making process within the institution (Atwell 1996:13). It relates to the power and influence of the various stakeholders like academic and administrative staff, students and the community and to the ways in which an organisation divides its labour into distinct tasks and then achieves coordination among them; in other words, it can be regarded as a system of agreements among the organisational actors with respect to the performance of activities directed towards a set of common goals (Binsbergen et al. 1994:220; Balderston 1995:55).

Like Atwell's, Corson's (1976:9) definition of governance focuses on decision making:

By the term 'governance' I mean the processes by which decisions are made, who participates in these processes, the structure that relates those individuals, the effort that is made to see to it that decisions once made are carried out, and the processes used to evaluate the results that are achieved.

Peterson (1986:1) agrees that governance at the institutional level refers to the processes and structures through which individuals and groups participate in and influence decision processes in higher education, and points out that it is concerned with broad institutional rather than internal organisational issues. Traditionally governance pays particular attention to defining and differentiating the appropriate 
roles of constituencies and major decision structures and processes. The focus is on relationships: "The term 'governance' refers to the interrelationship among major roles, structures, and patterns of authority in the decision-making process in academic organizations" (Peterson 1986:3).

Governance cannot be studied or discussed in isolation from the related functions of management and leadership. Governance, management and leadership are simultaneously bound together and differentiated by the notion of decisions: governance implies both the structures and the processes of decision making, management denotes the structures and processes for implementing or executing the decisions taken by governance structures, whereas leadership refers to the structures (positions, offices and formal roles) and processes through which individuals seek to influence decisions (Peterson 1986:3, 4). It can be concluded, therefore, that although it is possible to draw a distinction between management and governance in higher education institutions, it is never simple to do so and the relationship between governance and management is one fraught with complexity. This complexity is intensified when pressures on institutions mount or where institutions operate in a climate of change or uncertainty.

Following from the premise that governance is about decision making, one should also interrogate what decisions are taken on. In universities governance involves decisions about the purpose and mission of the institution, and about the policies, programmes and resources required to achieve the mission. In addition, governance also concerns academic policies and affairs.

The above conceptualisation of governance more or less describes the 'traditional' definition of governance. Important and critical questions would be: What happens to governance of universities in times of change. Can and do governing bodies instigate or promote change and transformation? How does change impact on the relationships between difference governance structures? The effect of change on the university as an organisation as theorised by Barnett (2000) and applied to South African higher education is discussed below.

\section{UNDERSTANDING THE UNIVERSITY IN TIMES OF CHANGE}

During times of organisational reform and transformation, universities are particularly fragile. To describe this state of fragility, Barnett (2000) uses four concepts that he claims are key to understanding the post-modern university: uncertainty, unpredictability, challengeability and contestability. Sociologically, these factors relate to the conditions of the world, but also to the state of being in which the university finds itself today. 
Barnett (2000:66) points out that "[i]t is an age of uncertainty and unpredictability because it has become an age of challengeability and contestability".

Although in developing countries universities are to a larger or lesser extent prone to similar forces for change as those experienced by institutions in developed countries (cf. Green and Hayward 1998), , historical, political and economic factors cause these institutions to demonstrate subtle but important differences in nuances as far as the above-mentioned four concepts are concerned.

Barnett (2000:65) declares that "[u]ncertainty is that state of being in which one cannot be certain. Uncertainty is partly cognitive, but it is primarily experiential: it is an expression of one's mode of being in the world." At present, universities in South Africa are uncertain about many things: what government, the public and employers expect from them, such as what their role in the new South Africa should be, how they can play that role effectively, how they should be meeting the needs of the new generation of students, how they should be coping with the demands of globalisation, and what the effects of the global economic crisis on them would be. Since universities have traditionally had vague objectives and diffuse missions, further intensification of uncertainty in the university's context may contribute to growing dissent between actors in institutional governance and management. It is conceivable that less clarity about the university's 'state of being' may lead to growing disparities in what the council, senate and management believe the institution should stand for.

The world of South African universities has also become highly unpredictable. Moving from an isolated, divided system in the apartheid era towards a single coordinated system with higher levels of participation and responsiveness, within a developing economy and poor quality of primary and secondary education, South African higher education faces a multitude of challenges. Not only have government subsidies for universities been declining constantly, but unpaid student fees and rising expenses have brought some institutions to the brink of financial disaster. The effects of the meltdown in the global economy will certainly be felt by South African universities in decreasing third-stream income from research contracts and foundations, and in larger numbers of students who are unable to meet their financial obligations. Such conditions of unpredictability further exacerbate the complexities of planning, policy setting and decision making, thus impacting negatively on governance and management activities.

According to Barnett (2000:65), challengeability describes a state of affairs in which the assumptions on which we depended, even though we were hardly aware of them, 
are revealed and found inadequate. Such assumptions relate to both the way that universities have traditionally organised knowledge and how they have traditionally organised themselves. In South Africa the traditional organisation of knowledge into qualifications along disciplinary lines is fast being replaced by inter- and multidisciplinary programmes of learning. Furthermore, the typical organisational structure of departments, which are housed in faculties, is being changed to suit the programmebased approach. This has led in some institutions to the development of a matrix organisational structure with departments on the one axis and programmes on the other. Other examples are those of particularly merged institutions which collapsed former academic departments into schools, and are increasingly moving towards multi-disciplinary, inter-disciplinary and trans-disciplinary programmes and research projects. The implications of such decisions for the composition and role of academic governance structures such as faculty boards and Senate are far-reaching, to name one example.

Barnett's theory (2000) furthermore argues that contestability is that state of affairs in which a proposition or framework might be subjected to the counter-punch of a rival proposition or framework. One example of contestability relates to the core business of universities. A university qualification has traditionally been a much sought after academic achievement. This is borne out by the rapid and ongoing massification of higher education worldwide - the majority of the population still seems to believe firmly in the value of education and training, also at higher levels. The assumption on which universities thus depended was that they had something worthwhile to offer, that this was valued and that they would therefore be highly regarded in and by society. In South Africa, however, this assumption has been challenged by the absence of the expected massification of higher education. Even though there has been a steady increase in participation rates of blacks in particular, the actual growth in the system has been much slower and smaller than expected. Slogans like 'Liberation before education', and pronouncements by public figures that 'you don't need education to be a leader' (after the election of Mr Jacob Zuma as President) have added to a disregard of the traditional inherent worth or value of higher education.

In applying Barnett's theory to South African higher education, I have illustrated above that our universities are prone to the uncertainty, unpredictability, challengeability and contestability of rapidly and radically changing internal and external environments. Coughlan (2006:582) makes the point that higher education has never been static, and that it has always been subject to change; yet, the challenges faced by higher education 
in a transforming South African society are even "more intense and extensive" than ever before.

Against this background the question posed by Tapper and Palfreyman (1998:143) is of importance: "If universities are functioning in a radically changed environment which requires them to adopt both different purposes and to restructure their ties to state and society, does it not then follow that they need to govern themselves differently?" This is echoed by Talburt (2005:459) who cites a line of thinking that the current 'crisis' of higher education requires the reform of governance "to enable efficient decision making so that universities may respond effectively to changing 'environments'". This calls for an exploration of the 'traditional' models of institutional governance.

\section{MODELS OF INSTITUTIONAL GOVERNANCE}

For many scholars the classic model of governance is that of the autonomous, selfgoverning institution. However, Rhoades (1992) points out that all systems consist of a mix of academic (collegial), political and bureaucratic types of authority. These 'standard' models of governance "invoke notions of community, position, and expertisebased authority, and pluralistic politics, all related to legitimate authority" (Rhoades 1992:1377). Interrogating these models of institutional governance, and exploring the ways and reasons for their changing, might shed some light on the current state of institutional governance.

In his discussion of governance models, Rhoades (1992:1377) typifies the collegial model of academic governance as one that "emphasizes non-hierarchical, cooperative decision making and the significance of faculty self determination. Various campus constituencies are knit together by common interests and by a sense of academic community that legitimizes the concerns of these parties." The two most important principles of the collegial model are firstly, the idea of a community of scholars in which decisions are a matter of consensus, and secondly, the idea of professional authority that is based on competence rather than on position. This model reflects common interest, what Birnbaum (1988:85) calls "sharing power and values in a community of equals". Tapper and Palfreyman (1998:145) believe that "integral to the idea of collegiality is that nothing can be achieved unless it has the formal blessing of the collective membership".

Collegiality has been presented as the traditional view of higher education governance in which members' loyalty and commitment bind them to organisational goals, leading to consensus decision making. Yet, Rhoades (1992:1379) admits that "in 
the post-1960s era one would be hard pressed to find evidence in the literature of a collegial model of governance in operation", and points out that the expansion and assertion of bureaucratic/managerial authority has become more evident. In their study of institutional governance, Tapper and Palfreyman (1998:157) found that there is considerable evidence to suggest that collegial forms of governance in higher education are becoming less influential and less used.

Max Weber's bureaucratic model suggests in essence that bureaucracies are networks of social groups dedicated to limited goals and organised for maximum efficiency (Baldridge et al. 1986:16). A bureaucratic process model means that routines and procedures are used to resolve decisions.

In order to accommodate professional organisations like higher education institutions in the bureaucratic model, Mintzberg developed the model of the professional bureaucracy in which the professional and the bureaucratic co-exist. In the professional bureaucracy allegiance is to the profession or discipline rather than to the organisation and adherence to professional values rather than to organisational goals binds members together; the "existence of professional values, which guide, motivate, and control members, makes this 'self-government' possible" (Hardy 1990:395). Another characteristic of the professional bureaucracy is the decentralisation of power and responsibility which in itself creates certain tensions. Bess (2006:532) believes that universities "as professional bureaucracies must live with both the structural conflict engendered by democratic decision making and the functional ambiguities of mixed democratic and bureaucratic systems".

Most higher education institutions are composed of large numbers of individuals and groups that in some ways operate autonomously, but in other ways remain interdependent. It is this interdependence that often gives rise to political behaviour. Politics and power only become relevant when individuals or institutions must rely on others for some necessary resources, in other words when interdependence forces them to become concerned about or interested in the activities of others (Birnbaum 1988: 132).

The political model, developed by Baldridge in the 1970s, assumes that complex organisations like higher education institutions can be studied as miniature political systems. The model focuses on policy-forming processes, because major policies commit an organisation to definite goals and set the strategies for reaching those goals (Baldridge et al. 1986:20). These authors postulate that governance is less about professional authority than about "a process of political negotiation, lobbying, and 
coalition formation in which leaders, acting as members of state, strategize, mediate, and fashion compromises" (Baldridge et al. 1977, cited by Rhoades 1992:1377).

Although the political model encapsulates self-interest, and emphasises dissensus and conflict among interest groups, institutions which display these characteristics are not constantly in turmoil and a state of instability. Birnbaum $(1988: 136,137)$ explains why:

- Organizations tend to develop continuing and quasi-stable dominant coalitions whose established power serves to inhibit overt conflict.

- Individuals belong to more than one group and they participate in many political processes, each of which involves different people; therefore deep cleavages dividing major groups on many issues are unlikely.

- Most people in political communities are indifferent and not concerned about most issues most of the time.

- Disruptive conflict is inhibited, because power in higher education tends to be issue specific (see also Baldridge et al. 1986:20; Hardy 1990:398).

Most scholars would agree that in practice institutional governance shows characteristics of a variety of models. Furthermore, new concerns that pose altogether different challenges for higher education managers and leaders have arisen. The preoccupation with money and management shares centre stage with issues of quality, institutional effectiveness, and some very fundamental questions about whom higher education is serving and how well it is being done. Also, leading more heterogeneous institutions requires different skills - as staff and student bodies change, so must institutions and their leaders. Even at the traditional collegial institutions of Oxford and Cambridge central administration has become much more interventionist "requiring, for example, faculties and departments to justify costs which seem exceptionally inflated or how they intend to rectify apparent failings which have been identified by outside parties. It may be too soon, and too bold, to talk of central planning but clearly there is a more pervasive managerial ethos" (Tapper and Palfreyman 1998:158) The higher education environment is also marked by intense competition among institutions - for students, for research grants, for private sector funding and for research and development contracts, amongst others, leading to entrepreneurial initiatives by academic leaders. This raises questions about matters such as academic integrity, the nature of academic hierarchy, and the distribution of resources (Tapper and Palfreyman 1998). A traditional model of collegial governance can thus be threatened as much by the market as by the state. Clark, for example (cited by Rhoades 1992:1378), distinguishes at the 
institutional level only between trustee authority and bureaucratic authority, and for Clark bureaucracy is synonymous with managerialism, in other words, with top-down control.

International and local evidence suggests two things: firstly, that a hybrid model of higher education governance is developing, one that is moving away from collegiality, that is neither purely bureaucratic nor purely political, but one that tries to respond to primarily external pressures through a sort of corporate or managerialist model; and secondly, that there is a growing uneasiness with the notable increase in the power of administrators and other officials as distinct from the authority of the professoriate in the governance and management of academic institutions.

It seems appropriate therefore to return to the question posed earlier: If universities have to function within changed environments, forcing them to adapt their purposes, structures and processes, should institutional governance not change as well?

\section{CHANGES IN SOUTH AFRICAN HIGHER EDUCATION}

Some of the changes in South African higher education have already been alluded to. A study by the Centre for Higher Education Transformation (CHET 2000) shows that vice-chancellors of South African universities regard the issue of financial stability as the most important challenge facing their institutions. As pointed out above, in a context where there is stiff competition for scarce resources (whether at a systems or an institutional level) it seems as if collegial models of governance make way for more political or corporate models.

In the recent past several media reports pointed to growing levels of tension or even conflict between different actors (individuals and groups) in institutional governance. One such example is that of the University of KwaZulu-Natal where the council in December 2008 appointed an internal panel to investigate complaints of lack of academic freedom at the university. Staff members reportedly said that there was widespread dissatisfaction with the university's management style (Mail \& Guardian 13-16 March 2009:6) and that academics were becoming increasingly dissatisfied with this model. David Coldwell (27 November 2008) writes in the Mail \& Guardian Online:

The call of managerial efficiency has taken precedence and has all but destroyed the fragile infrastructure that made universities distinctive. Job descriptions, performance appraisals, managerial procedures and processes have sprung up and flooded the campuses where none were required before. As a general 
rule, these corporatist manifestations have had a severely debilitating effect on academic morale. Caught in a pincer movement between the two relentless forces of massification and managerialism, academic has wilted. The need, on the one hand, to attend to matters of financial and managerial efficiency, while on the other being confronted with the requirement of accommodating increasing student numbers, more teaching, marking and administration, while having fewer resources to fall back on and less time to achieve particular objectives, means that academics are being managerially monitored and controlled as never before.

Other examples include those of the University of the Free State where in 2008 a number of factors, amongst others, dissensus between council and management, led to the stepping down of the vice-chancellor, and Stellenbosch University where differences between some council members and management resulted in distasteful mudslinging in the media.

In addition to this somewhat anecdotal evidence, a number of recent studies provide evidence of a lack of trust among actors and dissatisfaction with governance arrangements. In a study done in 2007 by Wolhuter, Higgs and Higgs, academics were asked to score their influence in shaping key academic policies at departmental, faculty, and institution level. They had to indicate their response on a four-point Likert scale, with 1 signifying 'very influential', 2 'somewhat influential', 3 'a little influential' and 4 'not at all influential'.

The mean responses were as follows:

- departmental level: 2.12

- faculty level: 2.65

- institutional level: 3.73

Whereas academics felt that they had some influence in shaping key academic policies at departmental level and a little influence at faculty level, they had no influence in shaping such policies at institutional level (Wolhuter et al. 2007).

Johnson (2006) cites the study done by Webster and Mosoetsa (2001) on the changing nature of academic work as a consequence of managerialism in six South African universities. This study shows that academic work has become subject to more managerial control which has often resulted in a sense of loss of community and feeling of powerlessness among staff (Johnson 2006:61). Johnson followed this study with her own study among academics at the University of the Witwatersrand, which, amongst 
others, found that academics felt they had less access to information, which made it increasingly difficult for them to make informed decisions, and even when they were consulted, the consultative process seemed meaningless. Other comments pointed to changed relationships between academics and senior colleagues in managerial positions. Words used in this regard include 'mistrust' and 'bad attitude'. Respondents also believed that the university had become more managerial and corporate, and that managers seemed to have higher status and better remuneration. The most telling remark, symbolising the death of collegialism, was: "The social fabric of the department has disintegrated" (Johnson 2006:69).

According to Malcolm (quoted by Gerritsen 2008), the move towards a more managerial style of leadership has "increased stress on the governance-management nexus". A contributing factor is the complexity of today's universities that often makes it difficult for the lay members of council to understand them. This is exacerbated when council members are elected or appointed because they represent specific constituencies instead of having particular competencies in governance. Furthermore, some council members may be inclined to promote their own parochial interests (or that of their 'constituency') in council deliberations rather than fulfilling their obligation to serve the best interest of the institution as custodians.

\section{A NEW MODEL OF INSTITUTIONAL GOVERNANCE FOR SOUTH AFRICAN UNIVERSITIES?}

Although no formal large-scale studies on institutional governance in South African universities have been done lately, I believe sufficient evidence exists to conclude that current governance arrangements do not inspire confidence in some of the major stakeholders in the institution. Trakman believes that the functional values of any governance model depends on how it is applied in a particular case and that "each governance model is only as effective as those who craft it along with those who order their lives in light of it" (2008:64). Is it possible then to find a 'new' model of institutional governance for South African universities which are operating in conditions of uncertainty, unpredictability, challengeability and contestability, and if so, what should such a model be like?

When considering an appropriate institutional governance model for current South African higher education, Coughlan (2006:585) suggests a hybrid model which she

calls 'managed managerialism" "that will give a modern university a fighting chance of being able to respond to the new challenges and the pace at which they are coming 
while enjoying the trust of the academy". She goes on to say: "Managed managerialism enables universities to take on only enough of the principles of effective corporate type management to ensure that the deliberative environment that academic autonomy demands will not be under threat" (Coughlan 2006:588).

In their study on changing patterns of governance for Australian universities, Harman and Treadgold (2007) found that, like overseas universities, Australian universities too, during the 1980s and 1990s, moved away from the traditional collegial model to a model more closely aligned with business corporations. Questions about the appropriateness of the latter model for universities have prompted them to look for other options. They propose a trusteeship or trustee model, and describe the duty of a trustee as "to preserve, protect and enhance the value of assets under her/his control and deal fairly with any returns these assets may provide" (Harman and Treadgold 2007:16,17). They conclude by saying: "As a trusteeship model attempts to blend benefits from the 'corporate' model with a more community-oriented approach for the long-term benefit of the institution, it could thus be seen as a more sensible approach to governance" (Harman and Treadgold 2007:26).

It remains to be seen whether either of the models proposed above, or any other model, would provide solutions to the institutional governance challenges that South African universities are facing. I wish to conclude simply by pointing out some basic points of departure that need to be kept in mind for institutional governance to become more effective in fulfilling its purpose.

\section{CONCLUSION: FOR THE COMMON GOOD}

Firstly, the nature of the university as an organisation and the complexity of the context in which universities currently operate pre-empt the probability of clear-cut, 'neat' answers to questions or solutions to problems. Decision making in institutional governance more often than not requires the weighing of the pros and cons of different propositions, and settling for the option which will do the least harm. It is very seldom possible to find a perfect solution that will serve the best interests of the institution and satisfy all role-players. This incommensurability of higher education should be acknowledged by all actors involved in institutional governance. There should be recognition of the competing interests in governance and tolerance of those differences without endorsing divisive actions.

Secondly, it has become clear that a university can only be governed effectively if the different actors (council, management, academic staff/senate) share the same 
vision for the institution, agree on the ways and means to realise that vision, and play their respective roles appropriately. This implies that the actors should have clarity on the nature of a university, as well as an understanding of the environment in which the particular institution is operating. In the relationship between governance and management structures the rules by which players conduct themselves need to be clear and accepted by both parties.

Thirdly, a sense of trust among the main role-players is a prerequisite. Gerritsen (2009:99) argues that "tension, trust [and] power" are some of the words associated with the relationship between the Vice-Chancellor and Chair of Council, and quotes the Association of Universities and Colleges of Canada chair, Tom Traves:

The university president is the linchpin in this trusting relationship insofar as she or he requires the confidence of faculty, staff and students of the university to exercise presidential powers that are often based on a kind of moral authority, and, at the same time, the president requires the trust of the university's board, that she or he is carrying out essential duties in an effective manner.

Fourthly, communication seems to be a prerequisite for trust to be created and strengthened. Bess (2006) argues that uncertainty thrives in a culture of limited communication, especially among different, often opposing, political groups. Information that is exchanged should be "modulated by a belief in each other's competence and trustworthiness" (Bess 2006:532). The different actors in institutional governance must take time to consider their modes of communication - not only to clarify meaning, but also to assure counterparts of their sincerity and of the validity of their perspectives.

'Good' university governance does not simply happen. It is the product of informed, selfless and concerted efforts of all actors. "Ultimately, governance models are created by people to govern people. They are only as good as they who devise and apply them, as well as those who live by them" (Trakman 2008:77).

\section{REFERENCES}

Atwell RH. 1996. Higher education governance in despair. Journal for Higher Education Management, 11 (2).

Balderston FE. 1995. Managing today's university. Strategies for viability, change and excellence. San Francisco: Jossey-Bass Publishers.

Baldridge JV, Curtis DV, Ecker GP \& Riley GL. 1986. Alternative models of governance in higher education. In: MW Peterson (ed). ASHE Reader on organization and governance in higher education. Lexington: Ginn Press. 
Barnett R. 2000. Realizing the university in an age of supercomplexity. Buckingham: Society for Research into Higher Education \& Open University Press.

Bess JL. 2006. Toward strategic ambiguity: Antidote to managerialism in governance. In: JC Smart (ed). Higher Education: Handbook of Theory and Research Volume XXI. Dordrecht: Springer.

Binsbergen P, De Boer H \& Van Vught F. 1994. Comparing governance structures of higher education institutions: Towards a conceptual framework. In: L Goedegebuure \& F van Vught (eds). Comparative policy studies in higher education. Utrecht: Center for Higher Education Policy Studies.

Birnbaum R. 1988. How colleges work. London: Jossey-Bass.

CHET (Centre for Higher Education Transformation). 2000. Leadership and institutional change in higher education. Pretoria: CHET.

Coldwell D. 2008. Mail \& Guardian Online. 27 November.

Corson J. 1976. Changes in the governance of institutions of postsecondary education. Changing patterns of governance in higher education. Tuscon: University of Arizona. (ERIC report).

Coughlan FJ. 2006. Bridging the divide: Managed managerialism. South African Journal of Higher Education, 20(5):582-591.

Frederiks M, Westerheijden D \& Weusthof P. 1994. Stakeholders in quality. Improvement or accountability in five quality assessment systems in higher education. In: L Goedegebuure \& F van Vught (eds). Comparative policy studies in higher education. Utrecht: Centre for Higher Education Policy Studies.

Gerritsen J. 2009. Balancing the governance-management seesaw. In: A global view of the key issues confronting higher education. University World News.

Green MF and Hayward FM. 1998. Toward a new leadership model. In: MF Green (ed). Leaders for a new era. Strategies for higher education. New York: Macmillan.

Hardy C. 1990. Putting power into university governance. In: JC Smart (ed). Higher education: Handbook of theory and research. Vol. Vl. New York: Agathon Press.

Harman K \& Treadgold E. 2007. Changing patterns of governance for Australian universities. Higher Education Research and Development, 26(1):13-29.

Hartman N \& Scott I. 1990. Introduction. In: N Hartman \& I Scott (eds). Restructuring South African tertiary education: Academic contributions to the debate on rationalisation. Johannesburg: UDUSA.

Johnson B. 2006. South African academia in crisis: the spread of 'contrived collegial managerialism'. South African Journal of Higher Education, 20(1):60-73.

Kaplan GE. 2006. Institutions of academic governance and institutional theory: A framework for further research. In: JC Smart (ed). Higher Education: Handbook of theory and research. Vol. XXI. Dordrecht: Springer.

Kauffman JF. 1993. Governing boards. In: A Levine (ed). Higher learning in America 1980-2000. Baltimore: The John Hopkins University Press. 
Lockwood, G. 1985. Governance. In: G Lockwood \& J Davies (eds). Universities: The management challenge. Windsor: The NFER-NELSON Publishing Company \& SRHE.

Mail \& Guardian, 13-16 March 2009.

Peterson, MW. 1986. Introduction. In: MW Peterson (ed). ASHE Reader on Organization and Governance in Higher Education. Lexington: Ginn Press.

Rhoades G. 1992. Governance: Models. In: BR Clark \& GR Neave (eds). The Encyclopedia of Higher Education. Vol. 2: Analytical perspectives. Oxford: Pergamon Press.

Talburt S. 2005. Ideas of a university, faculty governance, and governmentality. In: JC Smart (ed). Higher Education: Handbook of Theory and Research Volume XX. Dordrecht: Springer.

Tapper T \& Palfreyman D. 1998. Continuity and change in the collegial tradition. Higher Education Quarterly, 52(2):142-161.

Trakman L. 2008. Modelling university governance. Higher Education Quarterly, $62(1 / 2): 63-83$.

Wolhuter CC, Higgs L \& Higgs P. 2007. South Africa: Rapid change and re-integration with the global community. In: W Locke \& U Teichler (eds). The changing conditions for Academic Work and Careers in Select Countries. Kassel: INCHER, University of Kassel. 


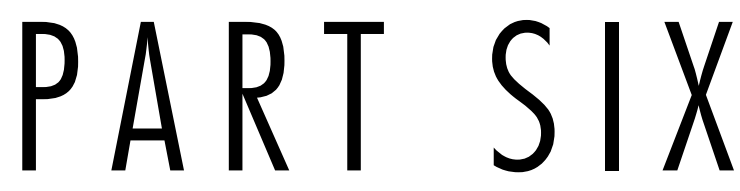
RESEARCH FRONTIERS AND AGENDAS 


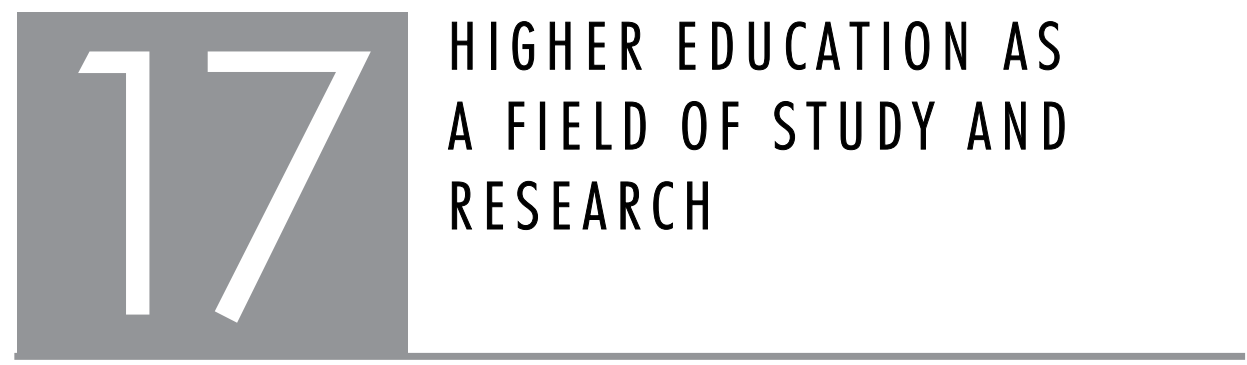

Eli Bitzer \& Annette Wilkinson

\section{ABSTRACT}

In this chapter we address four issues concerning HE as a field of study and research. We start off by discussing the typical characteristics of a field of study as opposed to a discipline, then we trace a number of moments in the development of HE studies and research internationally and locally. Next we try to suggest a way to 'map' the field in South Africa against the background of international mappings and finally we suggest a number of issues to consider for possible future research to extend and promote HE as a field of study and research - particularly in South Africa.

\section{INTRODUCTION}

It is widely agreed that higher education (HE) in its variety of forms contributes to social and economic development through at least four major missions:

1. The formation of human capital (primarily through teaching)

2. Building knowledge bases (primarily through research and knowledge development)

3. The dissemination and use of knowledge (by interacting with the users of knowledge)

4. The maintenance of knowledge (inter-generational storage and transmission of knowledge)

(OECD 2008) 
Yet, while HE considers itself to be a universal sector of society, its research, structures, curricula, governance and organisation vary greatly and seem deeply rooted in national, cultural and policy contexts (Schwarz and Teichler 2000). It therefore appears most fitting to study $\mathrm{HE}$ as a phenomenon or research object from a range of angles and perspectives. As HE has expanded enormously during the past decade or two, research interest in the field has grown significantly and it is well known that this research matters, as the character and performance of HE systems and institutions have considerable implications for all members of society, whether they engage directly with them or not (Brennan and Teichler 2008).

Earlier, a typical approach to study the field of HE was to explore programmes that emphasised the field as a focus or study object (Dressel and Mayhew 1974) and later encyclopedic versions (Knowles 1977; Clark and Neave 1992), in-depth articles of topical issues in 'handbook' format (Smart 1985; 2008) or comprehensive works on topical issues (Teichler and Sadlak 2000; Schwarz and Teichler 2000) were produced. Also of note is the proliferation of scholarly and popular academic journals, commissioned research and investigative reports concerning $\mathrm{HE}$ systems and burning issues in countries internationally that emerged in the past 15 to 20 years.

In South Africa there were reports of "an active, but confused field, lacking many of the attributes of scholarly work that you find in well-recognised disciplines or fields of study with their learning programmes" (Strydom 2002). Apparently, the study field of $\mathrm{HE}$ locally lacked academics of stature who were largely absent in professing from a position of research expertise and practical experience. This lack of expertise was confirmed by various viewpoints (Kraak 1999; Le Grange 2002; Muller 2000), although the Council on Higher Education (2004) hailed successes in its review of South African HE in the decade after the first democratic election in 1994 and beyond (Council on Higher Education 2004).

\section{HIGHER EDUCATION: DISCIPLINE OR FIELD OF STUDY?}

With developments and progress in higher education studies and research over the past two decades questions might arise as to whether $\mathrm{HE}$ as an object of study has not reached disciplinary status. This is a legitimate question as many prominent works and methodologies have pointed in that direction (see for instance Kogan, Baver, Bleiklie and Henkel 2006), several scholars have made seminal contributions and many research units and professors of higher education have been instituted. 
However, Dressel and Mayhew (1974) have outlined at least six criteria for a field to be termed a discipline: Firstly, a general body of knowledge should exist that can be forced into a reasonably logical taxonomy so that scholars could tell, at least quantitatively, where the knowledge gaps exist. Secondly, it should possess both a specialised vocabulary and a generally accepted basic literature that outlines its parameters. Thirdly, some generally accepted body of theory and some generally understood techniques for theory testing and revision should exist. This criterion is supplemented by the essential of a generally accepted body of consistently applied techniques for analysis or a generally agreed set of methodologies. The fourth criterion is that a recognised sequence of experiences for the preparation of researchers or knowledge workers should be in place and fifthly it is expected that the discipline should have reached a level of maturity that occupies a defined space in relation to other disciplines. A sixth and final criterion is that in a mature discipline considerable energy is devoted to solving basic or theoretical questions as well as to theory building. By applying this set of criteria in their own evaluation of higher education as a discipline in 1974, Dressel and Mayhew came to the conclusion that higher education "appears to be a field of study - ill-defined at the parameters - ... and has not yet attained that distinction" (p. 7).

By 2000, Fourie and Strydom (in Schwarz and Teichler 2000) came to the same conclusion when they pointed out that HE researchers in South Africa had to cope with a lack of an independent disciplinary base and a shortage of trained young $\mathrm{HE}$ researchers. In addition, they found a lack of specialists in the field of $H E$, little collaboration among $\mathrm{HE}$ research units and individual researchers, an absence of a widely accepted, well articulated theoretical framework and methodology suitable for addressing the diverse South African scene and an unreliable funding base.

It seems that the non-disciplinary status of $\mathrm{HE}$ is widely recognised. Brennan and Teichler (2008) point out that, in Europe, research on HE was undertaken by only a few hundred persons prior to the 1970s. In reports on trends within the humanities and social sciences, HE research was treated as a sub-area of educational research and it was only during and after the 1970s that research and studies on HE began to take a more prominent position as the public awareness of inter-relationships between education and economic growth, social mobility, student unrest and reform efforts increased. The 1980s and 1990s also saw more interest in HE in the wake of debates that included the knowledge society, new HE steering modes and increasing internationalisation. Currently the debates and work that involve, for example, the Bologna and Lisbon processes in Europe, stimulate further research and interest in $\mathrm{HE}$. 
In Section 5 of the Encyclopedia of Higher Education (Kerr and Neave 1992), several disciplinary perspectives on HE are highlighted. One such perspective (Fulton 1992) indicates "Higher Education Studies" as one disciplinary perspective. Fulton (1992:1810) explains this stance as not being "the application of social science (and indeed other) disciplines to an understanding of higher education", but rather as taking "a distinctive approach to higher education that transcends these separate disciplinary perspectives". He then goes on to consider the organisational context in which the study of HE has developed and examines the question of what the content of a HE studies perspective could be. According to Fulton, a crucial area in which an $\mathrm{HE}$ studies perspective seems to be more than the sum of its parts lies in the interaction between the public and private lives of $\mathrm{HE}$ institutions. Although this single indication cannot be claimed as a possible embrionic start of $\mathrm{HE}$ as a discipline in its own right, it succeeded in examining a unique contribution to explain parts of the academic enterprise.

In summary, we conclude on the discipline/field-of-study debate that there is little evidence that HE as a field of study owns the characteristics of a discipline. Nor does it portray itself as a mature field of study because of its vast and complex nature and also because HE as a phenomenon can be studied from an almost endless number of perspectives using an endless number of methodological combinations and permutations. In South Africa, in particular, HE as an emerging field of systematic study and research is far less developed than in most developed countries although it has been in existence for over four decades. We shall attempt to address aspects of this issue in the next section.

\section{DEVELOPMENT OF THE FIELD}

It is obviously impossible to sketch an account of the developments of the field of HE studies and research in one chapter - particulaly if a chronological view is taken. The aim of this section is rather to provide a few broad 'brush strokes' or examples of developments rather than to paint a complete picture. In doing so, we highlight some 'developmental moments' internationally (especially post-1960) and in South Africa (from as far back as we could detect developments) as they have emerged from literature and from our own backgound knowledge and experience of $\mathrm{HE}$ as an emerging field of study and research. 


\section{Examples of international developments and contributions}

Just as Flexner's (1930) work may stand out as seminal in representing a comparative study of university systems, the contribution of Dressel and Mayhew (1974) stands out as probably one of the most comprehensive in outlining programmes of study and research in HE in the United States at the time. In view of their emphasis on the promotion of research and scholarship, highlighting HE problems that point towards emerging models of studying HE and future prospects, we consider their book as ground breaking. It aptly pointed to the lack of a theoretical base for HE studies, provided some first accounts of institutional histories in the United States since 1887 and outlined the emergence of doctoral study programmes in HE. The contributions of university presidents who became interested in the field (e.g. Clark Kerr, James Perkins and Warren Bennis) as well as the work of educational agencies and associations which enabled a range of new publication options characterising the era, were also explored by Dressel and Mayhew. Towards the end of their introduction to the book (p. 31) they concluded:

What emerges then is an active, confused field, lacking many of the attributes of a discipline, yet demanding more disciplined effort. Its future is obscure; but if the present lines of development are strengthened and if the many perplexities are resolved, it may join the band of established specialities such as history, sociology and medicine, which once were in similar limbo.

Similarly, in his foreword to the International Encylopedia of Higher Education (IEHE 1977) edited by AS Knowles, Clark Kerr (the then chairperson of the Carnegie Council on Policy Studies in Higher Education) hailed the IEHE as of an "international dimension, not just a local or regional one" and acknowledged that "a nearly impossible task has been accomplished" (p. 15a). The IEHE was prompted by the wide acceptance of its forerunner, the Handbook of College and University Administration (1971), of which Knowles was the editor-in-chief. This publication brought together in one publication many major aspects concerning the field of HE. The IEHE represents a global perspective describing national HE systems, academic fields of study within higher education institutions, educational associations, research centres, institutes and documentation centres, academic and administrative policies and procedures as well as issues and trends in HE of the time. Among others, the IEHE contains articles about the systems of higher education in 198 countries and territories, 282 articles on (which were then) contemporary topics in HE, 142 fields of study offered in HE and their availability around the world, information on 314 associations (including societies, committees and commissions) and contact details of a selection of 91 major research 
and development centres and institutes in the field of $\mathrm{HE}$. In the subject index of the IEHE, Africa alone, for example, attracted no fewer than 96 entries. The IEHE indeed has served not only as an important instrument to bring $\mathrm{HE}$ as a field of study and practice into the open and to foster multinational technology transfer, but also to enrich the understanding of the variance and the relationships among HE systems, institutions and the communities they serve.

In our view, another major contribution to the development of the field was the publication of the Ecyclopedia of Higher Education (EHE 1992) edited by Burton Clark and Guy Neave. This formidable work, encompassing four volumes, contains descriptive data of national systems of higher education (Volume 1), analytical perspectives (Volumes 2 and 3 - see Annexure 2 for details on the different sections and topics included in these perspectives) from several academic disciplines and indexes (Volume 4). Of particular interest are the analytical perspectives that delved more deeply into five salient areas, namely (1) HE and society, (2) The institutional fabric of the HE system, (3) Governance, administration and finance, (4) Faculty and students, and (5) Disciplinary perspectives on HE. One contribution that was included as part of the latter area and apparently seems highly relevant as a contributing element to the development of the field is an article by Fulton (in Kerr and Neave 1992:1810). This contribution points out that HE studies is not just one among the many focuses of study within the core disciplines, but proposes that in terms of an organisational perspective, HE had (as early as the 1990s) disclosed the embryonic features of a discipline - at least in the US. Fulton found that the proliferation of HE master's and doctoral study programmes gave rise to or resulted from at least three developments. Firstly, autonomous departments or specialist divisions of HE were created (mainly within schools of Education) and these provided organisational structures and specialist teaching staff complements through which HE studies developed. This, in turn, also helped to support the development of professional associations and journals, similar to what was apparently experienced in Europe (see Teichler 1989). Secondly, the expansion of higher education provision increasingly forced HE institutions into institutional research projects that addressed issues such as competition, marketing, data-based decision making, quality assurance, student progress and student access. Much research concerning these issues involved $\mathrm{HE}$ expertise and postgraduate students. And thirdly, as a possible result of the increased size of HE systems and an growth in student diversity, many research projects were directed towards teaching and learning in HE. State universities and colleges in the US in particular had set up special research and development centres with a remit to promote reflection on teaching, learning and assessment matters, as well as staff 
development in these fields. Fulton (1992) purports that all three these developments were given greater exposure by the growing availability of information systems since the late 1950s.

Outside of the US, reports on HE, such as the report of the Robbins Committee in the UK in 1963 and comparative studies of the Organisation for Economic Cooperation and Development (OECD), also provided much impetus for new research avenues. Examples include higher education specialist research based at the London School of Economics and work of researchers from economic and sociology backgrounds based in Paris, the Leverhulme inquiry into the future of HE (1979-1983) and work sponsored by the Nuffield Foundation and the Rowntree Trust in the UK (Fulton 1992). In the US, two higher education reviews funded by the Carnegie Commission on HE (1967-1973) and the Carnegie Council on Policy Studies (1974-1980) were responsible for a number of influential policy proposals and, more importantly, for an upsurge in newly commissioned scholarship and research published by McGraw Hill and Jossey-Bass publishers. Similar effects were recorded in countries such as Sweden, where the Research on Higher Education Programme (RHEP) supported by the National Board of Universities and Colleges had contributed since 1971.

It appears that at least four models of financial support for research into HE were operative during the period prior to the 1990s: In the US a model of multiple funding sources prevailed which apparently promoted a rich variety of research topics and approaches. In contrast, the Swedish model supported research with earmarked government funding for fewer, but more quality projects of national interest, while the model used in China followed the same line, but in a political context that inhibited creative projects. In the UK and Western Europe, according to Fulton (1992), the funding model represented a more 'hand to mouth' approach where an unstable division of research between governments and institutions prevailed with a shortage of alternative funding sources implying a vulnerability to changes in funders' preoccupations.

A number of specialised centres and research units have contributed in important ways to the field of HE. Fulton (1992:1815) emphasises them as exceptional cases for playing a part in developing the field "out of all proportions to their numerical size". They include the Higher Education Research Group (directed by Burton Clark at Yale University), the Comparative Higher Education Research Group (at the University of California, Los Angeles), the Centre for Studies in Higher Education at the University of California: Berkeley, the Centre for the Study of Higher Education at Melbourne University in Australia, the Centre for Vocational and Higher Education Research at 
Kassel in Germany and the Centre for Higher Education Policy Studies in Twente, The Netherlands. Furthermore, a number of specialised scholarly journals, ranging from Higher Education to the Journal of Higher Education and Studies in Higher Education were prominent in furthering the field while members of societies such as the Association for the Study of Higher Education (ASHE), the Higher Education section of the American Educational Research Association (AERA) and the Association for Institutional Research (AIR) made important initial research contributions. Apart from these centres and associations, Fulton points to the nature of the field by highlighting the research approaches that were followed as well as the early book publications (the 'great books of $\mathrm{HE}^{\prime}$ ) that influenced further research and writing. He concluded that at least in the early 1990s HE appeared to be a rapidly changing field where the changes in higher education systems and institutions happened fast enough to require constant reassessment. One of the advantages of the field was (and probably still is) that it can draw freely on other disciplinary perspectives it may find appropriate. At the same time, this is also a drawback, since new 'immigrants' to the field who are trained in 'core disciplines' will always tend to use and foreground their own preferred methods and issues.

In our view another developmental thrust was the contribution of the publication Higher Education: Handbook of Theory and Research that saw its 23rd edition in 2008. The Handbook, currently edited by John Smart and sponsored by the Association of Institutional Research (AIR) and the Association for the Study of Higher Education (ASHE) has been published since 1986 and none fewer than 242 excellent and in-depth articles have been included in these volumes. The collection ranges from Pascarella's seminal contribution on how college environments influence students' learning and their cognitive development (the very first article in the Handbook in 1986) to Feldman, Yang's most recent (2009) article on China's return into the higher education community. A brief inspection of the 242 articles indicates that the contributing authors were/are all leaders in their respective areas of specialisation, that the articles cover a wide range of highly relevant topics and issues and that their nature ranges between in-depth qualitative, quantitative, and mixed mode research as well as personal and analytical reflections over career spans in HE research. The value of these contributions is, in our view, that they represent in most cases groundbreaking research and ideas that assisted in major ways in shaping the research and publications that followed on them.

The last developmental instance we want to highlight is the publication series of the Society for Research into Higher Education (SRHE) and Open University Press. 
The series has, over the past 10 or more years, published excellent scholarly and some very professional and practical works in $\mathrm{HE}$, including a range of books in areas such as staff and students, theory and history, policy and content, planning and management, supervision and postgraduate issues, research skills and study skills. Authors such as Barnett (Beyond all reason, The limits of competence, Improving higher education, The idea of higher education, Realizing the university in an age of supercomplexity), Tight (Researching higher education), Biggs (Teaching for quality learning at university), Becher and Trowler (Academic tribes and territories) and many others have made relevant contributions by stimulating debate and research in the field of HE. Publications from SRHE and Open University Press are cited numerously at conferences and in publications worldwide. In our view they have made (and are still making), a substantial contribution.

A recent 'developmental moment' that needs mention, and has the potential to contribute widely to debates and further publications on HE research, is a report by John Brennan (UK), Jürgen Enders (The Netherlands), Chriatine Musselin (France), Ulrich Teichler (Germany) and Jussi Välimaa (Finland) titled Higher Education looking forward: An agenda for future research. The report, which focuses mainly on the UK and Europe and is sponsored by the European Science Foundation (ESF), questions the relationships and connections between contemporary social and economic changes, the changes happening in HE and the roles of academics. This also leads to other questions for which, according to the authors, new forms of social science methodologies will probably be needed. They include questions such as: How might new forms of comparative research achieve a better understanding of the interactions between $\mathrm{HE}$ and society, and the different forms these take in Europe and more widely? How do national, regional and local contexts help to determine the characteristics of HE systems? What is the role of public authorities? Do different types of HE institutions have different relationships with the wider social and economic worlds which they are part of? Must universities adopt new functions and blur their boundaries with other social institutions to retain their importance in the knowledge society? The report also characterises current HE research as small and theme-based with varied institutional bases implicating risks and dangers as well as challenges and opportunities. Some of these questions are reminiscent of those put (in a less sophisticated manner, though) by Professor Charles Kendall Adams in addressing the Phi Beta Kappa Society of the University of Vermont on the relationship between higher education and national prosperity (as far back as 1876!). 
These are but a few examples in scratching the surface of a wealth of resources that have enhanced and are still enhancing the international development of HE as a field of study and research. We shall now turn to developments in South Africa and again, these are merely examples that do not pretend to provide a complete picture.

\section{Examples of South African developments and contributions}

The aftermath of the first democratic election and a peaceful transition of power in South Africa in 1994 saw a proliferation of policy documents, workshops, conferences, papers and publications on HE (see Table 17.1). It may not be far-fetched to say that the newly elected ANC government and the so-called progressive groupings and leaders wanted to transform the whole of the educational dispensation as quickly and as radically as possible. While this position could be understood after many years of domination and missed opportunities, it was also an approach with risk, as education systems do not change easily and radically unless much energy and resources are invested in them. This was exactly the challenge posed to the newly elected authorities: Radical policies and plans were being set in place, but only limited funding was available for their implementation. Therefore, it was not before the 2000s that the implementation of transformational plans really began to take shape and that HE in particular started experiencing major changes. These changes, accompanied by new challenges such as broadening student access, increasing student funding and effecting equity brought new dimensions to HE research and study opportunities, as we shall try to explain (also see the chapter on policy analysis by Hay and Monnapula-Mapesela as well as other chapters on the university as a HE institution in this book).

TABLE 17.1 A summary of key HE policy and publication initiatives at a national level (1990-2009)

\begin{tabular}{|c|l|}
\hline Date & \multicolumn{1}{|c|}{ Initiative or process } \\
\hline 1990 & $\begin{array}{l}\text { The National Education Coordinating Committee (NECC) starts HE policy } \\
\text { proposals in view of the African National Congress (ANC) gaining the political } \\
\text { power. }\end{array}$ \\
\hline $1992-1994$ & $\begin{array}{l}\text { Policy proposals by the Union of Democratic University Staff Associations } \\
\text { (UDUSA) and the Education Policy Unit (EPU) at the University of the Western } \\
\text { Cape. Publication of the National Education Policy Initiative (NEPI) report: } \\
\text { Post-secondary Education. }\end{array}$ \\
\hline $1995-1996$ & $\begin{array}{l}\text { Promulgation of the South African Qualifications Authority Act (No. } 58 \text { of } \\
\text { 1995). Establishment of the National Commission on Higher Education } \\
\text { (NCHE). Publication of the report: A framework for transformation (1996). }\end{array}$ \\
\hline
\end{tabular}




\begin{tabular}{|c|c|}
\hline Date & Initiative or process \\
\hline 1997 & $\begin{array}{l}\text { Publication of the Green Paper and White Paper 3: A programme for the } \\
\text { transformation of higher education. Release of a Bill on Higher Education and } \\
\text { the adoption of the Higher Education Act, No. } 101 \text { of } 1997 \text {. } \\
\text { Requirement for all HE qualifications to be recorded and registered on the } \\
\text { National Qualifications Framework (NQF). Extensive curriculum restructuring. }\end{array}$ \\
\hline 1998 & $\begin{array}{l}\text { Establishment of the Council on Higher Education (CHE) and its standing } \\
\text { committee, the Higher Education Quality Committee (HEQC). Ministry } \\
\text { initiatives around private HE. HE qualifications to be accredited on the NQF } \\
\text { and initiatives to start the work of the HEQC. }\end{array}$ \\
\hline 1999 & $\begin{array}{l}\text { Passing of the National Students Financial Aid Scheme (NASFAS). Initiatives to } \\
\text { launch the accreditation process of } 50 \mathrm{MBA} \text { programmes at } 24 \text { institutions. }\end{array}$ \\
\hline 2000 & $\begin{array}{l}\text { Release of CHE report: Towards a new higher education landscape: Meeting } \\
\text { the equity, quality and social development imperatives of South Africa in the } \\
\text { twenty-first century. Group appointed to report on language policy for HE, } \\
\text { including the use of Afrikaans as language of instruction. CHE evaluation of } \\
\text { the technikon qualifications quality assurance body (SERTEC) and the Quality } \\
\text { Promotion Unit (QPU). }\end{array}$ \\
\hline 2001 & $\begin{array}{l}\text { National Working Group (NGW) releases the report: The restructuring of the } \\
\text { higher education system in South Africa. Cabinet approves ministry proposals } \\
\text { to reduce } 36 \text { public institutions to } 23 \text { through mergers and incorporations. } \\
\text { All teachers' training colleges to be incorporated into universities' faculties of } \\
\text { education. It is proposed that all techikons become universities of technology } \\
\text { through mergers and transformational measures. Initiatives to review } \\
\text { cooperative governance in HE. }\end{array}$ \\
\hline 2002 & $\begin{array}{l}\text { CHE requested by the ministry to investigate distance education provision in } \\
\text { South Africa. CHE releases a research report: Governance in South African } \\
\text { higher education and a policy report: Promoting good governance in South } \\
\text { African higher education. }\end{array}$ \\
\hline 2003 & $\begin{array}{l}\text { CHE provides advice to the ministry on an interdependent National } \\
\text { Qualifications Framework (NQF) for higher education. }\end{array}$ \\
\hline 2004 & $\begin{array}{l}\text { Several publications from the CHE, including South African higher education } \\
\text { in the first decade of democracy, Higher Education Qualifications Framework } \\
\text { (HEQF - draft for discussion), Higher education and social transformation - } \\
\text { a South African case study. }\end{array}$ \\
\hline $2005-2007$ & $\begin{array}{l}\text { Several publications and advisory documents from the CHE, including Towards } \\
\text { a framework for quality promotion and capacity development in education } \\
\text { (2005), Academic freedom, institutional autonomy and public accountability } \\
\text { in higher education (2006), Higher education monitor: A case for improving } \\
\text { teaching and learning in South African higher education (2007) and the } \\
\text { HEQC evaluative study of institutional audits in } 2006 \text { (2007). }\end{array}$ \\
\hline 2008 & $\begin{array}{l}\text { The Higher Education Amendment Bill is published to make provision for the } \\
\text { implementation of the HEQF in HE institutions in South Africa. }\end{array}$ \\
\hline 2009 & $\begin{array}{l}\text { CHE publishes a report on Postgraduate studies in South Africa: A statistical } \\
\text { profile. }\end{array}$ \\
\hline
\end{tabular}

(Some of the detail in Table 17.1 was adapted from Cloete et al. 2004: National policy and a regional response in South African higher education: 10-16)

One may well ask what the situation was regarding HE study and research before 1994. Documented history reveals an interesting number of brush strokes. The first 
indications of institutionalised education beyond schooling in South Africa emerged with the establishment of the "Zuid Afrikaanse Athenaeum" or ZAA (South African Athenaeum or South African College - SAC) in Cape Town on 1 October 1829. By 1837 this institution, which offered advanced education to young men and prepared them for the examinations of the University of London, received full college status (Coetzee and Van Rooy 1949:17). The ZAA/SAC thus became the forerunner to the first examining body in South Africa, the University of the Cape of Good Hope (UCGH), which was established in 1873. Several colleges were subsequently established and affiliated to the UCGH, many of whose histories were aptly recorded by FC Metrowich in a BEd thesis (Metrowich 1929). Before 1873, church-related institutions for theological training such as the Theological Seminary of the Dutch Reformed Church in Stellenbosch (1859) and the Theological School of the Reformed Church in Burg(h)ersdorp (1869) were founded. These were followed by institutions for specific purposes such as the Womens' College in Wellington (South Africa) which many years later (1907) became the Huguenot University College. Metrowich's study is a most valuable source in the sense that it recorded a general survey of HE facilities in South Africa under the regime of the UCGH between 1873 and 1916. It also analysed the main defects of the system and described attempts to reform both before the South African war in 1899 and after the war - covering the year 1910 when South Africa became a Union. Metrowich's contribution closes with an account of a report by the Van der Horst University Commission (1928) which recommended a number of drastic changes to the HE system in South Africa at the time (also see Annexure 17.2 for a list of universities established between 1829 and 1970, as well as Annexure 17.3 for the position of public universities in South Africa in 2009).

The purpose here is obviously not to reflect on the historical development of HE in South Africa per se, but rather to capture some key moments in the furthering of studies and research in the field of HE. For this, one has to look at sources beyond early legislation and policy formation in South Africa's colonial past. One such source is a publication by EG Malherbe (1925), a lecturer in Education at the University of Cape Town at the time. Malherbe published an account of over 500 pages of South African education covering the period between 1652 (when the first Dutch settlers arrived at the Cape of Good Hope) and 1922. In Malherbe's bibliography, a number of interesting sources are listed which might indicate a set of very loosely organised HE research activities in South Africa during the earlier colonial periods. Examples of artifacts include a copy of correspondence between the Colonial Government and the South African College between 1829 and 1854 (dated 1854), a lecture by GG Cillie titled 'Ontwikkeling 
van de Hogere Onderwijs in Zuid-Afrika' ('The development of higher education in South Africa') dated 1918, a lecture by EM Clarke: 'Higher education of women in South Africa' (1905), a published document by AS Kidd in Grahamstown (1912): Higher education in the Cape Colony in the period 1874 to 1910, and an article by G Knoethe: 'Kijkies in de Geschiedenis van ons Hoger Onderwijs' ('Glimpses into the history of our higher education'), Potchefstroom (1913).

Another useful source is number of research reports on education published by the then South African Council for Educational and Social Research (SACESR), which appeared in the 1930s. Topics included (some now quite embarrassing) titles such as The learning ability of the South African native, The educatability of the South African native and The relationship of entrance age to academic sucess of university students. The latter study by Malherbe and Cook (1938) was an inclusive survey of first-year students at nine (so-called 'European') universities that existed at the time. Comparative work involving international participation was part of the study that attempted to answer questions such as: How old are students when they enter universities? Is there a trend to attend university at an earlier stage? Do younger entrants do better or worse at university? How do the results of students that did a post-matriculation year compare to those that did not? This study seems to be one of the first of its kind in South Africa that did not only make use of a rather sophisticated survey methodology, but also reported quite sophisticated research results and findings.

Following a significant contribution by Reyburn (1934) in an area of study which was then known as 'tertiary didactics' or the methodology of teaching in higher education, a book titled Beginsels en metodes van die Hoër Onderwys (Principles and methods of higher education) was published by Coetzee and Van Rooy (1949). It was used at many (particularly Afrikaans-medium) universities as a resource for staff and educational development. Useful in particular was a chapter by Coetzee in which he highlighted, from contemporary sources, issues such as the history of university education (in the Western World), the role and place of the university in society, the professor-student relationship, teaching methods and techniques as well as the issue of discipline in the university curriculum. The chapter ends with a discussion of university administration and organisation. The rest of the book provided more detailed discussions of educational/ instructional issues in a range of disciplines taught at universities such as theology, philosophy, education, classics, languages, mathematics, biology, geography and others. In a nutshell, Coetzee and Van Rooy succeeded in providing a framework for educational development on the one hand, and in setting a relevant research agenda 
for higher educationists which was actively explored in the 1960s and beyond, as we shall try to illustrate.

After South Africa became an independent republic in 1961 and the Nationalist Party was firmly in power, many new universities were established - mainly to serve the apartheid agenda (see Annexure 17.2 for a chronological version of the establishment of universities in South Africa between 1829 and 1970). It was also a time when studies in $\mathrm{HE}$ began to flourish and public addresses and publications in book and other formats appeared more frequently. Many of these documents reflected a range of issues and challenges important to $\mathrm{HE}$ at the time, such as race relations (Behr 1969; 1970), the roles and functions of the university (Versveld 1962), university and society (Thom 1965), student revolt (Gouws 1973), academic freedom (Esterhuyse 1973), university research (Arndt 1973) and university teaching (Pauw 1969; Behr and MacMillan 1971). One source of particular note was a book by JR Pauw, a prominent researcher of university education of the 1960/1970 era. Pauw, who had a background in education, made an in-depth study of the Western university and related these characteristics to the position of universities in South Africa at the time. He addressed issues such as the university of 'yesterday' (universities in the Middle Ages), the university of 'today' (the modern Western university), a changing student body and its implications for university teaching, the university and society, academic freedom and the university of 'tomorrow' (a perspective of what universities might look like in the future). Seen in South African terms, Pauw's work was seminal at the time although he did not address the volatile political context in his future perspective and did not pay any attention to university models outside of the Western world. What he did include as an annexure to the book were comments on and a critique of the report by the Van Wyk De Vries Commission (VWDVC) that was published in October 1974. This Commission, under the chairmanship of Judge J van Wyk de Vries, was appointed by the then Nationalist Government in 1968 to investigate major aspects of university education in South Africa. Although it addressed a number of important points including academic freedom, governance, the legal position of universities, the relationship with the State, the establishment of advisory bodies on higher education, the relationship between universities and professional councils, financing universities and student unrest, it failed to address important structural issues that divided the higher education system and the people of South Africa. This included the fact that in the apartheid era, universities for different racial groupings were accountable to different government departments and consequently little or no coherence existed in the HE system. Needless to say, the VWDVC report sparked heated debates from 
different audiences, a proliferation of research projects and many publications on most of the issues the commission reported on.

Apart from Nationalist government initiatives to investigate aspects of $\mathrm{HE}$, there were increasing efforts from $\mathrm{HE}$ institutions and associations to focus on a number of current issues spanning the 15 years between 1975 and 1990. One of the recommendations from the VWDVC report had to do with the obligation of universities to enhance the throughput rates of undergraduate students in particular. This sparked a number of initiatives to establish units for teaching and learning support at various universities. The first university to do so was the then Rand Afrikaans University (RAU) under the leadership of the late Professor Gerrit Vilioen who later became minister of education in the Nationalist (FW de Klerk) government. The Bureau for University Education at the RAU published various articles and reports of quality in their in-house bulletin for academic staff, the 'Bulletin for Lecturers'. Most other universities followed suit and an array of such units and bulletins appeared in this period. Collectively they did excellent work to put $\mathrm{HE}$ on the research agenda and from their ranks a number of master's and doctoral programmes in HE were established (mostly under the auspices of faculties of education). As a result, the South African Association for Research and Development (SAARDHE) was founded in 1979 and the South African Journal of Higher Education (SAJHE) emerged in 1987. In the latter case the Committee for University Principals (CUP), an advisory body on $\mathrm{HE}$, assisted financially to enable the publication of the SAJHE. This journal is still a major outlet for HE research in 2009. On the other side of the bench, mostly driven by the more 'liberal, English' universities were those academics and staff who were most critical of what the more 'conservative, mainly Afrikaans' universities were doing. Therefore they openly challenged apartheid legislation by increasingly accommodating (mostly black) students from disadvantaged backgrounds and exploring ways to support these students academically. The research conducted in this respect made their contribution to HE most relevant. Academic development units were subsequently established at a number of institutions. Academic development officers formed a national association, the South African Association for Academic Development (SAAAD) and held their first national conference in 1985. SAAAD later became defunct and was relaunched in 2002 as the South African Academic Development Association (SAADA) which then became the Higher Education Learning and Teaching Association (HELTASA). This association still makes valuable contributions to HE studies and research.

In the late 1980s and early 1990s three important developments added much to the momentum of HE studies and research. Financially supported by the Human Sciences 
Research Council (HSRC), the first Unit for Research into HE was established under the leadership of Kalie Strydom at the Free State University. The initial work of the Unit centred on issues of quality assurance and leadership in HE. Studies on HE as a field of study in South Africa, student access to $\mathrm{HE}$, regional educational cooperation as well as international comparative studies were published by the Unit. In addition, and through its projects, research training for developing future HE researchers formed part of the Unit's work. The early 1990s also saw the formation of the Post-Secondary Research Group convened by Nico Cloete and Mfundu Nkhulu. This group, consisting of 21 research members from varied backgrounds and supported by the National Education Coordinating Committee of the ANC, conducted a National Education Policy Investigation. From the investigation a report, Post-secondary Education (NEPI 1992), was published which provided an overview of the South African post-secondary situation and addressed a number of important $\mathrm{HE}$ issues that included inequalities and equity in the HE system, student access, student development, institutional inequalities and staffing inequalities. It finally proposed a number of policy options and a possible future HE policy structure that was taken into the realms of the political change in 1994 and the consequent investigation of $\mathrm{HE}$ by the National Commission on Higher Education in 1996. Addressing a different sphere of work, but also of extreme importance in the development of HE research, was the formation of the Southern African Association for Institutional Research (SAAIR) in 1994. With its affiliation to the Association for Institutional Research (AIR) in the USA, SAAIR is a dynamic and active association that involves members from institutional research units at all universities, organises conferences and conducts independent research on such issues as student retention and reporting of HE management information (see www.saair.org.za).

Against this background it is unfortunate that one has to leave out details of important research contributions supported by international funding agencies such as the Ford Foundation and donations by the British, Dutch and Nordic governments to South African $\mathrm{HE}$ researchers. Other valuable contributions that deserve to be mentioned are the many postgraduate programmes and study opportunities provided by universities (see an example of a listing of programmes offered by 2009 in Annexure 17.4) and contributions by newly established research outfits such as the Centre for Higher Education Transformation (CHET) and independent education policy units.

Invariably, this brief exploration begs the question: How can the field of HE studies and research in South Africa be classified or 'mapped'? This question is addressed next. 


\section{MAPPING THE FIELD OF HIGHER EDUCATION STUDIES AND RESEARCH}

Considering the various observations and uncertainties about HE studies and research in general and in South Africa specifically, this chapter would not be complete without an effort to answer a number of questions relating to the nature and scope of the field in South Africa. We therefore attempt to provide some 'map' of the field which might put the reader in a better position to consider developments in the field as well as its strengths and weaknesses when compared to international maps.

We took notice of Teichler's overview of research on higher education in Europe (Teichler 2005) and the aspects he covers in the overview. These include references to the relatively small size of the field, the varying interest among countries and institutions, the diversity of institutional settings where higher education is studied and researched, the impact of national priorities on the themes being studied and the mixed nature of journals and joint associations.

Without attempting to cover all these aspects, the following questions directed us in our 'mapping' exercise:

1. What is the (thematic) nature of higher education studies and research in South Africa? Are there particular South African emphases in the research? How do these relate to international trends? Does available evidence suggest a possible/ unique categorisation of current higher education research themes in South Africa?

2. Where in South Africa is HE formally studied? What are the institutional or organisational settings where HE is studied? What is studied in the various programmes?

3. How stable is the professional basis of higher education research in the country? (Formal associations? Journals? Other forums and outlets? The researchers? Communities of practice?)

We believe that some clarity on the above questions can contribute to the enhanced status and a further recognition of the field of study and its standing in national as well as international terms. However, due to the limitations of a single chapter, we focus on the first question and leave the others as either summarised data or pointers for future research. 


\section{THE THEMATIC NATURE OF HIGHER EDUCATION RESEARCH IN SOUTH AFRICA}

Clarity on the thematic nature of higher education studies and research in the country can be an important starting point towards addressing uncertainties and ignorance about the field and providing a possible answer to those who ask: What is it all about? (Strydom 2002). At the same time awareness can be created of the 'uniqueness' or elements of 'disciplinarity' in the field, in particular themes or sub-themes that will not be found or studied as part of the curricula or research agendas of any other discipline. A classification can also assist students of higher education in locating and demarcating their studies within the broader field. International classifications, in particular those of Teichler and Tight, can provide frameworks against which South African trends can be judged.

\section{International classifications of HE studies and research}

Teichler, an authority in the field of higher education research, has suggested a classification of higher education research which gives a useful indication of the nature and extent of the field in the absence of clear delineation. He proposes four broad categories or spheres of knowledge in higher education, because it is his view that a classification of a research area based on themes might be "short-lived" as "major concerns change rapidly" (Teichler 2005:440). He suggests four typical areas of research for each sphere and relates them to the disciplinary settings of those undertaking the research (Teichler 1996:440-443; 2005:450-451):

1. Quantitative-structural aspects such as access, admission, types of institutions, and graduation employment and job opportunities (often informed by economists and sociologists)

2. Knowledge- and subject-related aspects relating to disciplinarity, academic/professional, skills and competences, quality, research on teachingcurricula relationships (mainly informed by education, sociology and history)

3. Person- and process-related aspects, including teaching and learning, communication, counselling and assessment of academic staff and students (with education, psychology and sociology involved)

4. Organisation and governance related to administration, planning, management, funding and decision making (mainly from the angle of law, political science and public or business administration) 
Frackmann (1997, in Tight 2003:6) suggests five clusters or issues for research in Western Europe, namely: (1) the role and function of higher education; (2) the nature of knowledge and learning; (3) coordination and mechanisms between society and higher education; (4) learning and teaching and (5) higher education and European integration. In this categorisation, the regional (European) interest and the place provided for interaction between higher education and society are of interest. Similarly, a separate category was assigned to "higher education and society" - showing some correspondence with the category of "social psychology" in the classifications of Clark and Neave (1992, in Teichhler 2005). Seen from a South African perspective, it is not always clear within which of the widely-accepted Teichler areas or "spheres of knowledge" this important aspect (HE and society) should be grouped.

For current purposes of a national categorisation, which may serve as a South African map of higher education studies and research, we regard Tight's (2003) more detailed categorisation of themes or issues in higher education as a valuable and very practical starting point. His research was based on the analysis of 406 articles in 17 specialist higher education journals published in English outside North America during 2000. This work resulted in the identification of the following eight major themes and subthemes or issues (Tight 2003:7; 2004:6):

1. Teaching and learning - including approaches to studying, learning styles and pedagogical styles

2. Course design - including assessment, competencies, the higher education curriculum, learning technologies, portfolios, reflection, writing and postgraduate study

3. The student experience - including access, counselling, motivation, diversity, success and non-completion, employment and evaluation

4. Quality - including course evaluation, grading and outcomes, national monitoring practices and system standards

5. System policy - including economics of scale, funding, national policies, policy studies, globalisation, massification and returns on investment

6. Institutional management - including autonomy, departments, institutional leadership and governance, institutional development and history, institutional structure, mergers, marketisation and relationships between higher education, industry and community 
7. Academic work - including careers, induction, mobility, professionalism, academic roles, academic development, training, writing and women academics

8. Knowledge - including the nature of research, disciplinarity, forms of knowledge, research, and the nature of the university

Tight (2003:7-8; 2004:6) acknowledges that a definite listing is not possible and that overlapping among categories will always occur. He justifies the inclusion of specifically the quality category in terms of the amount of attention it had received at that point. He also describes his approach as "indicative and useful" with the possibility that others would identify "more, less, or different" categories. We are of the opinion that this built-in flexibility makes the Tight framework even more useful and attractive for possible adaptation in any 'mapping' endeavour.

The question thus arises whether or to what extent the Teichler "spheres of knowledge" and the Tight categorisation cover or represent current higher education research and study trends in South Africa. Based on our experiences of the field of HE in South Africa, we intuitively feel the necessity of a more prominent place for the abundance of research undertaken and published on the transformation of higher education since democratisation in 1994 and efforts of addressing inequities in all spheres of postsecondary education. In considering this era, there is uncertainty about the possible placement and prominence of higher education community links, with emphasis on the socio-cultural aspects, as well as about the growing importance of the application of the information communication technologies (ICTs) in HE. In our search for directives in this regard we were guided by a number of classifications undertaken in the South African context.

\section{South African classifications of HE studies and research}

The classifications we discuss in this section were either based on analyses of the publications in a recognised higher education journal or on postgraduate study topics registered with the National Research Foundation (NRF). Both approaches can be regarded as reliable and valid sources of information, although not entirely comparable. Closer consideration of these studies proved, however, that both might at least provide clear indications of the thematic nature of and trends in HE research at specific periods of time. 


\section{The analysis of Muller (1993-1997)}

Muller (1998) undertook a worthwhile analysis of 371 higher education research topics registered on the Nexus Database at the NRF in the five-year period covering 1993 to 1997. The sample included 164 completed and 207 ongoing research studies. When combined, the two most popular study topics at that stage proved to be student learning (26\%) and curriculum development (22\%). These were followed by topics each comprising less than $10 \%$ of the total, including instructional practices, Course evaluation, teacher training, technology in education, bridging courses, student career/ counselling, governance of $\mathrm{HE}$ and staff development.

It is interesting to note that the emphasis in most of the studies during this period was on aspects related to students and teaching. The scope of the research on postgraduate level is furthermore surprisingly narrow for the period during and just after the transition to a democratic government in 1994, with relatively little attention to the spheres of knowledge described by Teichler as "Quantitative Structural" and "Organisation and Governance" respectively. The question therefore arises whether changes in society and in particular those brought about by legislation aimed at changing the higher education scene are more strongly reflected in higher education research undertaken since the late 1990s. Uys and Frick's research (2009) sheds some light on the matter.

\section{The analysis of Uys and Frick (1987-2007)}

In applying an innovative approach to topic modelling Uys and Frick (forthcoming) analysed all 1,237 abstracts of articles published in the South African Journal of Higher Education (SAJHE) in the period 1987 to 2007 . The analysis comprised the electronic 'counting' of keywords by using the software program CAT (Computer Analysis Toolkit). As rationale for this major endeavour the authors hold that the way in which societal change at a broad level, and educational change in particular, influences academic discourses may be reflected in what a journal such as SAJHE offers its readership (Uys and Frick forthcoming).

The researchers did not make use of predetermined topics or coding, but 50 broad topics, each associated with a large number of keywords and phrases, emerged from the computer-aided categorisation. The authors undertook several types of analysis, all providing very interesting research trends, such as the following list of the 10 topics best covered over the 20-year period: 
1. Institutional research (National Plan for Higher Education)

2. Factors influencing student performance

3. Learning theory

4. Institutional research (General and institutional self-representation)

5. Quality assurance

6. Academic staff and development

7. Academic performance

8. Teacher training

9. Postgraduate supervision

10. Teaching evaluation

Although not directly comparable with the Muller's listing when source (postgraduate studies vs. published research) and period of undertaking (1993-1997 vs. 1987-2007) are compared, at least two major observations can be made: (1) the high priority assigned to institutional research and in particular, legislation aimed at steering $\mathrm{HE}$ into desired directions (for example, the national Plan for Higher education and quality issues) which were not 'visible' in the Muller listing and (2) the occurrence and presumably high priority assigned to student and staff matters on both lists with a noticeable absence of curriculum development/design from Uys and Frick's 'Top 10' topic list.

A better comparison with the Muller listing is, however, made possible in one of their other analyses. A highly informative account of research trends (as reflected in SAJHE articles) can be found in their graphical representation of so-called topic time trends. This representation clearly depicts the fluctuating trends, the topics becoming less popular over time, as well as those becoming more attractive in recent years. When considering the time period of 1993-1998 for example, the trends identified by Muller are confirmed. Some of the research trends of the middle 1990s are also very prominent in the Uys and Frick listing of topics with the longest duration over the period of investigation (1987-2007). Student-related matters (counselling, performance, learning), academic staff matters and aspects of teaching, course design and teaching evaluation seem to have been of longstanding importance over the last two decades. The correspondence in findings between the two classifications based on different sources (postgraduate studies and journal publications respectively) provides a clear indication that research trends are more likely to be time-dependent than dependent on source of publication. 
The Uys and Frick time trend analysis can be regarded as a valuable overview of research trends in higher education in South Africa. Reference to their observations regarding more recent trends also becomes relevant in the discussion of the analyses by Wilkinson and Van Jaarsveldt (2009).

\section{The analyses of Wilkinson and Van Jaarsveldt (2003-2008)}

Wilkinson and Van Jaarsveldt (2009) had a somewhat different purpose in mind with their analyses. They are both lecturers and supervisors in a large postgraduate programme in higher education studies and had identified the need to provide a more consistent demarcation of their field to the many students currently undertaking studies in the field. Their analyses included articles recently published in the field of higher education as well as postgraduate studies registered at the NRF. In the first phase of an ongoing project all 159 articles published in the SAJHE in 2006 and 2007 were manually coded and categorised. In their analysis an attempt was made to link the research trends/topics they had identified to the Tight classification and, in so doing, to determine possible adaptations needed to make it more applicable to the local scene. The adapted classification was then applied in the analysis of registered postgraduate research topics. The rationale was that the use of an empirically based and internationally recognised classification as a foundation in the possible adaptation to national research priorities may be a constructive move towards bringing some order and legitimacy in a very blurry field.

The preliminary analysis of the articles in the SAJHE substantiated the following observations:

- The Tight categorisation is, to a large degree, applicable to South African publications on $\mathrm{HE}$, although the sub-categories do not always suit the SA emphasis and may need at least re-phrasing in some instances.

- International trends like the one on quality and audits, as recognised by Tight, were confirmed, with a decrease in interest already noticeable. The growing importance of and interest in the role and use of information communication technologies (ICTs) in HE suggests a possible new theme (that may replace the Quality theme in time).

- As can be expected, higher education transformation issues are on the forefront. Although most themes could be fitted into one of the main categories a need was recognised for an additional (SA) category in this regard. 
- The emphasis on the linking of South African HE with and responsibility towards society/communities does not fit comfortably into the Tight framework, and suggests an additional category (relating to relevant socio-cultural aspects).

In the second phase of their project, Wilkinson and Van Jaarsveldt applied the suggested expanded version of Tight in an analysis of the topics of 382 master's and doctoral studies with a clear HE focus registered at the NRF and completed in the period 2003-2008. (The expanded version comprised three additional themes relating to transformation, community links and ICTs.) The findings are displayed in Figure 17.1.

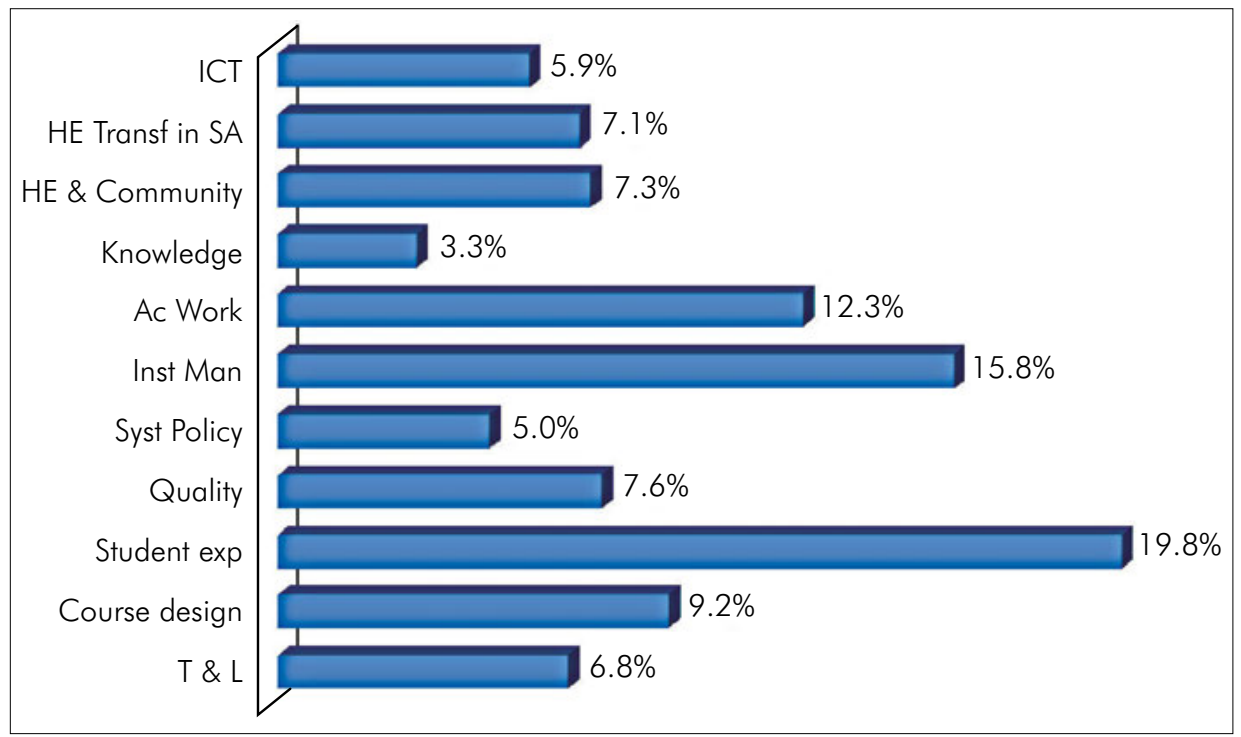

${ }^{*} \mathrm{ICT}$-Information and Communication Technology; HE Transf-Higher Education Transformation in South Africa; Ac Work - Academic work; Inst Man - Institutional Management; Syst Policy Systems and Policy; Student exp - Student experiences; T \& L ) Teaching and Learning.

FIGURE 17.1 Themes of $\mathrm{M}$ and $\mathrm{D}$ studies related to $\mathrm{HE}$ registered at the NRF and completed in 2003-2008 ( $N=382)$

A consideration of the distribution of research topics into themes shows clear correspondence with the topics and the occurrence thereof in Uys and Frick's (forthcoming) analysis, with a confirmation of some of the trends already visible in the 1990s in Muller's (1998) analysis. Student and staff matters are shown as longstanding priority research areas. The three additional categories make up about 
$20 \%$ of the research and support the argument for their inclusion as research themes. A further consideration of the representation of topic time trends in Uys and Frick's (forthcoming) analysis of also substantiates this extension, as most of the more recent trends displayed relate to topics in the two additional new (country-specific) categories. Examples are topics related to indigenous knowledge systems (IKS), HIV and AIDS, the restructuring of $\mathrm{HE}$, the contemporary/African university, academic freedom and democracy, access to higher education and wellness of academics.

All three analyses reflect the diversity of issues covered in research on HE in South Africa as well as the interdisciplinarity of the contributions. The correspondence with international themes and research priorities is very obvious, in particular when it comes to themes that transcend nationality, such as student and academic matters, teaching and learning, access, course design, institutional management and quality. The element of stability noticed here not only confirms the applicability of Teichler's four broad spheres of knowledge, but also suggests the existence of a particular body of knowledge consistently linked to the field of higher education studies - despite time span or the nature of the interdisciplinary involvement. The applicability of the Tight categorisation has also been confirmed. His classification provides flexibility with the possibility of removing outdated themes or adding themes, in particular new trends or research priorities distinctive to a particular country.

Preliminary findings have thus confirmed the need for at least two new categories. The first would focus on South African HE in transition with sub-themes related to democracy, transformation, equity, changing the higher education landscape, relevance and African involvement. The second category would relate to South African $\mathrm{HE}$ and society/community links, relationships and responsibilities, which would address community engagement issues including aspects of service learning, HIV and AIDS research related to higher education and many topics with a socio-cultural origin, including research on IKS and other cultural differences impacting on HE. It is also foreseen that the strong emphasis on quality monitoring will fade away to some extent - most likely to make way for research related to the ICTs. [This observation may not hold ground in all contexts when considering the OECD's (2008) Synthesis Report on Tertiary Education that indicates the assuring and improving of quality as one of the targeted policy directions of the future.] The suggested extension of the Tight classification at this stage would display at least two additional categories with a suggestion that ICTs may soon replace Quality in Category 4 (see list in Figure 17.2): 


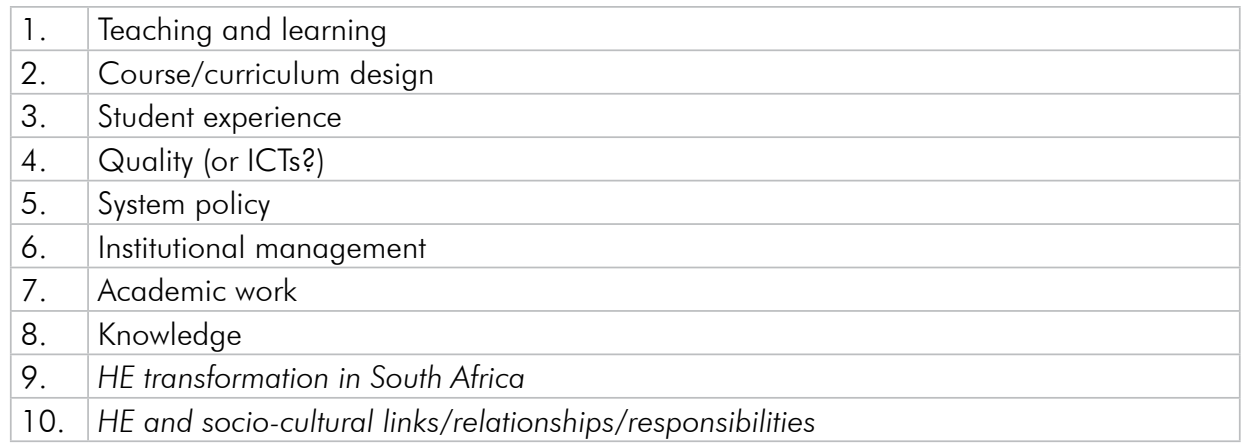

FIGURE 17.2 A South African extension of Tight's (2003) classification of themes in $\mathrm{HE}$ studies and research (the suggested additions in italics)

We also suggest that any 'explanation' of the scope and nature of higher education studies and research in a South African context can soundly be based on the four broader "spheres of knowledge" of Teichler. However, the consideration of a fifth sphere can make this framework even more applicable to the South African HE scene. Such a sphere may include socio-cultural aspects relating to trends/links/relationships impacting on $\mathrm{HE}$, but also indicating a responsibility agenda for HE (thus mostly country specific).

It must be taken into account that our suggestions are based on empirical studies and intend to place current HE studies and research trends in South Africa within an international frame; they do not indicate the gaps and obvious shortcomings in the South African HE research agenda that were also identified or attend to methodological trends. The extensions suggested here do show some correspondence with the three priority areas for debate and action identified at the 1998 UNESCO World Conference on Higher Education in the $21^{\text {st }}$ Century (the three areas comprising $\mathrm{HE}$ and development; new trends and innovations in $\mathrm{HE}$; and $\mathrm{HE}$, culture and society). When the sub-categories of these broad areas are considered, however, the gaps in the SA research agenda become even more obvious and alarming. The Overview Report on Tertiary Education by the OECD (2008) also points to challenging policy directions that urgently need study and research in all countries. This aspect needs further inquiry.

\section{CONCLUSION}

There seems to be little doubt that the studying of $\mathrm{HE}$ as a phenomenon remains important. The accusation that higher education institutions are good at studying 
everything except themselves appears to be something of the past if one considers the proliferation of studies and publications on HE during the past 10 to 15 years - in South Africa in particular after demoracy in 1994. However, there is a lack of evidence that HE studies and research in the country have reached maturity. Considering our brief review of the history and a possible map for HE studies and research in South Africa we want to make three salient points. Firstly, it seems clear that HE studies and research had an unstable and fragmented past with very few leaders and scholars who were able to take the field forward. Apparently, much of the initial research was directed at the level of policy formation and linked to the country's unstable and volatile political and social history. Much of the impetus for these studies thus originated from political changes or government initiatives to investigate the HE system at various junctures. Secondly, the emergence of institutional units for teaching, learning and academic development was instrumental in sparking new structures and programmes for HE studies and research. Their research agendas were clearly not confined to these three areas, but addressed wider issues such as governance, institutional autonomy, leadership, staff issues and theoretical underpinnings of higher education. Although the period 1960-1994 was one during which South Africa was internationally isolated, $\mathrm{HE}$ research did not stagnate and many initiatives have paid good dividends until the present day. Thirdly, one of the most productive developmental eras for HE studies and research was in the post-apartheid years when working groups, institutions, associations and non-governmental institutes such as the CHE started cooperating. While initial efforts were mainly directed at the policy and systemic level, other areas of prime interest such as student access, student throughput, quality promotion, academic freedom, the effects of internationalisation and globalisation, language and indigenisation and the nature of knowledge emerged as research topics, involving a variety of methodologies.

In terms of mapping the field, we have asked three prominent questions. The first relates to the nature of HE studies and research in South Africa. Based on our analysis of publications from at least three different exercises, it seems that the South African map possibly justifies two new broad themes or classes of research when compared to Tight's (2003) classification and at least one additional 'sphere of knowledge' of HE studies and research when related to Teichler's (2005) classification. This finding of course needs to be further investigated, particularly in terms of methodologies used and gaps in research. Our second mapping question asked about the locations and content of formal study programmes in HE in South Africa. Annexure 17.4 reveals a spectrum of qualifications and the universities that offer them in South Africa. We found 
it extremely difficult, however, to determine the exact content of these programmes as not many are published on websites or elsewhere. More research in this area will definitely be needed to determine the range and scope of these qualifications and to find out whether and in which ways they possibly relate to one another. The third question on mapping concerns the professional stability of $\mathrm{HE}$ as a field in South Africa. From the historical and publication analysis we conclude that although $\mathrm{HE}$ as a field of study is professionally better off than it was 15 or 20 years ago, it is far from stable. Therefore, for future research into South African HE studies and inquiry we suggest a number of possible priorities. One is the need to document, more accurately than is currently the case, the historical development of HE in South Africa - particularly against the background of a divided past of the country and the field. Obviously, more accounts of reality from more participants and researchers need to be recorded and critically discussed to get closer to a true representation of the development of the field. Another area of study - and linked to the third question we have put forward in our 'mapping' section of this chapter - could be to investigate ways and means by which the uncoordinated and fragmented theoretical and professional basis of the field might be strengthened. Several options exist. One might be to follow the route of the American Educational Research Association (AERA) and investigate possibilities for the creation of a strong 'division' or interest group for HE studies and research within the ambit of broad educational research. Another might be to investigate possibilities towards a more coherent, single dispensation for HE studies and research in South Africa that takes into account the important work of associations in the area of teaching and learning (HELTASA), HE inquiry more generally (SAARDHE), institutional research (SAAIR), independent investigations via private and expert personal initiatives and funding, governmetal/ministry and semi-governmental research (Department of Education, the Council on Higher Education, Higher Education South Africa) and research bodies and institutes such as the National Research Foundation and institutional research and development centres. What also needs to be accounted for is the work contributed by professional councils such as the South African Institute for Chartered Accountants (SAICA), the Engineering Council of South Africa (ECSA) and the Health Professions Council of South Africa (HPCSA).

In our evaluation of HE research in South Africa from a variety of sources we tend to agree with Tight (2004a) who found in his analysis of 406 articles in 17 prominent HE journals that theoretical perspectives of the field are very implicit and that engagement with theory is still very much absent. One implication, as suggested by Tight (2004a:411), is that researchers in the field should be encouraged to engage more 
with theory in order for the field or the community of practice to gain more credibility and respect. This view is also shared by Clegg (2007). Another implication is that HE studies and research should be recognised by all concerned as an interdisciplinary field where multiple communities of practice operate and that effective ways should be found through which researchers from different backgrounds and perspectives can be joined together.

A particular concern is that the relationship between South African studies and research in $\mathrm{HE}$ and that of the rest of Africa remains an unexplored field. Institutions such as the Centre for Higher Education Transformation (CHET) are looking into this area more closely from a comparative perspective, but as in Europe a number of years ago, African higher education is extremely diverse and many programmes of study and research in $\mathrm{HE}$ as a field are either not recorded or are non-existent. The Association for African Universities (AAU), the African Higher Education Forum (AHEF) and Leaders of Higher Education in Africa (LHEA) play major roles in facilitating debates, projects and programmes in HE studies and research, while UNESCO, the World Bank and Foundations have sponsored such research, but to date not many of these studies have been taken seriously or have been related to South African HE by scholars in the field. Other issues that probably need further investigation, particularly with regard to the present developmental phase in South Africa's history, are diversity studies, sustainable financing of $\mathrm{HE}$, the role of $\mathrm{HE}$ in a developing economy, $\mathrm{HE}$ and social responsibility, democracy in and through $\mathrm{HE}$ and the continuous quest for quality.

There are at least four related reasons why studying the field of $\mathrm{HE}$ is needed (Tight 2003). One is that HE matters much to both a country as a whole and to each citizen. It is therefore worthy of a better understanding and, where possible, of improvement. A second reason is that HE is a field of interest for most who work in it and who are concerned about it. Many aspects of $\mathrm{HE}$ are intriguing in terms of their complexity, their relatedness or their comparability to other systems or practices. This makes both small- and large-scale research projects most useful and valuable. A third reason constitutes research for credit. In some contexts (not in South Africa as yet) HE practitioners are required, as part of their initial or continuing professional training, to study aspects of improving their roles as teachers and researchers in HE institutions. In most instances this requirement involves small-scale pieces of research on HE that make valuable, contextualised contributions. The fourth reason is for publication, which has been extended from purely disciplinary publications to including publications on aspects of $\mathrm{HE}$ that locate practitioners within the debates related to their professional roles. Most of these reasons hold water for the South African context, while publishing 
research and encouraging those in HE academic and support roles to do so are all needed to theoretically enhance and professionalise the field and move beyond off the cuff, personal experiences and mere perceptions of HE as an enterprise and a field of study. It is hoped that this chapter might have added in a humble way to this pursuit.

\section{REFERENCES}

Adams CK. 1876. The relations of higher education to national prosperity. An oration delivered before the Phi Beta Kappa Society. University of Vermont: 27 June [Online]. Available: http://quod.lib.umich.edu/cgi/text [2008, 18 November].

Arndt RR. 1973. Navorsing: Beroepsvoorbereiding of beroepsafrigting? [Research: Occupational preparation or occupational training?]. Included in an in-house publication of the Rand Afrikaans University: The role of the RAU as city university.

Behr AL. 1969. University colleges for Non-Whites. Johannesburg: Institute for Race Relations. Memo No. 7/69.

Behr AL. 1970. Some aspects of education in South Africa for the seventies with special reference to our Indian community. Stanger: Unpublished address to the Stanger Branch of the South African Indian Teachers' Association.

Behr AL \& MacMillan RG. 1971. Education in South Africa. 2nd Edition. Pretoria: JL van Schaik.

Brennan J \& Teichler U. 2008. The future of higher education and of higher education research. Higher Education, 56(3):259-264.

Brennan J, Enders J, Musselin C, Teichler U \& Välimaa J. 2008. Higher education looking forward: An agenda for future research. European Science Foundation: Synthesis report of the ESF forward look on higher education in Europe beyond 2010: Resolving conflicting social and economic expectations [Online]. Available: www.esf.org/publications.

Clegg S. 2007. Extending the boundaries of research into higher education. In: Enhancing Education, Theory and Scholarship. Proceedings of the $30^{\text {th }}$ HERDSA annual conference [CD ROM]. Adelaide, Australia. 8-1 1 July.

Coetzee JC \& Van Rooy DJ. 1949. Beginsels en metodes van die hoër onderwys [Principles and methods of higher education]. Pretoria: JL van Schaik Ltd.

Council on Higher Education. 2004. South African higher education in the first decade of democracy. Pretoria: $\mathrm{CHE}$.

Dressel PL \& Mayhew LB. 1974. Higher education as a field of study. San Francisco: JosseyBass.

Esterhuyse WP. 1973. Akademiese Vryheid [Academic Freedom]. Bulletin vir Dosente [Bulletin for Lecturers], 6(1):1-5. Stellenbosch University.

Flexner A. 1930. Universities: American, English, German. London: Oxford University Press.

Fourie M \& Strydom AH. 2000. Relationships among higher education research, policy and practice in South Africa. In: S Schwarz \& U Teichler (eds). The institutional basis of higher education research. Dordrecht: Kluwer Academic. 
Fulton J. 1992. Higher Education Studies. In: C Kerr \& GR Neave (eds). The Encyclopedia of Higher Education (Section 5). Oxford: Pergamon Press. 1809-1811.

Gouws SJL. 1973. Studente-opstande in pedagogiese perspektief [Student revolt in pedagogical perspective]. Rand Afrikaans University.

Kerr C \& Neave GR (eds). 1992. The Encyclopedia of Higher Education. Vol. 2. Oxford: Pergamon Press.

Kogan M, Baver M, Bleiklie I \& Henkel M (eds). 2006. Transforming higher education: A comparative study. Series: Higher Education Dynamics. Vol. 13. 2nd Edition. Dordrecht: Springer.

Knowles AS (ed). 1977. The International Encyclopedia of Higher Education. San Francisco: Jossey-Bass Publishers.

Kraak A. 1999. Investigating new knowledge production: A South African higher education case study. Paper at the international conference: Re-organising knowledge, transforming institutions - Knowing, knowledge and the university in the twenty-first century. Amherst, University of Massachusetts. 17-19 September.

Le Grange LL. 2002. Challenges for higher education transformation in South Africa: integrating the local and the global. South African Journal of Higher Education, 16(1):67-73.

Malherbe EG. 1925. Education in South Africa (1652-1922). Cape Town: Juta

Metrowich FC. 1929. The development of higher education in South Africa: 1873-1927. Cape Town: Maskew Miller.

Muller A. 1998. Trends in research in higher education. Presentation made during a workshop presented at the University of the Orange Free State. Unpublished. Bloemfontein: UOFS/ Unit for Research into Higher Education. 11 March.

Muller J. 2000. What knowledge is of most worth for the millenial citizen? University of Cape Town: Unpublished paper.

NEPI (National Education Policy Initiative). 1992. Post-secondary education. Cape Town: Oxford University Press/NECC.

OECD (Organisation for Economic Cooperation and Development). 2008. Tertiary Education for the Knowledge Society. Thematic Review of Tertiary Education: Synthesis Report. Paris: OECD.

Pauw JR. 1969. Die Westerse Universiteit. Pretoria: Boekhandel De Jong.

Pauw JR. 1971. Eerstejaar op die kampus. Pretoria: Boekhandel De Jong.

Reyburn H. 1934. The university and university education. University of Cape Town.

Schwarz S \& Teichler U (eds). 2000. The institutional basis of higher education research. Dordrecht: Kluwer Academic.

Smart JC (ed). 1985. Higher Education: Handbook of theory and research. Volume 1. Dordrecht: Springer.

Smart JC (ed). 2008. Higher Education: Handbook of theory and research. Volume 23. Dordrecht: Springer. 
Strydom AH. 2002. Globalisation and higher education studies in South Africa. South African Journal of Higher Education, 16(1):91-98.

Teichler U. 1989. Research on higher education in Europe: Some aspects of recent developments. Unpublished paper delivered at the EAIR conference. Trier: 27-29 August.

Teichler U. 1996. Comparative higher education: potentials and pitfalls. Higher Education, 32(4):431-465.

Teichler U. 2005. Research on higher education in Europe. European Journal of Education, 40(4):447-469.

Teichler U \& Sadlak J. Higher Education Research: Its relationship to policy and practice. Issues in Higher Education Series. Paris: International Association of Universities.

Thom HB. 1965. Universiteit en maatskappy [University and society]. University of Stellenbosch.

Tight M. 2003. Researching higher education. Berkshire: Society for research into Higher Education \& Open University Press.

Tight M (ed). 2004. The Routledge-Falmer Reader in Higher Education. London: RoutledgeFalmer.

Tight M. 2004a. Research into Higher Education: An a-theoretical community of practice. Higher Education Research and Development, 23(4):395-41 1.

UNESCO (United Nations Educational Scientific and Cultural Organization). 1998. World Conference on Higher Education in the $21^{\text {st }}$ Century. WCHE Thematic debates [Online]. Available: http://portal.unesco.org/education/en/ev [2009, 5 March].

Uys JW \& Frick BL. 2009. The application of text analytical techniques to elctronic journal articles. Forthcoming.

Versveld M. 1962. Rondom die middeleeve [Around the middle ages]. Cape Town: Nasionale Boekhandel.

Wilkinson AC \& Van Jaarsveldt DE. 2009. Trends in South African higher education studies and research. Preliminary findings. Unpublished. Bloemfontein: University of the Free State/Centre for Higher education Studies and Development.

Young R. 2009. Enter the dragon? China's higher education returns to the world community: The case of Peking University. In: JC Smart (ed). Higher Education: Handbook of Theory and Research. Volume 24. Dordrecht: Springer. 


\section{ANNEXURE 17.1}

\section{ANALYTICAL PERSPECTIVES FROM THE ENCYCLOPEDIA OF HIGHER EDUCATION} (CLARK AND NEAVE 1992)

\begin{tabular}{|c|c|}
\hline \multicolumn{2}{|c|}{ Section 1: HE and society } \\
\hline \multicolumn{2}{|c|}{ Examples of topics } \\
\hline Applied research and technology transfer & Business and industry contributions to $\mathrm{HE}$ \\
\hline HE and economic development & Economics of $\mathrm{HE}$ \\
\hline HE and government & HE and local communities \\
\hline Occupational structures and $\mathrm{HE}$ & Adult participation in $\mathrm{HE}$ \\
\hline $\begin{array}{l}\text { Credentials of } \mathrm{HE} \text { and the value of } \\
\text { qualifications }\end{array}$ & International equivalence of qualifications \\
\hline Qualifications and earnings & Equality and $\mathrm{HE}$ \\
\hline HE and human resource provision & National models of HE and society \\
\hline Non-Western societies and HE & Schools and HE \\
\hline \multicolumn{2}{|c|}{ Section 2: The institutional fabric of HE } \\
\hline \multicolumn{2}{|c|}{ Examples of topics: } \\
\hline Undergraduate HE & Graduate HE \\
\hline Adult and continuing $\mathrm{HE}$ & Business schools \\
\hline Community colleges & Junior colleges \\
\hline Systems of HE (e.g. unitary/binary) & Distance HE \\
\hline Private HE & Institutes of technology \\
\hline Liberal arts colleges & Multicampus institutions \\
\hline \multicolumn{2}{|c|}{ Section 3: Governance, administration and finance } \\
\hline \multicolumn{2}{|c|}{ Examples of topics: } \\
\hline Academic freedom & Accreditation \\
\hline Student affairs & Finance \\
\hline Governance models & Leadership \\
\hline Sytems planning & Research funding \\
\hline Accountability & Academic administration \\
\hline Coordination of subsystems & Student financial aid \\
\hline Institutional autonomy & Performance indicators \\
\hline Strategic planning & Privatisation \\
\hline \multicolumn{2}{|c|}{ Section 4: Faculty and students: Teaching, learning and research } \\
\hline \multicolumn{2}{|c|}{ Examples of topics: } \\
\hline Access to $\mathrm{HE}$ & Academic labour markets \\
\hline The undergraduate and graduate curriculum & Degree structures, credit, duration and transfer \\
\hline Longterm effects of $\mathrm{HE}$ & Students: Non-traditional and minority \\
\hline Students: Third-age and part-time & Student achievement \\
\hline Student attrition and retention & Student cultures \\
\hline Student development & Student movements and associations \\
\hline Faculty and professional service & Faculty and student interaction \\
\hline Faculty cultures & Faculty recruitment, promotion and tenure \\
\hline Faculty and research & Faculty rewards and incentives \\
\hline
\end{tabular}


PART SIX • RESEARCH FRONTIERS AND AGENDAS

\begin{tabular}{|l|l|}
\hline Faculty vitality & The professoriate: History and status \\
\hline Teaching in HE & Student learning \\
\hline Learning assessment & \\
\hline \multicolumn{1}{|c|}{ Section 5: Disciplinary perspectives on HE } \\
\hline & Examples of topics \\
\hline Anthropology & Comparative education \\
\hline Economics & Higher education studies \\
\hline History & Linguistics and rhetorical studies \\
\hline Women's studies & Macrosociology \\
\hline Microsociology & Philosophy \\
\hline Policy analysis & Political economy \\
\hline Public administration & Social psychology \\
\hline
\end{tabular}




\section{ANNEXURE 17.2}

THE ESTABLISHMENT OF UNIVERSITIES IN SOUTH AFRICA (1829-1970)

\begin{tabular}{|c|c|}
\hline Year & Activity \\
\hline 1829 & $\begin{array}{l}\text { South African College is established (since } 1918 \text { officially the University of Cape } \\
\text { Town). Prepared students for degree examinations of London University. }\end{array}$ \\
\hline 1855 & $\begin{array}{l}\text { Grey College in Bloemfontein established. Since } 1935 \text { the University College of } \\
\text { the Orange Free State and in } 1950 \text { the University of the Orange Free State. }\end{array}$ \\
\hline 1855 & $\begin{array}{l}\text { St. Andrews College established in Grahamstown. Since } 1904 \text { Rhodes University } \\
\text { College and } 1951 \text { Rhodes University. }\end{array}$ \\
\hline 1866 & $\begin{array}{l}\text { Stellenbosch Gymnasium established. Since } 1881 \text { Stellenbosch College, which } \\
\text { became Victoria College in } 1887 \text { and the University of Stellenbosch in } 1918 .\end{array}$ \\
\hline 1869 & $\begin{array}{l}\text { Theological School of the Reformed Church established at Burg(h)ersdorp. } \\
\text { Transferred to Potchefstroom in } 1915 \text { and became Potchefstroom University } \\
\text { College in } 1921 \text { (under the auspices of the University of South Africa) and in } \\
1951 \text { the Potchefstroom University for Christian Higher Education. }\end{array}$ \\
\hline 1873 & $\begin{array}{l}\text { University of Cape of Good Hope became an examining university for } \\
\text { established colleges in South Africa. Ceased to exist when the University of South } \\
\text { Africa was established in 1918. }\end{array}$ \\
\hline 1874 & $\begin{array}{l}\text { The Huguenot Seminary established in Wellington, South Africa. Became the } \\
\text { Huguenot College (a university-type institution) in } 1907 \text { and ceased to exist as a } \\
\text { university-type institution in } 1950 \text {. }\end{array}$ \\
\hline 1896 & $\begin{array}{l}\text { The School of Mines established in Kimberley. Moved to Johannesburg as } \\
\text { the Transvaal Technical Institute in } 1903 \text { and became the Transvaal University } \\
\text { College in 1906, the South African School of Mines and Technology in } 1910 \\
\text { and the University of the Witwatersrand in } 1921 .\end{array}$ \\
\hline 1908 & $\begin{array}{l}\text { A branch of the Transvaal University College established in Pretoria. Became } \\
\text { independent of the SA School of Mines and Technology in } 1910 \text { and became } \\
\text { the University of Pretoria in } 1930 \text {. }\end{array}$ \\
\hline 1910 & $\begin{array}{l}\text { The University College of Natal established at Pietermaritzburg. Extended } \\
\text { to Durban in } 1922 \text {. Became the University of Natal with campuses in } \\
\text { Pietermaritzburg and Durban in } 1949 .\end{array}$ \\
\hline 1916 & $\begin{array}{l}\text { The South African Native College at Fort Hare. Became the University College } \\
\text { of Fort Hare in } 1952 \text { and affiliated with Rhodes University, Grahamstown. } \\
\text { Functioned under the auspices of the Minister of Bantu Education from } 1960 \\
\text { and became the University of Fort Hare in } 1970 .\end{array}$ \\
\hline 1918 & $\begin{array}{l}\text { The University of South Africa established. Initially only an examining authority, } \\
\text { but became a correspondence/distance university in } 1951 .\end{array}$ \\
\hline 1959 & $\begin{array}{l}\text { University College for Indians established in Durban. Became the University of } \\
\text { Durban-Westville in } 1971 .\end{array}$ \\
\hline 1959 & $\begin{array}{l}\text { University College of the North established at Turfloop (mainly for Sotho- } \\
\text { speaking blacks). Became the University of the North in } 1970 .\end{array}$ \\
\hline 1959 & $\begin{array}{l}\text { The University College of Zululand established at Ngoye. Became the University } \\
\text { of Zululand in } 1970 .\end{array}$ \\
\hline 1960 & $\begin{array}{l}\text { The University College of the Western Cape established for 'coloureds' at } \\
\text { Bellville. Became the University of the Western Cape in } 1970 .\end{array}$ \\
\hline 1965 & The University of Port Elizabeth established. \\
\hline 1967 & The Rand Afrikaans University established. \\
\hline
\end{tabular}

(Adapted from Pauw JR. 1971. Eerstejaar op die kampus [First-year student on the campus]. Pretoria: Boekhandel De Jong) 


\section{ANNEXURE 17.3}

\section{CURRENT PUBLIC UNIVERSITIES IN SOUTH AFRICA (AS IN 2009 - ALPHABETICALLY)}

\begin{tabular}{|c|c|}
\hline $\begin{array}{l}\text { Cape } \\
\text { Peninsula } \\
\text { University of } \\
\text { Technology }\end{array}$ & $\begin{array}{l}\text { Incorporating the former Cape and Peninsula technikons, the university is } \\
\text { the largest in the Western Cape, with over 25,000 students on two main } \\
\text { campuses, in Bellville and Cape Town. } \\
\text { The university's IT Centre is the largest of its kind in Africa, housing 1,400 } \\
\text { computers, various laboratories, a state-of-the-art video conference room } \\
\text { and lecture theatre, and two e-business rooms. }\end{array}$ \\
\hline $\begin{array}{l}\text { Central } \\
\text { University of } \\
\text { Technology }\end{array}$ & $\begin{array}{l}\text { Incorporates the former Technikon Free State and Vista University (Welkom } \\
\text { campus). Although the language of instruction is English, the university plans } \\
\text { to offer parallel instruction in Afrikaans and Sesotho. Over } 100 \text { courses } \\
\text { are offered in three faculties: management; engineering, information and } \\
\text { communication sciences; and health and environmental sciences. } \\
\text { The university is based in Bloemfontein and has a number of centres that } \\
\text { can provide research and other technological services to private companies, } \\
\text { particularly smaller businesses. This fits in with the university's vision of } \\
\text { engaging with its community and providing its students with opportunities for } \\
\text { experiential learning. }\end{array}$ \\
\hline $\begin{array}{l}\text { Durban } \\
\text { University of } \\
\text { Technology }\end{array}$ & $\begin{array}{l}\text { Incorporates the former ML Sultan, Natal and Mangosuthu technikons, as } \\
\text { well as the former University of Zululand (Umlazi campus). The university } \\
\text { has major campuses in Durban and Pietermaritzburg as well as satellite } \\
\text { campuses in Umlazi. }\end{array}$ \\
\hline $\begin{array}{l}\text { Mangosuthu } \\
\text { Technikon }\end{array}$ & $\begin{array}{l}\text { Mangosuthu Technikon is a modern higher education institution offering } \\
\text { superior quality, technologically advanced programmes and services in } \\
\text { engineering, natural sciences and management sciences to almost 10,000 } \\
\text { students. }\end{array}$ \\
\hline $\begin{array}{l}\text { Nelson } \\
\text { Mandela } \\
\text { Metropolitan } \\
\text { University }\end{array}$ & $\begin{array}{l}\text { Incorporates the former PE Technikon, University of Port Elizabeth and Vista } \\
\text { University (Port Elizabeth campus). The university has more than } 20,000 \\
\text { students and about 2,000 staff members spread across eight campuses in } \\
\text { the Port Elizabeth in the Eastern Cape and George in the Western Cape. }\end{array}$ \\
\hline $\begin{array}{l}\text { North-West } \\
\text { University }\end{array}$ & $\begin{array}{l}\text { North-West University has more than } 45,000 \text { students spread over four } \\
\text { campuses, offers parallel instruction in Afrikaans, English and Setswana, and } \\
\text { is experimenting with simultaneous instruction on its Potchefstroom campus. }\end{array}$ \\
\hline $\begin{array}{l}\text { Rhodes } \\
\text { University }\end{array}$ & $\begin{array}{l}\text { Situated in the Eastern Cape town of Grahamstown, Rhodes University } \\
\text { has a } 100 \text {-year history of academic excellence. Perhaps best known for its } \\
\text { journalism department, Rhodes has around } 500 \text { academic staff and 7,000 } \\
\text { students. }\end{array}$ \\
\hline $\begin{array}{l}\text { Stellenbosch } \\
\text { University }\end{array}$ & $\begin{array}{l}\text { Situated in the wine-growing region of Stellenbosch, } 60 \mathrm{~km} \text { from Cape Town, } \\
\text { Stellenbosch University is one of South Africa's leading research institutions. } \\
\text { The university's Centre for Invasion Biology, a Department of Science and } \\
\text { Technology centre of excellence, studies the impact of invasive plant species } \\
\text { on southern Africa's agriculture, biodiversity and ecotourism. } \\
\text { The university has four campuses: the main campus at Stellenbosch, the } \\
\text { health sciences faculty at Tygerberg Hospital, the business school in Bellville, } \\
\text { and military sciences faculty in Saldanha. }\end{array}$ \\
\hline
\end{tabular}




\begin{tabular}{|c|c|}
\hline $\begin{array}{l}\text { Tshwane } \\
\text { University of } \\
\text { Technology }\end{array}$ & $\begin{array}{l}\text { Incorporating the former Northern Gauteng, North-West and Pretoria } \\
\text { technikons, the university offers over } 180 \text { programmes, some of these unique } \\
\text { to the institution, such as sport and exercise technology, equine studies, } \\
\text { medical orthotics and prosthetics, and environmental management. } \\
\text { The university offers masters and doctoral programmes in addition to } \\
\text { degrees, certificates and diplomas, and boasts more postgraduate students } \\
\text { than any other South African university of technology. }\end{array}$ \\
\hline $\begin{array}{l}\text { University of } \\
\text { Cape Town }\end{array}$ & $\begin{array}{l}\text { South Africa's oldest university, founded in 1829, has one of the most } \\
\text { picturesque campuses in the world, situated on the slopes of Table } \\
\text { Mountain's Devil's Peak and overlooking Rondebosch in Cape Town. } \\
\text { The university is regarded as one of the top research institutions on the } \\
\text { continent, with more "A"-rated scientists than any other South African } \\
\text { university. According to National Research Foundation criteria, " } \mathrm{A} \text { "-rated } \\
\text { scientists are "leading international scholars in their field [known] for the high } \\
\text { quality and impact of their recent research outputs". } \\
\text { The university is home to Groote Schuur Hospital, where the world's first } \\
\text { heart transplant took place in } 1967 \text {. }\end{array}$ \\
\hline $\begin{array}{l}\text { University of } \\
\text { Fort Hare }\end{array}$ & $\begin{array}{l}\text { Fort Hare, dating back to 1916, is the oldest historically black university in } \\
\text { the country. It has been the academic home of many of South Africa's most } \\
\text { prominent leaders, including Nelson Mandela, Oliver Tambo, Govan Mbeki, } \\
\text { and Mangosuthu Buthelezi. In 2005, the university was awarded the Order } \\
\text { of the Baobab - SA's highest civilian honour - for its contribution to the } \\
\text { country's leadership. } \\
\text { Fort Hare has three Eastern Cape campuses, in Alice, Bisho and East } \\
\text { London. The university offers a range of degrees and diplomas in its faculties } \\
\text { of education, science and agriculture, social sciences and humanities, } \\
\text { management and commerce, and at the Nelson Mandela School of Law. }\end{array}$ \\
\hline $\begin{array}{l}\text { University of } \\
\text { Johannesburg }\end{array}$ & $\begin{array}{l}\text { Incorporating the former Rand Afrikaans University, Technikon Witwatersrand } \\
\text { and Vista University (Johannesburg campuses), the university offers both } \\
\text { technical and academic programmes for around } 45,000 \text { students. The } \\
\text { university has built a new School of Travel and Tourism on its Auckland Park } \\
\text { campus, at a cost of about R70 million. }\end{array}$ \\
\hline $\begin{array}{l}\text { University } \\
\text { of KwaZulu- } \\
\text { Natal }\end{array}$ & $\begin{array}{l}\text { Incorporating the former Durban-Westville and Natal universities, the } \\
\text { university covers five campuses in Durban and Pietermaritzburg. }\end{array}$ \\
\hline $\begin{array}{l}\text { University of } \\
\text { Limpopo }\end{array}$ & $\begin{array}{l}\text { Formerly the University of the North, which was home to many prominent } \\
\text { anti-apartheid activists of the 1970s and ' } 80 \text { s. Situated in South Africa's } \\
\text { northern Limpopo province, the university provides training in three faculties: } \\
\text { humanities; management sciences and law; and sciences, health and } \\
\text { agriculture. }\end{array}$ \\
\hline $\begin{array}{l}\text { University of } \\
\text { Pretoria }\end{array}$ & $\begin{array}{l}\text { Officially established in } 1930 \text { - but with roots stretching back to the founding } \\
\text { of the Normal College for teacher training in } 1902 \text { - the university is one } \\
\text { of South Africa's largest, with almost } 40,000 \text { students, including over } 2,000 \\
\text { international students from } 60 \text { countries. The university's Gordon Institute } \\
\text { of Business Science, established in Johannesburg in } 2000 \text {, has already } \\
\text { earned an international reputation, while its faculty of veterinary science at } \\
\text { Onderstepoort is the only one of its kind in South Africa. }\end{array}$ \\
\hline $\begin{array}{l}\text { University of } \\
\text { South Africa }\end{array}$ & $\begin{array}{l}\text { Incorporating the former Unisa, Technikon SA and Vista University (distance } \\
\text { education), the Pretoria-based University of South Africa offers distance } \\
\text { education programmes - both academic and technical - to students across } \\
\text { the country and the region. The university's Centre for African Renaissance } \\
\text { Study is an interdisciplinary research institution with a mandate to develop } \\
\text { outward to the whole of Africa and diasporic Africa. }\end{array}$ \\
\hline
\end{tabular}


University of

the Free State

University of

the Western

Cape

University

of the

Witwatersrand

University of

Venda

University of Zululand

Vaal University

of Technology

Walter Sisulu

University
Established in 1904, the university is home to around 20,000 students, 16,000 on the main Bloemfontein campus and 3,000 enrolled in the university's distance and internet learning programmes.

Originally established in 1959 as an ethnic college for "coloured" students, the university has grown into an internationally recognised institution, providing facilities for over 12,000 students across 68 departments and 16 institutes, schools and research centres.

Situated in Johannesburg, Wits University is one of the country's leading research institutions. A cosmopolitan campus close to the city centre, Wits attracts a large number of students from across Africa. Since full university status was granted in 1922, Wits has produced more than 100,000 graduates across a range of disciplines.

The university offers degrees in the faculties of engineering and the built environment, humanities, health sciences, science and commerce.

Wits hosts the Department of Science and Technology's Centre of Excellence in Strong Materials, the Wits Institute for Social and Economic Research, and the Wits Business School.

The University of Venda for Science and Technology, situated in

Thohoyandou in Limpopo, offers career-focussed programmes in the fields of health, agriculture and rural development; humanities, management sciences and law; and natural and applied sciences.

Based in KwaDlangezwa, the university positions itself as the leading local, rurally based comprehensive institution offering career-focused undergraduate and postgraduate education, including wide ranging research opportunities.

The university has around 15,000 students spread across its main campus in Vanderbiilpark, $60 \mathrm{~km}$ southwest of Johannesburg, and four satellite campuses, which include the Sebokeng campus of the former Vista University.

Incorporating the former Border and Eastern Cape technikons and the University of the Transkei, the university has around 20,000 students spread across its campuses in East London, Butterworth, Queenstown and Mthatha. The university offers a range of degrees, certificates and diplomas in 11 faculties, and hosts an MBChB programme in Mthatha.

(Source: http://www.southafrica.info/about/education/universities.htm) 
ANNEXURE 17.4

SOUTH AFRICAN UNIVERSITIES THAT OFFER FORMAL POSTGRADUATE PROGRAMMES IN HE STUDIES AND THE TYPE OF PROGRAMMES ON OFFER (AS IN 2009)

\begin{tabular}{|c|c|c|}
\hline INSTITUTION & PROGRAMMES OFFERED & DESIGNATED FACULTY \\
\hline \multirow{3}{*}{$\begin{array}{l}\text { Nelson Mandela } \\
\text { Metropolitan } \\
\text { University }\end{array}$} & Postgraduate Certificate in HE & Faculty of Education \\
\hline & MEd & Faculty of Education \\
\hline & $\mathrm{PhD}$ & Faculty of Education \\
\hline \multirow{2}{*}{ UNISA } & $\begin{array}{l}\text { Postgraduate Diploma in Tertiary } \\
\text { Education }\end{array}$ & College of Human Sciences \\
\hline & $\begin{array}{l}\text { Master of Education with } \\
\text { specialisation in Adult Education }\end{array}$ & College of Human Sciences \\
\hline $\begin{array}{l}\text { Tshwane University } \\
\text { of Technology }\end{array}$ & $\begin{array}{l}\text { Higher Diploma in Higher } \\
\text { Education and Training }\end{array}$ & $\begin{array}{l}\text { Faculty of Humanities: Department } \\
\text { of Educational Studies }\end{array}$ \\
\hline $\begin{array}{l}\text { University of Fort } \\
\text { Hare }\end{array}$ & $\begin{array}{l}\text { Postgraduate Diploma in Higher } \\
\text { Education and Training (PGDHET) }\end{array}$ & $\begin{array}{l}\text { Faculty of Education: School of } \\
\text { Postgraduate Studies }\end{array}$ \\
\hline $\begin{array}{l}\text { Cape Peninsula } \\
\text { University of } \\
\text { Technology }\end{array}$ & $\begin{array}{l}\text { Higher Diploma in Higher } \\
\text { Education and Training }\end{array}$ & $\begin{array}{l}\text { Faculty of Education and Social } \\
\text { Sciences }\end{array}$ \\
\hline $\begin{array}{l}\text { University of } \\
\text { Pretoria }\end{array}$ & $\begin{array}{l}\text { Postgraduate Certificate in Higher } \\
\text { Education(PGCHE) }\end{array}$ & Faculty of Education \\
\hline \multirow{2}{*}{$\begin{array}{l}\text { University of the } \\
\text { Witwatersrand }\end{array}$} & $\begin{array}{l}\text { Certificate Programme in Higher } \\
\text { Education Management }\end{array}$ & $\begin{array}{l}\text { Graduate School of Public and } \\
\text { Development Management }\end{array}$ \\
\hline & $\begin{array}{l}\text { Master of Education in Tertiary } \\
\text { Teaching }\end{array}$ & $\begin{array}{l}\text { Faculty of Humanities: School of } \\
\text { Education }\end{array}$ \\
\hline \multirow{2}{*}{$\begin{array}{l}\text { University of } \\
\text { KwaZulu-Natal }\end{array}$} & $\begin{array}{l}\text { Postgraduate Diploma in Higher } \\
\text { Education }\end{array}$ & $\begin{array}{l}\text { Faculty of Education: School of Adult } \\
\text { and HE } \\
\text { Centre for HE Studies }\end{array}$ \\
\hline & Master's in Higher Education & $\begin{array}{l}\text { Faculty of Education: School of Adult } \\
\text { and HE } \\
\text { Centre for HE Studies }\end{array}$ \\
\hline \multirow{2}{*}{$\begin{array}{l}\text { University of Cape } \\
\text { Town }\end{array}$} & $\begin{array}{l}\text { Postgraduate Diploma in } \\
\text { Education }\end{array}$ & $\begin{array}{l}\text { Centre for Higher Education } \\
\text { Development }\end{array}$ \\
\hline & Master's in Education (ICT) & $\begin{array}{l}\text { Centre for Higher Education } \\
\text { Development }\end{array}$ \\
\hline \multirow{3}{*}{$\begin{array}{l}\text { Stellenbosch } \\
\text { University }\end{array}$} & MPhil in Higher Education & Faculty of Education \\
\hline & $\mathrm{PhD}$ & Faculty of Education \\
\hline & MPhil (Health Sciences Education) & Faculty of Health Sciences \\
\hline $\begin{array}{l}\text { University of the } \\
\text { Western Cape }\end{array}$ & $\begin{array}{l}\text { MEd in Higher Education - } \\
\text { Policy Analysis, Leadership and } \\
\text { Management }\end{array}$ & Faculty of Education \\
\hline \multirow{2}{*}{$\begin{array}{l}\text { University of } \\
\text { Johannesburg }\end{array}$} & MEd in Higher Education & Faculty of Education \\
\hline & $\mathrm{PhD}$ in Higher Education & Faculty of Education \\
\hline
\end{tabular}




\begin{tabular}{c|l|l|}
\multicolumn{1}{c|}{ INSTITUTION } & \multicolumn{1}{|c|}{ PROGRAMMES OFFERED } & \multicolumn{1}{|c|}{ DESIGNATED FACULTY } \\
\hline \multirow{3}{*}{ Rhodes University } & $\begin{array}{l}\text { Postgraduate Diploma in Higher } \\
\text { Education }\end{array}$ & $\begin{array}{l}\text { Centre of Higher Education } \\
\text { Research, Teaching and Learning }\end{array}$ \\
$\begin{array}{l}\text { Master's in Education (Higher } \\
\text { Education) } \\
\text { PhD }\end{array}$ & Faculty of Education \\
\hline \multirow{2}{*}{$\begin{array}{l}\text { University of the } \\
\text { Free State }\end{array}$} & $\begin{array}{l}\text { Advanced Diploma in Higher (or } \\
\text { Further) Education }\end{array}$ & $\begin{array}{l}\text { Centre for Higher Education Studies } \\
\text { and Development (Faculty of } \\
\text { Humanities) }\end{array}$ \\
\cline { 2 - 3 } $\begin{array}{ll}\text { MA (Higher Education Studies) } \\
\text { PhD (Higher Education Studies) }\end{array}$ & $\begin{array}{l}\text { Master's (Health Professions } \\
\text { Education) } \\
\text { PhD (Health Professions } \\
\text { Education) }\end{array}$ & Faculty of Health Sciences \\
\hline
\end{tabular}

(Compiled by Nalize Marais, Centre for Higher Education Studies and Development, University of the Free State) 


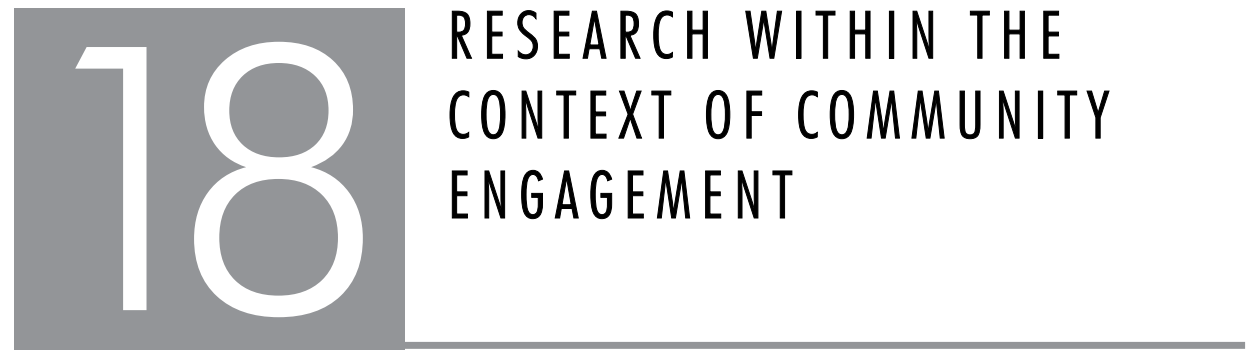

\section{Ruth Albertyn \& Priscilla Daniels}

\section{ABSTRACT}

Community engagement is a concept with a complexity of meanings, approaches and application. Derived from the scholarship of engagement of Boyer, community engagement reflects a commitment to relevance within the context of higher education institutions. The chapter aims to explore the issues that emerge in the continuing debate around engagement with communities. This is done from the perspective of the global era that impacts on knowledge production which is integral to the mission of community engagement. The South African response to engagement also reflects conflicting interpretations and imperatives that influence the application of community engagement in universities. The dichotomies in the conceptualisations of community engagement influence higher educational institutions on three levels: that of management, the academics in their teaching and learning, and the community. The concepts of knowledge and power have implications for all three levels of engagement. These will all impact on efficacy and sustainability of engagement efforts. The issues and challenges on these levels are highlighted for further debate. Possible avenues for research on the level of management, the academic and the community are suggested.

\section{INTRODUCTION}

In a continually changing context, higher education institutions (HEls) are required to equip graduates by putting processes into place to facilitate the production of knowledge and development of skills needed to live in a diverse society. HEls are also required to enable students to make responsible informed decisions, and to work collaboratively with the view of contributing to social transformation. This challenges 
modes of teaching and learning, research and community engagement, and calls for radical changes in higher education institutions regarding developing new institutional cultures.

Globalisation is at the core of a discussion on the context of community engagement (CE) within higher education. Social responsiveness and accountability are not only moral imperatives, but also fundamental elements of the knowledge society and Mode 2 knowledge production. The latter refers to knowledge created in broader transdisciplinary, social and economic contexts - that occurs within contexts of application and involves greater involvement with local communities and governments (Gibbons, Limoges, Nowotny, Schwartzman, Scott and Trow 1994). This has implications for institutions in policy formulation and for academics in their conscious mission regarding their scholarship in higher education. Implications of globalisation for development, specifically within the politico-historical African/South African context, increase the urgency of being responsive to communities where HEls are situated. Developing nations have added pressure of dealing with global changes whilst struggling with difficulties arising from inadequate responses to old persisting challenges (Maruatona 2007; Papoutsaki and Rooney 2006).

In this chapter, several concepts are discussed. They have various interpretations at different higher education institutions addressing social responsiveness of HEls. The Higher Education Quality Committee (HEQC) defines CE as "initiatives and processes through which the expertise of the higher education institution in the areas of teaching and research are applied to address issues relevant to its community. Community engagement typically finds expression in a variety of forms, ranging from informal and relatively unstructured activities to formal and structured academic programmes" (HEQC 2006:12). While there are debates around the interpretation of community engagement, we accept the HEQC definition as it represents the framework against which HEls are audited. CE is therefore a vehicle to fulfil the outreach role of academics and Boyer's scholarship of engagement (1990, 1997). However, academics most often neglect this aspect when they are faced with the pressures of multiple roles. This may partly be due to the research role having high prestige and recognition within the academic environment (Bitzer 2006; Boyer 1997). Universities have different missions, cultures, histories and community contexts that require consideration. The reality is that we need to infuse CE in the teaching, learning and research institutional cultures of higher education institutions in South Africa to facilitate the manner in which institutions decide to embrace CE. The ways of integrating the three roles of academics proposed by Waghid (2002) could play a role in ensuring a symbiotic relationship between the 
university and the context where it is situated. This symbiosis should be acknowledged, maintained and nurtured to ensure the relevance, stature and sustainability of HEls in South Africa.

Within the South African higher education landscape this relevance imperative is acknowledged and policies ${ }^{25}$ are in place for implementation. However, the reality suggests that implementation is problematic on various levels. In this chapter, related CE challenges and issues for management, the teaching and learning environment, and the community within HEls are identified. The implications for research are also highlighted.

Figure 18.1 is a synthesis of the literature. It provides a representation of how research is informed by various institutional cultures at higher education institutions within a South African context on which they impact by their existence in the global reality.

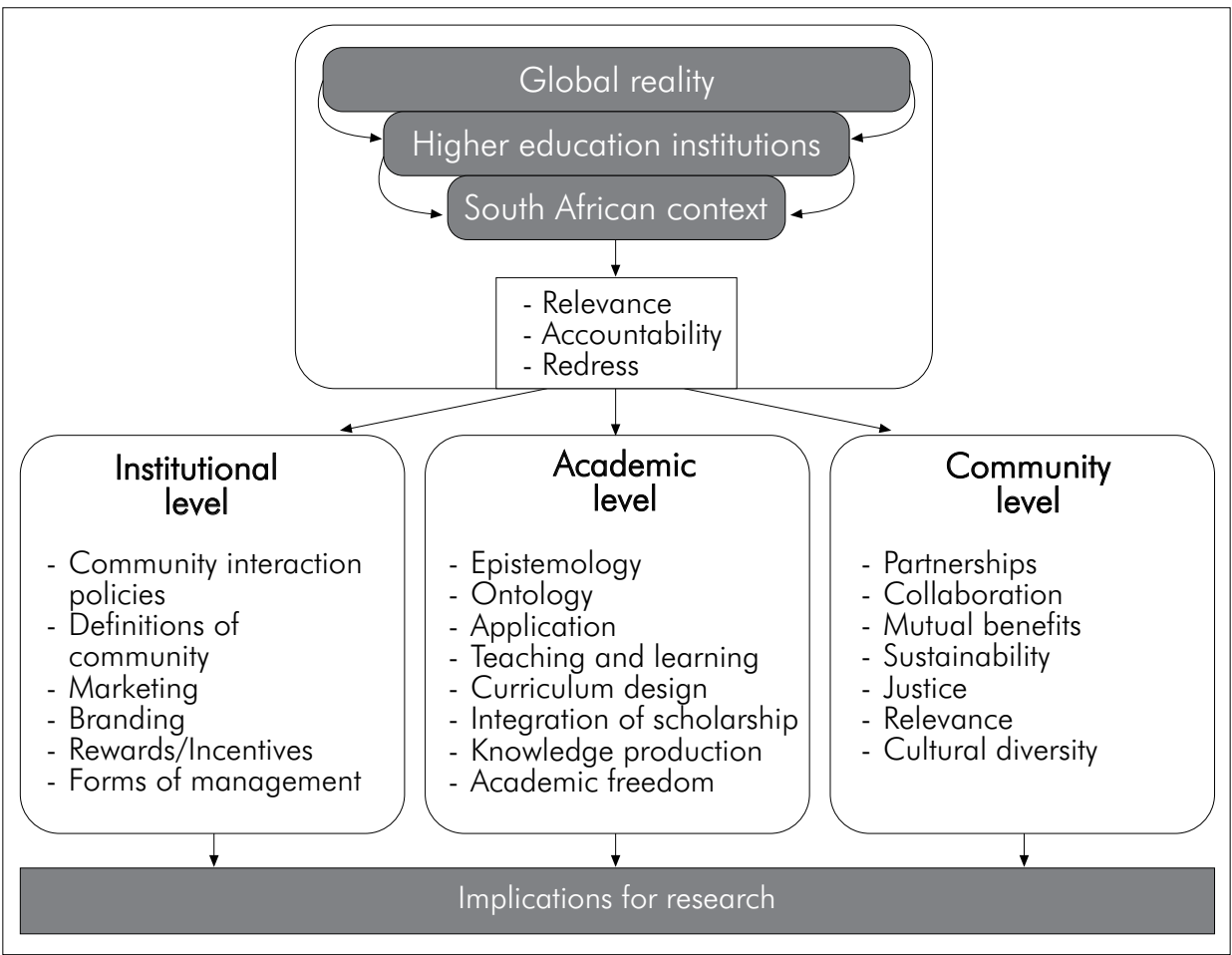

FIGURE 18.1 Issues related to community engagement

25 Green Paper on Higher Education Transformation 2 (DoE 1996); Education White Paper 3: A Programme for Higher Education Transformation (1997); Higher Education Act (1997) Founding Document of the HEQC (2001). 


\section{ROLE OF UNIVERSITIES}

In an era of globalisation and universal change, transitions impact on HEls. Le Grange (2005) comments on two sets of pressures, namely intrinsic pressures related to epistemological challenges, and external pressures related to the rapid pace and dissemination of information and 'commodification' ${ }^{26}$ of knowledge. This 'push' and 'pull' appears to be a theme that runs through any discussion on CE within HEls in the global era and impacts in various ways. It relates to the South African context and the need for transformation versus the pressures of global competitiveness. It is evident in opposing pressures in the two different modes of knowledge production practised on a micro-level. It is found at the level of discussion regarding academic freedom versus responsiveness to the context of the university and it lies at the heart of issues of the structure of knowledge, power discourses and the definitions of communities (Hall 2008; Henkel 2007; Sall, Lebeau and Kassimir 2003). Given the contexts of HEls in addressing social responsiveness, $C E$ is often perceived as 'unsafe' terrain as it has not really been linked to teaching and learning and research in an academic framework. In a presentation by Gibbons at the 2006 Council for Higher Education conference, he identifies a metaphor called 'agora' that proposes a public space where "science and the public meet" to provide the opportunity for production of "socially robust knowledge" (CHE 2007:24). The issue of knowledge production is a key concern in higher education.

Various authors have discussed the changes in the current reality of the global context. These changes are related to economic implications, as well as to the epistemological changes reflected by the so-called Mode 1 and Mode 2 knowledge production (Gibbons et al. 1994; Bloland 2005; Pearson 2005; Hazelkorn 2004; Kraak 2004). They fundamentally influence the core business of the HEls. The implications for HEls relate to multi- and transdisciplinarity, socially distributed knowledge, dispersion of knowledge production sites, implosion of disciplinary boundaries, applied lifelong learning, and the need for knowledge workers who are highly skilled and productive to provide the competitive advantage to the economy (Aitchison 2004; Bloland 2005; Imenda 2005; Sall et al. 2003). Jonathan (2001) refers to this as an ethos of individual competition and the reproduction of social advantage in HEls.

The moral imperative of HEls provides a look at the other side of the coin. This social transformative aspect in response to changes in the political arena in South Africa

26 This is in line with the current demand for graduates who can perform and contribute to the knowledge economy characteristic of the globalised era (McAlpine and Norton 2006). 
has been noted (Andreasson 2006; Horsthemke 2004; Kraak 2004; Jansen 2002; Waghid 2002; Gultig 2000). HEls should be the vital centres of a nation's work, and science should be of practical service to the nation where there is active respect for the concerns and challenges faced by society. Confidence in HEls grows as academics serve a greater purpose and participate in building a more just society (Mseleku 2004; Boyer 1997). Daniels (2007) believes that the success of education in attaining a civil society lies in preparing the higher education student to function in an ever-changing world.

The role of CE expected of academics is seen as being in line with Boyer's scholarship of application. The varying terms, definitions, interpretations and approaches to CE have caused much debate (Hall 2008). Often definitions of community within the South African context have been limiting and prescriptive. This is especially true of those that focus on service. Consequently, certain disciplines have been excluded, as their field does not lend itself to these limiting definitions of community. Service learning, an integrative strategy that has a theoretical base and a methodology for applying engagement, could be seen as one approach to interacting with the community. The broad definition of scholarship of engagement (application), however, entails the application of disciplinary knowledge and skill to address important societal problems (Braxton 2005). Boyer (1997:92) explains that

[t] he scholarship of engagement means connecting the rich resources of the university to our most pressing social, civic and ethical problems ... [lt] also means creating a special climate in which academic and civic cultures communicate more continuously and more creatively with each other, helping to enlarge ... the universe of human discourse and enriching the quality of life for all of us.

Boyer proposes that research should contribute to push back frontiers of human knowledge (discovery), to place discoveries within a larger context and create more interdisciplinary conversations (integration), to keep the flame of scholarships alive and avoid discontinuity (dissemination), to apply knowledge to avoid irrelevance and be more vigorously engaged in matters of the day (application). The integration of various scholarships therefore seems crucial to the professional development of academics.

\section{SOUTH AFRICAN HIGHER EDUCATION CONTEXT}

Where knowledge and information are key areas embodying development, the challenge for HEls in South Africa is to "produce knowledge through research and teaching and learning programmes" (HESA 2007:15). In most countries, governments as major 
funders of higher education have a vested interest in the quality of higher education processes and products (Brennan and Shah 2000). Cloete and Muller (1998:532) explain that "[i]n the case of South Africa, this context is that of a developing and modernising African country in a period of transition from racial discrimination and oppression towards a democratic polity with constitutional provisions for social justice and equal opportunity".

The South African democratisation process has been underpinned by various political and economic reforms providing guidelines for transformation. The Reconstruction and Development Plan (ANC 1994) provided a framework to redress the past imbalances. The document also highlighted the need for transformation through partnership, community development and collaboration between communities, services (both governmental and non-governmental), the private sector and higher education institutions. In its 2007 document, Higher Education South Africa maintains that "[c]arefully conceptualised and planned, such engagement can create and advance economic, social and cultural opportunities and development respectively" (HESA 2007:18). In order to develop sustainable communities and overcome complex social problems, collaborative solutions need to be facilitated by equal partnerships between role-players. In this way assets, strengths and capacities will be enhanced.

Reddy (2004:38) points out that community engagement aspects are embedded in South African policy documents such as the Green Paper on Higher Education Transformation of 1996 and the White Paper on Higher Education of 1997, which emphasised the following goals:

... social responsibility and awareness amongst students of the role of higher education in social and economic development through community service programmes; producing skilled graduates competent in critical, analytical and communication skills to deal with change, diversity and tolerance to opposing views.

The Department of Education's National Plan for Higher Education (2001), the Founding Document (HEQC 2001) of the Higher Education Quality Committee (HEQC) of the Council on Higher Education (CHE), the Criteria for Institutional Audits (HEQC 2004a) and the Criteria for Programme Accreditation (HEQC 2004b) also outlined CE and linked it to issues of quality assurance. The Founding Document (HEQC 2001) identified "knowledge-based community service" as one of the three areas - along with teaching and learning, and research - for the accreditation and quality assurance of higher education. This highlights the shift in the kind of knowledge 
which is needed in society. Muller and Subotsky (2001:167) affirm that higher HEls "will have to adjust from being adept producers of (mainly disciplinary) knowledge to being creative reconfigurers of knowledge in solving increasingly complex problems".

According to Asmal (2002), the process of contextualised engagement for HEls in a knowledge-driven world encompasses the following three aspects:

- The development of human resources: human talent and potential need to be mobilised to contribute to life in a rapidly changing society;

- High-level skills training: training and provision of person power to strengthen the country's enterprises, service and infrastructure. This requires the development of workers with skills, who are socially responsible and conscious of their role in national development;

- Production acquisition and application of new knowledge: continuous technological improvement and innovation for national growth and competitiveness driven by vibrant research and development systems, integrating the research and training capacity of higher education with the needs of industry and of social reconstruction.

In the policy framework for higher education, the National Commission on Higher Education (NCHE 1996) identified three vital principles: increased participation, greater responsiveness and increased cooperation and partnerships. Greater responsiveness would require new forms of management and assessment of knowledge production, dissemination and curricula. It was hoped that this would result in a more dynamic interaction between higher education and society, which would promote development and accountability.

\section{IMPLICATIONS FOR HIGHER EDUCATION INSTITUTIONS}

In view of the growing pressure for greater corporate accountability, neither public nor private institutions can afford to ignore the imperative to act responsibly towards their stakeholders. Since global realities are forcing HEls to reconsider their paradigms, new arenas are opening up for debate and research. Another 'push/pull' within a discussion on CE refers to contrasting pressures of engagement for relevance (internal or moral imperative) and for accountability (external), which relates to social corporate responsibility. This is the 'agora' Gibbons (2007) refers to where societal and scientific problems are debated and solutions negotiated. Knowledge is seen as a public and private good, the key to economic advance and social inclusion (Henkel 2007). Hall 
(2008) indicates that CE can be seen as a key public good in the 'third sector', filling the space between the private sector, on the one hand, and the role of the state in providing infrastructure and social transfers on the other. These opposing factors will influence practice on various levels.

\section{Institutional level}

Universities should play a role in defining the development agenda rather than responding to short-term demands by governments. They may thus help to maintain accountability while providing a source of debate on current directions and visions of future society (Sall et al. 2003). There needs to be mobilisation of awareness and consciousness that not only coincide with national goals, but are also a constructive criticism of them (Singh 2005).

Universities present a mirror image of the society where they are located (Sall et al. 2003). A survey of policies and practices has shown that although South African HEls referred to community service in their mission, there was little indication of whether this was included in their policy or strategic planning processes (Perold 1998:46). It is thus a clear mandate to universities to become relevant and focus on the needs of the communities it serves and to develop students with commitment to service in communities. Boyte (1998:32) contends that "to address the crisis in democracy from the vantage of higher education will require that we recast the work of our institutions as public work. This will mean that we re-examine our scholarship and the nature of our disciplines, our reward systems, our purposes and our institutional practices." HEls need to reflect on their view and concretisation of the scholarship of engagement. These relate to the mobilisation of the development of human resources as well as of knowledge and professional skills, and the production, acquisition and application of new knowledge. The process of initiating discussion and debate on the issue of CE in South Africa can be led by Hall's (2008) paper on CE and could provide the catalyst to stimulate this debate.

No single strategy can bring about academic renewal. The scholarship of engagement as indicated by Boyer should therefore present an opportunity to participate in thoughtful reflection on practice, provide a framework for this introspection, present a set of guidelines for implementation with regard to the production of knowledge, and apply assessment through peer review and channels of communication and publication (Holland and Ramalay 2008). Holland and Ramalay (2008) propose various strategies, namely planning, leadership, engagement strategies, accountability 
frameworks and more institutions taking routine, strategic or transformative approaches to the engagement process. The means of ensuring this process includes situating CE within academic disciplines and interdisciplinary programmes, providing incentives (monetary and staff development opportunities) in order for academics to engage in CE, and linking the research outputs of CE activities with staff reward structures (Smith 2008). This implies that the university needs to develop the infrastructure which seeks to align CE into the existing core functions through the infusion into policies or through the development of policy. For higher education institutions to incorporate a scholarship of engagement as proposed by Boyer would imply that institutions seek to align existing practices to include the central tenets proposed by his model and that CE either becomes infused into the existing practices or become a separate but distinct core function of the institution.

For effective implementation there need to be theoretical underpinnings to lead action in CE. Mapesela, Leboena and Setenane (2005) warn against action pursued without a conscious mission. The lack of a theoretical framework within the field of CE needs to be addressed for academics to see its value. However, Barnett (2004) states that in the era of super-complexity, there are too many frameworks of meaning to understand what they mean and how they relate to each other. Thus managing risk and uncertainty become a major task in higher education. According to Bloland (2005), traditional modernist rational approaches should still be used to solve problems, but frameworks of meaning and new meta-narratives need to be developed, examined and argued. There should thus not be a notion of a unified purpose of universities, but plurality of departments, ideas and debate should be recognised as the basis for developing news skills and ideas. The various types of HEls (traditional universities, universities of technology and merged institutions) with their specific characteristics and foci have an impact on the accomplishment of the mission of CE and this should be borne in mind in terms of the application of the policies. Singh (2003) suggests that one must guard against narrow understandings of engagement and that universities and their contexts should negotiate the terms of engagement. Guidelines for good practice may thus be more appropriate than policy imperatives. The definition of community should also be flexible and open to interpretation based on the discipline and context in question.

In the quest for relevance and true development, policies may have the effect of being disciplinary rather than empowering in intent and could as such work against development (Andreasson 2006; Vambe 2005). Community engagement should also not just be window dressing. Policies should be in place for ethical practice with empowering intent and reciprocal benefits. On the other hand, the importance of 
corporate social responsibility within organisational environments has become a fait accompli and is a vital part of the competitive advantage that one organisation has over another. The practice of engagement has thus become a strategic imperative. Weerts and Sandman (2008) found that HEls who succeeded in their CE strategy were those who incorporated the engagement imperative in the corporate branding of the university.

This form of scholarly undertaking creates opportunities for academics to engage in academically relevant work that aligns itself with institutional mission and vision and community needs. In this way, HEls adhere to national policies through engagement activities responsive to development challenges. It also gives institutions intellectual visibility and credibility as HEls engage proactively with society at an intellectual and cultural level.

\section{Academic level}

The scholarship of engagement is often seen in isolation and is rarely linked explicitly to the scholarship of teaching (Kreber 2005). Integration of the various scholarships to ensure a balanced professional development is needed. There tends to be a gap between knowledge and development practices. CE is often perceived as an 'add on' activity and academics are often reluctant to engage in this activity (Sall et al. 2003: 144). Ideally, CE should be connected to the key performance areas of HEls, i.e. teaching, learning and research, and community. This implies that for academics their research and teaching must be aligned with the equity commitment.

Community engagement presents an opportunity for academics to fulfil their moral citizenship through academic involvement. Engagement can facilitate the connection and can link the community to the curriculum in ways that bring new meaning to the why, what and how of learning, teaching and research approaches at universities. Opportunities for transdisciplinary knowledge need to be created so that graduates will be able to develop necessary skills to enable them to apply knowledge in creative ways. This goal is facilitated by an interdisciplinary approach to teaching, learning and research. Academic research on CE and contributing to an emerging trans-disciplinary body of knowledge presents several advantages for academics. These include extra space to publish, being a role-player in the development of new and emerging areas of knowledge creation, working across disciplines and with other academics, and being at the forefront of developing innovative models of integrating CE into various disciplines. The prospect of CE within higher education, its staff, academic interest 
groups and individual disciplines resides in its viability and its relevance to intellectual discipline and pedagogy (Zlotkowski 1995). In order for this gap to be narrowed, research is required.

Much has been written about the qualities required of students within the global economy. This is expounded by Barnett (2004) who concludes that the increasing complex environment would require teaching and learning strategies to change. There should be a move from the emphasis on knowledge and skills acquisition to the preparation of students to deal with super-complexity. This focus on ontology and away from epistemology is propounded by Dall'Alba and Barnacle (2007) who believe that students need to learn how to 'be' in the realities of the knowledge economy. This has implications for teaching and learning in HEls. The scholarship of application provides the unique opportunity for students to gain experience in being exposed to supercomplexity. It provides a forum for the application of skills learned and the possibility of problem solving where accountability and relevance are required for students to dig more deeply than just their knowledge acquired in formal study. This involves a spiritual dimension, what Barnett (2004) refers to as the emphasis on 'being'. Educational goals of developing skills of self-management, autonomy and social responsibility are also fostered in the process of CE as students go out into the community and are involved in solving real problems. This provides them with the opportunity to develop intellectually (critical thinking) and morally (social responsibility).

Global trends also have an impact on teaching and learning. There has been a noticeable trend in South Africa towards facilitation of learning rather than transmission teaching (Horsthemke 2004). Educators can prepare students for the changing environment by creating opportunities for them to put coursework theories into practice in their own world situations (Daniels 2007). The generation and development of knowledge is therefore contextual in nature (Makgoba, in Horsthemke 2004). Bloland (2005) refers to disciplinary boundary implosions, where academics no longer remain within their disciplines, but explore core subjects in other disciplines leading to demystification of disciplines and increasing criticism of each other's fields. Imenda (2005) mentions three sociological foundations for educational reforms in South Africa, of which two are directly related to CE. These entail becoming involved in communities outside of the physical boundaries of HEls and having education take place at various sites. Implications for curriculum design and for integrated approaches to learning and teaching are imminent. According to Le Grange (2005:1214), "engagement involves a process of negotiation about what knowledge is most worth producing and also how the knowledge might be produced - the ontological and epistemological frameworks 
underpinning the knowledge production process are interrogated no matter what form or mode of knowledge". Academic professionals need to take the responsibility of seeking meaning in the changing environment. They should also interpret it for society and find solutions (Bloland 2005).

Organisations have a further role in securing a sustainable future for humanity by avoiding socio-economic and environment crises. This has implications for ethics, morality and sustainability, which are at the interface (boundary) of the HEls and the community. Issues of social equity and justice should be generic components of all courses, as students will face these issues in the communities where they will be engaged. This may be through CE, in whatever form, appropriate to the field of specialisation, and within the community where they will be working once qualified. In any professional development and identity formation of students, this is an issue that needs to be addressed. It also includes the development of their social responsibility.

\section{Community level}

The Talloires Network (2005:12) emphasises that HEs need to be committed to strengthening their civic roles and social responsibilities:

Higher education must extend itself for the good of the society to embrace communities near and far. In doing so, we will promote our core missions of teaching, research and service. The university should use the processes of education and research to respond to, serve and strengthen its communities for local and global citizenship

HEls therefore need to engage with the redefinition and importance of their role in the social development agenda. Knowledge production and distribution have moved beyond the boundaries of the university and are produced and consumed in many different physical sites. This situation challenges the modernist higher education's control of knowledge. Consequently, higher education is losing its knowledge monopoly (Bloland 2005). As a result, the significance of community knowledge systems is being taken seriously (Kolawole 2005; Vambe 2005) and there is an increased awareness that learning within community settings needs to be recognised. Singh (2005) contends that values in post-apartheid South Africa must go beyond the individualism of human capital theory; it should focus on the social fabric that binds individuals to social formations and intersect to create cultural capital for different groups. Participatory and democratic structures of community-based research projects are fundamental to how the university fulfils its public mission through research (Berman 2007). Knowledge 
generated by grassroots people should be valued, documented, preserved and made accessible to all stakeholders (Kolawole 2005). Henkel (2007:90) further states that in the global era, knowledge has become democratised with a decreased distinction between 'experts' and 'non-experts'. She quotes Noworthy and colleagues (2001) who say that contemporary society 'speaks back to science'.

The World Declaration on Higher Education for the $21^{\text {st }}$ Century identifies areas where $\mathrm{HEl}$ could become relevant to society (Kolawole 2005). Relevance should be assessed by what society expects of institutions and what they do. It should be a reinforcement of the role of service to society through transdisciplinary and interdisciplinary approaches to analyse problems and issues to ultimately create a new society. For a mission such as CE there benefits need to accrue to both partners. Reciprocal learning is at the core of sustainability, a key factor in any CE initiative. The principles of social justice and ethical practice are integral in this process. Butin (2006) criticised service learning for the university dominance of the partnership in practice. The research agenda is often dictated by the academics, and the impacts are mainly measured with a university interest bias. Weerts and Sandmann (2008) report on the "two way approach", "mutual benefits" and "collaborative model", which are different from the more traditional approaches to CE. The change in approach from needs-based to asset-based community development illustrates this shift in attitude. These processes, however, take time to implement and with an already pressured environment, the question remains whether these approaches are in reality implemented during CE initiatives.

The scholarship of engagement broadens and deepens public aspects of academic scholarship. Barker (2004: 123) identified five core elements of engagement scholarship, each of which has a distinctly different focus: (1) Public scholarship employs forums open to the community created through the process of public deliberation enabling a greater comprehension of community problems and issues; (2) participatory research stresses the dynamic role of society in engaging in the creation of knowledge, emphasising and promoting participation and focusing on the marginalised or previously excluded groups; (3) community partnerships focus on scholarly engagement practice aimed at bringing about social transformation; (4) the development of public information networks identifies resources and assets in communities and (5) the development of civic skills or civic literacy through engagement in teaching, research and outreach improves democratic processes, ensuring that disciplines supply the community with the knowledge required for reflective judgments on issues (Barker 2004:129-132). The emphasis is on reducing the separation between the expert specialist and the lay public. Each of the five core elements has its own methodology and conception of 
democracy, and most central tenets overlap with each other. They are interrelated as they share the common practice of a problem-driven approach located in the public domain (community), subsequently contributing to the common democratic good of society and social transformation. This calls for a new approach or a different lens for viewing and identifying research problems, which ensures that research is relevant and that it narrows the gap between universities and the communities they serve. Universities have the opportunity of using public funding for academic endeavour for the public good. In practising integrated scholarship in CE, certain approaches are better suited for research. Applied research methods to address context-specific research problems would be most appropriate (Barker 2004; Gibbons 2007).

There is a pressing need to understand the complex relationship between $\mathrm{HE}$ and society and research is needed 'on the ground' to reveal the ways in which African universities and societies intersect and mutually shape each other (Sall et al. 2003: 144). The focus clearly needs to be on mutuality as this will ensure sustainability.

\section{IMPLICATIONS FOR RESEARCH}

Relevant engagement with communities within the African context requires the creation of new knowledge spaces through negotiation whereby social strategies and technical devices are used to produce new knowledge (Le Grange 2005). Mseleku (2004) believes that South African universities tend to be extensions of European universities and that they are not rooted in the African experience. Clearly, through engaging with communities and producing relevant research, $\mathrm{HE}$ will contribute towards creating an African identity in its institutions. The scholarship of engagement places community issues on the scholarly agenda and provides an opportunity for integration across teaching, research and service. It provides the opportunity to contribute to the body of knowledge, namely to the development of new technology, materials or methods and the integration of knowledge or technology, which will lead to new interpretations and applications in the arena of CE.

Engaging in research in communities could motivate academics currently not involved in community engagement to expand their area of practice. This could be so especially if the definition of community is broadened. Stanton (2007) identifies some reasons for CE research. These are: documenting the impact of CE on students and/or community partners; constructing new theoretical models; placing CE in an African context and incorporating the perspectives of universities, the public sector, industry, professional bodies and community members; placing CE within the paradigms and theories of 
disciplines and developing/expanding its language; structuring CE curricular activities within the larger context of teaching and learning; evaluating CE effectiveness with regard to partnerships and institutionalisation; documenting innovative activities and sharing within an academic context and for assessment and quality management. These appear as compelling reasons for engaging in CE research. Based on the discussion in this chapter there are various research statements which are suggested as foci for research. They are discussed below.

The motivations for policies on CE at national and institutional level will be influenced by the realities of those implementing the policies and the disjuncture, and which may have arisen due to rapid global changes. This needs to be addressed, possibly through the following research statements:

- Identification of the governance issues that institutions in South Africa are facing, as this will influence the CE mission of universities;

- The changing patterns of governance in the global era within the South African higher educational context;

- Identification of the CE issues in mission statements and quality management policies of universities;

- Identification of resources and incentives for academics for CE.

Academics that are experiencing the manifestation of global pressures in the implementation of their task may be hesitant to respond to the moral imperatives of CE. The narrow definition of community may be excluding academics in disciplines other than the more service-oriented disciplines. The extent to which this is the case may be the focus of the following research:

- Identification of the attitudes of academics to CE;

- Identification of the academics' definition and perception of community;

- Identification of barriers and facilitating factors for CE.

There is a need for research regarding the positive 'pull' factors that will encourage CE. These are:

- Identification of possibilities of third-stream funding for CE;

- Identification of capacity-building needs regarding accessing funds;

- Identification of ways to link academic valued outputs to CE activities;

- Identification of partnerships with external communities; 
- Identification of collaborative research possibilities.

In the evaluation of Community Higher Education Service Partnership (CHESP), a national service learning initiative at several higher education institutions, Mouton and Wildschut (in Lazarus 2007) state that service learning scholarship tends to be a-theoretical, descriptive, anecdotal and impressionistic. They state that the field seems to be dominated by practitioners rather than by theoreticians. Thus there is a call for deeper theoretical and conceptual reflection on CE.

Other aspects for research include:

- Deconstruction of knowledge structures informing practice of academics;

- Challenging policies of their institutions regarding CE;

- The need to develop meta-narratives and new frameworks of meaning.

It still seems unclear what is being done in terms of the influence of CE on communities and the processes through which these are achieved. There is a need for academia to recognise, understand and respect multiple ways of knowing, interpretation and practice. Possible areas of research could be:

- The view that communities have of the university as a resource;

- Identification of communities appropriate for engagement by various disciplines;

- Identification of current assets and needs of target communities to ensure a match of activities;

- Identification of power and knowledge structures in communities;

- Identification of appropriate approaches to CE within various contexts;

- Monitoring and evaluation to ensure that partnerships remain relevant.

In conclusion: the scholarship of engagement and the community engagement brief of academics is the scholarship often most neglected in practice. Issues and challenges raised in this chapter illustrate the complexity of the CE debate. Cognisance of the dual pressures in the CE discourse in higher education keeps the agenda open for research on multiple levels. A broader definition of community may be required within the global era due to the opposing pressures of relevance and global competitiveness. The epistemology underpinning practice may influence academics in the integration of the scholarship of engagement with the other scholarships. In this way CE will be integrated into practice and not exist as an add-on. Dichotomies of autonomy and accountability have implications on various levels and if academic freedom with the 
application of community engagement is encouraged and valued, there may be a positive acceptance of the imperative with resultant sustainability.

\section{REFERENCES}

Aitchison J. 2004. Lifelong learning in South Africa: Dreams and delusions. International Journal of Lifelong Education, 23(6):517-544.

ANC (African National Congress). 1994. White Paper on Reconstruction and Development: Government's Strategy for Fundamental Transformation [Online]. Available: http://www. anc.org.za/ancdocs/policy/white.html [2009, 2 March].

Andreasson S. 2006. The African National Congress and its critics: "Predatory liberalism", black empowerment and intra-alliance tensions in post-apartheid South Africa.

Democratization, 13(2):303-322.

Asmal K. 2002. Press Statement by the Minister of Education, Professor Kader Asmal, MP, on the Transformation and Reconstruction of the Higher Education System [Online]. Available: http://education.pwv.gov.za/Media/Statements_2002/may02/he.htm Statement dated 30 May 2002 [2009, 2 March].

Barker D. 2004. The scholarship of engagement: A taxonomy of five emerging practices. Journal of Higher Education Outreach and Engagement, 9(2):123-137.

Barnett R. 2004. Learning for an unknown future. Higher Education Research and Development, 23(3):247-261.

Berman K. 2007. Shifting the paradigm: The need for assessment criteria for community engaged research in the visual arts. Unpublished paper. "Postgraduate supervision: The state of the art and the artists." Stellenbosch: Stellenbosch University. April.

Bitzer EM. 2006. Restoring the status of teaching scholarship at a research-oriented university. South African Journal of Higher Education, 20(4):372-390.

Bloland HG. 2005. Whatever happened to postmodernism in higher education? No requiem in the new millennium. The Journal of Higher Education, 76(2):121-150.

Boyer EL. 1990. Scholarship reconsidered: Priorities of the professoriate. Princeton, NJ: Carnegie Foundation for the Advancement of Teaching.

Boyer EL. 1997. Ernest L Boyer: Selected speeches 1979-1995. Princeton, NJ: Carnegie Foundation for the Advancement of Teaching.

Boyte H. 1998. Off the playground of civic society: Freeing democracy's powers for the $27^{\text {st }}$ century. Minneapolis, MN: Center for Democracy and Citizenship, University of Minnesota.

Braxton JM. 2005. Reflections on a scholarship of practice. Review of Higher Education, 28(2):285-293.

Brennan J \& Shah T. 2000. Quality assessment and institutional change: Experiences from 14 countries. Higher education, 40(1):331-349.

Butin DW. 2006. Introduction: Future Directions for Service Learning in Higher Education. International Journal of Teaching and Learning in Higher Education, 18(1):1-4. 
Council on Higher Education (CHE), Higher Education Quality Committee (HEQC), JET Education Services (JET) \& Community Higher Education Service Partnerships (CHESP). 2007. Community Engagement in Higher Education. Proceedings of the Conference held in Cape Town from 3-5 September 2006. Pretoria: CHE.

Cloete N \& Muller J. 1998. South African Higher Education Reform: What comes after PostColonialism? European Review, 6(4):525-542.

Dall'Alba G \& Barnacle R. 2007. An ontological turn for higher education. Studies in Higher Education, 32(6):679-691.

Daniels D. 2007. Advancing critical thinking about adult basic education through academic service learning. Education as change, 11 (3):23-36.

Department of Education. 2001. Draft National Plan for Higher Education [Online]. Available: http://www.education.gov.za/Documents/policies/NationalPlanHE2001 .pdf [2009, 2 March].

Gibbons M. 2007. Engagement as a core value in a Mode 2 society. Presentation to the Council on Higher Education and CHESP conference, "Community Engagement and Higher Education". Pretoria: CHE.

Gibbons M, Limoges C, Nowotny H, Schwartzman S, Scott P \& Trow M. 1994. The new production of knowledge: The dynamics of science and research in contemporary societies. London: Sage Publications.

Gultig J. 2000. The university in post-apartheid South Africa: New ethos and divisions. South African Journal of Higher Education, 14(1):37-52.

Hall M. 2008. Community Engagement in South African Higher Education. NRF/CHE Workshop. Pretoria: CSIR Convention Centre. 22 August.

Hazelkorn E. 2004. Growing research: Challenges for late developers and newcomers. Higher Education Management and Policy, 16(1):119-140.

Henkel M. 2007. Can academic autonomy survive in the knowledge society? A perspective from Britain. Higher Education Research and Development, 26(1):87-99.

HEQC (Higher Education Quality Committee). 2001. Founding document. Pretoria: Council on Higher Education.

HEQC (Higher Education Quality Committee). 2004a. Criteria for institutional audits. Pretoria: Council on Higher Education.

HEQC (Higher Education Quality Committee). 2004b. Criteria for programme accreditation. Pretoria: Council on Higher Education.

HEQC (Higher Education Quality Committee). 2006. A Good Practice Guide for Self evaluation. Instruments for Managing the Quality of Service-learning. Pretoria: Council on Higher Education.

HESA (Higher Education South Africa). 2007. The challenge of renewal and engagement: Public higher education in South Africa. Report submitted to the Presidential Working Group on Higher Education meeting held in Pretoria on 8 May. Pretoria: Council on Higher Education. 
Holland B \& Ramalay J. 2008. Creating a supportive environment for community-university engagement: Conceptual frameworks. Keynote address to the Higher Education Research and Development Society of Australasia (HERDSA) Annual Conference, "Engaging Communities". New Zealand: Rotorua. 1-4 July.

Horsthemke K. 2004. Knowledge, education and the limits of Africanisation. Journal of Philosophy of Education, 38(4):571-587.

Imenda SN. 2005. The idea of a South African university and implications for knowledge production. South African Journal of Higher Education, 19(special issue): 1405-1418.

Jansen JD. 2002. Mode 2 knowledge and institutional life: Taking Gibbons on a walk through a South African university. Higher Education, 43:507-521.

Jonathan R. 2001. Higher education transformation and the public good. Kagisano: CHE Higher Education Discussion Series, 1:35-89.

Kolawole OD. 2005. Mainstreaming local people's knowledge and implications for higher education in the South. South African Journal of Higher Education, 19/special issue): 1427-1443.

Kraak A. 2004. Discursive tensions in South African higher education, 1990-2002. Journal of Studies in International Education, 8(3):244-280.

Kreber C. 2005. Charting a critical course on the scholarship of university teaching movement. Studies in Higher Education, 30(4):389-405.

Lazarus J. 2007. Embedding service learning in South African higher education: The catalytic role of the CHESP initiative. Education as change, 11 (3):91-108.

Le Grange L. 2005. The 'idea of engagement' and 'the African University in the $21^{\text {st }}$ Century': Some reflections. South African Journal of Higher Education, 19(special issue):1208-1219.

Mapesela MLE, Leboena A \& Setenane MF. 2005. Africa(n)-focused research: Two case studies from Lesotho. South African Journal of Higher Education, 19(special issue):1255-1266.

Maruatona T. 2007. Lifelong learning for facilitating democratic participation in Africa. International Journal for Lifelong Education, 25(6):547-560.

Mseleku T. 2004. African scholarship: Some challenges facing intellectuals in South African Higher education institutions. Ingede. Journal of African Scholarship, 1(2):1-3.

Muller J \& Subotsky G. 2001. What knowledge is needed in the new millennium? Organisation, 8(2):263-182.

NCHE (National Commission on Higher Education). 1996. An Overview of a new policy framework for Higher Education Transformation. Report submitted to the Minister of Education on 22 August 1996 [Online]. Available: http://www.llnw.creamermedia.co.za/ articles/attachments/04394_higher educationtransformation.pdf [2009, 19 May].

Papoutsaki E \& Rooney D. 2006. Colonial legacies and neo-colonial practices in Papua New Guinean higher education. Higher Education Research and Development, 25(4):421-433.

Pearson M. 2005. Framing research on doctoral education in Australia in a global context. Higher Education Research and Development, 24(2):119-134.

Perold H. 1998. Community service in higher education: Final report. Johannesburg: Joint Education Trust. 
Reddy T. 2004. Higher Education and Social Transformation: South Africa Case Study. Pretoria: Council on Higher Education.

Sall E, Lebeau Y \& Kassimir R. 2003. The public dimensions of the University in Africa. JHEA/ RESA, 1 (1):126-148.

Singh A. 2005. Towards a theory of national consciousness: Values and beliefs in education as a contribution to 'cultural capital' in post-apartheid South Africa. Journal of Asian and African Studies, 40(5):323-343.

Singh M. 2003. Universities and society: Whose terms of engagement? In: S Bjarnason \& P Coldstream (eds). The idea of engagement: universities in society. London: ACU.

Smith J. 2008. Building the third core function; or: From lip-service to action the executive management of a socially responsive vision. Keynote delivered at Community Engagement Symposium. Stellenbosch: Stellenbosch University. 18 November.

Stanton T. 2007. Research in service-learning. Presentation at Service-learning capacity building programme. Bellville: University of the Western Cape. 19 September.

Talloires Network. 2005. Strengthening the civic roles and social responsibilities of higher education: Building a global network. Report of the Talloires Conference. Tufts University. Boston: Perold and Associates.

Vambe MT. 2005. Opening and transforming South African education. Open Learning, 20(3):285-293.

Waghid Y. 2002. Knowledge production and higher education transformation in South Africa: Towards reflexivity in university teaching, research and community service. Higher Education, 43:457-488.

Weerts DJ \& Sandman LR. 2008. Building a two-way street: Challenges and opportunities for community engagement at research universities. The Review of Higher Education, 32(1):73-106.

Zlotkowski E. 1995. Does service-learning have a future? Michigan Journal of Community Service-Learning, 3:123-133. 


\section{HIGHER EDUCATION}

STUDIES AND RESEARCH

IN SOUTH AFRICA

\section{PERSPECTIVES ON GAINING \\ AUTHORITY AND POWER}

\section{Kalie Strydom}

\section{ABSTRACT}

This chapter encapsulates my thoughts and views on higher educationists and researchers working in the field of study and research in South Africa with regard to work done in the various chapters of this book, as well as work in progress in HE studies and research.

Essentially, my argument involves the matter of gaining authority in the form of expert knowledge, striving for excellence and insight via practical experience in higher education studies and research. Such authority leads to power that will influence policy, planning and the practical implementation thereof in higher education. I sketch the way forward regarding the recognition of higher education studies and research by briefly discussing a few points of departure that could possibly assist us in gaining authority regarding this field of study.

My points of departure involve the understanding of

- global and local pressures, trends, issues and challenges in higher education, which is the object of our study;

- the implications of the present expansion of higher education in relation to our own fields of study and research;

- the limitations of our thematic higher education authority, and

- the necessity of a quality association or society for studies and research in higher education. 
My summative perspective illustrates the practicality of the above-mentioned points of departure with regard to typical areas or themes of study in higher education, thereby emphasising the complex role and task of the higher educationist and researcher.

\section{INTRODUCTORY ORIENTATION}

The perspectives shared in this chapter are intended to amplify the valuable and interesting perspectives and themes contained in this book, without doing them an injustice through simplification. My experience of more than three decades in higher education studies and research has taught me that authority in this field of study is only gained through expert knowledge and insight by practically experiencing as many areas or themes in higher education as possible. Authority also eludes one to the extent that the use of sufficient primary and secondary sources in research and the preparation of publications is not always possible. I am fortunate to have had the privilege of reading the chapters comprising this book, which have provided me with so many critical and useful sources regarding numerous areas or themes on higher education studies and research. It is with sincerity that I acknowledge the hard work and dedication that has gone into this publication.

Reading these chapters also reminded me, at this juncture in my life, of how so many highly appreciated colleagues struggled for years for the recognition of higher education as a field of study in the interest of theory and practice in South Africa. Various chapters in this book, together with the Council on Higher Education (CHE 2004) and the Organisation for Economic and Cultural Development (OECD 2008) reports, deal with the legal and policy implications in higher education, and illustrate the valuable contributions made by higher education studies and research. However, the above-mentioned resources also refer to critical issues and challenges with regard to sensitive policy-implementation processes, monitoring and evaluation, which flag unanticipated gaps and consequences in higher education in South Africa. These issues, gaps, challenges and consequences are addressed in various chapters in the book. Examples are the university as a key concept, universities and public goods, the university in a contemporary era, the university curriculum, teaching and learning and social justice, academic development in higher education, assessment and evaluation, professional development of academics, research within the context of community interaction, quality promotion, institutional cultures, governance in higher education as well as higher education and the world of work. Most of these perspectives and themes are related to broader key policy issues in different reports (CHE 2004; OECD 2008; SARUA 2009) on institutional restructuring, equity (access 
with success), teaching and learning, postgraduate studies and research, community service (engagement), quality assurance, accountability (finances), governance, and global or regional or local needs and other challenges in higher education.

There are many reasons for the above-mentioned consequences, gaps, uncertainties and challenges that the field of higher education in South Africa faces. However, for the purpose of this chapter, the most prominent areas or themes of concern are those of authority with regard to expert knowledge, striving for excellence and insight gained through practical experience as well as the related power relations in higher education. At times executives of higher education institutions, representatives and officials within government, representatives in councils, and leaders in business and industry lack the kind of authority in higher education that should ideally be based on higher education studies and research. Although they possess authority and power within other valuable fields of study, which might be relevant in terms of higher education, by definition they are not higher educationists and researchers. We do, however, realise that the implication of such a bold statement entails that we ought to become experts with regard to policies, planning and implementation of higher education in a local, as well as global context, should our authority in higher education studies and research be acknowledged.

This, in turn, raises the question as to why higher educationists and researchers are often not in a position to influence the interpretation and implementation of policies and planning in higher education. Authority in this field encompasses an understanding of where we are and how we reached this point. Furthermore, it entails envisioning solutions through research to the successful continuation from where we are, to where we want to be in higher education. Researchers should comprehend and acknowledge the professionalism and thoroughness demanded by authority in terms of studies and research in higher education.

As a result of the lack of appreciation and recognition, as well as power-authority relations in higher education, some higher educationists and researchers put very little effort into scholarly work and into producing reliable and valid research. My world view and experience regarding higher education, however, does not support such negativity. We must rather find ways to illustrate our authority in higher education studies and research with the firm belief that this will provide recognition and opportunities (power) within the field. 
After this sermon, I am prepared to be confronted with the million dollar question of how we, as higher educationists and researchers, can find ways of gaining authority in higher education.

\section{A FUTURE PERSPECTIVE ON GAINING AUTHORITY IN HIGHER EDUCATION STUDIES AND RESEARCH}

There are a number of points of departure that I firmly believe will always influence our authority in this particular field of study, namely expert knowledge, striving for excellence and insight gained via practical experience. In the four subsections that follow I suggest a number of options to take higher education studies and research forward during the next number of years in South Africa.

\section{Understanding global and local pressures, trends, issues and challenges in higher education - the object of our study}

Some of the references in this book, as well as some of the latest influential literature on higher education (European Science Foundation 2008; OECD 2008; SARUA 2008), emphasise vast changes in and a growing focus on higher or tertiary education in most countries of the world. Higher education sees itself as being one of the most universal sectors of society. Yet, its systems, structures and institutions vary greatly, with the tendency to be deeply rooted in regional, national and local contexts. This is well illustrated by the highly differentiated policies and planning for higher education.

The literature on higher education is often unclear as to whether the thematic reference to higher education concerns the research undertaken on higher education or the disciplinary background of the researchers (e.g. education, sociology and economics). Furthermore, it is unclear whether published literature (books, articles or reports) on higher education is in actual fact either a type of research, 'consultancy', 'development work' or the information- and evidence-based pondering of policy-makers and practitioners (Teichler 2005).

With reference to these difficulties faced by higher education regarding studying and research, I refer to the latest report on higher education in South Africa, produced by the South African Ministerial Committee (RSA DoE 2008), appointed to deal with the progress towards transformation, social cohesion and the elimination of discrimination in public higher education institutions. This investigation focused on discrimination in public higher education institutions, with specific emphasis on racism; making 
appropriate recommendations to combat discrimination and promote social cohesion. The Committee's Terms of Reference stated that it had to report on the following:

- The nature and extent of racism and racial discrimination in public higher education, particularly in university residences. While the emphasis should be on racial discrimination, other forms of discrimination based on, for example, gender, ethnicity and disability should also be considered.

- Steps that have been taken by institutions to combat discrimination. These include an assessment of good practice, as well as the shortcomings of the existing interventions.

And

- Advise the Minister of Education and the key constituencies in higher education on the policies, strategies and interventions needed to combat discrimination, as well as on ways to promote inclusive institutional cultures for staff and students, based on the values and principles enshrined in the Constitution.

- Identify implications for other sectors of the education system.

To fulfil this mammoth task on such a sensitive issue, the appointed committee's investigation was based on a combination of documentary analyses and interaction with higher education stakeholders and constituent groupings. These included the following:

- An overview of current trends in the higher education system, based on quantitative data contained in the Higher Education Management Information System (HEMIS);

- A survey of the relevant literature pertinent to the key areas or themes of the investigation;

- Analyses of institutional submissions, as well as of policy and strategic documents, including the Higher Education Quality Committee (HEQC) Institutional Audit Reports;

- An analysis of a questionnaire on the development and implementation of policies relating to transformation, discrimination and social cohesion within higher education institutions;

- Analyses of submissions received from both national organisations and individuals, resulting from a public call for submissions via the media; 
- Visits to all institutions to solicit the views of institutional stakeholders and constituencies, including councils, executive managements, student leaders, academic and support staff representatives, as well as staff associations and trade unions;

- Consultation with national student and trade union organisations.

The committee seemed to think that it had adequate time, resources and finally evidence to publish an explosive report on pervasive racial and sexual discrimination in South African universities, including the failure of university authorities to confront it. It included wide-ranging recommendations that could affect the funding of higher education institutions and shape their institutional policy-making and implementation (Mail \& Guardian 2009).

I do not want to discuss the merit of this report in any detail, but in terms of our topic, higher education studies and research, the above-mentioned report is problematic. It fails to establish a link to a specific field or theme of study in the domain of the established disciplines that address this theme. This type of problem faced by researchers in higher education is typical. In terms of its findings and recommendations, this report might also not get the support it deserves, since many executives and actors within higher education institutions might not base their reaction to the report on systematic knowledge in higher education studies and research, but rather on ideological bias regarding the unique institutional political and practical demands within their specific contexts. A further question is whether this report can be regarded as reliable, valid systematic knowledge within higher education studies and research. Although our field of study has gradually created a fairly well-respected body of knowledge over the last four decades that deserves attention and can support problem solving and decision making in numerous areas or themes concerning higher education, the area or theme of racial discrimination within the South African context is an example of where there is limited comparable literature available within higher education.

The above-mentioned point of departure and reference to an example of an important report illustrate difficulties experienced in this field of study to gain authority. It emphasises that higher education studies and research will only be better recognised if research within this field begins with a good understanding of comparable higher education areas or themes (lessons learned) across the world, as well as within regions and countries. Moreover, it is important to realise that higher education is predominantly regulated at a national level: legislation, administration, approval of institutions, curricula and credentials, teaching staff careers, research promotion and 
similar features all tend to be set at either a national level or at the regional level within nations. Therefore, it is not surprising to note that most research on higher education is shaped predominantly by its specific context and that it is not necessarily applicable at a global level. Hence, global and national perspectives regarding various areas or themes of higher education studies should be well understood, bearing national and local differences in mind when addressing the institutional basis of higher education research and the relationships between higher education research and higher education policy and practice (Teichler 2005).

Part of the way forward for higher educationists and researchers involves careful consideration of the global and local (or glocal) picture of the various areas or themes comprising higher education by consulting scholarly work, literature reviews and indepth research or study before considering publications on the pressures, trends, issues and challenges within higher education. More than three decades ago, Dressel and Mayhew (1974:112) noted the following: "Higher education as a field of study embraces so many different subjects ... that it fits well with no single theoretical base as does medicine with the biological sciences. It can never be a discipline, and certainly not a quantitative one, like physics. Rather researchers should adopt Wilhelm Dilthey's concept of verstehen, or understanding."

This understanding is gained by doing the utmost with whatever research methodologies work best to describe, analyse and suggest improved designs and developments for areas or themes in higher education and universities to foster activities of advanced intellectual training and discovery. George Keller (1998) stated that too much of today's 'empirical' higher education research consists of abstracted armchair and computer findings. The actual observation of campus practices, norms and behaviour needs to increase. Research also involves getting the 'feel' of a campus or set of institutions in collaboration with a carefully trained observers and participants, as well as gaining applicable data and statistics.

Some hard-core quantitative researchers will object by stating that true empiricism is impressionistic and anthropological, not precise and scientific. But life, and especially everyday life in colleges and universities, is not disposed to tidy mathematics. It is complex, seldom predictable and seething with thinly shrouded emotions. Higher education researchers need to choose between devotion to their orderly quantitative methods and a deep understanding of the messy academic world. I suggest choosing the latter (also see Keller 1998). 


\section{Understanding the implications of the present expansion of higher education in relation to the field of study and research}

The expansion of higher education has global, regional and local dimensions and it shapes the lives of individual citizens, as illustrated in this book. Moreover, the object of higher education as a field of study forms the institutional basis of all academic disciplines and the contribution of systematic knowledge to the future of society. In this sense it is a constituent of social sciences and humanities, drawing on a multitude of disciplines, as well as on theme-based areas exposed to high expectations of social relevance. I refer to the report Higher Education Looking Forward: An Agenda for Future Research (European Science Foundation 2008) where prominent higher educationists such as John Brennan, Jürgen Enders, Christine Musselin, Ulrich Teichler and Jussi Välimaa so accurately concluded that areas or themes addressed in higher education studies and research have a tendency to be influenced by relatively short-term institutional, national and supranational concerns, debates and policies about higher education. This was clearly illustrated earlier in the example of the ministerial report. However, higher education researchers also strive to analyse salient long-term issues and trends concerning the relationship between higher education and the creation and development of so-called 'knowledge societies'. Regarding higher education, these knowledge societies shape the social order as far as social privileges, meritocracy, equity and social cohesion are concerned. They also deal with the balance between the pursuit of knowledge and critical functions of higher education and utilitarian expectations of other parts of society, as well as the modes of regulation of higher education, including the respective roles played by market forces, the academic profession and its leaders, the state and other stakeholders (European Science Foundation 2008).

As regards what can be learnt from the content of this book, together with the example of the ministerial report referred to earlier, higher education studies and research still constitute a small, fragmented field of study in the developed world, even more so in developing countries. In such countries, only a few people in humanities and social sciences or sub-areas of education research grapple with critical areas or themes within higher education in order to influence policy and practice in higher education. In South Africa, there are perhaps a hundred or so individuals seriously interested in this field of study. The paucity of numbers and interest is, in all probability, mainly the result of apartheid in the higher education sector. Meanwhile, the radical transformation agenda from the early 1990s required higher education policy and planning to eradicate backlogs and support socio-economic growth and development on the way 
to an open and democratic knowledge society. Unfortunately, it seems as though many of these individuals function within the academic constraints of institutional support services and faculties of education and not in research institutes that provide greater scientific recognition and growth as a field of study. In the late 1980s and 1990s the transformational needs in higher education in South Africa led to the establishment of a few small higher education studies and research centres that could be compared to some extent to the research institutes functioning in North America, the UK and Europe. Unfortunately, however, these centres are currently concentrating most of their efforts on postgraduate higher education studies, as well as on institutional needs for higher education research regarding specific challenges within these higher education institutions (i.e. forms of institutional research).

The field of higher education studies and research in South Africa will only prosper if the National Research Foundation (NRF) and other funders can be persuaded to support a project, as was done by the European Science Foundation with its rationale to examine higher education and research within a wider context of social science research, and by relating it to more general conceptual frameworks such as human capital theories, theories of power, inequality and social exclusion, theories of organisations and new public management. In so doing, the European Science Foundation hoped to begin to address some of the larger questions concerning the changing relationship between higher education and society and develop research agendas that would be relevant, to researchers as well as to policy-makers and practitioners. The European Science Foundation's (ESF) project identified five interconnected areas or themes among research literature and reports in Europe:

1. Higher education and the needs of the knowledge society

2. Higher education and the achievement (or prevention) of equity and social justice

3. Higher education and its communities; interconnections and interdependencies

4. Steering and governance of higher education

5. Differentiation and diversity of institutional forms and professional roles

Draft reports on these five areas or themes were critiqued by groups of scholars at workshops in Kassel, Helsinki and Paris, at an interim conference in Brussels and, finally, in a dialogue with researchers from other fields and young higher education researchers at an ESF conference in Vadstena, Sweden. At the Brussels conference, a start was made on the process of synthesising the messages emanating from the five thematic reports, with regard to what was and was not known, as well as to the implications for future research agendas. This process of synthesis is continued by 
the ESF report. The aim is to propose an agenda for future research on the changing relationship between higher education and society, to suggest that this agenda may be more deserving of the attention of researchers from a wider range of social science fields than it has typically received, and to remind future researchers, whatever their backgrounds, of the existing body of theory and research on which future work should be built (European Science Foundation 2008).

The significance of this type of research is well summarised in the outline of an ongoing international research project organised by the US Social Science Research Council (SSRC):

Topping the agenda of most international organisations are priorities related to easing the transition to a knowledge-based economy, ensuring we do not become a world of 'haves' and 'have-nots', and advocating educational opportunity as an inherent right. Clearly, accessible higher education and progressive research is inherently integrated into all these priorities; these lofty goals will unwittingly fail if we do not understand how public research universities function in this global world of liberalising markets, deregulated states, and privatising societies.

Given the situation and what is recognizably at stake, it is surprising that the transformation of public research universities has not received more concerted analytic attention. ... The issues are not only ripe for social science examination; they are in need of international and interdisciplinary interpretation, explanation, and discussions (SSRC 2005, in European Science Foundation 2008:6).

These perspectives, taken from this book and the ESF report, explain in no uncertain terms that higher educationists and researchers in South Africa should realise that our field of study has very little hope to gain the authority that leads to powerful recognition in scientific circles if we do not confront certain brutal issues forcing change in our approach to HE studies and research. One of the brutal issues that need to be confronted was addressed in the previous paragraph of this chapter; another issue is the inability of individuals and centres of higher education studies, as isolated institutions, to make a significant difference to higher education in South Africa with regard to their post-graduate programmes. Research on higher education is often institutionally embedded in units serving the institution's administration ('institutional research'), in supporting human resources (e.g. 'staff development'), or in policy-related settings of applied higher education research. Moreover, the borderline between researchers and practitioners has become increasingly fluid due to the involvement of various kinds of higher education professionals and administrators such as rectors' associations, scholars and students involved in higher education policy, evaluation experts, and 
management consultants. This state of affairs will not change easily, because of South African higher education institutions' daily needs, interests and challenges, which need to be addressed in some way or other, if only on short-term basis. However, there is a need for the collaborative harnessing of the limited available expertise in higher education studies and research in South Africa. This need could be addressed by establishing a cluster of significant areas or themes within higher education that will be researched in close collaboration among a few strategically positioned higher education research institutes in regions as well as in all the universities in order to promote first-rate higher education.

The existing higher education centres or units, situated at a few universities, should also make further sincere efforts to collaborate regarding undergraduate and postgraduate studies in higher education. There is little doubt that existing higher education studies programmes fulfil a valuable role and that colleagues working in these units or centres show great dedication. However, I doubt that many will deny the immense contribution that collaborative curriculum design, development and delivery, recognition of expertise and specialities of centres to excellent higher education study programmes could make to improve the quality and service within higher education study programmes. The question then remains why such collaboration is absent in South Africa.

In a study commissioned by the network of executive directors of academic consortia, titled 'Uncommon Wisdom: Making cooperation work in South African Higher Education' (Gibbon and Parekh 2001), various institutional issues and concerns that complicate effective and meaningful cooperation and collaboration between institutions were highlighted:

- Institutions compete with one another for students and resources.

- Similar instructional Visions and Missions result in their reluctance to relinquish sole ownership of academic offerings and identify complementary programmes in other institutions.

- Areas seen as key to the niche of one institution may be fiercely guarded.

- Motives and intentions of stronger, well-endowed institutions are viewed with suspicion and resentment.

- The developmental goals and objectives of institutions vary.

- Conflicting personalities and a lack of direction of institutional leadership are obvious challenges.

- Clear incentives to cooperate or sanctions for failing to cooperate are lacking. 
- There is a perception of threatened job security within institutions.

- Geographical distances challenge collaboration between institutions.

Some of the barriers to joint academic programmes, including higher education study programmes, were the following:

- Potential loss of income by way of subsidy and student fees.

- Registration and graduation of students.

- Different fee levels.

- Differing and occasionally conflicting academic rules.

- Difficulty in determining overall responsibility and coordination of mark allocation.

- A lack of compatibility in academic ethos and approach.

- Inter-institutional differences regarding quality of teaching and academic options.

- Difficulty in arranging student and staff mobility, particularly when institutions are not in close proximity to each other.

- Variations regarding the structure of the academic year, complicating planning and scheduling joint academic options.

- Delayed repeal legislation, resulting in awarding of joint degrees.

- Current funding constraints.

This report also stated that collaboration in research and research capacity building has been successful and probably warrants greater development. Academics are accustomed to working across institutional, regional and national boundaries in this area and such collaboration will become increasingly important in knowledge-based economies in the future (Gibbon and Parekh 2001).

The above observations provide another good reason why higher education research institutes should be considered on a partnership basis in specific regions of South Africa.

\section{Understanding the limitations of our thematic higher education authority}

As previously mentioned, there are a few higher education studies centres or units in South Africa that focus predominantly on providing postgraduate programmes in higher education studies. Some of these centres or units conduct collaborative research projects on valuable areas or themes for higher education. Examples of such 
collaboration include those by the Council on Higher Education, the branch for higher education within the Department of Education, the National Research Foundation, the Centre for Higher Education Transformation and others.

One chapter in this book (Bitzer and Wilkinson) refers to a mapping exercise directed by the following questions:

1. What is the (thematic) nature of higher education studies and research in South Africa? Are there particular South African emphases in the research? How do these relate to international trends? Does available evidence suggest a possible or unique categorisation of current higher education research areas or themes in South Africa?

2. Where in South Africa is HE formally studied? What are the institutional or organisational settings where HE is studied? What is studied in the various programmes?

3. How stable is the professional basis of higher education research in the country? (Formal associations? Journals? Other forums and outlets? The researchers? Communities of practice?)

The particular chapter can be consulted for further details, but my view is that the area of higher education studies and research is defined by the fact that it is multidisciplinary, drawing on numerous areas or themes within disciplines such as education, psychology, sociology, political sciences, economics and business studies, law and history. These disciplines inform higher education research, both conceptually and methodologically. A challenge for higher education research is the maintenance of these multidisciplinary sources in order to enhance quality and to avoid being driven excessively by thematic concerns and policy agendas. However, creative theme-based research has the potential, and often the need, to transcend disciplinary perspectives.

Other disciplinary fields contribute to higher education research, although some of the areas or themes addressed are positioned outside and cut across the various disciplinary areas. Moreover, since higher education addresses general aspects of teaching and learning, research and the accumulation of knowledge, it is dependent on expert cooperation in all disciplines, regardless of whether or not they contribute directly to higher education research (European Science Foundation 2008).

In the previous section I explained that higher education research in South Africa lacks a stable institutional base within higher education institutions in the form of regional 
collaborative research institutes. These institutes can provide a link between higher education research and many areas of study in the humanities and social sciences.

In some instances, scholars in various domains of the humanities and social sciences address higher education issues regarding short-term projects or projects covering a certain period of their academic career. In other instances, scholars of these disciplines could either become fully fledged higher educationists or have the potential to contribute more meaningfully to areas or themes in higher education if they were linked to higher education research institutes.

These overlapping peripheries between research and other sources of expertise are also more pronounced in higher education than in other disciplines and fields of study, because there is only one scientific journal for higher education studies and research in South Africa. Opportunities for the average higher educationist to publish in other South African journals and higher education journals in, for instance, Europe, the United Kingdom, North America and Australia are limited because of the highly competitive environment.

In this context, the 2008 ESF report can once again be particularly helpful, because it effectively recognises the fact that the variety of institutional settings and the vague margin between research and practice offer ample opportunities for broadening the scope of higher education research and its practical relevance within many different kinds of publications (for instance, scholarly journals). The ESF report is also helpful in challenging higher education researchers to avoid losing themselves in daily concerns and practical expectations. A reflective exercise of this nature, noting past and current achievements and problems, looking ahead to possible future research topics and areas for inquiry, and designing research strategies for the future, is vital for the reasons I have alluded to. It also contributes to thematic research, however blessed as well as endangered by somewhat unorthodox conditions and characteristics (European Science Foundation 2008).

From the surveys reported in the ESF 2008 publication the following broad areas or themes in higher education studies and research were highlighted:

- Quantitative-structural aspects of higher education systems (e.g. access and admission, patterns of institutions and programmes, student enrolment and flow, graduation and graduate employment); 
- Knowledge aspects (e.g. developments of research and curricula, issues of quality and relevance, concepts and measurement of competences, job requirements of professional utilisation of knowledge);

- Aspects of processes and persons (teaching and learning, research processes and organisation, students, the academic profession, emergence of higher education professions);

- Organisational aspects of higher education (steering and management, state and stakeholders, functions and powers of the academic professions within governance, institutional settings, costs and funding).

This section attempted to explain the limitations of the thematic approach within higher education studies and research taken by researchers working in multiple disciplines and posts within higher education institutions, government, support services and other institutions. It also pointed to the immense task of higher educationists to simultaneously do scholarly work via continuous global literature review and publication of practical solutions through research for local higher education institutions amidst the demands of their unique national and regional contexts.

\section{The necessity for one outstanding association or society for studies and research in higher education}

There are many good examples of higher education associations or societies in North America, the United Kingdom, Europe and Australia that generally strive to

- stimulate new forms of research and inquiry into higher education as a field of study;

- assist in developing research capacity in relation to the field;

- encourage and support those entering the field of higher education studies;

- develop a network of scholars and researchers in the field of higher education studies;

- offer presentation of research and scholarship in the field;

- promote the development and widening of research methodologies in the field;

- provide opportunities for the publication of research and scholarship in the field; and

- develop opportunities through which researchers in the field can engage with policy makers, practitioners within higher education and other potential interested parties so that research may shape policy and practices. 
One of the means to promote the above-mentioned aims or purposes would be to establish one strong association or society for higher education that might fulfil these aims and purposes by

- maintaining and developing a South African and international database of researchers and scholars in the field;

- seeking to encourage the work of those recently embarking on research in the field;

- conducting conferences and seminars that bring researchers together, and enable researchers, policy-makers and others to engage with each other;

- producing and supporting various forms of research-based publications;

- establishing and supporting numerous networks of members, each focused on clusters in a particular area or theme within higher education where research may have a role to play, and

- providing advice to and engaging with relevant national and international research and policy debates (SRHE 2008).

The above-mentioned aims and ways of promoting higher education studies and research cannot be met in a country such as South Africa without the realisation that we cannot sustain three or more higher education and research associations supported by a minimal number of experts and researchers, with very little time and resources available due to current circumstances mostly beyond their control. The existing higher education associations in South African higher education should have the vision and courage to form one strong association to better fulfil the aims and purposes stated for an outstanding association or society for higher education.

As previously explained, the above-mentioned association or society should also be guided by strategic clusters of research in higher education in the interest of excellence in South African higher education, as was done by the European Science Foundation via its 2008 HELF report for Europe. The one outstanding higher education association or society should also realise that it cannot serve all the needs, interests, challenges and problems of higher education in South Africa, but should rather focus its efforts on the types of strategic purposes that may maximise the contribution to excellence in higher education studies and research. Examples of such strategic purposes are the following:

- Working to enhance the role of higher education research within the higher education sector; 
- Encouraging and supporting researchers recently entering the field of higher education research;

- Providing opportunities for the publication of research and scholarship;

- Organising conferences and seminars that bring researchers together, as well as enabling researchers, policy makers and others to engage with one another (SRHE 2008).

\section{SUMMATIVE PERSPECTIVES}

This chapter's premise is the realisation by higher educationists and researchers in South Africa that authority cannot be gained and no meaningful contributions can be made to the debate on the future of higher education in South Africa without active and progressive study, research and networking in the field of higher education studies and research. The points of departure explained earlier in this chapter can be practically illustrated by reference to the World Bank's document 'The Challenges of Establishing World-Class Universities' (Salmi 2009). This publication deals with various areas or themes in higher education, starting with the broad theme of the university as an institution and ranking of universities, which are supported by subsidiary areas or themes relating to talented academic staff, abundant resources, appropriate governance, success factors and, as always, transformation. The themes are briefly discussed below.

Firstly, it would be important for any higher educationist and researcher in the field to understand this document so that the paradox of the 'global' world-class university, as Altbach succinctly and accurately observed, does not apply when he says that "everyone wants one, no one knows what it is, and no one knows how to get one" (Altbach 2004, as quoted in the executive summary of Salmi 2009).

Secondly, the points of departure expect higher educationists and researchers to understand the implications of this World Bank document within our regional (Africa or Southern African Developing Countries) and South African context in terms of a developing continent and country. A report prepared by Higher Education South Africa (HESA 2009) in connection with higher education leaders illustrates the importance of a specific context by discussing definitional difficulties of universities and by emphatically stating that there is no longer an institute that can simplistically be referred to as 'a university'. By using the term 'university' one is immediately required to use additional adjectives to describe it; red-brick, Ivy League, historically disadvantaged, Land Grant, universities of technology and comprehensives are some descriptions given 
to add precision to an amorphous term. Current higher education debates around managerialism, entrepreneurialism, massification, information or communication or technology channels, distance, borderless opportunities and threats make use of terms that attempt to redefine the term 'university'. Less obvious is the continued use of the term 'university' without problematising its very nature. Due to current South African higher education debates and the changing government relations, the term 'university' is essentially a euphemism for an entity that cannot be fully described. Taking global and local perspectives of world class universities into account will hopefully help to avoid delusions of grandeur with regard to higher education policies, planning and implementation in South Africa.

Thirdly, it is important to realise that there are very few people, if any, who could ever claim to be experts through research in all the areas or themes that come to the fore in, for instance, the World Bank publication. The fact remains that, in most cases, higher educationists and researchers can only become experts in one or a few areas or themes of study and research in higher education. These thematic limitations will hopefully result in collaboration and networking with other higher educationists and researchers in understanding this World Bank Document. A networking approach is needed in most areas or themes in higher education, which would not only influence but also broaden our authority within the field of study. There are, of course, various ways of increasing authority, but regional research institutes and one outstanding association or society for higher education studies and research would most likely be one of the best ways to support networking and the understanding of broader areas or themes in higher education, in relation to subsidiary areas or themes of specialisation in higher education studies and research.

In the South African context, two of the latest areas or themes that appeared in the University World News, are Karen MacGregor's references to a "communist taking charge of higher education" (2009a) and the push to graduate more PhDs (2009b). Again, as per the points of departure mentioned earlier in this chapter, higher educationists and researchers need to react with authority and insight to such articles and to many other views expressed to avoid unnecessary tensions or conflict and to support progress in higher education.

Perhaps it is rather fitting and maybe not absurd to end with the Dinokeng Scenarios (2009) and its three futures for South Africa tailored specifically for our roles as higher educationists and researchers. The Dinokeng document refers to South Africa's broader challenges of social and economic hardship, particularly with regard to unemployment 
and poverty, safety and security, education and health, which are currently exacerbated by a global economic crisis. The scenarios state that if we fail to recognise the severity of our challenges and fail to address them, we will experience rapid disintegration and decline, resulting in our 'walking apart or behind' instead of 'walking together' in South Africa. The global and local pressures for change in higher education are fuelled by challenges such as a possible financial disaster, competitive threats, a lack of visionary leadership, threatened markets, organisational pressures and poor benchmark performance. The pressures against change are those pertaining to the inertia of systems and institutional comfort zones resisting change, a lack of applicable knowledge and skills in leadership and management (governance), the shrinking back from the workload involved and a lack of recognition of entrepreneurial staff, visionless day-to-day focus, ivory-tower arrogance and a 'not my agenda' stance. Higher educationists or researchers and leaders in higher education at institutional, government and other levels will also be unsuccessful, should we fail to 'walk together'. The Dinokeng Scenarios' definition of 'walking together' could refer to a collaborative and enabling state in higher education with limited power, where engaged and active role-players or stakeholders or leaders in higher education are supported by higher educationists and researchers with authority.

\section{REFERENCES}

CHE (Council on Higher Education). 2004. South African Higher Education in the First Decade of Democracy. CHE. November.

Dinokeng Scenarios. 2009. 3 futures for South Africa [Online]. Available: www. dinokengscenarios.co.za [2009, 27 May].

Dressel P \& Mayhew L. 1974. Higher education as a field of study. San Francisco: Jossey-Bass.

European Science Foundation. 2008. Higher education looking forward: An agenda for future research. Strasbourg: European Science Foundation.

Gibbon T \& Parekh A. 2001. Uncommon wisdom: Making cooperation work in South African higher education. A report commissioned by the network of executive directors of academic consortia. Pretoria: COD Print.

HESA (Higher Education South Africa). 2009. First among equals - Stories from higher education leaders in South Africa. Pretoria: Higher Education South Africa.

Keller G. 1998. Does higher education research need revisions? The Review of Higher Education, 21 (3):267-278.

MacGregor K. 2009a. South Africa: Communist takes charge of higher education. University World News, 24 May:Issue 0077.

MacGregor K. 2009b. South Africa: Push to graduate more PhDs. University World News, 31 May:Issue 0030. 
OECD (Organisation for Economic Cooperation and Development). 2008. Reviews of national policies for education. South Africa. Paris: OECD Publications.

Pretorius C \& Dibetle M. 2009. Degrees of racism. Mail \& Guardian, 1 May.

RSA DoE (Republic of South Africa. Department of Education). 2008. Report of the ministerial committee on transformation and social cohesion and the elimination of discrimination in public higher education institutions. Pretoria: Department of Education.

Salmi J. 2009. The challenge of establishing world-class universities. Washington DC: The World Bank.

SARUA (Southern African Regional Universities Association). 2008. Mainstreaming higher education in national and regional development in Southern Africa. Johannesburg: SARUA.

SRHE (Society for Research into Higher Education). 2008. Annual Report 2008. London: SRHE.

Teichler U. 2005. Research on higher education in Europe. European Journal of Education, 40(4):447-469. 


\title{
A BRIEF TRIBUTE TO KALIE STRYDOM FOR HIS CONTRIBUTIONS TO HIGHER EDUCATION STUDIES AND RESEARCH
}

\begin{abstract}
ndries Hermanus (Kalie) Strydom was born in Bloemfontein on 5 July 1940. He matriculated at Grey College, Bloemfontein, in 1958 and continued his studies at the (then) University of the Orange Free State where he obtained a BA degree, a Higher Education Diploma, a BEd, an MEd and a DEd, as well as an MA degree in Philosophy.
\end{abstract}

He started his academic career in 1969 when he was appointed as a lecturer and later as a senior lecturer at the University of the Orange Free State. Only five years later (in 1974) he was promoted to professor and head of the Department of Didactics at Stellenbosch University - an exceptional achievement - since, at the age of 35, he was the youngest professor to be appointed at a Faculty of Education in South Africa at the time. In April 1977 he returned to the University of the Orange Free State as professor and was subsequently promoted to Chief Director of the Research Unit into Higher Education and in 1996 to Chief Director of the Strategic Service at the University of the Free State. Since 2000 he has been the Acting Director of the Free State Higher Education Consortium (FSHEC) and a senior researcher at the Centre for Higher Education Studies and Development (CHESD) at the University of the Free State.

For more than two decades Kalie Strydom has been associated with excellence in educational research, especially in the field of higher education. His academic career can best be described as a lifetime of dedication to accountable research, aimed at the advancement of higher education in South Africa. As a result he is regarded as an acclaimed researcher in the field of higher education - nationally, as well as in international circles. Apart from having undertaken a vast number of independent research trips to countries abroad - which include Canada, various American States, Germany, the United Kingdom, the Netherlands and Australia - Professor Strydom has appeared as a guest speaker at 39 conferences and other occasions. In addition, he 
has presented papers at 19 international conferences, and at 70 conferences in South Africa on a variety of aspects of education. This underscores the fact that his work is widely held in high regard and that he has made a valuable contribution to the field of higher education in this country.

Kalie Strydom's publications include 54 research articles, contributions as author, coauthor and editor of 11 books, 18 technical reports to different national/provincial education departments, the CUP, the CHE, and other educational associations. He has also contributed a number of editorial reviews. Although a number of these investigate the issue of quality assurance - a field within which he has become a well-known authority - it is evident from his list of publications that his research interests comprise a variety of extremely relevant themes. This proves to be one of his most commendable attributes: the ability to address the educational issues of the day. As such he has contributed widely to the areas of didactics, higher education management and leadership, human resources management and curriculum development, strategic planning, higher education policy, open learning and multicultural education.

His most outstanding research projects include research on all the different aspects of quality assurance, access with success, governance in higher education, regional development and engagement as well as performance management of institutions and staff in higher education and further education and training (FET). He has, therefore, played a significant role in the process of transformation of higher education in South Africa, both through his research and development work.

His expertise in various fields of higher education culminated in community service, which includes a research and development project on a bridging mechanism at tertiary level, and membership of various statutory councils. He is the coordinator of a Task Group of the National Commission on Higher Education, an executive member of the Organising Committee of the CUP Conference on the future of universities in South Africa, and a member of the Human Science Research Council (HSRC). In addition, he serves on the Disciplinary Chief Committee for Education and the HSRC Research Committee for Educational Sciences. As the Founder Chairman and first President of the South African Association for Research and Development in Higher Education (SAARDHE) and chairperson of the Urban Foundation of the Free State and Northern Cape Region, he played a major role in furthering the interests of higher education. $\mathrm{He}$ continued in this tradition by chairing the working group of the Executive Committee for Post-secondary Education and Training Forum of the Free State Province. 
Professor Strydom has been a member of various local, national and international academic associations and other organisations. He has also served on a number of different committees of the UFS, the South African Universities' Vice-Chancellors' Association (SAUVCA), the Centre for Science Development (CSD), the Human Sciences Research Council (HSRC), the Free State Higher and Further Education and Training Trust (as Chairman), the Independent Examinations Board, and the National Commission for Higher Education. He was a member of the Education Committee of the Committee of University Principals (CUP) for a period of 20 years and served on the Academic Planning Committee of the CUP for nine years. His contribution to higher education through representation in a leadership role does, however, not remain limited to South Africa alone. He was a member of the American Council on Education (ACE), the Association for Study in Higher Education (ASHE), the Society for Research into Higher Education (SRHE), the African Association of Universities (AAU) the University Council of the National University of Lesotho (for five years until 2001), the Council of the Central University of Technology (from 2002-2007), the Council of Motheo FET College and the Provincial Board for FET Colleges in the Free State. In addition, he was the Africa representative on the Foreign Committee of the Association for Institutional Research in the USA.

Other awards received by Professor Strydom during his academic career include study at the Goethe Institut in West Germany, a number of bursaries from the VCHO (an association for Higher Education) and the HSRC, as well as the Johann Pauw Memorial Award of SAARDHE (1990), an Outstanding Professor Merit Award at the University of the Free State (1998-2000), the South African Education Association medal and reward for outstanding research and the Harold Wolpe Memorial Award of the South African Association for Research and Development in Higher Education.

In 2000 Kalie Strydom retired as Chief Director: Academic Planning and Development at the University of the Free State. He was then asked to act as Director of the Free State Regional Development and Engagement Trust at higher and further education and training levels and as senior researcher in the Centre for Higher Education Studies and Development of the UFS.

As Acting Director of the FSHEC and senior researcher Professor Strydom has prepared documents advising top management, lectured in the master's degree programme for Higher Education Studies (HES) and supported doctoral students in HES on many different aspects of regional engagement and development with specific emphasis on widening participation (access with success), regional strategic planning and impact 
studies, skills acquisition, human resources management and development and higher education as a field of study.

This book might serve as a small token of appreciation for the sterling work Professor Strydom has done throughout a career in higher education studies and research. I am sure that most, if not all, of his students, colleagues and staff would share the appreciation for the valuable contributions he has made at various levels of promoting the field in South Africa. 


\section{INDEX}

A

academic

academic development $45,275,315$ $323,388,395,430$

academic freedom $61,63,73,82$,

$107,112,359,382,393,395$,

412,424

academic performance 90,312

academic potential 44

academic professional development $255-260,264-268,274,316$

academic renewal 257,416

academics $6,15,18,2-31$,

$41-45,62,66,72,79,80,86$,

$90,106,113,116,129,130$,

141-176, 184-189, 194, 198,

237, 245-249, 255-257, 262,

266-267, 276, 283-291, 300,

$314,323,332,340,350-351$,

$359,360-361,370,377,383$

$388,393,409-424,430$

academic staff development 21, 259

academic standards 25, 217

academic support 17, 21, 86, 214, 314,320

academic work 148, 360

accountability 7-10, 19,44, 107, 111 ,

$186,196,199,212,225,263$,

$271,294-298,350,379,410$,

$415-419,424,431$

activity theory 229, 241, 248

African higher education 3-6, 14-17, $21-23,31,43,57-58,73,104$, $105,107,108,109,111-112$, $124,155-165,170-183,189$, $194-196,212,247,266,275-$ $277,313,343,353-361,379$, $397,411-413,439-446$

African Higher Education Forum 397

African university 59, 85, 156, 167-171, $294,341,393,405$

American Council on Education 311

American Educational Research Association 376, 396

\section{assessment}

assessment 8, 29, 56, 97, 133-135, $146,158,165,169,176,183$.

$213,217-224,257-273,291$, $320,374,386-387,402,415$ $423,430-433$

assessment policy 190

formative assessment 185, 195

quality assessment 8,199

summative assessment $185,186,195$, 222

Association for African Universities 397

Association for Institutional Research 376,384

Association for the Study of Higher Education 376

attitude 288, 361, 421

\section{B}

Bureau for University Education 308, 383

C

Centre for Higher and Adult Education 268-273, 315

Centre for Higher Education Studies and Development 408

Centre for Higher Education Transformation 359, 384, 397 , 441

classification $11,134,237,386,391$ 395

community

community engagement $74,116,212$, $315,393,409-418,422-425$

community service $59,188,414-416$, 431

Community Higher Education Service Partnership 424

compassionate imagining 71-85, 98 
conceptual change 296-297

constructivist 30, 190, 239, 269

Council on Higher Education 14-16, $108,128,148,208,313,322$, $332,370,379,396,414,430$, 441

curriculum

curriculum 16, 22-63, 73, 88, 93-97, $110-111,123-198,210,216$, 220, 230-235, 241-249, 259$265,271-273,291-298,308$, $314-323,350,379,381-394$, $401,418-419,430,439$

curriculum alignment 148, 198 curriculum analysis 135, 145, 167 curriculum change 123-129, 140-152 curriculum design 24, 36-38, 110 , $161,245,259,273,323,394$, 419,439

curriculum issues xvi, 16, 155-160, $165,170,176-177,244$

curriculum reform 37, 44-45, 295

D

Democratic deliberation 77,79

Department of Education 16, 30, 65, $108,112-114,155,166-174$, $320,396,414,441$

\section{development}

continuous professional development 284

personal development 61, 287

skills development 6, 265

staff development 21-27, 220-224, 256-259, 291, 308-313, 374, $389,417,438$

discipline 4, 30, 40, 62, 73, 104, 107, $135,142,150,189,191-198$, 206-211, 256-307, 318, 345, $357,369-374,381,386,417$ 419,435
E

economic development $7,12,33-34$, $71-75,82,369,401,414$

education

adult education 310

contact and distance education 155 $156,169,176$

content-based education and training 190

distance and adult education systems 310

distance education 155-159, 168 $171,176,194,265,321,379$, 405

liberal education 103, 155-160, 175-176, 345

medical education 190-191

outcomes-based education 189, 192-194, 260, 294-295

Education Policy Unit 378

Encyclopedia of Higher Education 372, 401

European Science Foundation 377, 432-438, $441-444$

F

fairness 64, 185, 194, 198

feedback 137, 150, 184-185, 193-196, 209-222, 259, 316

field of study $4,66,256,270-274,287$, 293, 305, 313-322, 369-378, $384-385,396-398,429-446$

G

globalisation 9, 103, 109, 117, 170, $174,263,283-284,295,317$, $354,387,395,410,412$

governance $9-13,43,62,71-72,210$, $314,337,343,349-363,370$, 379-389, 395, 423, 430-437, 443-447 
$\mathrm{H}$

\section{higher education}

higher education change 297

higher education curriculum 25, 155 $171,176-179,387$

higher education development 45

higher education institutions 7-19,58, $82-83,104,112,156,160,170$, $177,185-197,204,264,269-$ $270,298,306,309,317-318$, 332-343, 352-357, 373, 394, 409-417, 424, 431-443

higher education landscape 14,74 , 103, 186, 263, 286, 318, 379, 393,411

higher education policy 6-8, 30-31, 53-54, 103-111, 230, 248, 315, 435-438

higher education programmes 26 , $112,160,197,317$

higher education quality 13

higher education research 56, 64 385-389, 435-445

higher education studies $32,42-45$, 53-54, 65, 155, 268, 277, 283, $289,298,299,305-323,370$ 385-394, 429-446

higher education studies and research $155,277,305-306,311,314$, $319,323,370,385-387,394$, 429-446

higher education transformation 391 international higher education 39 mass higher education 165 paradigm in higher education 231 public higher education 160, 284, 432-433

Higher Education Management Information System 433

Higher Education Qualifications Framework 187, 206, 260, 350, 379

Higher Education Quality Committee $15-16,112,128,148,155,168$ $187,205,313,338,350,379$ $410,414,433$

Higher Education Research and Development Society of Australasia 268
Higher Education South Africa 37, 322, $396,414,445$

I

\section{institutional}

institutional autonomy $19,82,112$, 379,395

institutional governance $349-363$

institutional management 343,393

institutional research $319,374,384$, $390,396,437-438$

institutional culture 6, 151, 258, 262$264,331-345$

internationalisation 9, 155-159, 170 $176,317,371,395$

$\mathrm{K}$

knowledge

embedded knowledge 126-132, 137-139, 188

indigenous knowledge 89-90, 393 indigenous knowledge systems 393 interdisciplinary knowledge 175, 197 knowledge development 53, 63-65, $229,239,242-244,369$

knowledge economy 66, 104-107, $112-116,196,412,419$

knowledge production 103, 108-111, 160-162, 177, 183-188, 255, $295,409-415,420$

knowledge transfer 238-239, 246-248 knowledge transmission 53, 189 work knowledge 161

\section{L}

leadership 16, 37, 123, 137, 144-151, 204, 265-277, 291, 306-314, $319-323,338,353,361,383$ $387,395,405,416,439,447$

\section{learning}

experiential learning 216, 229, 234, $247,251,273,404$

learning assessment 194

learning outcomes 127, 133, 157 .

$158,184-186,191-198,271,289$ 
learning programmes 109-111, 159, 208, 210, 273, 295, 370, 406, 413

learning theory 30, 42, 309-312

problem-based learning 30, 38, 229, $231-233,244$

recognition of prior learning 165,206 , 266

teaching and learning 6, 16, 22-24, 30-32, 36-46, 80-97, 167, 183-

$185,190,195-199,210,220$, $233,240,249,259-275,283-$ $312,319-321,374,379,383$, $386,393,396,409-423,430$ $431,441-443$

workplace learning 244

lecturer 58, 90-98, 137, 140, 169, 184-189, 194-195, 215, 220, 238, 257-258, 271, 284-286, 290-296, 320, 380

M

management $12,19,38,55,62-65$, $73,104,107,114,135,148$, 204, 210-212, 218-220, 227, $249,265,271,294,306-315$, $322,338,343,351-363,377$, 384-387, 393-394, 404-423, $437-447$

$\mathrm{N}$

National Commission on Higher Education 13, 31, 58, 108, 230, $313,378,384,415$

National Education Policy Investigation 58,384

National Plan for Higher Education 14 , $58,166,342,350,390,414$

National Research Foundation 98, 388, 396, 405, 437, 441

National Students Financial Aid Scheme 379

National Working Group 379

$\mathbf{P}$

paradigm $53-55,64-65,87,130,157$, $231,238-239,307,323$ participatory research 421

Pedagogy 220

perspective $3,21-23,35,43-45,53-63$, 74, 85, 96, 123-127, 148, 184, $193,203,259,263,267,274$ $275,287,294,305,312-315$, $321,323,372-374,382,387$, $397,409,430,432$

philosophy $39,54-55,66,104,107$, $161-162,198,258,307,333$, 381

policy

policy analysis 3-6, 17-18, 378

policy development 3-8, 11-12, 17$18,31,37,109,259,265,319$

policy documents $57,109,342-343$, 378,414

policy issues 17,430

political model 357,358

postgraduate

postgraduate $57,62,151,167-169$, $175,212-214,292,299-305$ $315-321,374,377,384-391$, 405-407, 431, 437-440

postgraduate studies 318, 390-391, 431,439

postgraduate supervision 214,315 317

Postgraduate Certificate in Higher Education 267, 270, 273, 407

Postgraduate Diploma in Higher Education and Training 407

professional

professional 28-40, 44, 55-57, 66, $116,162,188-197,204-220$, $227,236,255-276,283-288$, 292-300, 308-322, 351-357, $374,377,382-386,396-401$ 413-422, 430, 437, 441-443

professional behaviour 192

professional competence 197, 257, $261,262-263,288$

professional development 32,44 , 194, 255-274, 283-288, 293, 297-300, 312-318, 413, 418 420,430

professor 88-91, 130-132, 140, 305, $310,317,381$

Professor 289, 308, $311-314,341-344$, 377,383 


\section{programme}

programme design $110,188,208$ $210,276,316$

programme development 19, 40, 231

programme evaluation 205-214, 221, 225

Q

\section{quality}

quality assessment 8,199

quality assurance $9,46,111,128$, $148,162,169,184-188,203$ -

214, 224-225, 298, 313-314,

$374,379,384,414,431$

Quality Promotion Unit 379

\section{R}

recognition of prior learning 165,206 , 266

redress $13-14,22-23,31,62,108,166$, 231,414

relevance $54-59,76,130,198,214$, $216,295,296,393,409,411$. $419,424,436,442-443$

Research Development Initiative for Black Academics 16

Research on Higher Education Programme 375

\section{resource}

resource 13, 95, 166, 214, 229, 247 , $248,381,401,424$

resources 5-12, 17-26, 35, 42-44, $74,82,87-88,95,97,104,107$, $157,161-167,177-178,188$ $189,212-213,249,263-265$, 273-274, 322-323, 333-336, $353-360,378,413-416,421$ $423,430-445$

\section{$\mathrm{S}$}

\section{scholarship}

scholarship $32-46,55,66,71,188$ 255-267, 274-276, 283-291, $300,323,339,373-375,409$ $424,443-445$

scholarship of discovery 258 scholarship of engagement 257 409-424

scholarship of integration 288

scholarship of teaching and learning $42,259-260,267,274$

science

science $14,56-60,73,106,114$, 133-135, 145-150, 161-162, $175,203-206,212,218,232$ $236,249,305-308,372,377$, $386,405-406,412-413,421$, $437-438$

Science $26-29,32,40,66,145,206$ 207, 221-224, 307, 341-342, $377,404-406,432,436-444$

social justice $85-88,93,96,149,414$, $421,430,437$

social responsiveness 410-412

Society for Research into Higher Education 309, 376

South African Association for Research and Development in Higher Education 54, 309

South African College 380, 403

South African Journal of Higher Education 194, 259, 309, 319, 383, 389

staff

staff appraisal 311-314

staff development 21,22, 27, 220, $224,256,259,291,308-313$, $374,389,417,438$

\section{Staff and Educational Development} Association 268

standards $25,31,134,148-150,158$, 176, 184-188, 208, 213-225, $257-273,284,291,387$

student

placement 24, 37-45, 388

recruitment 44, 213-219, 401

student access 73, 374-378, 384, 395

student career 389

student counselling 321

student equity 14-15, 24

student experience 335,387

student performance $27,32,36,313$, 390 


\section{HIGHER EDUCATION IN SOUTH AFRICA}

student recruitment 213, 218

student selection $24,29,44-45$

$\mathrm{T}$

teacher training $16,147,160-163,389$, 405

teaching and learning $6,16,22-24$, 30-46, 80-97, 167, 183-185, 190, 195-199, 210, 220, 233, 240, 249, 259-260, 267-275, 283-300, 308-312, 319-321, $374,379,383,386,393,396$, 409-431, 441-443

tertiary didactics 381

theories 39, 89, 94-95, 236, 255-256, $419,422,437$

transdisciplinary $105,183,188,230$, $323,410,418-421$

transformation 5-24, 43, 56, 62, 67, $106-116,124,130-133,143-$ $151,171-172,179,186,237$, 255-257, 265, 289, 298-299, $317-318,333,340-344,353$, $378-379,388,391-394,409$. $414,421-422,432-438,445$

typology $11,160,235$

U

Ubuntu 76, 83, 123, 129, 130-152, 296

undergraduate 9, 32-43, 57-77, 94, $129,151,169,175,203-218$, 225, 269, 294-296, 341, 383, 401, 406, 439

university

public universities $81,380,404$

public university $72,81,126$

university community 56, 78, 293, 337

university mission 41

University of the Cape of Good Hope 380

W

world of work 63, 161, 189-197, 229, 295,430 


\section{- ACRONYMS}

AD/ASP Academic Development/Support Programme

AAU Association for African Universities

ACE American Council on Education

AD/ASP Academic Development/Support Programme

AERA American Educational Research Association

AFT Advocates for Transformation

AHEF African Higher Educational Forum

AIR Association for Institutional Research

ANC African National Congress

APD Academic Professional Development

ASHE Association for the Study of Higher Education

ASP Academic Support Programme

ASPECT Academic Support Programme for Engineering in Cape Town

BUE Bureau for University Education

CAT Computer Analysis Toolkit

CE Community Engagement

CESM Classification of Educational Subject Matter

CHAE Centre for Higher and Adult Education

CHE Council on Higher Education

CHESD Centre for Higher Education Studies and Development

CHESP Community Higher Education Service Partnership

CHET Centre for Higher Education Transformation

CPD Continuing Professional Development

CPE Continuing Professional Education

CPL Continuing Professional Learning

CPUT Cape Peninsula University of Technology

CREST Centre for Research and Science and Technology

CSC Centre for Student Counselling

CSD Centre for Science Development

CTP Committee of Technikon Principals

CUP Committee of University Principals

DoE Department of Education

ECSA Engineering Council of South Africa

EGS Education Guarantee Scheme

EHE Encyclopedia of Higher Education

ELT Experiential Learning Theory

EPU Education Policy Unit

ESF European Science Foundation

ESL English as a Second Language 
ETDP SETA Education, Training and Development Practices Sector Education and Training Authority

FET Further Education and Training

FSHEC Free State Higher Education Consortium

GER Gross Enrolment Rate

HBI/HDI Historically Black/Disadvantaged Institutions

HE Higher Education

HED Higher Education Development

HEI Higher Education Institution

HELF Higher Education Looking Forward

HELTASA Higher Education Learning and Teaching Association of Southern Africa

HEMIS Higher Education Management Information System

HEQC Higher Education Quality Committee (of the CHE)

HEQF Higher Education Qualifications Framework

HERDSA Higher Education Research and Development Society of Australasia

HESA Higher Education South Africa

HET Higher Education and Training

HICD Human and Institutional Capacity Development

HPCSA Health Professions Council of South Africa

HSRC Human Science Research Council

IBSS International Bibliography of Social Sciences

ICT Information and Communication Technologies

IEHE International Encyclopedia of Higher Education

IF Institutional Forum

IKS Indigenous Knowledge Systems

IMF International Monetary Fund

ISI International Scientific Information

IT Information Technology

ITLS Improving Teaching and Learning for Success

JIPSA Joint Initiative for Priority Skills Acquisition

KKK Kwere Kwere - a sound imitating expression meaning an ununderstandable cacophonic language

LHEA Leaders of Higher Education in Africa

MS Microsoft

NASFAS National Students Financial Aid Scheme

NCHE National Commission on Higher Education

NEPI National Education Policy Investigation

NPHE National Plan for Higher Education

NQF National Qualifications Framework

NRF National Research Foundation

NWG National Working Group

OBE Outcome Based Education 
OECD Organisation for Economic and Cultural Development

OSP Overarching Strategic Plan

OUP Oxford University Press

PBL Problem Based Learning

PGCE Postgraduate Certificate in Education

PGCHE Postgraduate Certificate in Higher Education

PGCHET Postgraduate Certificate in Higher Education and Training

PGDE Postgraduate Diploma in Education

PGDHET Postgraduate Diploma in Higher Education and Training

PQM Programme and Qualification Mix

QA Quality Assurance

QPU Quality Promotion Unit

RAU Rand Afrikaans University

REDIBA Research Development Initiative for Black Academics

RHEP Research on Higher Education Programme

RiT Research-in-Training

RPL Recognition of Prior Learning

RSA Republic of South Africa

SA South Africa

SAAAD Southern African Association for Academic Development

SAADA South African Academic Development Association

SAAIR Southern African Association for Institutional Research

SAARDHE South African Association for Research and Development in Higher Education

SAC South African College

SADC Southern Africa Development Community

SAICA South African Institute for Chartered Accountants

SAJHE South African Journal of Higher Education

SAQA South African Qualification Act

SARUA Southern African Regional Universities Association

SAUVCA South African Universities Vice-Chancellors Association

SEDA Staff and Educational Development Association

SERTEC Certification Council for Technikon Education

SMI Strategic Management Indicator

SoTL Scholarship of Teaching and Learning

SRC Southern Regional Congress

SRHE Society for Research into Higher Education

SSRC Social Science Research Council

SU Stellenbosch University

TF Transformation Forum

TQM Total Quality Management

UCGH University of the Cape of Good Hope 
UCT University of Cape Town

UDUSA Union of Democratic University Staff Associations

UFS University of the Free State

UNESCO United Nations Educational Scientific and Cultural Organisation

UNIFY University of the North's, Science Foundation Year

UP University of Pretoria

WWDVC Van Wyk De Vries Commission

WASC Western Association of Schools and Colleges

WiR Women-in-Research

ZAA Zuid Afrikaanse Athenaeum 
A most stimulating collection of articles on the current state of South African higher education and of scholarly inquiry into key issues of higher education in South Africa, as well as in other parts of the world. There is a considerable richness of ideas, findings, reflections and analyses which should make the book very relevant to informing and inspiring much of the current debate about higher education in South Africa and about priorities in further research on higher education. The coverage of pertinent issues is broad and encompassing, if understandably not altogether complete; it ranges from questions of policy and epistemology to matters of curriculum, governance and professional development, and to frontiers and agendas for further research; one would have wished for more attention to issues of financing and of the relationship between universities and the state, especially as regards university autonomy. While the analyses are competently cognisant of the literature and scholarly debates in higher education internationally, they remain focused on the particular problems of South African higher education and its further development.

Hans N Weiler

Professor of Education and Political Science, Emeritus Stanford University, USA

In my judgement, this book should be of considerable interest to higher education researchers outside of South Africa, as well as within, for the general and comparative assessments it makes. The South African higher education researchers included within its covers have clearly engaged with research and writing from many parts of the world, which they have then applied to make sense of their own condition.

Malcolm Tight

Professor in Higher Education, Lancaster University, UK

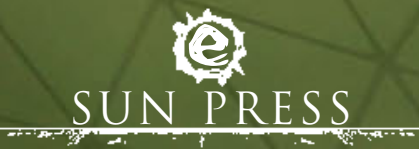

